U.S. DEPARTMENT OF COMMERCE

National Bureau of Standards

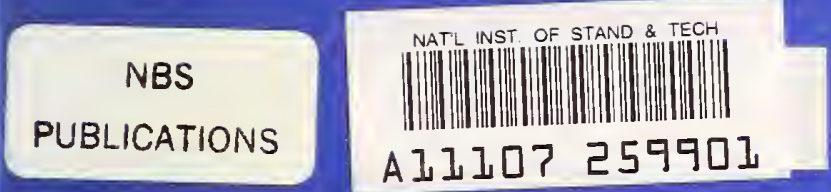

NBS Special Publication 708

\title{
Standard Reference Data Publications \\ 1964-1984
}

Joan C. Sauerwein and Geraldine R. Dalton

NBS NBS NBS NBS NBS NBS NBS. NBS NBS NBS 3S NBS NBS NBS NBS NBS NBS NBS NBS NBS NB NBS NBS NBS NBS NBS NBS NBS NBS NBS NBS iS NBS NBS NBS NBS NBS NBS NBS NBS NBS NB $N B S N B S N B S$ NBS NBS NBS NBS NBS NBS NBS IS NBS NBS NBS NBS NBS NBS NBS NBS NBS NB NBS NBS NBS NBS NBS NBS NBS NBS NBS NBS iS NBS NBS NBS NBS NBS NBS NBS NBS NBS NB NBS NBS NBS NBS NBS NBS NBS NBS NBS NBS iS NBS NBS NBS NBS NBS NBS NBS NBS NBS NB NBS NBS NBS National Bureau of Standards NBS NBS iS NBS NBS NBS NBS NBS NBS NBS NBS NBS NB $Q C$ NBS NBS NBS NBS NBS NBS NBS NBS NBS 1 S NBS NBS NBS NBS NBS NBS NBS NBS NB, 
he National Bureau of Standards' was established by an act of Congress on March 3, 1901. The Bureau's overall goal is to strengthen and advance the nation's science and technology and facilitate their effective application for public benefit. To this end, the Bureau conducts research and provides: (1) a basis for the nation's physical measurement system, (2) scientific and technological services for industry and government, (3) a technical basis for equity in trade, and (4) technical services to promote public safety. The Bureau's technical work is performed by the National Measurement Laboratory, the National Engineering Laboratory, the Institute for Computer Sciences and Technology, and the Institute for Materials Science and Engineering.

\section{The National Measurement Laboratory}

Provides the national system of physical and chemical measurement; coordinates the system with measurement systems of other nations and furnishes essential services leading to accurate and uniform physical and chemical measurement throughout the Nation's scientific community, industry, and commerce; provides advisory and research services to other Government agencies; conducts physical and chemical research; develops, produces, and distributes Standard Reference Materials; and provides calibration services. The Laboratory consists of the following centers:
- Basic Standards ${ }^{2}$

- Radiation Research

- Chemical Physics

- Analytical Chemistry

\section{The National Engineering Laboratory}

Provides technology and technical services to the public and private sectors to address national needs and to solve national problems; conducts research in engineering and applied science in support of these efforts; builds and maintains competence in the necessary disciplines required to carry out this research and technical service; develops engineering data and measurement capabilities; provides engineering measurement traceability services; develops test methods and proposes engineering standards and code changes; develops and proposes new engineering practices; and develops and improves mechanisms to transfer results of its research to the ultimate user. The Laboratory consists of the following centers:
- Applied Mathematics

- Electronics and Electrical Engineering ${ }^{2}$

- Manufacturing Engineering

- Building Technology

- Fire Research

- Chemical Engineering ${ }^{2}$

\section{The Institute for Computer Sciences and Technology}

Conducts research and provides scientific and technical services to aid Federal agencies in the selection, acquisition, application, and use of computer technology to improve effectiveness and economy in Government operations in accordance with Public Law 89-306 (40 U.S.C. 759), relevant Executive Orders, and other directives; carries out this mission by managing the Federal Information Processing Standards Program, developing Federal ADP standards guidelines, and managing Federal participation in ADP voluntary standardization activities; provides scientific and technological advisory services and assistance to Federal agencies; and provides the technical foundation for computer-related policies of the Federal Government. The Institute consists of the following centers:
- Programming Science and Technology

- Computer Systems Engineering

\section{The Institute for Materials Science and Engineering}

Conducts research and provides measurements, data, standards, reference materials, quantitative understanding and other technical information fundamental to the processing, structure, properties and performance of materials; addresses the scientific basis for new advanced materials technologies; plans research around cross-country scientific themes such as nondestructive evaluation and phase diagram development; oversees Bureau-wide technical programs in nuclear reactor radiation research and nondestructive evaluaiion; and broadly disseminates generic technical information resulting from its programs. The Institute consists of the following Divisions:
- Ceramics

- Fracture and Deformation ${ }^{3}$

- Polymers

- Metallurgy

- Reactor Radiation 


\section{NBS Special Publication 708}

\section{Standard Reference Data Publications 1964-1984}

Joan C. Sauerwein

Geraldine R. Dalton

Office of Standard Reference Data

National Bureau of Standards

Gaithersburg, MD 20899

Supersedes NBS SP 612

December 1985

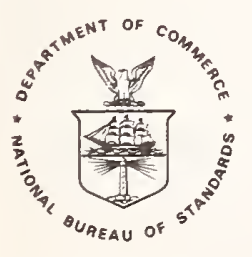

U.S. Department of Commerce Maloolm Baldrige, Secretary National Bureau of Standards Emest Ambler, Director 


\section{Library of Congress}

Catalog Card Number: 85-600607

National Bureau of Standards

Special Publication 708

Natl. Bur. Stand. (U.S.),

Spec. Publ. 708

143 pages (Dec. 1985)

CODEN: XNBSAV
U.S. Government Printing Office

Washington: 1985
For sale by the Superintendent of Documents,

U.S. Government Printing Office, Washington, DC 20402 


\section{Foreword}

The National Standard Reference Data System was established in 1963 for the purpose of promoting the critical evaluation and dissemination of numerical data of the physical sciences. The program is coordinated by the Office of Standard Reference Data of the National Bureau of Standards but involves the efforts of many groups in universities, government laboratories, and private industry. The primary aim of the program is to provide compilations of critically evaluated physical and chemical property data. These tables are published in the Journal of Physical and Chemical Reference Data, in the NSRDS-NBS series of the National Bureau of Standards, and through other appropriate channels. Other outputs of the program include bibliographies, computer programs for handling data, and databases in magnetic tape format.

This listing includes all publications which have appeared since establishment of this program in 1964. Indexes to authors, properties, and material classes are given, as well as information on ordering publications.

David R. Lide, Director

Office of Standard Reference Data 


\section{Contents}

Introduction ...................... 1

Journal of Physical and Chemical Reference Data . 2

Reprints........................ 2

Supplements ...................... 13

Reprint Packages ...................... 13

Other NSRDS Data Publications ............ 14

Critical Bibliographies and Indexes

Critical Bibliographies and Indexes in the NBS

Series
Critical Bibliographies and Indexes from Other

Publishers........................ 25

Computer Programs for Handling Technical Data. . 27

NBS Magnetic Tape Series................. 28

Author Index........................ 29

Materials Index....................... 78

Properties Index ...................... 94

Ordering Information. .................. 129

23 Price Lists ......................... 131 


\title{
Standard Reference Data Publications \\ $1964 \cdot 1984$
}

\author{
Joan C. Sauerwein and Geraldine R. Dalton \\ Office of Standard Rejerence Data, National Bureau of Standards, Gaithersburg, MD 20899
}

The National Bureau of Standards' Office of Standard Reference Data manages a network of data centers that prepare evaluated data bases of physical and chemical properties of substances. Data bases are available in printed form, on magnetic tapes and through on-line computer networks. This document provides a comprehensive list of the products available from the National Standard Reference Data System (NSRDS) for the years 1964-1984, including indexes qualified by author, material, and property terms. Ordering information and current prices can be found at the end of this document.

Key words: bibliographies; chemical properties; evaluated data; indexes; materials properties; physical properties; publication list.

\section{Introduction}

The National Standard Reference Data System (NSRDS), established in 1963, coordinates on a national scale the compilation and dissemination of reference data in the physical sciences. Under the Standard Reference Data Act (Public Law 90-396) the National Bureau of Standards (NBS) of the U.S. Department of Commerce has the primary responsibility in the Federal Government for providing reliable scientific and technical data. The Office of Standard Reference Data at NBS coordinates a complex of data evaluation centers, located in university, industrial, and other Government laboratories as well as within NBS.
These centers compile and critically evaluate numerical physical and chemical property data retrieved from the world's scientific literature.

This publications list includes NSRDS data compilations, critical reviews, and other publications which are available from various sources. Indexes by author, property, and materials class are included. Prices and ordering instructions for publications listed are given in this document and further information may be obtained from:

\footnotetext{
Office of Standard Reference Data

National Bureau of Standards Gaithersburg, MD 20899
} 


\section{Reprints}

1

Gaseous Diffusion Coefficients - T. R. Marrero and E. A. Mason. J Phys Chem Ref Data 1, 1(1972).

2

Selected Values of Critical Supersaturation for Nucleation of Liquids from the Vapor - G. M. Pound. J Phys Chem Ref Data 1, 119(1972).

3

Selected Values of Evaporation and Condensation Coefficients for Simple Substances - G. M. Pound. J Phys Chem Ref Data 1, 135(1972).

4

Atlas of the Observed Absorption Spectrum of Carbon Monoxide between 1060 and $1900 \AA$ - S. G. Tilford and J. D. Simmons. J Phys Chem Ref Data 1, 147(1972).

5

Tables of Molecular Vibrational Frequencies, Part 5 - Takehiko Shimanouchi. J Phys Chem Ref Data 1, 189(1972).

6

Selected Values of Heats of Combustion and Heats of Formation of Organic Compounds Containing the Elements C, H, N, O, P, and S Eugene S. Domalski. J Phys Chem Ref Data 1, 221(1972).

7

Thermal Conductivity of the Elements - Cho Y. Ho, Robert W. Powell, and Peter E. Liley. J Phys Chem Ref Data 1, 279(1972).

\section{8}

The Spectrum of Molecular Oxygen - Paul H. Krupenie. J Phys Chem Ref Data 1, 423(1972).

\section{9}

A Critical Review of the Gas-Phase Reaction Kinetics of the Hydroxyl Radical - William E. Wilson, Jr. J Phys Chem Ref Data 1, 535(1972).

10

Molten Salts: Volume 3, Nitrates, Nitrites, and Mixtures. Electrical Conductance, Density, Viscosity, and Surface Tension Data - George J. Janz, Ursula Krebs, H. F. Siegenthaler, and Reginald P. T. Tomkins. J Phys Chem Ref Data 1, 581(1972).

11

High Temperature Properties and Decomposition of Inorganic Salts, Part 3. Nitrates and Nitrites - Kurt H. Stern. J Phys Chem Ref Data 1, 747(1972).

12

High-Pressure Calibration: A Critical Review - D. L. Decker, W. A. Bassett, Leo Merrill, H. T. Hall, and J. D. Barnett. J Phys Chem Ref Data 1, 773(1972).
13

The Surface Tension of Pure Liquid Compounds - Joseph J. Jasper. J Phys Chem Ref Data 1, 841(1972).

14

Microwave Spectra of Molecules of Astrophysical Interest, I. Formaldehyde, Formamide, and Thioformaldehyde - Donald R. Johnson, Frank J. Lovas, and William H. Kirchhoff. J Phys Chem Ref Data 1, 1011(1972).

15

Osmotic Coefficients and Mean Activity Coefficients of Uni-Univalent Electrolytes in Water at $25^{\circ} \mathrm{C}-$ Walter J. Hamer and Yung-Chi Wu. J Phys Chem Ref Data 1, 1047(1972).

16

The Viscosity and Thermal Conductivity Coefficients of Gaseous and Liquid Fluorine - Howard J. M. Hanley and R. Prydz. J Phys Chem Ref Data 1, 1101(1972).

17

Microwave Spectra of Molecules of Astrophysical Interest, II. Methylenimine - William H. Kirchhoff, Donald R. Johnson, and Frank J. Lovas. J Phys Chem Ref Data 2, 1(1973).

18

Analysis of Specific Heat Data in the Critical Region of Magnetic Solids - F. J. Cook. J Phys Chem Ref Data 2, 11(1973).

19

Evaluated Chemical Kinetic Rate Constants for Various Gas Phase Reactions - Keith Schofield. J Phys Chem Ref Data 2, 25(1973).

20

Atomic Transition Probabilities for Forbidden Lines of the Iron Group Elements (A Critical Data Compilation for Selected Lines) - Melvin W. Smith and Wolfgang L. Wiese. J Phys Chem Ref Data 2, 85(1973).

\section{1}

Tables of Molecular Vibrational Frequencies, Part $6-$ Takehiko Shimanouchi. J Phys Chem Ref Data 2, 121(1973).

22

Compilation of Energy Band Gaps in Elemental and Binary Compound Semiconductors and Insulators - W. H. Strehlow and E. L. Cook. J Phys Chem Ref Data 2, 163(1973).

\section{3}

Microwave Spectra of Molecules of Astrophysical Interest, III. Methanol - R. M. Lees, Frank J. Lovas, William H. Kirchhoff, and Donald R. Johnson. J Phys Chem Ref Data 2, 205(1973).

\section{4}

Microwave Spectra of Molecules of Astrophysical Interest, IV. Hydrogen Sulfide - Paul Helminger, Frank C. De Lucia, and William H. Kirchhoff. J Phys Chem Ref Data 2, 215(1973). 
Tables of Molecular Vibrational Frequencies, Part 7 - Takehiko Shimanouchi. J Phys Chem Ref Data 2, 225(1973).

26

Energy Levels of Neutral Helium ( ${ }^{4} \mathrm{He}$ I) - William C. Martin. J Phys Chem Ref Data 2, 257(1973).

\section{7}

Survey of Photochemical and Rate Data for Twenty-eight Reactions of Interest in Atmospheric Chemistry - Robert F. Hampson, Jr., W. Braun, R. L. Brown, David Garvin, John T. Herron, Robert E. Huie, M. J. Kurylo, A. H. Laufer, J. D. McKinley, H. Okabe, M. D. Scheer, W. Tsang, D. H. Stedman, editor(s). J Phys Chem Ref Data 2, 267(1973).

\section{8}

Compilation of the Static Dielectric Constant of Inorganic Solids K. F. Young and Hans P. R. Frederikse. J Phys Chem Ref Data 2, 313(1973).

\section{9}

Soft X-Ray Emission Spectra of Metallic Solids: Critical Review of Selected Systems - Archie J. McAlister, Ronald C. Dobbyn, John R. Cuthill, and M. L. Williams. J Phys Chem Ref Data 2, 411(1973).

\section{0}

Ideal Gas Thermodynamic Properties of Ethane and Propane - Jing Chao, Randolph C. Wilhoit, and Bruno J. Zwolinski. J Phys Chem Ref Data 2, 427(1973).

\section{1}

An Analysis of Coexistence Curve Data for Several Binary Liquid Mixtures Near Their Critical Points - A. Stein and G. F. Allen. J Phys Chem Ref Data 2, 439(1973).

\section{2}

Rate Constants for the Reactions of Atomic Oxygen $\left(O{ }^{3} \mathrm{P}\right)$ with Organic Compounds in the Gas Phase - John T. Herron and Robert E. Huie. J Phys Chem Ref Data 2, 467(1973).

\section{3}

First Spectra of Neon, Argon, and Xenon 136 in the $1.2-4.0 \mu \mathrm{m}$ Region - Curtis J. Humphreys. J Phys Chem Ref Data 2, 519(1973).

\section{4}

Elastic Properties of Metals and Alloys, I. Iron, Nickel, and IronNickel Alloys - Hassell M. Ledbetter and R. P. Reed. J Phys Chem Ref Data 2, 531(1973).

\section{5}

The Viscosity and Thermal Conductivity Coefficients of Dilute Argon, Krypton, and Xenon - Howard J. M. Hanley. J Phys Chem Ref Data 2, 619(1973).

\section{6}

Diffusion in Copper and Copper Alloys, Part I. Volume and Surface Self-Diffusion in Copper - Daniel B. Butrymowicz, John R. Manning, and Michael E. Read. J Phys Chem Ref Data 2, 643(1973).
The 1973 Least-Squares Adjustment of the Fundamental Constants - E. Richard Cohen and Barry N. Taylor. J Phys Chem Ref Data 2, 663(1973).

\section{8}

The Viscosity and Thermal Conductivity Coefficients of Dilute Nitrogen and Oxygen - Howard J. M. Hanley and James F. Ely. J Phys Chem Ref Data 2, 735(1973).

\section{9}

Thermodynamic Properties of Nitrogen Including Liquid and Vapor Phases from $63 \mathrm{~K}$ to $2000 \mathrm{~K}$ with Pressures to 10,000 Bar - Richard T. Jacobsen and Richard B. Stewart. J Phys Chem Ref Data 2, 757(1973).

\section{0}

Thermodynamic Properties of Helium-4 from 2 to $1500 \mathrm{~K}$ at Pressures to $10^{8} \mathrm{~Pa}-$ Robert D. McCarty. J Phys Chem Ref Data 2, 923(1973).

\section{1}

Molten Salts: Volume 4, Part 1, Fluorides and Mixtures. Electrical Conductance, Density, Viscosity, and Surface Tension Data - George J. Janz, G. L. Gardner, Ursula Krebs, and Reginald P. T. Tomkins. J Phys Chem Ref Data 3, 1(1974).

\section{2}

Ideal Gas Thermodynamic Properties of Eight Chloro- and Fluoromethanes - A. S. Rodgers, Jing Chao, Randolph C. Wilhoit, and Bruno J. Zwolinski. J Phys Chem Ref Data 3, 117(1974).

\section{3}

Ideal Gas Thermodynamic Properties of Six Chloroethanes - Jing Chao, A. S. Rodgers, Randolph C. Wilhoit, and Bruno J. Zwolinski. J Phys Chem Ref Data 3, 141(1974).

\section{4}

Critical Analysis of Heat-Capacity Data and Evaluation of Thermodynamic Properties of Ru, Ph, Pd, Ir, and Pt from 0 to $300 \mathrm{~K}$. A Survey of the Literature Data on Osmium - George T. Furukawa, Martin L. Reilly, and John S. Gallagher. J Phys Chem Ref Data 3, 163(1974).

\section{5}

Microwave Spectra of Molecules of Astrophysical Interest, V. Water Vapor - Frank C. De Lucia, Paul Helminger, and William $\mathrm{H}$. Kirchhoff. J Phys Chem Ref Data 3, 211 (1974).

\section{6}

Microwave Spectra of Molecules of Astrophysical Interest, VI. Carbonyl Sulfide and Hydrogen Cyanide - Arthur G. Maki. J Phys Chem Ref Data 3, 221(1974).

\section{7}

Microwave Spectra of Molecules of Astrophysical Interest, VII. Carbon Monoxide, Carbon Monosulfide, and Silicon Monoxide Frank J. Lovas and Paul H. Krupenie. J Phys Chem Ref Data 3, 245(1974).. 
Microwave Spectra of Molecules of Astrophysical Interest, VIII. Sulfur Monoxide - Eberhard Tiemann. J Phys Chem Ref Data 3, 259(1974).

49

Tables of Molecular Vibrational Frequencies, Part 8 - Takehiko Shimanouchi. J Phys Chem Ref Data 3, 269(1974).

\section{0}

JANAF Thermochemical Tables, 1974 Supplement — Malcolm W. Chase, Jr., J. L. Curnutt, A. T. Hu, H. Prophet, A. N. Syverud, and L. C. Walker. J Phys Chem Ref Data 3, 311(1974).

\section{1}

High Temperature Properties and Decomposition of Inorganic Salts, Part 4. Oxy-Salts of the Halogens - Kurt H. Stern. J Phys Chem Ref Data 3, 481(1974).

\section{2}

Diffusion in Copper and Copper Alloys, Part II. Copper-Silver and Copper-Gold Systems - Daniel B. Butrymowicz, John R. Manning, and Michael E. Read. J Phys Chem Ref Data 3, 527(1974).

\section{3}

Microwave Spectral Tables, I. Diatomic Molecules - Frank J. Lovas and Eberhard Tiemann. J Phys Chem Ref Data 3, 609(1974).

\section{4}

Ground Levels and Ionization Potentials for Lanthanide and Actinide Atoms and Ions - William C. Martin, Lucy Hagan, Joseph Reader, and Jack Sugar. J Phys Chem Ref Data 3, 771(1974).

\section{5}

Behavior of the Elements at High Pressures - John Francis Cannon. J Phys Chem Ref Data 3, 781(1974).

\section{6}

Reference Wavelengths from Atomic Spectra in the Range $5 \AA$ to $25000 \AA ̊$ - Victor Kaufman and Bengt Edlén. J Phys Chem Ref Data 3, 825(1974).

\section{7}

Elastic Properties of Metals and Alloys, II. Copper - Hassell M. Ledbetter and E. R. Naimon. J Phys Chem Ref Data 3, 897(1974).

\section{8}

A Critical Review of H-Atom Transfer in the Liquid Phase: Chlorine Atom, Alkyl, Trichloromethyl, Alkoxy, and Alkylperoxy Radicals D. G. Hendry, T. Mill, L. Piszkiewicz, J. A. Howard, and H. K. Eigenmann. J Phys Chem Ref Data 3, 937(1974).

\section{9}

The Viscosity and Thermal Conductivity Coefficients for Dense Gaseous and Liquid Argon, Krypton, Xenon, Nitrogen, and Oxygen Howard J. M. Hanley, Robert D. McCarty, and W. M. Haynes. J Phys Chem Ref Data 3, 979(1974).

60

JANAF Thermochemical Tables, 1975 Supplement - Malcolm W. Chase, Jr., J. L. Curnutt, H. Prophet, R. A. McDonald, and A. N. Syverud. J Phys Chem Ref Data 4, 1(1975).
Diffusion in Copper and Copper Alloys, Part III. Diffusion in Systems Involving Elements of the Groups IA, IIA, IIIB, IVB, VB, and VIIB - Daniel B. Butrymowicz, John R. Manning, and Michael E. Read. J Phys Chem Ref Data 4, 177(1975).

\section{2}

Ideal Gas Thermodynamic Properties of Ethylene and Propylene Jing Chao and Bruno J. Zwolinski. J Phys Chenı Ref Data 4, 251(1975).

\section{3}

Atomic Transition Probabilities for Scandium and Titanium (A Critical Data Compilation of Allowed Lines) - Wolfgang L. Wiese and Jeffrey R. Fuhr. J Phys Chem Ref Data 4, 263(1975).

\section{4}

Energy Levels of Iron, Fe I through Fe XXVI - Joseph Reader and Jack Sugar. J Phys Chem Ref Data 4, 353(1975).

\section{5}

Ideal Gas Thermodynamic Properties of Six Fluoroethanes - S. S. Chen, A. S. Rodgers, Jing Chao, Randolph C. Wilhoit, and Bruno J. Zwolinski. J Phys Chem Ref Data 4, 441(1975).

\section{6}

Ideal Gas Thermodynamic Properties of the Eight Bromo- and Iodomethanes - Shanti A. Kudchadker and Arvind P. Kudchadker. J Phys Chem Ref Data 4, 457(1975).

\section{7}

Atomic Form Factors, Incoherent Scattering Functions, and Photon Scattering Cross Sections - John H. Hubbell, W. J. Veigele, E. A. Briggs, R. T. Brown, D. T. Cromer, and R. J. Howerton. J Phys Chem Ref Data 4, 471(1975).

\section{8}

Binding Energies in Atomic Negative Ions - H. Hotop and W. C. Lineberger. J Phys Chem Ref Data 4, 539(1975).

\section{9}

A Survey of Electron Swarm Data - J. Dutton. J Phys Chem Ref Data 4, 577(1975).

\section{0}

Ideal Gas Thermodynamic Properties and Isomerization of n-Butane and Isobutane - S. S. Chen, Randolph C. Wilhoit, and Bruno J. Zwolinski. J Phys Chem Ref Data 4, 859(1975).

\section{1}

Molten Salts: Volume 4, Part 2, Chlorides and Mixtures. Electrical Conductance, Density, Viscosity, and Surface Tension Data - George J. Janz, Reginald P. T. Tomkins, Carolyn B. Allen, J. R. Downey, Jr., G. L. Gardner, Ursula Krebs, and S. K. Singer. J Phys Chem Ref Data 4, 871(1975).

\section{3}

Scaled Equation of State Parameters for Gases in the Critical Region - J. M. H. Levelt Sengers, W. L. Greer, and Jan V. Sengers. J Phys Chem Ref Data 5, 1(1976). 
Microwave Spectra of Molecules of Astrophysical Interest, IX. Acetaldehyde - A. Bauder, Frank J. Lovas, and Donald R. Johnson. J Phys Chem Ref Data 5, 53(1976).

75

Microwave Spectra of Molecules of Astrophysical Interest, X. Isocyanic Acid - G. Winnewisser, W. H. Hocking, and M. C. L. Gerry. J Phys Chem Ref Data 5, 79(1976).

76

Diffusion in Copper and Copper Alloys, Part IV. Diffusion in Systems Involving Elements of Group VIII - Daniei B. Butrymowicz, John R. Manning, and Michael E. Read. J Phys Chem Ref Data 5, 103(1976).

77

A Critical Review of the Stark Widths and Shifts of Spectral Lines from Non-Hydrogenic Atoms - N. Konjević and J. R. Roberts. J Phys Chem Ref Data 5, 209(1976).

78

Experimental Stark Widths and Shifts for Non-Hydrogenic Spectral Lines of Ionized Atoms (A Critical Review and Tabulation of Selected Data) - N. Konjević and Wolfgang L. Wiese. J Phys Chem Ref Data 5, 259(1976).

79

Atlas of the Absorption Spectrum of Nitric Oxide (NO) between 1420 and $1250 \AA$ A - E. Miescher and F. Alberti. J Phys Chem Ref Data 5, 309(1976).

\section{0}

Ideal Gas Thermodynamic Properties of Propanone and 2-Butanone - Jing Chao and Bruno J. Zwolinski. J Phys Chem Ref Data 5, 319(1976).

\section{1}

Refractive Index of Alkali Halides and Its Wavelength and Temperature Derivatives - H. H. Li. J Phys Chem Ref Data 5, 329(1976).

\section{2}

Tables of Critically Evaluated Oscillator Strengths for the Lithium Isoelectronic Sequence - Georgia A. Martin and Wolfgang L. Wiese. J Phys Chem Ref Data 5, 537(1976).

\section{3}

Ideal Gas Thermodynamic Properties of Six Chlorofluoromethanes - S. S. Chen, Randolph C. Wilhoit, and Bruno J. Zwolinski. J Phys Chem Ref Data 5, 571(1976).

\section{4}

Survey of Superconductive Materials and Critical Evaluation of Selected Properties - Benjamin W. Roberts. J Phys Chem Ref Data 5, 581(1976).

\section{5}

Nuclear Spins and Moments - Gladys H. Fuller. J Phys Chem Ref Data 5, 835(1976).
Nuclear Moments and Moment Ratios as Determined by Mössbauer Spectroscopy - John G. Stevens and B. D. Dunlap. J Phys Chem Ref Data 5, 1093(1976).

\section{7}

Rate Coefficients for Ion-Molecule Reactions, I. Ions Containing C and $\mathrm{H}-\mathrm{L}$. Wayne Sieck and Sharon G. Lias. J Phys Chem Ref Data 5, 1123(1976).

\section{8}

Microwave Spectra of Molecules of Astrophysical Interest, XI. Silicon Sulfide - Eberhard Tiemann. J Phys Chem Ref Data 5, 1147(1976).

\section{0}

Diffusion in Copper and Copper Alloys, Part V. Diffusion in Systems Involving Elements of Group VA - Daniel B. Butrymowicz, John R. Manning, and Michael E. Read. J Phys Chem Ref Data 6, 1(1977).

\section{1}

The Calculated Thermodynamic Properties of Superfluid Helium-4 - James S. Brooks and Russell J. Donnelly. J Phys Chem Ref Data 6, 51(1977).

\section{2}

Thermodynamic Properties of Normal and Deuterated Methanols S. S. Chen, Randolph C. Wilhoit, and Bruno J. Zwolinski. J Phys Chem Ref Data 6, 105(1977).

93

The Spectrum of Molecular Nitrogen - Alf Lofthus and Paul H. Krupenie. J Phys Chem Ref Data 6, 113(1977).

\section{4}

Energy Levels of Chromium, Cr I through Cr XXIV - Jack Sugar and Charles H. Corliss. J Phys Chem Ref Data 6, 317(1977).

95

The Activity and Osmotic Coefficients of Aqueous Calcium Chloride at 298.15 K - Bert R. Staples and Ralph L. Nuttall. J Phys Chem Ref Data 6, 385(1977).

\section{6}

Molten Salts: Volume 4, Part 3, Bromides and Mixtures, Iodides and Mixtures. Electrical Conductance, Density, Viscosity, and Surface Tension Data - George J. Janz, Reginald P. T. Tomkins, Carolyn B. Allen, J. R. Downey, Jr., and S. K. Singer. J Phys Chem Ref Data 6, 409(1977).

97

The Viscosity and Thermal Conductivity Coefficients for Dense Gaseous and Liquid Methane - Howard J. M. Hanley, W. M. Haynes, and Robert D. McCarty. J Phys Chem Ref Data 6, 597(1977).

\section{8}

Phase Diagrams and Thermodynamic Properties of Ternary Copper-Silver Systems - Y. Austin Chang, Daniel Goldberg, and Joachim P. Neumann. J Phys Chem Ref Data 6, 621(1977) 
Crystal Data Space-Group Tables - Alan D. Mighell, Helen M. Ondik, and Bettijoyce Breen Molino. J Phys Chem Ref Data 6, 675(1977).

100

Energy Levels of One-Electron Atoms - Glen W. Erickson. J Phys Chem Ref Data 6, 831(1977).

101

Rate Constants for Reactions of $\mathrm{ClO}_{\star}$ of Atmospheric Interest $-\mathrm{R}$. T. Watson. J Phys Chem Ref Data 6, 871(1977).

\section{2}

NMR Spectral Data: A Compilation of Aromatic Proton Chemical Shifts in Mono- and Di-Substituted Benzene - B. L. Shapiro and L. E. Mohrmann. J Phys Chem Ref Data 6, 919(1977).

\section{3}

Tables of Molecular Vibrational Frequencies. Consolidated Volume II - Takehiko Shimanouchi. J Phys Chem Ref Data 6, 993(1977).

\section{4}

Effects of Isotopic Composition, Temperature, Pressure, and Dissolved Gases on the Density of Liquid Water - George S. Kell. J Phys Chem Ref Data 6, 1109(1977).

\section{5}

Viscosity of Water Substance - New International Formulation and Its Background - A. Nagashima. J Phys Chem Ref Data 6, 1133(1977).

\section{Erratum}

Erratum: Viscosity of Water Substance - New International Formulation and Its Background - A. Nagashima. J Phys Chem Ref Data 12, 403p. (1983).

\section{6}

A Correlation of the Existing Viscosity and Thermal Conductivity Data of Gaseous and Liquid Ethane - Howard J. M. Hanley, K. E. Gubbins, and S. Murad. J Phys Chem Ref Data 6, 1167(1977).

\section{7}

Elastic Properties of Zinc: A Compilation and a Review - Hassell M. Ledbetter. J Phys Chem Ref Data 6, 1181(1977).

\section{8}

Behavior of the AB-Type Compounds at High Pressures and High Temperatures - Leo Merrill. J Phys Chem Ref Data 6, 1205(1977).

\section{9}

Energy Levels of Manganese, Mn I through Mn XXV - Charles $\mathrm{H}$. Corliss and Jack Sugar. J Phys Chem Ref Data 6, 1253(1977).

\section{0}

Tables of Atomic Spectral Lines for the $10000 \AA$ to $40000 \AA$ Region — Michael Outred. J Phys Chem Ref Data 7, 1(1978).

\section{1}

Evaluated Activity and Osmotic Coefficients for Aqueous Solutions The Alkaline Earth Metal Halides - Robert Goldberg and Ralph L. Nuttall. J Phys Chem Ref Data 7, 263(1978).
Microwave Spectra of Molecules of Astrophysical Interest, XII. Hydroxyl Radical - Robert A. Beaudet and Robert L. Poynter. J Phys Chem Ref Data 7, 311(1978).

\section{3}

Ideal Gas Thermodynamic Properties of Methanoic and Ethanoic Acids - Jing Chao and Bruno J. Zwolinski. J Phys Chem Ref Data 7, 363(1978).

\section{4}

Critical Review of Hydrolysis of Organic Compounds in Water Under Environmental Conditions - W. Mabey and T. Mill. J Phys Chem Ref Data 7, 383(1978).

\section{5}

Ideal Gas Thermodynamic Properties of Phenol and Cresols Shanti A. Kudchadker, Arvind P. Kudchadker, Randolph C. Wilhoit, and Bruno J. Zwolinski. J Phys Chem Ref Data 7, 417(1978).

\section{6}

Densities of Liquid $\mathrm{CH}_{4 \mathrm{a}} \mathrm{X}_{\mathrm{a}}(\mathrm{X}=\mathrm{Br}, \mathrm{I})$ and $\mathrm{CH}_{4(\mathrm{a}+\mathrm{b}+\mathrm{c}+\mathrm{d})} \mathrm{F}_{\mathrm{a}} \mathrm{Cl}_{\mathrm{b}} \mathrm{Br}_{\mathrm{c}} \mathrm{I}_{\mathrm{d}}$ Halomethanes - Arvind P. Kudchadker, Shanti A. Kudchadker, P. R. Patnaik, and P. P. Mishra. J Phys Chem Ref Data 7, 425(1978).

\section{7}

Microwave Spectra of Molecules of Astrophysical Interest, XIII. Cyanoacetylene - Walter J. Lafferty and Frank J. Lovas. J Phys Chem Ref Data 7, 441(1978).

\section{8}

Atomic Transition Probabilities for Vanadium, Chromium, and Manganese (A Critical Data Compilation of Allowed Lines) - S. M. Younger, Jeffrey R. Fuhr, Georgia A. Martin, and Wolfgang L. Wiese. J Phys Chem Ref Data 7, 495(1978).

\section{9}

Thermodynamic Properties of Ammonia - Lester Haar and John S. Gallagher. J Phys Chem Ref Data 7, 635(1978).

\section{0}

JANAF Thermochemical Tables, 1978 Supplement - Malcolm W. Chase, Jr., J. L. Curnutt, R. A. McDonald, and A. N. Syverud. J Phys Chem Ref Data 7, 793(1978).

\section{1}

Viscosity of Liquid Water in the Range $-8^{\circ} \mathrm{C}$ to $150^{\circ} \mathrm{C}$ - Joseph Kestin, Mordechai Sokolov, and William A. Wakeham. J Phys Chem Ref Data 7, 941(1978).

\section{2}

The Molar Volume (Density) of Solid Oxygen in Equilibrium with Vapor - Hans M. Roder. J Phys Chem Ref Data 7, 949(1978).

\section{3}

Thermal Conductivity of Ten Selected Binary Alloy Systems - Cho Y. Ho, M. W. Ackerman, K. Y. Wu, S. G. Oh, and T. N. Havill. J Phys Chem Ref Data 7, 959(1978) 
Semi-Empirical Extrapolation and Estimation of Rate Constants for Abstraction of $\mathrm{H}$ from Methane by $\mathrm{H}, \mathrm{O}, \mathrm{HO}$, and $\mathrm{O}_{2}-$ Robert Shaw. J Phys Chem Ref Data 7, 1179(1978).

\section{5}

Energy Levels of Vanadium, V I through V XXIII - Jack Sugar and Charles H. Corliss. J Phys Chem Ref Data 7, 1191(1978).

\section{6}

Recommended Atomic Electron Binding Energies, 1s to $6 \mathrm{p}_{3 / 2}$, for the Heavy Elements, $Z=84$ to $103-$ F. T. Porter and M. S. Freedman. J Phys Chem Ref Data 7, 1267(1978).

\section{7}

Ideal Gas Thermodynamic Properties of $\mathrm{CH}_{4(\mathrm{a}+\mathrm{b}+\mathrm{c}+\mathrm{d})} \mathrm{F}_{\mathrm{a}} \mathrm{Cl}_{b} \mathrm{Br}_{\mathrm{c}} \mathrm{I}_{d}$ Halomethanes - Shanti A. Kudchadker and Arvind P. Kudchadker. J Phys Chem Ref Data 7, 1285(1978).

\section{8}

Critical Review of Vibrational Data and Force Field Constants for Polyethylene - John Barnes and Bruno Fanconi. J Phys Chem Ref Data 7, 1309(1978).

\section{9}

Tables of Molecular Vibrational Frequencies, Part 9 - Takehiko Shimanouchi, Hiroatsu Matsuura, Yoshiki Ogawa, and Issei Harada. J Phys Chem Ref Data 7, 1323(1978).

130

Microwave Spectral Tables II. Triatomic Molecules - Frank J. Lovas. J Phys Chem Ref Data 7, 1445(1978).

131

Energy Levels of Titanium, Ti I through Ti XXII - Charles H. Corliss and Jack Sugar. J Phys Chem Ref Data 8, 1(1979).

\section{2}

The Spectrum and Energy Levels of the Neutral Atom of Boron (B I) - G. A. Odintzova and A. R. Striganov. J Phys Chem Ref Data 8, 63(1979).

\section{3}

Relativistic Atomic Form Factors and Photon Coherent Scattering Cross Sections - John H. Hubbell and I. Øverb $\varnothing$. J Phys Chem Ref Data 8, 69(1979).

\section{4}

Microwave Spectra of Molecules of Astrophysical Interest, XIV. Vinyl Cyanide (Acrylonitrile) - M. C. L. Gerry, K. Yamada, and G. Winnewisser. J Phys Chem Ref Data 8, 107(1979).

\section{5}

Molten Salts: Volume 4, Part 4, Mixed Halide Melts. Electrical Conductance, Density, Viscosity, and Surface Tension Data - George J. Janz, Reginald P. T. Tomkins, and Carolyn B. Allen. J Phys Chem Ref Data 8, 125(1979).

\section{6}

Atomic Radiative and Radiationless Yields for $\mathrm{K}$ and $\mathrm{L}$ Shells Morris O. Krause. J Phys Chem Ref Data 8, 307(1979).
Natural Widths of Atomic K and L Levels, $\mathrm{K} \alpha$ X-Ray Lines and Several KLL Auger Lines - Morris O. Krause and J. H. Oliver. J Phys Chem Ref Data 8, 329(1979).

\section{8}

Electrical Resistivity of Alkali Elements - T. C. Chi. J Phys Chem Ref Data 8, 339(1979).

\section{9}

Electrical Resistivity of Alkaline Earth Elements - T. C. Chi. J Phys Chem Ref Data 8, 439(1979).

140

Vapor Pressures and Boiling Points of Selected Halomethanes Arvind P. Kudchadker, Shanti A. Kudchadker, R. P. Shukla, and P. R. Patnaik. J Phys Chem Ref Data 8, 499(1979).

\section{1}

Ideal Gas Thermodynamic Properties of Selected Bromoethanes and Iodoethane - Shanti A. Kudchadker and Arvind P. Kudchadker. J Phys Chem Ref Data 8, 519(1979).

\section{2}

Thermodynamic Properties of Normal and Deuterated Naphthalenes - S. S. Chen, Shanti A. Kudchadker, and Randolph C. Wilhoit. J Phys Chem Ref Data 8, 527(1979).

\section{3}

Microwave Spectra of Molecules of Astrophysical Interest, XV. Propyne - A. Bauer, D. Boucher, J. Burie, J. Demaison, and A. Dubrulle. J Phys Chem Ref Data 8, 537(1979).

\section{4}

A Correlation of the Viscosity and Thermal Conductivity Data of Gaseous and Liquid Propane - Paul M. Holland, Howard J. M. Hanley, K. E. Gubbins, and J. M. Haile. J Phys Chem Ref Data, 8, 559(1979).

\section{5}

Microwave Spectra of Molecules of Astrophysical Interest, XVI. Methyl Formate - A. Bauder. J Phys Chem Ref Data 8, 583(1979).

\section{6}

Molecular Structures of Gas-Phase Polyatomic Molecules Determined by Spectroscopic Methods - Marlin D. Harmony, Victor W. Laurie, Robert L. Kuczkowski, Richard H. Schwendeman, D. A. Ramsay, Frank J. Lovas, Walter J. Lafferty, and Arthur G. Maki. J Phys Chem Ref Data 8, 619(1979).

147

Critically Evaluated Rate Constants for Gaseous Reactions of Several Electronically Excited Species - Keith Schofield. J Phys Chem Ref Data 8, 723(1979).

\section{8}

A Review, Evaluation, and Correlation of the Phase Equilibria, Heat of Mixing, and Change in Volume on Mixing for Liquid Mixtures of Methane + Ethane - M. J. Hiza, R. C. Miller, and Arthur J. Kidnay. J Phys Chem Ref Data 8, 799(1979). 
Energy levels of Aluminum, Al I through Al XIII - William C. Martin and Romuaid Zalubas. J Phys Chem Ref Data 8, 817(1979).

150

Energy Levels of Calcium, Ca I through Ca XX - Jack Sugar and Charles H. Corliss. J Phys Chem Ref Data 8, 865(1979).

\section{1}

Evaluated Activity and Osmotic Coefficients for Aqueous Solutions: Iron Chloride and the Bi-Univalent Compounds of Nickel and Cobalt - Robert N. Goldberg, Ralph L. Nuttall, and Bert R. Staples. J Phys Chem Ref Data 8, 923(1979).

152

Evaluated Activity and Osmotic Coefficients for Aqueous Solutions: Bi-Univaient Compounds of Lead, Copper, Manganese, and Uranium - Robert N. Goldberg. J Phys Chem Ref Data 8, 1005(1979).

\section{3}

Microwave Spectra of Molecules of Astrophysical Interest, XVII. Dimethyl Ether - Frank J. Lovas, H. Lutz, and H. Dreizler. J Phys Chem Ref Data 8, 1051(1979).

\section{4}

Energy Levels of Potassium, K I through $\mathrm{K}$ XIX - Charles $\mathrm{H}$. Corliss and Jack Sugar. J Phys Chem Ref Data 8, 1109(1979).

\section{5}

Electrical Resistivity of Copper, Gold, Palladium, and Silver - R. A. Matula. J Phys Chem Ref Data 8, 1147(1979).

\section{6}

Energy Levels of Magnesium, Mg I through Mg XII - William C. Martin and Romuald Zalubas. J Phys Chem Ref Data 9, 1(1980).

\section{7}

Microwave Spectra of Molecules of Astrophysical Interest. XVIII. Formic Acid - Edmond Willemot, Didier Dangoisse, Nicole Monnanteuil, and Jean Bellet. J Phys Chem Ref Data 9, 59(1980).

\section{8}

Refractive Index of Alkaline Earth Halides and Its Wavelength and Temperature Derivatives - H. H. Li. J Phys Chem Ref Data 9, 161(1980).

\section{9}

Evaluated Kinetic and Photochemical Data for Atmospheric Chemistry - D. L. Baulch, R. A. Cox, Robert F. Hampson, Jr., J. A. Kerr, J. Troe, and R. T. Watson. J Phys Chem Ref Data 9, 295(1980).

\section{0}

Energy Levels of Scandium, Sc I through Sc XXI - Jack Sugar and Charles H. Corliss. J Phys Chem Ref Data 9, 473(1980).

\section{1}

A Compilation of Kinetic Parameters for the Thermal Degradation of n-Alkane Molecules - D. L. Allara and Robert Shaw. J Phys Chem Ref Data 9, 523(1980).
Refractive Index of Silicon and Germanium and Its Wavelength and Temperature Derivatives - H. H. Li. J Phys Chem Ref Data 9, $561(1980)$

163

Microwave Spectra of Molecules of Astrophysical Interest. XIX. Methyl Cyanide - D. Boucher, J. Burie, A. Bauer, A. Dubrulle, and J. Demaison. J Phys Chem Ref Data 9, 659(1980).

\section{4}

A Review, Evaluation, and Correlation of the Phase Equilibria, Heat of Mixing, and Change in Volume on Mixing for Liquid Mixtures of Methane + Propane - R. C. Miller, Arthur J. Kidnay, and M. J. Hiza. J Phys Chem Ref Data 9, 721(1980).

\section{5}

Saturation States of Heavy Water - P. G. Hill and R. D. Chris MacMillan. J Phys Chem Ref Data 9, 735(1980).

\section{6}

The Solubility of Some Sparingly Soluble Lead Salts: An Evaluation of the Solubility in Water and Aqueous Electrolyte Solution - $\mathrm{H}$. Lawrence Clever and Francis J. Johnston. J Phys Chem Ref Data 9, 751(1980).

\section{7}

Molten Salts Data As Reference Standards for Density, Surface Tension, Viscosity and Electrical Conductance: $\mathrm{KNO}_{3}$ and $\mathrm{NaCl}-$ George J. Janz. J Phys Chem Ref Data 9, 791(1980).

\section{8}

Molten Salts: Volume 5, Part 1. Additional Single and MultiComponent Salt Systems. Electrical Conductance, Density, Viscosity, and Surface Tension Data - George J. Janz and Reginald P. T. Tomkins. J Phys Chem Ref Data 9, 831(1980).

\section{9}

Pair, Triplet, and Total Atomic Cross Sections (and Mass Attenuation Coefficients) for $1 \mathrm{MeV}-100 \mathrm{GeV}$ Photons in Elements $\mathrm{Z}=1$ to $100-$ John H. Hubbell, Heinz A. Gimm, and I. Qverb $\varnothing$. J Phys Chem Ref Data 9, 1023(1980).

\section{0}

Tables of Molecular Vibrational Frequencies, Part 10 - Takehiko Shimanouchi, Hiroatsu Matsuura, Yoshiki Ogawa, and Issei Harada. J Phys Chem Ref Data 9, 1149(1980).

\section{1}

An Improved Representative Equation for the Dynamic Viscosity of Water Substance - J. T. R. Watson, R. S. Basu, and Jan V. Sengers. J Phys Chem Ref Data 9, 1255(1980).

\section{2}

Static Dielectric Constant of Water and Steam - M. Uematsu and E. U. Franck. J Phys Chem Ref Data 9, 1291(1980).

\section{3}

Compilation and Evaluation of Solubility Data in the Mercury (I) Chloride-Water System - Y. Marcus. J Phys Chem Ref Data 9, 1307(1980). 
Evaluated Activity and Osmotic Coefficients for Aqueous Solutions: Bi-Univalent Compounds of Zinc, Cadmium, and Ethylene Bis(Trimethylammonium) Chloride and Iodide - Robert N. Goldberg. J Phys Chem Ref Data 10, 1(1981).

\section{5}

Tables of the Dynamic and Kinematic Viscosity of Aqueous $\mathrm{KCl}$ Solutions in the Temperature Range $25-150^{\circ} \mathrm{C}$ and the Pressure Range 0.1-35 MPa - Joseph Kestin, H. Ezzat Khalifa, and Robert J. Correia. J Phys Chem Ref Data 10, 57(1981).

\section{6}

Tables of the Dynamic and Kinematic Viscosity of Aqueous $\mathrm{NaCl}$ Solutions in the Temperature Range $20-150^{\circ} \mathrm{C}$ and the Pressure Range 0.1-35 MPa - Joseph Kestin, H. Ezzat Khalifa, and Robert J. Correia. J Phys Chem Ref Data 10, 71(1981).

177

Heat Capacity and Other Thermodynamic Properties of Linear Macromolecules. I. Selenium - Umesh Gaur, Hua-Cheng Shu, Aspy Metha, and Bernhard Wunderlich. J Phys Chem Ref Data 10, 89(1981).

\section{8}

Heat Capacity and Other Thermodynamic Properties of Linear Macromolecules. II. Polyethylene - Umesh Gaur and Bernhard Wunderlich. J Phys Chem Ref Data 10, 119(1981).

\section{9}

Energy Levels of Sodium, Na I through Na XI - William C. Martin and Romuald Zalubas. J Phys Chem Ref Data 10, 153(1981).

\section{0}

Energy Levels of Nickel, Ni I through Ni XXVIII - Charles H. Corliss and Jack Sugar. J Phys Chem Ref Data 10, 197(1981).

\section{1}

Ion Product of Water Substance, $0-1000^{\circ} \mathrm{C}, 1-10,000$ Bars. New International Formulation and Its Background - William L. Marshall and E. U. Franck. J Phys Chem Ref Data 10, 295(1981).

\section{2}

Atomic Transition Probabilities for Iron, Cobalt, Nickel: A Critical Data Compilation of Allowed Lines - Jeffrey R. Fuhr, Georgia A. Martin, Wolfgang L. Wiese, and S. M. Younger. J Phys Chem Ref Data 10, 305(1981).

\section{3}

Thermodynamic Tabulations for Selected Phases in the System $\mathrm{CaO}-\mathrm{Al}_{2} \mathrm{O}_{3}-\mathrm{SiO}_{2}-\mathrm{H}_{2} \mathrm{O}$ at $101.325 \mathrm{kPa}(\mathrm{l}$ atm. $)$ between 273.15 and 1800 K - John L. Haas, Jr., Gilpin R. Robinson, Jr., and Bruce S. Hemingway. J Phys Chem Ref Data 10, 575(1981).

\section{4}

Evaluated Activity and Osmotic Coefficients for Aqueous Solutions: Thirty-Six Uni-Bivalent Electrolytes - Robert N. Goldberg. J Phys Chem Ref Data 10, 671(1981).

\section{5}

Activity and Osmotic Coefficients of Aqueous Alkali Metal Nitrites - Bert R. Staples. J Phys Chem Ref Data 10, 765(1981).
Activity and Osmotic Coefficients of Aqueous Sulfuric Acid at 298.15 K - Bert R. Staples. J Phys Chem Ref Data 10, 779(1981).

\section{7}

Rate Constants for the Decay and Reactions of the Lowest Electronically Excited Singlet State of Molecular Oxygen in Solution - Francis Wilkinson and James G. Brummer. J Phys Chem Ref Data 10, 809(1981).

\section{8}

Heat Capacity and Other Thermodynamic Properties of Linear Macromolecules. III. Polyoxides - Umesh Gaur and Bernhard Wunderlich. J Phys Chem Ref Data 10, 1001(1981).

\section{9}

Heat Capacity and Other Thermodynamic Properties of Linear Macromolecules. IV. Polypropylene - Umesh Gaur and Bernhard Wunderlich. J Phys Chem Ref Data 10, 1051(1981).

\section{0}

Tables of $\mathrm{N}_{2} \mathrm{O}$ Absorption Lines for the Calibration of Tunable Infrared Lasers from $522 \mathrm{~cm}^{-1}$ to $657 \mathrm{~cm}^{-1}$ and from $1115 \mathrm{~cm}^{-1}$ to 1340 $\mathrm{cm}^{-1}-$ W. B. Olson, Arthur G. Maki, and Walter J. Lafferty. J Phys Chem Ref Data 10, 1065(1981).

191

Microwave Spectra of Molecules of Astrophyical Interest. XX. Methane - I. Ozier, M. C. L. Gerry, and A. G. Robiette. J Phys Chem Ref Data 10, 1085(1981).

192

Energy Levels of Cobalt, Co I through Co XXVII - Jack Sugar and Charles H. Corliss. J Phys Chem Ref Data 10, 1097(1981).

\section{3}

A Critical Review of Henry's Law Constants for Chemicals of Environmental Interest - Donald Mackay and Wan Ying Shiu. J Phys Chem Ref Data 10, 1175(1981).

\section{4}

Journal of Physical and Chemical Reference Data Cummulative Indexes, Volumes 1 to $10 \mathrm{~J}$ Phys Chem Ref Data 10, 1205(1981).

\section{5}

A Fundamental Equation of State for Heavy Water - P. G. Hill, R. D. Chris MacMillan, and V. Lee. J Phys Chem Ref Data 11, 1(1982).

\section{Erratum}

Erratum: A Fundamental Equation of State for Heavy Water - P. G. Hill, R. D. Chris MacMillan, and V. Lee. J Phys Chem Ref Data 12, 1065(1983).

\section{6}

Volumetric Properties of Aqueous Sodium Chloride Solutions - P. S. Z. Rogers and Kenneth S. Pitzer. J Phys Chem Ref Data 11, 15(1982). 
Ideal Gas Thermodynamic Properties of $\mathrm{CH}_{3}, \mathrm{CD}_{3}, \mathrm{CD}_{4}, \mathrm{C}_{2} \mathrm{D}_{2}$, $\mathrm{C}_{2} \mathrm{D}_{4}, \mathrm{C}_{2} \mathrm{D}_{6}, \mathrm{C}_{2} \mathrm{H}_{6}, \mathrm{CH}_{3} \mathrm{~N}_{2} \mathrm{CH}_{3}$, and $\mathrm{CD}_{3} \mathrm{~N}_{2} \mathrm{CD}_{3}-$ Krishna $\mathrm{M}$. Pamidimukkala, David Rogers, and Gordon B. Skinner. J Phys Chem Ref Data 11, 83(1982).

198

Peak Absorption Coefficients of Microwave Absorption Lines of Carbonyl Sulphide - Z. Kisiel and D. J. Millen. J Phys Chem Ref Data 11, 101(1982).

\section{9}

Vibrational Contributions to Molecular Dipole Polarizabilities David M. Bishop and Lap M. Cheung. J Phys Chem Ref Data 11, 119(1982).

\section{0}

Energy Levels of Iron, Fe I through Fe XXVI - Charles H. Corliss and Jack Sugar. J Phys Chem Ref Data 11, 135(1982).

\section{1}

Microwave Spectra of Molecules of Astrophysical Interest. XXI. Ethanol $\left(\mathrm{C}_{2} \mathrm{H}_{5} \mathrm{OH}\right)$ and Propionitrile $\left(\mathrm{C}_{2} \mathrm{H}_{5} \mathrm{CN}\right)$ - Frank J. Lovas $J$ Phys Chem Ref Data 11, 251(1982).

\section{2}

Heat Capacity and Other Thermodynamic Properties of Linear Macromolecules. V. Polystyrene - Umesh Gaur and Bernhard Wunderlich. J Phys Chem Ref Data 11, 313(1982).

\section{3}

Evaluated Kinetic and Photochemical Data for Atmospheric Chemistry: Supplement I. CODATA Task Group on Chemical Kinetics D. L. Baulch, R. A. Cox, P. J. Crutzen, Robert F. Hampson, Jr., J. A. Kerr, J. Troe, and R. T. Watson. J Phys Chem Ref Data 11, 327(1982).

\section{4}

Molten Salts Data: Diffusion Coefficients in Single and MultiComponent Salt Systems - George J. Janz and Narottam P. Bansal. J Phys Chem Ref Data 11, 505(1982).

\section{Erratum}

Erratum: Molten Salts Data: Diffusion Coefficients in Single and Multi-Component Salt Systems - George J. Janz and Narottam P. Bansal. J Phys Chem Ref Data 13, 305(1984).

\section{5}

JANAF Thermochemical Tables, 1982 Supplement - Malcolm W. Chase, Jr., J. L. Curnutt, J. R. Downey, Jr., R. A. McDonald, A. N. Syverud, and E. A. Valenzuela. J Phys Chem Ref Data 11, 695(1982).

\section{6}

Critical Evaluation of Vapor-Liquid Equilibrium, Heat of Mixing, and Volume Change of Mixing Data. General Procedures - Buford D. Smith, Ol Muthu, Ashok Dewan, and Matthew Gierlach. J Phys Chem Ref Data 11, 941(1982).

\section{7}

Rate Coefficients for Vibrational Energy Transfer Involving the Hydrogen Halides - Stephen R. Leone. J Phys Chem Ref Data 11, 953(1982).
Behavior of the $\mathrm{AB}_{2}$-Type Compounds at High Pressures and High Temperatures - Leo Merrill. J Phys Chem Ref Data 11, 1005(1982).

\section{9}

Heat Capacity and Other Thermodynamic Properties of Linear Macromolecules. VI. Acrylic Polymers - Umesh Gaur, Suk-fai Lau, Brent B. Wunderlich, and Bernhard Wunderlich. J Phys Chem Ref Data 11, 1065(1982).

\section{0}

Molecular Form Factors and Photon Coherent Scattering Cross Sections of Water - L. R. M. Morin. J Phys Chem Ref Data 11, 1091(1982).

\section{1}

Evaluation of Binary PTxy Vapor-Liquid Equilibrium Data for $\mathrm{C}_{0}$ Hydrocarbons. Benzene + Cyclohexane - Buford D. Smith, Ol Muthu, Ashok Dewan, and Matthew Gierlach. J Phys Chem Ref Data 11, 1099(1982).

\section{2}

Evaluation of Binary Excess Enthalpy Data for $\mathrm{C}_{6}$ Hydrocarbons. Benzene + Cyclohexane - Buford D. Smith, Ol Muthu, Ashok Dewan, and Matthew Gierlach. J Phys Chem Ref Data 11, 1127(1982).

\section{3}

Evaluation of Binary Excess Volume Data for $C_{6}$ Hydrocarbons. Benzene + Cyclohexane - Buford D. Smith, Ol Muthu, Ashok Dewan, and Matthew Gierlach. J Phys Chem Ref Data 11, 1151(1982).

\section{4}

Thermodynamic Properties of Steam in the Critical Region - J. M. H. Levelt Sengers, B. Kamgar-Parsi, F. W. Balfour, and Jan V. Sengers. J Phys Chem Ref Data 12, 1(1983).

\section{5}

Heat Capacity and Other Thermodynamic Properties of Linear Macromolecules. VII. Other Carbon Backbone Polymers - Umesh Gaur, Brent B. Wunderlich, and Bernhard Wunderlich. J Phys Chem Ref Data 12, 29(1983).

\section{6}

Heat Capacity and Other Thermodynamic Properties of Linear Macromolecules. VIII. Polyesters and Polyamides - Umesh Gaur, Suk-fai Lau, Brent B. Wunderlich, and Bernhard Wunderlich. J Phys Chem Ref Data 12, 65(1983).

\section{7}

Heat Capacity and Other Thermodynamic Properties of Linear Macromolecules. IX. Final Group of Aromatic and Inorganic Polymers - Umesh Gaur, Suk-fai Lau, and Bernhard Wunderlich. J Phys Chem Ref Data 12, 91(1983).

\section{8}

An Annotated Compilation and Appraisal of Electron Swarm Data in Electronegative Gases - Jean W. Gallagher, Earl C. Beaty, J. Dutton, and L. C. Pitchford. J Phys Chem Ref Data 12, 109(1983). 
The Solubility of Oxygen and Ozone in Liquids - Rubin Battino, Timothy R. Rettich, and Toshihiro Tominaga. J Phys Chem Ref Data 12, 163(1983).

\section{0}

Recommemded Values for the Thermal Expansivity of Silicon from 0 to $1000 \mathrm{~K}-$ C. A. Swenson. J Phys Chem Ref Data 12, 179(1983).

\section{1}

Electrical Resistivity of Ten Selected Binary Alloy Systems - Cho Y. Ho, M. W. Ackerman, K. Y. Wu, T. N. Havill, R. H. Bogaard, R. A. Matula, S. G. Oh, and H. M. James. J Phys Chem Ref Data 12, 183(1983).

\section{2}

Energy Levels of Silicon, Si I through Si XIV - William C. Martin and Romuald Zalubas. J Phys Chem Ref Data 12, 323(1983).

\section{3}

Evaluation of Binary PTxy Vapor-Liquid Equilibrium Data for $\mathrm{C}_{6}$ Hydrocarbons. Benzene + Hexane - Buford D. Smith, Ol Muthu, and Ashok Dewan. J Phys Chem Ref Data 12, 381(1983).

\section{4}

Evaluation of Binary Excess Enthalpy Data for $\mathrm{C}_{6}$ Hydrocarbons. Benzene + Hexane - Buford D. Smith, O1 Muthu, and Ashok Dewan. J Phys Chem Ref Data 12, 389(1983).

\section{5}

Evaluation of Binary Excess Volume Data for $\mathrm{C}_{6}$ Hydrocarbons. Benzene + Hexane - Buford D. Smith, Ol Muthu, and Ashok Dewan. J Phys Chem Ref Data 12, 395(1983).

\section{6}

Atlas of the High Temperature Water Vapor Spectrum in the 3000 to $4000 \mathrm{~cm}^{-1}$ Region - A. S. Pine, M. J. Coulombe, C. CamyPeyret,and J-M. Flaud. J Phys Chem Ref Data 12, 413(1983).

\section{7}

Small-Angle Rayleigh Scattering of Photons at High Energies: Tabulations of Relativisitic HFS Modified Atomic Form Factors - D. Schaupp, M. Schumacher, F. Smend, P. Rullhusen, and John H. Hubbell. J Phys Chem Ref Data 12, 467(1983).

\section{8}

Thermodynamic Properties of $\mathrm{D}_{2} \mathrm{O}$ in the Critical Region - B. Kamgar-Parsi, J. M. H. Levelt Sengers, and Jan V. Sengers. J Phys Chem Ref Data 12, 513(1983).

\section{9}

Chemical Kinetic Data Sheets for High-Temperature Chemical Reactions - N. Cohen and K. R. Westberg. J Phys Chem Ref Data 12, 531(1983).

\section{0}

Molten Salts: Volume 5, Part 2. Additional Single and MultiComponent Salt Systems. Electrical Conductance, Density, Vicosity and Surface Tension Data - George J. Janz and Reginald P. T. Tomkins. J Phys Chem Ref Data 12, 591(1983).
International Tables of the Surface Tension of Water - N. B. Vargaftik, B. N. Volkov, and L. D. Voljak. J Phys Chem Ref Data 12, 817(1983).

\section{2}

Evaluated Theoretical Cross Section Data for Charge Exchange of Multiply Charged Ions with Atoms. I. Hydrogen A tom-Fully Stripped Ion Systems - R. K. Janev, B. H. Bransden, and Jean W. Gallagher. J Phys Chem Ref Data 12, 829(1983).

\section{3}

Evaluated Theoretical Cross Section Data for Charge Exchange of Multiply Charged Ions with Atoms. II. Hydrogen Atom-Partially Stripped Ions Systems - Jean W. Gallagher, B. H. Bransden, and R. K. Janev. J Phys Chem Ref Data 12, 873(1983).

\section{4}

Recommended Data on the Electron Impact Ionization of Light Atoms and Ions - K. L. Bell, H. B. Gilbody, J. G. Hughes, A. E. Kingston, and Francis J. Smith. J Phys Chem Ref Data 12, 891(1983).

\section{5}

A Correlation of the Viscosity and Thermal Conductivity Data of Gaseous and Liquid Ethylene - Paul M. Holland, B. E. Eaton, and Howard J. M. Hanley. J Phys Chem Ref Data 12, 917(1983).

\section{6}

Transport Properties of Liquid and Gaseous $\mathrm{D}_{2} \mathrm{O}$ over a Wide Range of Temperature and Pressure - N. Matsunaga and A. Nagashima. J Phys Chem Ref Data 12, 933(1983).

\section{7}

Thermochemical Data for Gaseous Monoxides - J. B. Pedley and E. M. Marshall. J Phys Chem Ref Data 12, 967(1983).

\section{8}

Vapor Pressure of Coal Chemicals - Jing Chao, C. T. Lin, and T. H. Chung. J Phys Chem Ref Data 12, 1033(1983).

\section{9}

Thermodynamic Properties of Aqueous Sodium Chloride Solutions - Kenneth S. Pitzer, J. Christopher Peiper, and R. H. Busey. J Phys Chem Ref Data 13, 1(1984).

\section{0}

Refractive Index of $\mathrm{ZnS}, \mathrm{ZnSe}$, and $\mathrm{ZnTe}$ and Its Wavelength and Temperature Derivatives - H. H. Li. J Phys Chem Ref Data 13, 103(1984).

\section{1}

High Temperature Vaporization Behavior of Oxides. I. Alkali Metal Binary Oxides - R. H. Lamoreaux and D. L. Hildenbrand. J Phys Chem Ref Data 13, 151(1984).

\section{2}

Thermophysical Properties of Fluid $\mathrm{H}_{2} \mathrm{O}$ - Joseph Kestin, Jan V. Sengers, B. Kamgar-Parsi, and J. M. H. Levelt Sengers. J Phys Chem Ref Data 13, 175(1984). 
Representative Equations for the Viscosity of Water Substance Jan V. Sengers and B. Kamgar-Parsi. J Phys Chem Ref Data 13, 185(1984).

\section{4}

Atlas of the Schumann-Runge Absorption Bands of $\mathrm{O}_{2}$ in the Wavelength Region 175-205 nm - K. Yoshino, D. E. Freeman, and W. H. Parkinson. J Phys Chem Ref Data 13, 207(1984).

\section{5}

Equilibrium and Transport Properties of the Noble Gases and Their Mixtures at Low Density - Joseph Kestin, K. Knierim, E. A. Mason, B. Najafi, S. T. Ro, and M. Waldman. J Phys Chem Ref Data 13, 229(1984).

\section{6}

Evaluation of Kinetic and Mechanistic Data for Modeling of Photochemical Smog - Roger Atkinson and Alan C. Lloyd. J Phys Chem Ref Data 13, 315(1984).

\section{7}

Rate Data for Inelastic Collision Processes in the Diatomic Halogen Molecules - J. I. Steinfeld. J Phys Chem Ref Data 13, 445(1984).

\section{8}

Water Solubilities of Polynuclear Aromatic and Heteroaromatic Compounds - Robert S. Pearlman, Samuel H. Yalkowsky, and Sujit Banerjee. J Phys Chem Ref Data 13, 555(1984).

\section{9}

The Solubility of Nitrogen and Air in Liquids - Rubin Battino, Timothy R. Rettich, and Toshihiro Tominaga. J Phys Chem Ref Data 13, 563(1984).

\section{0}

Thermophysical Properties of Fluid $\mathrm{D}_{2} \mathrm{O}$ - Joseph Kestin, Jan V. Sengers, B. Kamgar-Parsi, and J. M. H. Levelt Sengers. J Phys Chem Ref Data 13, 602(1984).

\section{1}

Experimental Stark Widths and Shifts for Spectral Lines of Neutral Atoms (A Critical Review of Selected Data for the Period 1976 to 1982) - N. Konjević, M. S. Dimitrijević, and Wolfgang L. Wiese. J Phys Chem R.ef Data 13, 619(1984).

\section{2}

Experimental Stark Widths and Shifts for Spectral Lines of Positive Ions (A Critical Review and Tabulation of Selected Data for the Period 1976 to 1982) - N. Konjević, M. S. Dimitrijević, and Wolfgang L. Wiese. J Phys Chem Ref Data 13, 649(1984).

\section{3}

A Review of Deuterium Triple-Point Temperatures - L. A. Schwalbe and E. R. Grilly. J Phys Chem Ref Data 13, 687(1984).
Evaluated Gas Phase Basicities and Proton Affinities of Molecules: Heats of Formation of Protonated Molecules - Sharon G. Lias, Joel F. Liebman, and Rhoda D. Levin. J Phys Chem Ref Data 13, 695(1984).

\section{5}

Isotopic Abundances and Atomic Weights of the Elements - Paul De Bièvre, Marc Gallet, Norman E. Holden, and I. Lynus Barnes. J Phys Chem Ref Data 13, 809(1984).

\section{6}

Representative Equations for the Thermal Conductivity of Water Substance - Jan V. Sengers, J. T. R. Watson, R. S. Basu, B. KamgarParsi, and R. C. Hendricks. J Phys Chem Ref Data 13, 893(1984).

257

Ground-State Vibrational Energy Levels of Polyatomic Transient Molecules - Marilyn E. Jacox. J Phys Chem Ref Data 13, 945(1984).

\section{8}

Electrical Resistivity of Selected Elements - P. D. Desai, T. K. Chu, H. M. James, and Cho Y. Ho. J Phys Chem Ref Data 13, 1069(1984).

\section{9}

Electrical Resistivity of Vanadium and Zirconium - P. D. Desai, H. M. James, and Cho Y. Ho. J Phys Chem Ref Data 13, 1097(1984).

260

Electrical Resistivity of Aluminum and Manganese - P. D. Desai, H. M. James, and Cho Y. Ho. J Phys Chem Ref Data 13, 1131(1984).

\section{1}

Standard Chemical Thermodynamic Properties of Alkane Isomer Groups - Robert A. Alberty and Catherine A. Gehrig. J Phys Chem Ref Data 13, 1173(1984).

\section{2}

Evaluated Theoretical Cross Section Data for Charge Exchange of Multiply Charged Ion with Atoms. III. Non-Hydrogenic Target Atoms - R. K. Janev and Jean W. Gallagher. J Phys Chem Ref Data 13, 1199(1984).

\section{3}

Heat Capacity of Reference Materials: Cu and W- G. K. White and S. J. Collocott. J Phys Chem Ref Data 13, 1251(1984).

\section{4}

Evaluated Kinetic and Photochemical Data for Atmospheric Chemistry: Supplement II. CODATA Task Group on Gas Phase Chemical Kinetics - D. L. Baulch, R. A. Cox, Robert F. Hampson, Jr., J. A. Kerr, J. Troe, and R. T. Watson. J Phys Chem Ref Data 13, 1259(1984). 


\section{Supplements}

Physical and Thermodynamic Properties of Aliphatic Alcohols Randolph C. Wilhoit and Bruno J. Zwolinski. J Phys Chem Ref Data 2, Suppl. 1(1973).

Thermal Conductivity of the Elements: A Comprehensive Review Cho Y. Ho, Robert W. Powell, and Peter E. Liley. J Phys Chem Ref Data 3, Suppl. 1(1974).

Energetics of Gaseous Ions - Henry M. Rosenstock, Keith Draxl, B. W. Steiner, and John T. Herron. J Phys Chem Ref Data 6, Suppl. 1(1977).

Evaluated Kinetic Data for High Temperature Reactions, Volume 4. Homogeneous Gas Phase Reactions of Halogen- and CyanideContaining Species - D. L. Baulch, J. Duxbury, S. J. Grant, and D. C. Montague. J Phys Chem Ref Data 10, Suppl. 1(1981).

Thermophysical Properties of Fluids. I. Argon, Ethylene, Parahydrogen, Nitrogen, Nitrogen Trifluoride, and Oxygen - Ben A. Younglove. J Phys Chem Ref Data 11, Suppl. 1(1982).

The NBS Tables of Chemical Thermodynamic Properties. Selected Values for Inorganic and $C_{1}$ and $C_{2}$ Organic Substances in SI Units Donald D. Wagman, William H. Evans, Vivian B. Parker, Richard H. Schumm, Iva Halow, Sylvia M. Bailey, Kenneth L. Churney, and Ralph L. Nuttall. J Phys Chem Ref Data 11, Suppl. 2(1982).

Heat Capacities and Entropies of Organic Compounds in the Condensed Phase - Eugene S. Domalski, William H. Evans, and Elizabeth D. Hearing. J Phys Chem Ref Data 13, Suppl. 1(1984).

\section{Reprint Packages}

Package No. Title and Contents of Package
Al
4 Molecular Vibrational Frequencies Reprint Nos. 103, 129, 170 and NSRDS 39

JANAF Thermochemical Tables, 3rd ed. out in late 1985
A3
19 Atomic Energy Levels
Reprint Nos. 26, 54, 64, 68, 94, 100, 109, 125, $126,131,132,149,150,154,156,160,179$, 180 and 192

Reprint Nos. 33, 56, 77, 78, 110 and 132

5 Atomic Transition Probabilities

Reprint Nos. 20, 63, 82, 118 and 182

Molecules in Space

Reprint Nos. 14, 17, 23, 24, 45, 46, 47, 48, $74,75,88,112,117,134,143,145,153,157$, 163 and 191

A7 9 Chemical Data Relevant to Air Pollution Reprint Nos. 1, 9, 19, 27, 32, 87, 101, 147 and 159

7 Molecular Spectra

Reprint Nos. 4, 8, 53, 79, 93, 130 and 146

9 Thermodynamic Properties of Electrolyte Solutions

Reprint Nos. 15, 95, 111, 151, 152, 174, 184, 185 and 186

B1 12 Ideal Gas Thermodynamic Properties Reprint Nos. 30, 42, 43, 62, 65, 66, 70, 80, $83,113,115$, and 141

3 Elastic Properties of Metals and Alloys Reprint Nos. 34, 57, and 107

3 Resistivity Reprint Nos. 138, 139 and 155

7 Molten Salts

Reprint Nos. 10, 41, 71, 96, 135, 167, and 168

3 Refractive Index

Reprint Nos. 81, 158 and 162

B6

11 Viscosity and Thermal Conductivity of Fluids Reprint Nos. 16, 35, 38, 59, 97, 106, 121, 144, 171,175 and 176

B7 $10 \quad$ Properties of Water Reprint Nos. 45, 104, 105, 171, 172, 181, 210, 214,226

4 Properties of Heavy Water

Reprint Nos. 165, 195, 228, 236

B9

9 Linear Micromolecules Reprint Nos. 177, 178, 188, 189, 202, 209, 215, 216 and 217 


\section{Other NSRDS Data Publlcatlons}

\section{NSRDS-NBS Serles}

National Standard Reference Data System Plan of Operation Edward L. Brady and M. Wallenstein. NSRDS-NBS 1, 12p. (1965).

2

Thermal Properties of Aqueous Uni-Univalent Electrolytes Vivian B. Parker. NSRDS-NBS 2, 68p. (1965).

\section{Sec. 1}

Selected Tables of Atomic Spectra: A. Atomic Energy Levels Second Edition; B. Multiplet Tables; Si II, Si III, Si IV - Charlotte E. Moore. NSRDS-NBS 3, 35p. (1965).

\section{Sec. 2}

Selected Tables of Atomic Spectra: A. Atomic Energy Levels Second Edition: B. Multiplet Tables; Si I - Charlotte E. Moore. NSRDS-NBS 3, 22p. (1967).

\section{Sec. 3}

Selected Tables of Atomic Spectra: A. Atomic Energy Levels Second Edition; B. Multiplet Tables; C I, C II, C III - Charlotte E. Moore. NSRDS-NBS 3, 73p. (1970).

\section{Sec. 4}

Selected Tables of Atomic Spectra: A. Atomic Energy Levels Second Edition; B. Multiplet Tables; N IV, N V, N VI, N VII Charlotte E. Moore. NSRDS-NBS 3, 46p. (1971).

\section{Sec. 5}

Selected Tables of Atomic Spectra: A. Atomic Energy Levels Second Edition; B. Multiplet Tables; N I, N II, N III - Charlotte E. Moore. NSRDS-NBS 3, 80p. (1975).

\section{Sec. 6}

Selected Tables of Atomic Spectra: A. Atomic Energy Levels Second Edition; B. Multiplet Tables; H I, D, T - Charlotte E. Moore. NSRDS-NBS 3, 32p. (1972).

\section{Sec. 7}

Selected Tables of Atomic Spectra: A. Atomic Energy Levels Second Edition; B. Multiplet Tables; O I - Charlotte E. Moore. NSRDS-NBS 3, 33p. (1976).

\section{Sec. 8}

Selected Tables of Atomic Spectra: A. Atomic Energy Levels Second Edition; B. Multiplet Tables; O VI, O VII , O VIII — Charlotte E. Moore. NSRDS-NBS 3, 31p. (1979).

\section{Sec. 9}

Selected Tables of Atomic Spectra: A. Atomic Energy Levels Second Edition; B. Multiplet Tables; O V - Charlotte E. Moore. NSRDS-NBS 3, 21p. (1980).

\section{Sec. 10}

Selected Tables of Atomic Spectra: A. Atomic Energy levels - Second Edition; B. Multiplet Tables; O IV - Charlotte E. Moore. NSRDS-NBS 3, 21p. (1983).

\section{Sec. 11}

Selected Tables of Atomic Spectra: A. Atomic Energy Levels - Second Edition; B. Multiplet Tables; O III - Charlotte E. Moore. NSRDS-NBS 3, ...p. (1985).

\section{Vol. 1}

Atomic Transition Probabilities. Elements Hyodrogen through Neon - Wolfgang L. Wiese, Melvin W. Smith, and Barbara M. Glennon. NSRDS-NBS 4, 153p. (1966).

5

The Band Spectrum of Carbon Monoxide - Paul H. Krupenie. NSRDS-NBS 5, 87p. (1966).

6

Tables of Molecular Vibrational Frequencies, Part 1 - Takehiko Shimanouchi. NSRDS-NBS 6, 56p. (1967).

7

High Temperature Properties and Decomposition of Inorganic Salts, Part 1. Sulfates - Kurt H. Stern and E. L. Weise. NSRDS-NBS 7, 38p. (1966).

8

Thermal Conductivity of Selected Materials - Robert W. Powell, Cho Y. Ho, and Peter E. Liley. NSRDS-NBS 8, 68p. (1966).

9

Tables of Bimolecular Gas Reactions - Aubrey F. TrotmanDickenson and G. S. Milne. NSRDS-NBS 9, 129p. (1967).

10

Selected Values of Electric Dipole Moments for Molecules in the Gas Phase - Ralph D. Nelson, Jr., David R. Lide, Jr., and Arthur A. Maryott. NSRDS-NBS 10, 49p. (1967).

\section{1}

Tables of Molecular Vibrational Frequencies, Part 2 - Takehiko Shimanouchi. NSRDS-NBS 11, 38p. (1967).

\section{2}

Tables for the Rigid Asymmetric Rotor: Transformation Coefficients from Symmetric to Asymmetric Bases and Expectation Values of $\mathrm{P}^{2<{ }_{2}}, \mathrm{P}^{4}<{ }_{2}$, and $\mathrm{P}^{6<{ }_{2}}-$ Richard H. Schwendeman. NSRDS-NBS 12 , 102p. (1968).

\section{3}

Hydrogenation of Ethylene on Metallic Catalysts - Juro Horiuti and Koshiro Miyahara. NSRDS-NBS 13, 62p. (1968).

\section{4}

X-Ray Wavelengths and X-Ray Atomic Energy Levels - Joyce A. Bearden and A. F. Burr. NSRDS-NBS 14, 66p. (1967).

15

Molten Salts: Volume 1. Electrical Conductance, Density, and Viscosity Data - George J. Janz, F. W. Dampier, G. R. Lakshminarayanan, P. K. Lorenz, and Reginald P. T. Tomkins. NSRDS-NBS 15, 140p. (1968). 
Thermal Conductivity of Selected Materials, Part 2 - Cho Y. Ho, Robert W. Powell, and Peter E. Liley. NSRDS-NBS 16, 146p. (1968).

17

Tables of Molecular Vibrational Frequencies, Part 3 - Takehiko Shimanouchi. NSRDS-NBS 17, 39p. (1968).

18

Critical Analysis of the Heat-Capacity Data of the Literature and Evaluation of Thermodynamic Properties of Copper, Silver, and Gold from 0 to $300 \mathrm{~K}$ - George T. Furukawa, W. G. Saba, and Martin L. Reilly. NSRDS-NBS 18, 49p. (1968).

19

Thermodynamic Properties of Ammonia as an Ideal Gas - Lester Haar. NSRDS-NBS 19, 10p. (1968).

20

Gas Phase Reaction Kinetics of Neutral Oxygen Species - Harold S. Johnston. NSRDS-NBS 20, 49p. (1968).

\section{1}

Kinetic Data on Gas Phase Unimolecular Reactions - Sidney W. Benson and Harry E. O'Neal. NSRDS-NBS 21, 645p. (1970).

\section{2}

Atomic Transition Probabilities, Volume II. Sodium through Calcium - Wolfgang L. Wiese, Melvin W. Smith, and Barbara M. Miles. NSRDS-NBS 22, 268p. (1969).

\section{3}

Partial Grotrian Diagrams of Astrophysical Interest - Charlotte E. Moore and Paul W. Merrill. NSRDS-NBS 23, 65p. (1968).

\section{4}

Theoretical Mean Activity Coefficients of Strong Electrolytes in Aqueous Solutions from 0 to $100^{\circ} \mathrm{C}-$ Walter J. Hamer. NSRDS-NBS 24, 271p. (1968).

\section{5}

Electron Impact Excitation of Atoms - Benjamin L. Moiseiwitsch and Steven J. Smith. NSRDS-NBS 25, 120p. (1968).

\section{6}

Ionization Potentials, Appearance Potentials, and Heats of Formation of Gaseous Positive Ions - Joseph L. Franklin, J. G. Dillard, Henry M. Rosenstock, John T. Herron, Keith Draxl, and Frank H. Field. NSRDS-NBS 26, 289p. (1969).

\section{7}

Thermodynamic Properties of Argon from the Triple Point to $300 \mathrm{~K}$ at Pressures to 1000 Atmospheres - A. L. Gosman, Robert D. McCarty, and Jerome G. Hust. NSRDS-NBS 27, 153p. (1969).

\section{8}

Molten Salts: Volume 2. Section 1. Electrochemistry of Molten jalts. Gibbs Free Energies and Excess Free Energies from EquilibriumType Cells, Section 2. Surface Tension Data - George J. Janz, Chr. G. M. Dijkhuis, G. R. Lakshminarayanan, Reginald P. T. Tomkins, and J. Wong. NSRDS-NBS 28, 116p. (1968).
Photon Cross Sections, Attenuation Coefficients, and Energy Absorption Coefficients from $10 \mathrm{keV}$ to $100 \mathrm{GeV}$ - John H. Hubbell. NSRDS-NBS 29, 85p. (1969).

\section{0}

High Temperature Properties and Decomposition of Inorganic Salts, Part 2. Carbonates - Kurt H. Stern and E. L. Weise. NSRDS-NBS 30, 27p. (1969).

\section{1}

Bond Dissociation Energies in Simple Molecules - B. DeB. Darwent. NSRDS-NBS 31, 48p. (1970).

\section{2}

Phase Behavior in Binary and Multicomponent Systems at Elevated Pressures: n-Pentane and Methane-n-Pentane - Virginia M. Berry and Bruce H. Sage. NSRDS-NBS 32, 79p. (1970).

\section{3}

Electrolytic Conductance and the Conductances of the Halogen Acids in Water - Walter J. Hamer and H. J. DeWane. NSRDS-NBS 33, 37p. (1970).

\section{4}

Ionization Potentials and Ionization Limits Derived from the Analyses of Optical Spectra - Charlotte E. Moore. NSRDS-NBS 34, 22p. (1970).

\section{Vol.I}

Atomic Energy Levels as Derived from the Analyses of Optical Spectra, Volume I. ${ }^{1} \mathrm{H}$ to ${ }^{23} \mathrm{~V}$ - Charlotte E. Moore. NSRDS-NBS 35, 358p. (1971).

\section{Vol.II}

Atomic Energy Levels as Derived from the Analyses of Optical Spectra, Volume II. ${ }^{24} \mathrm{Cr}$ to ${ }^{41} \mathrm{Nb}$ - Charlotte E. Moore. NSRDS-NBS 35, 263p. (1971).

\section{Vol.Ill}

Atomic Energy Levels as Derived from the Analysis of Optical Spectra, Volume III. ${ }^{42} \mathrm{Mo}$ to ${ }^{57} \mathrm{La},{ }^{72} \mathrm{Hf}$ to ${ }^{89} \mathrm{Ac}$ - Charlotte E. Moore. NSRDS-NBS 35, 289p. (1971).

\section{6}

Critical Micelle Concentrations of Aqueous Surfactant Systems Pasupati Mukerjee and Karol J. Mysels. NSRDS-NBS 36, 222p. (1971).

\section{7}

JANAF Thermochemical Tables, Second Edition - Daniel R. Stull and H. Prophet. NSRDS-NBS 37, 1141p. (1971).

\section{8}

Critical Review of Ultraviolet Photoabsorption Cross Sections for Molecules of Astrophysical and Aeronomic Interest - Robert D. Hudson. NSRDS-NBS 38, 114p. (1971).

\section{9}

Tables of Molecular Vibrational Frequencies, Consolidated Volume I - Takehiko Shimanouchi. NSRDS-NBS 39, 167p. (1972). 
A Multiplet Table of Astrophysical Interest, Revised Edition, Part I. Table of Multiplets, Part II. Finding List of All Lines in the Table of Multiplets - Charlotte E. Moore. NSRDS-NBS 40, 261p. (1972).

\section{1}

Crystal Structure Transformations in Binary Halides - C. N. R. Rao and M. Natarajan. NSRDS-NBS 41, 57p. (1972).

\section{2}

Selected Specific Rates of Reactions of the Solvated Electron in Alcohols - Edgar Watson, Jr. and Sathyabhama Roy. NSRDS-NBS 42, 27p. (1972).

\section{3}

Selected Specific Rates of Reactions of Transients from Water in Aqueous Solution, 1. Hydrated Electron - Michael Anbar, Mark Bambenek, and Alberta B. Ross. NSRDS-NBS 43, 69p. (1973).

\section{Suppl.}

Selected Specific Rates of Reactions of Transients from Water in Aqueous Solution, 1. Hydrated Electron, Supplemental Data Alberta B. Ross. NSRDS-NBS 43, Suppl.(1975).

\section{4}

The Radiation Chemistry of Gaseous Ammonia - Donald B. Peterson. NSRDS-NBS 44, 41p. (1974).

\section{5}

Radiation Chemistry of Nitrous Oxide Gas, Primary Processes, Elementary Reactions and Yields - George R. A. Johnson. NSRDS-NBS 45, 29p. (1973).

\section{6}

Reactivity of the Hydroxyl Radical in Aqueous Solutions - Leon M. Dorfman and Gerald E. Adams. NSRDS-NBS 46, 72p. (1973).

\section{7}

Tables of Collision Integrals and Second Virial Coefficients for the $(\mathrm{m}, 6,8)$ Intermolecular Potential Function - Max Klein, Howard J. M. Hanley, Francis J. Smith, and Paul M. Holland. NSRDS-NBS 47, 161 p. (1974).

48

Radiation Chemistry of Ethanol: A Review of Data on Yields, Reaction Rate Parameters, and Spectral Properties of Transients - Gordon R. Freeman. NSRDS-NBS 48, 44p. (1974).

\section{9}

Transition Metal Oxides, Crystal Chemistry, Phase Transition, and Related Aspects - C. N. R. Rao and G. V. Subba Rao. NSRDS-NBS 49, 140p. (1974).

50

Resonances in Electron Impact on Atoms and Diatomic Molecules - George J. Schulz. NSRDS-NBS 50, 120p. (1973).

\section{1}

Selected Specific Rates of Reactions of Transients from Water in Aqueous Solution, II. Hydrogen Atom - Michael Anbar, Farhataziz, and Alberta B. Ross. NSRDS-NBS 51, 66p. (1975).
Electronic Absorption and Internal and External Vibrational Data of Atomic and Molecular Ions Doped in Alkali Halide Crystals - Suresh C. Jain, A. V. R. Warrier, and Suresh K. Agarwal. NSRDS-NBS 52, 55p. (1974).

53

Crystal Structure Transformations in Inorganic Nitrites, Nitrates, and Carbonates - C. N. R. Rao, Brahm Prakash, and M. Natarajan. NSRDS-NBS 53, 55p. (1975).

\section{4}

The Radiolysis of Methanol: Product Yields, Rate Constants, and Spectroscopic Parameters of Intermediates - J. H. Baxendale and Peter Wardman. NSRDS-NBS 54, 33p. (1975).

\section{5}

Property Index to NSRDS Data Compilations, 1964-1972 - David R. Lide, Jr., Gertrude B. Sherwood, Charles H. Douglass, and Herman M. Weisman. NSRDS-NBS 55, 21p. (1975).

\section{6}

Crystal Structure Transformations in Inorganic Sulfates, Phosphates, Perchlorates, and Chromates - C. N. R. Rao and Brahm Prakash. NSRDS-NBS 56, 37p. (1975).

57

Yields of Free Ions Formed in Liquids by Radiation - Augustine $\mathrm{O}$. Allen. NSRDS-NBS 57, 38p. (1976).

\section{8}

Drift Mobilities and Conduction Band Energies of Excess Electrons in Dielectric Liquids - Augustine O. Allen. NSRDS-NBS 58, 23p. (1976).

\section{9}

Selected Specific Rates of Reactions of Transients from Water in Aqueous Solution, III. Hydroxyl Radical and Perhydroxyl Radical and Their Radical Ions - Farhataziz and Alberta B. Ross. NSRDS-NBS 59, 126p. (1977).

60

Atomic Energy Levels - The Rare-Earth Elements, the Spectra of La, Ce, Pr, Nd, Pm, Sm, Eu, Gd, Tb, Dy, Ho, Er, Tm, Yb, Lu William C. Martin, Romuald Zalubas, and Lucy Hagan. NSRDS-NBS 60, 422p. (1978).

\section{Part I}

Physical Properties Data Compilations Relevant to Energy Storage. I. Molten Salts: Eutectic Data - George J. Janz, Carolyn B. Allen, J. R. Downey, Jr., and Reginald P. T. Tomkins. NSRDS-NBS 61, 244p. (1978).

\section{Part II}

Physical Properties Data Compilations Relevant to Energy Storage. II. Molten Salts: Data on Single and Multi-Component Systems George J. Janz, Carolyn B. Allen, Narottam P. Bansal, R. M. Murphy, and Reginald P. T. Tomkins. NSRDS-NBS 61, 420p. (1979). 


\section{Part III}

Physical Properties Data Compilations Relevant to Energy Storage. III. Engineering Properties of Single and Polycrystaline Sodium Beta and Beta" Alumina - G. R. Miller and D. G. Paquette. NSRDS-NBS 61, 19p. (1979).

\section{Part IV}

Physical Properties Data Compilations Relevant to Energy Storage. IV. Molten Salts: Data on Additional Single and Multi-Component Salt Systems - George J. Janz and Reginald P. T. Tomkins. NSRDS-NBS 61, 870p. (1981).

\section{Part V}

Physical Properties Data Compilations Relevant to Energy Storage. V. Mechanical Properties Data on Alloys for Use in Flywheels Hassell M. Ledbetter. NSRDS-NBS 61, 42p. (1982).

\section{2}

Compilation of Rate Constants for the Reactions of Metal Ions in Unusual Valency States - George V. Buxton and Robin M. Sellers. NSRDS-NBS 62, 68p. (1978).

\section{Vols. $1,2,3,4$}

EPA/NIH Mass Spectral Data Base, Volume 1. Molecular Weights 30-186; Volume 2. Molecular Weights 16-273; Volume 3. Molecular Weights 273-381; Volume 4. Molecular Weights 381-1674 - Stephen R. Heller and G. W. A. Milne. NSRDS-NBS 63, 1,2,3,4(1978).

\section{Suppl. 1}

EPA/NIH Mass Spectral Data Base, Supplement 1 - Stephen R. Heller and G. W. A. Milne. NSRDS-NBS 63, Suppl. 1(1980).

\section{Suppl. 2}

EPA/NIH Mass Spectral Data Base, Supplement 2 - Stephen R. Heller, G. W. A. Milne, and Lewis H. Gevantman. NSRDS-NBS 63, Suppl. 2(1983).

\section{4}

Rate Coefficients for Ion-Molecule Reactions, Organic Ions Other Than Those Containing Only $\mathrm{C}$ and $\mathrm{H}-\mathrm{L}$. Wayne Sieck. NSRDSNBS 64, 27p. (1980).

\section{5}

Rate Constants for Reactions of Inorganic Radicals in Aqueous Solution - Alberta B. Ross and Pedatsur Neta. NSRDS-NBS 65, 62p. (1979).

\section{6}

Ion Energetics Measurements, Supplement I. 1971-1973 - Henry M. Rosenstock, D. Sims, S. S. Schroyer, and W. J. Webb. NSRDS-NBS 66, 380p. (1980).

\section{7}

Table of Recommended Rate Constants for Chemical Reactions Occurring in Combustion - Francis Westley. NSRDS-NBS 67, 110p. (1980).

\section{8}

Tables of Line Spectra of the Elements, Part 1. Wavelengths and Intensities, Part 2. Transition Probabilities -- Joseph Reader, Charles H. Corliss, Wolfgang L. Wiese, and Georgia A. Martin. NSRDS-NBS 68, 415p. (1980).
Optical Spectra of Nonmetallic Inorganic Transient Species in Aqueous Solution - Gordon L. Hug. NSRDS-NBS 69, 167p. (1981).

70

Rate Constants for Reactions of Aliphatic Carbon-Centered Radicals in Aqueous Solution - Alberta B. Ross and Pedatsur Neta. NSRDS-NBS 70, 96p. (1982).

\section{1}

Ionization Potential and Appearance Potential Measurements, 1971-1981 - Rhoda D. Levin and Sharon G. Lias. NSRDS-NBS 71, 634p. (1982).

\section{2}

Tables of Rate Constants for Gas Phase Chemical Reactions of Sulfur Compounds (1971-1980) - Francis Westley. NSRDS-NBS 72, 42p. 42p. (1982).

\section{NBS Technicai Notes}

\section{0-3}

Selected Values of Chemical Thermodynamic Properties. Tables for the First Thirty-Four Elements in the Standard Order of Arrangement - Donald D. Wagman, William H. Evans, Vivian B. Parker, Iva Halow, Sylvia M. Bailey, and Richard H. Schumm. NBS Tech. Note 270, 264p. (1968).

\section{0-4}

Selected Values of Chemical Thermodynamic Properties. Tables for Elements 35 through 53 in the Standard Order of Arrangement Donald D. Wagman, William H. Evans, Vivian B. Parker, Iva Halow, Sylvia M. Bailey, and Richard H. Schumm. NBS Tech. Note 270, 152p. (1969).

\section{0-5}

Selected Values of Chemical Thermodynamic Properties. Tables for Elements 54 through 61 in the Standard Order of Arrangement Donald D. Wagman, William H. Evans, Vivian B. Parker, Iva Halow, Sylvia M. Bailey, Richard H. Schumm, and Kenneth L. Churney. NBS Tech. Note 270, 49p. (1971).

\section{0-6}

Selected Values of Chemical Thermodynamic Properties. Tables for the Alkaline Earth Elements (Elements 92 through 97 in the Standard Order of Arrangement) - Vivian B. Parker, Donald D. Wagman, and William H. Evans. NBS Tech. Note 270, 124p. (1971).

\section{0-7}

Selected Values of Chemical Thermodynamic Properties. Tables for the Lanthanide (Rare Earth) Elements (Elements 62 through 76 in the Standard Order of Arrangement) - Richard H. Schumm, Donald D. Wagman, Sylvia M. Bailey, William H. Evans, and Vivian B. Parker. NBS Tech. Note 270, 84p. (1973).

\section{0- 8}

Selected Values of Chemical Thermodynamic Properties: Compounds of Uranium, Protactinium, Thorium, Actinitum, and the Alkali Metals - Donald D. Wagman, William H. Evans, Vivian B. Parker, Richard H. Schumm, and Ralph L. Nuttall. NBS Tech. Note 270, 149p. (1981). 
Liquid Densities of Oxygen, Nitrogen, Argon, and Parahydrogen Hans M. Roder, Robert D. McCarty, and V. J. Johnson. NBS Tech. Note 361, 1972(1973).

\section{8}

Compendium of ab initio Calculations of Molecular Energies and Properties - Morris Krauss. NBS Tech. Note 438, 139p.

\section{4}

Critically Evaluated Transition Probabilities for Ba I and II - Barbara M. Miles and Wolfgang L. Wiese. NBS Tech. Note 474, 22p. (1969).

\section{4}

A Review of Rate Constants of Selected Reactions of Interest in Re-Entry Flow Fields in the Atmosphere - M. H. Bortner. NBS Tech. Note 484, 62p. (1969).

\section{1}

Comparison of Theoretical and Experimental Photoeffect Data, 0.1 $\mathrm{keV}$ to $1.5 \mathrm{MeV}-$ John H. Hubbell and W. J. Veigele. NBS Tech. Note $901,47 p$. (1976).

\section{8}

Total Photon Absorption Cross Section Measurements, Theoretical Analysis and Evaluations for Energies above $10 \mathrm{MeV}-$ Heinz A. Gimm and John H. Hubbell. NBS Tech. Note 968, 81p. (1978).

\section{3}

Properties of Selected Superconductive Materials, 1978 Supplement - Benjamin W. Roberts. NBS Tech. Note 983, 103p. (1978).

\section{5}

An Equation of State for Fluid Ethylene - Robert D. McCarty and Richard T. Jacobsen. NBS Tech. Note 1045, 164p. (1981).

1051

Thermophysical Properties of Isobutane from 114 to $700 \mathrm{~K}$ at Pressures to $70 \mathrm{MPa}-$ Robert D. Goodwin and W. M. Haynes. NBS Tech. Note 1051, 199p. (1982).

\section{NBS Monographs}

\section{Vol. 1}

Microwave Spectral Tables, Volume I. Diatomic Molecules - Paul F. Wacker, M. Mizushima, J. D. Petersen, and J. R. Ballard. NBS Monograph 70, 171p. (1964).

\section{Vol. II}

Microwave Spectral Tables, Volume II. Line Strengths of Asymmetric Rotors - Paul F. Wacker and M. R. Pratto. NBS Monograph 70, 349p. (1964).

\section{Vol. III}

Microwave Spectral Tables, Volume III. Polyatomic Molecules with Internal Rotation - Paul F. Wacker, M. S. Cord, D. G. Burkhard, J. D. Petersen, and R. F. Kukol. NBS Monograph 70, 275p. (1969).

\section{Vol. IV}

Microwave Spectral Tables, Volume IV. Polyatomic Molecules without Internal Rotation - M. S. Cord, J. D. Petersen, M. S. Lojko, and R. H. Haas. NBS Monograph 70, 419p. (1968).
Microwave Spectral Tables, Volume V. Spectral Line Listing - M. S. Cord, M. S. Lojko, and J. D. Petersen. NBS Monograph 70, 533p. (1968).

\section{4}

Thermodynamic and Related Properties of Parahydrogen from the Triple Point to $100 \mathrm{~K}$ at Pressures to 340 Atmospheres - Hans M. Roder, Lloyd A. Weber, and Robert D. Goodwin. NBS Monograph 94, 116p. (1965).

\section{5}

The Calculation of Rotational Energy Levels and Rotational Line Intensities in Diatomic Molecules - Jon T. Hougen. NBS Monograph 115, 54p. (1970).

\section{4}

Space Groups and Lattice Complexes - W. Fisher, Hans Burzlaff, Erwin Hellner, and Joseph D. H. Donnay. NBS Monograph 134, 177p. (1973).

\section{3}

The First Spectrum of Hafnium (Hf I) - William F. Meggers and Charlotte E. Moore. NBS Monograph 153, 123p. (1976).

\section{7}

Physical Properties Data for Rock Salt - Lewis H. Gevantman. NBS Monograph 167, 288p. (1981).

169

Thermophysical Properties of Normal Butane from 135 to $700 \mathrm{~K}$ at Pressures to $70 \mathrm{MPa}-$ W. M. Haynes and Robert D. Goodwin. NBS Monograph 169, 197p. (1982).

170

Thermophysical Properties of Propane from 85 to $700 \mathrm{~K}$ at Pressures to $70 \mathrm{MPa}-$ Robert D. Goodwin and W. M. Haynes. NBS Monograph 170, 249p. (1982).

\section{NBS Special Publication}

\section{3}

Reaction Rate and Photochemical Data for Atmospheric Chemistry - 1977 - Robert F. Hampson, Jr. and David Garvin. NBS Spec. Publ. 513, 111p. (1978).

\section{Joint Institute for Laboratory Astrophysics Reports}

6

Compilation of Low Energy Electron Collision Cross Section Data Part I. Ionization, Dissociative Processes, Vibrational and Rotational Excitation - Lee J. Kieffer. JILA Report 6, 95p. (1969).

7

Compilation of Low Energy Electron Collsion Cross Section Data. Part II. Line and Level Excitation - Lee J. Kieffer. JILA Report 7, 167p. (1969).

13

Compilation of Electron Collision Cross Section Data for Modelling Gas Discharge Lasers - Lee J. Kieffer. JILA. Report 13, 139p. (1973). 


\section{NBS Interim Reports}

\section{5-770}

Equation of State for Ammonia - Lester Haar and John S. Gallagher. NBSIR 75-770, 27p. (1975).

\section{5-968}

Selected Thermochemical Data Compatible with CODATA Recommendations - Vivian B. Parker, Donald D. Wagman, and David Garvin. NBSIR 75-968, 35p. (1976).

\section{6-1002}

Industrial Process Data for Fluids: A Survey of Current Research at the National Bureau of Standards - Howard J. White, Jr. NBSIR 76-1002, 54p. (1976).

\section{$76-1034$}

Chemical Thermodynamic Properties of Compounds of Sodium, Potassium, and Rubidium: An Interim Tabulation of Selected Material - Donald D. Wagman, William H. Evans, Vivian B. Parker, and Richard H. Schumm. NBSIR 76-1034, 76p. (1976).

\section{6-1147}

A Combined Least Sums and Least Squares Approach to the Evaluation of Thermodynamic Data Networks - David Garvin, Vivian B. Parker, Donald D. Wagman, and William H. Evans. NBSIR 76-1147, 41p. (1976).

\section{$77-860$}

Provisional Thermodynamic Functions of Propane from 85 to $700 \mathrm{~K}$ at Pressures to 700 Bar - Robert D. Goodwin. NBSIR 77.860, 240p. (1977).

\section{7-865}

Thermodynamic and Related Properties of Oxygen from the Triple Point to $300 \mathrm{~K}$ at Pressures to 1000 Bar - Lloyd A. Weber. NBSIR 77.865, 162p. (1977).

\section{7-1300}

A Computer Assisted Evaluation of the Thermochemical Data of the Compounds of Thorium - Donald D. Wagman, Richard H. Schumm, and Vivian B. Parker. NBSIR 77.1300, 94p. (1977).

\section{$78-1479$}

Thermodynamic Properties of Miscellaneous Materials - Eugene S. Domalski, William H. Evans, and Thomas L. Jobe, Jr. NBSIR 78-1479, 69p. (1981).

\section{9-1777}

A Compendium of Gas Phase Basicity and Proton Affinity Measurements - K. N. Hartman, Sharon G. Lias, P. J. Ausloos, Henry M. Rosenstock, S. S. Schroyer, C. Schmidt, D. Martinsen, and G. W. A. Milne. NBSIR 79-1777, 563p. (1979).

\section{9-1941}

Table of Recommended Rate Constants for Chemical Reactions Occurring in Combustion - Francis Westley. NBSIR 79-1941, 169p. (1979).

\section{0-2029}

The Thermochemical Properties of Uranium-Halogen Containing Compounds - Vivian B. Parker. NBSIR 80-2029, 173p. (1980).

\section{0-2032}

Kinetic and Photochemical Data for Atmospheric Chemistry, Reactions of the Nitrogen Oxides - Robert F. Hampson, Jr. NBSIR 80.2032, 89p. (1980).

\section{$81-2217$}

Feasiblility Study: Compilation and Evaluation of Properties Data for Basalt, Granite, Tuff, and Shale - Lewis H. Gevantman. NBSIR 81-2217, 259p. (1981).

\section{$81-2253$}

A Thermodynamic Surface for Water: The Formulation and Computer Program - Lester Haar, John S. Gallagher, and George S. Kell. NBSIR 81.2253, 38p. (1981).

\section{$81-2254$}

Tables of Experimental Rate Constants for Chemical Reactions Occurring in Combustion (1971-1977) - Francis Westley. NBSIR 81-2254, 302p. (1981).

\section{$81-2276$}

A Compilation of Thermodynamic and Transport Properties of Aqueous Sulfuric Acid - Bert R. Staples and Theresa F. Wobbeking. NBSIR 81-2276, 26p. (1981).

\section{$81-2341$}

Chemical Thermodynamic Data Banks - David Garvin, Vivian B. Parker, and Donald D. Wagman. NBSIR 81-2341, 30p. (1981).

\section{$81-2343$}

Thermodynamic Properties of Solid Aluminosilicates at Elevated Temperatures - Richard H. Schumm. NBSIR 81-2343, 57p. (1981).

\section{1-2345}

A Report on Thermodynamic Data for Desulfurization Processes Vivian B. Parker, Bert R. Staples, Thomas L. Jobe, Jr., and David B. Neumann. NBSIR 81-2345, 89p. (1981)

\section{NSRDS Data Publicatlons from other Publishers}

$\pi+\mathrm{p}, \pi+\mathrm{n}$, and $\pi+\mathrm{d}$ 1nteractions - A Compilation: Parts I and I1 Denyse M. Chew, Victor P. Henri, Thomas A. Lasinski, Thomas G. Trippe, Fumiyo Uchiyama, Frederick C. Winkelmann and Particle Data Group. UCRL 53, Springfield, VA: NTIS, 213p. (1973). LBL 53; Part II is on microfiche located in the back cover pocket, Al0.

$\pi \mathrm{N}$ Particle-Wave Amplitudes - David J. Herndon, Angela BarbaroGaltieri, Arthur H. Rosenfeid and Particle Data Group. UCRL 20030 $\pi$ N, Springfield, VA: NT1S, 85p. (1970). UCRL $20030 \pi \mathrm{N}, \mathrm{A} 05$.

$\pi \mathrm{N}$ Two-Body Scattering Data, 1. A User's Guide to the Lovelace-Almehed Data Tape - Claude Lovelace, Sverkei Almehed, Fumiyo Uchiyama, Robert Kelly, Victor P. Henri and Particle Data Group. UCRL 63, Springfield, VA: NTIS, 146p. (1973). LBL 63, A07.

A Compilation of YN Reactions - Odette Benary, Naomi Barash-Schmidt, LeRoy R. Price, Arthur H. Rosenfeld, Gideon Alexander and Particle Data Group. UCRL 20000YN, Springfield, VA: NTIS, 70p. (1970). UCRL-20 000 YN, A04.

Atomic Gas Laser Transition Data, A Critical Evaluation - William Ralph Bennett, Jr., New York: IF1/Plenum, 293p. (1979), ISBN: 0-306-65187-4 
Bulletin of Alloy Phase Diagrams - Joanne Murray, editor(s) and American Society for Metals. Bull Alloy Phase Diag 3, Metals Park, OH: American Society for Metals, 130.p. (1982), ISBN: 01970216.

Chemical Kinetic and Photochemical Data Sheets for Atmospheric Reactions - Robert F. Hampson, Jr. Fed Aviation Admin EE 80-17, Springfield, VA: NTIS, 490p. (1980). FAA-EE-80-17, A21.

Coblentz Society Evaluated Infrared Reference Spectra, Volumes 6 to 10 and Cumulative Coblentz Indexes - American Society for Testing and Materials; Coblentz Society; Joint Committee on Atomic and Molecular Physical Data. Coblentz Soc Infr Spect 6-10, Philadelphia, PA: Sadtler Research Laboratories, 5001p. (1975).

Combustion Fundamentals for Waste Incineration - American Society of Mechanical Engineers, Research Committee on Industrial and Municipal Wastes., New York: American Society of Mechanical Engineers, 212p. (1974).

Contributions to the Data on Theoretical Metallurgy, XVI. Thermodynamic Properties of Nickel and lts Inorganic Compounds - Alla D. Mah and Louis B. Pankratz. U.S. Bur Mines Bull 668, Springfield, VA: NTIS, 125p. (1976). U.S. Bureau of Mines Bulletin 668, A06.

Crystal Data Determinative Tables. Third Edition Volume 1: Organic Com. pounds - Joseph D. H. Donnay and Helen M. Ondik., Swarthmore, PA: JCPDS-International Center for Diffraction Data, 855p. (1972).

Crystal Data Determinative Tables, Third Edition Volume 2: Inorganic Compounds - Joseph D. H. Donnay and Helen M. Ondik., Swarthmore, PA: JCPDS.International Center for Diffraction Data, 1748p. (1973).

Crystal Data Determinative Tables, Third Edition Volume 3. Organic Compounds - Joseph D. H. Donnay, Olga Kennard, David G. Watson, and John R. Rodgers., Swarthmore, PA: JCPDS-International Center for Diffraction Data, 748p. (1978).

Crystal Data Determinative Tables, Third Edition Volume 4. Inorganic Compounds - Joseph D. H. Donnay, Helen M. Ondik, and Alan D. Mighell., Swarthmore, PA: JCPDS-InternationaI Center for Diffraction Data, 1308p. (1978).

Crystal Data Determinative Tables, Third Edition, Volume 5. Organic Compounds - Olga Kennard, David G. Watson, John E. Davies, John R. Rodgers, editor(s). 5, Swarthmore, PA, JCPDS-International Center for Diffraction Data,(1983).

Crystal Data Determinative Tables, Third Edition, Volume 6. Organic Compounds - Olga Kennard, David G. Watson, John E. Davies, editor(s). 6, Swarthmore, PA, JCPDS-International Center for Diffraction Data,(1983).

Derived Thermodynamic Properties of Ethylene - Roland H. Harrison and Donald R. Douslin. J Chem Eng Data. 22, Washington, DC: American Chemical Society, 24.p. (1977).

Desk Book of Infrared Spectra - Clara D. Craver and Coblentz Society; Joint Committee on Atomic and Molecular Physical Data., Kirkwood, MO: The Coblentz Society, 498p. (1977).

Diffusion Rate Data and Mass Transport Phenomena in Copper Systems Daniel B. Butrymowicz, John R. Manning, and Michael E. Read. INCRA Monograph V, New York: International Copper Research Association, Inc., 322p. (1977).

Diffusion Rate Data and Mass Transport Phenomena for Copper Systems, Part II - Daniel B. Butrymowicz, John R. Manning, and Michael E. Read. INCRA Monograph VIII, New York: International Copper Research Association, Inc., 701p. (1982).
Dissociation in Heavy Particle Collisions - G. W. McClure and James M. Peek. At Mol Collis Proc Ser, New York: Wiley-Interscience, 198p. (1972), ISBN: 0-4.71-5816-8.

Electron Impact lonization Cross-Section Data for Atoms, Atomic lons, and Diatomic Molecules: 1. Experimental Data - Lee J. Kieffer and Gordon H. Dunn. Rev Mod Phys. 38, New York: American Institute of Physics, 35p. (1966).

Excitation in Heavy Particle Collisions - Edward W. Thomas. At Mol Collis Proc Ser, New York: Wiley-Interscience, 436p. (1972), ISBN: 0.471-8589-0.

Infrared Spectra of Halogenated Hydrocarbons - Clara D. Craver and Coblentz Society; Joint Committee on Atomic and Molecular Physical Data., Kirkwood, MO: The Coblentz Society, 125p. (1977).

Infrared Spectra of Plasticizers and Other Additives - Clara D. Craver and Coblentz Society; Joint Committee on Atomic and Molecular Physical Data. , Kirkwood, MO: The Coblentz Society, 152p. (1977).

Ion-Molecule Reactions - Earl W. McDaniel, V. Cermak, A. Dalgarno, E. E. Ferguson, and L. Friedman. At Mol Collis Proc Ser, New York: Wiley. Interscience, 374p. (1970), ISBN: 0-471-5838-3.

$\mathrm{K}^{0}<-1 \mathrm{~N}$ Interactions - A Compilation - Particle Data Group. UCRL-LBL 55, Springfield, VA: NTIS, 56p. (1972). LBL 55, A04.

LNG Materials \& Fluids, A User's Manual of Property Data in Graphic Format - Douglas Mann and U.S. National Bureau of Standards., Boulder, CO: U.S. National Bureau of Standards, Cryogenic Division, 11p. (1977).

LNG Materials \& Fluids, A User's Manual of Property Data in Graphic Format, First Supplement - Douglas Mann and U.S. NationaI Bureau of Standards. Suppl. 1, Boulder, CO: U.S. National Bureau of Standards, 11p. (1978).

LNG Materials \& Fluids, A User's Manual of Property Data in Graphic Format, Second Supplement - Douglas Mann and U.S. National Bureau of Standards. Suppl. 2, Boulder, CO: U.S. National Bureau of Standards, 11p. (1980).

Low Energy Electron-Collision Cross Section Data. Part III. TotaI Scattering; Differential Elastic Scattering - Lee J. Kieffer. At Data. 2, New York: Academic Press, 293p. (1971).

Metallic Shifts in NMR: A Review of the Theory and Comprehensive Critical Data Compilation of Metallic Materials - Gesina Cynthia Carter, Lawrence H. Bennett, and Daniel J. Kahan. Prog Mater Sci, Oxford, New York: Pergamon Press, 2350p. (1977), ISBN: 0-08-02114-7.

NBS/NRC Steam Tables, Thermodynamic and Transport Properties and Computer Programs for Vapor and Liquid States of Water - Lester Haar, John S. Gallagher, and George S. Kell., New York: Hemisphere Press, 320p. (1984).

NN and ND Interactions - A Compilation - James E. Enstrom, Thomas Ferbel, Paul F. Slattery, Barry L. Werner, Zaven G. T. Guiragossian, Yoshio Sumi, Toshihiro Yoshida and Particle Data Group. UCRL-LBL 58, Berkeley, CA: Lawrence Berkeley Laboratory, U. of California, 281p. (1972). LBL 58.

Nuclear Wallet Cards - Virginia S. Shirley, C. Michael Lederer and National Nuclear Data Center. 1979, Upton, NY: National Nuclear Data Center, Brookhaven National Laboratory, 40p. (1979). Title, no charge.

Phase Diagrams and Thermodynamic Properties of Ternary Copper-Metal Systems - Y. Austin Chang, Joachim P. Neumann, A. Mikula, and Daniel Goldberg. INCRA Monograph VI, New York: International Copper Recearch Association, Inc., 702p. (1979). 
Phase Diagrams and Thermodynamic Properties of Ternary Copper-SulfurMetal Systems - Y. Austin Chang, Joachim P. Neumann, and U. V. Choudary. 1NCRA Monograph VII, New York: International Copper Research Association, lnc., 19lp. (1979).

Pressure, Volume, Temperature Relations of Ethylene - Donald R. Douslin and Roland H. Harrison. J Chem Thermody 76, New York, London:, 301p. (1976).

Problems with the Prandtl Number of Steam - Jan V. Sengers, R. S. Basu, B. Kamgar.Parsi, and Joseph Kestin. Mech Eng 104, New York, NY, 60p. (1982).

Review of Particle Properties, 25th Anniversary Edition - Particle Data Group. Phys Lett B 111B, Springfield, VA: NTIS, 316p. (1982).

Selected Thermodynamic Values and Phase Diagrams for Copper and Some of Its Binary Alloys - Ralph Hultgren and Pramond D. Desai. INCRA Monograph I, New York: International Copper Research Association, Inc., 204p. (1973).

Selected Values of the Thermodynamic Properties of Binary Alloys Ralph Hultgren, Pramond D. Desai, Donald T. Hawkins, M. Gleiser, and Kenneth K. Kelley., Metals Park, OH: American Society for Metals, 1435p. (1973).

Selected Values of the Thermodynamic Properties of the Elements - Ralph Hultgren, Pramond D. Desai, Donald T. Hawkins, M. Gleiser, Kenneth K. Kelley, and Donald D. Wagman., Metals Park, OH: American Society for Metals, 636p. (1973).

Table of lsotopes, Seventh Edition - C. Michael Lederer, Virginia S. Shirley, Edgardo Browne, Janis M. Dairiki, and Raymond E. Doebler., New York: Wiley-Interscience, 1628p. (1978), ISBN: 0-471-0417-3.

The Critical-Region Equation of State of Ethene and the Effect of Small Impurities - J. R. Hastings, J. M. H. Levelt Sengers, and F. W. Balfour. J Chem Thermody 12, London: Academic Press Inc., 1009p. (1980).

The Thermodynamic Properties of Aqueous Inorganic Copper Systems Paul Duby. INCRA Monograph IV, New York: International Copper Research Association, 1nc., 132p. (1977).

Theory of Charge Exchange - R. A. Mapletun., New York: WileyInterscience, 284p. (1971), ISBN: 0-471-5678-7.

Theory of the lonization of Atoms by Electron Impact - M. R. H. Rudge. Rev Mod Phys 40, .., 564p. (1968).

Thermodynamic Data for Waste Incineration - American Society of Mechanical Engineers, Research Committee on IndustriaI and Municipal Wastes., New York: American Society of Mechanical Engineers, 160p. (1979).

Thermodynamic Properties of Copper and Its Inorganic Compounds Edward G. King, Alla D. Mah, and Louis B. Pankratz. INCRA Monograph II, New York: International Copper Research Association, Inc., 257p. (1973).

Thermodynamic Properties of Copper-Slag Systems — Carlos Diaz. INCRA Monograph III, New York: International Copper Research Association, Inc., 178p. (1976).

Total Electron-Atom Collision Cross Sections at Low Energies - A Critical Review - Benjamin Bederson. Rev Mod Phys 43, 999, 601p. (1971).

\section{Translations from the Russian}

Electric Conductivity of Ferroelectrics - V. M. Gurevich. Russian Transl., Springfield, VA: NT1S, 366p. (1971). TT 70-50180, A16.
Handbook of Hardness Data - G. V. Samsonov and A. A. 1van'ko. Russian Transl., Springfield, VA: NTIS, 69p. (1970). TT 70-50177, A04.

Handbook of Phase Diagrams of Silicate Systems, Vol. I. Binary Systems, Second Revised Edition - N. A. Toropov, V. P. Barzakovskii, V. V. Lapin, N. N. Kurtseva, J. Schmorak, editor(s). Russian Transl., Springfield, VA: NTIS, 730p. (1970). TT 71-50040, A26.

Handbook of Phase Diagrams of Silicate Systems, Vol. I1. MetalOxygen Compounds in Silicate Systems, Second Revised Edition - N. A. Toropov, V. P. Barzakovskii, 1. A. Bondar', and Yu. P. Udalov. Russian Transl., Springfield, VA: NTIS, 329p. (1972). TT 71-50041, A15.

Handbook of Thermodynamic Data on Geological Substances - G. B. Naumov, B. N. Ryzhenko, and I. L. Khodakovsky. Russian Transl., Springfield, VA: NTIS, 340p. (1974). TT 73-53051 or PB226 722, A15.

Heavy Water, Thermophysical Properties - V. A. Kirillin, Ya. Z. Kazavchinskii, P. M. Kessel'man, S. L. Rivkin, A. E. Sheindlin, E. E. Shpil'rain, V. V. Sychev, and D. L. Timrot. Russian Transl., Springfield, VA: NTIS, 273p. (1971). TT 70-50094, A12.

Isochoric Heat Capacity of Water and Steam - M. P. Vukalovich, Kh. I. Amirkhanov, G. V. Stepanov, and B. G. Alibekov. Russian Transl., Springfield, VA: NTIS, 215p. (1974). TT 72-52002, A10.

Properties of Liquid and Solid Hydrogen - B. N. Esel'son, Y. P. Blagoi, V.N. Grigor'ev, V. G. Manzhelii, S. A. Mikhailenko, and N. P. Neklyudov. Russian Transl., Springfield, VA: NTIS, 126p. (1971). TT 70-50179, A07.

Rate Constants of Gas Phase Reactions, Reference Book - V. N. Kondratiev, L. J. Holtschlag, R. M. Fristrom, editor(s). Russian Transl., Springfield, VA: NT1S, 434p. (1972). COM 72-10014, A19.

Surface Ionization - E. Ya. Zandberg and N. L. Ionov. Russian Transl., Springfield, VA: NTIS, 364p. (1971). TT 70-50148, A16.

Thermodynamic and Thermophysical Properties of Combustion Products, Volume I. Computation Methods - V. P. Glushko, V. E. Alemasov, A. F. Dregalin, A. P. Tishin, and V. A. Khudyakov. Russian Transl., Springfield, VA: NTIS, 453p. (1974). TT 74-50019, A20.

Thermodynamic and Thermophysical Properties of Combustion Products, Volume Il. Oxygen-Based Propellants - V. P. Glushko, V. E. Alemasov, A. F. Dregalin, A. P. Tishin, V. A. Khudyakov, and V. N. Kostin. Russian Transl., Springfield, VA: NTIS, 505p. (1975). TT 74-50032, A22.

Thermodynamic and Thermophysical Properties of Combustion Products, Volume III. Oxygen- and Air-Based Propellant - V. P. Glushko, V. E. Alemasov, A. F. Dregalin, A. P. Tishin, V. A. Khudyakov, and V. N. Kostin. Russian Transl., Springfield, VA: NTIS, 648p. (1975). TT 75-50007, A26.

Thermodynamic and Thermophysical Properties of Combustion Products, Volume IV. Nitrogen Tetroxide-Based Propellants - V. P. Glushko, V. E. Alemasov, A. F. Dregalin, A. P. Tishin, V. A. Khudyakov, and V. N. Kostin. Russian Transl., Springfield, VA: NTIS, 540p. (1976). TT 76-50007, A23.

Thermodynamic and Thermophysical Properties of Helium - A. F. Alyab'ev, N. V. Tsederberg, V. N. Popov, and N. A. Morozova. Russian Transl., Springfield, VA: NTIS, 260p. (1971). TT 70-50096, A12.

Thermodynamic and Transport Properties of Ethylene and Propylene - I. A. Neduzhii. Russian Transl. Springfield, VA: NTIS, 206p. (1972). COM 75-11276, A10. 
Thermophysical Properties of Air and Air Components - A. A. Vasserman, Ya. Z. Kazavchinskii, V. A. Rabinovich, and A. M. Zhuravlev, Russian Transl. Springfield, VA: NTIS, 402p. (1971). TT 70-50095, A18.

Thermophysical Properties of Freon-22 - A. V. Kletskii. Russian Transl. Springfield, VA: NTIS, 72p. (1971). TT 70-50178, A04.

Thermophysical Properties of Gases and Liquids, No. $1-$ V. A. Rabinovich. Russian Transl. Springfield, VA: NTIS, 214p. (1970). TT 69-55091, A 10, the translation of volumes 2, 3, and 4 have the title: Thermophysical Properties of Matter and Substances.

Thermophysical Properties of Gaseous and Liquid Methane - V. A. Zagoruchenko and A. M. Zhuravlev, Russian Transl. Springfield, VA: NTIS, 251p. (1970). TT 70-50097, A 12.
Thermophysical Properties of Liquid Air and Its Components - A. A. Vasserman and V. A. Rabinovich. Russian Transl. Springfield, VA: NTIS, 255p. (1970). TT 69-55092, Al2.

Thermophysical Properties of Matter and Substances, Volume 2 V. A. Rabinovich. Russian Transl., Springfield, VA: NTIS, 395p. (1974). TT 72-52001, A17, the translation of volume 1 has the title: Thermophysical Properties of Gases and Liquids.

Thermophysical Properties of Matter and Substances, Volume 3 V. A. Rabinovich. Russian Transl. Springfield, VA: NTIS, 212p. (1975). TT 73-52009, A10, the translation of volume 1 has the title: Thermophysical Properties of Gases and Liquids.

Thermophysical Properties of Matter and Substances, Volume 4 V. A. Rabinovich. Russian Transl., Springfield, VA: NTIS, 179p. (1975). TT 73-52029, A09, the translation of volume 1 has the title: Thermophysical Properties of Gases and Liquids. 


\section{Critical Bibliographies and Indexes in the NBS Series}

\section{NBS Special Publications}

\section{1}

Bibliography on Flame Spectroscopy. Analytical Applications, 1800-1966 - Radu Mavrodineanu. NBS Spec. Publ. 281, 155p. (1967).

\section{Sect. I}

Bibliography on the Analyses of Optical Atomic Spectra. Section 1. ${ }^{1} \mathrm{H}_{-}{ }^{23} \mathrm{~V}$ - Charlotte E. Moore. NBS Spec. Publ. 306, 80p. (1968).

\section{Sect.II}

Bibliography on the Analyses of Optical Atomic Spectra. Section 2. ${ }^{24} \mathrm{Cr}-{ }^{41} \mathrm{Nb}$ - Charlotte E. Moore. NBS Spec. Publ. 306, 57p. (1969).

\section{Sect.III}

Bibliography on the Analyses of Optical A tomic Spectra. Section 3. ${ }^{42} \mathrm{Mo}-{ }^{57} \mathrm{La}$ and ${ }^{72} \mathrm{Hf}-{ }^{89} \mathrm{Ac}-$ Charlotte E. Moore. NBS Spec. Publ. 306, 37p. (1969).

\section{Sect.IV}

Bibliography on the Analyses of Optical Atomic Spectra. Section 4. ${ }^{57} \mathrm{La}-{ }^{71} \mathrm{Lu}$ and ${ }^{89} \mathrm{Ac}-{ }^{99}$ Es - Charlotte E. Moore. NBS Spec. Publ. 306, 48p. (1969).

\section{4}

The NBS Alloy Data Center: Permuted Materials Index - Gesina Cynthia Carter, Daniel J. Kahan, Lawrence H. Bennett, John R. Cuthill, and Ronald C. Dobbyn. NBS Spec. Publ. 324, 683p. (1971).

\section{9}

Heavy-Atom Kinetic Isotope Effects, An Indexed Bibliography Marvin J. Stern and Max Wolfsberg. NBS Spec. Publ. 349, 43p. (1972).

\section{2}

Chemical Kinetics in the C-O-S and H-N-O-S Systems: A Bibliography - 1899 through June 1971 — Francis Westley. NBS Spec. Publ. 362, 75p. (1972).

\section{3}

Bibliography on Atomic Energy Levels and Spectra, July 1968 through June 1971 - Lucy Hagan and William C. Martin. NBS Spec. Publ. 363, 109p. (1972).

\section{Suppl. 1}

Bibliography on Atomic Energy Levels and Spectra, July 1971 through June 1975 - Lucy Hagan. NBS Spec. Publ. 363, Suppl. I(1977).

\section{Suppl. 2}

Bibliography on Atomic Energy Levels and Spectra, July 1975 through June 1979 - Romuald Zalubas and Arlene Albright. NBS Spec. Publ. 363, Suppl. 2(1980).

\section{6}

Bibliography on Atomic Line Shapes and Shifts (1899 through March 1972) - Jeffrey R. Fuhr, Wolfgang L. Wiese, and Larry J. Roszman. NBS Spec. Publication 366, 165p. (1972).

\section{Suppl. 1}

Bibliography on Atomic Line Shapes and Shifts (April 1972 through June 1973) - Jeffrey R. Fuhr, Larry J. Roszman, and Wolfgang L. Wiese. NBS Spec. Publ. 366, Suppl. 1(1974).

\section{Suppl. 2}

Bibliography on Atomic Line Shapes and Shifts (July 1973 through May 1975) - Jeffrey R. Fuhr, Georgia A. Martin, and Beverly J. Specht. NBS Spec. Publ. 366, Suppl. 2(1975).

\section{Suppl. 3}

Bibliography on Atomic Line Shapes and Shifts (June 1975 through June 1978) - Jeffrey R. Fuhr, Beverly J. Miller, and Georgia A. Martin. NBS Spec. Publ. 366, Suppl. 3(1978).

\section{9}

Soft X-Ray Emission Spectra of Metallic Solids: Critical Review of Selected Systems and Annotated Spectral Index - Archie J. McAlister, Ronald C. Dobbyn, John R. Cuthill, and M. L. Williams. NBS Spec. Publ. 369, 180p. (1974).

\section{1}

A Supplementary Bibliography of Kinetic Data on Gas Phase Reactions of Nitrogen, Oxygen, and Nitrogen Oxides - Francis Westley. NBS Spec. Publ. 371, 93p. (1973).

\section{Suppl. 1}

Supplementary Bibliography of Kinetic Data on Gas Phase Reactions of Nitrogen, Oxygen, and Nitrogen Oxides (1972 - 1973) - Francis Westley. NBS Spec. Publ. 371, Suppl. 1(1975).

\section{0}

Photonuclear Reaction Data, 1973 - Everett G. Fuller, Henry M. Gerstenberg, H. J. Vander Molen, and T. C. Dunn. NBS Spec. Publ. 380, 134p. (1973).

\section{Suppl. 1}

Photonuclear Data Index, 1973-1977 - Everett G. Fuller and Henry M. Gerstenberg. NBS Spec. Publ. 380, Suppl. 1(1978).

\section{1}

Bibliography of Ion-Molecule Reaction Rate Data (January 1950 October 1971) - George A. Sinnott. NBS Spec. Publ. 381, 75p. (1973).

\section{2}

Vibrationally Excited Hydrogen Halides: A Bibliography on Chemical Kinetics of Chemiexcitation and Energy Transfer Processes (1958 through 1973) - Francis Westley. NBS Spec. Publ. 392, 84p. (1974).

\section{Sect. 1}

Critical Surveys of Data Sources: Mechanical Properties of Metals - R. B. Gavert, Robert L. Moore, and John H. Westbrook. NBS Spec. Publ. 396, 90p. (1974). 


\section{Sect.2}

Critical Surveys of Data Sources: Ceramics - Dorothea M. Johnson and James F. Lynch. NBS Spec. Publ. 396, 56p. (1975).

\section{Sect.3}

Critical Surveys of Data Sources: Corrosion of Metals - Ronald Diegle and Walter K. Boyd. NBS Spec. Publ. 396, 42p. (1976).

\section{Sect. 4}

Critical Surveys of Data Sources: Electrical and Magnetic Properties of Metals - M. J. Carr, R. B. Gavert, Robert L. Moore, H. W. Wawrousek, and John H. Westbrook. NBS Spec. Publ. 396, 96p. (1976).

\section{6}

Bibliography of Low Energy Electron and Photon Cross Section Data (through December 1974) - Lee J. Kieffer. NBS Spec. Publ. 426, 222p. (1976).

\section{Suppl. 1}

Bibliography of Low Energy Electron and Photon Cross Section Data (January 1975 to December 1977) - Jean W. Gallagher, John R. Rumble, Jr., and Earl C. Beaty. NBS Spec. Publ. 426, Suppl. 1(1979).

\section{Sect. $1,2,3$}

Bibliography of Infrared Spectroscopy through $1960-$ C. N. R. Rao, S. K. Dikshit, Shanti A. Kudchadker, D. S. Gupta, V. A. Narayan, and John J. Comeford. NBS Spec. Publ. 428, 1,2,3(1976).

\section{9}

Chemical Kinetics of the Gas Phase Combustion of Fuels (A Bibliography on the Rates and Mechanisms of Oxidation of Aliphatic $C_{1}$ to $\mathrm{C}_{10}$ Hydrocarbons and of Their Oxygenated Derivatives) - Francis Westley. NBS Spec. Publ. 449, 142p. (1976).

\section{4}

An Annotated Bibliography of Compiled Thermodynamic Data Sources for Biochemical and Aqueous Systems (1930 to 1975), Equilibrium, Enthalpy, Heat Capacity, and Entropy Data - George T. Armstrong and Robert N. Goldberg. NBS Spec. Publ. 454, 71p. (1976).

\section{8}

Nitrogen Oxychlorides: A Bibliography on Data for Physical and Chemical Properties of $\mathrm{ClNO}, \mathrm{ClNO}_{2}$, and $\mathrm{ClNO}_{3}$ - Francis Westley. NBS Spec. Publ. 478, 54p. (1977).

\section{5}

A Bibliography of Sources of Experimental Data Leading to Activity or Osmotic Coefficients for Polyvalent Electrolytes in Aqueous Solution - Robert N. Goldberg, Bert R. Staples, Ralph L. Nuttall, and R. Arbuckle. NBS Spec. Publ. 485, 57p. (1977).

\section{Vols. 1,2}

Applications of Phase Diagrams, Proceedings of a Workshop Held at the National Bureau of Standards, Gaithersburg, Maryland, January 10-12, 1977, Volumes 1 and $2-$ Gesina Cynthia Carter, editor(s). NBS Spec. Publ. 496, 1622p. (1978).

\section{5}

Bibliography on Atomic Transition Probabilities (1914 through October 1977) - Beverly J. Miller, Jeffrey R. Fuhr, and Georgia A. Martin. NBS Spec. Publ. 505, 283p. (1978).

\section{Suppl.}

Bibliography on Atomic Transition Probabilities (November 1977 through March 1980) - Beverly J. Miller, Jeffrey R. Fuhr, and Georgia A. Martin. NBS Spec. Publ. 505, Suppl.(1980).

\section{1}

Summary Report on the Workshop on High Temperature Chemical Kinetics: Applications to Combustion Research - David Garvin, R. L. Brown, Robert F. Hampson, Jr., M. J. Kurylo, and W. Tsang. NBS Spec. Publ. 531, 94p. (1978).

\section{7}

A Bibliography of Sources of Experimental Data Leading to Thermal Properties of Binary Aqueous Electrolyte Solutions - David Smith-Magowan and Robert N. Goldberg. NBS Spec. Publ. 537, 94p. (1979).

\section{8}

A Catalog of Data Compilations on Photochemical and Photophysical Processes in Solution - James G. Brummer, W. Phillip Helman, and Alberta B. Ross. NBS Spec. Publ. 578, 27p. (1980).

\section{3}

Data Index for Energy Transfer Collisions of Atoms and Molecules - 1970-1979 - Jean W. Gallagher, Janet Van Blerkom, Earl C. Beaty, and John R. Rumble, Jr. NBS Spec. Publ. 593, 349p. (1981).

\section{2}

Standard Reference Data Publications, 1964-1980 - Gertrude B. Sherwood. NBS Spec. Publ. 612, 125p. (1981).

\section{NBS Technical Notes}

\section{1}

A Bibliography on Ion-Molecule Reactions. January 1900 to March 1966 - F. N. Harllee, Henry M. Rosenstock, and John T. Herron. NBS Tech. Note 291, 40p. (1966).

\section{4}

The NBS Alloy Data Center: Function, Bibliographic System, Related Data Centers, and Reference Books - Gesina Cynthia Carter, Lawrence H. Bennett, John R. Cuthill, and Daniel J. Kahan. NBS Tech. Note 464, 163p. (1968).

\section{4}

Annotated Accession List of Data Compilations of the NBS Office of Standard Reference Data - Herman M. Weisman and Gertrude B. Sherwood. NBS Tech. Note 554, 196p. (1970).

\section{8}

A Bibliography of the Russian Reference Data Holdings of the Library of the Office of Standard Reference Data - Gertrude B. Sherwood and Howard J. White, Jr. NBS Tech. Note 848, 23p. (1974).

\section{7}

Critical Evaluation of Data in the Physical Sciences - A Status Report on the National Standard Reference Data System, January 1977 Stephen A. Rossmassler. NBS Tech. Note 947, 88p. (1977). 
488 Sec. 1

An Ultraviolet Multiplet Table, Section I. The Spectra of Hydrogen through Vanadium - Charlotte E. Moore. NBS Circular 488, 78p. (I950).

\section{Sec. 2}

An Ultraviolet Multiplet Table, Section 2. The Spectra of Chromium through Niobium - Charlotte E. Moore. NBS Circular 488, 115p. (1952).

\section{Sec. 3}

An Ultraviolet Multiplet Table, Section 3. The Spectra of Molybdenum to Lanthanum and Hafnium to Radium - Charlotte E. Moore. NBS Circular 488, 94p. (1962).

\section{Sec. 4}

An Ultraviolet Multiplet Table, Section 4. Finding List for Spectra of the Elements Hydrogen to Niobium ( $Z=1$ to 41$)$ - Charlotte $E$. Moore. NBS Circular 488, 65p. (1962).

\section{Sec. 5}

An Ultraviolet Multiplet Table, Section 5. Finding List for Spectra of the Elements Molybdenum to Lanthanum ( $Z=42$ to 57), Hafnium to Radium ( $Z=72$ to 88$)$ - Charlotte E. Moore. NBS Circular 488,

\section{Office of Standard Reference Data Bibliographies}

\section{0-1 Vol. 1}

High Pressure Bibliography 1900-1968, Volume I. Section I. Bibliography, Section II. Author Index - Leo Merrill. OSRD Bibl. 70-1, Vol. 1(1970).

\section{0-1 Vol. 2}

High Pressure Bibliography I900-1968, Volume II. Subject Index Leo Merrill. OSRD Bibl. 70-1, Vol. 2(1970).

\section{0-2}

The NBS Alloy Data Center: Author Index - Gesina Cynthia Carter, Daniel J. Kahan, Lawrence H. Bennett, John R. Cuthill, and Ronald C. Dobbyn. OSRD Bibl. 70-2, 413p. (I970).

\section{0-3}

Semiempirical and Approximate Methods for Molecular Calculations - Bibliography and KWIC Index - George A. Henderson and Sandra Frattali. OSRD Bibl. 70-3, 293p. (1970).

\section{$70-4$}

Bibliography of Photoabsorption Cross Section Data - Robert D. Hudson and Lee J. Kieffer. OSRD Bibl. 70-4, 47p. (1970).

\section{$71-1$}

Bibliography on Properties of Defect Centers in Alkali Halides Suresh C. Jain, S. A. Khan, H. K. Sehgal, V. K. Garg, and R. K. Jain. OSRD Bibl. 71-1, 293p. (I97I).

\section{$71-2$}

A Bibliography of Kinetic Data on Gas Phase Reactions of Nitrogen, Oxygen, and Nitrous Oxides - Francis Westley. OSRD Bibl. 71-2, 140p. (1971).
18

Bibliography of Low Energy Electron and Photon Cross Section Data (1978) - Jean W. Gallagher and Earl C. Beaty. JILA Report 18, 148p. (1980).

\section{0}

A Bibliography of Electron Swarm Data - Earl C. Beaty, J. Dutton, and L. C. Pitchford. JILA Report 20, 252p. (1979).

\section{1}

Bibliography of Low Energy Electron and Photon Cross Section Data (1979) - Jean W. Gallagher and Earl C. Beaty. JILA Report 21, 127p. (I981).

\section{NBS Interim Reports}

\section{6-1061}

Annotated Bibliography on Proton Affinities - K. N. Hartman, Sharon G. Lias, P. J. Ausloos, and Henry M. Rosenstock. NBSIR 76-1061, 52p. (1976).

\section{Critical Bibliographies and Indexes from Other Publishers}

\begin{abstract}
A Compilation of Volumes I-IV of Bibliography on High Pressure Research with Author and Subject Indexes - John Francis Cannon and Leo Merrill., Springfield, VA: NTIS, 385p. (1972). in two volumes, Vol. 1. PB 191 174, A17; Vol. 2. PB 191174.
\end{abstract}

A Guide to Sources of Information on Materials - Robert S. Marvin, Gertrude B. Sherwood, C. T. Lynch, editor(s)., Cleveland, OH: CRC Press, 603p. (1975). Chapter 10 in Handbook of Materials Science, Volume III. Nonmetallic Materials and Publications, C. T. Lynch, Editor.

An Indexed Compilation of Experimental High Energy Physics Literature - Particle Data Group. UCRL-LBL 90, Springfield, VA: NTIS, 430p. (1978). LBL 90, A19.

Bibliography of High Pressure Research, Volume XIl (1979) - Leo Merrill., Provo, UT: High Pressure Data Center, Brigham Young University,(1979). Bimonthly, order from Data Center.

Binary Fluorides, Free Molecular Structures and Force Fields, A Bibliography (1957-1975) - Donald T. Hawkins, Lawrence S. Bernstein, Warren E. Falconer, and William Klemperer., New York: 1Fl/Plenum, 253p. (1976), ISBN: 0-306-6601-3.

Biweekly List of Papers on Radiation Chemistry and Photochemistry Annual Cumulation with Keyword and Author indexes, Vol. 11. 1978 - Radiation Chemistry Data Center. Rad Chem 11, Springfield, VA: NTIS, 768p. (1979). PB 226368 , A99.

Biweekly List of Papers on Radiation Chemistry and Photochemistry Annual Cumulation with Keyword and Author Indexes, Vol. 12. 1979 - Radiation Chemistry Data Center. Rad Chem 12, Springfield, VA: NTIS, 748p. (1980). PB 81-113 680, A26. 
Biweekly List of Papers on Radiation Chemistry and Photochemistry Annual Cumulation with Keyword and Author Indexes, Vol. 13. 1980 - Radiation Chemistry Data Center. Rad Chem 13, Springfield, VA: NTIS, 704p. (1981). PB 82.122 995, A26.

Biweekly List of Papers on Radiation Chemistry and Photochemistry Annual Cumulation with Keyword and Author Indexes, Vol. 14. 1981 - Radiation Chemistry Data Center. Rad Chem 14, Springfield, VA: NTIS, 534p. (1982). PB 82-214 487, A22.

Biweekly List of Papers on Radiation Chemistry and Photochemistry Annual Cumuluation with Keyword and Author Indexes, Vol. 15. $1982-$ Radiation Chemistry Data Center. Rad Chem 15, Springfield, VA: NTIS, 448p. (1983). PB 83-203638, A19.

Biweekly List of Papers on Radiation Chemistry and Photochemistry Vol. 17. 1984 - Radiation Chemistry Data Center. Rad Chem, Notre Dame, IN Radiation Chem. Data Center, U. of Notre Dame, 44p. (1984). \$25.00; the Biweekly List, Vol. 17 (1984) plus the Annual Cumulation, " 16 (1983), $\$ 35.00$; foreign and airmail postage rates available upon req.

Biweekly List of Papers on Radiation Chemistry and Photochemistry Annual Cumuluation with Keyword and Author Indexes, Vol. 16. $1983-$ Radiation Chemistry Data Center. Rad Chem 16, Springfield, VA: NTIS, 444p. (1984).

Biweekly List of Papers on Radiation Chemistry, Annual Cumulation with Keyword and Author Indexes, Vol. 7. 1974 - Radiation Chemistry Data Center. Rad Chem 7, Springfield, VA: NTIS, 553p. (1975). COM 75-11475, A24.

Biweekly List of Papers on Radiation Chemistry, Annual Cumulation with Keyword and Author Indexes, Vol. 8. 1975 - Radiation Chemistry Data Center. Rad Chem 8, Springfield, VA: NTIS, 670p. (1976). PB 275 025, A26.

Biweekly List of Papers on Radiation Chemistry, Annual Cumulation with Keyword and Author Indexes, Vol. 9. 1976 - Radiation Chemistry Data Center. Rad Chem 9, Springfield, VA: NTIS, 707p. (1977). PB 268 699, A26.

Biweekly List of Papers on Radiation Chemistry, Annual Cumulation with Keyword and Author Indexes, Vol. 10. 1977 - Radiation Chemistry Data Center. Rad Chem 10, Springfield, VA: NTIS, 695p. (1978). PB 291876 , A26.

Bulletin of Chemical Thermodynamics, Volume 24/1981 - Robert D. Freeman, editor(s) and International Union of Pure and Applied Chemistry, Commission 1.2 on Thermodynamics. Bull Chem Thermody 24, Stillwater, OK: Thermochemistry, Department of Chemistry, Oklahoma State University, 504p. (1982). 0149.2268, bona fide personal subscriptions are less; prices of previous Bulletins available upon request.

Bulletin of Chemical Thermodynamics, Volume 25/1982 - Robert D. Freeman and International Union of Pure and Applied Chemistry. Bull Chem Thermody 25, Stillwater, OK: Thermochemistry, Department of Chemistry, Oklahoma State University, 544p. (1982). 0149-2268, bona fide personal subscriptions are less; prices of previous Bulletins are available upon request.

Compilation of Volumes V.IX of the Bibliography on High Pressure Research with Author and Subject Indexes - Leo Merrill., Provo, UT: High Pressure Data Center, Brigham Young University, (1979). in microfiche only.

Equilibrium Properties of Fluid Mixtures, 2. A Bibliography of Experimental Data on Selected Fluids - M. J. Hiza, Arthur J. Kidnay, and R. C. Miller., New York: IFI/Plenum, 258p. (1982), ISBN: 0-306-6602-4.

Equilibrium Properties of Fluid Mixtures, A Bibliograplyy on Fluids of Cryogenic Interest - M. J. Hiza, Arthur J. Kidnay, and R. C. Miller., NewYork: IFl/Plenum, 166p. (1975), ISBN: 0-306-6601-6.

High Pressure Bibliography, 1968-1971, with Author and Subject Indexes - John Francis Cannon and Leo Merrill., Provo, UT: High Pressure Data Center, Brigham Young University, 189p. (1972). in microfiche only.
Liquid Vapor Equilibria on Systems of Interest in Cryogenics, A Survey Arthur J. Kidnay, M. J. Hiza, and R. C. Miller. Cryogenics 13, London: Academic Press, 575p. (1973).

Mossbauer Effect Data Index Covering the 1966-1968 Literature — John G. Stevens and Virginia E. Stevens., New York: IFI/Plenum, 522p. (1975), ISBN: 0-306-6516.9.

Mossbauer Effect Data Index Covering the 1969 Literature - John G. Stevens and Virginia E. Stevens., New York: 1FI/Plenum, 281p. (1970), ISBN: 0-306-6514-8.

Mossbauer Effect Data Index Covering the 1970 Literature - John G. Stevens and Virginia E. Stevens., New York: IFI/Plenum, 369p. (1972), ISBN: 0-306-6514-6.

Mossbauer Effect Data lndex Covering the 1971 Literature - John G. Stevens and Virginia E. Stevens., New York: IFI/Plenum, 430p. (1972), ISBN: 0-306-6514-4.

Mossbauer Effect Data Index Covering the 1972 Literature - John G. Stevens and Virginia E. Stevens., New York: IFI/Plenum, 488p. (1973), ISBN: 0-306-6514-2.

Mossbauer Effect Data Index Covering the 1973 Literature - John G. Stevens and Virginia E. Stevens., New York: IFI/Plenum, 495p. (1975), ISBN: 0.306.6514-0.

Mossbauer Effect Data Index Covering the 1974 Literature - John G. Stevens and Virginia E. Stevens., New York: IFI/Plenum, 397p. (1975), ISBN: 0-306-6514-9.

Mossbauer Effect Data Index Covering the 1975 Literature - John G. Stevens and Virginia E. Stevens., New York: IFI/Plenum, 445p. (1977), ISBN: 0-306-6514-7.

Mossbauer Effect Data Index Covering the 1976 Literature - John G. Stevens and Virginia E. Stevens., New York: IFI/Plenum, 355p. (1978), ISBN: 0-306-6514-1.

Mossbauer Effect Data Index, 1958-1965 - A. H. Muir, K. J. Ando, and Helen M. Coogan., New York: Interscience Publishers, 35lp. (1966).

Mossbauer Effect Reference and Data Journal - John G. Stevens, Virginia E. Stevens, Richard M. White, Janet L. Gibson, editor(s). Moss Eff Ref Data J 6, Ashville, NC: Mossbauer Effect Data Center, U. of N. C., (1983).

Thesaurus for Radiation Chemistry - Alberta B. Rass and Radiation Chemistry Data Center. Rad Chem. 1, Springfield, VA: NTIS, 48p. (1977). UND-RCDC-1, A03.

Weekly List of Papers on Radiation Chemistry, Index and Cumulation, Volume IV, Numbers 1.26, January through June 1971 - Radiation Chemistry Data Center. Rad Chem. IV, 1-26(1971). COM 71.01103, A13.

Weekly List of Papers on Radiation Chemistry, Index and Cumulation, Volume IV, Numbers 27.52, July through December 1971 - Radiation Chemistry Data Center. Rad Chem. IV, 26-52(1972). COM 72-10266, Al3.

Weekly List of Papers on Radiation Chemistry, Index and Cumulation, Volume V, Numbers 1.26, January through June 1972 - Radiation Chemistry Data Center. Rad Chem. V, 1-26(1972). COM 72-10621, A14.

Weekly List of Papers in Radiation Chemistry, Index and Cumulation, Volume V, Numbers 27-52, July through December 1972 - Radiation Chem. istry Data Center. Rad Chem. V, 27-52(1973). COM 73-10281, A15.

Weekly List of Papers on Radiation Chemistry, Index and Cumulation, Volume VI, Numbers 1-26, January through June 1973 - Radiation Chemistry Data Center. Rad Chem. VI, 1-26(1973). COM 73-11878, A18.

Weekly List of Papers on Radiation Chemistry, Index and Cumulation, Volume VI, Numbers 27-52, July through December 1973 - Radiation Chemistry Data Center. Rad Chem. VI, 27.5(1974). COM 74-10899, Al6. istry Data Center. Rad Chem. V, 27-52(1973). COM 73-10281, A15. 


\section{NBS Technical Notes}

Reform: A General-Purpose Program for Manipulating Formatted Data Files - Robert McClenon and Joseph Hilsenrath. NBS Tech. Note 444, 25p. (1968).

\section{6}

PRECISE: A Multiple Precision Version of OMNITAB - Alfred E. Bean and Joseph Hilsenrath. NBS Tech. Note 446, 84p. (1968).

\section{0}

EDPAC: Utility Programs for Computer-Assisted Editing, Copy Production, and Data Retrieval - Carla G. Messina and Joseph Hilsenrath. NBS Tech. Note 470, 76p. (1969).

\section{0}

Edit-Insertion Programs for Automatic Typesetting of Computer Printout - Carla G. Messina and Joseph Hilsenrath. NBS Tech. Note 500, 47p. (1970).

\section{0}

COMBO: A General-Purpose Program for Searching, Annotating, Encoding-Decoding, and Reformatting Data Files - Robert McClenon and Joseph Hilsenrath. NBS Tech. Note 700, 72p. (1972).

\section{8}

Subroutine for the Calculation of CODEN Check Characters David Garvin. NBS Tech. Note 738, 16p. (1972).

\section{0}

SETAB: An Edit-Insert Program for Automatic Typesetting of Spectroscopic and Other Computerized Tables - Robert C. Thompson and Joseph Hilsenrath. NBS Tech. Note 740, 32p. (1973).

\section{0}

Description of the Magnetic Tape Version of the Bulletin of Thermodynamics and Thermochemistry, No. 14 - Robert McClenon, William H. Evans, David Garvin, and Blanton C. Duncan. NBS Tech. Note 760, 32p. (1973).

\section{0}

Complete Clear Text Representation of Scientific Documents in Machine-Readable Form - Blanton C. Duncan and David Garvin. NBS Tech. Note 820, 58p. (1974).

\section{3}

The NIRA Computer Program Package (Photonuclear Data Center) - H. J. Vander Molen and Henry M. Gerstenberg. NBS Tech. Note 903, 34p. (1976).

\section{8}

Computer Programs for the Evaluation of Activity and Osmotic Coefficients - Bert R. Staples and Ralph L. Nuttall. NBS Tech. Note 928, 60p. (1976).
1039

A Computer Program for the Prediction of Viscosity and Thermal Conductivity in Hydrocarbon Mixtures - James F. Ely and Howard J. M. Hanley. NBS Tech. Note 1039, 83p. (1981).

\section{8}

Interactive FORTRAN Program to Calculate Thermophysical Properties of Seven Fluids - Ben A. Younglove. NBS Tech. Note 1048, 56p. (1982).

\section{2}

Summary of On-Line or Interactive Physico-Chemical Numerical Data Systems - Joseph Hilsenrath. NBS Tech. Note 1122, 29p. (1980).

\section{1}

NBS AIDS80: A FORTRAN Program for Crystallographic Data Evaluation - Alan D. Mighell, C. R. Hubbard, and Judy K. Stalick. NBS Tech. Note 1141, 54p. (1981).

\section{7}

Test Problems and Results for OMNITAB 80 - Sally T. Peavy and Shirley G. Bremer. NBS Tech. Note 1147, 316p. (1981).

\section{6}

Utility Programs for Generating the Hershey Character Fonts on Microcomputers and Laboratory Plotters - C. E. Dick and Joseph Hilsenrath. NBS Tech. Note 1176, 49p. (1983).

\section{NBS Handbooks}

\section{1}

OMNITAB, A Computer Program for Statistical and Numerical Analysis - Joseph Hilsenrath, Guy G. Ziegler, Carla G. Messina, P. J. Walsh, and R. H. Herbold. NBS Handbook 101, 256p. (1968).

\section{5}

OMNIDATA, An Interactive System for Data Retrieval, Statistical and Graphical Analysis, and Data-Base Management, A User's Manual - Joseph Hilsenrath and Bettijoyce Breen. NBS Handbook 125, 294p. (1978).

\section{NBS Speclal Publlcatlons}

\section{4}

A Contribution to Computer Typesetting Techniques: Tables of $\mathrm{Co}$ ordinates for Hershey's Repertory of Occidental Type Fonts and Graphic Symbols - Norman M. Wolcott and Joseph Hilsenrath. NBS Spec. Publ. 424, 177p. (1976).

\section{NBS Interim Report}

\section{8-1432}

Automation of the Ion Energetics Data Center - Robert C. Thompson, W. J. Webb, and Henry M. Rosenstock. NBSIR 78-1432, 84p. (1978). 


\section{NBS Magnetic Tape Serles}

\section{NBS Standard Reference Database 1}

EPA/NIH Mass Spectral Data Base Magnetic Tape - Stephen R. Heller and G. W. A. Milne. NBS Standard Reference Database 1 A1, Washington, DC: NBS Office of Standard Reference Data,(updated periodically). Call (301) 921-2228 for specific instructions.

\section{NBS Standard Reference Database 2}

NBS Chemical Thermodynamics Database NBS Standard Reference Database 2, Washington, D.C.; NBS, Office of Standard Reference Data,(updated periodically). Call (301)921-2228 for specific instructions.

\section{NBS Standard Reference Database 3}

NBS Crystal Data Identification File, NBS Standard Reference Database 3, Washington, D.C.; NBS, Office of Standard Reference Data,(updated periodically). Lease agreements obtained from JCPDS 1601 Park Ln Swarthmore PA (215)328-9400.

\section{NBS Standard Reference Database 4}

Thermophysical Properties of Hydrocarbon Mixtures (TRAPP), NBS Standard Reference Database 4, Washington, D.C.; NBS, Office of Standard Reference Data,(updated periodically). Call (301)921-2228 for specific instructions.

\section{NBS Standard Reference Database 5}

Thermophysical Properties of Helium, NBS Standard Reference Database 5, Washington, D.C.; NBS, Office of Standard Reference Data,(updated periodically). Call (301)921-2228 for specific instructions.

\section{NBS Standard Reference Database 6}

Interactive Fortran Program to Calculate Thermophysical Properties of 6 Fluids, NBS Standard Reference Database 6, Washington, D.C.; NBS, Office of Standard Reference Data,(updated periodically). Call (301)921-2228 for specific instructions.

\section{NBS Standard Reference Database 9}

Activity and Osmotic Coefficients of Aqueous Electrolyte Solutions, NBS Standard Reference Database 9, Washington, D.C.; NBS, Office of Standard Reference Data,(updated periodically). Call (301)921-2228 for specific instructions.

\section{NBS Standard Reference Database 10}

Thermophysical Properties of Water, NBS Standard Reference Database 10, Washington, D.C.; NBS, Office of Standard Reference Data,(updated periodically). Call (301)921-2228 for specific instructions. 


\section{Ackerman, M. W.}

Electrical Resistivity of Ten Selected Binary Alloy Systems - Cho Y. Ho, M. W. Ackerman, K. Y. Wu, T. N. Havill, R. H. Bogaard, R. A. Matula, S. G. Oh, and H. M. James. J Phys Chem Ref Data 12, 183(1983).

Thermal Conductivity of Ten Selected Binary Alloy Systems - Cho Y. Ho, M. W. Ackerman, K. Y. Wu, S. G. Oh, and T. N. Havill. J Phys Chem Ref Data 7, 959(1978).

\section{Adams, Gerald E.}

Reactivity of the Hydroxyl Radical in Aqueous Solutions - Leon M. Dorfman and Gerald E. Adams. NSRDS-NBS 46, 72p. (1973).

\section{Agarwal, Suresh K.}

Electronic Absorption and Internal and External Vibrational Data of A tomic and Molecular Ions Doped in Alkali Halide Crystals - Suresh C. Jain, A. V. R. Warrier, and Suresh K. Agarwal. NSRDS-NBS 52, 55p. (1974).

\section{Alberti, F.}

Atlas of the Absorption Spectrum of Nitric Oxide (NO) between 1420 and $1250 \AA$ - E. Miescher and F. Alberti. J Phys Chem Ref Data 5, 309(1976).

\section{Alberty, Robert A.}

Standard Chemical Thermodynamic Properties of Alkane Isomer Groups - Robert A. Alberty and Catherine A. Gehrig. J Phys Chem Ref Data 13, 1173(1984).

\section{Albright, Arlene}

Bibliography on Atomic Energy Levels and Spectra, July 1975 through June 1979 - Romuald Zalubas and Arlene Albright. NBS Spec. Publ. 363, Suppl. 2(1980).

\section{Alemasov, V. E.}

Thermodynamic and Thermophysical Properties of Combustion Products, Volume I. Computation Methods - V. P. Glushko, V. E. Alemasov, A. F. Dregalin, A. P. Tishin, and V. A. Khudyakov. Russian Transl. Springfield, VA: NTIS, 453p. (1974). TT 74-50019, A20.

Thermodynamic and Thermophysical Properties of Combustion Products, Volume II. Oxygen-Based Propellants - V. P. Glushko, V. E. Alemasov, A. F. Dregalin, A. P. Tishin, V. A. Khudyakov, and V. N. Kostin. Russian Transl. Springfield, VA: NTIS, 505p. (1975). TT 74-50032, A22.

Thermodynamic and Thermophysical Properties of Combustion Products, Volume III. Oxygen- and Air-Based Propellant - V. P. Glushko, V. E. A lemasov, A. F. Dregalin, A. P. Tishin, V. A. Khudyakov, and V. N. Kostin. Russian Transl. Springfield, VA: NTIS, 648p. (1975). TT 75-50007, A26.

Thermodynamic and Thermophysical Properties of Combustion Products, Volume IV. Nitrogen Tetroxide-Based Propellants - V. P. Glushko, V. E. Alemasov, A. F. Dregalin, A. P. Tishin, V. A. Khudyakov, and V. N. Kostin. Russian Transl. Springfield, VA: NTIS, 540p. (1976). TT 76-50007, A23.

\section{Alexander, Gideon}

A Compilation of YN Reactions - Odette Benary, Naomi BarashSchmidt, LeRoy R. Price, Arthur H. Rosenfeld, Gideon Alexander and Particle Data Group. UCRL 20000YN, Springfield, VA: NTIS, 70p. (1970). UCRL-20 000 YN, A04.
Alibekov, B. G.

Isochoric Heat Capacity of Water and Steam - M. P. Vukalovich, Kh. I. Amirkhanov, G. V. Stepanov, and B. G. Alibekov. Russian Transl. Springfield, VA: NTIS, 215p. (1974). TT 72-52002, A10.

Allara, D. L.

A Compilation of Kinetic Parameters for the Thermal Degradation of n-Alkane Molecules - D. L. Allara and Robert Shaw. J Phys Chem Ref Data 9, 523(1980).

\section{Allen, Augustine 0.}

Drift Mobilities and Conduction Band Energies of Excess Electrons in Dielectric Liquids - Augustine O. Allen. NSRDS-NBS 58, 23p. (1976).

Yields of Free Ions Formed in Liquids by Radiation - Augustine O. Allen. NSRDS-NBS 57, 38p. (1976).

\section{Allen, Carolyn B.}

Molten Salts: Volume 4, Part 2, Chlorides and Mixtures. Electrical Conductance, Density, Viscosity, and Surface Tension Data - George J. Janz, Reginald P. T. Tomkins, Carolyn B. Allen, J. R. Downey, Jr., G. L. Gardner, Ursula Krebs, and S. K. Singer. J Phys Chem Ref Data 4, 871(1975).

Molten Salts: Volume 4, Part 3, Bromides and Mixtures, Iodides and Mixtures. Electrical Conductance, Density, Viscosity, and Surface Tension Data - George J. Janz, Reginald P. T. Tomkins, Carolyn B. Allen, J. R. Downey, Jr., and S. K. Singer. J Phys Chem Ref Data 6 409(1977).

Molten Salts: Volume 4, Part 4, Mixed Halide Melts. Elec trical Conductance, Density, Viscosity, and Surface Tension Data George J. Janz, Reginald P. T. Tomkins, and Carolyn B. Allen. J Phys Chem Ref Data 8, 125(1979).

Physical Properties Data Compilations Relevant to Energy Storage. I. Molten Salts: Eutectic Data - George J. Janz, Carolyn B. Allen, J. R. Downey, Jr., and Reginald P. T. Tomkins. NSRDS-NBS 61, 244p. (1978).

Physical Properties Data Compilations Relevant to Energy Storage. II. Molten Salts: Data on Single and Multi-Component Systems George J. Janz, Carolyn B. Allen, Narottam P. Bansal, R. M. Murphy, and Reginald P. T. Tomkins. NSRDS-NBS 61, 420p. (1979).

Allen, G. F.

An Analysis of Coexistence Curve Data for Several Binary Liquid Mixtures Near Their Critical Points - A. Stein and G. F. Allen. J Phys Chem Ref Data 2, 439(1973).

\section{Almehed, Sverkei}

$\pi \mathrm{N}$ Two-Body Scattering Data, I. A User's Guide to the LovelaceAlmehed Data Tape - Claude Lovelace, Sverkei Almehed, Fumiyo Uchiyama, Robert Kelly, Victor P. Henri and Particle Data Group. UCRL 63, Springfield, VA: NTIS, 146p. (1973). LBL 63, A07.

\section{Alyab'ev, A. F.}

Thermodynamic and Thermophysical Froperties of Helium - A. F. Alyab'ev, N. V. Tsederberg, V. N. Popov, and N. A. Morozova. Russian Transl. Springfield, VA: NTIS, 260p. (1971). TT 70-50096, A12.

\section{Amirkhanov, Kh. I.}

Isochoric Heat Capacity of Water and Steam - M. P. Vukalovich, Kh. I. Amirkhanov, G. V. Stepanov, and B. G. Alibekov. Russian Transl. Springfield, VA: NTIS, 215p. (1974). TT 72-52002, A 10. 
Anbar, Mlchael

Selected Specific Races of Reactions of Transients from Water in Aqueous Solution, 1. Hydrated Electron - Michael Anbar, Mark Bambenek, and Alberta B. Ross. NSRDS-NBS 43, 69p. (1973).

Selected Specific Rates of Reactions of Transients from Water in Aqueous Solution, II. Hydrogen Atom - Michael Anbar, Farhataziz, and Alberta B. Ross. NSRDS-NBS 51, 66p. (1975).

Ando, K. J.

Mossbauer Effect Data Index, 1958-1965 - A. H. Muir, K. J. Ando, and Helen M. Coogan. New York: Interscience Publishers, 35lp. (1966).

\section{Arbuckle, $R$.}

A Bibliography of Sources of Experimental Data Leading to Activity or Osmotic Coefficients for Polyvalent Electrolytes in Aqueous Solution - Robert N. Goldberg, Bert R. Staples, Ralph L. Nuttall, and R. Arbuckle. NBS Spec. Publ. 485, 57p. (1977).

\section{Armstrong, George T.}

An Annotated Bibliography of Compiled Thermodynamic Data Sources for Biochemical and Aqueous Systems (1930 to 1975), Equilibrium, Enthalpy, Heat Capacity, and Entropy Data - George T. Armstrong and Robert N. Goldberg. NBS Spec. Publ. 454, 71p. (1976).

Heating Values of Natural Gas and Its Components - George T. Armstrong and Thomas L. Jobe, Jr. NBSIR 82-2401, 164p. (1982).

\section{Atkinson, Roger}

Evaluation of Kinetic and Mechanistic Data for Modeling of Photochemical Smog - Roger Atkinson and Alan C. Lloyd. J Phys Chem Ref Data 13, 315(1984).

\section{Ausloos, P. J.}

A Compendium of Gas Phase Basicity and Proton Affinity Measurements - K. N. Hartman, Sharon G. Lias, P. J. Ausloos, Henry M. Rosenstock, S. S. Schroyer, C. Schmidt, D. Martinsen, and G. W. A. Milne. NBSIR 79-1777, 563p. (1979).

Annotated Bibliography on Proton Affinities - K. N. Hartman, Sharon G. Lias, P. J. Ausloos, and Henry M. Rosenstock. NBSIR 76-1061, 52p. (1976).

\section{Balley, Sylvla M.}

Selected Values of Chemical Thermodynamic Properties. Tables for the First Thirty-Four Elements in the Standard Order of Arrangement - Donald D. Wagman, William H. Evans, Vivian B. Parker, Iva Halow, Sylvia M. Bailey, and Richard H. Schumm. NBS Tech. Note 270, 264p. (1968).

Selected Values of Chemical Thermodynamic Properties. Tables for Elements 35 through 53 in the Standard Order of Arrangement Donald D. Wagman, William H. Evans, Vivian B. Parker, Iva Halow, Sylvia M. Bailey, and Richard H. Schumm. NBS Tech. Note 270, 152p. (1969).

Selected Values of Chemical Thermodynamic Properties. Tables for Elements 54 through 61 in the Standard Order of Arrangement Donald D. Wagman, William H. Evans, Vivian B. Parker, Iva Halow, Sylvia M. Bailey, Richard H. Schumm, and Kenneth L. Churney. NBS Tech. Note 270, 49p. (1971).

Selected Values of Chemical Thermodynamic Properties. Tables for the Lanthanide (Rare Earth) Elements (Elements 62 through 76 in the Standard Order of Arrangement) - Richard H. Schumm, Donald D. Wagman, Sylvia M. Bailey, William H. Evans, and Vivian B. Parker. NBS Tech. Note 270, 84p. (1973).
The NBS Tables of Chemical Thermodynamic Properties. Selected Values for Inorganic and $C_{1}$ and $C_{2}$ Organic Substances in SI Units Donald D. Wagman, William H. Evans, Vivian B. Parker, Richard H. Schumm, Iva Halow, Sylvia M. Bailey, Kenneth L. Churney, and Ralph L. Nuttall. J Phys Chem Ref Data 11, Suppl. 2(1982).

\section{Balfour, F. W.}

The Critical-Region Equation of State of Ethene and the Effect of Small Impurities - J. R. Hastings, J. M. H. Levelt Sengers, and F. W. Balfour. J Chem Thermody 12, London: Academic Press Inc., 1009p. (1980).

Thermodynamic Properties of Steam in the Critical Region - J. M. H. Levelt Sengers, B. Kamgar-Parsi, F. W. Balfour, and Jan V. Sengers. J Phys Chem Ref Data 12, 1(1983).

Ballard, J. R.

Microwave Spectral Tables, Volume I. Diatomic Molecules - Paul F. Wacker, M. Mizushima, J. D. Petersen, and J. R. Ballard. NBS Monograph 70, 171p. (1964).

\section{Bambenek, Mark}

Selected Specific Rates of Reactions of Transients from Water in Aqueous Solution, 1. Hydrated Electron - Michael Anbar, Mark Bambenek, and Alberta B. Ross. NSRDS-NBS 43, 69p. (1973).

\section{Banerjee, Sujit}

Water Solubilities of Polynuclear Aromatic and Heteroaromatic Compounds - Robert S. Pearlman, Samuel H. Yalkowsky, and Sujit Banerjee. J Phys Chem Ref Data 13, 555(1984).

\section{Bansal, Narottam P.}

Erratum: Molten Salts Data: Diffusion Coefficients in Single and Multi-Component Salt Systems - George J. Janz and Narottam P. Bansal. J Phys Chem Ref Data 13, 305(1984).

Molten Salts Data: Diffusion Coefficients in Single and MultiComponent Salt Systems - George J. Janz and Narottam P. Bansal. J Phys Chem Ref Data 11, 505(1982).

Physical Properties Data Compilations Relevant to Energy Storage. II. Molten Salts: Data on Single and Multi-Component Systems George J. Janz, Carolyn B. Allen, Narottam P. Bansal, R. M. Murphy, and Reginald P. T. Tomkins. NSRDS-NBS 61, 420p. (1979).

\section{Barash-Schmidt, Naomi}

A Compilation of YN Reactions - Odette Benary, Naomi BarashSchmidt, LeRoy R. Price, Arthur H. Rosenfeld, Gideon Alexander and Particle Data Group. UCRL 20000YN, Springfield, VA: NTIS, 70p. (1970). UCRL-20 000 YN, A04.

\section{Barbaro-Galtieri, Angela}

$\pi \mathrm{N}$ Particle-Wave Amplitudes - David J. Herndon, Angela Barbaro-Galtieri, Arthur H. Rosenfeld and Particle Data Group. UCRL $20030 \pi \mathrm{N}$, Springfield, VA: NTIS, 85p. (1970). UCRL 20030 $\pi \mathrm{N}, \mathrm{A} 05$.

\section{Barnes, I. Lynus}

Isotopic Abundances and Atomic Weights of the Elements - Paul De Bièvre, Marc Gallet, Norman E. Holden, and I. Lynus Barnes. J Phys Chem Ref Data 13, 809(1984).

\section{Barnes, John}

Critical Review of Vibrational Data and Force Field Constants for Polyethylene - John Barnes and Bruno Fanconi. J Phys Chem Ref Data 7, 1309(1978). 
Barnett, J. D.

High-Pressure Calibration: A Critical Review - D. L. Decker, W. A. Bassett, Leo Merrill, H. T. Hall, and J. D. Barnett. J Phys Chem Ref Data 1, 773(1972).

\section{Barzakovskii, V. P.}

Handbook of Phase Diagrams of Silicate Systems, Vol. I. Binary Systems, Second Revised Edition - N. A. Toropov, V. P. Barzakovskii, V. V. Lapin, N. N. Kurtseva, J. Schmorak, editor(s). Russian Transl. Springfield, VA: NTIS, 730p. (1970). TT 71-50040, A26.

Handbook of Phase Diagrams of Silicate Systems, Vol. II. MetalOxygen Compounds in Silicate Systems, Second Revised Edition - N. A. Toropov, V. P. Barzakovskii, I. A. Bondar', and Yu. P. Udalov. Russian Transl. Springfield, VA: NTIS, 329p. (1972). TT 71-50041, A15.

\section{Bassett, W. A.}

High-Pressure Calibration: A Critical Review - D. L. Decker, W. A. Bassett, Leo Merrill, H. T. Hall, and J. D. Barnett. J Phys Chem Ref Data 1, 773(1972).

\section{Basu, R. S.}

An Improved Representative Equation for the Dynamic Viscosity of Water Substance - J. T. R. Watson, R. S. Basu, and Jan V. Sengers. J Phys Chem Ref Data 9, 1255(1980).

Problems with the Prandtl Number of Steam - Jan V. Sengers, R. S. Basu, B. Kamgar-Parsi, and Joseph Kestin. Mech Eng 104, New York, NY, 60p. (1982).

Representative Equations for the Thermal Conductivity of Water Substance - Jan V. Sengers, J. T. R. Watson, R. S. Basu, B. KamgarParsi, and R. C. Hendricks. J Phys Chem Ref Data 13, 893(1984).

\section{Battino, Rubin}

The Solubility of Nitrogen and Air in Liquids - Rubin Battino, Timothy R. Rettich, and Toshihiro Tominaga. J Phys Chem Ref Data 13, 563(1984).

The Solubility of Oxygen and Ozone in Liquids - Rubin Battino, Timothy R. Rettich, and Toshihiro Tominaga. J Phys Chem Ref Data 12, 163(1983).

\section{Bauder, $\mathbf{A}$.}

Microwave Spectra of Molecules of Astrophysical Interest, IX. Acetaldehyde - A. Bauder, Frank J. Lovas, and Donald R. Johnson. J Phys Chem Ref Data 5, 53(1976).

Microwave Spectra of Molecules of Astrophysical Interest, XVI. Methyl Formate - A. Bauder. J Phys Chem Ref Data 8, 583(1979).

\section{Bauer, A.}

Microwave Spectra of Molecules of Astrophysical Interest, XV. Propyne - A. Bauer, D. Boucher, J. Burie, J. Demaison, and A. Dubrulle. J Phys Chem Ref Data 8, 537(1979).

Microwave Spectra of Molecules of Astrophysical Interest. XIX. Methyl Cyanide - D. Boucher, J. Burie, A. Bauer, A. Dubrulle, and J. Demaison. J Phys Chem Ref Data 9, 659(1980).

\section{Baulch, D. L.}

Evaluated Kinetic Data for High Temperature Reactions, Volume 4. Homogeneous Gas Phase Reactions of Halogen- and CyanideContaining Species - D. L. Baulch, J. Duxbury, S. J. Grant, and D. C. Montague. J Phys Chem Ref Data 10, Suppl. 1(1981).
Evaluated Kinetic and Photochemical Data for Atmospheric Chemistry - D. L. Baulch, R. A. Cox, Robert F. Hampson, Jr., J. A. Kerr, J. Troe, and R. T. Watson. J Phys Chem Ref Data 9, 295(1980).

Evaluated Kinetic and Photochemical Data for Atmospheric Chemistry: Supplement I. CODATA Task Group on Chemical Kinetics D. L. Baulch, R. A. Cox, P. J. Crutzen, Robert F. Hampson, Jr., J. A. Kerr, J. Troe, and R. T. Watson. J Phys Chem Ref Data 11, 327(1982).

Evaluated Kinetic and Photochemical Data for Atmospheric Chemistry: Supplement II. CODATA Task Group on Gas Phase Chemical Kinetics - D. L. Baulch, R. A. Cox, Robert F. Hampson, Jr., J. A. Kerr, J. Troe, and R. T. Watson. J Phys Chem Ref Data 13, 1259(1984).

\section{Baxendale, J. H.}

The Radiolysis of Methanol: Product Yields, Rate Constants, and Spectroscopic Parameters of Intermediates - J. H. Baxendale and Peter Wardman. NSRDS-NBS 54, 33p. (1975).

\section{Bean, Alfred E.}

PRECISE: A Multiple Precision Version of OMNITAB - Alfred E. Bean and Joseph Hilsenrath. NBS Tech. Note 446, 84p. (1968).

\section{Bearden, Joyce A.}

X-Ray Wavelengths and X-Ray Atomic Energy Levels - Joyce A. Bearden and A. F. Burr. NSRDS-NBS 14, 66p. (1967).

\section{Beaty, Earl C.}

A Bibliography of Electron Swarm Data - Earl C. Beaty, J. Dutton, and L. C. Pitchford. JILA Report 20, 252p. (1979).

An Annotated Compilation and Appraisal of Electron Swarm Data in Electronegative Gases - Jean W. Gallagher, Earl C. Beaty, J. Dutton, and L. C. Pitchford. J Phys Chem Ref Data 12, 109(1983).

Bibliography of Low Energy Electron and Photon Cross Section Data (January 1975 to December 1977) - Jean W. Gallagher, John R. Rumble, Jr., and Earl C. Beaty. NBS Spec. Publ. 426, Suppl. 1(1979).

Bibliography of Low Energy Electron and Photon Cross Section Data (1978) - Jean W. Gallagher and Earl C. Beaty. JILA Report 18, 148p. (1980).

Bibliography of Low Energy Electron and Photon Cross Section Data (1979) - Jean W. Gallagher and Earl C. Beaty. JILA Report 21, 127p. (1981).

Data Index for Energy Transfer Collisions of Atoms and Molecules - 1970-1979 - Jean W. Gallagher, Janet Van Blerkom, Earl C. Beaty, and John R. Rumble, Jr. NBS Spec. Publ. 593, 349p. (1981).

\section{Beaudet, Robert A.}

Microwave Spectra of Molecules of Astrophysical Interest, XII. Hydroxyl Radical — Robeit A. Beaudet and Robert L. Poynter. J Phys Chem Ref Data 7, 311(1978).

\section{Bederson, Benjamin}

Total Electron-Atom Collision Cross Sections at Low Energies - A Critical Review - Benjamin Bederson. Rev Mod Phys 43, 999, 601p. (1971).

\section{Bell, K. L.}

Recommended Data on the Electron Impact Ionization of Light Atoms and Ions - K. L. Bell, H. B. Gilbody, J. G. Hughes, A. E. Kingston, and Francis J. Smith. J Phys Chem Ref Data 12, 891(1983). 
Bellet, Jean

Microwave Spectra of Molecules of Astrophysical Interest. XVIII. Formic Acid - Edmond Willemot, Didier Dangoisse, Nicole Monnanteuil, and Jean Bellet. J Phys Chem Ref Data 9, 59(1980).

\section{Benary, Odette}

A Compilation of YN Reactions - Odette Benary, Naomi BarashSchmidt, LeRoy R. Price, Arthur H. Rosenfeld, Gideon Alexander and Particle Data Group. UCRL 20000YN, Springfield, VA: NTIS, 70p. (1970). UCRL-20 000 YN, A04.

\section{Bennett, Lawrence $\mathrm{H}$.}

Metallic Shifts in NMR: A Review of the Theory and Comprehensive Critical Data Compilation of Metallic Materials - Gesina Cynthia Carter, Lawrence H. Bennett, and Daniel J. Kahan. Prog Mater Sci, Oxford, New York: Pergamon Press, 2350p. (1977), ISBN: 0-08-02114-7.

The NBS Alloy Data Center: Author Index - Gesina Cynthia Carter, Daniel J. Kahan, Lawrence H. Bennett, John R. Cuthill, and Ronald C. Dobbyn. OSRD Bibl. 70-2, 413p. (1970).

The NBS Alloy Data Center: Function, Bibliographic System, Related Data Centers, and Reference Books - Gesina Cynthia Carter, Lawrence H. Bennett, John R. Cuthill, and Daniel J. Kahan. NBS Tech. Note 464, 163p. (1968).

The NBS Alloy Data Center: Permuted Materials Index - Gesina Cynthia Carter, Daniel J. Kahan, Lawrence H. Bennett, John R. Cuthill, and Ronald C. Dobbyn. NBS Spec. Publ. 324, 683p. (1971).

\section{Bennett, William Ralph, Jr.}

Atomic Gas Laser Transition Data, A Critical Evaluation William Ralph Bennett, Jr. New York: IFI/Plenum, 293p. (1979), ISBN: 0-306-65187-4.

\section{Benson, Sidney W.}

Kinetic Data on Gas Phase Unimolecular Reactions - Sidney W. Benson and Harry E. O'Neal. NSRDS-NBS 21, 645p. (1970).

\section{Berger, M. J.}

Stopping Powers and Ranges of Electrons and Positrons - M. J. Berger and S. M. Seltzer. NBSIR 82-2550, 164p. (1982).

\section{Bernstein, Lawrence S.}

Binary Fluorides, Free Molecular Structures and Force Fields, A Bibliography (1957-1975) - Donald T. Hawkins, Lawrence S. Bernstein, Warren E. Falconer, and William Klemperer. New York: IFI/Plenum, 253p. (1976), ISBN: 0-306-6601-3.

\section{Berry, Virginia M.}

Phase Behavior in Binary and Multicomponent Systems at Elevated Pressures: n-Pentane and Methane-n-Pentane - Virginia M. Berry and Bruce H. Sage. NSRDS-NBS 32, 79p. (1970).

\section{Bishop, David M.}

Vibrational Contributions to Molecular Dipole Polarizabilities David M. Bishop and Lap M. Cheung. J Phys Chem Ref Data 11, 119(1982).

\section{Blagoi, Y. P.}

Properties of Liquid and Solid Hydrogen - B. N. Esel'son, Y. P. Blagoi, V.N. Grigor'ev, V. G. Manzhelii, S. A. Mikhailenko, and N. P.
Neklyudov, Russian Transl. Springfield, VA: NTIS, 126p. (1971). TT 70-50179, A07.

\section{Bogaard, R. H.}

Electrical Resistivity of Ten Selected Binary Alloy Systems - Cho Y. Ho, M. W. Ackerman, K. Y. Wu, T. N. Havill, R. H. Bogaard, R. A. Matula, S. G. Oh, and H. M. James. J Phys Chem Ref Data 12, 183(1983).

\section{Bondar', I. A.}

Handbook of Phase Diagrams of Silicate Systems, Vol. II. MetalOxygen Compounds in Silicate Systems, Second Revised Edition - N. A. Toropov, V. P. Barzakovskii, I. A. Bondar', and Yu. P. Udalov. Russian Transl. Springfield, VA: NTIS, 329p. (1972). TT 71-50041, A15.

\section{Bortner, M. H.}

A Review of Rate Constants of Selected Reactions of Interest in Re-Entry Flow Fields in the Atmosphere - M. H. Bortner. NBS Tech. Note 484, 62p. (1969).

\section{Boucher, D.}

Microwave Spectra of Molecules of Astrophysical Interest, XV. Propyne - A. Bauer, D. Boucher, J. Burie, J. Demaison, and A. Dubrulle. J Phys Chem Ref Data 8, 537(1979).

Microwave Spectra of Molecules of Astrophysical Interest. XIX. Methyl Cyanide - D. Boucher, J. Burie, A. Bauer, A. Dubrulle, and J. Demaison. J Phys Chem Ref Data 9, 659(1980).

\section{Boyd, Walter K.}

Critical Surveys of Data Sources: Corrosion of Metals - Ronald Diegle and Walter K. Boyd. NBS Spec. Publ. 396, 42p. (1976).

\section{Brady, Edward L.}

National Standard Reference Data System Plan of Operation Edward L. Brady and M. Wallenstein. NSRDS-NBS 1, 12p. (1965).

\section{Bransden, B. H.}

Evaluated Theoretical Cross Section Data for Charge Exchange of Multiply Charged Ions with Atoms. I. Hydrogen A tom-Fully Stripped Ion Systems - R. K. Janev, B. H. Bransden, and Jean W. Gallagher. J Phys Chem Ref Data 12, 829(1983).

Evaluated Theoretical Cross Section Data for Charge Exchange of Multiply Charged Ions with Atoms. II. Hydrogen Atom-Partially Stripped Ions Systems - Jean W. Gallagher, B. H. Bransden, and R. K. Janev. J Phys Chem Ref Data 12, 873(1983).

\section{Braun, W.}

Survey of Photochemical and Rate Data for Twenty-eight Reactions of Interest in Atmospheric Chemistry - Robert F. Hampson, Jr., W. Braun, R. L. Brown, David Garvin, John T. Herron, Robert E. Huie, M. J. Kurylo, A. H. Laufer, J. D. McKinley, H. Okabe, M. D. Scheer, W. Tsang, D. H. Stedman, editor(s). J Phys Chem Ref Data 2, 267(1973).

\section{Breen, Bettijoyce}

OMNIDATA, An Interactive System for Data Retrieval, Statistical and Graphical Analysis, and Data-Base Management, A User's Manual - Joseph Hilsenrath and Bettijoyce Breen. NBS Handbook 125, 294p. (1978). 


\section{Bremer, Shirley G.}

Test Problems and Results for OMNITAB 80 - Sally T. Peavy and Shirley G. Bremer. NBS Tech. Note 1147, 316p. (1981).

\section{Brewer, Leo}

Simplification of Thermodynamic Calculations Through Dimensionless Entropies (Comments) - Kenneth S. Pitzer and Leo Brewer. J Phys Chem Ref Data 8, 917(1979).

\section{Briggs, E. A .}

Atomic Form Factors, Incoherent Scattering Functions, and Photon Scattering Cross Sections - John H. Hubbell, W. J. Veigele, E. A. Briggs, R. T. Brown, D. T. Cromer, and K. J. Howerton. J Phys Chem Ref Data 4, 471(1975).

\section{Brooks, James S.}

The Calculated Thermodynamic Properties of Superfluid Helium-4 - James S. Brooks and Russell J. Donnelly. J Phys Chem Ref Data 6 , 51(1977).

\section{Brown, R. L.}

Summary Report on the Workshop on High Temperature Chemical Kinetics: Applications to Combustion Research - David Garvin, R. L. Brown, Robert F. Hampson, Jr., M. J. Kurylo, and W. Tsang. NBS Spec. Publ. 531, 94p. (1978).

Survey of Photochemical and Rate Data for Twenty-eight Reactions of Interest in Atmospheric Chemistry - Robert F. Hampson, Jr., W. Braun, R. L. Brown, David Garvin, John T. Herron, Robert E. Huie, M. J. Kurylo, A. H. Laufer, J. D. McKinley, H. Okabe, M. D. Scheer, W. Tsang, D. H. Stedman, editor(s). J Phys Chem Ref Data 2, 267(1973).

\section{Brown, R. T.}

Atomic Form Factors, Incoherent Scattering Functions, and Photon Scattering Cross Sections - John H. Hubbell, W. J. Veigele, E. A. Briggs, R. T. Brown, D. T. Cromer, and R. J. Howerton. J Phys Chem Ref Data 4, 471(1975).

\section{Browne, Edgardo}

Table of Isotopes, Seventh Edition - C. Michael Lederer, Virginia S. Shirley, Edgardo Browne, Janis M. Dairiki, and Raymond E. Doebler. New York: Wiley-Interscience, 1628p. (1978), ISBN: 0-471-0417-3.

\section{Brummer, James $G$.}

A Catalog of Data Compilations on Photochemical and Photophysical Processes in Solution - James G. Brummer, W. Phillip Helman, and Alberta B. Ross. NBS Spec. Publ. 578, 27p. (1980).

Rate Constants for the Decay and Reactions of the Lowest Electronically Excited Singlet State of Molecular Oxygen in Solution - Francis Wilkinson and James G. Brummer. J Phys Chem Ref Data 10, 809(1981).

\section{Burle, J.}

Microwave Spectra of Molecules of Astrophysical Interest, XV. Propyne - A. Bauer, D. Boucher, J. Burie, J. Demaison, and A. Dubrulle. J Phys Chem Ref Data 8, 537(1979).

Microwave Spectra of Molecules of Astrophysical Interest. XIX. Methyl Cyanide - D. Boucher, J. Burie, A. Bauer, A. Dubrulle, and J. Demaison. J Phys Chem Ref Data 9, 659(1980).

\section{Burkhard, D. G.}

Microwave Spectral Tables, Volume III. Polyatomic Molecules with Internal Rotation - Paul F. Wacker, M. S. Cord, D. G. Burkhard, J. D. Petersen, and R. F. Kukol. NBS Monograph 70, 275p. (1969).

Burr, A. F.

X-Ray Wavelengths and X-Ray Atomic Energy Levels - Joyce A. Bearden and A. F. Burr. NSRDS-NBS 14, 66p. (1967).

\section{Burzlafi, Hans}

Space Groups and Lattice Complexes - W. Fisher, Hans Burzlaff, Erwin Hellner, and Joseph D. H. Donnay. NBS Monograph 134, 177p. (1973).

\section{Busey, R. H.}

Thermodynamic Properties of Aqueous Sodium Chloride Solutions - Kenneth S. Pitzer, J. Christopher Peiper, and R. H. Busey. J Phys Chem Ref Data 13, 1(1984).

\section{Butrymowicz, Daniel B.}

Diffusion Rate Data and Mass Transport Phenomena in Copper Systems - Daniel B. Butrymowicz, John R. Manning, and Michael E. Read. INCRA. Monograph V, New York: International Copper Research Association, Inc., 322p. (1977).

Diffusion Rate Data and Mass Transport Phenomena for Copper Systems, Part II - Daniel B. Butrymowicz, John R. Manning, and Michael E. Read. INCRA Monograph VIII, New York: International Copper Research Association, Inc., 701p. (1982).

Diffusion in Copper and Copper Alloys, Part I. Volume and Surface Self-Diffusion in Copper - Daniel B. Butrymowicz, John R. Manning, and Michael E. Read. J Phys Chern Ref Data 2, 643(1973).

Diffusion in Copper and Copper Alloys, Part II. Copper-Silver and Copper-Gold Systems - Daniel B. Butrymowicz, John R. Manning, and Michael E. Read. J Phys Chem Ref Data 3, 527(1974).

Diffusion in Copper and Copper Alloys, Part III. Diffusion in Systems Involving Elements of the Groups IA, IIA, IIIB, IVB, VB, and VIIB - Daniel B. Butrymowicz, John R. Manning, and Michael E. Read. J Phys Chem Ref Data 4, 177(1975).

Diffusion in Copper and Copper Alloys, Part IV. Diffusion in Systems Involving Elements of Group VIII - Daniel B. Butrymowicz, John R. Manning, and Michael E. Read. J Phys Chem Ref Data 5, 103(1976)

Diffusion in Copper and Copper Alloys, Part V. Diffusion in Systems Involving Elements of Group VA - Daniel B. Butrymowicz, John R. Manning, and Michael E. Read. J Phys Chem Ref Data 6, 1(1977).

\section{Buxton, George V.}

Compilation of Rate Constants for the Reactions of Metal Ions in Unusual Valency States - George V. Buxton and Robin M. Sellers. NSRDS-NBS 62, 68p. (1978).

\section{Camy-Peyret, C.}

Atlas of the High Temperature Water Vapor Spectrum in the 3000 to $4000 \mathrm{~cm}^{-1}$ Region - A. S. Pine, M. J. Coulombe, C. Camy-Peyret, and J-M. Flaud. J Phys Chem Ref Data 12, 413(1983).

\section{Cannon, John Francis}

A Compilation of Volumes I-IV of Bibliography on High Pressure Research with Author and Subject Indexes - John Francis Cannon and Leo Merrill. Springfield, VA: NTIS, 385p. (1972). in two volumes, Vol. 1. PB 191 174, A17; Vol. 2. PB 191174. 
Behavior of the Elements at High Pressures - John Francis Cannon. J Phys Chem Ref Data 3, 781(1974).

High Pressure Bibliography, 1968-1971, with Author and Subject Indexes - John Francis Cannon and Leo Merrill. Provo, UT: High Pressure Data Center, Brigham Young University, 189p. (1972). in microfiche only.

Carr, M. J.

Critical Surveys of Data Sources: Electrical and Magnetic Properties of Metals - M. J. Carr, R. B. Gavert, Robert L. Moore, H. W. Wawrousek, and John H. Westbrook. NBS Spec. Publ. 396, 96p. (1976).

\section{Carter, Gesina Cynthia}

Applications of Phase Diagrams, Proceedings of a Workshop Held at the National Bureau of Standards, Gaithersburg, Maryland, January 10-12, 1977, Volumes 1 and 2 - Gesina Cynthia Carter, editor(s). NBS Spec. Publ. 496, 1622p. (1978).

Metallic Shifts in NMR: A Review of the Theory and Comprehensive Critical Data Compilation of Metallic Materials - Gesina Cynthia Carter, Lawrence H. Bennett, and Daniel J. Kahan. Prog Mater Sci, Oxford, New York: Pergamon Press, 2350p. (1977), ISBN: 0-08-02114-7.

The NBS Alloy Data Center: Author Index - Gesina Cynthia Carter, Daniel J. Kahan, Lawrence H. Bennett, John R. Cuthill, and Ronald C. Dobbyn. OSRD Bibl. 70-2, 413p. (1970).

The NBS Alloy Data Center: Function, Bibliographic System, Related Data Centers, and Reference Books - Gesina Cynthia Carter, Lawrence H. Bennett, John R. Cuthill, and Daniel J. Kahan. NBS Tech. Note 464, 163p. (1968).

The NBS Alloy Data Center: Permuted Materials Index - Gesina Cynthia Carter, Daniel J. Kahan, Lawrence H. Bennett, John R. Cuthill, and Ronald C. Dobbyn. NBS Spec. Publ. 324, 683p. (1971).

\section{Cermak, V.}

Ion-Molecule Reactions - Earl W. McDaniel, V. Cermak, A. Dalgarno, E. E. Ferguson, and L. Friedman. At Mol Collis Proc Ser, New York: Wiley-Interscience, 374p. (1970), ISBN: 0-471-5838-3.

\section{Chang, Y. Austin}

Phase Diagrams and Thermodynamic Properties of Ternary Copper-Silver Systems - Y. Austin Chang, Daniel Goldberg, and Joachim P. Neumann. J Phys Chem Ref Data 6, 621(1977).

Phase Diagrams and Thermodynamic Properties of Ternary CopperMetal Systems - Y. Austin Chang, Joachim P. Neumann, A. Mikula, and Daniel Goldberg. INCRA Monograph VI, New York: International Copper Research Association, Inc., 702p. (1979).

Phase Diagrams and Thermodynamic Properties of Ternary CopperSulfur-Metal Systems - Y. Austin Chang, Joachim P. Neumann, and U. V. Choudary. INCRA Monograph VII, New York: International Copper Research Association, Inc., 191p. (1979).

\section{Chao, Jing}

Ideal Gas Thermodynamic Properties of Ethane and Propane - Jing Chao, Randolph C. Wilhoit, and Bruno J. Zwolinski. J Phys Chem Ref Data 2, 427(1973)

Ideal Gas Thermodynamic Properties of Eight Chloro- and Fluoromethanes - A. S. Rodgers, Jing Chao, Randolph C. Wilhoit, and Bruno J. Zwolinski. J Phys Chem Ref Data 3, 117(1974).

Ideal Gas Thermodynamic Properties of Six Chloroethanes - Jing Chao, A. S. Rodgers, Randolph C. Wilhoit, and Bruno J. Zwolinski. J Phys Chem Ref Data 3, 141(1974).

Ideal Gas Thermodynamic Properties of Ethylene and Propylene Jing Chao and Bruno J. Zwolinski. J Phys Chem Ref Data 4, 251(1975). Ideal Gas Thermodynamic Properties of Six Fluoroethanes - S. S. Chen, A. S. Rodgers, Jing Chao, Randolph C. Wilhoit, and Bruno J. Zwolinski. J Phys Chem Ref Data 4, 441(1975).
Ideal Gas Thermodynamic Properties of Propanone and 2-Butanone - Jing Chao and Bruno J. Zwolinski. J Phys Chem Ref Data 5, 319(1976).

Idea! Gas Thermodynamic Properties of Methanoic and Ethanoic Acids - Jing Chao and Bruno J. Zwolinski. J Phys Chem Ref Data 7, 363(1978).

Vapor Pressure of Coal Chemicals - Jing Chao, C. T. Lin, and T. H. Chung. J Phys Chem Ref Data 12, 1033(1983).

\section{Chase, Malcolm W., Jr.}

JANAF Thermochemical Tables, 1974 Supplement - Malcolm W. Chase, Jr., J. L. Curnutt, A. T. Hu, H. Prophet, A. N. Syverud, and L. C. Walker. J Phys Chem Ref Data 3, 311(1974).

JANAF Thermochemical Tables, 1975 Supplement - Malcolm W. Chase, Jr., J. L. Curnutt, H. Prophet, R. A. McDonald, and A. N. Syverud. J Phys Chem Ref Data 4, 1(1975).

JANAF Thermochemical Tables, 1978 Supplement - Malcolm W. Chase, Jr., J. L. Curnutt, R. A. McDonald, and A. N. Syverud. J Phys Chem Ref Data 7, 793(1978).

JANAF Thermochemical Tables, 1982 Supplement - Malcolm W. Chase, Jr., J. L. Curnutt, J. R. Downey, Jr., R. A. McDonald, A. N. Syverud, and E. A. Valenzuela. J Phys Chem Ref Data 11, 695(1982).

\section{Chen, S. S.}

Ideal Gas Thermodynamic Properties of Six Fluoroethanes - S. S. Chen, A. S. Rodgers, Jing Chao, Randolph C. Wilhoit, and Bruno J. Zwolinski. J Phys Chem Ref Data 4, 441(1975).

Ideal Gas Thermodynamic Properties and Isomerization of n-Butane and Isobutane - S. S. Chen, Randolph C. Wilhoit, and Bruno J. Zwolinski. J Phys Chem Ref Data 4, 859(1975).

Ideal Gas Thermodynamic Properties of Six Chlorofluoromethanes - S. S. Chen, Randolph C. Wilhoit, and Bruno J. Zwolinski. J Phys Chem Ref Data 5, 571(1976).

Thermodynamic Properties of Normal and Deuterated Methanols S. S. Chen, Randolph C. Wilhoit, and Bruno J. Zwolinski. J Phys Chem Ref Data 6, 105(1977).

Thermodynamic Properties of Normal and Deuterated Naphthalenes - S. S. Chen, Shanti A. Kudchadker, and Randolph C. Wilhoit. J Phys Chem Ref Data 8, 527(1979).

\section{Cheung, Lap M.}

Vibrational Contributions to Molecular Dipole Polarizabilities David M. Bishop and Lap M. Cheung. J Phys Chem Ref Data 11, 119(1982).

\section{Chew, Denyse $M$.}

$\pi+\mathrm{p}, \pi+\mathrm{n}$, and $\pi+\mathrm{d}$ Interactions - A Compilation: Parts I and II Denyse M. Chew, Victor P. Henri, Thomas A. Lasinski, Thomas G. Trippe, Fumiyo Uchiyama, Frederick C. Winkelmann and Particle Data Group. UCRL 53, Springfield, VA: NTIS, $213 p$. (1973). LBL 53; Part II is on microfiche located in the back cover pocket, A10.

Chi, T. C.

Electrical Resistivity of Alkali Elements - T. C. Chi. J Phys Chem Ref Data 8, 339(1979).

Electrical Resistivity of Alkaline Earth Elements - T. C. Chi. J Phys Chem Ref Data 8, 439(1979).

\section{Choudary, U. V.}

Phase Diagrams and Thermodynamic Properties of Ternary Copper-Sulfur-Metal Systems - Y. Austin Chang, Joachim P. Neumann, and U. V. Choudary. INCRA Monograph VII, New York: International Copper Research Association, Inc., 191p. (1979). 
Chu, T. K.

Electrical Resistivity of Selected Elements - P. D. Desai, T. K. Chu, H. M. James, and Cho Y. Ho. J Phys Chem Ref Data 13, 1069(1984).

\section{Chung, T. $\mathrm{H}_{\text {. }}$}

Vapor Pressure of Coal Chemicals - Jing Chao, C. T. Lin, and T. H. Chung. J Phys Chem Ref Data 12, 1033(1983).

\section{Churney, Kenneth L.}

Selected Values of Chemical Thermodynamic Properties. Tables for Elements 54 through 61 in the Standard Order of Arrangement Donald D. Wagman, William H. Evans, Vivian B. Parker, Iva Halow, Sylvia M. Bailey, Richard H. Schumm, and Kenneth L. Churney. NBS Tech. Note 270, 49p. (1971).

The NBS Tables of Chemical Thermodynamic Properties. Selected Values for Inorganic and $C_{1}$ and $C_{2}$ Organic Substances in SI Units Donald D. Wagman, William H. Evans, Vivian B. Parker, Richard H. Schumm, Iva Halow, Sylvia M. Bailey, Kenneth L. Churney, and Ralph L. Nuttall. J Phys Chem Ref Data 11, Suppl. 2(1982).

\section{Clever, $\boldsymbol{H}$. Lawrence}

The Solubility of Some Sparingly Soluble Lead Salts: An Evaluation of the Solubility in Water and Aqueous Electrolyte Solution - H. Lawrence Clever and Francis J. Johnston. J Phys Chem Ref Data 9, 751(1980).

\section{Cohen, E. Richard}

The 1973 Least-Squares Adjustment of the Fundamental Constants - E. Richard Cohen and Barry N. Taylor. J Phys Chem Ref Data 2, 663(1973).

\section{Cohen, N.}

Chemical Kinetic Data Sheets for High-Temperature Chemical Reactions - N. Cohen and K. R. Westberg. J Phys Chem Ref Data 12, 531(1983).

\section{Collocott, S. J.}

Heat Capacity of Reference Materials: $\mathrm{Cu}$ and W - G. K. White and S. J. Collocott. J Phys Chem Ref Data 13, 1251(1984).

\section{Comeford, John J.}

Bibliography of Infrared Spectroscopy through $1960-$ C. N. R. Rao, S. K. Dikshit, Shanti A. Kudchadker, D. S. Gupta, V. A. Narayan, and John J. Comeford. NBS Spec. Publ. 428, 1,2,3(1976).

\section{Coogan, Helen M.}

Mossbauer Effect Data Index, 1958-1965 - A. H. Muir, K. J. Ando, and Helen M. Coogan. New York: Interscience Publishers, 351p. (1966).

\section{Cook, E. L.}

Compilation of Energy Band Gaps in Elemental and Binary Compound Semiconductors and Insulators - W. H. Strehlow and E. L. Cook. J Phys Chem Ref Data 2, 163(1973).

\section{Cook, F. J.}

Analysis of Specific Heat Data in the Critical Region of Magnetic Solids - F. J. Cook. J Phys Chem Ref Data 2, 11(1973).
Cord, M. S.

Microwave Spectral Tables, Volume IV. Polyatomic Molecules without Internal Rotation - M. S. Cord, J. D. Petersen, M. S. Lojko, and R. H. Haas. NBS Monograph 70, 419p. (1968).

Microwave Spectral Tables, Volume III. Polyatomic Molecules with Internal Rotation - Paul F. Wacker, M. S. Cord, D. G. Burkhard, J. D. Petersen, and R. F. Kukol. NBS Monograph 70, 275p. (1969).

Microwave Spectral Tables, Volume V. Spectral Line Listing - M. S. Cord, M. S. Lojko, and J. D. Petersen. NBS Monograph 70, 533p. (1968).

\section{Corliss, Charles $H_{a}$}

Energy Levels of Calcium, Ca I through Ca XX - Jack Sugar and Charles H. Corliss. J Phys Chem Ref Data 8, 865(1979).

Energy Levels of Chromium, Cr I through Cr XXIV - Jack Sugar and Charles H. Corliss. J Phys Chem Ref Data 6, 317(1977).

Energy Levels of Cobalt, Co I through Co XXVII - Jack Sugar and Charles H. Corliss. J Phys Chem Ref Data 10, 1097(1981).

Energy Levels of Iron, Fe I through Fe XxvI - Charles H. Corliss and Jack Sugar. J Phys Chem Ref Data 11, 135(1982).

Energy Levels of Manganese, Mn I through Mn XXV - Charles $\mathrm{H}$. Corliss and Jack Sugar. J Phys Chem Ref Data 6, 1253(1977).

Energy Levels of Nickel, Ni I through Ni XXVIII - Charles H. Corliss and Jack Sugar. J Phys Chem Ref Data 10, 197(1981).

Energy Levels of Potassium, K I through $\mathrm{K}$ XIX - Charles $\mathrm{H}$. Corliss and Jack Sugar. J Phys Chem Ref Data 8, 1109(1979).

Energy Levels of Scandium, Sc I through Sc XXI - Jack Sugar and Charles H. Corliss. J Phys Chem Ref Data 9, 473(1980).

Energy Levels of Titanium, Ti I through Ti XXII - Charles H. Corliss and Jack Sugar. J Phys Chem Ref Data 8, 1(1979).

Energy Levels of Vanadium, V I through V XXIII - Jack Sugar and Charles H. Corliss. J Phys Chem Ref Data 7, 1191(1978).

Tables of Line Spectra of the Elements, Part 1. Wavelengths and Intensities, Part 2. Transition Probabilities - Joseph Reader, Charles H. Corliss, Wolfgang L. Wiese, and Georgia A. Martin. NSRDS-NBS 68, 415p. (1980).

\section{Correla, Robert ل J.}

Tables of the Dynamic and Kinematic Viscosity of Aqueous $\mathrm{KCl}$ Solutions in the Temperature Range $25-150^{\circ} \mathrm{C}$ and the Pressure Range 0.1-35 MPa - Joseph Kestin, H. Ezzat Khalifa, and Robert J. Correia. J Phys Chem Ref Data 10, 57(1981).

Tables of the Dynamic and Kinematic Viscosity of Aqueous $\mathrm{NaCl}$ Solutions in the Temperature Range $20-150^{\circ} \mathrm{C}$ and the Pressure Range 0.1-35 MPa - Joseph Kestin, H. Ezzat Khalifa, and Robert J. Correia. J Phys Chem Ref Data 10, 71(1981).

\section{Coulombe, M. J.}

Atlas of the High Temperature Water Vapor Spectrum in the 3000 to $4000 \mathrm{~cm}^{-1}$ Region - A. S. Pine, M. J. Coulombe, C. Camy-Peyret, and J-M. Flaud. J Phys Chem Ref Data 12, 413(1983).

\section{Cox, R. A.}

Evaluated Kinetic and Photochemical Data for Atmospheric Chemistry - D. L. Baulch, R. A. Cox, Robert F. Hampson, Jr., J. A. Kerr, J. Troe, and R. T. Watson. J Phys Chem Ref Data 9, 295(1980).

Evaluated Kinetic and Photochemical Data for Atmospheric Chemistry: Supplement I. CODATA Task Group on Chemical Kinetics D. L. Baulch, R. A. Cox, P. J. Crutzen, Robert F. Hampson, Jr., J. A. Kerr, J. Troe, and R. T. Watson. J Phys Chem Ref Data 11, 327(1982).

Evaluated Kinetic and Photochemical Data for Atmospheric Chemistry: Supplement II. CODATA Task Group on Gas Phase Chemical Kinetics - D. L. Baulch, R. A. Cox, Robert F. Hampson, Jr., J. A. Kerr, J. Troe, and R. T. Watson. J Phys Chem Ref Data 13, 1259(1984).

\section{Craver, Clara D.}

Desk Book of Infrared Spectra - Clara D. Craver and Coblentz Society; Joint Committee on Atomic and Molecular Physical Data. Kirkwood, MO: The Coblentz Society, 458p. (1977). 
Infrared Spectra of Halogenated Hydrocarbons - Clara D. Craver and Coblentz Society; Joint Committee on Atomic and Molecular Physical Data. Kirkwood, MO: The Coblentz Society, 125p. (1977).

Infrared Spectra of Plasticizers and Other Additives - Clara D. Craver and Coblentz Society; Joint Committee on Atomic and Molecular Physical Data., Kirkwood, MO: The Coblentz Society, 152p. (1977).

\section{Cromer, D. T.}

Atomic Form Factors, Incoherent Scattering Functions, and Photon Scattering Cross Sections - John H. Hubbell, W. J. Veigele, E. A. Briggs, R. T. Brown, D. T. Cromer, and R. J. Howerton. J Phys Chem VRef Data 4, 471(1975).

\section{Crutzen, P. J.}

Evaluated Kinetic and Photochemical Data for Atmospheric Chemistry: Supplement I. CODATA Task Group on Chemical Kinetics D. L. Baulch, R. A. Cox, P. J. Crutzen, Robert F. Hampson, Jr., J. A. Kerr, J. Troe, and R. T. Watson. J Phys Chem Ref Data 11, 327(1982).

\section{Curnutt, J. L.}

JANAF Thermochemical Tables, 1974 Supplement - Malcolm W. Chase, Jr., J. L. Curnutt, A. T. Hu, H. Prophet, A. N. Syverud, and L. C. Walker. J Phys Chem Ref Data 3, 311(1974).

JANAF Thermochemical Tables, 1975 Supplement - Malcolm W. Chase, Jr., J. L. Curnutt, H. Prophet, R. A. McDonald, and A. N. Syverud. J Phys Chem Ref Data 4, 1(1975).

JANAF Thermochemical Tables, 1978 Supplement - Malcolm W. Chase, Jr., J. L. Curnutt, R. A. McDonald, and A. N. Syverud. J Phys Chem Ref Data 7, 793(1978).

JANAF Thermochemical Tables, 1982 Supplement - Malcolm W. Chase, Jr., J. L. Curnutt, J. R. Downey, Jr., R. A. McDonald, A. N. Syverud, and E. A. Valenzuela. J Phys Chem Ref Data 11, 695(1982).

\section{Cuthill, John R.}

Soft X-Ray Emission Spectra of Metallic Solids: Critical Review of Selected Systems - Archie J. McAlister, Ronald C. Dobbyn, John R. Cuthill, and M. L. Williams. J Phys Chem Ref Data 2, 411(1973).

Soft X-Ray Emission Spectra of Metallic Solids: Critical Review of Selected Systems and Annotated Spectral Index - Archie J. McAlister, Ronald C. Dobbyn, John R. Cuthill, and M. L. Williams. NBS Spec. Publ. 369, 180p. (1974).

The NBS Alloy Data Center: Author Index - Gesina Cynthia Carter, Daniel J. Kahan, Lawrence H. Bennett, John R. Cuthill, and Ronald C. Dobbyn. OSRD Bibl. 70-2, 413p. (1970).

The NBS Alloy Data Center: Function, Bibliographic System, Related Data Centers, and Reference Books - Gesina Cynthia Carter, Lawrence H. Bennett, John R. Cuthill, and Daniel J. Kahan. NBS Tech. Note 464, 163p. (1968).

The NBS Alloy Data Center: Permuted Materials Index - Gesina Cynthia Carter, Daniel J. Kahan, Lawrence H. Bennett, John R. Cuthill, and Ronald C. Dobbyn. NBS Spec. Publ. 324, 683p. (1971).

\section{Dairiki, Janis $M$.}

Table of Isotopes, Seventh Edition - C. Michael Lederer, Virginia S. Shirley, Edgardo Browne, Janis M. Dairiki, and Raymond E. Doebler. New York: Wiley-Interscience, 1628p. (1978), ISBN: 0-471-0417-3.

\section{Dalgarno, A.}

Ion-Molecule Reactions - Earl W. McDaniel, V. Cermak, A. Dalgarno, E. E. Ferguson, and L. Friedman. At Mol Collis Proc Ser, New York: Wiley-Interscience, 374p. (1970), ISBN: 0-471-5838-3.

\section{Dampier, F. W.}

Molten Salts: Volume 1. Electrical Conductance, Density, and Viscosity Data - George J. Janz, F. W. Dampier, G. R. Lakshminarayanan, P. K. Lorenz, and Reginald P. T. Tomkins. NSRDS-NBS 15, 140p. (1968).

\section{Dangoisse, Didier}

Microwave Spectra of Molecules of Astrophysical Interest. XVIII. Formic Acid - Edmond Willemot, Didier Dangoisse, Nicole Monnanteuil, and Jean Bellet. J Phys Chem Ref Data 9, 59(1980).

\section{Darwent, B. DeB.}

Bond Dissociation Energies in Simple Molecules - B. DeB. Darwent. NSRDS-NBS 31, 48p. (1970).

\section{Davies, John E.}

Crystal Data Determinative Tables, Third Edition, Volume 5. Organic Compounds - Olga Kennard, David G. Watson, John E. Davies, John R. Rodgers, editor(s). 5, Swarthmore, PA, JCPDS-International Center for Diffraction Data,(1983).

Crystal Data Determinative Tables, Third Edition, Volume 6. Organic Compounds - Olga Kennard, David G. Watson, John E. Davies, editor(s). 6, Swarthmore, PA, JCPDS-International Center for Diffraction Data,(1983).

\section{De Bière, Paul}

Isotopic Abundances and Atomic Weights of the Elements - Paul De Bièvre, Marc Gallet, Norman E. Holden, and I. Lynus Barnes. J Phys Chem Ref Data 13, 809(1984).

\section{De Lucia, Frank C.}

Microwave Spectra of Molecules of Astrophysical Interest, IV. Hydrogen Sulfide - Paul Helminger, Frank C. De Lucia, and William H. Kirchhoff. J Phys Chem Ref Data 2, 215(1973).

Microwave Spectra of Molecules of Astrophysical Interest, V. Water Vapor - Frank C. De Lucia, Paul Helminger, and William $\mathbf{H}$. Kirchhoff. J Phys Chem Ref Data 3, 211(1974).

\section{DeWane, H. J.}

Electrolytic Conductance and the Conductances of the Halogen Acids in Water - Walter J. Hamer and H. J. DeWane. NSRDS-NBS 33, 37p. (1970).

\section{Decker, D. L.}

High-Pressure Calibration: A Critical Review - D. L. Decker, W. A. Bassett, Leo Merrill, H. T. Hall, and J. D. Barnett. J Phys Chem Ref Data 1, 773(1972).

\section{Demaison, J.}

Microwave Spectra of Molecules of Astrophysical Interest, XV. Propyne - A. Bauer, D. Boucher, J. Burie, J. Demaison, and A. Dubrulle. J Phys Chem Ref Data 8, 537(1979).

Microwave Spectra of Molecules of Astrophysical Interest. XIX. Methyl Cyanide - D. Boucher, J. Burie, A. Bauer, A. Dubrulle, and J. Demaison. J Phys Chem Ref Data 9, 659(1980).

\section{Desai, P. D.}

Electrical Resistivity of Aluminum and Manganese - P. D. Desai, H. M. James, and Cho Y. Ho. J Phys Chem Ref Data 13, 1131(1984).

Electrical Resistivity of Selected Elements -- P. D. Desai, T. K. Chu, H. M. James, and Cho Y. Ho. J Phys Chem Ref Data 13, 1069(1984).

Electrical Resistivity of Vanadium and Zirconium - P. D. Desai, H. M. James, and Cho Y. Ho. J Phys Chem Ref Data 13, 1097(1984). 


\section{Desai, Pramond D.}

Selected Thermodynamic Values and Phase Diagrams for Copper and Some of Its Binary Alloys - Ralph Hultgren and Pramond D. Desai. INCRA Monograph I, New York: International Copper Research Association, Inc., 204p. (1973).

Selected Values or the Thermodynamic Properties of Binary Alloys Ralph Hultgren, Pramond D. Desai, Donald T. Hawkins, M. Gleiser, and Kenneth K. Kelley. Metals Park, OH: American Society for Metals, 1435p. (1973).

Selected Values of the Thermodynamic Properties of the Elements Ralph Hultgren, Pramond D. Desai, Donald T. Hawkins, M. Gleiser, Kenneth K. Kelley, and Donald D. Wagman. Metals Park, OH: American Society for Metals, 636p. (1973).

\section{Dewan, Ashok}

Critical Evaluation of Vapor-Liquid Equilibrium, Heat of Mixing, and Volume Change of Mixing Data. General Procedures - Buford D. Smith, O1 Muthu, Ashok Dewan, and Matthew Gierlach. J Phys Chem Ref Data 11, 941(1982).

Evaluation of Binary Excess Enthalpy Data for $\mathrm{C}_{6}$ Hydrocarbons. Benzene + Cyclohexane - Buford D. Smith, Ol Muthu, Ashok Dewan, and Matthew Gierlach. J Phys Chem Ref Data 11, 1127(1982).

Evaluation of Binary Excess Enthalpy Data for $\mathrm{C}_{6}$ Hydrocarbons. Benzene + Hexane - Buford D. Smith, Ol Muthu, and Ashok Dewan. J Phys Chem Ref Data 12, 389(1983).

Evaluation of Binary Excess Volume Data for $\mathrm{C}_{6}$ Hydrocarbons. Benzene + Cyclohexane - Buford D. Smith, Ol Muthu, Ashok Dewan, and Matthew Gierlach. J Phys Chem Ref Data 11, 1151(1982).

Evaluation of Binary Excess Volume Data for $\mathrm{C}_{6}$ Hydrocarbons. Benzene + Hexane - Buford D. Smith, Ol Muthu, and Ashok Dewan. J Phys Chem Ref Data 12, 395(1983).

Evaluation of Binary PTxy Vapor-Liquid Equilibrium Data for $\mathrm{C}_{6}$ Hydrocarbons. Benzene + Cyclohexane - Buford D. Smith, Ol Muthu, Ashok Dewan, and Matthew Gierlach. J Phys Chem Ref Data 11, 1099 (1982).

Evaluation of Binary PTxy Vapor-Liquid Equilibrium Data for $\mathrm{C}_{6}$ Hydrocarbons. Benzene + Hexane - Buford D. Smith, Ol Muthu, and Ashok Dewan. J Phys Chem Ref Data 12, 381(1983).

\section{Dlaz, Carlos}

Thermodynamic Properties of Copper-Slag Systems - Carlos Diaz. INCRA Monograph III, New York: International Copper Research Association, Inc., 178p. (1976).

\section{Dlck, C. E.}

Utility Programs for Generating the Hershey Character Fonts on Microcomputers and Laboratory Plotters - C. E. Dick and Joseph Hilsenrath. NBS Tech. Note 1176, 49p. (1983).

\section{Dlegle, Ronald}

Critical Surveys of Data Sources: Corrosion of Metals - Ronald Diegle and Walter K. Boyd. NBS Spec. Publ. 396, 42p. (1976).

\section{Dljkhuis, Chr. G. M.}

Molten Salts: Volume 2. Section 1. Electrochemistry of Molten Salts. Gibbs Free Energies and Excess Free Energies from Equilibrium-Type Cells, Section 2. Surface Tension Data - George J. Janz, Chr. G. M. Dijkhuis, G. R. Lakshminarayanan, Reginald P. T. Tomkins, and J. Wong. NSRDS-NBS 28, 116p. (1968).
Dikshit, S. K.

Bibliography of Infrared Spectroscopy through 1960 - C. N. R. Rao, S. K. Dikshit, Shanti A. Kudchadker, D. S. Gupta, V. A. Narayan, and John J. Comeford. NBS Spec. Publ. 428, 1,2,3(1976).

\section{Dillard, J. G.}

Ionization Potentials, Appearance Potentials, and Heats of Formation of Gaseous Positive Ions - Joseph L. Franklin, J. G. Dillard, Henry M. Rosenstock, John T. Herron, Keith Draxl, and Frank H. Field. NSRDSNBS 26, 289p. (1969).

\section{Dimitrijevic, M. S.}

Experimental Stark Widths and Shifts for Spectral Lines of Neutral Atoms (A Critical Review of Selected Data for the Period 1976 to 1982) - N. Konjević, M. S. Dimitrijević, and Wolfgang L. Wiese. J Phys Chem Ref Data 13, 619(1984).

Experimental Stark Widths and Shifts for Spectral Lines of Positive Ions (A Critical Review and Tabulation of Selected Data for the Period 1976 to 1982) - N. Konjević, M. S. Dimitrijević, and Wolfgang L. Wiese. J Phys Chem Ref Data 13, 649(1984).

\section{Dobbyn, Ronald C.}

Soft X-Ray Emission Spectra of Metallic Solids: Critical Review of Selected Systems - Archie J. McAlister, Ronald C. Dobbyn, John R. Cuthill, and M. L. Williams. J Phys Chem Ref Data 2, 411(1973).

Soft X-Ray Emission Spectra of Metallic Solids: Critical Review of Selected Systems and Annotated Spectral Index - Archie J. McAlister, Ronald C. Dobbyn, John R. Cuthill, and M. L. Williams. NBS Spec. Publ. 369, 180p. (1974).

The NBS Alloy Data Center: Author Index - Gesina Cynthia Carter, Daniel J. Kahan, Lawrence H. Bennett, John R. Cuthill, and Ronald C. Dobbyn. OSRD Bibl. 70-2, 413p. (1970).

The NBS Alloy Data Center: Permuted Materials Index - Gesina Cynthia Carter, Daniel J. Kahan, Lawrence H. Bennett, John R. Cuthill, and Ronald C. Dobbyn. NBS Spec. Publ. 324, 683p. (1971).

\section{Doebler, Raymond E.}

Table of Isotopes, Seventh Edition - C. Michael Lederer, Virginia S. Shirley, Edgardo Browne, Janis M. Dairiki, and Raymond E. Doebler. New York: Wiley-Interscience, 1628p. (1978), ISBN: 0-471-0417-3.

\section{Domalski, Eugene S.}

Heat Capacities and Entropies of Organic Compounds in the Condensed Phase - Eugene S. Domalski, William H. Evans, and Elizabeth D. Hearing. J Phys Chem Ref Data 13, Suppl. 1(1984).

Selected Values of Heats of Combustion and Heats of Formation of Organic Compounds Containing the Elements C, H, N, O, P, and S Eugene S. Domalski. J Phys Chem Ref Data 1, 221(1972).

Thermodynamic Properties of Miscellaneous Materials - Eugene S. Domalski, William H. Evans, and Thomas L. Jobe, Jr. NBSIR 78-1479, 69p. (1981). 


\section{Donnay, Joseph D. H.}

Crystal Data Determinstive Tables, Third Edition Volume 1: Organic Compounds - Joseph D. H. Donnay and Helen M. Ondik. Swarthmore, PA: JCPDS-International Center for Diffraction Data, 855p. (1972).

Crystal Data Determinative Tables, Third Edition Volume 2: Inorganic Compounds - Joseph D. H. Donnay and Helen M. Ondik. Swarthmore, PA: JCPDS-International Center for Diffraction Data, 1748p. (1973).

Crystal Data Determinative Tables, Third Edition Volume 3. Organic Compounds - Joseph D. H. Donnay, Olga Kennard, David G. Watson, and John R. Rodgers. Swarthmore, PA: JCPDS-International Center for Diffraction Data, 748p. (1978).

Crystal Data Determinative Tables, Third Edition Volume 4. Inorganic Compounds - Joseph D. H. Donnay, Helen M. Ondik, and Alan D. Mighell. Swarthmore, PA: JCPDS-International Center for Diffraction Data, 1308p. (1978).

Space Groups and Lattice Complexes - W. Fisher, Hans Burzlaff, Erwin Hellner, and Joseph D. H. Donnay. NBS Monograph 134, 177p. (1973).

\section{Donnelly, Russell J.}

The Calculated Thermodynamic Properties of Superfluid Helium-4 - James S. Brooks and Russell J. Donnelly. J Phys Chem Ref Data 6, 51(1977).

\section{Dorfman, Leon $\mathrm{M}$.}

Reactivity of the Hydroxyl Radical in Aqueous Solutions - Leon M. Dorfman and Gerald E. Adams. NSRDS-NBS 46, 72p. (1973).

\section{Douglass, Charles $\mathrm{H}$.}

Property Index to NSRDS Data Compilations, 1964-1972 - David R. Lide, Jr., Gertrude B. Sherwood, Charles H. Douglass, and Herman M. Weisman. NSRDS-NBS 55, 21p. (1975).

\section{Douslin, Donald R.}

Derived Thermodynamic Properties of Ethylene - Roland $\mathbf{H}$. Harrison and Donald R. Douslin. J Chem Eng Data. 22, Washington, DC: American Chemical Society, 24p. (1977).

Pressure, Volume, Temperature Relations of Ethylene - Donald R. Douslin and Roland H. Harrison. J Chem Thermody 76, New York, London:, 301p. (1976).

\section{Downey, J. R., Jr.}

JANAF Thermochemical Tables, 1982 Supplement - Malcolm W. Chase, Jr., J. L. Curnutt, J. R. Downey, Jr., R. A. McDonald, A. N. Syverud, and E. A. Valenzuela. J Phys Chem Ref Data 11, 695(1982).

Molten Salts: Volume 4, Part 2, Chlorides and Mixtures. Electrical Conductance, Density, Viscosity, and Surface Tension Data - George J. Janz, Reginald P. T. Tomkins, Carolyn B. Allen, J. R. Downey, Jr., G. L. Gardner, Ursula Krebs, and S. K. Singer. J Phys Chem Ref Data 4, 871(1975).

Molten Salts: Volume 4, Part 3, Bromides and Mixtures, Iodides and Mixtures. Electrical Conductance, Density, Viscosity, and Surface Tension Data - George J. Janz, Reginald P. T. Tomkins, Carolyn B. Allen, J. R. Downey, Jr., and S. K. Singer. J Phys Chem Ref Data 6, 409(1977).

Physical Properties Data Compilations Relevant to Energy Storage. I. Molten Salts: Eutectic Data - George J. Janz, Carolyn B. Allen, J. R. Downey, Jr., and Reginald P. T. Tomkins. NSRDS-NBS 61, 244p. (1978).

\section{Draxl, Kelth}

Energetics of Gaseous Ions - Henry M. Rosenstock, Keith Draxl, B. W. Steiner, and John T. Herron. J Phys Chem Ref Data 6, Suppl. 1(1977).

Ionization Potentials, Appearance Potentials, and Heats of Formation of Gaseous Positive Ions - Joseph L. Franklin, J. G. Dillard, Henry M. Rosenstock, John T. Herron, Keith Draxl, and Frank H. Field. NSRDS-NBS 26, 289p. (1969).

\section{Dregalin, A. F.}

Thermodynamic and Thermophysical Properties of Combustion Products, Volume I. Computation Methods - V. P. Glushko, V. E. Alemasov, A. F. Dregalin, A. P. Tishin, and V. A. Khudyakov. Russian Transl. Springfield, VA: NTIS, 453p. (1974). TT 74-50019, A20.

Thermodynamic and Thermophysical Properties of Combustion Products, Volume II. Oxygen-Based Propellants - V. P. Glushko, V. E. Alemasov, A. F. Dregalin, A. P. Tishin, V. A. Khudyakov, and V. N. Kostin. Russian Transl. Springfield, VA: NTIS, 505p. (1975). TT 74-50032, A22.

Thermodynamic and Thermophysical Properties of Combustion Products, Volume III. Oxygen- and Air-Based Propellant - V. P. Glushko, V. E. Alemasov, A. F. Dregalin, A. P. Tishin, V. A. Khudyakov, and V. N. Kostin. Russian Transl. Springfield, VA: NTIS, 648p. (1975). TT 75-50007, A26.

Thermodynamic and Thermophysical Properties of Combustion Products, Volume IV. Nitrogen Tetroxide-Based Propellants - V. P. Glushko, V. E. Alemasov, A. F. Dregalin, A. P. Tishin, V. A. Khudyakov, and V. N. Kostin. Russian Transl. Springfield, VA: NTIS, 540p. (1976). TT 76-50007, A23.

\section{Dreizler, $\mathrm{H}_{\text {. }}$}

Microwave Spectra of Molecules of Astrophysical Interest, XVII. Dimethyl Ether - Frank J. Lovas, H. Lutz, and H. Dreizler. J Phys Chem Ref Data 8, 1051(1979).

\section{Dubrulle, A.}

Microwave Spectra of Molecules of Astrophysical Interest, XV. Propyne - A. Bauer, D. Boucher, J. Burie, J. Demaison, and A. Dubrulle. J Phys Chem Ref Data 8, 537(1979).

Microwave Spectra of Molecules of Astrophysical Interest. XIX. Methyl Cyanide - D. Boucher, J. Burie, A. Bauer, A. Dubrulle, and J. Demaison. J Phys Chem Ref Data 9, 659(1980).

\section{Duby, Paul}

The Thermodynamic Properties of Aqueous Inorganic Copper Systems - Paul Duby. INCRA Monograph IV, New York: International Copper Research Association, Inc., 132p. (1977).

\section{Duncan, Blanton C.}

Complete Clear Text Representation of Scientific Documents in Machine-Readable Form - Blanton C. Duncan and David Garvin. NBS Tech. Note 820, 58p. (1974).

Description of the Magnetic Tape Version of the Bulletin of Thermodynamics and Thermochemistry, No. 14 - Robert McClenon, William H. Evans, David Garvin, and Blanton C. Duncan. NBS Tech. Note 760, 32p. (1973).

\section{Dunlap, B. D.}

Nuclear Moments and Moment Ratios as Determined by Mössbauer Spectroscopy - John G. Stevens and B. D. Dunlap. J Phys Chem Ref Data 5, 1093(1976).

\section{Dunn, Gordon H.}

Electron Impact Ionization Cross-Section Data for Atoms, Atomic Ions, and Diatomic Molecules: I. Experimental Data - Lee J. Kieffer and Gordon H. Dunn. Rev Mod Phys. 38, New York: American Institute of Physics, 35p. (1966). 
Dunn, T. C.

Photonuclear Reaction Data, 1973 - Everett G. Fuller, Henry M. Gerstenberg, H. J. Vander Molen, and T. C. Dunn. NBS Spec. Publ. 380, 134p. (1973).

\section{Dutton, J.}

A Bibliography of Electron Swarm Data - Earl C. Beaty, J. Dutton, and L. C. Pitchford. JILA Report 20, 252p. (1979).

A Survey of Electron Swarm Data - J. Dutton. J Phys Chem Ref Data 4, 577(1975).

An Annotated Compilation and Appraisal of Electron Swarm Data in Electronegative Gases - Jean W. Gallagher, Earl C. Beaty, J. Dutton, and L. C. Pitchford. J Phys Chern Ref Data 12, 109(1983).

\section{Duxbury, J.}

Evaluated Kinetic Data for High Temperature Reactions, Volume 4. Homogeneous Gas Phase Reactions of Halogen- and CyanideContaining Species - D. L. Baulch, J. Duxbury, S. J. Grant, and D. C. Montague. J Phys Chem Ref Data 10, Suppl. 1(1981).

Eaton, B. E.

A Correlation of the Viscosity and Thermal Conductivity Data of Gaseous and Liquid Ethylene - Paul M. Holland, B. E. Eaton, and Howard J. M. Hanley. J Phys Chem Ref Data 12, 917(1983).

\section{Edlén, Bengt}

Reference Wavelengths from Atomic Spectra in the Range $5 \AA$ to $25000 \AA$ - Victor Kaufman and Bengt Edlén. J Phys Chem Ref Data 3, 825(1974).

\section{Eigenmann, H. K.}

A Critical Review of H-Atom Transfer in the Liquid Phase: Chlorine Atom, Alkyl, Trichloromethyl, Alkoxy, and Alkylperoxy Radicals D. G. Hendry, T. Mill, L. Piszkiewicz, J. A. Howard, and H. K. Eigenmann. J Phys Chem Ref Data 3, 937(1974).

Ely, James F.

A Computer Program for the Prediction of Viscosity and Thermal Conductivity in Hydrocarbon Mixtures - James F. Ely and Howard J. M. Hanley. NBS Tech. Note 1039, 83p. (1981).

The Viscosity and Thermal Conductivity Coefficients of Dilute Ni. trogen and Oxygen - Howard J. M. Hanley and James F. Ely. J Phys Chem Ref Data 2, 735(1973).

\section{Enstrom, James E.}

NN and ND Interactions - A Compilation - James E. Enstrom, Thomas Ferbel, Paul F. Slattery, Barry L. Werner, Zaven G. T. Guiragossian, Yoshio Sumi, Toshihiro Yoshida and Particle Data Group. UCRL-LBL 58, Berkeley, CA: Lawrence Berkeley Laboratory, U. of California, 281p. (1972). LBL 58.

\section{Erickson, Glen W.}

Energy Levels of One-Electron Atoms - Glen W. Erickson. J Phys Chem Ref Data 6, 831(1977).

\section{Esel'son, B. N.}

Properties of Liquid and Solid Hydrogen - B. N. Esel'son, Y. P. Blagoi, V.N. Grigor'ev, V. G. Manzhelii, S. A. Mikhailenko, and N. P. Neklyudov. Russian Transl. Springfield, VA: NTIS, 126p. (1971). TT 70-50179, A07.

\section{Evans, William $\mathrm{H}$.}

A Combined Least Sums and Least Squares Approach to the Evaluation of Thermodynamic Data Networks - David Garvin, Vivian B. Parker, Donald D. Wagman, and William H. Evans. NBSIR 76-1147, 41p. (1976).
Chemical Thermodynamic Properties of Compounds of Sodium, Potassium, and Rubidium: An Interim Tabulation of Selected Material Donald D. Wagman, William H. Evans, Vivian B. Parker, and Richard H. Schumm. NBSIR 76-1034, 76p. (1976).

Description of the Magnetic Tape Version of the Bulletin of Thermodynamics and Thermochemistry, No. 14 - Robert McClenon, William H. Evans, David Garvin, and Blanton C. Duncan. NBS Tech. Note 760, 32p. (1973).

Heat Capacities and Entropies of Organic Compounds in the Condensed Phase - Eugene S. Domalski, William H. Evans, and Elizabeth D. Hearing. J Phys Chem Ref Data 13, Suppl. 1(1984).

Selected Values of Chemical Thermodynamic Properties. Tables for the First Thirty-Four Elements in the Standard Order of Arrangement - Donald D. Wagman, William H. Evans, Vivian B. Parker, Iva Halow, Sylvia M. Bailey, and Richard H. Schumm. NBS Tech. Note 270, 264p. (1968).

Selected Values of Chemical Thermodynamic Properties. Tables for Elements 35 through 53 in the Standard Order of Arrangement Donald D. Wagman, William H. Evans, Vivian B. Parker, Iva Halow, Sylvia M. Bailey, and Richard H. Schumm. NBS Tech. Note 270, 152p. (1969).

Selected Values of Chemical Thermodynamic Properties. Tables for Elements 54 through 61 in the Standard Order of Arrangement Donald D. Wagman, William H. Evans, Vivian B. Parker, Iva Halow, Sylvia M. Bailey, Richard H. Schumm, and Kenneth L. Churney. NBS Tech. Note 270, 49p. (1971).

Selected Values of Chemical Thermodynamic Properties. Tables for the Alkaline Earth Elements (Elements 92 through 97 in the Standard Order of Arrangement) - Vivian B. Parker, Donald D. Wagman, and William H. Evans. NBS Tech. Note 270, 124p. (1971).

Selected Values of Chemical Thermodynamic Properties. Tables for the Lanthanide (Rare Earth) Elements (Elements 62 through 76 in the Standard Order of Arrangement) - Richard H. Schumm, Donald D. Wagman, Sylvia M. Bailey, William H. Evans, and Vivian B. Parker. NBS Tech. Note 270, 84p. (1973).

Selected Values of Chemical Thermodynamic Properties: Compounds of Uranium, Protactinium, Thorium, Actinium, and the Alkali Metals - Donald D. Wagman, William H. Evans, Vivian B. Parker, Richard H. Schumm, and Ralph L. Nuttall. NBS Tech. Note 270, 149p. (1981).

The NBS Tables of Chemical Thermodynamic Properties. Selected Values for Inorganic and $C_{1}$ and $C_{2}$ Organic Substances in SI Units Donald D. Wagman, William H. Evans, Vivian B. Parker, Richard H. Schumm, Iva Halow, Sylvia M. Bailey, Kenneth L. Churney, and Ralph L. Nuttall. J Phys Chem Ref Data 11, Suppl. 2(1982).

Thermodynamic Properties of Miscellaneous Materials - Eugene S. Domalski, William H. Evans, and Thomas L. Jobe, Jr. NBSIR 78-1479, 69p. (1981).

\section{Falconer, Warren E.}

Binary Fluorides, Free Molecular Structures and Force Fields, A Bibliography (1957-1975) - Donald T. Hawkins, Lawrence S. Bernstein, Warren E. Falconer, and William Klemperer. New York: IFI/Plenum, 253p. (1976), ISBN: 0-306-6601-3.

\section{Fanconi, Bruno}

Critical Review of Vibrational Data and Force Field Constants for Polyethylene - John Barnes and Bruno Fanconi. J Phys Chem Ref Data 7, 1309(1978).

\section{Farhataziz}

Selected Specific Rates of Reactions of Transients from Water in Aqueous Solution, II. Hydrogen Atom - Michael Anbar, Farhataziz, and Alberta B. Ross. NSRDS-NBS 51, 66p. (1975).

Selected Specific Rates of Reactions of Transients from Water inAqueous Solution, III. Hydroxyl Radical and Perhydroxyl Radical and Their Radical Ions - Farhataziz and Alberta B. Ross. NSRDS-NBS 59, 126p. (1977). 


\section{Ferbel, Thomas}

NN and ND Interactions - A Compilation - James E. Enstrom, Thomas Ferbel, Paul F. Slattery, Barry L. Werner, Zaven G. T. Guiragossian, Yoshio Sumi, Toshihiro Yoshida and Particle Data Group. UCRL-LBL 58, Berkeley, CA: Lawrence Berkeley Laboratory, U. of California, 281p. (1972). LBL 58.

\section{Ferguson, E. E.}

Ion-Molecule Reactions - Earl W. McDaniel, V. Cermak, A. Dalgarno, E. E. Ferguson, and L. Friedman. At Mol Collis Proc Ser, New York: Wiley-Interscience, 374p. (1970), ISBN: 0-471-5838-3.

\section{Field, Frank H.}

Ionization Potentials, Appearance Potentials, and Heats of Formation of Gaseous Positive Ions - Joseph L. Franklin, J. G. Dillard, Henry M. Rosenstock, John T. Herron, Keith Draxl, and Frank H. Field. NSRDS-NBS 26, 289p. (1969).

Fisher, W.

Space Groups and Lattice Complexes - W. Fisher, Hans Burzlaff, Erwin Hellner, and Joseph D. H. Donnay. NBS Monograph 134, 177p. (1973).

\section{Fivozinsky, Sherman P.}

Medical Physics Data Book - Thomas N. Padikal and Sherman P. Fivozinsky. NBS Handbook 138, 127p. (1982).

Flaud, J-M.

Atlas of the High Temperature Water Vapor Spectrum in the 3000 to $4000 \mathrm{~cm}^{-1}$ Region - A. S. Pine, M. J. Coulombe, C. Camy-Peyret, and J-M. Flaud. J Phys Chem Ref Data 12, 413(1983).

\section{Franck, E. U.}

Ion Product of Water Substance, $0-1000^{\circ} \mathrm{C}, 1-10,000$ Bars. New International Formulation and Its Background - William L. Marshall and E. U. Franck. J Phys Chem Ref Data 10, 295(1981).

Static Dielectric Constant of Water and Steam - M. Uematsu and E. U. Franck. J Phys Chem Ref Data 9, 1291(1980).

\section{Franklin, Joseph L.}

Ionization Potentials, Appearance Potentials, and Heats of Formation of Gaseous Positive Ions - Joseph L. Franklin, J. G. Dillard, Henry M. Rosenstock, John T. Herron, Keith Draxl, and Frank H. Field. NSRDS-NBS 26, 289p. (1969).

\section{Frattali, Sandra}

Semiempirical and Approximate Methods for Molecular Calculations - Bibliography and KWIC Index - George A. Henderson and Sandra Frattali. OSRD Bibl. 70-3, 293p. (1970).

\section{Frederikse, Hans P. R.}

Compilation of the Static Dielectric Constant of Inorganic Solids K. F. Young and Hans P. R. Frederikse. J Phys Chem Ref Data 2, 313(1973).

\section{Freedman, M. S.}

Recommended Atomic Electron Binding Energies, $1 \mathrm{~s}$ to $6 \mathrm{p}_{3 / 2}$, for the Heavy Elements, $Z=84$ to $103-$ F. T. Porter and M. S. Freedman. J Phys Chem Ref Data 7, 1267(1978).

\section{Freeman, D. E.}

Atlas of the Schumann-Runge Absorption Bands of $\mathrm{O}_{2}$ in the Wavelength Region 175-205 nm - K. Yoshino, D. E. Freeman, and W. H. Parkinson. J Phys Chem Ref Data 13, 207(1984).

\section{Freeman, Gordon R.}

Radiation Chemistry of Ethanol: A Review of Data on Yields, Reaction Rate Parameters, and Spectral Properties of Transients - Gordon R. Freeman. NSRDS-NBS 48, 44p. (1974).

\section{Freeman, Robert D.}

Bulletin of Chemical Thermodynamics, Volume 24/1981 - Robert D. Freeman, editor(s) and International Union of Pure and Applied Chemistry, Commission 1.2 on Thermodynamics. Bull Chem Thermody 24, Stillwater, OK: Thermochemistry, Department of Chemistry, Oklahoma State University, 504p. (1982). 0149-2268, bona fide personal subscriptions are less; prices of previous Bulletins available upon request.

Bulletin of Chemical Thermodynamics, Volume 25/1982 - Robert D. Freeman and International Union of Pure and Applied Chemistry. Bull Chem Thermody 25, Stillwater, OK: Thermochemistry, Department of Chemistry, Oklahoma State University, 544p. (1982). 0149-2268, bona fide personal subscriptions are less; prices of previous Bulletins are available upon request.

\section{Friedman, $L$.}

Ion-Molecule Reactions - Earl W. McDaniel, V. Cermak, A. Dalgarno, E. E. Ferguson, and L. Friedman. At Mol Collis Proc Ser, New York: Wiley-Interscience, 374p. (1970), ISBN: 0-471-5838-3.

\section{Fristrom, R. M.}

Rate Constants of Gas Phase Reactions, Reference Book - V. N. Kondratiev, L. J. Holtschlag, R. M. Fristrom, editor(s). Russian Transl. Springfield, VA: NTIS, 434p. (1972). COM 72-10014, A19.

\section{Fuhr, Jeffrey R.}

Atomic Transition Probabilities for Scandium and Titanium (A Critical Data Compilation of Allowed Lines) - Wolfgang L. Wiese and Jeffrey R. Fuhr. J Phys Chem Ref Data 4, 263(1975).

Atomic Transition Probabilities for Vanadium, Chromium, and Manganese (A Critical Data Compilation of Allowed Lines) - S. M. Younger, Jeffrey R. Fuhr, Georgia A. Martin, and Wolfgang L. Wiese. J Phys Chem Ref Data 7, 495(1978).

Atomic Transition Probabilities for Iron, Cobalt, Nickel: A Critical Data Compilation of Allowed Lines - Jeffrey R. Fuhr, Georgia A. Martin, Wolfgang L. Wiese, and S. M. Younger. J Phys Chem Ref Data 10, 305(1981).

Bibliography on Atomic Line Shapes and Shifts (1899 through March 1972) - Jeffrey R. Fuhr, Wolfgang L. Wiese, and Larry J. Roszman. NBS Spec. Publication 366, 165p. (1972).

Bibliography on Atomic Line Shapes and Shifts (April 1972 through June 1973) - Jeffrey R. Fuhr, Larry J. Roszman, and Wolfgang L. Wiese. NBS Spec. Publ. 366, Suppl. 1(1974).

Bibliography on Atomic Line Shapes and Shifts (July 1973 through May 1975) - Jeffrey R. Fuhr, Georgia A. Martin, and Beverly J. Specht. NBS Spec. Publ. 366, Suppl. 2(1975).

Bibliography on Atomic Line Shapes and Shifts (June 1975 through June 1978) - Jeffrey R. Fuhr, Beverly J. Miller, and Georgia A. Martin. NBS Spec. Publ. 366, Suppl. 3(1978).

Bibliography on Atomic Transition Probabilities (1914 through October 1977) - Beverly J. Miller, Jeffrey R. Fuhr, and Georgia A. Martin. NBS Spec. Publ. 505, 283p. (1978).

Bibliography on Atomic Transition Probabilities (November 1977 through March 1980) - Beverly J. Miller, Jeffrey R. Fuhr, and Georgia A. Martin. NBS Spec. Publ. 505, Suppl.(1980). 


\section{Fuller, Everett G.}

Photonuclear Data Index, 1973-1977 - Everett G. Fuller and Henry M. Gerstenberg. NBS Spec. Publ. 380, Suppl. 1(1978).

Photonuclear Data Index, 1973-1981 (Supplement 2 to NBS Special Publication 380) - Everett G. Fuller and Henry M. Gerstenberg. NBSIR 82-2543, 139p. (1982).

Photonuclear Reaction Data, 1973 - Everett G. Fuller, Henry M. Gerstenberg, H. J. Vander Molen, and T. C. Dunn. NBS Spec. Publ. 380, 134p. (1973).

\section{Fuller, Gladys H.}

Nuclear Spins and Moments - Gladys H. Fuller. J Phys Chem Ref Data 5, 835(1976).

\section{Furukawa, George T.}

Critical Analysis of Heat-Capacity Data and Evaluation of Thermotynamic Properties of $\mathrm{Ru}, \mathrm{Ph}, \mathrm{Pd}, \mathrm{Ir}$, and Pt from 0 to $300 \mathrm{~K}$. A Survey ff the Literature Data on Osmium - George T. Furukawa, Martin L. Reilly, and John S. Gallagher. J Phys Chem Ref Data 3, 163(1974).

Critical Analysis of the Heat-Capacity Data of the Literature and Evaluation of Thermodynamic Properties of Copper, Silver, and Gold rom 0 to $300 \mathrm{~K}$ - George T. Furukawa, W. G. Saba, and Martin L. Reilly. NSRDS-NBS 18, 49p. (1968).

\section{Gallagher, Jean W.}

An Annotated Compilation and Appraisal of Electron Swarm Data n Electronegative Gases - Jean W. Gallagher, Earl C. Beaty, J. Jutton, and L. C. Pitchford. J Phys Chem Ref Data 12, 109(1983).

Bibliography of Low Energy Electron and Photon Cross Section Data (January 1975 to December 1977) - Jean W. Gallagher, John R. Rumble, Jr., and Earl C. Beaty. NBS Spec. Publ. 426, Suppl. 1(1979).

Bibliography of Low Energy Electron and Photon Cross Section Data (1978) - Jean W. Gallagher and Earl C. Beaty. JILA Report 18, [48p. (1980).

Bibliography of Low Energy Electron and Photon Cross Section Data (1979) - Jean W. Gallagher and Earl C. Beaty. JILA Report 21, 127p. (1981).

Data Index for Energy Transfer Collisions of Atoms and Molecules -1970-1979 - Jean W. Gallagher, Janet Van Blerkom, Earl C. Beaty, and John R. Rumble, Jr. NBS Spec. Publ. 593, 349p. (1981).

Evaluated Theoretical Cross Section Data for Charge Exchange of Multiply Charged Ions with Atoms. I. Hydrogen Atom-Fully Stripped Ion Systems - R. K. Janev, B. H. Bransden, and Jean W. Gallagher. J Phys Chem Ref Data 12, 829(1983).

Evaluated Theoretical Cross Section Data for Charge Exchange of Multiply Charged Ions with Atoms. II. Hydrogen Atom-Partially Stripped Ions Systems - Jean W. Gallagher, B. H. Bransden, and R. K. Janev. J Phys Chem Ref Data 12, 873(1983).

Evaluated Theoretical Cross Section Data for Charge Exchange of Multiply Charged Ion with Atoms. III. Non-Hydrogenic Target Atoms - R. K. Janev and Jean W. Gallagher. J Phys Chem Ref Data 13, 1199(1984).

\section{Gallagher, John S.}

A Thermodynamic Surface for Water: The Formulation and Computer Program - Lester Haar, John S. Gallagher, and George S. Kell. NBSIR 81-2253, 38p. (1981).

Critical Analysis of Heat-Capacity Data and Evaluation of Thermodynamic Properties of $\mathrm{Ru}, \mathrm{Ph}, \mathrm{Pd}, \mathrm{Ir}$, and Pt from 0 to $300 \mathrm{~K}$. A Survey of the Literature Data on Osmium - George T. Furukawa, Martin L. Reilly, and John S. Gallagher. J Phys Chem Ref Data 3, 163(1974).

Equation of State for Ammonia - Lester Haar and John S. Gallagher. NBSIR 75-770, 27p. (1975).

NBS/NRC Steam Tables, Thermodynamic and Transport Properties and Computer Programs for Vapor and Liquid States of Water Lester Haar, John S. Gallagher, and George S. Kell. New York: Hemisphere Press, 320p. (1984).
Thermodynamic Properties of Ammonia - Lester Haar and John S. Gallagher. J Phys Chem Ref Data 7, 635(1978).

\section{Gallet, Marc}

Isotopic Abundances and Atomic Weights of the Elements - Paul De Bièvre, Marc Gallet, Norman E. Holden, and I. Lynus Barnes. J Phys Chem Ref Data 13, 809(1984).

\section{Gardner, G. L.}

Molten Salts: Volume 4, Part 1, Fluorides and Mixtures. Electrical Conductance, Density, Viscosity, and Surface Tension Data - George J. Janz, G. L. Gardner, Ursula Krebs, and Reginald P. T. Tomkins. J Phys Chem Ref Data 3, 1(1974).

Molten Salts: Volume 4, Part 2, Chlorides and Mixtures. Electrical Conductance, Density, Viscosity, and Surface Tension Data - George J. Janz, Reginald P. T. Tomkins, Carolyn B. Allen, J. R. Downey, Jr., G. L. Gardner, Ursula Krebs, and S. K. Singer. J Phys Chem Ref Data 4, 871(1975).

\section{Garg, V. K.}

Bibliography on Properties of Defect Centers in Alkali Halides Suresh C. Jain, S. A. Khan, H. K. Sehgal, V. K. Garg, and R. K. Jain. OSRD Bibl. 71-1, 293p. (1971).

\section{Garvin, David}

A Combined Least Sums and Least Squares Approach to the Evaluation of Thermodynamic Data Networks - David Garvin, Vivian B. Parker, Donald D. Wagman, and William H. Evans. NBSIR 76-1147, 4lp. (1976).

Chemical Thermodynamic Data Banks - David Garvin, Vivian B. Parker, and Donald D. Wagman. NBSIR 81-2341, 30p. (1981).

Complete Clear Text Representation of Scientific Documents in Machine-Readable Form - Blanton C. Duncan and David Garvin. NBS Tech. Note 820, 58p. (1974).

Description of the Magnetic Tape Version of the Bulletin of Thermodynamics and Thermochemistry, No. 14 - Robert McClenon, William H. Evans, David Garvin, and Blanton C. Duncan. NBS Tech. Note 760, 32p. (1973).

Reaction Rate and Photochemical Data for Atmospheric Chemistry - 1977 - Robert F. Hampson, Jr. and David Garvin. NBS Spec. Publ. 513, 111p. (1978).

Selected Thermochemical Data Compatible with CODATA Recommendations - Vivian B. Parker, Donald D. Wagman, and David Garvin. NBSIR 75-968, 35p. (1976).

Subroutine for the Calculation of CODEN Check Characters David Garvin. NBS Tech. Note 738, 16p. (1972).

Summary Report on the Workshop on High Temperature Chemical Kinetics: Applications to Combustion Research - David Garvin, R. L. Brown, Robert F. Hampson, Jr., M. J. Kurylo, and W. Tsang. NBS Spec. Publ. 531, 94p. (1978).

Survey of Photochemical and Rate Data for Twenty-eight Reactions of Interest in Atmospheric Chemistry - Robert F. Hampson, Jr., W. Braun, R. L. Brown, David Garvin, John T. Herron, Robert E. Huie, M. J. Kurylo, A. H. Laufer, J. D. McKinley, H. Okabe, M. D. Scheer, W. Tsang, D. H. Stedman, editor(s). J Phys Chem Ref Data 2, 267(1973).

\section{Gaur, Umesh}

Heat Capacity and Other Thermodynamic Properties of Linear Macromolecules. I. Selenium - Umesh Gaur, Hua-Cheng Shu, Aspy Metha, and Bernhard Wunderlich. J Phys Chem Ref Data 10, 89(1981).

Heat Capacity and Other Thermodynamic Properties of Linear Macromolecules. II. Polyethylene - Umesh Gaur and Bernhard Wunderlich. J Phys Chem Ref Data 10, 119(1981). 
Heat Capacity and Other Thermodynamic Properties of Linear Macromolecules. III. Polyoxides - Umesh Gaur and Bernhard Wunderlich. J Phys Chein Ref Data 10, 1001(1981).

Heat Capacity and Other Thermodynamic Properties of Linear Macromolecules. IV. Polypropylene - Umesh Gaur and Bernhard Wunderlich. J Phys Chem Ref Data 10, 1051(1981).

Heat Capacity and Other Thermodynamic Properties of Linear Macromolecules. V. Polystyrene - Umesh Gaur and Bernhard Wunderlich. J Phys Chem Ref Data 11, 313(1982).

Heat Capacity and Other Thermodynamic Properties of Linear Macromolecules. VI. Acrylic Polymers - Umesh Gaur, Suk-fai Lau, Brent B. Wunderlich, and Bernhard Wunderlich. J Phys Chem Ref Data 11, 1065(1982).

Heat Capacity and Other Thermodynamic Properties of Linear Macromolecules. VII. Other Carbon Backbone Polymers - Umesh Gaur, Brent B. Wunderlich, and Bernhard Wunderlich. J Phys Chem Ref Data 12, 29(1983).

Heat Capacity and Other Thermodynamic Properties of Linear Macromolecules. VIII. Polyesters and Polyamides - Umesh Gaur, Suk-fai Lau, Brent B. Wunderlich, and Bernhard Wunderlich. J Phys Chem Ref Data 12, 65(1983).

Heat Capacity and Other Thermodynamic Properties of Linear Macromolecules. IX. Final Group of Aromatic and Inorganic Polymers Umesh Gaur, Suk-fai Lau, and Bernhard Wunderlich. J Phys Chem Ref Data 12, 91(1983).

\section{Gavert, R. B.}

Critical Surveys of Data Sources: Mechanical Properties of Metals - R. B. Gavert, Robert L. Moore, and John H. Westbrook. NBS Spec. Publ. 396, 90p. (1974).

Critical Surveys of Data Sources: Electrical and Magnetic Properties of Metals - M. J. Carr, R. B. Gavert, Robert L. Moore, H. W. Wawrousek, and John H. Westbrook. NBS Spec. Publ. 396, 96p. (1976).

\section{Gehrig, Catherine A.}

Standard Chemical Thermodynamic Properties of Alkane Isomer Groups - Robert A. Alberty and Catherine A. Gehrig. J Phys Chem Ref Data 13, 1173(1984).

\section{Gerry, M. C. L.}

Microwave Spectra of Molecules of Astrophysical Interest, X. Isocyanic Acid - G. Winnewisser, W. H. Hocking, and M. C. L. Gerry. J Phys Chem Ref Data 5, 79(1976).

Microwave Spectra of Molecules of Astrophysical Interest, XIV. Vinyl Cyanide (Acrylonitrile) - M. C. L. Gerry, K. Yamada, and G. Winnewisser. J Phys Chem Ref Data 8, 107(1979).

Microwave Spectra of Molecules of Astrophyical Interest. XX. Methane - I. Ozier, M. C. L. Gerry, and A. G. Robiette. J Phys Chem Ref Data 10, 1085(1981).

\section{Gerstenberg, Henry M.}

Photonuclear Data Index, 1973-1977 - Everett G. Fuller and Henry M. Gerstenberg. NBS Spec. Publ. 380, Suppl. 1(1978).

Photonuclear Data Index, 1973-1981 (Supplement 2 to NBS Special Publication 380) - Everett G. Fuller and Henry M. Gerstenberg. NBSIR 82-2543, 139p. (1982).

Photonuclear Reaction Data, 1973 - Everett G. Fuller, Henry M. Gerstenberg, H. J. Vander Molen, and T. C. Dunn. NBS Spec. Publ. 380, 134p. (1973).

The NIRA Computer Program Package (Photonuclear Data Center) - H. J. Vander Molen and Henry M. Gerstenberg. NBS Tech. Note 903, 34p. (1976).

\section{Gevantman, Lewis $\mathrm{H}$.}

EPA/NIH Mass Spectral Data Base, Supplement 2 - Stephen R. Heller, G. W. A. Milne, and Lewis H. Gevantman. NSRDS-NBS 63, Suppl. 2(1983).
Feasiblility Study: Compilation and Evaluation of Properties Data for Basalt, Granite, Tuff, and Shale - Lewis H. Gevantman. NBSIR 81-2217, 259p. (1981).

Physical Properties Data for Basalt - Lewis H. Gevantman. NBSIR 82-2587, 751p. (1982).

Physical Properties Data for Rock Salt - Lewis H. Gevantman. NBS Monograph 167, 288p. (1981).

\section{Gibsen, Janet L.}

Mossbauer Effect Reference and Data Journal - John G. Stevens, Virginia E. Stevens, Richard M. White, Janet L. Gibson, editor(s). Moss Eff Ref Data J 6, Ashville, NC: Mossbauer Effect Data Center, U. of N. C., (1983).

\section{Gierlach, Matthew}

Critical Evaluation of Vapor-Liquid Equilibrium, Heat of Mixing, and Volume Change of Mixing Data. General Procedures - Buford D. Smith, Ol Muthu, Ashok Dewan, and Matthew Gierlach. J Phys Chem Ref Data 11, 941(1982).

Evaluation of Binary Excess Enthalpy Data for $\mathrm{C}_{6}$ Hydrocarbons. Benzene + Cyclohexane - Buford D. Smith, Ol Muthu, Ashok Dewan, and Matthew Gierlach. J Phys Chem Ref Data 11, 1127(1982).

Evaluation of Binary Excess Volume Data for $\mathrm{C}_{6}$ Hydrocarbons. Benzene + Cyclohexane - Buford D. Smith, Ol Muthu, Ashok Dewan, and Matthew Gierlach. J Phys Chem Ref Data 11, 1151(1982).

Evaluation of Binary PTxy Vapor-Liquid Equilibrium Data for $\mathrm{C}_{6}$ Hydrocarbons. Benzene + Cyclohexane - Buford D. Smith, Ol Muthu, Ashok Dewan, and Matthew Gierlach. J Phys Chem Ref Data 11, 1099(1982).

\section{Gilbody, H. B.}

Recommended Data on the Electron Impact Ionization of Light Atoms and Ions - K. L. Bell, H. B. Gilbody, J. G. Hughes, A. E. Kingston, and Francis J. Smith. J Phys Chem Ref Data 12, 891(1983).

\section{Gimm, Heinz A.}

Pair, Triplet, and Total Atomic Cross Sections (and Mass Attenuation Coefficients) for $1 \mathrm{MeV}-100 \mathrm{GeV}$ Photons in Elements $\mathrm{Z}=1$ to 100 - John H. Hubbell, Heinz A. Gimm, and I. $\emptyset$ verb $\varnothing$. J Phys Chem Ref Data 9, 1023(1980).

Total Photon Absorption Cross Section Measurements, Theoretical Analysis and Evaluations for Energies above $10 \mathrm{MeV}-\mathrm{Heinz} \mathrm{A}$. Gimm and John H. Hubbell. NBS Tech. Note 968, 81p. (1978).

\section{Gleiser, M.}

Selected Values of the Thermodynamic Properties of Binary Alloys - Ralph Hultgren, Pramond D. Desai, Donald T. Hawkins, M. Gleiser, and Kenneth K. Kelley. Metals Park, OH: American Society for Metals, 1435p. (1973).

Selected Values of the Thermodynamic Properties of the Elements - Ralph Hultgren, Pramond D. Desai, Donald T. Hawkins, M. Gleiser, Kenneth K. Kelley, and Donald D. Wagman. Metals Park, OH: American Society for Metals, 636p. (1973).

\section{Glennon, Barbara M.}

Atomic Transition Probabilities. Elements Hydrogen through Neon - Wolfgang L. Wiese, Melvin W. Smith, and Barbara M. Glennon. NSRDS-NBS 4, 153p. (1966).

\section{Glushko, V. P.}

Thermodynamic and Thermophysical Properties of Combustion Products, Volume I. Computation Methods - V. P. Glushko, V. E. Alemasov, A. F. Dregalin, A. P. Tishin, and V. A. Khudyakov. Russian Transl. Springfield, VA: NTIS, 453p. (1974). TT 74-50019, A20. 
Thermodynamic and Thermophysical Properties of Combustion Products, Volume II. Oxygen-Based Propellants - V. P. Glushko, V. E. Alemasov, A. F. Dregalin, A. P. Tishin, V. A. Khudyakov, and V. N. Kostin. Russian Transl. Springfield, VA: NTIS, 505p. (1975). TT 74-50032, A22.

Thermodynamic and Thermophysical Properties of Combustion Products, Volume III. Oxygen- and Air-Based Propellant - V. P. Glushko, V. E. Alemasov, A. F. Dregalin, A. P. Tishin, V. A. Khudyakov, and V. N. Kostin. Russian Transl. Springfield, VA: NTIS, 648p. (1975). TT 75-50007, A26.

Thermodynamic and Thermophysical Properties of Combustion Products, Volume IV. Nitrogen Tetroxide-Based Propellants - V. P. Glushko, V. E. Alemasov, A. F. Dregalin, A. P. Tishin, V. A. Khudyakov, and V. N. Kostin. Russian Transl. Springfield, VA: NTIS, 540p. (1976). TT 76-50007, A23.

\section{Goldberg, Daniel}

Phase Diagrams and Thermodynamic Properties of Ternary Copper-Silver Systems - Y. Austin Chang, Daniel Goldberg, and Joachim P. Neumann. J Phys Chem Ref Data 6, 621(1977).

Phase Diagrams and Thermodynamic Properties of Ternary CopperMetal Systems - Y. Austin Chang, Joachim P. Neumann, A. Mikula, and Daniel Goldberg. INCRA Monograph VI, New York: International Copper Research Association, Inc., 702p. (1979).

\section{Goldberg, Robert N.}

A Bibliography of Sources of Experimental Data Leading to Activity or Osmotic Coefficients for Polyvalent Electrolytes in Aqueous Solution - Robert N. Goldberg, Bert R. Staples, Ralph L. Nuttall, and R. Arbuckle. NBS Spec. Publ. 485, 57p. (1977).

A Bibliography of Sources of Experimental Data Leading to Thermal Properties of Binary Aqueous Electrolyte Solutions - David Smith-Magowan and Robert N. Goldberg. NBS Spec. Publ. 537, 94p. (1979).

An Annotated Bibliography of Compiled Thermodynamic Data Sources for Biochemical and Aqueous Systems (1930 to 1975), Equilibrium, Enthalpy, Heat Capacity, and Entropy Data - George T. Armstrong and Robert N. Goldberg. NBS Spec. Publ. 454, 71p. (1976).

Evaluated Activity and Osmotic Coefficients for Aqueous Solutions: The Alkaline Earth Metal Halides - Robert N. Goldberg and Ralph L. Nuttall. J Phys Chem Ref Data 7, 263(1978).

Evaluated Activity and Osmotic Coefficients for Aqueous Solutions: Iron Chloride and the Bi-Univalent Compounds of Nickel and Cobalt - Robert N. Goldberg, Ralph L. Nuttall, and Bert R. Staples. J Phys Chem Ref Data 8, 923(1979).

Evaluated Activity and Osmotic Coefficients for Aqueous Solutions: Bi-Univalent Compounds of Lead, Copper, Manganese, and Uranium - Robert N. Goldberg. J Phys Chem Ref Data 8, 1005(1979).

Evaluated Activity and Osmotic Coefficients for Aqueous Solutions: Bi-Univalent Compounds of Zinc, Cadmium, and Ethylene Bis(Trimethylammonium) Chloride and Iodide - Robert N. Goldberg. J Phys Chem Ref Data 10, 1(1981).

Evaluated Activity and Osmotic Coefficients for Aqueous Solutions: Thirty-Six Uni-Bivalent Electrolytes - Robert N. Goldberg. J Phys Chem Ref Data 10, 671(1981).

\section{Goodwin, Robert D.}

Provisional Thermodynamic Functions of Propane from 85 to $700 \mathrm{~K}$ at Pressures to 700 Bar - Robert D. Goodwin. NBSIR 77-860, 240p. (1977).

Thermodynamic and Related Properties of Parahydrogen from the Triple Point to $100 \mathrm{~K}$ at Pressures to 340 Atmospheres - Hans M. Roder, Lloyd A. Weber, and Robert D. Goodwin. NBS Monograph 94, 116p. (1965).

Thermophysical Properties of Isobutane from 114 to $700 \mathrm{~K}$ at Pressures to $70 \mathrm{MPa}$ - Robert D. Goodwin and W. M. Haynes. NBS Tech. Note 1051, 199p. (1982).
Thermophysical Properties of Normal Butane from 135 to $700 \mathrm{~K}$ at Pressures to $70 \mathrm{MPa}-$ W. M. Haynes and Robert D. Goodwin. NBS Monograph 169, 197p. (1982).

Thermophysical Properties of Propane from 85 to $700 \mathrm{~K}$ at Pressures to $70 \mathrm{MPa}$ - Robert D. Goodwin and W. M. Haynes. NBS Monograph 170, 249p. (1982).

\section{Gosman, A. L.}

Thermodynamic Properties of Argon from the Triple Point to $300 \mathrm{~K}$ at Pressures to 1000 Atmospheres - A. L. Gosman, Robert D. McCarty, and Jerome G. Hust. NSRDS-NBS 27, 153p. (1969).

\section{Grant, S. J.}

Evaluated Kinetic Data for High Temperature Reactions, Volume 4. Homogeneous Gas Phase Reactions of Halogen- and CyanideContaining Species - D. L. Baulch, J. Duxbury, S. J. Grant, and D. C. Montague. J Phys Chem Ref Data 10, Suppl. 1(1981).

\section{Greer, W. L.}

Scaled Equation of State Parameters for Gases in the Critical Region - J. M. H. Levelt Sengers, W. L. Greer, and Jan V. Sengers. J Phys Chem Ref Data 5, 1(1976).

\section{Grigor'ev, V.N.}

Properties of Liquid and Solid Hydrogen - B. N. Esel'son, Y. P. Blagoi, V.N. Grigor'ev, V. G. Manzhelii, S. A. Mikhailenko, and N. P. Neklyudov. Russian Transl. Springfield, VA: NTIS, 126p. (1971). TT 70-50179, A07.

\section{Grilly, E. R.}

A Review of Deuterium Triple-Point Temperatures - L. A. Schwalbe and E. R. Grilly. J Phys Chem Ref Data 13, 687(1984).

\section{Gubbins, K. E.}

A Correlation of the Existing Viscosity and Thermal Conductivity Data of Gaseous and Liquid Ethane - Howard J. M. Hanley, K. E. Gubbins, and S. Murad. J Phys Chem Ref Data 6, 1167(1977).

A Correlation of the Viscosity and Thermal Conductivity Data of Gaseous and Liquid Propane - Paul M. Holland, Howard J. M. Hanley, K. E. Gubbins, and J. M. Haile. J Phys Chem Ref Data 8, 559(1979).

Erratum: A Correlation of the Existing Viscosity and Thermal Conductivity Data of Gaseous and Liquid Ethane - Howard J. M. Hanley, K. E. Gubbins, and S. Murad. J Phys Chem Ref Data 10, 799(1981).

\section{Guiragossian, Zaven G. T.}

NN and ND Interactions - A Compilation - James E. Enstrom, Thomas Ferbel, Paul F. Slattery, Barry L. Werner, Zaven G. T. Guiragossian, Yoshio Sumi, Toshihiro Yoshida and Particle Data Group. UCRL-LBL 58, Berkeley, CA: Lawrence Berkeley Laboratory, U. of California, 281p. (1972). LBL 58.

\section{Gupta, D. S.}

Bibliography of Infrared Spectroscopy through 1960 - C. N. R. Rao, S. K. Dikshit, Shanti A. Kudchadker, D. S. Gupta, V. A. Narayan, and John J. Comeford. NBS Spec. Publ. 428, 1,2,3(1976).

\section{Gurevich, V. M.}

Electric Conductivity of Ferroelectrics - V. M. Gurevich. Russian Transl. Springfield, VA: NTIS, 366p. (1971). TT 70-50180, A16. 


\section{Haar, Lester}

A Thermodynamic Surface for Water: The Formulation and Computer Program - Lester Haar, John S. Gallagher, and George S. Kell. NBSIR 81-2253, 38p. (1981).

Equation of State for Ammonia - Lester Haar and John S. Gallagher. NBSIR 75-770, 27p. (1975).

NBS/NRC Steam Tables, Thermodynamic and Transport Properties and Computer Programs for Vapor and Liquid States of Water Lester Haar, John S. Gallagher, and George S. Kell. New York: Hemisphere Press, 320p. (1984).

Thermodynamic Properties of Ammonia as an Ideal Gas - Lester Haar. NSRDS-NBS 19, 10p. (1968).

Thermodynamic Properties of Ammonia - Lester Haar and John S. Gallagher. J Phys Chem Ref Data 7, 635(1978).

Haas, John L., Jr.

Thermodynamic Tabulations for Selected Phases in the System $\mathrm{CaO}-\mathrm{Al}_{2} \mathrm{O}_{3}-\mathrm{SiO}_{2}-\mathrm{H}_{2} \mathrm{O}$ at $101.325 \mathrm{kPa}$ (1 atm.) between 273.15 and 1800 K - John L. Haas, Jr., Gilpin R. Robinson, Jr., and Bruce S. Hemingway. J Phys Chem Ref Data 10, 575(1981).

\section{Haas, R. H.}

Microwave Spectral Tables, Volume IV. Polyatomic Molecules without Internal Rotation - M. S. Cord, J. D. Petersen, M. S. Lojko, and R. H. Haas. NBS Monograph 70, 419p. (1968).

\section{Hagan, Lucy}

Atomic Energy Levels - The Rare-Earth Elements, the Spectra of $\mathrm{La}, \mathrm{Ce}, \mathrm{Pr}, \mathrm{Nd}, \mathrm{Pm}, \mathrm{Sm}, \mathrm{Eu}, \mathrm{Gd}, \mathrm{Tb}, \mathrm{Dy}, \mathrm{Ho}, \mathrm{Er}, \mathrm{Tm}, \mathrm{Yb}, \mathrm{Lu}-$ William C. Martin, Romuald Zalubas, and Lucy Hagan. NSRDS-NBS 60, 422p. (1978).

Bibliography on Atomic Energy Levels and Spectra, July 1968 through June 1971 - Lucy Hagan and William C. Martin. NBS Spec. Publ. 363, 109p. (1972).

Bibliography on Atomic Energy Levels and Spectra, July 1971 through June 1975 - Lucy Hagan. NBS Spec. Publ. 363, Suppl. 1(1977).

Ground Levels and Ionization Potentials for Lanthanide and Actinide Atoms and Ions - William C. Martin, Lucy Hagan, Joseph Reader, and Jack Sugar. J Phys Chem Ref Data 3, 771(1974).

Haile, J. M.

A Correlation of the Viscosity and Thermal Conductivity Data of Gaseous and Liquid Propane - Paul M. Holland, Howard J. M. Hanley, K. E. Gubbins, and J. M. Haile. J Phys Chem Ref Data 8, 559(1979).

Hall, H. T.

High-Pressure Calibration: A Critical Review - D. L. Decker, W. A. Bassett, Leo Merrill, H. T. Hall, and J. D. Barnett. J Phys Chem Ref Data 1, 773(1972).

\section{Halow, Iva}

Selected Values of Chemical Thermodynamic Properties. Tables for the First Thirty-Four Elements in the Standard Order of Arrangement - Donald D. Wagman, William H. Evans, Vivian B. Parker, Iva Halow, Sylvia M. Bailey, and Richard H. Schumm. NBS Tech. Note 270, 264p. (1968).

Selected Values of Chemical Thermodynamic Properties. Tables for Elements 35 through 53 in the Standard Order of Arrangement Donald D. Wagman, William H. Evans, Vivian B. Parker, Iva Halow, Sylvia M. Bailey, and Richard H. Schumm. NBS Tech. Note 270, 152p. (1969).

Selected Values of Chemical Thermodynamic Properties. Tables for Elements 54 through 61 in the Standard Order of Arrangement -
Donald D. Wagman, William H. Evans, Vivian B. Parker, Iva Halow, Sylvia M. Bailey, Richard H. Schumm, and Kenneth L. Churney. NBS Tech. Note 270, 49p. (1971).

The NBS Tables of Chemical Thermodynamic Properties. Selected Values for Inorganic and $C_{1}$ and $C_{2}$ Organic Substances in SI Units Donald D. Wagman, William H. Evans, Vivian B. Parker, Richard H. Schumm, Iva Halow, Sylvia M. Bailey, Kenneth L. Churney, and Ralph L. Nuttall. J Phys Chem Ref Data 11, Suppl. 2(1982).

\section{Hamer, Walter J.}

Electrolytic Conductance and the Conductances of the Halogen Acids in Water - Walter J. Hamer and H. J. DeWane. NSRDS-NBS 33, 37p. (1970).

Osmotic Coefficients and Mean Activity Coefficients of UniUnivalent Electrolytes in Water at $25{ }^{\circ} \mathrm{C}-$ Walter J. Hamer and Yung-Chi Wu. J Phys Chem Ref Data 1, 1047(1972).

Revised Values of the Osmotic Coefficients and Mean Activity Coefficients of Sodium Nitrate in Water at $25^{\circ} \mathrm{C}$ (Comments) - Yung-Chi Wu and Walter J. Hamer. J Phys Chem Ref Data 9, 513(1980).

Theoretical Mean Activity Coefficients of Strong Electrolytes in Aqueous Solutions from 0 to $100^{\circ} \mathrm{C}-$ Walter J. Hamer. NSRDS-NBS 24, 271p. (1968).

\section{Hampson, Robert F., Jr.}

Chemical Kinetic and Photochemical Data Sheets for Atmospheric Reactions - Robert F. Hampson, Jr. Fed Aviation Admin EE 80-17, Springfield, VA: NTIS, 490p. (1980). FAA-EE-80-17, A21.

Evaluated Kinetic and Photochemical Data for Atmospheric Chemistry - D. L. Baulch, R. A. Cox, Robert F. Hampson, Jr., J. A. Kerr, J. Troe, and R. T. Watson. J Phys Chem Ref Data 9, 295(1980).

Evaluated Kinetic and Photochemical Data for Atmospheric Chemistry: Supplement I. CODATA Task Group on Chemical Kinetics D. L. Baulch, R. A. Cox, P. J. Crutzen, Robert F. Hampson, Jr., J. A. Kerr, J. Troe, and R. T. Watson. J Phys Chem Ref Data 11, 327(1982).

Evaluated Kinetic and Photochemical Data for Atmospheric Chemistry: Supplement II. CODATA Task Group on Gas Phase Chemical Kinetics - D. L. Baulch, R. A. Cox, Robert F. Hampson, Jr., J. A. Kerr, J. Troe, and R. T. Watson. J Phys Chem Ref Data 13, 1259(1984).

Kinetic and Photochemical Data for Atmospheric Chemistry, Reactions of the Nitrogen Oxides - Robert F. Hampson, Jr. NBSIR 80-2032, 89p. (1980).

Reaction Rate and Photochemical Data for Atmospheric Chemistry - 1977 - Robert F. Hampson, Jr. and David Garvin. NBS Spec. Publ. 513, 111p. (1978).

Summary Report on the Workshop on High Temperature Chemical Kinetics: Applications to Combustion Research - David Garvin, R. L. Brown, Robert F. Hampson, Jr., M. J. Kurylo, and W. Tsang. NBS Spec. Publ. 531, 94p. (1978).

Survey of Photochemical and Rate Data for Twenty-eight Reactions of Interest in Atmospheric Chemistry - Robert F. Hampson, Jr., W. Braun, R. L. Brown, David Garvin, John T. Herron, Robert E. Huie, M. J. Kurylo, A. H. Laufer, J. D. McKinley, H. Okabe, M. D. Scheer, W. Tsang, D. H. Stedman, editor(s). J Phys Chem Ref Data 2, 267(1973).

\section{Hanley, Howard J. M.}

A Computer Program for the Prediction of Viscosity and Thermal Conductivity in Hydrocarbon Mixtures - James F. Ely and Howard J. M. Hanley. NBS Tech. Note 1039, 83p. (1981).

A Correlation of the Existing Viscosity and Thermal Conductivity Data of Gaseous and Liquid Ethane - Howard J. M. Hanley, K. E. Gubbins, and S. Murad. J Phys Chem Ref Data 6, 1167(1977).

A Correlation of the Viscosity and Thermal Conductivity Data of Gaseous and Liquid Propane - Paul M. Holland, Howard J. M. Hanley, K. E. Gubbins, and J. M. Haile. J Phys Chem Ref Data 8, 559(1979). 
A Correlation of the Viscosity and Thermal Conductivity Data of Gaseous and Liquid Ethylene - Paul M. Holland, B. E. Eaton, and Howard J. M. Hanley. J Phys Chem Ref Data 12, 917(1983).

Erratum: A Correlation of the Existing Viscosity and Thermal Conductivity Data of Gaseous and Liquid Ethane - Howard J. M. Hanley, K. E. Gubbins, and S. Murad. J Phys Chem Ref Data 10, 799(1981).

Tables of Collision Integrals and Second Virial Coefficients for the $(m, 6,8)$ Intermolecular Potential Function - Max Klein, Howard J. M. Hanley, Francis J. Smith, and Paul M. Holland. NSRDS-NBS 47, 161p. (1974).

The Viscosity and Thermal Conductivity Cuefficients of Gaseous and Liquid Fluorine - Howard J. M. Hanley and R. Prydz. J Phys Chem Ref Data 1, 1101(1972).

The Viscosity and Thermal Conductivity Coefficients of Dilute Argon, Krypton, and Xenon - Howard J. M. Hanley. J Phys Chem Ref Data 2, 619(1973).

The Viscosity and Thermal Conductivity Coefficients of Dilute Nitrogen and Oxygen - Howard J. M. Hanley and James F. Ely. J Phys Chem Ref Data 2, 735(1973).

The Viscosity and Thermal Conductivity Coefficients for Dense Gaseous and Liquid Argon, Krypton, Xenon, Nitrogen, and Oxygen Howard J. M. Hanley, Robert D. McCarty, and W. M. Haynes. J Phys Chem Ref Data 3, 979(1974).

The Viscosity and Thermal Conductivity Coefficients for Dense Gaseous and Liquid Methane - Howard J. M. Hanley, W. M. Haynes, and Robert D. McCarty. J Phys Chem Ref Data 6, 597(1977).

\section{Harada, Issei}

Tables of Molecular Vibrational Frequencies, Part 9 - Takehiko Shimanouchi, Hiroatsu Matsuura, Yoshiki Ogawa, and Issei Harada. J Phys Chem Ref Data 7, 1323(1978).

Tables of Molecular Vibrational Frequencies, Part 10 - Takehiko Shimanouchi, Hiroatsu Matsuura, Yoshiki Ogawa, and Issei Harada. J Phys Chem Ref Data 9, 1149(1980).

\section{Harllee, F. N.}

A Bibliography on Ion-Molecule Reactions. January 1900 to March 1966 - F. N. Harllee, Henry M. Rosenstock, and John T. Herron. NBS Tech. Note 291, 40p. (1966).

\section{Harmony, Marlin D.}

Molecular Structures of Gas-Phase Polyatomic Molecules Determined by Spectroscopic Methods - Marlin D. Harmony, Victor W. Laurie, Robert L. Kuczkowski, Richard H. Schwendeman, D. A. Ramsay, Frank J. Lovas, Walter J. Lafferty, and Arthur G. Maki. J Phys Chem Ref Data 8, 619(1979).

\section{Harrlson, Roland $\mathrm{H}$.}

Derived Thermodynamic Properties of Ethylene - Roland $\mathbf{H}$. Harrison and Donald R. Douslin. J Chem Eng Data. 22, Washington, DC: American Chemical Society, 24p. (1977).

Pressure, Volume, Temperature Relations of Ethylene - Donald R. Douslin and Roland H. Harrison. J Chem Thermody 76, New York, London:, 301p. (1976).

\section{Hartman, K. N.}

A Compendium of Gas Phase Basicity and Proton Affinity Measurements - K. N. Hartman, Sharon G. Lias, P. J. Ausloos, Henry M. Rosenstock, S. S. Schroyer, C. Schmidt, D. Martinsen, and G. W. A. Milne. NBSIR 79.1777, 563p. (1979).

Annotated Bibliography on Proton Affinities - K. N. Hartman, Sharon G. Lias, P. J. Ausloos, and Henry M. Rosenstock.NBSIR76-1061, 52p. (1976).
Hastings, J. R.

The Critical-Region Equation of State of Ethene and the Effect of Small Impurities - J. R. Hastings, J. M. H. Levelt Sengers, and F. W. Balfour. J Chem Thermody 12, London: Academic Press Inc., 1009p. (1980).

\section{Havill, T. N.}

Electrical Resistivity of Ten Selected Binary Alloy Systems - Cho Y. Ho, M. W. Ackerman, K. Y. Wu, T. N. Havill, R. H. Bogaard, R. A. Matula, S. G. Oh, and H. M. James. J Phys Chem Ref Data 12, 183(1983).

Thermal Conductivity of Ten Selected Binary Alloy Systems - Cho Y. Ho, M. W. Ackerman, K. Y. Wu, S. G. Oh, and T. N. Havill. J Phys Chem Ref Data 7, 959(1978).

\section{Hawkins, Donald T.}

Binary Fluorides, Free Molecular Structures and Force Fields, A Bibliography (1957-1975) - Donald T. Hawkins, Lawrence S. Bernstein, Warren E. Falconer, and William Klemperer. New York: IFI/Plenum, 253p. (1976), ISBN: 0-306-6601-3.

Selected Values of the Thermodynamic Properties of Binary Alloys - Ralph Hultgren, Pramond D. Desai, Donald T. Hawkins, M. Gleiser, and Kenneth K. Kelley. Metals Park, OH: American Society for Metals, 1435p. (1973).

Selected Values of the Thermodynamic Properties of the Elements - Ralph Hultgren, Pramond D. Desai, Donald T. Hawkins, M. Gleiser, Kenneth K. Kelley, and Donald D. Wagman. Metals Park, OH: American Society for Metals, 636p. (1973).

\section{Haynes, W. M.}

The Viscosity and Thermal Conductivity Coefficients for Dense Gaseous and Liquid Argon, Krypton, Xenon, Nitrogen, and Oxygen Howard J. M. Hanley, Robert D. McCarty, and W. M. Haynes. J Phys Chem Ref Data 3, 979(1974).

The Viscosity and Thermal Conductivity Coefficients for Dense Gaseous and Liquid Methane - Howard J. M. Hanley, W. M. Haynes, and Robert D. McCarty. J Phys Chem Ref Data 6, 597(1977).

Thermophysical Properties of Isobutane from 114 to $700 \mathrm{~K}$ at Pressures to $70 \mathrm{MPa}$ - Robert D. Goodwin and W. M. Haynes. NBS Tech. Note 1051, 199p. (1982).

Thermophysical Properties of Normal Butane from 135 to $700 \mathrm{~K}$ at Pressures to $70 \mathrm{MPa}-$ W. M. Haynes and Robert D. Goodwin. NBS Monograph 169, 197p. (1982).

Thermophysical Properties of Propane from 85 to $700 \mathrm{~K}$ at Pressures to $70 \mathrm{MPa}$ - Robert D. Goodwin and W. M. Haylies. NBS Monograph 170, 249p. (1982).

\section{Hearing, Elizabeth D.}

Heat Capacities and Entropies of Organic Compounds in the Condensed Phase - Eugene S. Domalski, William H. Evans, and Elizabeth D. Hearing. J Phys Chem Ref Data 13, Suppl. 1(1984).

\section{Heller, Stephen R.}

EPA/NIH Mass Spectral Data Base Magnetic Tape - Stephen $\mathbf{R}$. Heller and G. W. A. Milne. NBS Standard Reference Database 1 A1, Washington, DC: NBS Office of Standard Reference Data,(updated periodically). Call (301) 921-2228 for specific instructions.

EPA/NIH Mass Spectral Data Base, Supplement 1 - Stephen R. Heller and G. W. A. Milne. NSRDS-NBS 63, Suppl. 1(1980).

EPA/NIH Mass Spectral Data Base, Supplement 2 - Stephen R. Heller, G. W. A. Milne, and Lewis H. Gevantman. NSRDS-NBS 63, Suppl. 2(1983). 
EPA/NIH Mass Spectral Data Base, Volume 1. Molecular Weights 30-186; Volume 2. Molecular Weights 16-273; Volume 3. Molecular Weights 273-381; Volume 4. Molecular Weights 381-1674 - Stephen R. Heller and G. W. A. Milne. NSRDS-NBS 63, 1,2,3,4(1978).

\section{Hellner, Erwin}

Space Groups and Lattice Complexes - W. Fisher, Hans Burzlaff, Erwin Hellner, and Joseph D. H. Donnay. NBS Monograph 134, 177p. (1973).

\section{Helman, W. PhIIIIp}

A Catalog of Data Compilations on Photochemical and Photophysical Processes in Solution - James G. Brummer, W. Phillip Helman, and Alberta B. Ross. NBS Spec. Publ. 578, 27p. (1980).

\section{Helminger, Paul}

Microwave Spectra of Molecules of Astrophysical Interest, IV. Hydrogen Sulfide - Paul Helminger, Frank C. De Lucia, and William H. Kirchhoff. J Phys Chem Ref Data 2, 215(1973).

Microwave Spectra of Molecules of Astrophysical Interest, V. Water Vapor - Frank C. De Lucia, Paul Helminger, and William H. Kirchhoff. J Phys Chem Ref Data J, 211(1974).

\section{Hemlngway, Bruce S.}

Thermodynamic Tabulations for Selected Phases in the System $\mathrm{CaO}-\mathrm{Al}_{2} \mathrm{O}_{3}-\mathrm{SiO}_{2}-\mathrm{H}_{2} \mathrm{O}$ at $101.325 \mathrm{kPa}$ (1 atm.) between 273.15 and 1800 K - John L. Haas, Jr., Gilpin R. Robinson, Jr., and Bruce S. Hemingway. J Phys Chem Ref Data 10, 575(1981).

\section{Henderson, George A.}

Semiempirical and Approximate Methods for Molecular Calculations - Bibliography and KWIC Index - George A. Henderson and Sandra Frattali. OSRD Bibl. 70-3, 293p. (1970).

\section{Hendricks, R. C.}

Representative Equations for the Thermal Conductivity of Water Substance - Jan V. Sengers, J. T. R. Watson, R. S. Basu, B. KamgarParsi, and R. C. Hendricks. J Phys Chem Ref Data 13, 893(1984).

\section{Hendry, D. G.}

A Critical Review of H-Atom Transfer in the Liquid Phase: Chlorine Atom, Alkyl, Trichloromethyl, Alkoxy, and Alkylperoxy Radicals D. G. Hendry, T. Mill, L. Piszkiewicz, J. A. Howard, and H. K. Eigenmann. J Phys Chem Ref Data 3, 937(1974).

\section{Henrl, Victor P.}

$\pi+\mathrm{p}, \pi+\mathrm{n}$, and $\pi+\mathrm{d}$ Interactions - A Compilation: Parts I and II Denyse M. Chew, Victor P. Henri, Thomas A. Lasinski, Thomas G. Trippe, Fumiyo Uchiyama, Frederick C. Winkelmann and Particle Data Group. UCRL 53, Springfield, VA: NTIS, 213p. (1973). LBL 53; Part II is on microfiche located in the back cover pocket, A10. $\pi \mathrm{N}$ Two-Body Scattering Data, I. A User's Guide to the LovelaceAlmehed Data Tape - Claude Lovelace, Sverkei Almehed, Fumiyo Uchiyama, Robert Kelly, Victor P. Henri and Particle Data Group. UCRL 63, Springfield, VA: NTIS, 146p. (1973). LBL 63, A07.

\section{Herbold, R. H.}

OMNITAB, A Computer Program for Statistical and Numerical Analysis - Joseph Hilsenrath, Guy G. Ziegler, Carla G. Messina, P. J. Walsh, and R. H. Herbold. NBS Handbook 101, 256p. (1968).

\section{Herndon, Davld J.}

$\pi \mathrm{N}$ Particle-Wave Amplitudes - David J. Herndon, Angela Barbaro-Galtieri, Arthur H. Rosenfeld and Particle Data Group.
UCRL 20030 $\pi$ N, Springfield, VA: NTIS, 85p. (1970). UCRL 20030 $\pi \mathrm{N}, \mathrm{A} 05$.

\section{Herron, John T.}

A Bibliography on Ion-Molecule Reactions. January 1900 to March 1966 - F. N. Harllee, Henry M. Rosenstock, and John T. Herron. NBS Tech. Note 291, 40p. (1966).

Energetics of Gaseous Ions - Henry M. Rosenstock, Keith Draxl, B. W. Steiner, and John T. Herron. J Phys Chem Ref Data 6, Suppl. 1(1977).

Ionization Potentials, Appearance Potentials, and Heats of Formation of Gaseous Positive Ions - Joseph L. Franklin, J. G. Dillard, Henry M. Rosenstock, John T. Herron, Keith Draxl, and Frank H. Field. NSRDS-NBS 26, 289p. (1969).

Rate Constants for the Reactions of Atomic Oxygen $\left(\mathrm{O}{ }^{3} \mathrm{P}\right)$ with Organic Compounds in the Gas Phase - John T. Herron and Robert E. Huie. J Phys Chem Ref Data 2, 467(1973).

Survey of Photochemical and Rate Data for Twenty-eight Reactions of Interest in Atmospheric Chemistry - Robert F. Hampson, Jr., W. Braun, R. L. Brown, David Garvin, John T. Herron, Robert E. Huie, M. J. Kurylo, A. H. Laufer, J. D. McKinley, H. Okabe, M. D. Scheer, W. Tsang, D. H. Stedman, editor(s). J Phys Chem Ref Data 2, 267(1973).

\section{Hilidenbrand, D. L.}

High Temperature Vaporization Behavior of Oxides. I. Alkali Metal Binary Oxides - R. H. Lamoreaux and D. L. Hildenbrand. J Phys Chem Ref Data 13, 151(1984).

Hill, P. G.

A Fundamental Equation of State for Heavy Water - P. G. Hill, R. D. Chris MacMillan, and V. Lee. J Phys Chem Ref Data 11, 1(1982).

Erratum: A Fundamental Equation of State for Heavy Water - P. G. Hill, R. D. Chris MacMillan, and V. Lee. J Phys Chem Ref Data 12, 1065(1983).

Saturation States of Heavy Water - P. G. Hill and R. D. Chris MacMillan. J Phys Chem Ref Data 9, 735(1980).

\section{Hilsenrath, Joseph}

A Contribution to Computer Typesetting Techniques: Tables of Coordinates for Hershey's Repertory of Occidental Type Fonts and Graphic Symbols - Norman M. Wolcott and Joseph Hilsenrath. NBS Spec. Publ. 424, 177p. (1976).

COMBO: A General-Purpose Program for Searching, Annotating, Encoding-Decoding, and Reformatting Data Files - Robert McClenon and Joseph Hilsenrath. NBS Tech. Note 700, 72p. (1972).

EDPAC: Utility Programs for Computer-Assisted Editing, Copy Production, and Data Retrieval - Carla G. Messina and Joseph Hilsenrath. NBS Tech. Note 470, 76p. (1969).

Edit-Insertion Programs for Automatic Typesetting of Computer Printout - Carla G. Messina and Joseph Hilsenrath. NBS Tech. Note 500, 47p. (1970).

Fortran Programs for Text Editing, File Manipulation and Automatic Typsetting - Carla G. Messina, Robert McClenon, and Joseph Hilsenrath. OSRD Mag. Tape A2, Washington, DC: Office of Standard Reference Data,(1973). COM 71-003 885 or PB 183 142, T05.

OMNIDATA, An Interactive System for Data Retrieval, Statistical and Graphical Analysis, and Data-Base Management, A User's Manual - Joseph Hilsenrath and Bettijoyce Breen. NBS Handbook 125, 294p. (1978).

OMNITAB, A Computer Program for Statistical and Numerical Analysis - Joseph Hilsenrath, Guy G. Ziegler, Carla G. Messina, P. J. Walsh, and R. H. Herbold. NBS Handbook 101, 256p. (1968).

PRECISE: A Multiple Precision Version of OMNITAB - Alfred E. Bean and Joseph Hilsenrath. NBS Tech. Note 446, 84p. (1968). 
Reform: A General-Purpose Program for Manipulating Formatted Data Files - Robert McClenon and Joseph Hilsenrath. NBS Tech. Note 444, 25p. (1968).

SETAB: An Edit-Insert Program for Automatic Typesetting of Spectroscopic and Other Computerized Tables - Robert C. Thompson and Joseph Hilsenrath. NBS Tech. Note 740, 32p. (1973).

Summary of On-Line or Interactive Physico-Chemical Numerical Data Systems - Joseph Hilsenrath. NBS Tech. Note 1122, 29p. (1980).

Tables of Coordinates for Hershey's Repertory of Type Fonts and Graphic Symbols - Norman M. Wolcott and Joseph Hilsenrath. OSRD Mag. Tape A12, Washington, DC: Office of Standard Reference Data,(1977). Hershey tape.

Utility Programs for Generating the Hershey Character Fonts on Microcomputers and Laboratory Plotters - C. E. Dick and Joseph Hilsenrath. NBS Tech. Note 1176, 49p. (1983).

Hiza, M. J.

A Review, Evaluation, and Correlation of the Phase Equilibria, Heat of Mixing, and Change in Volume on Mixing for Liquid Mixtures of Methane + Ethane - M. J. Hiza, R. C. Miller, and Arthur J. Kidnay. J Phys Chem Ref Data 8, 799(1979).

A Review, Evaluation, and Correlation of the Phase Equilibria, Heat of Mixing, and Change in Volume on Mixing for Liquid Mixtures of Methane + Propane - R. C. Miller, Arthur J. Kidnay, and M. J. Hiza. J Phys Chem Ref Data 9, 721(1980).

Equilibrium Properties of Fluid Mixtures, A Bibliography on Fluids of Cryogenic Interest - M. J. Hiza, Arthur J. Kidnay, and R. C. Miller. New York: IFI/Plenum, 166p. (1975), ISBN: 0-306-6601-6.

Equilibrium Properties of Fluid Mixtures, 2. A Bibliography of Experimental Data on Selected Fluids - M. J. Hiza, Arthur J. Kidnay, and R. C. Miller. New York: IFI/Plenum, 258p. (1982), ISBN: 0-306-6602-4.

Liquid Vapor Equilibria on Systems of Interest in Cryogenics, A Survey - Arthur J. Kidnay, M. J. Hiza, and R. C. Miller. Cryogenics 13, London: Academic Press, 575p. (1973).

\section{Ho, Cho Y.}

Electrical Resistivity of Aluminum and Manganese - P. D. Desai, H. M. James, and Cho Y. Ho. J Phys Chem Ref Data 13, 1131(1984).

Electrical Resistivity of Selected Elements - P. D. Desai, T. K. Chu, H. M. James, and Cho Y. Ho. J Phys Chem Ref Data 13, 1069(1984).

Electrical Resistivity of Ten Selected Binary Alloy Systems - Cho Y. Ho, M. W. Ackerman, K. Y. Wu, T. N. Havill, R. H. Bogaard, R. A. Matula, S. G. Oh, and H. M. James. J Phys Chem Ref Data 12, 183(1983).

Electrical Resistivity of Vanadium and Zirconium - P. D. Desai, H. M. James, and Cho Y. Ho. J Phys Chem Ref Data 13, 1097(1984).

Thermal Conductivity of Selected Materials - Robert W. Powell,

Cho Y. Ho, and Peter E. Liley. NSRDS-NBS 8, 68p. (1966).

Thermal Conductivity of Selected Materials, Part 2 - Cho Y. Ho,

Robert W. Powell, and Peter E. Liley. NSRDS-NBS 16, 146p. (1968).

Thermal Conductivity of Ten Selected Binary Alloy Systems - Cho

Y. Ho, M. W. Ackerman, K. Y. Wu, S. G. Oh, and T. N. Havill. J Phys Chem Ref Data 7, 959(1978).

Thermal Conductivity of the Elements - Cho Y. Ho, Robert W. Powell, and Peter E. Liley. J Phys Chem Ref Data 1, 279(1972).

Thermal Conductivity of the Elements: A Comprehensive Review Cho Y. Ho, Robert W. Powell, and Peter E. Liley. J Phys Chem Ref Data 3, Suppl. 1(1974).

\section{Hocking, W. H.}

Microwave Spectra of Molecules of Astrophysical Interest, X. Isocyanic Acid - G. Winnewisser, W. H. Hocking, and M. C. L. Gerry. J Phys Chem Ref Data 5, 79(1976).

\section{Holden, Norman E.}

Isotopic Abundances and Atomic Weights of the Elements - Paul De Bièvre, Marc Gallet, Norman E. Holden, and I. Lynus Barnes. J Phys Chem Ref Data 13, 809(1984).

\section{Holland, Paul $M$.}

A Correlation of the Viscosity and Thermal Conductivity Data of Gaseous and Liquid Propane - Paul M. Holland, Howard J. M. Hanley, K. E. Gubbins, and J. M. Haile. J Phys Chem Ref Data 8, 559(1979).

A Correlation of the Viscosity and Thermal Conductivity Data of Gaseous and Liquid Ethylene - Paul M. Holland, B. E. Eaton, and Howard J. M. Hanley. J Phys Chem Ref Data 12, 917(1983).

Tables of Collision Integrals and Second Virial Coefficients for the $(m, 6,8)$ Intermolecular Potential Function - Max Klein, Howard J. M. Hanley, Francis J. Smith, and Paul M. Holland. NSRDS-NBS 47, 161p. (1974).

\section{Holtschlag, L. J.}

Rate Constants of Gas Phase Reactions, Reference Book - V. N. Kondratiev, L. J. Holtschlag, R. M. Fristrom, editor(s). Russian Transl. Springfield, VA: NTIS, 434p. (1972). COM 72-10014, A19.

\section{Horiuti, Juro}

Hydrogenation of Ethylene on Metallic Catalysts - Juro Horiuti and Koshiro Miyahara. NSRDS-NBS 13, 62p. (1968).

\section{Hotop, $\mathrm{H}$.}

Binding Energies in Atomic Negative Ions - H. Hotop and W. C. Lineberger. J Phys Chem Ref Data 4, 539(1975).

\section{Hougen, Jon T.}

The Calculation of Rotational Energy Levels and Rotational Line Intensities in Diatomic Molecules - Jon T. Hougen. NBS Monograph 115, 54p. (1970).

\section{Howard, J. A.}

A Critical Review of H-Atom Transfer in the Liquid Phase: Chlorine Atom, Alkyl, Trichloromethyl, Alkoxy, and Alkylperoxy Radicals D. G. Hendry, T. Mill, L. Piszkiewicz, J. A. Howard, and H. K. Eigenmann. J Phys Chem Ref Data 3, 937(1974).

\section{Howerton, R. J.}

Atomic Form Factors, Incoherent Scattering Functions, and Photon Scattering Cross Sections - John H. Hubbell, W. J. Veigele, E. A Briggs, R. T. Brown, D. T. Cromer, and R. J. Howerton. J Phys Chem Ref Data 4, 471(1975).

Hu, A. T.

JANAF Thermochemical Tables, 1974 Supplement - Malcolm W. Chase, Jr., J. L. Curnutt, A. T. Hu, H. Prophet, A. N. Syverud, and L. C. Walker. J Phys Chem Ref Data 3, 311(1974).

\section{Hubbard, C. R.}

NBS* AIDS80: A FORTRAN Program for Crystallographic Data Evaluation - Alan D. Mighell, C. R. Hubbard, and Judy K. Stalick. NBS Tech. Note 1141, 54p. (1981).

\section{Hubbell, John $\mathbf{H}$.}

Atomic Form Factors, Incoherent Scattering Functions, and Photon Scattering Cross Sections - John H. Hubbell, W. J. Veigele, E. A. Briggs, R. T. Brown, D. T. Cromer and R. J. Howerton. J Phys Chem Ref Data 4,471(1975]. 
Comparison of Theoretical and Experimental Photoeffect Data, 0.1 $\mathrm{keV}$ to $1.5 \mathrm{MeV}$ - John H. Hubbell and W. J. Veigele. NBS Tech. Note 901, 47p. (1976).

Pair, Triplet, and Total Atomic Cross Sections (and Mass Attenuation Coefficients) for $1 \mathrm{MeV}-100 \mathrm{GeV}$ Photons in Elements $Z=1$ to $100-$ John H. Hubbell, Heinz A. Gimm, and I. Øverb $\varnothing$. J Phys Chem Ref Data 9, 1023(1980).

Photon Cross Sections, Attenuation Coefficients, and Energy Absorption Coefficients from $10 \mathrm{keV}$ to $100 \mathrm{GeV}$ - John H. Hubbell. NSRDSNBS 29, 85p. (1969).

Relativistic Atomic Form Factors and Photon Coherent Scattering Cross Sections - John H. Hubbell and I. $\varnothing$ verb $\varnothing$. J Phys Chem Ref Data 8, 69(1979).

Small-Angle Rayleigh Scattering of Photons at High Energies: Tabulations of Relativisitic HFS Modified Atomic Form Factors - D. Schaupp, M. Schumacher, F. Smend, P. Rullhusen, and John H. Hubbell. J Phys Chem Ref Data 12, 467(1983).

Total Photon Absorption Cross Section Measurements, Theoretical Analysis and Evaluations for Energies above $10 \mathrm{MeV}$ - Heinz A. Gimm and John H. Hubbell. NBS Tech. Note 968, 81p. (1978).

\section{Hudson, Robert D.}

Bibliography of Photoabsorption Cross Section Data - Robert D. Hudson and Lee J. Kieffer. OSRD Bibl. 70-4, 47p. (1970).

Critical Review of Ultraviolet Photoabsorption Cross Sections for Molecules of Astrophysical and Aeronomic Interest - Robert D. Hudson. NSRDS-NBS 38, 114p. (1971).

\section{Hug, Gordon L.}

Optical Spectra of Nonmetallic Inorganic Transient Species in Aqueous Solution - Gordon L. Hug. NSRDS-NBS 69, 167p. (1981).

\section{Hughes, J. G.}

Recommended Data on the Electron Impact Ionization of Light At. oms and Ions - K. L. Bell, H. B. Gilbody, J. G. Hughes, A. E. Kingston, and Francis J. Smith. J Phys Chem Ref Data 12, 891(1983).

\section{Huie, Robert E.}

Rate Constants for the Reactions of Atomic Oxygen $\left(\mathrm{O}{ }^{3} \mathrm{P}\right)$ with Organic Compounds in the Gas Phase - John T. Herron and Robert E. Huie. J Phys Chem Ref Data 2, 467(1973).

Survey of Photochemical and Rate Data for Twenty-eight Reactions of Interest in Atmospheric Chemistry - Robert F. Hampson, Jr., W. Braun, R. L. Brown, David Garvin, John T. Herron, Robert E. Huie, M. J. Kurylo, A. H. Laufer, J. D. McKinley, H. Okabe, M. D. Scheer, W. Tsang, D. H. Stedman, editor(s). J Phys Chem Ref Data 2, 267(1973).

\section{Hultgren, Ralph}

Selected Thermodynamic Values and Phase Diagrams for Copper and Some of Its Binary Alloys - Ralph Hultgren and Pramond D. Desai. INCRA Monograph I, New York: International Copper Research Association, Inc., 204p. (1973).

Selected Values of the Thermodynamic Properties of Binary Alloys Ralph Hultgren, Pramond D. Desai, Donald T. Hawkins, M. Gleiser, and Kenneth K. Kelley. Metals Park, OH: American Society for Metals, 1435p. (1973).

Selected Values of the Thermodynamic Properties of the Elements Ralph Hultgren, Pramond D. Desai, Donald T. Hawkins, M. Gleiser, Kenneth K. Kelley, and Donald D. Wagman. Metals Park, OH: American Society for Metals, 636p. (1973).

\section{Humphreys, Curtis J.}

First Spectra of Neon, Argon, and Xenon 136 in the 1.2-4.0 $\mu \mathrm{m}$ Region - Curtis J. Humphreys. J Phys Chem Ref Data 2, 519(1973).

\section{Hust, Jerome G.}

Thermodynamic Properties of Argon from the Triple Point to $300 \mathrm{~K}$ at Pressures to 1000 Atmospheres - A. L. Gosman, Robert D. McCarty, and Jerome G. Hust. NSRDS-NBS 27, 153p. (1969).

\section{Ionov, N. L.}

Surface Ionization - E. Ya. Zandberg and N. L. Ionov. Russian Transl. Springfield, VA: NTIS, 364p. (1971). TT 70-50148, A 16.

\section{Ivan'ko, A. A.}

Handbook of Hardness Data - G. V. Samsonov and A. A. Ivan'ko. Russian Transl. Springfield, VA: NTIS, 69p. (1970). TT 70-50177, A04.

\section{Jacobsen, Richard T.}

An Equation of State for Fluid Ethylene - Robert D. McCarty and Richard T. Jacobsen. NBS Tech. Note 1045, 164p. (1981).

Thermodynamic Properties of Nitrogen Including Liquid and Vapor Phases from $63 \mathrm{~K}$ to $2000 \mathrm{~K}$ with Pressures to $10,000 \mathrm{Bar}$ - Richard T. Jacobsen and Richard B. Stewart. J Phys Chem Ref Data 2, 757(1973).

\section{Jacox, Marilyn E.}

Ground-State Vibrational Energy Levels of Polyatomic Transient Molecules - Marilyn E. Jacox. J Phys Chem Ref Data 13, 945(1984). Jain, R. K.

Bibliography on Properties of Defect Centers in Alkali Halides Suresh C. Jain, S. A. Khan, H. K. Sehgal, V. K. Garg, and R. K. Jain. OSRD Bibl. 71-1, 293p. (1971).

\section{Jain, Suresh C.}

Bibliography on Properties of Defect Centers in Alkali Halides Suresh C. Jain, S. A. Khan, H. K. Sehgal, V. K. Garg, and R. K. Jain. OSRD Bibl. 71-1, 293p. (1971).

Electronic Absorption and Internal and External Vibrational Data of Atomic and Molecular Ions Doped in Alkali Halide Crystals - Suresh C. Jain, A. V. R. Warrier, and Suresh K. Agarwal. NSRDS-NBS 52, 55p. (1974).

\section{James, H. M.}

Electrical Resistivity of Aluminum and Manganese - P. D. Desai, H. M. James, and Cho Y. Ho. J Phys Chem Ref Data 13, 1131(1984).

Electrical Resistivity of Selected Elements - P. D. Desai, T. K. Chu, H. M. James, and Cho Y. Ho. J Phys Chem Ref Data 13, 1069(1984).

Electrical Resistivity of Ten Selected Binary Alloy Systems - Cho Y. Ho, M. W. Ackerman, K. Y. Wu, T. N. Havill, R. H. Bogaard, R. A. Matula, S. G. Oh, and H. M. James. J Phys Chem Ref Data 12, 183(1983).

Electrical Resistivity of Vanadium and Zirconium - P. D. Desai, H. Hudson. NSRDS-NBS 38, 114p. (1971). 
Janev, R. K.

Evaluated Theoretical Cross Section Data for Charge Exchange of Multiply Charged Ions with Atoms. I. Hydrogen Atom-Fully Stripped Ion Systems - R. K. Janev, B. H. Bransden, and Jean W. Gallagher. J Phys Chem Ref Data 12, 829(1983).

Evaluated Theoretical Cross Section Data for Charge Exchange of Multiply Charged Ions with Atoms. II. Hydrogen Atom-Partially Stripped Ions Systems - Jean W. Gallagher, B. H. Bransden, and R. K. Janev. J Phys Chem Ref Data 12, 873(1983).

Evaluated Theoretical Cross Section Data for Charge Exchange of Multiply Charged Ion with Atoms. III. Non-Hydrogenic Target Atoms - R. K. Janev and Jean W. Gallagher. J Phys Chem Ref Data 13, 1199(1984).

\section{Janz, George J.}

Erratum: Molten Salts Data: Diffusion Coefficients in Single and Multi-Component Salt Systems - George J. Janz and Narottam P. Bansal. J Phys Chem Ref Data 13, 305(1984).

Molten Salts Data As Reference Standards for Density, Surface Tension, Viscosity and Electrical Conductance: $\mathrm{KNO}_{3}$ and $\mathrm{NaCl}-$ George J. Janz. J Phys Chem Ref Data 9, 791(1980).

Molten Salts Data: Diffusion Coefficients in Single and MultiComponent Salt Systems - George J. Janz and Narottam P. Bansal. J Phys Chem Ref Data 11, 505(1982).

Molten Salts: Volume 1. Electrical Conductance, Density, and Viscosity Data - George J. Janz, F. W. Dampier, G. R. Lakshminarayanan, P. K. Lorenz, and Reginald P. T. Tomkins. NSRDS-NBS 15, 140p. (1968).

Molten Salts: Volume 2. Section 1. Electrochemistry of Molten Salts. Gibbs Free Energies and Excess Free Energies from Equilibrium-Type Cells, Section 2. Surface Tension Data - George J. Janz, Chr. G. M. Dijkhuis, G. R. Lakshminarayanan, Reginald P. T. Tomkins, and J. Wong. NSRDS-NBS 28, 116p. (1968).

Molten Salts: Volume 3, Nitrates, Nitrites, and Mixtures. Electrical Conductance, Density, Viscosity, and Surface Tension Data - George J. Janz, Ursula Krebs, H. F. Siegenthaler, and Reginald P. T. Tomkins. J Phys Chem Ref Data 1, 581(1972).

Molten Salts: Volume 4, Part 1, Fluorides and Mixtures. Electrical Conductance, Density, Viscosity, and Surface Tension Data - George J. Janz, G. L. Gardner, Ursula Krebs, and Reginald P. T. Tomkins. J Phys Chem Ref Data 3, 1(1974).

Molten Salts: Volume 4, Part 2, Chlorides and Mixtures. Electrical Conductance, Density, Viscosity, and Surface Tension Data - George J. Janz, Reginald P. T. Tomkins, Carolyn B. Allen, J. R. Downey, Jr., G. L. Gardner, Ursula Krebs, and S. K. Singer. J Phys Chem Ref Data 4, 871(1975).

Molten Salts: Volume 4, Part 3, Bromides and Mixtures, Iodides and Mixtures. Electrical Conductance, Density, Viscosity, and Surface Tension Data - George J. Janz, Reginald P. T. Tomkins, Carolyn B. Allen, J. R. Downey, Jr., and S. K. Singer. J Phys Chem Ref Data 6, 409(1977).

Molten Salts: Volume 4, Part 4, Mixed Halide Melts. Electrical Conductance, Density, Viscosity, and Surface Tension Data - George J. Janz, Reginald P. T. Tomkins, and Carolyn B. Allen. J Phys Chem Ref Data 8, 125(1979).

Molten Salts: Volume 5, Part 1. Additional Single and MultiComponent Salt Systems. Electrical Conductance, Density, Viscosity, and Surface Tension Data - George J. Janz and Reginald P. T. Tomkins. J Phys Chem Ref Data 9, 831(1980).

Molten Salts: Volume 5, Part 2. Additional Single and MultiComponent Salt Systems. Electrical Conductance, Density, Vicosity and Surface Tension Data - George J. Janz and Reginald P. T. Tomkins. J Phys Chem Ref Data 12, 591(1983).

Physical Properties Data Compilations Relevant to Energy Storage. 1. Molten Salts: Eutectic Data - George J. Janz, Carolyn B. Allen, J. R. Downey, Jr., and Reginald P. T. Tomkins. NSRDS-NBS 61, 244p. (1978).

Physical Properties Data Compilations Relevant to Energy Storage. II. Molten Salts: Data on Single and Multi-Component Systems -
George J. Janz, Carolyn B. Allen, Narottam P. Bansal, R. M. Murphy, and Reginald P. T. Tomkins. NSRDS-NBS 61, 420p. (1979).

Physical Properties Data Compilations Relevant to Energy Storage. IV. Molten Salts: Data on Additional Single and Multi-Component Salt Systems - George J. Janz and Reginald P. T. Tomkins. NSRDS-NBS 61, 870p. (1981).

\section{Jasper, Joseph J.}

The Surface Tension of Pure Liquid Compounds - Joseph J. Jasper. J Phys Chem Ref Data 1, 841(1972).

\section{Jobe, Thomas L., Jr.}

A Report on Thermodynamic Data for Desulfurization Processes Vivian B. Parker, Bert R. Staples, Thomas L. Jobe, Jr., and David B. Neumann. NBSIR 81-2345, 89p. (1981).

Heating Values of Natural Gas and Its Components - George T. Armstrong and Thomas L. Jobe, Jr. NBSIR 82-2401, 164p. (1982).

Thermodynamic Properties of Miscellaneous Materials - Eugene S. Domalski, William H. Evans, and Thomas L. Jobe, Jr. NBSIR 78.1479, 69p. (1981).

\section{Johnson, Donald R.}

Microwave Spectra of Molecules of Astrophysical Interest, I. Formaldehyde, Formamide, and Thioformaldehyde - Donald R. Johnson, Frank J. Lovas, and William H. Kirchhoff. J Phys Chem Ref Data 1, 1011(1972).

Microwave Spectra of Molecules of Astrophysical Interest, II. Methylenimine - William H. Kirchhoff, Donald R. Johnson, and Frank J. Lovas. J Phys Chem Ref Data 2, 1(1973).

Microwave Spectra of Molecules of Astrophysical Interest, III. Methanol - R. M. Lees, Frank J. Lovas, William H. Kirchhoff, and Donald R. Johnson. J Phys Chem Ref Data 2, 205(1973).

Microwave Spectra of Molecules of Astrophysical Interest, IX. Acetaldehyde - A. Bauder, Frank J. Lovas, and Donald R. Johnson. Phys Chem Ref Data 5, 53(1976).

\section{Johnson, Dorothea M.}

Critical Surveys of Data Sources: Ceramics - Dorothea M. Johnson and James F. Lynch. NBS Spec. Publ. 396, 56p. (1975).

\section{Johnson, George R. A.}

Radiation Chemistry of Nitrous Oxide Gas, Primary Processes, Elementary Reactions and Yields - George R. A. Johnson. NSRDS-NBS 45, 29p. (1973).

\section{Johnson, V. J.}

Liquid Densities of Oxygen, Nitrogen, Argon, and Parahydrogen Hans M. Roder, Robert D. McCarty, and V. J. Johnson. NBS Tech. Note 361, 1972(1973).

\section{Johnston, Francis J.}

The Solubility of Some Sparingly Soluble Lead Salts: An Evaluation of the Solubility in Water and Aqueous Electrolyte Solution - H. Lawrence Clever and Francis J. Johnston. J Phys Chem Ref Data 9, 751(1980).

\section{Johnston, Harold S.}

Gas Phase Reaction Kinetics of Neutral Oxygen Species - Harold S. Johnston. NSRDS-NBS 20, 49p. (1968).

\section{Joseph, R. E.}

A Compilation of Thermodynamic and Transport Properties of Aqueous Potassium Hydroxide - R. E. Joseph and Bert R. Staples. NBSIR 81-2356, 17p. (1982). 


\section{Kahan, Daniel J.}

Metallic Shifts in NMR: A Review of the Theory and Comprehensive Critical Data Compilation of Metallic Materials - Gesina Cynthia Carter, Lawrence H. Bennett, and Daniel J. Kahan. Prog Mater Sci, Oxford, New York: Pergamon Press, 2350p. (1977), ISBN: 0-08-02114-7.

The NBS Alloy Data Center: Author Index - Gesina Cynthia Carter, Daniel J. Kahan, Lawrence H. Bennett, John R. Cuthill, and Ronald C. Dobbyn. OSRD Bibl. 70-2, 413p. (1970).

The NBS Alloy Data Center: Function, Bibliographic System, Related Data Centers, and Reference Books - Gesina Cynthia Carter, Lawrence H. Bennett, John R. Cuthill, and Daniel J. Kahan. NBS Tech. Note 464, 163p. (1968).

The NBS Alloy Data Center: Permuted Materials Index - Gesina Cynthia Carter, Daniel J. Kahan, Lawrence H. Bennett, John R. Cuthill, and Ronald C. Dobbyn. NBS Spec. Publ. 324, 683p. (1971).

\section{Kamgar-Parsi, B.}

Problems with the Prandtl Number of Steam - Jan V. Sengers, R. S. Basu, B. Kamgar-Parsi, and Joseph Kestin. Mech Eng 104, New York, NY, 60p. (1982).

Representative Equations for the Thermal Conductivity of Water Substance - Jan V. Sengers, J. T. R. Watson, R. S. Basu, B. KamgarParsi, and R. C. Hendricks. J Phys Chem Ref Data 13, 893(1984).

Representative Equations for the Viscosity of Water Substance Jan V. Sengers and B. Kamgar-Parsi. J Phys Chem Ref Data 13, 185(1984).

Thermodynamic Properties of $\mathrm{D}_{2} \mathrm{O}$ in the Critical Region - B. Kamgar-Parsi, J. M. H. Levelt Sengers, and Jan V. Sengers. J Phys Chem Ref Data 12, 513(1983).

Thermodynamic Properties of Steam in the Critical Region - J. M. H. Levelt Sengers, B. Kamgar-Parsi, F. W. Balfour, and Jan V. Sengers. J Phys Chem Ref Data 12, 1(1983).

Thermophysical Properties of Fluid $\mathrm{H}_{2} \mathrm{O}$ - Joseph Kestin, Jan V. Sengers, B. Kamgar-Parsi, and J. M. H. Levelt Sengers. J Phys Chem Ref Data 13, 175(1984).

Thermophysical Properties of Fluid $\mathrm{D}_{2} \mathrm{O}$ - Joseph Kestin, Jan V. Sengers, B. Kamgar-Parsi, and J. M. H. Levelt Sengers. J Phys Chem Ref Data 13, 602(1984).

\section{Kaufman, Victor}

Reference Wavelengths from Atomic Spectra in the Range $5 \AA$ to $25000 \AA$ - Victor Kaufman and Bengt Edlén. J Phys Chem Ref Data 3, 825(1974).

\section{Kazavchinskii, Ya. Z.}

Heavy Water, Thermophysical Properties - V. A. Kirillin, Ya. Z. Kazavchinskii, P. M. Kessel'man, S. L. Rivkin, A. E. Sheindlin, E. E. Shpil'rain, V. V. Sychev, and D. L. Timrot. Russian Transl. Springfield, VA: NTIS, 273p. (1971). TT 70-50094, A12.

Thermophysical Properties of Air and Air Components - A. A. Vasserman, Ya. Z. Kazavchinskii, V. A. Rabinovich, and A. M. Zhuravlev. Russian Transl. Springfield, VA: NTIS, 402p. (1971). TT 70-50095, A18.

\section{Kell, George S.}

A Thermodynamic Surface for Water: The Formulation and Computer Program - Lester Haar, John S. Gallagher, and George S. Kell. NBSIR 81-2253, 38p. (1981).

Effects of Isotopic Composition, Temperature, Pressure, and Dissolved Gases on the Density of Liquid Water - George S. Kell. J Phys Chem Ref Data 6, 1109(1977).

NBS/NRC Steam Tables, Thermodynamic and Transport Properties and Computer Programs for Vapor and Liquid States of Water Lester Haar, John S. Gallagher, and George S. Kell. New York: Hemisphere Press, 320p. (1984).

\section{Kelley, Kenneth K.}

Selected Values of the Thermodynamic Properties of Binary Alloys - Ralph Hultgren, Pramond D. Desai, Donald T. Hawkins, M. Gleiser, and Kenneth K. Kelley. Metals Park, OH: American Society for Metals, 1435p. (1973).

Selected Values of the Thermodynamic Properties of the Elements - Ralph Hultgren, Pramond D. Desai, Donald T. Hawkins, M. Gleiser, Kenneth K. Kelley, and Donald D. Wagman. Metals Park, OH: American Society for Metals, 636p. (1973).

\section{Kelly, Robert}

$\pi \mathrm{N}$ Two-Body Scattering Data, I. A User's Guide to the LovelaceAlmehed Data Tape - Claude Lovelace, Sverkei Almehed, Fumiyo Uchiyama, Robert Kelly, Victor P. Henri and Particle Data Group.

UCRL 63, Springfield, VA: NTIS, 146p. (1973). LBL 63, A07.

\section{Kennard, Olga}

Crystal Data Determinative Tables, Third Edition, Volume 5. Organic Compounds - Olga Kennard, David G. Watson, John E. Davies, John R. Rodgers, editor(s). 5, Swarthmore, PA, JCPDS-International Center for Diffraction Data,(1983).

Crystal Data Determinative Tables, Third Edition, Volume 6. Organic Compounds - Olga Kennard, David G. Watson, John E. Davies, editor(s). 6, Swarthmore, PA, JCPDS-International Center for Diffraction Data,(1983).

Crystal Data Determinative Tables, Third Edition Volume 3. Organic Compounds - Joseph D. H. Donnay, Olga Kennard, David G. Watson, and John R. Rodgers. Swarthmore, PA: JCPDS-International Center for Diffraction Data, 748p. (1978).

\section{Kerr, J. A.}

Evaluated Kinetic and Photochemical Data for Atmospheric Chemistry - D. L. Baulch, R. A. Cox, Robert F. Hampson, Jr., J. A. Kerr, J. Troe, and R. T. Watson. J Phys Chem Ref Data 9, 295(1980).

Evaluated Kinetic and Photochemical Data for Atmospheric Chemistry: Supplement I. CODATA Task Group on Chemical Kinetics D. L. Baulch, R. A. Cox, P. J. Crutzen, Robert F. Hampson, Jr., J. A. Kerr, J. Troe, and R. T. Watson. J Phys Chem Ref Data 11, 327(1982).

Evaluated Kinetic and Photochemical Data for Atmospheric Chemistry: Supplement II. CODATA Task Group on Gas Phase Chemical Kinetics - D. L. Baulch, R. A. Cox, Robert F. Hampson, Jr., J. A. Kerr, J. Troe, and R. T. Watson. J Phys Chem Ref Data 13, 1259(1984).

\section{Kessel'man, P. M.}

Heavy Water, Thermophysical Properties - V. A. Kirillin, Ya. Z. Kazavchinskii, P. M. Kessel'man, S. L. Rivkin, A. E. Sheindlin, E. E. Shpil'rain, V. V. Sychev, and D. L. Timrot. Russian Transl. Springfield, VA: NTIS, 273p. (1971). TT 70-50094, A12.

\section{Kestin, Joseph}

Equilibrium and Transport Properties of the Noble Gases and Their Mixtures at Low Density - Joseph Kestin, K. Knierim, E. A. Mason, B. Najafi, S. T. Ro, and M. Waldman. J Phys Chem Ref Data 13, 229(1984).

Problems with the Prandtl Number of Steam - Jan V. Sengers, R. S. Basu, B. Kamgar-Parsi, and Joseph Kestin. Mech Eng 104, New York, NY, 60p. (1982).

Tables of the Dynamic and Kinematic Viscosity of Aqueous $\mathrm{KCl}$ Solutions in the Temperature Range $25-150^{\circ} \mathrm{C}$ and the Pressure Range 0.1-35 MPa - Joseph Kestin, H. Ezzat Khalifa, and Robert J. Correia. J Phys Chem Ref Data 10, 57(1981). 
Tables of the Dynamic and Kinematic Viscosity of Aqueous $\mathrm{NaCl}$ Solutions in the Temperature Range $20-150^{\circ} \mathrm{C}$ and the Pressure Range 0.1-35 MPa - Joseph Kestin, H. Ezzat Khalifa, and Robert J. Correia. J Phys Chem Ref Data 10, 71(1981).

Thermophysical Properties of Fluid $\mathrm{H}_{2} \mathrm{O}$ - Joseph Kestin, Jan V. Sengers, B. Kamgar-Parsi, and J. M. H. Levelt Sengers. J Phys Chem Ref Data 13, 175(1984).

Thermophysical Properties of Fluid $\mathrm{D}_{2} \mathrm{O}$ - Joseph Kestin, Jan V. Sengers, B. Kamgar-Parsi, and J. M. H. Levelt Sengers. J Phys Chem Ref Data 13, 602(1984).

Viscosity of Liquid Water in the Range $-8^{\circ} \mathrm{C}$ to $150^{\circ} \mathrm{C}$ - Joseph Kestin, Mordechai Sokolov, and William A. Wakeham. J Phys Chem Ref Data 7, 941(1978).

\section{Khalifa, H. Ezzat}

Tables of the Dynamic and Kinematic Viscosity of Aqueous $\mathrm{KCl}$ Solutions in the Temperature Range $25-150^{\circ} \mathrm{C}$ and the Pressure Range 0.1-35 MPa - Joseph Kestin, H. Ezzat Khalifa, and Robert J. Correia. J Phys Chem Ref Data 10, 57(1981).

Tables of the Dynamic and Kinematic Viscosity of Aqueous $\mathrm{NaCl}$ Solutions in the Temperature Range $20-150^{\circ} \mathrm{C}$ and the Pressure Range 0.1-35 MPa - Joseph Kestin, H. Ezzat Khalifa, and Robert J. Correia. J Phys Chem Ref Data 10, 71(1981).

\section{Khan, S. A.}

Bibliography on Properties of Defect Centers in Alkali Halides Suresh C. Jain, S. A. Khan, H. K. Sehgal, V. K. Garg, and R. K. Jain. OSRD Bibl. 71-1, 293p. (1971).

\section{Khodakovsky, I. L.}

Handbook of Thermodynamic Data on Geological Substances - G. B. Naumov, B. N. Ryzhenko, and I. L. Khodakovsky. Russian Transl. Springfield, VA: NTIS, 340p. (1974). TT 73-53051 or PB226 722, A15.

\section{Khudyakov, V. A.}

Thermodynamic and Thermophysical Properties of Combustion Products, Volume I. Computation Methods - V. P. Glushko, V. E. Alemasov, A. F. Dregalin, A. P. Tishin, and V. A. Khudyakov. Russian Transl. Springfield, VA: NTIS, 453p. (1974). TT 74-50019, A20.

Thermodynamic and Thermophysical Properties of Combustion Products, Volume II. Oxygen-Based Propellants - V. P. Glushko, V. E. Alemasov, A. F. Dregalin, A. P. Tishin, V. A. Khudyakov, and V. N. Kostin. Russian Transl. Springfield, VA: NTIS, 505p. (1975). TT 74-50032, A22.

Thermodynamic and Thermophysical Properties of Combustion Products, Volume III. Oxygen- and Air-Based Propellant - V. P. Glushko, V. E. Alemasov, A. F. Dregalin, A. P. Tishin, V. A. Khudyakov, and V. N. Kostin. Russian Transl. Springfield, VA: NTIS, 648p. (1975). TT 75-50007, A26.

Thermodynamic and Thermophysical Properties of Combustion Products, Volume IV. Nitrogen Tetroxide-Based Propellants - V. P. Glushko, V. E. Alemasov, A. F. Dregalin, A. P. Tishin, V. A. Khudyakov, and V. N. Kostin. Russian Transl. Springfield, VA: NTIS, 540p. (1976). TT 76-50007, A23.

\section{KIdnay, Arthur J.}

A Review, Evaluation, and Correlation of the Phase Equilibria, Heat of Mixing, and Change in Volume on Mixing for Liquid Mixtures of Methane + Ethane - M. J. Hiza, R. C. Miller, and Arthur J. Kidnay. J Phys Chem Ref Data 8, 799(1979).

A Review, Evaluation, and Correlation of the Phase Equilibria, Heat of Mixing, and Change in Volume on Mixing for Liquid Mixtures of Methane + Propane - R. C. Miller, Arthur J. Kidnay, and M. J. Hiza. J Phys Chem Ref Data 9, 721(1980).
Equilibrium Properties of Fluid Mixtures, A Bibliography on Fluids of Cryogenic Interest - M. J. Hiza, Arthur J. Kidnay, and R. C. Miller. New York: IFI/Plenum, 166p. (1975), ISBN: 0-306-6601-6.

Equilibrium Properties of Fluid Mixtures, 2. A Bibliography of Experimental Data on Selected Fluids - M. J. Hiza, Arthur J. Kidnay, and R. C. Miller. New York: IFI/Plenum, 258p. (1982), ISBN: 0-306-6602-4.

Liquid Vapor Equilibria on Systems of Interest in Cryogenics, A Survey - Arthur J. Kidnay, M. J. Hiza, and R. C. Miller. Cryogenics 13, London: Academic Press, 575p. (1973).

\section{Kieffer, Lee J.}

Bibliography of Low Energy Electron and Photon Cross Section Data (through December 1974) - Lee J. Kieffer. NBS Spec. Publ. 426, 222p. (1976).

Bibliography of Photoabsorption Cross Section Data - Robert D. Hudson and Lee J. Kieffer. OSRD Bibl. 70-4, 47p. (1970).

Compilation of Electron Collision Cross Section Data for Modelling Gas Discharge Lasers - Lee J. Kieffer. JILA Report 13, 139p. (1973).

Compilation of Low Energy Electron Collision Cross Section Data Part I. Ionization, Dissociative Processes, Vibrational and Rotational Excitation - Lee J. Kieffer. JILA Report 6, 95p. (1969).

Compilation of Low Energy Electron Collsion Cross Section Data. Part II. Line and Level Excitation - Lee J. Kieffer. JILA Report 7, 167p. (1969).

Electron Impact Ionization Cross-Section Data for Atoms, Atomic Ions, and Diatomic Molecules: I. Experimental Data - Lee J. Kieffer and Gordon H. Dunn. Rev Mod Phys. 38, New York: American Institute of Physics, 35p. (1966).

Low Energy Electron-Collision Cross Section Data. Part III. Total Scattering; Differential Elastic Scattering - Lee J. Kieffer. At Data. 2, New York: Academic Press, 293p. (1971).

\section{King, Edward G.}

Thermodynamic Properties of Copper and Its Inorganic Compounds - Edward G. King, Alla D. Mah, and Louis B. Pankratz. INCRA Monograph II, New York: International Copper Research Association, Inc., 257p. (1973).

\section{KIngston, A. E.}

Recommended Data on the Electron Impact Ionization of Light Atoms and Ions - K. L. Bell, H. B. Gilbody, J. G. Hughes, A. E. Kingston, and Francis J. Smith. J Phys Chem Ref Data 12, 891(1983).

\section{KIrchhoff, William $\mathrm{H}$.}

Microwave Spectra of Molecules of Astrophysical Interest, I. Formaldehyde, Formamide, and Thioformaldehyde - Donald R. Johnson, Frank J. Lovas, and William H. Kirchhoff. J Phys Chem Ref Data 1, 1011(1972).

Microwave Spectra of Molecules of Astrophysical Interest, II. Methylenimine - William H. Kirchhoff, Donald R. Johnson, and Frank J. Lovas. J Phys Chem Ref Data 2, 1(1973).

Microwave Spectra of Molecules of Astrophysical Interest, III. Methanol - R. M. Lees, Frank J. Lovas, William H. Kirchhoff, and Donald R. Johnson. J Phys Chem Ref Data 2, 205(1973).

Microwave Spectra of Molecules of Astrophysical Interest, IV. Hydrogen Sulfide - Paul Helminger, Frank C. De Lucia, and William H. Kirchhoff. J Phys Chem Ref Data 2, 215(1973).

Microwave Spectra of Molecules of Astrophysical Interest, V. Water Vapor - Frank C. De Lucia, Paul Helminger, and William H. Kirchhoff. J Phys Chem Ref Data 3, 21 1(1974). . 
Kirillin, V. A.

Heavy Water, Thermophysical Properties - V. A. Kirillin, Ya. Z. Kazavchinskii, P. M. Kessel'man, S. L. Rivkin, A. E. Sheindlin, E. E. Shpil'rain, V. V. Sychev, and D. L. Timrot. Russian Transl. Springfield, VA: NTIS, 273p. (1971). TT 70-50094, A12.

\section{Kisiel, Z.}

Peak Absorption Coefficients of Microwave Absorption Lines of Carbonyl Sulphide - Z. Kisiel and D. J. Millen. J Phys Chem Ref Data 11, 101(1982).

\section{Klein, Max}

Tables of Collision Integrals and Second Virial Coefficients for the $(m, 6,8)$ Intermolecular Potential Function - Max Klein, Howard J. M. Hanley, Francis J. Smith, and Paul M. Holland. NSRDS-NBS 47, 161p. (1974).

\section{Klemperer, William}

Binary Fluorides, Free Molectilar Structures and Force Fields, A Bibliography (1957-1975) - Donald T. Hawkins, Lawrence S. Bernstein, Warren E. Falconer, and William Klemperer. New York: IFI/Plenum, 253p. (1976), ISBN: 0-306-6601-3.

\section{Kletskii, A. V.}

Thermophysical Properties of Freon-22 - A. V. Kletskii. Russian Transl. Springfield, VA: NTIS, 72p. (1971). TT 70-50178, A04.

\section{Knierim, K.}

Equilibrium and Transport Properties of the Noble Gases and Their Mixtures at Low Density - Joseph Kestin, K. Knierim, E. A. Mason, B. Najafi, S. T. Ro, and M. Waldman. J Phys Chem Ref Data 13, 229(1984).

\section{Kondratiev, V. N.}

Rate Constants of Gas Phase Reactions, Reference Book - V. N. Kondratiev, L. J. Holtschlag, R. M. Fristrom, editor(s). Russian Transl. Springfield, VA: NTIS, 434p. (1972). COM 72-10014, A19.

\section{Konjevic, $\mathbf{N}$.}

A Critical Review of the Stark Widths and Shifts of Spectral Lines from Non-Hydrogenic Atoms - N. Konjević and J. R. Roberts. J Phys Chem Ref Data 5, 209(1976).

Experimental Stark Widths and Shifts for Non-Hydrogenic Spectral Lines of Ionized Atoms (A Critical Review and Tabulation of Selected Data) - N. Konjević and Wolfgang L. Wiese. J Phys Chem Ref Data 5, 259(1976).

Experimental Stark Widths and Shifts for Spectral Lines of Neutral Atoms (A Critical Review of Selected Data for the Period 1976 to 1982) - N. Konjević, M. S. Dimitrijević, and Wolfgang L. Wiese. J Phys Chem Ref Data 13, 619(1984).

Experimental Stark Widths and Shifts for Spectral Lines of Positive Ions (A Critical Review and Tabulation of Selected Data for the Period 1976 to 1982) - N. Konjević, M. S. Dimitrijević, and Wolfgang L. Wiese. J Phys Chem Ref Data 13, 649(1984).

Kostin, V. N.

Thermodynamic and Thermophysical Properties of Combustion Products, Volume II. Oxygen-Based Propellants - V. P. Glushko, V. E. Alemasov, A. F. Dregalin, A. P. Tishin, V. A. Khudyakov, and V. N. Kostin. Russian Transl. Springfield, VA: NTIS, 505p. (1975). TT 74-50032, A22.

Thermodynamic and Thermophysical Properties of Combustion Products, Volume III. Oxygen- and Air-Based Propellant - V. P. Glushko, V. E. Alemasov, A. F. Dregalin, A. P. Tishin, V. A.
Khudyakov, and V. N. Kostin. Russian Transl. Springfield, VA: NTIS, 648p. (1975). TT 75-50007, A26.

Thermodynamic and Thermophysical Properties of Combustion Products, Volume IV. Nitrogen Tetroxide-Based Propellants - V. P. Glushko, V. E. Alemasov, A. F. Dregalin, A. P. Tishin, V. A. Khudyakov, and V. N. Kostin. Russian Transl. Springfield, VA: NTIS, 540p. (1976). TT 76-50007, A23.

\section{Krause, Morris 0.}

Atomic Radiative and Radiationless Yields for $\mathrm{K}$ and $\mathrm{L}$ Shells Morris O. Krause. J Phys Chem Ref Data 8, 307(1979).

Natural Widths of Atomic K and L Levels, K $\alpha$ X-Ray Lines and Several KLL Auger Lines - Morris O. Krause and J. H. Oliver. J Phys Chem Ref Data 8, 329(1979).

\section{Krauss, Morris}

Compendium of ab initio Calculations of Molecular Energies and Properties - Morris Krauss. NBS Tech. Note 438, 139p. (1967).

\section{Krebs, Ursula}

Molten Salts: Volume 3, Nitrates, Nitrites, and Mixtures. Electrical Conductance, Density, Viscosity, and Surface Tension Data - George J. Janz, Ursula Krebs, H. F. Siegenthaler, and Reginald P. T. Tomkins. J Phys Chem Ref Data 1, 581(1972).

Molten Salts: Volume 4, Part 1, Fluorides and Mixtures. Electrical Conductance, Density, Viscosity, and Surface Tension Data - George J. Janz, G. L. Gardner, Ursula Krebs, and Reginald P. T. Tomkins. J Phys Chem Ref Data 3, 1(1974).

Molten Salts: Volume 4, Part 2, Chlorides and Mixtures. Electrical Conductance, Density, Viscosity, and Surface Tension Data - George J. Janz, Reginald P. T. Tomkins, Carolyn B. Allen, J. R. Downey, Jr., G. L. Gardner, Ursula Krebs, and S. K. Singer. J Phys Chem Ref Data 4, 871(1975).

\section{Krupenie, Paul $\mathrm{H}$.}

Microwave Spectra of Molecules of Astrophysical Interest, VII. Carbon Monoxide, Carbon Monosulfide, and Silicon Monoxide - Frank J. Lovas and Paul H. Krupenie. J Phys Chem Ref Data 3, 245(1974).

The Band Spectrum of Carbon Monoxide - Paul H. Krupenie. NSRDS-NBS 5, 87p. (1966).

The Spectrum of Molecular Nitrogen - Alf Lofthus and Paul H. Krupenie. J Phys Chem Ref Data 6, 113(1977).

The Spectrum of Molecular Oxygen - Paul H. Krupenie. J Phys Chem Ref Data 1, 423(1972).

\section{Kuczkowski, Robert L.}

Molecular Structures of Gas-Phase Polyatomic Molecules Determined by Spectroscopic Methods - Marlin D. Harmony, Victor W. Laurie, Robert L. Kuczkowski, Richard H. Schwendeman, D. A. Ramsay, Frank J. Lovas, Walter J. Lafferty, and Arthur G. Maki. J Phys Chem Ref Data 8, 619(1979).

\section{Kudchadker, Arvind P.}

Densities of Liquid $\mathrm{CH}_{4-\mathrm{a}} \mathrm{X}_{\mathrm{a}}(\mathrm{X}=\mathrm{Br}, \mathrm{I})$ and $\mathrm{CH}_{4(\mathrm{a}+\mathrm{b}+\mathrm{c}+\mathrm{d})} \mathrm{F}_{\mathrm{a}} \mathrm{Cl}_{b} \mathrm{Br}_{\mathrm{c}} \mathrm{I}_{d}$ Halomethanes - Arvind P. Kudchadker, Shanti A. Kudchadker, P. R. Patnaik, and P. P. Mishra. J Phys Chem Ref Data 7, 425(1978).

Ideal Gas Thermodynamic Properties of the Eight Bromo- an Iodomethanes - Shanti A. Kudchadker and Arvind P. Kudchadker. J Phys Chem Ref Data 4, 457(1975).

Ideal Gas Thermodynamic Properties of Phenol and Cresols Shanti A. Kudchadker, Arvind P. Kudchadker, Randolph C. Wilhoit, and Bruno J. Zwolinski. J Phys Chem Ref Data 7, 417(1978).

Ideal Gas Thermodynamic Properties of $\mathrm{CH}_{4(a+b+c+d)} \mathrm{F}_{\mathrm{a}} \mathrm{Cl}_{b} \mathrm{Br}_{\mathrm{c}} \mathrm{I}_{\mathrm{d}}$ Halomethanes - Shanti A. Kudchadker and Arvind P. Kudchadker. J Phys Chem Ref Data 7, 1285(1978). 
Ideal Gas Thermodynamic Properties of Selected Bromoethanes and Iodoethane - Shanti A. Kudchadker and Arvind P. Kudchadker. J Phys Chem Ref Data 8, 519(1979).

Vapor Pressures and Boiling Points of Selected Halomethanes Arvind P. Kudchadker, Shanti A. Kudchadker, R. P. Shukla, and P. R. Patnaik. J Phys Chem Ref Data 8, 499(1979).

\section{Kudchadker, Shanti A.}

Bibliography of Infrared Spectroscopy through 1960 - C. N. R. Rao, S. K. Dikshit, Shanti A. Kudchadker, D. S. Gupta, V. A. Narayan, and John J. Comeford. NBS Spec. Publ. 428, 1,2,3(1976).

Densities of Liquid $\mathrm{CH}_{4 \mathrm{a}} \mathrm{X}_{\mathrm{a}}(\mathrm{X}=\mathrm{Br}, \mathrm{I})$ and $\mathrm{CH}_{4(\mathrm{a}+\mathrm{b}+\mathrm{c}+\mathrm{d})} \mathrm{F}_{\mathrm{a}} \mathrm{Cl}_{\mathrm{b}} \mathrm{Br}_{\mathrm{c}} \mathrm{I}_{\mathrm{d}}$ Halomethanes - Arvind P. Kudchadker, Shanti A. Kudchadker, P. R.

Patnaik, and P. P. Mishra. J Phys Chem Ref Data 7, 425(1978).

Ideal Gas Thermodynamic Properties of the Eight Bromo- an Iodomethanes - Shanti A. Kudchadker and Arvind P. Kudchadker. J Phys Chem Ref Data 4, 457(1975).

Ideal Gas Thermodynamic Properties of Phenol and Cresols Shanti A. Kudchadker, Arvind P. Kudchadker, Randolph C. Wilhoit, and Bruno J. Zwolinski. J Phys Chem Ref Data 7, 417(1978).

Ideal Gas Thermodynamic Properties of $\mathrm{CH}_{4(\mathrm{a}+\mathrm{b}+\mathrm{c}+\mathrm{d})} \mathrm{F}_{\mathrm{a}} \mathrm{Cl}_{b} \mathrm{Br}_{\mathrm{c}} \mathrm{I}_{\mathrm{d}}$ Halomethanes - Shanti A. Kudchadker and Arvind P. Kudchadker. J Phys Chem Ref Data 7, 1285(1978).

Ideal Gas Thermodynamic Properties of Selected Bromoethanes and Iodoethane - Shanti A. Kudchadker and Arvind P. Kudchadker. J Phys Chem Ref Data 8, 519(1979).

Thermodynamic Properties of Normal and Deuterated Naphthalenes - S. S. Chen, Shanti A. Kudchadker, and Randolph C. Wilhoit. J Phys Chem Ref Data 8, 527(1979).

Vapor Pressures and Boiling Points of Selected Halomethanes Arvind P. Kudchadker, Shanti A. Kudchadker, R. P. Shukla, and P. R. Patnaik. J Phys Chem Ref Data 8, 499(1979).

Kukol, R. F.

Microwave Spectral Tables, Volume III. Polyatomic Molecules with Internal Rotation - Paul F. Wacker, M. S. Cord, D. G. Burkhard, J. D. Petersen, and R. F. Kukol. NBS Monograph 70, 275p. (1969).

\section{Kurtseva, N. N.}

Handbook of Phase Diagrams of Silicate Systems, Vol. I. Binary Systems, Second Revised Edition - N. A. Toropov, V. P. Barzakovskii, V. V. Lapin, N. N. Kurtseva, J. Schmorak, editor(s). Russian Transl. Springfield, VA: NTIS, 730p. (1970). TT 71-50040, A26.

Kurylo, M. J.

Summary Report on the Workshop on High Temperature Chemical Kinetics: Applications to Combustion Research - David Garvin, R. L. Brown, Robert F. Hampson, Jr., M. J. Kurylo, and W. Tsang. NBS Spec. Publ. 531, 94p. (1978).

Survey of Photochemical and Rate Data for Twenty-eight Reactions of Interest in Atmospheric Chemistry - Robert F. Hampson, Jr., W. Braun, R. L. Brown, David Garvin, John T. Herron, Robert E. Huie, M. J. Kurylo, A. H. Laufer, J. D. McKinley, H. Okabe, M. D. Scheer, W. Tsang, D. H. Stedman, editor(s). J Phys Chem Ref Data 2, 267(1973).

\section{Lafferty, Walter J.}

Microwave Spectra of Molecules of Astrophysical Interest, XIII. Cyanoacetylene - Walter J. Lafferty and Frank J. Lovas. J Phys Chem Ref Data 7, 441(1978).

Molecular Structures of Gas-Phase Polyatomic Molecules Determined by Spectroscopic Methods - Marlin D. Harmony, Victor W. Laurie, Robert L. Kuczkowski, Richard H. Schwendeman, D. A. Ramsay, Frank J. Lovas, Walter J. Lafferty, and Arthur G. Maki. J Phys Chem Ref Data 8, 619(1979).
Tables of $\mathrm{N}_{2} \mathrm{O}$ Absorption Lines for the Calibration of Tunable Infrared Lasers from $522 \mathrm{~cm}^{-1}$ to $657 \mathrm{~cm}^{-1}$ and from $1115 \mathrm{~cm}^{-1}$ to $1340 \mathrm{~cm}^{-1}$ - W. B. Olson, Arthur G. Maki, and Walter J. Lafferty. J Phys Chem Ref Data 10, 1065(1981).

\section{Lakshminarayanan, G. R.}

Molten Salts: Volume 1. Electrical Conductance, Density, and Viscosity Data - George J. Janz, F. W. Dampier, G. R. Lakshminarayanan, P. K. Lorenz, and Reginald P. T. Tomkins. NSRDS-NBS 15, 140p. (1968).

Molten Salts: Volume 2. Section 1. Electrochemistry of Molten Salts. Gibbs Free Energies and Excess Free Energies from Equilibrium-Type Cells, Section 2. Surface Tension Data - George J. Janz, Chr. G. M. Dijkhuis, G. R. Lakshminarayanan, Reginald P. T. Tomkins, and J. Wong. NSRDS-NBS 28, 116p. (1968).

\section{Lamoreaux, R. H.}

High Temperature Vaporization Behavior of Oxides. I. Alkali Metal Binary Oxides - R. H. Lamoreaux and D. L. Hildenbrand. J Phys Chem Ref Data 13, 151(1984).

\section{Lapin, V. V.}

Handbook of Phase Diagrams of Silicate Systems, Vol. I. Binary Systems, Second Revised Edition - N. A. Toropov, V. P. Barzakovskii, V. V. Lapin, N. N. Kurtseva, J. Schmorak, editor(s). Russian Transl. Springfield, VA: NTIS, 730p. (1970). TT 71-50040, A26.

\section{Lasinski, Thomas A.}

$\pi+\mathrm{p}, \pi+\mathrm{n}$, and $\pi+\mathrm{d}$ Interactions - A Compilation: Parts I and II Denyse M. Chew, Victor P. Henri, Thomas A. Lasinski, Thomas G. Trippe, Fumiyo Uchiyama, Frederick C. Winkelmann and Particle Data Group. UCRL 53, Springfield, VA: NTIS, 213p. (1973). LBL 53; Part II is on microfiche located in the back cover pocket, A10.

\section{Lau, Suk-fai}

Heat Capacity and Other Thermodynamic Properties of Linear Macromolecules. VI. Acrylic Polymers - Umesh Gaur, Suk-fai Lau, Brent B. Wunderlich, and Bernhard Wunderlich. J Phys Chem Ref Data 11, 1065(1982).

Heat Capacity and Other Thermodynamic Properties of Linear Macromolecules. VIII. Polyesters and Polyamides - Umesh Gaur, Suk-fai Lau, Brent B. Wunderlich, and Bernhard Wunderlich. J Phys Chem Ref Data 12, 65(1983).

Heat Capacity and Other Thermodynamic Properties of Linear Macromolecules. IX. Final Group of Aromatic and Inorganic Polymers Umesh Gaur, Suk-fai Lau, and Bernhard Wunderlich. J Phys Chem Ref Data 12, 91(1983).

\section{Laufer, A. H.}

Survey of Photochemical and Rate Data for Twenty-eight Reactions of Interest in Atmospheric Chemistry - Robert F. Hampson, Jr., W. Braun, R. L. Brown, David Garvin, John T. Herron, Robert E. Huie, M. J. Kurylo, A. H. Laufer, J. D. McKinley, H. Okabe, M. D. Scheer, W. Tsang, D. H. Stedman, editor(s). J Phys Chem Ref Data 2, 267(1973).

\section{Laurie, Victor W.}

Molecular Structures of Gas-Phase Polyatomic Molecules Determined by Spectroscopic Methods - Marlin D. Harmony, Victor W. Laurie, Robert L. Kuczkowski, Richard H. Schwendeman, D. A. Ramsay, Frank J. Lovas, Walter J. Lafferty, and Arthur G. Maki. J Phys Chem Ref Data 8, 619(1979). 


\section{Ledbetter, Hassell M.}

Elastic Properties of Metals and Alloys, I. Iron, Nickel, and IronNickel Alloys - Hassell M. Ledbetter and R. P. Reed. J Phys Chem Ref Data 2, 531(1973).

Elastic Properties of Metals and Alloys, II. Copper - Hassell M. Ledbetter and E. R. Naimon. J Phys Chem Ref Data 3, 897(1974).

Elastic Properties of Zinc: A Compilation and a Review - Hassell M. Ledbetter. J Phys Chem Ref Data 6, 1181(1977).

Physical Properties Data Compilations Relevant to Energy Storage. V. Mechanical Properties Data on Alloys for Use in Flywheels Hassell M. Ledbetter. NSRDS-NBS 61, 42p. (1982).

\section{Lederer, C. Michael}

Nuclear Wallet Cards - Virginia S. Shirley, C. Michael Lederer and National Nuclear Data Center. 1979, Upton, NY: National Nuclear Data Center, Brookhaven National Laboratory, 40p. (1979). Title, no charge.

Table of Isotopes, Seventh Edition - C. Michael Lederer, Virginia S. Shirley, Edgardo Browne, Janis M. Dairiki, and Raymond E. Doebler. New York: Wiley-Interscience, 1628p. (1978), ISBN: 0-471-0417-3.

Lee, $V$.

A Fundamental Equation of State for Heavy Water - P. G. Hill, R. D. Chris MacMillan, and V. Lee. J Phys Chem Ref Data 11, 1(1982).

Erratum: A Fundamental Equation of State for Heavy Water - P. G. Hill, R. D. Chris MacMillan, and V. Lee. J Phys Chem Ref Data 12, 1065(1983).

\section{Lees, F. $M$.}

Microwave Spectra of Molecules of Astrophysical Interest, III. Methanol - R. M. Lees, Frank J. Lovas, William H. Kirchhoff, and Donald R. Johnson. J Phys Chem Ref Data 2, 205(1973).

\section{Leone, Stephen R.}

Rate Coefficients for Vibrational Energy Transfer Involving the Hydrogen Halides - Stephen R. Leone. J Phys Chem Ref Data 11, 953(1982).

\section{Levin, Ernest M.}

Phase Diagrams for Ceramists - Ernest M. Levin, Carl R. Robbins, Howard F. McMurdie, editor(s). American Ceramic Society; Columbus, Ohio, 601p. (1964), ISBN: 0-916094-04-9.

Phase Diagrams for Ceramists 1969 Supplement - Ernest M. Levin, Carl R. Robbins, Howard F. McMurdie, editor(s). American Ceramic Society; Columbus, Ohio, 625p. (1969), ISBN: 0.916094-05-7.

Phase Diagrams for Ceramists 1975 Supplement - Ernest M. Levin, Howard F. McMurdie, editor(s). American Ceramic Society; Columbus, Ohio, 513p. (1975).

\section{Levin, Rhoda D.}

Evaluated Gas Phase Basicities and Proton Affinities of Molecules: Heats of Formation of Protonated Molecules - Sharon G. Lias, Joel F. Liebman, and Rhoda D. Levin. J Phys Chem Ref Data 13, 695(1984).

Ionization Potential and Appearance Potential Measurements, 1971-1981 - Rhoda D. Levin and Sharon G. Lias. NSRDS-NBS 71, 634p. (1982).

\section{LI, H. H.}

Refractive Index of Alkali Halides and Its Wavelength and Temperature Derivatives - H. H. Li. J Phys Chem Ref Data 5, 329(1976).

Refractive Index of Alkaline Earth Halides and Its Wavelength and Temperature Derivatives - H. H. Li. J Phys Chem Ref Data 9, 161(1980).
Refractive Index of Silicon and Germanium and Its Wavelength and Temperature Derivatives - H. H. Li. J Phys Chem Ref Data 9, 561(1980).

Refractive Index of $\mathrm{ZnS}, \mathrm{ZnSe}$, and $\mathrm{ZnTe}$ and Its Wavelength and Temperature Derivatives - H. H. Li. J Phys Chem Ref Data 13, 103(1984).

\section{Lias, Sharon G.}

A Compendium of Gas Phase Basicity and Proton Affinity Measurements - K. N. Hartman, Sharon G. Lias, P. J. Ausloos, Henry M. Rosenstock, S. S. Schroyer, C. Schmidt, D. Martinsen, and G. W. A. Milne. NBSIR 79-1777, 563p. (1979).

Annotated Bibliography on Proton Affinities - K. N. Hartman, Sharon G. Lias, P. J. Ausloos, and Henry M. Rosenstock. NBSIR 76-1061, 52p. (1976).

Evaluated Gas Phase Basicities and Proton Affinities of Molecules: Heats of Formation of Protonated Molecules - Sharon G. Lias, Joel F. Liebman, and Rhoda D. Levin. J Phys Chem Ref Data 13, 695(1984).

Ionization Potential and Appearance Potential Measurements, 1971-1981 — Rhoda D. Levin and Sharon G. Lias. NSRDS.NBS 71, 634p. (1982).

Rate Coefficients for Ion-Molecule Reactions, I. Ions Containing C and $\mathrm{H}-\mathrm{L}$. Wayne Sieck and Sharon G. Lias. J Phys Chem Ref Data 5, 1123(1976).

\section{Lide, David R., Jr.}

Property Index to NSRDS Data Compilations, 1964-1972 - David R. Lide, Jr., Gertrude B. Sherwood, Charles H. Douglass, and Herman M. Weisman. NSRDS-NBS 55, 21 p. (1975).

Selected Values of Electric Dipole Moments for Molecules in the Gas Phase - Ralph D. Nelson, Jr., David R. Lide, Jr, and Arthur A. Maryott. NSRDS-NBS 10, 49p. (1967).

The Effect of Computers on the Generation and Use of Technical Data — David R. Lide, Jr., editor(s). NBSIR 84-2907, 1p. (1984).

\section{Liebman, Joel F.}

Evaluated Gas Phase Basicities and Proton Affinities of Molecules: Heats of Formation of Protonated Molecules - Sharon G. Lias, Joel F. Liebman, and Rhoda D. Levin. J Phys Chem Ref Data 13, 695(1984).

\section{Liley, Peter E.}

Thermal Conductivity of Selected Materials - Robert W. Powell, Cho Y. Ho, and Peter E. Liley. NSRDS-NBS 8, 68p. (1966).

Thermal Conductivity of Selected Materials, Part 2 - Cho Y. Ho, Robert W. Powell, and Peter E. Liley. NSRDS-NBS 16, 146p. (1968).

Thermal Conductivity of the Elements - Cho Y. Ho, Robert W. Powell, and Peter E. Liley. J Phys Chem Ref Data 1, 279(1972).

Thermal Conductivity of the Elements: A Comprehensive Review Cho Y. Ho, Robert W. Powell, and Peter E. Liley. J Phys Chem Ref Data 3, Suppl. 1(1974).

Lin, C. T.

Vapor Pressure of Coal Chemicals - Jing Chao, C. T. Lin, and T. H. Chung. J Phys Chem Ref Data 12, 1033(1983).

\section{Lineberger, W. C.}

Binding Energies in Atomic Negative Ions - H. Hotop and W. C. Lineberger. J Phys Chem Ref Data 4, 539(1975).

\section{Lioyd, Alan C.}

Evaluation of Kinetic and Mechanistic Data for Modeling of Photochemical Smog - Roger Atkinson and Alan C. Lloyd. J Phys Chem Ref Data 13, 315(1984). 


\section{Lofthus, Alf}

The Spectrum of Molecular Nitrogen - Alf Lofthus and Paul H. Krupenie. J Phys Chem Ref Data 6, 113(1977).

Lojko, M. S.

Microwave Spectral Tables, Volume IV. Polyatomic Molecules without Internal Rotation - M. S. Cord, J. D. Petersen, M. S. Lojko, and R. H. Haas. NBS Monograph 70, 419p. (1968).

Microwave Spectral Tables, Volume V. Spectral Line Listing - M. S. Cord, M. S. Lojko, and J. D. Petersen. NBS Monograph 70, 533p. (1968).

\section{Lorenz, P. K.}

Molten Salts: Volume 1. Electrical Conductance, Density, and Viscosity Data - George J. Janz, F. W. Dampier, G. R. Lakshminarayanan, P. K. Lorenz, and Reginald P. T. Tomkins. NSRDS-NBS 15, 140p. (1968).

\section{Lovas, Frank J.}

Microwave Spectra of Molecules of Astrophysicai Interest, I. Formaldehyde, Formamide, and Thioformaldehyde - Donald R. Johnson, Frank J. Lovas, and William H. Kirchhoff. J Phys Chem Ref Data 1, 1011(1972).

Microwave Spectra of Molecules of Astrophysical Interest, II. Methylenimine - William H. Kirchhoff, Donald R. Johnson, and Frank J. Lovas. J Phys Chem Ref Data 2, 1(1973).

Microwave Spectra of Molecules of Astrophysical Interest, III. Methanol - R. M. Lees, Frank J. Lovas, William H. Kirchhoff, and Donald R. Johnson. J Phys Chem Ref Data 2, 205(1973).

Microwave Spectra of Molecules of Astrophysical Interest, VII. Carbon Monoxide, Carbon Monosulfide, and Silicon Monoxide - Frank J. Lovas and Paul H. Krupenie. J Phys Chem Ref Data 3, 245(1974).

Microwave Spectra of Molecules of Astrophysical Interest, IX. Acetaldehyde - A. Bauder, Frank J. Lovas, and Donald R. Johnson. J Phys Chem Ref Data 5, 53(1976).

Microwave Spectra of Molecules of Astrophysical Interest, XIII. Cyanoacetylene - Walter J. Lafferty and Frank J. Lovas. J Phys Chem Ref Data 7, 441(1978).

Microwave Spectra of Molecules of Astrophysical Interest, XVII.

Dimethyl Ether - Frank J. Lovas, H. Lutz, and H. Dreizler. J Phys Chem Ref Data 8, 1051(1979).

Microwave Spectra of Molecules of Astrophysical Interest. XXI. Ethanol $\left(\mathrm{C}_{2} \mathrm{H}_{5} \mathrm{OH}\right)$ and Propionitrile $\left(\mathrm{C}_{2} \mathrm{H}_{5} \mathrm{CN}\right)$ - Frank J. Lovas. J Phys Chem Ref Data 11, 251(1982).

Microwave Spectral Tables II. Triatomic Molecules - Frank J. Lovas. J Phys Chem Ref Data 7, 1445(1978).

Microwave Spectral Tables, I. Diatomic Molecules - Frank J. Lovas and Eberhard Tiemann. J Phys Chem Ref Data 3, 609(1974).

Molecular Structures of Gas-Phase Polyatomic Molecules Determined by Spectroscopic Methods - Marlin D. Harmony, Victor W. Laurie, Robert L. Kuczkowski, Richard H. Schwendeman, D. A. Ramsay, Frank J. Lovas, Walter J. Lafferty, and Arthur G. Maki. J Phys Chem Ref Data 8, 619(1979).

\section{Lovelace, Claude}

$\pi \mathrm{N}$ Two-Body Scattering Data, I. A User's Guide to the LovelaceAlmehed Data Tape - Claude Lovelace, Sverkei Almehed, Fumiyo Uchiyama, Robert Kelly, Victor P. Henri and Particle Data Group. UCRL 63, Springfield, VA: NTIS, 146p. (1973). LBL 63, A07.

\section{Lutz, H.}

Microwave Spectra of Molecules of Astrophysical Interest, XVII. Dimethyl Ether - Frank J. Lovas, H. Lutz, and H. Dreizler. J Phys Chem Ref Data 8, 1051(1979).

\section{Lynch, C. T.}

A Guide to Sources of Information on Materials - Robert S. Marvin, Gertrude B. Sherwood, C. T. Lynch, editor(s). Cleveland, OH: CRC Press, 603p. (1975). Chapter 10 in Handbook of Materials Science, Volume III. Nonmetallic Materials and Publications, C. T. Lynch, Editor.

\section{Lynch, James F.}

Critical Surveys of Data Sources: Ceramics - Dorothea M. Johnson and James F. Lynch. NBS Spec. Publ. 396, 56p. (1975).

\section{Mabey, W.}

Critical Review of Hydrolysis of Organic Compounds in Water Under Environmental Conditions - W. Mabey and T. Mill. J Phys Chem Ref Data 7, 383(1978).

\section{MacMillan, R. D. Chris}

A Fundamental Equation of State for Heavy Water - P. G. Hill, R. D. Chris MacMillan, and V. Lee. J Phys Chem Ref Data 11, 1(1982).

Erratum: A Fundamental Equation of State for Heavy Water - P. G. Hill, R. D. Chris MacMillan, and V. Lee. J Phys Chem Ref Data 12, 1065(1983).

Saturation States of Heavy Water - P. G. Hill and R. D. Chris MacMillan. J Phys Chem Ref Data 9, 735(1980).

\section{Mackay, Donald}

A Critical Review of Henry's Law Constants for Chemicals of Environmental Interest - Donald Mackay and Wan Ying Shiu. J Phys Chem Ref Data 10, 1175(1981).

\section{Mah, Alla D.}

Contributions to the Data on Theoretical Metallurgy, XVI. Thermodynamic Properties of Nickel and Its Inorganic Compounds - Alla D. Mah and Louis B. Pankratz. U.S. Bur Mines Bull 668, Springfield, VA: NTIS, 125p. (1976). U.S. Bureau of Mines Bulletin 668, A06.

Thermodynamic Properties of Copper and Its Inorganic Compounds - Edward G. King, Alla D. Mah, and Louis B. Pankratz. INCRA Monograph III, New York: International Copper Research Association, Inc., 257p. (1973).

\section{Maki, Arthur G.}

Microwave Spectra of Molecules of Astrophysical Interest, VI. Carbonyl Sulfide and Hydrogen Cyanide - Arthur G. Maki. J Phys Chem Ref Data 3, 221(1974).

Molecular Structures of Gas-Phase Polyatomic Molecules Determined by Spectroscopic Methods - Marlin D. Harmony, Victor W. Laurie, Robert L. Kuczkowski, Richard H. Schwendeman, D. A. Ramsay, Frank J. Lovas, Walter J. Lafferty, and Arthur G. Maki. J Phys Chem Ref Data 8, 619(1979).

Tables of $\mathrm{N}_{2} \mathrm{O}$ Absorption Lines for the Calibration of Tunable Infrared Lasers from $522 \mathrm{~cm}^{-1}$ to $657 \mathrm{~cm}^{-1}$ and from $1115 \mathrm{~cm}^{-1}$ to 1340 $\mathrm{cm}^{-1}$ - W. B. Olson, Arthur G. Maki, and Walter J. Lafferty. J Phys Chem Ref Data 10, 1065(1981).

\section{Mann, Douglas}

LNG Materials \& Fluids, A User's Manual of Property Data in Graphic Format - Douglas Mann and U.S. National Bureau of Standards. Boulder, CO: U.S. National Bureau of Standards, Cryogenic Division, 11p. (1977).

LNG Materials \& Fluids, A User's Manual of Property Data in Graphic Format, First Supplement - Douglas Mann and U.S. National Bureau of Standards. Suppl. 1, Boulder, CO: U.S. National Bureau of Standards, 11p. (1978) 
LNG Materials \& Fluids, A User's Manual of Property Data in Graphic Format, Second Supplement - Douglas Mann and U.S. National Bureau of Standards. Suppl. 2, Boulder, CO: U.S. National Bureau of Standards, 11p. (1980).

\section{Manning, John R.}

Diffusion Rate Data and Mass Transport Phenomena in Copper Systems - Daniel B. Butrymowicz, John R. Manning, and Michael E. Read. INCRA Monograph V, New York: International Copper Research Association, Inc., 322p. (1977).

Diffusion Rate Data and Mass Transport Phenomena for Copper Systems, Part II - Daniel B. Butrymowicz, John R. Manning, and Michael E. Read. INCRA Monograph VIII, New York: International Copper Research Association, Inc., 701p. (1982).

Diffusior in Copper and Copper Alloys, Part I. Volume and Surface Self-Diffusion in Copper - Daniel B. Butrymowicz, John R. Manning, and Michael E. Read. J Phys Chem Ref Data 2, 643(1973).

Diffusion in Copper and Copper Alloys, Part II. Copper-Silver and Copper-Gold Systems - Daniel B. Butrymowicz, John R. Manning, and Michael E. Read. J Phys Chem Ref Data 3, 527(1974).

Diffusion in Copper and Copper Alloys, Part III. Diffusion in Systems Involving Elements of the Groups IA, IIA, IIIB, IVB, VB, and VIIB - Daniel B. Butrymowicz, John R. Manning, and Michael E. Read. J Phys Chem Ref Data 4, 177(1975).

Diffusion in Copper and Copper Alloys, Part IV. Diffusion in Systems Involving Elements of Group VIII - Daniel B. Butrymowicz, John R. Manning, and Michael E. Read. J Phys Chem Ref Data 5, 103(1976).

Diffusion in Copper and Copper Alloys, Part V. Diffusion in Systems Involving Elements of Group VA - Daniel B. Butrymowicz, John R. Manning, and Michael E. Read. J Phys Chem Ref Data 6, 1(1977).

\section{Manzhelii, V. G.}

Properties of Liquid and Solid Hydrogen - B. N. Esel'son, Y. P. Blagoi, V.N. Grigor'ev, V. G. Manzhelii, S. A. Mikhailenko, and N. P. Neklyudov. Russian Transl. Springfield, VA: NTIS, 126p. (1971). TT 70-50179, A07.

\section{Mapleton, R. A.}

Theory of Charge Exchange - R. A. Mapleton., New York: WileyInterscience, 284p. (1971), ISBN: 0-471-5678-7.

\section{Marcus, Y.}

Compilation and Evaluation of Solubility Data in the Mercury (I) Chloride-Water System - Y. Marcus. J Phys Chem Ref Data 9, 1307(1980).

\section{Marrero, T. R.}

Gaseous Diffusion Coefficients - T. R. Marrero and E. A. Mason. J Phys Chem Ref Data 1, 1(1972).

\section{Marshall, E. M.}

Thermochemical Data for Gaseous Monoxides - J. B. Pedley and E. M. Marshall. J Phys Chem Ref Data 12, 967(1983).

\section{Marshall, William L.}

Ion Product of Water Substance, $0-1000^{\circ} \mathrm{C}, 1-10,000$ Bars. New International Formulation and Its Background - William L. Marshall and E. U. Franck. J Phys Chem Ref Data 10, 295(1981).

\section{Martin, Georgia A.}

Atomic Transition Probabilities for Vanadium, Chromium, and Manganese (A Critical Data Compilation of Allowed Lines) - S. M.
Younger, Jeffrey R. Fuhr, Georgia A. Martin, and Wolfgang L. Wiese. J Phys Chem Ref Data 7, 495(1978).

Atomic Transition Probabilities for Iron, Cobalt, Nickel: A Critical Data Compilation of Allowed Lines - Jeffrey R. Fuhr, Georgia A. Martin, Wolfgang L. Wiese, and S. M. Younger. J Phys Chem Ref Data 10, 305(1981).

Bibliography on Atomic Line Shapes and Shifts (July 1973 through May 1975) - Jeffrey R. Fuhr, Georgia A. Martin, and Beverly J. Specht. NBS Spec. Publ. 366, Suppl. 2(1975).

Bibliography on Atomic Line Shapes and Shifts (June 1975 through June 1978) - Jeffrey R. Fuhr, Beverly J. Miller, and Georgia A. Martin. NBS Spec. Publ. 366, Suppl. 3(1978).

Bibliography on Atomic Transition Probabilities (1914 through October 1977) - Beverly J. Miller, Jeffrey R. Fuhr, and Georgia A. Martin. NBS Spec. Publ. 505, 283p. (1978).

Bibliography on Atomic Transition Probabilities (November 1977 through March 1980) - Beverly J. Miller, Jeffrey R. Fuhr, and Georgia A. Martin. NBS Spec. Publ. 505, Suppl.(1980).

Tables of Critically Evaluated Oscillator Strengths for the Lithium Isoelectronic Sequence - Georgia A. Martin and Wolfgang L. Wiese. J Phys Chem Ref Data 5, 537(1976).

Tables of Line Spectra of the Elements, Part 1. Wavelengths and Intensities, Part 2. Transition Probabilities - Joseph Reader, Charles H. Corliss, Wolfgang L. Wiese, and Georgia A. Martin. NSRDS-NBS 68, 415p. (1980).

\section{Martin, William C.}

Atomic Energy Levels - The Rare-Earth Elements, the Spectra of $\mathrm{La}, \mathrm{Ce}, \mathrm{Pr}, \mathrm{Nd}, \mathrm{Pm}, \mathrm{Sm}, \mathrm{Eu}, \mathrm{Gd}, \mathrm{Tb}, \mathrm{Dy}, \mathrm{Ho}, \mathrm{Er}, \mathrm{Tm}, \mathrm{Yb}, \mathrm{Lu}-$ William C. Martin, Romuald Zalubas, and Lucy Hagan. NSRDS-NBS 60, 422p. (1978).

Bibliography on Atomic Energy Levels and Spectra, July 1968 through June 1971 - Lucy Hagan and William C. Martin. NBS Spec. Publ. 363, 109p. (1972).

Energy Levels of Magnesium, Mg I through Mg XII - William C. Martin and Romuald Zalubas. J Phys Chem Ref Data 9, 1(1980).

Energy Levels of Neutral Helium $\left({ }^{4} \mathrm{He}\right.$ I) - William C. Martin. J Phys Chem Ref Data 2, 257(1973).

Energy Levels of Silicon, Si I through Si xIV - William C. Martin and Romuald Zalubas. J Phys Chem Ref Data 12, 323(1983).

Energy Levels of Sodium, Na I through Na XI - William C. Martin and Romuald Zalubas. J Phys Chem Ref Data 10, 153(1981).

Energy levels of Aluminum, Al I through Al XIII - William C. Martin and Romuald Zalubas. J Phys Chem Ref Data 8, 817(1979).

Ground Levels and Ionization Potentials for Lanthanide and Actinide Atoms and Ions - William C. Martin, Lucy Hagan, Joseph Reader, and Jack Sugar. J Phys Chem Ref Data 3, 771(1974).

\section{Martinsen, D.}

A Compendium of Gas Phase Basicity and Proton Affinity Measurements - K. N. Hartman, Sharon G. Lias, P. J. Ausloos, Henry M. Rosenstock, S. S. Schroyer, C. Schmidt, D. Martinsen, and G. W. A. Milne. NBSIR 79-1777, 563p. (1979).

\section{Marvin, Robert S.}

A Guide to Sources of Information on Materials - Robert S. Marvin, Gertrude B. Sherwood, C. T. Lynch, editor(s). Cleveland, $\mathrm{OH}$ : CRC Press, 603p. (1975). Chapter 10 in Handbook of Materials Science, Volume III. Nonmetallic Materials and Publications, C. T. Lynch, Editor.

\section{Maryott, Arthur A.}

Selected Values of Electric Dipole Moments for Molecules in the Gas Phase - Ralph D. Nelson, Jr., David R. Lide, Jr., and Arthur A. Maryott. NSRDS-NBS 10, 49p. (1967). 


\section{Mason, E. A.}

Equilibrium and Transport Properties of the Noble Gases and Their Mixtures at Low Density - Joseph Kestin, K. Knierim, E. A. Mason, B. Najafi, S. T. Ro, and M. Waldman. J Phys Chem Ref Data 13, 229(1984).

Gaseous Diffusion Coefficients - T. R. Marrero and E. A. Mason. J Phys Chem Ref Data 1, 1(1972).

\section{Matsunaga, $\mathbf{N}$.}

Transport Properties of Liquid and Gaseous $\mathrm{D}_{2} \mathrm{O}$ over a Wide Range of Temperature and Pressure - N. Matsunaga and A. Nagashima. J Phys Chem Ref Data 12, 933(1983).

\section{Matsuura, Hiroatsu}

Tables of Molecular Vibrational Frequencies, Part 9 - Takehiko Shimanouchi, Hiroatsu Matsuura, Yoshiki Ogaw a, and Issei Harada. J Phys Chem Ref Data 7, 1323(1978).

Tables of Molecular Vibrational Frequencies, Part 10 - Takehiko Shimanouchi, Hiroatsu Matsuura, Yoshiki Ogawa, and Issei Harada. J Phys Chem Ref Data 9, 1149(1980).

\section{Matula, R. A.}

Electrical Resistivity of Copper, Gold, Palladium, and Silver - R. A. Matula. J Phys Chem Ref Data 8, 1147(1979).

Electrical Resistivity of Ten Selected Binary Alloy Systems - Cho Y. Ho, M. W. Ackerman, K. Y. Wu, T. N. Havill, R. H. Bogaard, R. A. Matula, S. G. Oh, and H. M. James. J Phys Chem Ref Data 12, 183(1983).

\section{Mavrodineanu, Radu}

Bibliography on Flame Spectroscopy. Analytical Applications, 1800-1966 - Radu Mavrodineanu. NBS Spec. Publ. 281, 155p. (1967).

\section{McAlister, Archie J.}

Soft X-Ray Emission Spectra of Metallic Solids: Critical Review of Selected Systems - Archie J. McAlister, Ronald C. Dobbyn, John R. Cuthill, and M. L. Williams. J Phys Chem Ref Data 2, 411(1973).

Soft X-Ray Emission Spectra of Metallic Solids: Critical Review of Selected Systems and Annotated Spectral Index - Archie J. McAlister, Ronald C. Dobbyn, John R. Cuthill, and M. L. Williams. NBS Spec. Publ. 369, 180p. (1974).

\section{McCarty, Robert D.}

An Equation of State for Fluid Ethylene - Robert D. McCarty and Richard T. Jacobsen. NBS Tech. Note 1045, 164p. (1981).

Liquid Densities of Oxygen, Nitrogen, Argon, and Parahydrogen Hans M. Roder, Robert D. McCarty, and V. J. Johnso?. NBS Tech. Note 361, 1972(1973).

The Viscosity and Thermal Conductivity Coefficients for Dense Gaseous and Liquid Argon, Krypton, Xenon, Nitrogen, and Oxygen Howard J. M. Hanley, Robert D. McCarty, and W. M. Haynes. J Phys Chem Ref Data 3, 979(1974).

The Viscosity and Thermal Conductivity Coefficients for Dense Gaseous and Liquid Methane - Howard J. M. Hanley, W. M. Haynes, and Robert D. McCarty. J Phys Chem Ref Data 6, 597(1977).

Thermodynamic Properties of Argon from the Triple Point to $300 \mathrm{~K}$ at Pressures to 1000 Atmospheres - A. L. Gosman, Robert D. McCarty, and Jerome G. Hust. NSRDS-NBS 27, 153p. (1969).

Thermodynamic Properties of Helium- 4 from 2 to $1500 \mathrm{~K}$ at Pressures to $10^{8} \mathrm{~Pa}-$ Robert D. McCarty. J Phys Chem Ref Data 2, 923(1973).

\section{McClenon, Robert}

COMBO: A General-Purpose Program for Searching, Annotating, Encoding-Decoding, and Reformatting Data Files - Robert
McClenon and Joseph Hilsenrath. NBS Tech. Note 700, 72p. (1972).

Description of the Magnetic Tape Version of the Bulletin of Thermodynamics and Thermochemistry, No. 14 - Robert McClenon, William H. Evans, David Garvin, and Blanton C. Duncan. NBS Tech. Note 760, 32p. (1973).

Fortran Programs for Text Editing, File Manipulation and Automatic Typsetting - Carla G. Messina, Robert McClenon, and Joseph Hilsenrath. OSRD Mag. Tape A2, Washington, DC: Office of Standard Reference Data,(1973). COM 71-003 885 or PB 183 142, T05.

Reform: A General-Purpose Program for Manipulating Formatted Data Files - Robert McClenon and Joseph Hilsenrath. NBS Tech. Note 444, 25p. (1968).

\section{McClure, G. W.}

Dissociation in Heavy Particle Collisions - G. W. McClure and James M. Peek. At Mol Collis Proc Ser, New York: Wiley-Interscience, 198p. (1972), ISBN: 0-471-5816-8.

\section{McDaniel, Earl W.}

Ion-Molecule Reactions - Earl W. McDaniel, V. Cermak, A. Dalgarno, E. E. Ferguson, and L. Friedman. At Mol Collis Proc Ser, New York: Wiley-Interscience, 374p. (1970), ISBN: 0-471-5838-3.

\section{McDonald, R. A.}

JANAF Thermochemical Tables, 1975 Supplement - Malcolm W. Chase, Jr., J. L. Curnutt, H. Prophet, R. A. McDonald, and A. N. Syverud. J Phys Chem Ref Data 4, 1(1975).

JANAF Thermochemical Tables, 1978 Supplement — Malcolm W. Chase, Jr., J. L. Curnutt, R. A. McDonald, and A. N. Syverud. J Phys Chem Ref Data 7, 793(1978).

JANAF Thermochemical Tables, 1982 Supplement - Malcolm W. Chase, Jr., J. L. Curnutt, J. R. Downey, Jr., R. A. McDonald, A. N. Syverud, and E. A. Valenzuela. J Phys Chem Ref Data 11, 695(1982).

\section{McKInley, J. D.}

Survey of Photochemical and Rate Data for Twenty-eight Reactions of Interest in Atmospheric Chemistry - Robert F. Hampson, Jr., W. Braun, R. L. Brown, David Garvin, John T. Herron, Robert E. Huie, M. J. Kurylo, A. H. Laufer, J. D. McKinley, H. Okabe, M. D. Scheer, W. Tsang, D. H. Stedman, editor(s). J Phys Chem Ref Data 2, 267(1973).

\section{McMurdie, Howard F.}

Phase Diagrams for Ceramists - Ernest M. Levin, Carl R. Robbins, Howard F. McMurdie, editor(s). American Ceramic Society; Columbus, Ohio, 601p. (1964), ISBN: 0-916094-04-9.

Phase Diagrams for Ceramists 1969 Supplement - Ernest M. Levin, Carl R. Robbins, Howard F. McMurdie, editor(s). American Ceramic Society; Columbus, Ohio, 625p. (1969), ISBN: 0-916094-05-7.

Phase Diagrams for Ceramists 1975 Supplement - Ernest M. Levin, Howard F. McMurdie, editor(s). American Ceramic Society; Columbus, Ohio, 513p. (1975).

\section{Meggers, William F.}

The First Spectrum of Hafnium (Hf I) - William F. Meggers and Charlotte E. Moore. NBS Monograph 153, 123p. (1976).

\section{Merrill, Leo}

A Compilation of Volumes I-IV of Bibliography on High Pressure Research with Author and Subject Indexes - John Francis Cannon and Leo Merrill. Springfield, VA: NTIS, 385p. (1972). in two volumes, vol. 1 PB 191 174, A17; vol. 2 PB 191174. 
Behavior of the AB-Type Compounds at High Pressures and High Temperatures - Leo Merrill. J Phys Chem Ref Data 6, 1205(1977).

Behavior of the $\mathrm{AB}_{2}$-Type Compounds at High Pressures and High Temperatures - Leo Merrill. J Phys Chem Ref Data 11, 1005(1982).

Bibliography of High Pressure Research, Volume XII (1979) — Leo Merrill. Provo, UT: High Pressure Data Center, Brigham Young University, ..p. (1979). Bimonthly, order from Data Center.

Compilation of Volumes V-IX of the Bibliography on High Pressure Research with Author and Subject Indexes - Leo Merrill. Provo, UT: High Pressure Data Center, Brigham Young University, (1979). in microfiche only.

High Pressure Bibliography 1900-1968, Volume I. Section I. Bibliography, Section II. Author Index - Leo Merrill. OSRD Bibl. 70-1, Vol. 1(1970).

High Pressure Bibliography 1900-1968, Volume II. Subject Index Leo Merrill. OSRD Bibl. 70-1, Vol. 2(1970).

High Pressure Bibliography, 1968-1971, with Author and Subject Indexes - John Francis Cannon and Leo Merrill. Provo, UT: High Pressure Data Center, Brigham Young University, 189p. (1972). in microfiche only.

High-Pressure Calibration: A Critical Review - D. L. Decker, W. A. Bassett, Leo Merrill, H. T. Hall, and J. D. Barnett. J Phys Chem Ref Data 1, 773(1972).

\section{Merrill, Paul W.}

Partial Grotrian Diagrams of Astrophysical Interest - Charlotte E. Moore and Paul W. Merrill. NSRDS-NBS 23, 65p. (1968).

\section{Messina, Carla G.}

EDPAC: Utility Programs for Computer-Assisted Editing, Copy Production, and Data Retrieval - Carla G. Messina and Joseph Hilsenrath. NBS Tech. Note 470, 76p. (1969).

Edit-Insertion Programs for Automatic Typesetting of Computer Printout - Carla G. Messina and Joseph Hilsenrath. NBS Tech. Note 500, 47p. (1970).

Fortran Programs for Text Editing, File Manipulation and Automatic Typsetting - Carla G. Messina, Robert McClenon, and Joseph Hilsenrath. OSRD Mag. Tape A2, Washington, DC: Office of Standard Reference Data,(1973). COM 71-003 885 or PB 183 142, T05.

OMNITAB, A Computer Program for Statistical and Numerical Analysis - Joseph Hilsenrath, Guy G. Ziegler, Carla G. Messina, P. J. Walsh, and R. H. Herbold. NBS Handbook 101, 256p. (1968).

\section{Metha, Aspy}

Heat Capacity and Other Thermodynamic Properties of Linear Macromolecules. I. Selenium - Umesh Gaur, Hua-Cheng Shu, Aspy Metha, and Bernhard Wunderlich. J Phys Chem Ref Data 10, 89(1981).

\section{Miescher, E.}

Atlas of the Absorption Spectrum of Nitric Oxide (NO) between 1420 and $1250 \AA-$ E. Miescher and F. Alberti. J Phys Chem Ref Data 5, 309(1976).

\section{Mighell, Alan D.}

Crystal Data Space-Group Tables - Alan D. Mighell, Helen M. Ondik, and Bettijoyce Breen Molino. J Phys Chem Ref Data 6, 675(1977).

Crystal Data Determinative Tables, Third Edition Volume 4. Inorganic Compounds - Joseph D. H. Donnay, Helen M. Ondik, and Alan D. Mighell. Swarthmore, PA: JCPDS-International Center for Diffraction Data, 1308p. (1978).

NBS* AIDS80: A FORTRAN Program for Crystallographic Data Evaluation - Alan D. Mighell, C. R. Hubbard, and Judy K. Stalick. NBS Tech. Note 1141, 54p. (1981).

\section{Mikhailenko, S. A.}

Properties of Liquid and Solid Hydrogen - B. N. Esel'son, Y. P. Blagoi, V.N. Grigor'ev, V. G. Manzhelii, S. A. Mikhailenko, and N. P. Neklyudov. Russian Transl. Springfield, VA: NTIS, 126p. (1971). TT 70-50179, A07.

\section{Mikula, A.}

Phase Diagrams and Thermodynamic Properties of Ternary Copper-Metal Systems - Y. Austin Chang, Joachim P. Neumann, A. Mikula, and Daniel Goldberg. INCRA Monograph VI, New York: International Copper Research Association, Inc., 702p. (1979).

\section{Miles, Barbara M.}

Atomic Transition Probabilities, Volume II. Sodium through Calcium - Wolfgang L. Wiese, Melvin W. Smith, and Barbara M. Miles. NSRDS-NBS 22, 268p. (1969).

Critically Evaluated Transition Probabilities for Ba I and II Barbara M. Miles and Wolfgang L. Wiese. NBS Tech. Note 474, 22p. (1969).

\section{Mill, T.}

A Critical Review of H-Atom Transfer in the Liquid Phase: Chlorine Atom, Alkyl, Trichloromethyl, Alkoxy, and Alkylperoxy Radicals D. G. Hendry, T. Mill, L. Piszkiewicz, J. A. Howard, and H. K. Eigenmann. J Phys Chem Ref Data 3, 937(1974).

Critical Review of Hydrolysis of Organic Compounds in Water Under Environmental Conditions - W. Mabey and T. Mill. J Phys Chem Ref Data 7, 383(1978).

\section{Millen, D. J.}

Peak Absorption Coefficients of Microwave Absorption Lines of Carbonyl Sulphide - Z. Kisiel and D. J. Millen. J Phys Chem Ref Data 11, 101(1982).

\section{Miller, Beverly J.}

Bibliography on Atomic Line Shapes and Shifts (June 1975 through June 1978) - Jeffrey R. Fuhr, Beverly J. Miller, and Georgia A. Martin. NBS Spec. Publ. 366, Suppl. 3(1978).

Bibliography on Atomic Transition Probabilities (1914 through October 1977) - Beverly J. Miller, Jeffrey R. Fuhr, and Georgia A. Martin. NBS Spec. Publ. 505, 283p. (1978).

Bibliography on Atomic Transition Probabilities (November 1977 through March 1980) - Beverly J. Miller, Jeffrey R. Fuhr, and Georgia A. Martin. NBS Spec. Publ. 505, Suppl.(1980).

Miller, G. R.

Physical Properties Data Compilations Relevant to Energy Storage. III. Engineering Properties of Single and Polycrystalline Sodium Beta and Beta" Alumina - G. R. Miller and D. G. Paquette. NSRDS-NBS 61, 19p. (1979).

Miller, R. C.

A Review, Evaluation, and Correlation of the Phase Equilibria, Heat of Mixing, and Change in Volume on Mixing for Liquid Mixtures of Methane + Ethane - M. J. Hiza, R. C. Miller, and Arthur J. Kidnay. J Phys Chem Ref Data 8, 799(1979).

A Review, Evaluation, and Correlation of the Phase Equilibria, Heat of Mixing, and Change in Volume on Mixing for Liquid Mixtures of Methane + Propane - R. C. Miller, Arthur J. Kidnay, and M. J. Hiza. J Phys Chem Ref Data 9, 721(1980).

Equilibrium Properties of Fluid Mixtures, A Bibliography on Fluids of Cryogenic Interest - M. J. Hiza, Arthur J. Kidnay, and R. C. Miller. New York: IFI/Plenum, 166p. (1975), ISBN: 0-306-6601-6 
Equilibrium Properties of Fluid Mixtures, 2. A Bibliography of Experimental Data on Selected Fluids - M. J. Hiza, Arthur J. Kidnay, and R. C. Miller. New York: IFI/Plenum, 258p. (1982), ISBN: 0-306-6602-4.

Liquid Vapor Equilibria on Systems of Interest in Cryogenics, A Survey - Arthur J. Kidnay, M. J. Hiza, and R. C. Miller. Cryogenics 13, London: Academic Press, 575p. (1973).

Milne, G. S.

Tables of Bimolecular Gas Reactions - Aubrey F. TrotmanDickenson and G. S. Milne. NSRDS-NBS 9, 129p. (1967).

Mllne, G. W. A.

A Compendium of Gas Phase Basicity and Proton Affinity Measurements - K. N. Hartman, Sharon G. Lias, P. J. Ausloos, Henry M. Rosenstock, S. S. Schroyer, C. Schmidt, D. Marcinsen, and G. W. A. Milne. NBSIR 79-1777, 563p. (1979).

EPA/NIH Mass Spectral Data Base Magnetic Tape - Stephen R. Heller and G. W. A. Milne. NBS Standard Reference Database 1 A1, Washington, DC: NBS Office of Standard Reference Data,(updated periodically). Call (301) 921-2228 for specific instructions.

EPA/NIH Mass Spectral Data Base, Supplement 1 - Stephen R. Heller and G. W. A. Milne. NSRDS-NBS 63, Suppl. 1(1980).

EPA/NIH Mass Spectral Data Base, Supplement 2 - Stephen R. Heller, G. W. A. Milne, and Lewis H. Gevantman. NSRDS-NBS 63, Suppl. 2(1983).

EPA/NIH Mass Spectral Data Base, Volume 1. Molecular Weights 30-186; Volume 2. Molecular Weights 16-273; Volume 3. Molecular Weights 273-381; Volume 4. Molecular Weights 381-1674 - Stephen R. Heller and G. W. A. Milne. NSRDS-NBS 63, 1,2,3,4(1978).

Mlshra, P. P.

Densities of Liquid $\mathrm{CH}_{4 \mathrm{a}} \mathrm{X}_{\mathrm{a}}(\mathrm{X}=\mathrm{Br}, \mathrm{I})$ and $\mathrm{CH}_{4(\mathrm{a}+\mathrm{b}+\mathrm{c}+\mathrm{d})} \mathrm{F}_{\mathrm{a}} \mathrm{Cl}_{\mathrm{b}} \mathrm{Br}_{\mathrm{c}} \mathrm{I}_{\mathrm{d}}$ Halomethanes -- Arvind P. Kudchadker, Shanti A. Kudchadker, P. R. Patnaik, and P. P. Mishra. J Phys Chem Ref Data 7, 425(1978).

\section{Mlyahara, Koshlro}

Hydrogenation of Ethylene on Metallic Catalysts - Juro Horiuti and Koshiro Miyahara. NSRDS-NBS 13, 62p. (1968).

\section{Mizushima, $M$.}

Microwave Spectral Tables, Volume I. Diatomic Molecules - Paul F. Wacker, M. Mizushima, J. D. Petersen, and J. R. Ballard. NBS Monograph 70, 171p. (1964).

Mohrmann, L. E.

NMR Spectral Data: A Compilation of Aromatic Proton Chemical Shifts in Mono- and Di-Substituted Benzene - B. L. Shapiro and L. E. Mohrmann. J Phys Chem Ref Data 6, 919(1977).

\section{Molseiwltsch, Benjamin L.}

Electron Impact Excitation of Atoms - Benjamin L. Moiseiwitsch and Steven J. Smith. NSRDS-NBS 25, 120p. (1968).

\section{Mollno, Bettljoyce Breen}

Crystal Data Space-Group Tables - Alan D. Mighell, Helen M. Ondik, and Bettijoyce Breen Molino. J Phys Chem Ref Data 6, 675(1977).

\section{Monnanteull, Nicole}

Microwave Spectra of Molecules of Astrophysical Interest. XVIII. Formic Acid - Edmond Willemot, Didier Dangoisse, Nicole Monnanteuil, and Jean Bellet. J Phys Chem Ref Data 9, 59(1980).

\section{Montague, D. C.}

Evaluated Kinetic Data for High Temperature Reactions, Volume 4. Homogeneous Gas Phase Reactions of Halogen- and CyanideContaining Species - D. L. Baulch, J. Duxbury, S. J. Grant, and D. C. Montague. J Phys Chem Ref Data 10, Suppl. 1(1981).

\section{Moore, Charlotte E.}

A Multiplet Table of Astrophysical Interest, Revised Edition, Part I. Table of Multiplets, Part II. Finding List of All Lines in the Table of Multiplets - Charlotte E. Moore. NSRDS-NBS 40, 261p. (1972).

An Ultraviolet Multiplet Table, Section 1. The Spectra of Hydrogen through Vanadium - Charlotte E. Moore. NBS Circular 488, 78p. (1950).

An U1traviolet Multiplet Table, Section 2. The Spectra of Chromium through Niobium - Charlotte E. Moore. NBS Circular 488, 115p. (1952).

An Ultraviolet Multiplet Table, Section 3. The Spectra of Molybdenum to Lanthanum and Hafnium to Radium - Charlotte E. Moore. NBS Circular 488, 94p. (1962).

An Ultraviolet Multiplet Table, Section 4. Finding List for Spectra of the Elements Hydrogen to Niobium ( $Z=1$ to 41$)$ - Charlotte E. Moore. NBS Circular 488, 65p. (1962).

An Ultraviolet Multiplet Table, Section 5. Finding List for Spectra of the Elements Molybdenum to Lanthanum ( $Z=42$ to 57 ), Hafnium to Radium ( $Z=72$ to 88$)$ - Charlotte E. Moore. NBS Circular 488, 30p. (1962).

Atomic Energy Levels as Derived from the Analyses of Optical Spectra, Volume I. ' $\mathrm{H}$ to ${ }^{23} \mathrm{~V}$ - Charlotte E. Moore. NSRDS-NBS 35, 358p. (1971).

Atomic Energy Levels as Derived from the Analyses of Optical Spectra, Volume II. ${ }^{24} \mathrm{Cr}$ to ${ }^{41} \mathrm{Nb}-$ Charlotte E. Moore. NSRDS-NBS 35, 263p. (1971).

Atomic Energy Levels as Derived from the Analysis of Optical Spectra, Volume III. ${ }^{42} \mathrm{Mo}$ to ${ }^{57} \mathrm{La},{ }^{72} \mathrm{Hf}$ to ${ }^{89} \mathrm{Ac}$ - Charlotte E. Moore. NSRDS-NBS 35, 289p. (1971).

Bibliography on the Analyses of Optical Atomic Spectra. Section 1. ${ }^{1} \mathrm{H}^{23} \mathrm{~V}$ - Charlotte E. Moore. NBS Spec. Publ. 306, 80p. (1968).

Bibliography on the Analyses of Optical Atomic Spectra. Section 2. ${ }^{24} \mathrm{Cr}^{4}{ }^{41} \mathrm{Nb}$ - Charlotte E. Moore. NBS Spec. Publ. 306, 57p. (1969).

Bibliography on the Analyses of Optical Atomic Spectra. Section 3. ${ }^{42} \mathrm{Mo}-{ }^{57} \mathrm{La}$ and ${ }^{72} \mathrm{Hf} \cdot{ }^{89} \mathrm{Ac}-$ Charlotte E. Moore. NBS Spec. Publ. 306, 37p. (1969).

Bibliography on the Analyses of Optical Atomic Spectra. Section 4. ${ }^{57} \mathrm{La}-{ }^{71} \mathrm{Lu}$ and ${ }^{89} \mathrm{Ac}-{ }^{99}$ Es - Charlotte E. Moore. NBS Spec. Publ. 306, 48p. (1969).

Ionization Potentials and Ionization Limits Derived from the Analyses of Optical Spectra - Charlotte E. Moore. NSRDS-NBS 34, 22p. (1970).

Partial Grotrian Diagrams of Astrophysical Interest - Charlotte E. Moore and Paul W. Merrill. NSRDS-NBS 23, 65p. (1968).

Selected Tables of Atomic Spectra: A. Atomic Energy Levels - Second Edition; B. Multiplet Tables; Si II, Si III, Si IV - Charlotte E. Moore. NSRDS-NBS 3, 35p. (1965).

Selected Tables of Atomic Spectra: A. Atomic Energy Levels - Second Edition: B. Multiplet Tables; SiI - Charlotte E. Moore. NSRDSNBS 3, 22p. (1967).

Selected Tables of Atomic Spectra: A. Atomic Energy Levels - Second Edition; B. Multiplet Tables; C I, C II, C III - Charlotte E. Moore. NSRDS-NBS 3, 73p. (1970).

Selected Tables of Atomic Spectra: A. Atomic Energy Levels - Second Edition; B. Multiplet Tables; N IV, N V, N VI, N VII - Charlotte E. Moore. NSRDS-NBS 3, 46p. (1971).

Selected Tables of Atomic Spectra: A. Atomic Energy Levels - Second Edition; B. Multiplet Tables; H I, D, T - Charlotte E. Moore. NSRDS-NBS 3, 32p. (1972).

Selected Tables of Atomic Spectra: A. Atomic Energy Levels - Sec ond Edition; B. Multiplet Tables; N I, N II, N III, - Charlotte E. Moore. NSRDS-NBS 3, 80p.(1975). 
Selected Tables of Atoric Spectra: A. Atomic Energy Levels - Second Edition; B. Multiplet Tables; O I - Charlotte E. Moore. NSRDSNBS 3, 33p. (1976).

Selected Tables of Atomic Spectra: A. Atomic Energy Levels - Second Edition; B. Multiplet Tables; O VI, O VII , O VIII - Charlotte E. Moore. NSRDS-NBS 3, 3 I p. (1979).

Selected Tables of Atomic Spectra: A. Atomic Energy Levels - Second Edition; B. Multiplet Tables; O V - Charlotte E. Moore. NSRDSNBS 3, 21p. (1980).

Selected Tables of Atomic Spectra: A. Atomic Energy levels - Second Edition; B. Multiplet Tables; O IV - Charlotte E. Moore. NSRDS-NBS 3, 21p. (1983).

Selected Tables of Atomic Spectra: A. Atomic Energy Levels - Second Edition; B. Multiplet Tables; O III - Charlotte E. Moore. NSRDS-NBS 3, ...p. (1985).

The First Spectrum of Hafnium (Hf I) - William F. Meggers and Charlotte E. Moore. NBS Monograph 153, 123p. (1976).

\section{Moore, Robert L.}

Critical Surveys of Data Sources: Mechanical Properties of Metals - R. B. Gavert, Robert L. Moore, and John H. Westbrook. NBS Spec. Publ. 396, 90p. (1974).

Critical Surveys of Data Sources: Electrical and Magnetic Properties of Metals - M. J. Carr, R. B. Gavert, Robert L. Moore, H. W. Wawrousek, and John H. Westbrook. NBS Spec. Publ. 396, 96p. (1976).

Morin, L. R. M.

Molecular Form Factors and Photon Coherent Scattering Cross Sections of Water - L. R. M. Morin. J Phys Chem Ref Data 11, 1091(1982).

\section{Morozova, N. A.}

Thermodynamic and Thermophysical Properties of Helium - A. F. Alyab'ev, N. V. Tsederberg, V. N. Popov, and N. A. Morozova. Russian Transl. Springfield, VA: NTIS, 260p. (1971). TT 70-50096, A12.

Muir, A. H.

Mossbauer Effect Data Index, 1958-1965 - A. H. Muir, K. J. Ando, and Helen M. Coogan. New York: Interscience Publishers, 351p. (1966).

\section{Mukerjee, Pasupati}

Critical Micelle Concentrations of Aqueous Surfactant Systems Pasupati Mukerjee and Karol J. Mysels. NSRDS-NBS 36, 222p. (1971).

\section{Murad, S.}

A Correlation of the Existing Viscosity and Thermal Conductivity Data of Gaseous and Liquid Ethane - Howard J. M. Hanley, K. E. Gubbins, and S. Murad. J Phys Chem Ref Data 6, 1167(1977).

Erratum: A Correlation of the Existing Viscosity and Thermal Conductivity Data of Gaseous and Liquid Ethane - Howard J. M. Hanley, K. E. Gubbins, and S. Murad. J Phys Chem Ref Data 10, 799(1981).

\section{Murphy, R. M.}

Physical Properties Data Compilations Relevant to Energy Storage. II. Molten Salts: Data on Single and Multi-Component Systems George J. Janz, Carolyn B. Allen, Narottam P. Bansal, R. M. Murphy, and Reginald P. T. Tomkins. NSRDS-NBS 61, 420p. (1979).

\section{Murray, Joanne}

Bulletin of Alloy Phase Diagrams - Joanne Murray, editor(s) and American Society for Metals. Bull Alloy Phase Diag 3, Metals Park, OH: American Society for Metals, 130p. (1982), ISBN: 01970216.

\section{Muthu, OI}

Critical Evaluation of Vapor-Liquid Equilibrium, Heat of Mixing, and Volume Change of Mixing Data. General Procedures - Buford D. Smith, Ol Muthu, Ashok Dewan, and Matthew Gierlach. J Phys Chem Ref Data 11, 941(1982).

Definition of Recommended Values of Certain Thermodynamic Properties for the Ketones - Buford D. Smith and Ol Muthu. NBSIR 84-2811, 162p. (1983).

Evaluation of Binary Excess Enthalpy Data for $\mathrm{C}_{6}$ Hydrocarbons. Benzene + Cyclohexane - Buford D. Smith, Ol Muthu, Ashok Dewan, and Matthew Gierlach. J Phys Chem Ref Data 11, 1127(1982).

Evaluation of Binary Excess Enthalpy Data for $\mathrm{C}_{6}$ Hydrocarbons. Benzene + Hexane - Buford D. Smith, Ol Muthu, and Ashok Dewan. J Phys Chem Ref Data 12, 389(1983).

Evaluation of Binary Excess Volume Data for $\mathrm{C}_{6}$ Hydrocarbons. Benzene + Cyclohexane - Buford D. Smith, Ol Muthu, Ashok Dewan, and Matthew Gierlach. J Phys Chem Ref Data 11, 1151(1982),

Evaluation of Binary Excess Volume Data for $\mathrm{C}_{6}$ Hydrocarbons. Benzene + Hexane - Buford D. Smith, Ol Muthu, and Ashok Dewan. J Phys Chem Ref Data 12, 395(1983).

Evaluation of Binary PTxy Vapor-Liquid Equilibrium Data for $\mathrm{C}_{6}$ Hydrocarbons. Benzene + Cyclohexane - Buford D. Smith, Ol Muthu, Ashok Dewan, and Matthew Gierlach. J Phys Chem Ref Data 11, 1099(1982).

Evaluation of Binary PTxy Vapor-Liquid Equilibrium Data for $\mathrm{C}_{6}$ Hydrocarbons. Benzene + Hexane - Buford D. Smith, Ol Muthu, and Ashok Dewan. J Phys Chem Ref Data 12, 381(1983).

\section{Mysels, Karol J.}

Critical Micelle Concentrations of Aqueous Surfactant Systems Pasupati Mukerjee and Karol J. Mysels. NSRDS-NBS 36, 222p. (1971).

\section{Nagashima, A.}

Erratum: Viscosity of Water Substance - New International Formulation and Its Background - A. Nagashima. J Phys Chem Ref Data 12, 403p. (1983).

Transport Properties of Liquid and Gaseous $\mathrm{D}_{2} \mathrm{O}$ over a Wide Range of Temperature and Pressure - N. Matsunaga and A. Nagashima. J Phys Chem Ref Data 12, 933(1983).

Viscosity of Water Substance - New International Formulation and Its Background - A. Nagashima. J Phys Chem Ref Data 6, 1133(1977).

\section{Naimon, E. R.}

Elastic Properties of Metals and Alloys, II. Copper - Hassell M. Ledbetter and E. R. Naimon. J Phys Chem Ref Data 3, 897(1974).

\section{Najafi, B.}

Equilibrium and Transport Properties of the Noble Gases and Their Mixtures at Low Density - Joseph Kestin, K. Knierim, E. A. Mason, B. Najafi, S. T. Ro, and M. Waidman. J Phys Chem Ref Data 13, 229(1984).

\section{Narayan, V. A.}

Bibliography of Infrared Spectroscopy through 1960 - C. N. R. Rao, S. K. Dikshit, Shanti A. Kudchadker, D. S. Gupta, V. A. Narayan, and John J. Comeford. NBS Spec. Publ. 428, 1,2,3(1976) 


\section{Natarajan, M.}

Crystal Structure Transformations in Binary Halides - C. N. R. Rao and M. Natarajan. NSRDS-NBS 41, 57p. (1972).

Crystal Structure Transformations in Inorganic Nitrites, Nitrates, and Carbonates - C. N. R. Rao, Brahm Prakash, and M. Natarajan. NSRDS-NBS 53, 55p. (1975).

\section{Naumov, G. B.}

Handbook of Thermodynamic Data on Geological Substances - G. B. Naumov, B. N. Ryzhenko, and I. L. Khodakovsky. Russian Transl. Springfield, VA: NTIS, 340p. (1974). TT 73-53051 or PB226 722, A15.

\section{Neduzhii, I. A.}

Thermodynamic and Transport Properties of Ethylene and Propylene - I. A. Neduzhii. Russian Transl. Springficld, VA: NTIS, 206p. (1972). COM 75-11276, A 10.

\section{Neklyudov, N. P.}

Properties of Liquid and Solid Hydrogen - B. N. Esel'son, Y. P. Blagoi, V.N. Grigor'ev, V. G. Manzhelii, S. A. Mikhailenko, and N. P. Neklyudov. Russian Transl. Springfield, VA: NTIS, 126p. (1971). TT 70-50179, A07.

\section{Nelson, Ralph D., Jr.}

Selected Values of Electric Dipole Moments for Molecules in the Gas Phase - Ralph D. Nelson, Jr., David R. Lide, Jr., and Arthur A. Maryott. NSRDS-NBS 10, 49p. (1967).

\section{Neta, Pedatsur}

Rate Constants for Reactions of Aliphatic Carbon-Centered Radicals in Aqueous Solution - Alberta B. Ross and Pedatsur Neta. NSRDS-NBS 70, 96p. (1982).

Rate Constants for Reactions of Inorganic Radicals in Aqueous Solution - Alberta B. Ross and Pedatsur Neta. NSRDS-NBS 65, 62p. (1979).

\section{Neumann, David B.}

A Report on Thermodynamic Data for Desulfurization Processes Vivian B. Parker, Bert R. Staples, Thomas L. Jobe, Jr., and David B. Neumann. NBSIR 81.2345, 89p. (1981).

\section{Neumann, Joachim P.}

Phase Diagrams and Thermodynamic Properties of Ternary Copper-Silver Systems - Y. Austin Chang, Daniel Goldberg, and Joachim P. Neumann. J Phys Chem Ref Data 6, 621(1977).

Phase Diagrams and Thermodynamic Properties of Ternary CopperMetal Systems - Y. Austin Chang, Joachim P. Neumann, A. Mikula, and Daniel Goldberg. INCRA Monograph VI, New York: International Copper Research Association, Inc., 702p. (1979).

Phase Diagrams and Thermodynamic Properties of Ternary CopperSulfur-Metal Systems - Y. Austin Chang, Joachim P. Neumann, and U. V. Choudary. INCRA Monograph VII, New York: International Copper Research Association, Inc. 191 p. (1979).

\section{Nuttall, Ralph L.}

A Bibliography of Sources of Experimental Data Leading to Activity or Osmotic Coefficients for Polyvalent Electrolytes in Aqueous Solution - Robert N. Goldberg, Bert R. Staples, Ralph L. Nuttall, and R. Arbuckle. NBS Spec. Publ. 485, 57p. (1977).

Computer Programs for the Evaluation of Activity and Osmotic Coefficients - Bert R. Staples and Ralph L. Nuttall. NBS Tech. Note 928, 60p. (1976).
Evaluated Activity and Osmotic Coefficients for Aqueous Solutions: The Alkaline Earth Metal Halides - Robert N. Goldberg and Ralph L. Nuttall. J Phys Chem Ref Data 7, 263(1978).

Evaluated Activity and Osmotic Coefficients for Aqueous Solutions: Iron Chloride and the Bi-Univalent Compounds of Nickel and Cobalt - Robert N. Goldberg, Ralph L. Nuttall, and Bert R. Staples. J Phys Chem Ref Data 8, 923(1979).

Selected Values of Chemical Thermodynamic Properties: Compounds of Uranium, Protactinium, Thorium, Actinium, and the Alkali Metals - Donald D. Wagman, William H. Evans, Vivian B. Parker, Richard H. Schumm, and Ralph L. Nuttall. NBS Tech. Note 270, 149p. (1981).

The Activity and Osmotic Coefficients of Aqueous Calcium Chloride at 298.15 K - Bert R. Staples and Ralph L. Nuttall. J Phys Chem Ref Data 6, 385(1977).

The NBS Tables of Chemical Thermodynamic Properties. Selected Values for Inorganic and $C_{1}$ and $C_{2}$ Organic Substances in SI Units Donald D. Wagman, William H. Evans, Vivian B. Parker, Richard H. Schumm, Iva Halow, Sylvia M. Bailey, Kenneth L. Churney, and Ralph L. Nuttall. J Phys Chem Ref Data 11, Suppl. 2(1982).

\section{O'Neal, Harry E.}

Kinetic Data on Gas Phase Unimolecular Reactions - Sidney W. Benson and Harry E. O'Neal. NSRDS-NBS 21, 645p. (1970).

\section{Overbd, 1.}

Pair, Triplet, and Total Atomic Cross Sections (and Mass Attenuation Coefficients) for $1 \mathrm{MeV}-100 \mathrm{GeV}$ Photons in Elements $\mathrm{Z}=1$ to 100 - John H. Hubbell, Heinz A. Gimm, and I. Øverb $\varnothing$. J Phys Chem Ref Data 9, 1023(1980).

Relativistic Atomic Form Factors and Photon Coherent Scattering Cross Sections - John H. Hubbell and I. Øverbø. J Phys Chem Ref Data 8, 69(1979).

\section{Odintzova, G. A.}

The Spectrum and Energy Levels of the Neutral Atom of Boron (B I) - G. A. Odintzova and A. R. Striganov. J Phys Chem Ref Data 8, 63(1979).

\section{Ogawa, Yoshiki}

Tables of Molecular Vibrational Frequencies, Part 9 - Takehiko Shimanouchi, Hiroatsu Matsuura, Yoshiki Ogawa, and Issei Harada. J Phys Chem Ref Data 7, 1323(1978).

Tables of Molecular Vibrational Frequencies, Part 10 - Takehiko Shimanouchi, Hiroatsu Matsuura, Yoshiki Ogawa, and Issei Harada. J Phys Chem Ref Data 9, 1149(1980).

\section{Oh, S. G.}

Electrical Resistivity of Ten Selected Binary Alloy Systems - Cho Y. Ho, M. W. Ackerman, K. Y. Wu, T. N. Havill, R. H. Bogaard, R. A. Matula, S. G. Oh, and H. M. James. J Phys Chem Ref Data 12, 183(1983).

Thermal Conductivity of Ten Selected Binary Alloy Systems - Cho Y. Ho, M. W. Ackerman, K. Y. Wu, S. G. Oh, and T. N. Havill. J Phys Chem Ref Data 7, 959(1978).

\section{Okabe, $\mathrm{H}$.}

Survey of Photochemical and Rate Data for Twenty-eight Reactions of Interest in Atmospheric Chemistry - Robert F. Hampson, Jr.,W. Braun, R. L. Brown, David Garvin, John T. Herron, Robert E. Huie, M. J. Kurylo, A. H. Laufer, J. D. McKinley, H. Okabe, M. D. Scheer, W. Tsang, D. H. Stedman, editor(s). J Phys Chem Ref Data 2, 267(1973).

\section{Oliver, J. H.}

Natural Widths of Atomic $\mathrm{K}$ and L Levels, $\mathrm{K} \alpha \mathrm{X}$-Ray Lines and Several KLL Auger Lines - Morris O. Krause and J. H. Oliver. J Phys Chem Ref Data 8, 329(1979). 
Olson, W. B.

Tables of $\mathrm{N}_{2} \mathrm{O}$ Absorption Lines for the Calibration of Tunable Infrared Lasers from $522 \mathrm{~cm}^{-1}$ to $657 \mathrm{~cm}^{-1}$ and from $1115 \mathrm{~cm}^{-1}$ to 1340 $\mathrm{cm}^{-1}-$ W. B. Olson, Arthur G. Maki, and Walter J. Lafferty. J Phys Chem Ref Data 10, 1065(1981).

\section{Ondik, Helen M.}

Crystal Data Space-Group Tables - Alan D. Mighell, Helen M. Ondik, and Bettijoyce Breen Molino. J Phys Chem Ref Data 6, 675(1977).

Crystal Data Determinative Tables, Third Edition Volume 1: Organic Compounds - Joseph D. H. Donnay and Helen M. Ondik. Swarthmore, PA: JCPDS-International Center for Diffraction Data, 855p. (1972).

Crystal Data Determinative Tables, Third Edition Volume 2: Inorganic Compounds - Joseph D. H. Donnay and Helen M. Ondik. Swarthmore, PA: JCPDS-International Center for Diffraction Data, 1748p. (1973).

Crystal Data Determinative Tables, Third Edition Volume 4. Inorganic Compounds - Joseph D. H. Donnay, Helen M. Ondik, and Alan D. Mighell. Swarthmore, PA: JCPDS-International Center for Diffraction Data, 1308p. (1978).

\section{Outred, Michael}

Tables of Atomic Spectral Lines for the $10000 \AA$ to $40000 \AA$ Region - Michael Outred. J Phys Chem Ref Data 7, 1(1978).

\section{Ozier, I.}

Microwave Spectra of Molecules of Astrophyical Interest. XX. Methane - I. Ozier, M. C. L. Gerry, and A. G. Robiette. J Phys Chem Ref Data 10, 1085(1981).

\section{Padikal, Thomas N.}

Medical Physics Data Book - Thomas N. Padikal and Sherman P. Fivozinsky. NBS Handbook 138, 127p. (1982).

\section{Pamidimukkala, Krishna M.}

Ideal Gas Thermodynamic Properties of $\mathrm{CH}_{3}, \mathrm{CD}_{3}, \mathrm{CD}_{4}, \mathrm{C}_{2} \mathrm{D}_{2}$, $\mathrm{C}_{2} \mathrm{D}_{4}, \mathrm{C}_{2} \mathrm{D}_{6}, \mathrm{C}_{2} \mathrm{H}_{6}, \mathrm{CH}_{3} \mathrm{~N}_{2} \mathrm{CH}_{3}$, and $\mathrm{CD}_{3} \mathrm{~N}_{2} \mathrm{CD}_{3}-$ Krishna $\mathrm{M}$. Pamidimukkala, David Rogers, and Gordon B. Skinner. J Phys Chem Ref Data 11, 83(1982).

\section{Pankratz, Louis B.}

Contributions to the Data on Theoretical Metallurgy, XVI. Thermodynamic Properties of Nickel and Its Inorganic Compounds - Alla D. Mah and Louis B. Pankratz. U.S. Bur Mines Bull 668, Springfield, VA: NTIS, 125p. (1976). U.S. Bureau of Mines Bulletin 668, A06.

Thermodynamic Properties of Copper and Its Inorganic Compounds - Edward G. King, Alla D. Mah, and Louis B. Pankratz. INCRA Monograph II, New York: International Copper Research Association, Inc., 257p. (1973).

\section{Paquette, D. G.}

Physical Properties Data Compilations Relevant to Energy Storage. III. Engineering Properties of Single and Polycrystalline Sodium Beta and Beta" Alumina - G. R. Miller and D. G. Paquette. NSRDS-NBS 61, 19p. (1979).

\section{Parker, Vivian B.}

A Combined Least Sums and Least Squares Approach to the Evaluation of Thermodynamic Data Networks - David Garvin, Vivian B. Parker, Donald D. Wagman, and William H. Evans. NBSIR 76-1147, 41p. (1976).

A Computer Assisted Evaluation of the Thermochemical Data of the Compounds of Thorium - Donald D. Wagman, Richard H. Schumm, and Vivian B. Parker. NBSIR 77-1300, 94p. (1977).
A Report on Thermodynamic Data for Desulfurization Processes Vivian B. Parker, Bert R. Staples, Thomas L. Jobe, Jr., and David B. Neumann. NBSIR 81-2345, 89p. (1981).

Chemical Thermodynamic Data Banks - David Garvin, Vivian B. Parker, and Donald D. Wagman. NBSIR 81-2341, 30p. (1981).

Chemical Thermodynamic Properties of Compounds of Sodium, Potassium, and Rubidium: An Interim Tabulation of Selected Material Donald D. Wagman, William H. Evans, Vivian B. Parker, and Richard H. Schumm. NBSIR 76-1034, 76p. (1976).

Selected Thermochemical Data Compatible with CODATA Recommendations - Vivian B. Parker, Donald D. Wagman, and David Garvin. NBSIR 75-968, 35p. (1976).

Selected Values of Chemical Thermodynamic Properties. Tables for the First Thirty-Four Elements in the Standard Order of Arrangement - Donald D. Wagman, William H. Evans, Vivian B. Parker, Iva Halow, Sylvia M. Bailey, and Richard H. Schumm. NBS Tech. Note 270, 264p. (1968).

Selected Values of Chemical Thermodynamic Properties. Tables for Elements 35 through 53 in the Standard Order of Arrangement Donald D. Wagman, William H. Evans, Vivian B. Parker, Iva Halow, Sylvia M. Bailey, and Richard H. Schumm. NBS Tech. Note 270, 152p. (1969).

Selected Values of Chemical Thermodynamic Properties. Tables for Elements 54 through 61 in the Standard Order of Arrangement Donald D. Wagman, William H. Evans, Vivian B. Parker, Iva Halow, Sylvia M. Bailey, Richard H. Schumm, and Kenneth L. Churney. NBS Tech. Note 270, 49p. (1971).

Selected Values of Chemical Thermodynamic Properties. Tables for the Alkaline Earth Elements (Elements 92 through 97 in the Standard Order of Arrangement) - Vivian B. Parker, Donald D. Wagman, and William H. Evans. NBS Tech. Note 270, 124p. (1971).

Selected Values of Chemical Thermodynamic Properties. Tables for the Lanthanide (Rare Earth) Elements (Elements 62 through 76 in the Standard Order of Arrangement) - Richard H. Schumm, Donald D. Wagman, Sylvia M. Bailey, William H. Evans, and Vivian B. Parker. NBS Tech. Note 270, 84p. (1973).

Selected Values of Chemical Thermodynamic Properties: Compounds of Uranium, Protactinium, Thorium, Actinium, and the Alkali Metals - Donald D. Wagman, William H. Evans, Vivian B. Parker, Richard H. Schumm, and Ralph L. Nuttall. NBS Tech. Note 270, 149p. (1981).

The NBS Tables of Chemical Thermodynamic Properties. Selected Values for Inorganic and $C_{1}$ and $C_{2}$ Organic Substances in SI Units Donald D. Wagman, William H. Evans, Vivian B. Parker, Richard H. Schumm, Iva Halow, Sylvia M. Bailey, Kenneth L. Churney, and Ralph L. Nuttall. J Phys Chem Ref Data 11, Suppl. 2(1982).

The Thermochemical Properties of Uranium-Halogen Containing Compounds - Vivian B. Parker. NBSIR 80-2029, 173p. (1980).

Thermal Properties of Aqueous Uni-Univalent Electrolytes Vivian B. Parker. NSRDS-NBS 2, 68p. (1965).

Parkinson, W. H.

- Atlas of the Schumann-Runge Absorption Bands of $\mathrm{O}_{2}$ in the Wavelength Region 175-205 nm - K. Yoshino, D. E. Freeman, and W. H. Parkinson. J Phys Chem Ref Data 13, 207(1984).

\section{Patnaik, P. R.}

Densities of Liquid $\mathrm{CH}_{4 \mathrm{~s}} \mathrm{X}_{\mathrm{a}}(\mathrm{X}=\mathrm{Br}, \mathrm{I})$ and $\mathrm{CH}_{4(\mathrm{a}+b+c+d)} \mathrm{F}_{\mathrm{a}} \mathrm{Cl}_{b} \mathrm{Br}_{\mathrm{c}} \mathrm{I}_{\mathrm{d}}$ Halomethanes - Arvind P. Kudchadker, Shanti A. Kudchadker, P. R. Patnaik, and P. P. Mishra. J Phys Chem Ref Data 7, 425(1978).

Vapor Pressures and Boiling Points of Selected Halomethanes Arvind P. Kudchadker, Shanti A. Kudchadker, R. P. Shukla, and P. R. Patnaik. J Phys Chem Ref Data 8, 499(1979).

\section{Pearlman, Robert S.}

Water Solubilities of Polynuclear Aromatic and Heteroaromatic. Compounds - Robert S. Pearlman, Samuel H. Yalkowsky, and Sujit Banerjee. J Phys Chem Ref Data 13, 555(1984). 


\section{Peavy, Saily T.}

OMNITAB 80 Magnetic Tape - Sally T. Peavy. OSRD Mag. Tape , Washington, DC: NBS Office of Standard Reference Data,(1980). U.S. and foreign prices, for further information write, or call (301) 921-3651.

Test Problems and Results for OMNITAB 80 - Sally T. Peavy and Shirley G. Bremer. NBS Tech. Note 1147, 316p. (1981).

\section{Pediey, J. B.}

Thermochemical Data for Gaseous Monoxides - J. B. Pedley and E. M. Marshall. J Phys Chem Ref Data 12, 967(1983).

\section{Peek, James $M$.}

Dissociation in Heavy Particle Collisions - G. W. McClure and James M. Peek. At Mol Collis Proc Ser, New York: Wiley-Interscience, 198p. (1972), ISBN: 0-471-5816-8.

\section{Peiper, J. Christopher}

Thermodynamic Properties of Aqueous Sodium Chloride Solutions - Kenneth S. Pitzer, J. Christopher Peiper, and R. H. Busey. J Phys Chem Ref Data 13, 1(1984).

\section{Petersen, J. D.}

Microwave Spectral Tables, Volume I. Diatomic Molecules - Paul F. Wacker, M. Mizushima, J. D. Petersen, and J. R. Ballard. NBS Monograph 70, 171p. (1964).

Microwave Spectral Tables, Volume IV. Polyatomic Molecules without Internal Rotation - M. S. Cord, J. D. Petersen, M. S. Lojko, and R. H. Haas. NBS Monograph 70, 419p. (1968).

Microwave Spectral Tables, Volume III. Polyatomic Molecules with Internal Rotation - Paul F. Wacker, M. S. Cord, D. G. Burkhard, J. D. Petersen, and R. F. Kukol. NBS Monograph 70, 275p. (1969).

Microwave Spectral Tables, Volume V. Spectral Line Listing - M. S. Cord, M. S. Lojko, and J. D. Petersen. NBS Monograph 70, 533p. (1968).

\section{Peterson, Donaid B.}

The Radiation Chemistry of Gaseous Ammonia - Donald B. Peterson. NSRDS-NBS 44, 41p. (1974).

\section{Pine, A. S.}

Atlas of the High Temperature Water Vapor Spectrum in the 3000 to $4000 \mathrm{~cm}^{-1}$ Region - A. S. Pine, M. J. Coulombe, C. Camy-Peyret, and J-M. Flaud. J Phys Chem Ref Data 12, 413(1983).

\section{Piszkiewicz, L.}

A Critical Review of H-Atom Transfer in the Liquid Phase: Chlorine Atom, Alkyl, Trichloromethyl, Alkoxy, and Alkylperoxy Radicals D. G. Hendry, T. Mill, L. Piszkiewicz, J. A. Howard, and H. K. Eigenmann. J Phys Chem Ref Data 3, 937(1974).

Pitchford, L. C.

A Bibliography of Electron Swarm Data - Earl C. Beaty, J. Dutton, and L. C. Pitchford. JILA Report 20, 252p. (1979).

An Annotated Compilation and Appraisal of Electron Swarm Data in Electronegative Gases - Jean W. Gallagher, Earl C. Beaty, J. Dutton, and L. C. Pitchford. J Phys Chem Ref Data 12, 109(1983).

\section{Pitzer, Kenneth S.}

Simplification of Thermodynamic Calculations Through Dimensionless Entropies (Comments) - Kenneth S. Pitzer and Leo Brewer. J Phys Chem Ref Data 8, 917(1979).
Thermodynamic Properties of Aqueous Sodium Chloride Solutions - Kenneth S. Pitzer, J. Christopher Peiper, and R. H. Busey. J Phys Chem Ref Data 13, 1(1984).

Volumetric Properties of Aqueous Sodium Chloride Solutions - P. S. Z. Rogers and Kenneth S. Pitzer. J Phys Chem Ref Data 11, 15(1982).

\section{Popov, V. N.}

Thermodynamic and Thermophysical Properties of Helium - A. F. Alyab'ev, N. V. Tsederberg, V. N. Popov, and N. A. Morozova. Russian Transl. Springfield, VA: NTIS, 260p. (1971). TT 70-50096, A12.

\section{Porter, F. T.}

Recommended Atomic Electron Binding Energies, 1s to $6 \mathrm{p}_{3 / 2}$, for the Heavy Elements, $Z=84$ to $103-$ F. T. Porter and M. S. Freedman. J Phys Chem Ref Data 7, 1267(1978).

Pound, G. M.

Selected Values of Critical Supersaturation for Nucleation of Liquids from the Vapor - G. M. Pound. J Phys Chem Ref Data $\mathbb{1}$, 119(1972).

Selected Values of Evaporation and Condensation Coefficients for Simple Substances - G. M. Pound. J Phys Chem Ref Data 1, 135(1972).

\section{Poweil, Robert W.}

Thermal Conductivity of Selected Materials - Robert W. Powell, Cho Y. Ho, and Peter E. Liley. NSRDS-NBS 8, 68p. (1966).

Thermal Conductivity of Selected Materials, Part 2 - Cho Y. Ho, Robert W. Powell, and Peter E. Liley. NSRDS-NBS 16, 146p. (1968). Thermal Conductivity of the Elements - Cho Y. Ho, Robert W. Powell, and Peter E. Liley. J Phys Chem Ref Data 1, 279(1972).

Thermal Conductivity of the Elements: A Comprehensive Review Cho Y. Ho, Robert W. Powell, and Peter E. Liley. J Phys Chem Ref Data 3, Suppl. 1(1974).

\section{Poynter, Robert L.}

Microwave Spectra of Molecules of Astrophysical Interest, XII. Hydroxyl Radical — Robert A. Beaudet and Robert L. Poynter. J Phys Chem Ref Data 7, 311(1978).

\section{Prakash, Brahm}

Crystal Structure Transformations in Inorganic Nitrites, Nitrates, and Carbonates - C. N. R. Rao, Brahm Prakash, and M. Natarajan. NSRDS-NBS 53, 55p. (1975).

Crystal Structure Transformations in Inorganic Sulfates, Phosphates, Perchlorates, and Chromates - C. N. R. Rao and Brahm Prakash. NSRDS-NBS 56, 37p. (1975).

\section{Pratto, M. R.}

Microwave Spectral Tables, Volume II. Line Strengths of Asymmetric Rotors - Paul F. Wacker and M. R. Pratto. NBS Monograph 70, 349p. (1964).

\section{Price, LeRoy $\mathbf{R}$.}

A Compilation of YN Reactions - Odette Benary, Naomi BarashSchmidt, LeRoy R. Price, Arthur H. Rosenfeld, Gideon Alexander and Particle Data Group. UCRL 20000YN, Springfield, VA: NTIS, 70p. (1970). UCRL-20 000 YN, A04. 


\section{Prophet, $\mathrm{H}$.}

JANAF Thermochemical Tables, 1974 Supplement - Malcolm W. Chase, Jr., J. L. Curnutt, A. T. Hu, H. Prophet, A. N. Syverud, and L. C. Walker. J Phys Chem Ref Data 3, 311(1974).

JANAF Thermochemical Tables, 1975 Supplement - Malcolm W. Chase, Jr., J. L. Curnutt, H. Prophet, R. A. McDonald, and A. N. Syverud. J Phys Chem Ref Data 4, 1(1975).

JANAF Thermochemical Tables, Second Edition - Daniel R. Stull and H. Prophet. NSRDS-NBS 37, 1141p. (1971).

\section{Prydz, R.}

The Viscosity and Thermal Conductivity Coefficients of Gaseous and Liquid Fluorine - Howard J. M. Hanley and R. Prydz. J Phys Chem Ref Data 1, 1101(1972).

\section{Rabinovich, V. A.}

Thermophysical Properties of Air and Air Components - A. A. Vasserman, Ya. Z. Kazavchinskii, V. A. Rabinovich, and A. M. Zhuravlev. Russian Transl. Springfield, VA: NTIS, 402p. (1971). TT 70-50095, A 18.

Thermophysical Properties of Gases and Liquids, No. $1-$ V. A. Rabinovich. Russian Transl. Springfield, VA: NTIS, 214p. (1970). TT 69-55091, A.10, the translation of volumes 2, 3, and 4 have the title: Thermophysical Properties of Matter and Substances.

Thermophysical Properties of Liquid Air and Its Components - A. A. Vasserman and V. A. Rabinovich. Russian Transl. Springfield, VA: NTIS, 255p. (1970). TT 69-55092, A 12.

Thermophysical Properties of Matter and Substances, Volume 2 V. A. Rabinovich. Russian Transl. Springfield, VA: NTIS, 395p. (1974). TT 72-52001, A 17, the translation of volume 1 has the title: Thermophysical Properties of Gases and Liquids.

Thermophysical Properties of Matter and Substances, Volume 3 V. A. Rabinovich. Russian Transl. Springfield, VA: NTIS, 212p. (1975). TT 73-52009, A 10, the translation of volume 1 has the title: Thermophysical Properties of Gases and Liquids.

Thermophysical Properties of Matter and Substances, Volume 4 V. A. Rabinovich. Russian Transl. Springfield, VA: NTIS, 179p. (1975). TT 73-52029, A09, the translation of volume 1 has the title: Thermophysical Properties of Gases and Liquids.

\section{Ramsay, D. A.}

Molecular Structures of Gas-Phase Polyatomic Molecules Determined by Spectroscopic Methods - Marlin D. Harmony, Victor W. Laurie, Robert L. Kuczkowski, Richard H. Schwendeman, D. A. Ramsay, Frank J. Lovas, Walter J. Lafferty, and Arthur G. Maki. J Phys Chem Ref Data 8, 619(1979).

\section{Rao, C. N. R.}

Bibliography of Infrared Spectroscopy through 1960 - C. N. R. Rao, S. K. Dikshit, Shanti A. Kudchadker, D. S. Gupta, V. A. Narayan, and John J. Comeford. NBS Spec. Publ. 428, 1,2,3(1976).

Crystal Structure Transformations in Binary Halides - C. N. R. Rao and M. Natarajan. NSRDS-NBS 41, 57p. (1972).

Crystal Structure Transformations in Inorganic Nitrites, Nitrates, and Carbonates - C. N. R. Rao, Brahm Prakash, and M. Natarajan. NSRDS-NBS 53, 55p. (1975).

Crystal Structure Transformations in Inorganic Sulfates, Phosphates, Perchlorates, and Chromates - C. N. R. Rao and Brahm Prakash. NSRDS-NBS 56, 37p. (1975).

Transition Metal Oxides, Crystal Chemistry, Phase Transition, and Related Aspects - C. N. R. Rao and G. V. Subba Rao. NSRDS-NBS 49, 140p. (1974).
Rao, G. V. Subba

Transition Metal Oxides, Crystal Chemistry, Phase Transition, and Related Aspects - C. N. R. Rao and G. V. Subba Rao. NSRDS-NBS 49, 140p. (1974).

\section{Read, Michael E.}

Diffusion Rate Data and Mass Transport Phenomena in Copper Systems - Daniel B. Butrymowicz, John R. Manning, and Michael E. Read. INCRA Monograph V, New York: International Copper Research Association, Inc., 322p. (1977).

Diffusion Rate Data and Mass Transport Phenomena for Copper Systems, Part II - Daniel B. Butrymowicz, John R. Manning, and Michael E. Read. INCRA Monograph VIII, New York: International Copper Research Association, Inc., 701p. (1982).

Diffusion in Copper and Copper Alloys, Part I. Volume and Surface Self-Diffusion in Copper - Daniel B. Butrymowicz, John R. Manning, and Michael E. Read. J Phys Chem Ref Data 2, 643(1973).

Diffusion in Copper and Copper Alloys, Part II. Copper-Silver and Copper-Gold Systems - Daniel B. Butrymowicz, John R. Manning, and Michael E. Read. J Phys Chem Ref Data 3, 527(1974).

Diffusion in Copper and Copper Alloys, Part III. Diffusion in Systems Involving Elements of the Groups IA, IIA, IIIB, IVB, VB, and VIIB - Daniel B. Butrymowicz, John R. Manning, and Michael E. Read. J Phys Chem Ref Data 4, 177(1975).

Diffusion in Copper and Copper Alloys, Part IV. Diffusion in Systems Involving Elements of Group VIII - Daniel B. Butrymowicz, John R. Manning, and Michael E. Read. J Phys Chem Ref Data 5, 103(1976).

Diffusion in Copper and Copper Alloys, Part V. Diffusion in Systems Involving Elements of Group VA - Daniel B. Butrymowicz, John R. Manning, and Michael E. Read. J Phys Chem Ref Data 6, 1(1977).

\section{Reader, Joseph}

Energy Levels of Iron, Fe I through Fe XXVI - Joseph Reader and Jack Sugar. J Phys Chem Ref Data 4, 353(1975).

Ground Levels and Ionization Potentials for Lanthanide and Actinide Atoms and Ions - William C. Martin, Lucy Hagan, Joseph Reader, and Jack Sugar. J Phys Chem Ref Data 3, 771(1974).

Tables of Line Spectra of the Elements, Part 1. Wavelengths and Intensities, Part 2. Transition Probabilities - Joseph Reader, Charles H. Corliss, Wolfgang L. Wiese, and Georgia A. Martin. NSRDS-NBS 68, 415p. (1980).

\section{Reed, R. P.}

Elastic Properties of Metals and Alloys, I. Iron, Nickel, and IronNickel Alloys - Hassell M. Ledbetter and R. P. Reed. J Phys Chem Ref Data 2, 531(1973).

\section{Reilly, Martin L.}

Critical Analysis of Heat-Capacity Data and Evaluation of Thermodynamic Properties of Ru, Ph, Pd, Ir, and Pt from 0 to $300 \mathrm{~K}$. A Survey of the Literature Data on Osmium - George T. Furukawa, Martin L. Reilly, and John S. Gallagher. J Phys Chem Ref Data 3, 163(1974).

Critical Analysis of the Heat-Capacity Data of the Literature and Evaluation of Thermodynamic Properties of Copper, Silver, and Gold from 0 to $300 \mathrm{~K}$ - George T. Furukawa, W. G. Saba, and Martin L. Reilly. NSRDS-NBS 18, 49p. (1968).

\section{Rettich, Timothy R.}

The Solubility of Nitrogen and Air in Liquids - Rubin Battino, Timothy R. Rettich, and Toshihiro Tominaga. J Phys Chem Ref Data 13, 563(1984).

The Solubility of Oxygen and Ozone in Liquids - Rubin Battino, Timothy R. Rettich, and Toshihiro Tominaga. J Phys Chem Ref Data 12, 163(1983). 
Rivkin, S. L.

Heavy Water, Thermophysical Properties - V. A. Kirillin, Ya. Z. Kazavchinskii, P. M. Kessel'man, S. L. Rivkin, A. E. Sheindlin, E. E. Shpil'rain, V. V. Sychev, and D. L. Timrot. Russian Transl. Springfield, VA: NTIS, 273p. (1971). TT 70-50094, A12.

\section{Ro, S. T.}

Equilibrium and Transport Properties of the Noble Gases and Their Mixtures at Low Density - Joseph Kestin, K. Knierim, E. A. Mason, B. Najafi, S. T. Ro, and M. Waldman. J Phys Chem Ref Data 13, 229(1984).

\section{Robbins, Carl R.}

Phase Diagrams for Ceramists - Ernest M. Levin, Carl R. Robbins, Howard F. McMurdie, editor(s). American Ceramic Society; Columbus, Ohio, 601p. (1964), ISBN: 0-916094-04-9.

Phase Diagrams for Ceramists 1969 Supplement - Ernest M. Levin, Carl R. Robbins, Howard F. McMurdie, editor(s). American Ceramic Society: Columbus, Ohio, 625p. (1969), ISBN: 0-916094-05-7.

\section{Roberts, Benjamin W.}

Properties of Selected Superconductive Materials, 1978 Supplement - Benjamin W. Roberts. NBS Tech. Note 983, 103p. (1978).

Survey of Superconductive Materials and Critical Evaluation of Selected Properties - Benjamin W. Roberts. J Phys Chem Ref Data 5, 581(1976).

Roberts, J. R.

A Critical Review of the Stark Widths and Shifts of Spectral Lines from Non-Hydrogenic Atoms - N. Konjević and J. R. Roberts. J Phys Chem Ref Data 5, 209(1976).

Robiette, A. G.

Microwave Spectra of Molecules of Astrophyical Interest. XX. Methane - I. Ozier, M. C. L. Gerry, and A. G. Robiette. J Phys Chem Ref Data 10, 1085(1981).

\section{Roblnson, Gllpin R., Jr.}

Thermodynamic Tabulations for Selected Phases in the System $\mathrm{CaO} \cdot \mathrm{Al}_{2} \mathrm{O}_{3}-\mathrm{SiO}_{2}-\mathrm{H}_{2} \mathrm{O}$ at $101.325 \mathrm{kPa}$ (1 atm.) between 273.15 and 1800 K - John L. Haas, Jr., Gilpin R. Robinson, Jr., and Bruce S. Hemingway. J Phys Chem Ref Data 10, 575(1981).

\section{Roder, Hans M.}

Liquid Densities of Oxygen, Nitrogen, Argon, and Parahydrogen Hans M. Roder, Robert D. McCarty, and V. J. Johnson. NBS Tech. Note 361, 1972(1973).

The Molar Volume (Density) of Solid Oxygen in Equilibrium with Vapor - Hans M. Roder. J Phys Chem Ref Data 7, 949(1978).

Thermodynamic and Related Properties of Parahydrogen from the Triple Point to $100 \mathrm{~K}$ at Pressures to 340 Atmospheres - Hans M. Roder, Lloyd A. Weber, and Robert D. Goodwin. NBS Monograph 94, 116p. (1965).

\section{Rodgers, A. S.}

Ideal Gas Thermodynamic Properties of Eight Chloro- and Fluoromethanes - A. S. Rodgers, Jing Chao, Randolph C. Wilhoit, and Bruno J. Zwolinski. J Phys Chem Ref Data 3, 117(1974).

Ideal Gas Thermodynamic Properties of Six Chloroethanes - Jing Chao, A. S. Rodgers, Randolph C. Wilhoit, and Bruno J. Zwolinski. J Phys Chem Ref Data 3, 141(1974).

Ideal Gas Thermodynamic Properties of Six Fluoroethanes - S. S. Chen, A. S. Rodgers, Jing Chao, Randolph C. Wilhoit, and Bruno J. Zwolinski. J Phys Chem Ref Data 4, 441(1975).

\section{Rodgers, John R.}

Crystal Data Determinative Tables, Third Edition, Volume 3. Organic Compounds - Joseph D. H. Donnay, Olga Kennard, David G. Watson, and John R. Rodgers. Swarthmore, PA: JCPDS-International Center for Diffraction Data, 748p. (1978).

Crystal Data Determinative Tables, Third Edition, Volume 5. Organic Compounds - Olga Kennard, David G. Watson, John E. Davies, John R. Rodgers, editor(s). 5, Swarthmore, PA, JCPDS-International Center for Diffraction Data,(1983).

\section{Rogers, David}

Ideal Gas Thermodynamic Properties of $\mathrm{CH}_{3}, \mathrm{CD}_{3}, \mathrm{CD}_{4}, \mathrm{C}_{2} \mathrm{D}_{2}$, $\mathrm{C}_{2} \mathrm{D}_{4}, \mathrm{C}_{2} \mathrm{D}_{6}, \mathrm{C}_{2} \mathrm{H}_{6}, \mathrm{CH}_{3} \mathrm{~N}_{2} \mathrm{CH}_{3}$, and $\mathrm{CD}_{3} \mathrm{~N}_{2} \mathrm{CD}_{3}-$ Krishna $\mathrm{M}$. Pamidimukkala, David Rogers, and Gordon B. Skinner. J Phys Chem Ref Data 11, 83(1982).

\section{Rogers, P. S. Z.}

Volumetric Properties of Aqueous Sodium Chloride Solutions - P. S. Z. Rogers and Kenneth S. Pitzer. J Phys Chem Ref Data 11, 15(1982).

\section{Rosenfeld, Arthur H.}

$\pi \mathrm{N}$ Particle-Wave Amplitudes - David J. Herndon, Angela Barbaro-Galtieri, Arthur H. Rosenfeld and Particle Data Group. UCRL $20030 \pi \mathrm{N}$, Springfield, VA: NTIS, 85p. (1970). UCRL 20030 $\pi \mathrm{N}, \mathrm{A} 05$.

A Compilation of YN Reactions - Odette Benary, Naomi BarashSchmidt, LeRoy R. Price, Arthur H. Rosenfeld, Gideon Alexander and Particle Data Group. UCRL 20000YN, Springfield, VA: NTIS, 70p. (1970). UCRL-20 000 YN, A04.

\section{Rosenstock, Henry M.}

A Bibliography on Ion-Molecule Reactions. January 1900 to March 1966 - F. N. Harllee, Henry M. Rosenstock, and John T. Herron. NBS Tech. Note 291, 40p. (1966).

A Compendium of Gas Phase Basicity and Proton Affinity Measurements - K. N. Hartman, Sharon G. Lias, P. J. Ausloos, Henry M. Rosenstock, S. S. Schroyer, C. Schmidt, D. Martinsen, and G. W. A. Milne. NBSIR 79-1777, 563p. (1979).

Annotated Bibliography on Proton Affinities - K. N. Hartman, Sharon G. Lias, P. J. Ausloos, and Henry M. Rosenstock. NBSIR 76-1061, 52p. (1976).

Automation of the Ion Energetics Data Center - Robert C. Thompson, W. J. Webb, and Henry M. Rosenstock. NBSIR 78-1432, 84p. (1978).

Energetics of Gaseous Ions - Henry M. Rosenstock, Keith Draxl, B. W. Steiner, and John T. Herron. J Phys Chem Ref Data 6, Suppl. 1(1977).

Ion Energetics Measurements, Supplement I. 1971-1973 - Henry M. Rosenstock, D. Sims, S. S. Schroyer, and W. J. Webb. NSRDS-NBS 66, 380p. (1980).

Ionization Potentials, Appearance Potentials, and Heats of Formation of Gaseous Positive Ions - Joseph L. Franklin, J. G. Dillard, Henry M. Rosenstock, John T. Herron, Keith Draxl, and Frank H. Field. NSRDS-NBS 26, 289p. (1969).

\section{Ross, Alberta B.}

A Catalog of Data Compilations on Photochemical and Photophysical Processes in Solution - James G. Brummer, W. Phillip Helman, and Alberta B. Ross. NBS Spec. Publ. 578, 27p. (1980).

Rate Constants for Reactions of Aliphatic Carbon-Centered Radicals in Aqueous Solution - Alberta B. Ross and Pedatsur Neta. NSRDSNBS 70, 96p. (1982). 
Rate Constants for Reactions of Inorganic Radicals in Aqueous Solution - Alberta B. Ross and Pedatsur Neta. NSRDS-NBS 65, 62p. (1979).

Selected Specific Rates of Reactions of Transients from Water in Aqueous Solution, 1. Hydrated Electron - Michael Anbar, Mark Bambenek, and Alberta B. Ross. NSRDS-NBS 43, 69p. (1973).

Selected Specific Rates of Reactions of Transients from Water in Aqueous Solution, 1. Hydrated Electron, Supplemental Data Alberta B. Ross. NSRDS-NBS 43, Suppl.(1975).

Selected Specific Rates of Reactions of Transients from Water in Aqueous Solution, II. Hydrogen Atom - Michael Anbar, Farhataziz, and Alberta B. Ross. NSRDS-NBS 51, 66p. (1975).

Selected Specific Rates of Reactions of Transients from Water in Aqueous Solution, III. Hydroxyl Radical and Perhydroxyl Radical and Their Radical Ions - Farhataziz and Alberta B. Ross. NSRDS-NBS 59, 126p. (1977).

Thesaurus for Radiation Chemistry - Alberta B. Ross and Radiation Chemistry Data Center. Rad Chem. 1, Springfield, VA: NTIS, 48p. (1977). UND-RCDC-1, A03.

\section{Rossmassler, Stephen A.}

Critical Evaluation of Data in the Physical Sciences - A Status Report on the National Standard Reference Data System, January 1977 Stephen A. Rossmassler. NBS Tech. Note 947, 88p. (1977).

\section{Roszman, Larry J.}

Bibliography on Atomic Line Shapes and Shifts (1899 through March 1972) - Jeffrey R. Fuhr, Wolfgang L. Wiese, and Larry J.

Roszman. NBS Spec. Publication 366, 165p. (1972).

Bibliography on Atomic Line Shapes and Shifts (April 1972 through June 1973) - Jeffrey R. Fuhr, Larry J. Roszman, and Wolfgang L. Wiese. NBS Spec. Publ. 366, Suppl. 1(1974).

\section{Roy, Sathyabhama}

Selected Specific Rates of Reactions of the Solvated Electron in Alcohols - Edgar Watson, Jr. and Sathyabhama Roy. NSRDS-NBS 42, 27p. (1972).

\section{Rudge, M. R. H.}

Theory of the Ionization of Atoms by Electron Impact - M. R. H. Rudge. Rev Mod Phys 40, .., 564p. (1968).

\section{Rullhusen, P.}

Small-Angle Rayleigh Scattering of Photons at High Energies: Tabulations of Relativisitic HFS Modified A tomic Form Factors - D. Schaupp, M. Schumacher, F. Smend, P. Rullhusen, and John H. Hubbell. J Phys Chem Ref Data 12, 467(1983).

\section{Rumble, John R., Jr.}

Bibliography of Low Energy Electron and Photon Cross Section Data (January 1975 to December 1977) - Jean W. Gallagher, John R. Rumble, Jr., and Earl C. Beaty. NBS Spec. Publ. 426, Suppl. 1(1979).

Data Index for Energy Transfer Collisions of Atoms and Molecules - 1970-1979 - Jean W. Gallagher, Janet Van Blerkom, Earl C. Beaty, and John R. Rumble, Jr. NBS Spec. Publ. 593, 349p. (1981).

\section{Ryzhenko, B. N.}

Handbook of Thermodynamic Data on Geological Substances - G. B. Naumov, B. N. Ryzhenko, and I. L. Khodakovsky. Russian Transl. Springfield, VA: NTIS, 340p. (1974). TT 73-53051 or PB226 722, A15.
Saba, W. G.

Critical Analysis of the Heat-Capacity Data of the Literature and Evaluation of Thermodynamic Properties of Copper, Silver, and Gold from 0 to $300 \mathrm{~K}-$ George T. Furukawa, W. G. Saba, and Martin L. Reilly. NSRDS-NBS 18, 49p. (1968).

\section{Sage, Bruce $\mathrm{H}$.}

Phase Behavior in Binary and Multicomponent Systems at Elevated Pressures: n-Pentane and Methane-n-Pentane - Virginia M. Berry and Bruce H. Sage. NSRDS-NBS 32, 79p. (1970).

\section{Samsonov, G. V.}

Handbook of Hardness Data - G. V. Samsonov and A. A. Ivan'ko. Russian Transl. Springfield, VA: NTIS, 69p. (1970). TT 70-50177, A04.

\section{Schaupp, D.}

Small-Angle Rayleigh Scattering of Photons at High Energies: Tabulations of Relativisitic HFS Modified Atomic Form Factors - D. Schaupp, M. Schumacher, F. Smend, P. Rullhusen, and John H. Hubbell. J Phys Chem Ref Data 12, 467(1983).

\section{Scheer, M. D.}

Survey of Photochemical and Rate Data for Twenty-eight Reactions of Interest in Atmospheric Chemistry - Robert F. Hampson, Jr., W. Braun, R. L. Brown, David Garvin, John T. Herron, Robert E. Huie, M. J. Kurylo, A. H. Laufer, J. D. McKinley, H. Okabe, M. D. Scheer, W. Tsang, D. H. Stedman, editor(s). J Phys Chem Ref Data 2, 267(1973)

\section{Schmidt, C.}

A Compendium of Gas Phase Basicity and Proton Affinity Measurements - K. N. Hartman, Sharon G. Lias, P. J. Ausloos, Henry M. Rosenstock, S. S. Schroyer, C. Schmidt, D. Martinsen, and G. W. A. Milne. NBSIR 79-1777, 563p. (1979).

\section{Schmorak, J.}

Handbook of Phase Diagrams of Silicate Systems, Vol. I. Binary Systems, Second Revised Edition - N. A. Toropov, V. P. Barzakovskii, V. V. Lapin, N. N. Kurtseva, J. Schmorak, editor(s). Russian Transl. Springfield, VA: NTIS, 730p. (1970). TT 71-50040, A26.

\section{Schofleld, Keith}

Critically Evaluated Rate Constants for Gaseous Reactions of Several Electronically Excited Species - Keith Schofield. J Phys Chem Ref Data 8, 723(1979).

Evaluated Chemical Kinetic Rate Constants for Various Gas Phase Reactions - Keith Schofield. J Phys Chem Ref Data 2, 25(1973).

\section{Schroyer, S. S.}

A Compendium of Gas Phase Basicity and Proton Affinity Measurements - K. N. Hartman, Sharon G. Lias, P. J. Ausloos, Henry M. Rosenstock, S. S. Schroyer, C. Schmidt, D. Martinsen, and G. W. A. Milne. NBSIR 79.1777, 563p. (1979).

Ion Energetics Measurements, Supplement I. 1971-1973 - Henry M. Rosenstock, D. Sims, S. S. Schroyer, and W. J. Webb. NSRDS-NBS 66, 380p. (1980).

\section{Schulz, George J.}

Resonances in Electron Impact on Atoms and Diatomic Molecules - George J. Schulz. NSRDS-NBS 50, 120p. (1973). 


\section{Schumacher, $M$.}

Small-Angle Rayleigh Scattering of Photons at High Energies: Tabulations of Relativisitic HFS Modified Atomic Form Factors - D. Schaupp, M. Schumacher, F. Smend, P. Rullhusen, and John H. Hubbell. J Phys Chem Ref Data 12, 467(1983).

\section{Schumm, Richard H.}

A Computer Assisted Evaluation of the Thermochemical Data of the Compounds of Thorium - Donald D. Wagman, Richard H. Schumm, and Vivian B. Parker. NBSIR 77-1300, 94p. (1977).

Chemical Thermodynamic Properties of Compounds of Sodium, Potassium, and Rubidium: An Interim Tabulation of Selected Material Donald D. Wagman, William H. Evans, Vivian B. Parker, and Richard H. Schumm. NBSIR 76-1034, 76p. (1976).

Selected Values of Chemical Thermodynamic Properties. Tables for the First Thirty-Four Elements in the Standard Order of Arrangement - Donald D. Wagman, William H. Evans, Vivian B. Parker, Iva Halow, Sylvia M. Bailey, and Richard H. Schumm. NBS Tech. Note 270, 264p. (1968).

Selected Values of Chemical Thermodynamic Properties. Tables for Elements 35 through 53 in the Standard Order of Arrangement Donald D. Wagman, William H. Evans, Vivian B. Parker, Iva Halow, Sylvia M. Bailey, and Richard H. Schumm. NBS Tech. Note 270, 152p. (1969).

Selected Values of Chemical Thermodynamic Properties. Tables for Elements 54 through 61 in the Standard Order of Arrangement Donald D. Wagman, William H. Evans, Vivian B. Parker, Iva Halow, Sylvia M. Bailey, Richard H. Schumm, and Kenneth L. Churney. NBS Tech. Note 270, 49p. (1971).

Selected Values of Chemical Thermodynamic Properties. Tables for the Lanthanide (Rare Earth) Elements (Elements 62 through 76 in the Standard Order of Arrangement) - Richard H. Schumm, Donald D. Wagman, Sylvia M. Bailey, William H. Evans, and Vivian B. Parker. NBS Tech. Note 270, 84p. (1973).

Selected Values of Chemical Thermodynamic Properties: Compounds of Uranium, Protactinium, Thorium, Actinium, and the Alkali Metals - Donald D. Wagman, William H. Evans, Vivian B. Parker, Richard H. Schumm, and Ralph L. Nuttall. NBS Tech. Note 270, 149p. (1981).

The NBS Tables of Chemical Thermodynamic Properties. Selected Values for Inorganic and $C_{1}$ and $C_{2}$ Organic Substances in SI Units Donald D. Wagman, William H. Evans, Vivian B. Parker, Richard H. Schumm, Iva Halow, Sylvia M. Bailey, Kenneth L. Churney, and Ralph L. Nuttall. J Phys Chem Ref Data 11, Suppl. 2(1982).

Thermodynamic Properties of Solid Aluminosilicates at Elevated Temperatures - Richard H. Schumm. NBSIR 81-2343, 57p. (1981).

\section{Schwalbe, L. A.}

A Review of Deuterium Triple-Point Temperatures - L. A. Schwalbe and E. R. Grilly. J Phys Chem Ref Data 13, 687(1984).

\section{Schwendeman, RIchard H.}

Molecular Structures of Gas-Phase Polyatomic Molecules Determined by Spectroscopic Methods - Marlin D. Harmony, Victor W. Laurie, Robert L. Kuczkowski, Richard H. Schwendeman, D. A. Ramsay, Frank J. Lovas, Walter J. Lafferty, and Arthur G. Maki. J Phys Chem Ref Data 8, 619(1979).

Tables for the Rigid Asymmetric Rotor: Transformation Coefficients from Symmetric to Asymmetric Bases and Expectation Values of $\mathrm{P}^{2<-}{ }_{z}$, $\mathrm{P}^{\dagger<-}{ }_{z}$, and $\mathrm{P}^{6<-}{ }_{z}-$ Richard H. Schwendeman. NSRDS-NBS 12, $102 \mathrm{p}$. (1968).

\section{Sehgal, H. K.}

Bibliography on Properties of Defect Centers in Alkali Halides Suresh C. Jain, S. A. Khan, H. K. Sehgal, V. K. Garg, and R. K. Jain. OSRD Bibl. 71-1, 293p. (1971).

\section{Sellers, Robin M.}

Compilation of Rate Constants for the Reactions of Metal Ions in Unusual Valency States - George V. Buxton and Robin M. Sellers. NSRDS-NBS 62, 68p. (1978).

\section{Seltzer, S. M.}

Stopping Powers and Ranges of Electrons and Positrons - M. J. Berger and S. M. Seltzer. NBSIR 82-2550, 164p. (1982).

\section{Sengers, J. M. H. Levelt}

Scaled Equation of State Parameters for Gases in the Critical Region - J. M. H. Levelt Sengers, W. L. Greer, and Jan V. Sengers. J Phys Chem Ref Data 5, 1(1976).

The Critical-Region Equation of State of Ethene and the Effect of Small Impurities - J. R. Hastings, J. M. H. Levelt Sengers, and F. W. Balfour. J Chem Thermody 12, London: Academic Press Inc., 1009p. (1980).

Thermodynamic Properties of $\mathrm{D}_{2} \mathrm{O}$ in the Critical Region - B. Kamgar-Parsi, J. M. H. Levelt Sengers, and Jan V. Sengers. J Phys Chem Ref Data 12, 513(1983).

Thermodynamic Properties of Steam in the Critical Region - J. M. H. Levelt Sengers, B. Kamgar-Parsi, F. W. Balfour, and Jan V. Sengers. J Phys Chem Ref Data 12, 1(1983).

Thermophysical Properties of Fluid $\mathrm{H}_{2} \mathrm{O}$ - Joseph Kestin, Jan V. Sengers, B. Kamgar-Parsi, and J. M. H. Levelt Sengers. J Phys Chem Ref Data 13, 175(1984).

Thermophysical Properties of Fluid $\mathrm{D}_{2} \mathrm{O}$ - Joseph Kestin, Jan V. Sengers, B. Kamgar-Parsi, and J. M. H. Levelt Sengers. J Phys Chem Ref Data 13, 602(1984).

\section{Sengers, Jan V.}

An Improved Representative Equation for the Dynamic Viscosity of Water Substance - J. T. R. Watson, R. S. Basu, and Jan V. Sengers. J Phys Chem Ref Data 9, 1255(1980).

Problems with the Prandtl Number of Steam - Jan V. Sengers, R. S. Basu, B. Kamgar-Parsi, and Joseph Kestin. Mech Eng 104, New York, NY, 60p. (1982).

Representative Equations for the Thermal Conductivity of Water Substance - Jan V. Sengers, J. T. R. Watson, R. S. Basu, B. KamgarParsi, and R. C. Hendricks. J Phys Chem Ref Data 13, 893(1984).

Representative Equations for the Viscosity of Water Substance Jan V. Sengers and B. Kamgar-Parsi. J Phys Chem Ref Data 13, 185(1984).

Scaled Equation of State Parameters for Gases in the Critical Region - J. M. H. Levelt Sengers, W. L. Greer, and Jan V. Sengers. J Phys Chem Ref Data 5, 1(1976).

Thermodynamic Properties of $\mathrm{D}_{2} \mathrm{O}$ in the Critical Region - B. Kamgar-Parsi, J. M. H. Levelt Sengers, and Jan V. Sengers. J Phys Chem Ref Data 12, 513(1983).

Thermodynamic Properties of Steam in the Critical Region - J. M. H. Levelt Sengers, B. Kamgar-Parsi, F. W. Balfour, and Jan V. Sengers. J Phys Chem Ref Data 12, 1(1983).

Thermophysical Properties of Fluid $\mathrm{H}_{2} \mathrm{O}$ - Joseph Kestin, Jan V. Sengers, B. Kamgar-Parsi, and J. M. H. Levelt Sengers. J Phys Chem Ref Data 13, 175(1984).

Thermophysical Properties of Fluid $\mathrm{D}_{2} \mathrm{O}$ - Joseph Kestin, Jan V. Sengers, B. Kamgar-Parsi, and J. M. H. Levelt Sengers. J Phys Chem Ref Data 13, 602(1984).

\section{Shapiro, B. L.}

NMR Spectral Data: A Compilation of Aromatic Proton Chemical Shifts in Mono- and Di-Substituted Benzene - B. L. Shapiro and L. E. Mohrmann. J Phys Chem Ref Data 6, 919(1977). 


\section{Shaw, Robert}

A Compilation of Kinetic Parameters for the Thermal Degradation of n-Alkane Molecules - D. L. Allara and Robert Shaw. J Phys Chem Ref Data 9, 523(1980).

Semi-Empirical Extrapolation and Estimation of Rate Constants for Abstraction of $\mathrm{H}$ from Methane by $\mathrm{H}, \mathrm{O}, \mathrm{HO}$, and $\mathrm{O}_{2}-$ Robert Shaw. I Phys Chem Ref Data 7, 1179(1978).

\section{Sheindlin, A. E.}

Heavy Water, Thermophysical Properties - V. A. Kirillin, Ya. Z. Kazavchinskii, P. M. Kessel'man, S. L. Rivkin, A. E. Sheindlin, E. E. Shpil'rain, V. V. Sychev, and D. L. Timrot. Russian Transl. Springfield, VA: NTIS, 273p. (1971). TT 70-50094, A12.

\section{Sherwood, Gertrude B.}

A Bibliography of the Russian Reference Data Holdings of the Library of the Office of Standard Reference Data - Gertrude B. Sherwood and Howard J. White, Jr. NBS Tech. Note 848, 23p. (1974).

A Guide to Sources of Information on Materials - Robert S. Marvin, Gertrude B. Sherwood, C. T. Lynch, editor(s). Cleveland, OH: CRC Press, 603p. (1975). Chapter 10 in Handbook of Materials Science, Volume III. Nonmetallic Materials and Publications, C. T. Lynch, Editor.

Annotated Accession List of Data Compilations of the NBS Office of Standard Reference Data - Herman M. Weisman and Gertrude B. Sherwood. NBS Tech. Note 554, 196p. (1970).

Property Index to NSRDS Data Compilations, 1964-1972 - David R. Lide, Jr., Gertrude B. Sherwood, Charles H. Douglass, and Herman M. Weisman. NSRDS-NBS 55, 21p. (1975).

Standard Reference Data Publications, 1964-1980 - Gertrude B. Sherwood. NBS Spec. Publ. 612, 125p. (1981).

\section{Shimanouchi, Takehiko}

Tables of Molecular Vibrational Frequencies, Part 1 - Takehiko Shimanouchi. NSRDS-NBS 6, 56p. (1967).

Tables of Molecular Vibrational Frequencies, Part 2 - Takehiko Shimanouchi. NSRDS-NBS 11, 38p. (1967).

Tables of Molecular Vibrational Frequencies, Part 3 - Takehiko Shimanouchi. NSRDS-NBS 17, 39p. (1968).

Tables of Molecular Vibrational Frequencies, Consolidated Volume I - Takehiko Shimanouchi. NSRDS-NBS 39, 167p. (1972).

Tables of Molecular Vibrational Frequencies, Part 5 - Takehiko Shimanouchi. J Phys Chem Ref Data 1, 189(1972).

Tables of Molecular Vibrational Frequencies, Part 6 - Takehiko Shimanouchi. J Phys Chem Ref Data 2, 121(1973).

Tables of Molecular Vibrational Frequencies, Part 7 - Takehiko Shimanouchi. J Phys Chem Ref Data 2, 225(1973).

Tables of Molecular Vibrational Frequencies, Part 8 - Takehiko

Shimanouchi. J Phys Chem Ref Data 3, 269(1974).

Tables of Molecular Vibrational Frequencies. Consolidated Volume II - Takehiko Shimanouchi. J Phys Chem Ref Data 6, 993(1977).

Tables of Molecular Vibrational Frequencies, Part 9 - Takehiko Shimanouchi, Hiroatsu Matsuura, Yoshiki Ogawa, and Issei Harada. J Phys Chem Ref Data 7, 1323(1978).

Tables of Molecular Vibrational Frequencies, Part 10 - Takehiko Shimanouchi, Hiroatsu Matsuura, Yoshiki Ogawa, and Issei Harada. J Phys Chem Ref Data 9, 1149(1980).

\section{Shirley, Virginia S.}

Nuclear Wallet Cards — Virginia S. Shirley, C. Michael Lederer and National Nuclear Data Center. 1979, Upton, NY: National Nuclear Data Center, Brookhaven National Laboratory, 40p. (1979). Title, no charge.

Table of Isotopes, Seventh Edition - C. Michael Lederer, Virginia S. Shirley, Edgardo Browne, Janis M. Dairiki, and Raymond E.
Doebler. New York: Wiley-Interscience, 1628p. (1978), ISBN: 0-471-0417-3.

\section{Shiu, Wan Ying}

A Critical Review of Henry's Law Constants for Chemicals of Environmental Interest - Donald Mackay and Wan Ying Shiu. J Phys Chem Ref Data 10, 1175(1981).

\section{Shpil'rain, E. E.}

Heavy Water, Thermophysical Properties - V. A. Kirillin, Ya. Z. Kazavchinskii, P. M. Kessel'man, S. L. Rivkin, A. E. Sheindlin, E. E. Shpil'rain, V. V. Sychev, and D. L. Timrot. Russian Transl. Springfield, VA: NTIS, 273p. (1971). TT 70-50094, Al2.

\section{Shu, Hua-Cheng}

Heat Capacity and Other Thermodynamic Properties of Linear Macromolecules. I. Selenium - Umesh Gaur, Hua-Cheng Shu, Aspy Metha, and Bernhard Wunderlich. J Phys Chem Ref Data 10, 89(1981).

\section{Shukla, R. P.}

Vapor Pressures and Boiling Points of Selected Halomethanes Arvind P. Kudchadker, Shanti A. Kudchadker, R. P. Shukla, and P. R. Patnaik. J Phys Chem Ref Data 8, 499(1979).

\section{Sieck, L. Wayne}

Rate Coefficients for Ion-Molecule Reactions, I. Ions Containing C and $\mathrm{H}-\mathbf{L}$. Wayne Sieck and Sharon G. Lias. J Phys Chem Ref Data 5, 1123(1976).

Rate Coefficients for Ion-Molecule Reactions, Organic Ions Other Than Those Containing Only $\mathrm{C}$ and $\mathrm{H}-\mathrm{L}$. Wayne Sieck. NSRDSNBS 64, 27p. (1980).

\section{Siegenthaler, H. F.}

Molten Salts: Volume 3, Nitrates, Nitrites, and Mixtures. Electrical Conductance, Density, Viscosity, and Surface Tension Data - George J. Janz, Ursula Krebs, H. F. Siegenthaler, and Reginald P. T. Tomkins. J Phys Chem Ref Data 1, 581(1972).

\section{Simmons, J. D.}

Atlas of the Observed Absorption Spectrum of Carbon Monoxide between 1060 and $1900 \AA-$ S. G. Tilford and J. D. Simmons. J Phys Chem Ref Data 1, 147(1972).

\section{Sims, D.}

Ion Energetics Measurements, Supplement I. 1971-1973 - Henry M. Rosenstock, D. Sims, S. S. Schroyer, and 'W. J. Webb. NSRDS-NBS 66, 380p. (1980).

\section{Singer, S. K.}

Molten Salts: Volume 4, Part 2, Chlorides and Mixtures. Electrical Conductance, Density, Viscosity, and Surface Tension Data - George J. Janz, Reginald P. T. Tomkins, Carolyn B. Allen, J. R. Downey, Jr., G. L. Gardner, Ursula Krebs, and S. K. Singer. J Phys Chem Ref Data 4, 871(1975).

Molten Salts: Volume 4, Part 3, Bromides and Mixtures, Iodides and Mixtures. Electrical Conductance, Density, Viscosity, and Surface Tension Data - George J. Janz, Reginald P. T. Tomkins, Carolyn B. Allen, J. R. Downey, Jr., and S. K. Singer. J Phys Chem Ref Data 6, 409(1977). 


\section{SInnott, George A.}

Bibliography of Ion-Molecule Reaction Rate Data (January 1950 . October 1971) - George A. Sinnott. NBS Spec. Publ. 381, 75p. (1973).

\section{Skinner, Gordon B.}

Ideal Gas Thermodynamic Properties of $\mathrm{CH}_{3}, \mathrm{CD}_{3}, \mathrm{CD}_{4}, \mathrm{C}_{2} \mathrm{D}_{2}$, $\mathrm{C}_{2} \mathrm{D}_{4}, \mathrm{C}_{2} \mathrm{D}_{6}, \mathrm{C}_{2} \mathrm{H}_{6}, \mathrm{CH}_{3} \mathrm{~N}_{2} \mathrm{CH}_{3}$, and $\mathrm{CD}_{3} \mathrm{~N}_{2} \mathrm{CD}_{3}-$ Krishna $\mathrm{M}$. Pamidimukkala, David Rogers, and Gordon B. Skinner. J Phys Chem Ref Data 11, 83(1982).

\section{Slattery, Paul $\mathbf{F}$.}

NN and ND Interactions - A Compilation - James E. Enstrom, Thomas Ferbel, Paul F. Slattery, Barry L. Werner, Zaven G. T. Guiragossian, Yoshio Sumi, Toshihiro Yoshida and Particle Data Group. UCRL-LBL 58, Berkeley, CA: Lawrence Berkeley Laboratory, U. of California, 281p. (1972). LBL 58.

\section{Smend, $F$.}

Small-Angle Rayleigh Scattering of Photons at High Energies: Tabulations of Relativisitic HFS Modified Atomic Form Faciors - D. Schaupp, M. Schumacher, F. Smend, P. Rullhusen, and John H. Hubbell. J Phys Chem Ref Data 12, 467(1983).

\section{Smith, Buford D.}

Critical Evaluation of Vapor-Liquid Equilibrium, Heat of Mixing, and Volume Change of Mixing Data. General Procedures - Buford D. Smith, Ol Muthu, Ashok Dewan, and Matthew Gierlach. J Phys Chem Ref Data 11, 941(1982).

Definition of Recommended Values of Certain Thermodynamic Properties for the Ketones - Buford D. Smith and O1 Muthu. NBSIR 84-2811, 162p. (1983).

Evaluation of Binary Excess Enthalpy Data for $\mathrm{C}_{6}$ Hydrocarbons. Benzene + Cyclohexane - Buford D. Smith, Ol Muthu, Ashok Dewan, and Matthew Gierlach. J Phys Chem Ref Data 11, 1127(1982).

Evaluation of Binary Excess Enthalpy Data for $\mathrm{C}_{6}$ Hydrocarbons. Benzene + Hexane - Buford D. Smith, Ol Muthu, and Ashok Dewan. J Phys Chem Ref Data 12, 389(1983).

Evaluation of Binary Excess Volume Data for $\mathrm{C}_{6}$ Hydrocarbons. Benzene + Cyclohexane - Buford D. Smith, Ol Muthu, Ashok Dewan, and Matthew Gierlach. J Phys Chem Ref Data 11, 1151(1982).

Evaluation of Binary Excess Volume Data for $\mathrm{C}_{6}$ Hydrocarbons. Benzene + Hexane - Buford D. Smith, Ol Muthu, and Ashok Dewan. J Phys Chem Ref Data 12, 395(1983).

Evaluation of Binary PTxy Vapor-Liquid Equilibrium Data for $\mathrm{C}_{6}$ Hydrocarbons. Benzene + Cyclohexane - Buford D. Smith, O1 Muthu, Ashok Dewan, and Matthew Gierlach. J Phys Chem Ref Data 11, 1099(1982).

Evaluation of Binary PTxy Vapor-Liquid Equilibrium Data for $\mathrm{C}_{6}$ Hydrocarbons. Benzene + Hexane - Buford D. Smith, Ol Muthu, and Ashok Dewan. J Phys Chem Ref Data 12, 381(1983).

\section{Smlth, Francis J.}

Recommended Data on the Electron Impact Ionization of Light Atoms and Ions - K. L. Bell, H. B. Gilbody, J. G. Hughes, A. E. Kingston, and Francis J. Smith. J Phys Chem Ref Data 12, 891(1983).

Tables of Collision Integrals and Second Virial Coefficients for the $(\mathrm{m}, 6,8)$ Intermolecular Potential Function - Max Klein, Howard J. M. Hanley, Francis J. Smith, and Paul M. Holland. NSRDS-NBS 47, 161p. (1974).

\section{Smith, Melvin W.}

Atomic Transition Probabilities for Forbidden Lines of the Iron Group Elements (A Critical Data Compilation for Selected Lines) Melvin W. Smith and Wolfgang L. Wiese. J Phys Chem Ref Data 2, 85(1973).
Atomic Transition Probabilities, Volume II. Sodium through Calcium - Wolfgang L. Wiese, Melvin W. Smith, and Barbara M. Miles. NSRDS-NBS 22, 268p. (1969).

Atomic Transition Probabilities. Elements Hydrogen through Neon - Wolfgang L. Wiese, Melvin W. Smith, and Barbara M. Glennon. NSRDS-NBS 4, 153p. (1966).

\section{Smith, Steven J.}

Electron Impact Excitation of Atoms - Benjamin L. Moiseiwitsch and Steven J. Smith. NSRDS-NBS 25, 120p. (1968).

\section{Smith-Magowan, David}

A Bibliography of Sources of Experimental Data Leading to Thermal Properties of Binary Aqueous Electrolyte Solutions - David Smith-Magowan and Robert N. Goldberg. NBS Spec. Publ. 537, 94p. (1979).

\section{Sokolov, Mordechai}

Viscosity of Liquid Water in the Range $-8^{\circ} \mathrm{C}$ to $150^{\circ} \mathrm{C}$ - Joseph Kestin, Mordechai Sokolov, and William A. Wakeham. J Phys Chem Ref Data 7, 941(1978).

\section{Specht, Beverly J.}

Bibliography on Atomic Line Shapes and Shifts (July 1973 through May 1975) - Jeffrey R. Fuhr, Georgia A. Martin, and Beverly J. Specht. NBS Spec. Publ. 366, Suppl. 2(1975).

\section{Stalick, Judy K.}

NBS* AIDS80: A FORTRAN Program for Crystallographic Data Evaluation - Alan D. Mighell, C. R. Hubbard, and Judy K. Stalick. NBS Tech. Note 1141, 54p. (1981).

\section{Staples, Bert R.}

A Bibliography of Sources of Experimental Data Leading to Activity or Osmotic Coefficients for Polyvalent Electrolytes in Aqueous Solution - Robert N. Goldberg, Bert R. Staples, Ralph L. Nuttall, and R. Arbuckle. NBS Spec. Publ. 485, 57p. (1977).

A Compilation of Thermodynamic and Transport Properties of Aqueous Sulfuric Acid - Bert R. Staples and Theresa F. Wobbeking. NBSIR 81-2276, 26p. (1981).

A Compilation of Thermodynamic and Transport Properties of Aqueous Potassium Hydroxide - R. E. Joseph and Bert R. Staples. NBSIR 81-2356, 17p. (1982).

A Report on Thermodynamic Data for Desulfurization Processes Vivian B. Parker, Bert R. Staples, Thomas L. Jobe, Jr., and David B. Neumann. NBSIR 81-2345, 89p. (1981).

Activity and Osmotic Coefficients of Aqueous Alkali Metal Nitrites

- Bert R. Staples. J Phys Chem Ref Data 10, 765(1981).

Activity and Osmotic Coefficients of Aqueous Sulfuric Acid at 298.15 K - Bert R. Staples. J Phys Chem Ref Data 10, 779(1981).

Computer Programs for the Evaluation of Activity and Osmotic Coefficients - Bert R. Staples and Ralph L. Nuttall. NBS Tech. Note 928, 60p. (1976).

Evaluated Activity and Osmotic Coefficients for Aqueous Solutions: Iron Chloride and the Bi-Univalent Compounds of Nickel and Cobalt - Robert N. Goldberg, Ralph L. Nuttall, and Bert R. Staples. J Phys Chem Ref Data 8, 923(1979).

The Activity and Osmotic Coefficients of Aqueous Calcium Chloride at $298.15 \mathrm{~K}-$ Bert R. Staples and Ralph L. Nuttall. J Phys Chem Ref Data 6, 385(1977). 


\section{Stedman, D. $H$.}

Survey of Photochemical and Rate Data for Twenty-eight Reactions of Interest in Atmospheric Chemistry - Robert F. Hampson, Jr., W. Braun, R. L. Brown, David Garvin, John T. Herron, Robert E. Huie, M. J. Kurylo, A. H. Laufer, J. D. McKinley, H. Okabe, M. D. Scheer, W. Tsang, D. H. Stedman, editor(s). J Phys Chem Ref Data 2, 267(1973).

\section{Steln, A.}

An Analysis of Coexistence Curve Data for Several Binary Liquid Mixtures Near Their Critical Points - A. Stein and G. F. Allen. J Phys Chem Ref Data 2, 439(1973).

\section{Steiner, B. W.}

Energetics of Gaseous Ions - Henry M. Rosenstock, Keith Draxl, B. W. Steiner, and John T. Herron. J Phys Chem Ref Data 6, Suppl. 1(1977).

\section{Stelnfeld, J. I.}

Rate Data for Inelastic Collision Processes in the Diatomic Halogen Molecules - J. I. Steinfeld. J Phys Chem Ref Data 13, 445(1984).

\section{Stepanov, G. V.}

Isochoric Heat Capacity of Water and Steam - M. P. Vukalovich, Kh. I. Amirkhanov, G. V. Stepanov, and B. G. Alibekov. Russian Transl. Springfield, VA: NTIS, 215p. (1974). TT 72-52002, A10.

\section{Stern, Kurt H.}

High Temperature Properties and Decomposition of Inorganic Salts, Part 1. Sulfates - Kurt H. Stern and E. L. Weise. NSRDS-NBS 7, 38p. (1966).

High Temperature Properties and Decomposition of Inorganic Salts, Part 2. Carbonates - Kurt H. Stern and E. L. Weise. NSRDS-NBS 30, 27p. (1969).

High Temperature Properties and Decomposition of Inorganic Salts,

Part 3. Nitrates and Nitrites - Kurt H. Stern. J Phys Chem Ref Data 1, 747(1972).

High Temperature Properties and Decomposition of Inorganic Salts, Part 4. Oxy-Salts of the Halogens - Kurt H. Stern. J Phys Chem Ref Data 3, 481(1974).

\section{Stern, Marvin J.}

Heavy-Atom Kinetic Isotope Effects, An Indexed Bibliography Marvin J. Stern and Max Wolfsberg. NBS Spec. Publ. 349, 43p. (1972).

\section{Stevens, John G.}

Mossbauer Effect Data Index Covering the 1969 Literature - John G. Stevens and Virginia E. Stevens. New York: IFI/Plenum, 281p. (1970), ISBN: 0-306-6514-8.

Mossbauer Effect Data Index Covering the 1970 Literature - John G. Stevens and Virginia E. Stevens. New York: IFI/Plenum, 369p. (1972), ISBN: 0-306-6514-6.

Mossbauer Effect Data Index Covering the 1971 Literature - John G. Stevens and Virginia E. Stevens. New York: IFI/Plenum, 430p. (1972), ISBN: 0-306-6514-4.

Mossbauer Effect Data Index Covering the 1972 Literature - John G. Stevens and Virginia E. Stevens. New York: IFI/Plenum, 488p. (1973), ISBN: 0-306-6514-2.

Mossbauer Effect Data Index Covering the 1966-1968 Literature John G. Stevens and Virginia E. Stevens. New York: IFI/Plenum, 522p. (1975), ISBN: 0-306-6516-9.
Mossbauer Effect Data Index Covering the 1973 Literature - John G. Stevens and Virginia E. Stevens. New York: IFI/Plenum, 495p. (1975), ISBN: 0-306-6514-0.

Mossbauer Effect Data Index Covering the 1974 Literature - John G. Stevens and Virginia E. Stevens. New York: IFI/Plenun, 397p. (1975), ISBN: 0-306-6514-9.

Mossbauer Effect Data Index Covering the 1975 Literature - John G. Stevens and Virginia E. Stevens. New York: IFI/Plenum, 445p. (1977), ISBN: 0-306-6514-7.

Mossbauer Effect Data Index Covering the 1976 Literature - John G. Stevens and Virginia E. Stevens. New York: IFI/Plenum, 355p. (1978), ISBN: 0-306-6514-1.

Mossbauer Effect Reference and Data Journal - John G. Stevens, Virginia E. Stevens, Richard M. White, Janet L. Gibson, editor(s). Moss Eff Ref Data J 6, Ashville, NC: Mossbauer Effect Data Center, U. of N. C., (1983).

Nuclear Moments and Moment Ratios as Determined by Mössbauer Spectroscopy - John G. Stevens and B. D. Dunlap. J Phys Chem Ref Data 5, 1093(1976).

\section{Stevens, Virginia E.}

Mossbauer Effect Data Index Covering the 1969 Literature - John G. Stevens and Virginia E. Stevens. New York: IFI/Plenum, 281p. (1970), ISBN: 0-306-6514-8.

Mossbauer Effect Data Index Covering the 1970 Literature - John G. Stevens and Virginia E. Stevens. New York: IFI/Plenum, 369p. (1972), ISBN: 0-306-6514-6.

Mossbauer Effect Data Index Covering the 1971 Literature - John G. Stevens and Virginia E. Stevens. New York: IFI/Plenum, 430p. (1972), ISBN: 0-306-6514-4.

Mossbauer Effect Data Index Covering the 1972 Literature - John G. Stevens and Virginia E. Stevens. New York: IFI/Plenum, 488p. (1973), ISBN: 0-306-6514-2.

Mossbauer Effect Data Index Covering the 1966-1968 Literature John G. Stevens and Virginia E. Stevens. New York: IFI/Plenum, 522p. (1975), ISBN: 0-306-6516-9.

Mossbauer Effect Data Index Covering the 1973 Literature - John G. Stevens and Virginia E. Stevens. New York: IFI/Plenum, 495p. (1975), ISBN: 0-306-6514-0.

Mossbauer Effect Data Index Covering the 1974 Literature - John G. Stevens and Virginia E. Stevens. New York: IFI/Plenum, 397p. (1975), ISBN: 0-306-6514-9.

Mossbauer Effect Data Index Covering the 1975 Literature - John G. Stevens and Virginia E. Stevens. New York: IFI/Plenum, 445p. (1977), ISBN: 0-306-6514-7.

Mossbauer Effect Data Index Covering the 1976 Literature - John G. Stevens and Virginia E. Stevens. New York: IFI/Plenum, 355p. (1978), ISBN: 0-306-6514-1.

Mossbauer Effect Reference and Data Journal - John G. Stevens, Virginia E. Stevens, Richard M. White, Janet L. Gibson, editor(s). Moss Eff Ref Data J 6, Ashville, NC: Mossbauer Effect Data Center, U. of N. C., (1983).

\section{Stewart, Richard B.}

Thermodynamic Properties of Nitrogen Including Liquid and Vapor Phases from $63 \mathrm{~K}$ to $2000 \mathrm{~K}$ with Pressures to 10,000 Bar - Richard T. Jacobsen and Richard B. Stewart. J Phys Chem Ref Data 2, 757(1973).

\section{Strehlow, W. H.}

Compilation of Energy Band Gaps in Elemental and Binary Compound Semiconductors and Insulators - W. H. Strehlow and E. L. Cook. J Phys Chem Ref Data 2, 163(1973). 
Striganov, A. R.

The Spectrum and Energy Levels of the Neutral Atom of Boron (B I) - G. A. Odintzova and A. R. Striganov. J Phys Chem Ref Data 8, 63(1979).

\section{Stull, Daniel R.}

JANAF Thermochemical Tables, Second Edition - Daniel R. Stull and H. Prophet. NSRDS.NBS 37, 1141p. (1971).

\section{Sugar, Jack}

Energy Levels of Calcium, Ca I through Ca XX - Jack Sugar and Charles H. Corliss. J Phys Chem Ref Data 8, 865(1979).

Energy Levels of Chromium, Cr I through Cr XXIV - Jack Sugar and Charles H. Corliss. J Phys Chem Ref Data 6, 317(1977).

Energy Levels of Cobalt, Co I through Co XXVII - Jack Sugar and Charles H. Corliss. J Phys Chem Ref Data 10, 1097(1981).

Energy Levels of Iron, Fe I through Fe XXVI - Joseph Reader and Jack Sugar. J Phys Chem Ref Data 4, 353(1975).

Energy Levels of Iron, Fe I through Fe XXVI - Charles H. Corliss and Jack Sugar. J Phys Chem Ref Data 11, 135(1982).

Energy Levels of Manganese, Mn I through Mn XXV - Charles $\mathbf{H}$. Corliss and Jack Sugar. J Phys Chem Ref Data 6, 1253(1977).

Energy Levels of Nickel, Ni I through Ni XXVIII - Charles H. Corliss and Jack Sugar. J Phys Chem Ref Data 10, 197(1981).

Energy Levels of Potassium, K I through K XIX - Charles $\mathbf{H}$. Corliss and Jack Sugar. J Phys Chem Ref Data 8, 1109(1979).

Energy Levels of Scandium, Sc I through Sc XXI - Jack Sugar and

Charles H. Corliss. J Phys Chem Ref Data 9, 473(1980).

Energy Levels of Titanium, Ti I through Ti XXII - Charles H. Corliss and Jack Sugar. J Phys Chem Ref Data 8, 1(1979).

Energy Levels of Vanadium, V I through V XXIII - Jack Sugar and Charles H. Corliss. J Phys Chem Ref Data 7, 1191(1978).

Ground Levels and Ionization Potentials for Lanthanide and Actinide Atoms and Ions - William C. Martin, Lucy Hagan, Joseph Reader, and Jack Sugar. J Phys Chem Ref Data 3, 771(1974).

\section{Suml, Yoshlo}

NN and ND Interactions - A Compilation - James E. Enstrom, Thomas Ferbel, Paul F. Slattery, Barry L. Werner, Zaven G. T. Guiragossian, Yoshio Sumi, Toshihiro Yoshida and Particle Data Group. UCRL-LBL 58, Berkeley, CA: Lawrence Berkeley Laboratory, U. of California, 281p. (1972). LBL 58.

\section{Swenson, C. A.}

Recommemded Values for the Thermal Expansivity of Silicon from 0 to 1000 K - C. A. Swenson. J Phys Chem Ref Data 12, 179(1983).

\section{Sychev, V. V.}

Heavy Water, Thermophysical Properties - V. A. Kirillin, Ya. Z. Kazavchinskii, P. M. Kessel'man, S. L. Rivkin, A. E. Sheindlin, E. E. Shpil'rain, V. V. Sychev, and D. L. Timrot. Russian Transl. Springfield, VA: NTIS, 273p. (1971). TT 70-50094, A12.

\section{Syverud, A. N.}

JANAF Thermochemical Tables, 1974 Supplement - Malcolm W. Chase, Jr., J. L. Curnutt, A. T. Hu, H. Prophet, A. N. Syverud, and L. C. Walker. J Phys Chem Ref Data 3, 311(1974).

JANAF Thermochemical Tables, 1975 Supplement - Malcolm W. Chase, Jr., J. L. Curnutt, H. Prophet, R. A. McDonald, and A. N. Syverud. J Phys Chem Ref Data 4, 1(1975).

JANAF Thermochemical Tables, 1978 Supplement - Malcolm W. Chase, Jr., J. L. Curnutt, R. A. McDonald, and A. N. Syverud. J Phys Chem Ref Data 7, 793(1978).

JANAF Thermochemical Tables, 1982 Supplement - Malcolm W. Chase, Jr., J. L. Curnutt, J. R. Downey, Jr., R. A. McDonald, A. N. Syverud, and E. A. Valenzuela. J Phys Chem Ref Data 11, 695(1982).

\section{Taylor, Barry N.}

Numerical Comparisons of Several Algorithms for Treating Inconsistent Data in a Least-Squares Adjustment of the Fundamental Constants - Barry N. Taylor. NBSIR 81-2426, 87p. (1982).

The 1973 Least-Squares Adjustment of the Fundamental Constants - E. Richard Cohen and Barry N. Taylor. J Phys Chem Ref Data 2, 663(1973).

\section{Thomas, Edward W.}

Excitation in Heavy Particle Collisions - Edward W. Thomas. At Mol Collis Proc Ser, New York: Wiley-Interscience, 436p. (1972), ISBN: 0-471-8589-0.

\section{Thompson, Robert C.}

Automation of the Ion Energetics Data Center - Robert C. Thompson, W. J. Webb, and Henry M. Rosenstock. NBSIR 78-1432, 84p. (1978).

SETAB: An Edit-Insert Program for Automatic Typesetting of Spectroscopic and Other Computerized Tables - Robert C. Thompson and Joseph Hilsenrath. NBS Tech. Note 740, 32p. (1973).

\section{Tiemann, Eberhard}

Microwave Spectra of Molecules of Astrophysical Interest, VIII. Sulfur Monoxide - Eberhard Tiemann. J Phys Chem Ref Data 3, 259(1974).

Microwave Spectra of Molecules of Astrophysical Interest, XI. Silicon Sulfide - Eberhard Tiemann. J Phys Chem Ref Data 5, 1147(1976).

Microwave Spectral Tables, I. Diatomic Molecules - Frank J. Lovas and Eberhard Tiemann. J Phys Chem Ref Data 3, 609(1974).

\section{Tilford, S. G.}

Atlas of the Observed Absorption Spectrum of Carbon Monoxide between 1060 and $1900 \AA-$ S. G. Tilford and J. D. Simmons. J Phys Chem Ref Data 1, 147(1972).

\section{TImrot, D. L.}

Heavy Water, Thermophysical Properties - V. A. Kirillin, Ya. Z. Kazavchinskii, P. M. Kessel'man, S. L. Rivkin, A. E. Sheindlin, E. E. Shpil'rain, V. V. Sychev, and D. L. Timrot. Russian Transl. Springfield, VA: NTIS, 273p. (1971). TT 70-50094, A12.

\section{Tishin, A. P.}

Thermodynamic and Thermophysical Properties of Combustion Products, Volume I. Computation Methods - V. P. Glushko, V. E. Alemasov, A. F. Dregalin, A. P. Tishin, and V. A. Khudyakov. Russian Transl. Springfield, VA: NTIS, 453p. (1974). TT 74-50019, A20.

Thermodynamic and Thermophysical Properties of Combustion Products, Volume II. Oxygen-Based Propellants - V. P. Glushko, V. E. Alemasov, A. F. Dregalin, A. P. Tishin, V. A. Khudyakov, and V. N. Kostin. Russian Transl. Springfield, VA: NTIS, 505p. (1975). TT 74-50032, A22.

Thermodynamic and Thermophysical Properties of Combustion Products, Volume III. Oxygen- and Air-Based Propellant - V. P. Glushko, V. E. Alemasov, A. F. Dregalin, A. P. Tishin, V. A. Khudyakov, and V. N. Kostin. Russian Transl. Springfield, VA: NTIS, 648p. (1975). TT 75-50007, A26.

Thermodynamic and Thermophysical Properties of Combustion Products, Volume IV. Nitrogen Tetroxide-Based Propellants - V. P. Glushko, V. E. Alemasov, A. F. Dregalin, A. P. Tishin, V. A. Khudyakov, and V. N. Kostin. Russian Transl. Springfield, VA: NTIS, 540p. (1976). TT 76-50007, A23. 
Tominaga, Toshihiro

The Solubility of Nitrogen and Air in Liquids - Rubin Battino, Timothy R. Rettich, and Toshihiro Tominaga. J Phys Chem Ref Data 13, 563(1984).

The Solubility of Oxygen and Ozone in Liquids - Rubin Battino, Timothy R. Rettich, and Toshihiro Tominaga. J Phys Chem Ref Data 12, 163(1983).

\section{Tomkins, Reginald P. T.}

Molten Salts: Volume 1. Electrical Conductance, Density, and Viscosity Data - George J. Janz, F. W. Dampier, G. R. Lakshminarayanan, P. K. Lorenz, and Reginald P. T. Tomkins. NSRDS-NBS 15, 140p. (1968).

Molten Salts: Volume 2. Section 1. Electrochemistry of Molten Salts. Gibbs Free Energies and Excess Free Energies from Equilibrium-Type Cells, Section 2. Surface Tension Data - George J. Janz, Chr. G. M. Dijkhuis, G. R. Lakshminarayanan, Reginald P. T. Tomkins, and J. Wong. NSRDS-NBS 28, 116p. (1968).

Molten Salts: Volume 5, Part 1. Additional Single and MultiComponent Salt Systems. Electrical Conductance, Density, Viscosity, and Surface Tension Data - George J. Janz and Reginald P. T. Tomkins. J Phys Chem Ref Data 9, 831(1980).

Molten Salts: Volume 5, Part 2. Additional Single and MultiComponent Salt Systems. Electrical Conductance, Density, Vicosity and Surface Tension Data - George J. Janz and Reginald P. T. Tomkins. J Phys Chem Ref Data 12, 591(1983).

Molten Salts: Volume 3, Nitrates, Nitrites, and Mixtures. Electrical Conductance, Density, Viscosity, and Surface Tension Data - George J. Janz, Ursula Krebs, H. F. Siegenthaler, and Reginald P. T. Tomkins. J Phys Chem Ref Data 1, 581(1972).

Molten Salts: Volume 4, Part 1, Fluorides and Mixtures. Electrical Conductance, Density, Viscosity, and Surface Tension Data - George J. Janz, G. L. Gardner, Ursula Krebs, and Reginald P. T. Tomkins. J Phys Chem Ref Data 3, 1(1974).

Molten Salts: Volume 4, Part 2, Chlorides and Mixtures. Electrical Conductance, Density, Viscosity, and Surface Tension Data - George J. Janz, Reginald P. T. Tomkins, Carolyn B. Allen, J. R. Downey, Jr., G. L. Gardner, Ursula Krebs, and S. K. Singer. J Phys Chem Ref Data 4, 871(1975).

Molten Salts: Volume 4, Part 3, Bromides and Mixtures, Iodides and Mixtures. Electrical Conductance, Density, Viscosity, and Surface Tension Data - George J. Janz, Reginald P. T. Tomkins, Carolyn B. Allen, J. R. Downey, Jr., and S. K. Singer. J Phys Chem Ref Data 6, 409(1977).

Molten Salts: Volume 4, Part 4, Mixed Halide Melts. Electrical Conductance, Density, Viscosity, and Surface Tension Data - George J. Janz, Reginald P. T. Tomkins, and Carolyn B. Allen. J Phys Chem Ref Data 8, 125(1979).

Physical Properties Data Compilations Relevant to Energy Storage. I. Molten Salts: Eutectic Data - George J. Janz, Carolyn B. Allen, J. R. Downey, Jr., and Reginald P. T. Tomkins. NSRDS-NBS 61, 244p. (1978).

Physical Properties Data Compilations Relevant to Energy Storage. II. Molten Salts: Data on Single and Multi-Component Systems George J. Janz, Carolyn B. Allen, Narottam P. Bansal, R. M. Murphy, and Reginald P. T. Tomkins. NSRDS-NBS 61, 420p. (1979).

Physical Properties Data Compilations Relevant to Energy Storage. IV. Molten Salts: Data on Additional Single and Multi-Component Salt Systems - George J. Janz and Reginald P. T. Tomkins. NSRDS-NBS 61, 870p. (1981).

\section{Toropov, N. A.}

Handbook of Phase Diagrams of Silicate Systems, Vol. I. Binary Systems, Second Revised Edition - N. A. Toropov, V. P. Barzakovskii, V. V. Lapin, N. N. Kurtseva, J. Schmorak, editor(s). Russian Transl. Springfield, VA: NTIS, 730p. (1970). TT 71-50040, A26.
Handbook of Phase Diagrams of Silicate Systems, Vol. II. MetalOxygen Compounds in Silicate Systems, Second Revised Edition - N. A. Toropov, V. P. Barzakovskii, I. A. Bondar', and Yu. P. Udalov. Russian Transl. Springfield, VA: NTIS, 329p. (1972). TT 71-50041, A 15 .

\section{Trippe, Thomas G.}

$\pi+\mathrm{p}, \pi+\mathrm{n}$, and $\pi+\mathrm{d}$ Interactions - A Compilation: Parts I and II Denyse M. Chew, Victor P. Henri, Thomas A. Lasinski, Thomas G. Trippe, Fumiyo Uchiyama, Frederick C. Winkelmann and Particle Data Group. UCRL 53, Springfield, VA: NTIS, 213p. (1973). LBL 53; Part II is on microfiche located in the back cover pocket, A10.

Troe, J.

Evaluated Kinetic and Photochemical Data for Atmospheric Chemistry - D. L. Baulch, R. A. Cox, Robert F. Hampson, Jr., J. A. Kerr, J. Troe, and R. T. Watson. J Phys Chem Ref Data 9, 295(1980).

Evaluated Kinetic and Photochemical Data for Atmospheric Chemistry: Supplement I. CODATA Task Group on Chemical Kinetics D. L. Baulch, R. A. Cox, P. J. Crutzen, Robert F. Hampson, Jr., J. A. Kerr, J. Troe, and R. T. Watson. J Phys Chem Ref Data 11, 327(1982).

Evaluated Kinetic and Photochemical Data for Atmospheric Chemistry: Supplement II. CODATA Task Group on Gas Phase Chemical Kinetics - D. L. Baulch, R. A. Cox, Robert F. Hampson, Jr., J. A. Kerr, J. Troe, and R. T. Watson. J Phys Chem Ref Data 13, 1259(1984).

\section{Trotman-Dickenson, Aubrey}

Tables of Bimolecular Gas Reactions - Aubrey F. TrotmanDickenson and G. S. Milne. NSRDS-NBS 9, 129p. (1967).

\section{Tsang, W.}

Summary Report on the Workshop on High Temperature Chemical Kinetics: Applications to Combustion Research - David Garvin, R. L. Brown, Robert F. Hampson, Jr., M. J. Kurylo, and W. Tsang. NBS Spec. Publ. 531, 94p. (1978).

Survey of Photochemical and Rate Data for Twenty-eight Reactions of Interest in Atmospheric Chemistry - Robert F. Hampson, Jr., W. Braun, R. L. Brown, David Garvin, John T. Herron, Robert E. Huie, M. J. Kurylo, A. H. Laufer, J. D. McKinley, H. Okabe, M. D. Scheer, W. Tsang, D. H. Stedman, editor(s). J Phys Chem Ref Data 2, 267(1973).

\section{Tsederberg, N. V.}

Thermodynamic and Thermophysical Properties of Helium - A. F. Alyab'ev, N. V. Tsederberg, V. N. Popov, and N. A. Morozova. Russian Transl. Springfield, VA: NTIS, 260p. (1971). TT 70-50096, A12.

\section{Uchiyama, Fumiyo}

$\pi+\mathrm{p}, \pi+\mathrm{n}$, and $\pi+\mathrm{d}$ Interactions - A Compilation: Parts I and II Denyse M. Chew, Victor P. Henri, Thomas A. Lasinski, Thomas G. Trippe, Fumiyo Uchiyama, Frederick C. Winkelmann and Particle Data Group. UCRL 53, Springfield, VA: NTIS, 213p. (1973). LBL 53; Part II is on microfiche located in the back cover pocket, Al0.

$\pi \mathrm{N}$ Two-Body Scattering Data, I. A User's Guide to the LovelaceAlmehed Data Tape - Claude Lovelace, Sverkei Almehed, Fumiyo Uchiyama, Robert Kelly, Victor P. Henri and Particle Data Group. UCRL 63, Springfield, VA: NTIS, 146p. (1973). LBL 63, A07.

\section{Udalov, Yu. P.}

Handbook of Phase Diagrams of Silicate Systems, Vol. II. MetalOxygen Compounds in Silicate Systems, Second Revised Edition - N. A. Toropov, V. P. Barzakovskii, L. A. Bondar and Yu. P. Udalov. Russian Transl. Springfield, VA: NTIS, 325p. (1972). TT 71-5004-1, A15. 


\section{Uematsu, $M$.}

Static Dielectric Constant of Water and Steam - M. Uematsu and E. U. Franck. J Phys Chem Ref Data 9, 1291(1980).

\section{Valenzuela, E. A.}

JANAF Thermochemical Tables, 1982 Supplement - Malcolm W. Chase, Jr., J. L. Curnutt, J. R. Downey, Jr., R. A. McDonald, A. N. Syverud, and E. A. Valenzuela. J Phys Chem Ref Data 11, 695(1982).

\section{Van Blerkom, Janet}

Data Index for Energy Transfer Collisions of Atoms and Molecules - 1970-1979 - Jean W. Gallagher, Janet Van Blerkom, Earl C. Beaty, and John R. Rumble, Jr. NBS Spec. Publ. 593, 349p. (1981).

Vander Molen, H. J.

Photonuclear Reaction Data, 1973 - Everett G. Fuller, Henry M. Gerstenberg, H. J. Vander Molen, and T. C. Dunn. NBS Spec. Publ. 380, 134p. (1973).

The NIRA Computer Program Package (Photonuclear Data Center) - H. J. Vander Molen and Henry M. Gerstenberg. NBS Tech. Note 903, 34p. (1976).

\section{Vargaftik, N. B.}

International Tables of the Surface Tension of Water - N. B. Vargaftik, B. N. Volkov, and L. D. Voljak. J Phys Chem Ref Data 12, 817(1983).

\section{Vasserman, A. A.}

Thermophysical Properties of Air and Air Components - A. A. Vasserman, Ya. Z. Kazavchinskii, V. A. Rabinovich, and A. M. Zhuravlev. Russian Transl. Springfield, VA: NTIS, 402p. (1971). TT 70-50095, A18.

Thermophysical Properties of Liquid Air and Its Components - A. A. Vasserman and V. A. Rabinovich. Russian Transl. Springfield, VA: NTIS, 255p. (1970). TT 69-55092, A12.

\section{Veigele, W. J.}

Atomic Form Factors, Incoherent Scattering Functions, and Photon Scattering Cross Sections - John H. Hubbell, W. J. Veigele, E. A Briggs, R. T. Brown, D. T. Cromer, and R. J. Howerton. J Phys Chem Ref Data 4, 471(1975).

Comparison of Theoretical and Experimental Photoeffect Data, 0.1 $\mathrm{keV}$ to $1.5 \mathrm{MeV}-\mathrm{J}$ hh $\mathrm{H}$. Hubbell and W. J. Veigele. NBS Tech. Note 901, 47p. (1976).

\section{Voljak, L. D.}

International Tables of the Surface Tension of Water - N. B. Vargaftik, B. N. Volkov, and L. D. Voljak. J Phys Chem Ref Data 12, 817(1983).

\section{Volkov, B. N.}

International Tables of the Surface Tension of Water - N. B. Vargaftik, B. N. Volkov, and L. D. Voljak. J Phys Chem Ref Data 12, 817(1983).

\section{Vukalovich, M. P.}

Isochoric Heat Capacity of Water and Steam - M. P. Vukalovich, Kh. I. Amirkhanov, G. V. Stepanov, and B. G. Alibekov. Russian Transl. Springfield, VA: NTIS, 215p. (1974). TT 72-52002, A 10.

\section{Wacker, Paul F.}

Microwave Spectral Tables, Volume I. Diatomic Molecules - Paul F. Wacker, M. Mizushima, J. D. Petersen, and J. R. Ballard. NBS Monograph 70, 171p. (1964).

Microwave Spectral Tables, Volume II. Line Strengths of Asymmetric Rotors - Paul F. Wacker and M. R. Pratto. NBS Monograph 70, 349p. (1964).

Microwave Spectral Tables, Volume III. Polyatomic Molecules with Internal Rotation - Paul F. Wacker, M. S. Cord, D. G. Burkhard, J. D. Petersen, and R. F. Kukol. NBS Monograph 70, 275p. (1969).

\section{Wagman, Donald D.}

A Combined Least Sums and Least Squares Approach to the Evaluation of Thermodynamic Data Networks - David Garvin, Vivian B. Parker, Donald D. Wagman, and William H. Evans. NBSIR 76-1147, 41p. (1976).

A Computer Assisted Evaluation of the Thermochemical Data of the Compounds of Thorium - Donald D. Wagman, Richard H. Schumm, and Vivian B. Parker. NBSIR 77.1300, 94p. (1977).

Chemical Thermodynamic Data Banks - David Garvin, Vivian B. Parker, and Donald D. Wagman. NBSIR 81-2341, 30p. (1981).

Chemical Thermodynamic Properties of Compounds of Sodium, Potassium, and Rubidium: An Interim Tabulation of Selected Material - Donald D. Wagman, William H. Evans, Vivian B. Parker, and Richard H. Schumm. NBSIR 76-1034, 76p. (1976).

Selected Thermochemical Data Compatible with CODATA Recommendations - Vivian B. Parker, Donald D. Wagman, and David Garvin. NBSIR 75-968, 35p. (1976).

Selected Values of Chemical Thermodynamic Properties. Tables for the First Thirty-Four Elements in the Standard Order of Arrangement - Donald D. Wagman, William H. Evans, Vivian B. Parker, Iva Halow, Sylvia M. Bailey, and Richard H. Schumm. NBS Tech. Note 270, 264p. (1968).

Selected Values of Chemical Thermodynamic Properties. Tables for Elements 35 through 53 in the Standard Order of Arrangement Donald D. Wagman, William H. Evans, Vivian B. Parker, Iva Halow, Sylvia M. Bailey, and Richard H. Schumm. NBS Tech. Note 270, 152p. (1969).

Selected Values of Chemical Thermodynamic Properties. Tables for Elements 54 through 61 in the Standard Order of Arrangement Donald D. Wagman, William H. Evans, Vivian B. Parker, Iva Halow, Sylvia M. Bailey, Richard H. Schumm, and Kenneth L. Churney. NBS Tech. Note 270, 49p. (1971).

Selected Values of Chemical Thermodynamic Properties. Tables for the Alkaline Earth Elements (Elements 92 through 97 in the Standard Order of Arrangement) - Vivian B. Parker, Donald D. Wagman, and William H. Evans. NBS Tech. Note 270, 124p. (1971).

Selected Values of Chemical Thermodynamic Properties. Tables for the Lanthanide (Rare Earth) Elements (Elements 62 through 76 in the Standard Order of Arrangement) - Richard H. Schumm, Donald D. Wagman, Sylvia M. Bailey, William H. Evans, and Vivian B. Parker. NBS Tech. Note 270, 84p. (1973).

Selected Values of Chemical Thermodynamic Properties: Compounds of Uranium, Protactinium, Thorium, Actinium, and the Alkali Metals - Donald D. Wagman, William H. Evans, Vivian B. Parker, Richard H. Schumm, and Ralph L. Nuttall. NBS Tech. Note 270, 149p. (1981).

Selected Values of the Thermodynamic Properties of the Elements - Ralph Hultgren, Pramond D. Desai, Donald T. Hawkins, M. Gleiser, Kenneth K. Kelley, and Donald D. Wagman. Metals Park, OH: American Society for Metals, 636p. (1973). 
The NBS Tables of Chemical Thermodynamic Properties. Selected Values for Inorganic and $C_{1}$ and $C_{2}$ Organic Substances in SI Units Donald D. Wagman, William H. Evans, Vivian B. Parker, Richard H. Schumm, Iva Halow, Sylvia M. Bailey, Kenneth L. Churney, and Ralph L. Nuttall. J Phys Chem Ref Data 11, Suppl. 2(1982).

\section{Wakeham, William A.}

Viscosity of Liquid Water in the Range $-8^{\circ} \mathrm{C}$ to $150^{\circ} \mathrm{C}$ - Joseph Kestin, Mordechai Sokolov, and William A. Wakeham. J Phys Chem Ref Data 7, 941(1978).

\section{Waldman, M.}

Equilibrium and Transport Properties of the Noble Gases and Their Mixtures at Low Density - Joseph Kestin, K. Knierim, E. A. Mason, B. Najafi, S. T. Ro, and M. Waldman. J Phys Chem Ref Data 13, 229(1984).

\section{Walker, L. C.}

JANAF Thermochemical Tables, 1974 Supplement - Malcolm W. Chase, Jr., J. L. Curnutt, A. T. Hu, H. Prophet, A. N. Syverud, and L. C. Walker. J Phys Chem Ref Data 3, 311(1974).

\section{Wallenstein, $M$.}

National Standard Reference Data System Plan of Operation Edward L. Brady and M. Wallenstein. NSRDS-NBS 1, 12p. (1965).

\section{Walsh, P. J.}

OMNITAB, A Computer Program for Statistical and Numerical Analysis - Joseph Hilsenrath, Guy G. Ziegler, Carla G. Messina, P. J. Walsh, and R. H. Herbold. NBS Handbook 101, 256p. (1968).

\section{Wardman, Peter}

The Radiolysis of Methanol: Product Yields, Rate Constants, and Spectroscopic Parameters of Intermediates - J. H. Baxendale and Peter Wardman. NSRDS-NBS 54, 33p. (1975).

\section{Warrier, A. V. R.}

Electronic Absorption and Internal and External Vibrational Data of Atomic and Molecular Ions Doped in Alkali Halide Crystals - Suresh C. Jain, A. V. R. Warrier, and Suresh K. Agarwal. NSRDS-NBS 5, 55p. (1974).

\section{Watson, David G.}

Crystal Data Determinative Tables, Third Edition, Volume 5. Organic Compounds - Olga Kennard, David G. Watson, John E. Davies, John R. Rodgers, editor(s). 5, Swarthmore, PA, JCPDS-International Center for Diffraction Data,(1983).

Crystal Data Determinative Tables, Third Edition, Volume 6. Organic Compounds - Olga Kennard, David G. Watson, John E. Davies, editor(s). 6, Swarthmore, PA, JCPDS-International Center for Diffraction Data,(1983).

Crystal Data Determinative Tables, Third Edition Volume 3. Organic Compounds - Joseph D. H. Donnay, Olga Kennard, David G. Watson, and John R. Rodgers., Swarthmore, PA: JCPDS-International Center for Diffraction Data, 748p. (1978).

\section{Watson, Edgar, Jr.}

Selected Specific Rates of Reactions of the Solvated Electron in Alcohols - Edgar Watson, Jr. and Sathyabhama Roy. NSRDS-NBS 42, 27p. (1972).
Watson, J. T. R.

An Improved Representative Equation for the Dynamic Viscosity of Water Substance - J. T. R. Watson, R. S. Basu, and Jan V. Sengers. J Phys Chem Ref Data 9, 1255(1980).

Representative Equations for the Thermal Conductivity of Water Substance - Jan V. Sengers, J. T. R. Watson, R. S. Basu, B. KamgarParsi, and R. C. Hendricks. J Phys Chem Ref Data 13, 893(1984).

\section{Watson, R. T.}

Evaluated Kinetic and Photochemical Data for Atmospheric Chemistry - D. L. Baulch, R. A. Cox, Robert F. Hampson, Jr., J. A. Kerr, J. Troe, and R. T. Watson. J Phys Chem Ref Data 9, 295(1980).

Evaluated Kinetic and Photochemical Data for Atmospheric Chemistry: Supplement I. CODATA Task Group on Chemical Kinetics D. L. Baulch, R. A. Cox, P. J. Crutzen, Robert F. Hampson, Jr., J. A. Kerr, J. Troe, and R. T. Watson. J Phys Chem Ref Data 11, 327(1982),

Evaluated Kinetic and Photochemical Data for Atmospheric Chemistry: Supplement II. CODATA Task Group on Gas Phase Chemical Kinetics - D. L. Baulch, R. A. Cox, Robert F. Hampson, Jr., J. A.Kerr, J. Troe, and R. T. Watson. J Phys Chem Ref Data 13, 1259(1984).

Rate Constants for Reactions of $\mathrm{ClO}_{\mathrm{x}}$ of Atmospheric Interest - $\mathrm{R}$. T. Watson. J Phys Chem Ref Data 6, 871(1977).

\section{Wawrousek, H. W.}

Critical Surveys of Data Sources: Electrical and Magnetic Properties of Metals - M. J. Carr, R. B. Gavert, Robert L. Moore, H. W. Wawrousek, and John H. Westbrook. NBS Spec. Publ. 396, 96p. (1976).

\section{Webb, W. J.}

Automation of the Ion Energetics Data Center - Robert C. Thompson, W. J. Webb, and Henry M. Rosenstock. NBSIR 78-1432, 84p. (1978).

Ion Energetics Measurements, Supplement I. 1971-1973 - Henry M. Rosenstock, D. Sims, S. S. Schroyer, and W. J. Webb. NSRDS-NBS 66, 380p. (1980).

\section{Weber, Lloyd A.}

Thermodynamic and Related Properties of Parahydrogen from the Triple Point to $100 \mathrm{~K}$ at Pressures to 340 Atmospheres - Hans M. Roder, Lloyd A. Weber, and Robert D. Goodwin. NBS Monograph 94, 116p. (1965).

Thermodynamic and Related Properties of Oxygen from the Triple Point to $300 \mathrm{~K}$ at Pressures to $1000 \mathrm{Bar}$ - Lloyd A. Weber. NBSIR 77.865, 162p. (1977).

\section{Weise, E. L.}

High Temperature Properties and Decomposition of Inorganic Salts, Part 1. Sulfates - Kurt H. Stern and E. L. Weise. NSRDS-NBS 7, 38p. (1966).

High Temperature Properties and Decomposition of Inorganic Salts, Part 2. Carbonates - Kurt H. Stern and E. L. Weise. NSRDS-NBS 30, 27p. (1969).

\section{Weisman, Herman M.}

Annotated Accession List of Data Compilations of the NBS Office of Standard Reference Data - Herman M. Weisman and Gertrude B. Sherwood. NBS Tech. Note 554, 196p. (1970).

Property Index to NSRDS Data Compilations, 1964-1972 - David R. Lide, Jr., Gertrude B. Sherwood, Charles H. Douglass, and Herman M. Weisman. NSRDS-NBS 55, 21p. (1975). 
Werner, Barry L.

NN and ND Interactions - A Compilation - James E. Enstrom, Thomas Ferbel, Paul F. Slattery, Barry L. Werner, Zaven G. T. Guiragossian, Yoshio Sumi, Toshihiro Yoshida and Particle Data Group. UCRL-LBL 58, Berkeley, CA: Lawrence Berkeley Laboratory, U. of California, 281p. (1972). LBL 58.

\section{Westberg, K. R.}

Chemical Kinetic Data Sheets for High-Temperature Chemical Reactions - N. Cohen and K. R. Westberg. J Phys Chem Ref Data 12, 531(1983).

\section{Westbrook, John H.}

Critical Surveys of Data Sources: Mechanical Properties of Metals - R. B. Gavert, Robert L. Moore, and John H. Westbrook. NBS Spec. Publ. 396, 90p. (1974).

Critical Surveys of Data Sources: Electrical and Magnetic Properties of Metals - M. J. Carr, R. B. Gavert, Robert L. Moore, H. W. Wawrousek, and John H. Westbrook. NBS Spec. Publ. 396, 96p. (1976).

\section{Westley, Francis}

A Bibliography of Kinetic Data on Gas Phase Reactions of Nitrogen, Oxygen, and Nitrous Oxides - Francis Westley. OSRD Bibl. 71-2, 140p. (1971).

A Supplementary Bibliography of Kinetic Data on Gas Phase Reactions of Nitrogen, Oxygen, and Nitrogen Oxides - Francis Westley. NBS Spec. Publ. 371, 93p. (1973).

Chemical Kinetics in the C-O-S and H-N-O-S Systems: A Bibliography - 1899 through June 1971 - Francis Westley. NBS Spec. Publ. 362, 75p. (1972).

Chemical Kinetics of the Gas Phase Combustion of Fuels (A Bibliography on the Rates and Mechanisms of Oxidation of Aliphatic $C_{1}$ to $C_{10}$ Hydrocarbons and of Their Oxygenated Derivatives) - Francis Westley. NBS Spec. Publ. 449, 142p. (1976).

Nitrogen Oxychlorides: A Bibliography on Data for Physical and Chemical Properties of $\mathrm{ClNO}, \mathrm{ClNO}_{2}$, and $\mathrm{ClNO}_{3}-$ Francis Westley. NBS Spec. Publ. 478, 54p. (1977).

Supplementary Bibliography of Kinetic Data on Gas Phase Reac. tions of Nitrogen, Oxygen, and Nitrogen Oxides (1972 - 1973) - Francis Westley. NBS Spec. Publ. 371, Suppl. 1(1975).

Table of Recommended Rate Constants for Chemical Reactions Occurring in Combustion - Francis Westley. NBSIR 79.1941, 169p. (1979).

Table of Recommended Rate Constants for Chemical Reactions Occurring in Combustion - Francis Westley. NSRDS-NBS 67, 110p. (1980).

Tables of Experimental Rate Constants for Chemical Reactions Occurring in Combustion (1971-1977) - Francis Westley. NBSIR 81-2254, 302p. (1981).

Tables of Rate Constants for Gas Phase Chemical Reactions of Sulfur Compounds (1971-1980) - Francis Westley. NSRDS-NBS 72, 42p. (1982).

Vibrationally Excited Hydrogen Halides: A Bibliography on Chemical Kinetics of Chemiexcitation and Energy Transfer Processes (1958 through 1973) - Francis Westley. NBS Spec. Publ. 392, 84p. (1974).

\section{White, G. K.}

Heat Capacity of Reference Materials: $\mathrm{Cu}$ and W - G. K. White and S. J. Collocott. J Phys Chem Ref Data 13, 1251(1984).

White, Howard J., Jr.

A Bibliography of the Russian Reference Data Holdings of the Library of the Office of Standard Reference Data - Gertrude B. Sherwood and Howard J. White, Jr. NBS Tech. Note 848, 23p. (1974).
Industrial Process Data for Fluids: A Survey of Current Research at the National Bureau of Standards - Howard J. White, Jr. NBSIR 76-1002, 54p. (1976).

\section{Whlte, Richard M.}

Mossbauer Effect Reference and Data Journal - John G. Stevens, Virginia E. Stevens, Richard M. White, Janet L. Gibson, editor(s). Moss Eff Ref Data J 6, Ashville, NC: Mossbauer Effect Data Center, U. of N. C., (1983).

\section{Wlese, Wolfgang $\mathrm{L}$.}

Atomic Transition Probabilities for Forbidden Lines of the Iron Group Elements (A Critical Data Compilation for Selected Lines) Melvin W. Smith and Wolfgang L. Wiese. J Phys Chem Ref Data 2, 85(1973).

Atomic Transition Probabilities for Scandium and Titanium (A Critical Data Compilation of Allowed Lines) - Wolfgang L. Wiese and Jeffrey R. Fuhr. J Phys Chem Ref Data 4, 263(1975).

A tomic Transition Probabilities for Vanadium, Chromium, and Manganese (A Critical Data Compilation of Allowed Lines) - S. M. Younger, Jeffrey R. Fuhr, Georgia A. Martin, and Wolfgang L. Wiese. J Phys Chem Ref Data 7, 495(1978).

Atomic Transition Probabilities for Iron, Cobalt, Nickel: A Critical Data Compilation of Allowed Lines - Jeffrey R. Fuhr, Georgia A. Martin, Wolfgang L. Wiese, and S. M. Younger. J Phys Chem Ref Data 10, 305(1981).

Atomic Transition Probabilities, Volume II. Sodium through Calcium - Wolfgang L. Wiese, Melvin W. Smith, and Barbara M. Miles. NSRDS-NBS 22, 268p. (1969).

Atomic Transition Probabilities. Elements Hydrogen through Neon - Wolfgang L. Wiese, Melvin W. Smith, and Barbara M. Glennon. NSRDS-NBS 4, 153p. (1966).

Bibliography on Atomic Line Shapes and Shifts (1899 through March 1972) - Jeffrey R. Fuhr, Wolfgang L. Wiese, and Larry J. Roszman. NBS Spec. Publication 366, 165p. (1972).

Bibliography on Atomic Line Shapes and Shifts (April 1972 through June 1973) - Jeffrey R. Fuhr, Larry J. Roszman, and Wolfgang L. Wiese. NBS Spec. Publ. 366, Suppl. 1(1974).

Critically Evaluated Transition Probabilities for Ba I and II Barbara M. Miles and Wolfgang L. Wiese. NBS Tech. Note 474, 22p. (1969).

Experimental Stark Widths and Shifts for Non-Hydrogenic Spectral Lines of Ionized Atoms (A Critical Review and Tabulation of Selected Data) - N. Konjević and Wolfgang L. Wiese. J Phys Chem Ref Data 5, 259(1976).

Experimental Stark Widths and Shifts for Spectral Lines of Neutral Atoms (A Critical Review of Selected Data for the Period 1976 to 1982) - N. Konjević, M. S. Dimitrijević, and Wolfgang L. Wiese. J Phys Chem Ref Data 13, 619(1984).

Experimental Stark Widths and Shifts for Spectral Lines of Positive Ions (A Critical Review and Tabulation of Selected Data for the Period 1976 to 1982) - N. Konjević, M. S. Dimitrijević, and Wolfgang L. Wiese. J Phys Chem Ref Data 13, 649(1984).

Tables of Critically Evaluated Oscillator Strengths for the Lithium Isoelectronic Sequence - Georgia A. Martin and Wolfgang L. Wiese. J Phys Chem Ref Data 5, 537(1976).

Tables of Line Spectra of the Elements, Part 1. Wavelengths and Intensities, Part 2. Transition Probabilities - Joseph Reader, Charles H. Corliss, Wolfgang L. Wiese, and Georgia A. Martin. NSRDS-NBS 68, 415p. (1980).

\section{Wilhoit, Randolph C.}

Ideal Gas Thermodynamic Properties of Ethane and Propane - Jing Chao, Randolph C. Wilhoit, and Bruno J. Zwolinski. J Phys Chem Ref Data 2, 427(1973). 
Ideal Gas Thermodynamic Properties of Eight Chloro- and Fluoromethanes - A. S. Rodgers, Jing Chao, Randolph C. Wilhoit, and Bruno J. Zwolinski. J Phys Chem Ref Data 3, 117(1974).

Ideal Gas Thermodynamic Properties of Six Chloroethanes - Jing Chao, A. S. Rodgers, Randolph C. Wilhoit, and Bruno J. Zwolinski. J Phys Chem Ref Data 3, 141(1974).

Ideal Gas Thermodynamic Properties of Six Fluoroethanes - S. S. Chen, A. S. Rodgers, Jing Chao, Randolph C. Wilhoit, and Bruno J. Zwolinski. J Phys Chem Ref Data 4, 441(1975).

Ideal Gas Thermodynamic Properties and Isomerization of n-Butane and Isobutane - S. S. Chen, Randolph C. Wilhoit, and Bruno J. Zwolinski. J Phys Chem Ref Data 4, 859(1975).

Ideal Gas Thermodynamic Properties of Six Chlorofluoromethanes - S. S. Chen, Randolph C. Wilhoit, and Bruno J. Zwolinski. J Phys Chem Ref Data 5, 571(1976).

Ideal Gas Thermodynamic Properties of Phenol and Cresols Shanti A. Kudchadker, Arvind P. Kudchadker, Randolph C. Wilhoit, and Bruno J. Zwolinski. J Phys Chem Ref Data 7, 417(1978).

Physical and Thermodynamic Properties of Aliphatic Alcohols Randolph C. Wilhoit and Bruno J. Zwolinski. J Phys Chem Ref Data 2, Suppl. 1(1973).

Thermodynamic Properties of PNormal and Deuterated Methanols S. S. Chen, Randolph C. Wilhoit, and Bruno J. Zwolinski. J Phys Chem Ref Data 6, 105(1977).

Thermodynamic Properties of Normal and Deuterated Naphthalenes - S. S. Chen, Shanti A. Kudchadker, and Randolph C. Wilhoit. J Phys Chem Ref Data 8, 527(1979).

\section{Wilkinson, Francis}

Rate Constants for the Decay and Reactions of the Lowest Electronically Excited Singlet State of Molecular Oxygen in Solution - Francis Wilkinson and James G. Brummer. J Phys Chem Ref Data 10, 809(1981).

\section{Willemot, Edmond}

Microwave Spectra of Molecules of Astrophysical Interest. XVIII. Formic Acid - Edmond Willemot, Didier Dangoisse, Nicole Monnanteuil, and Jean Bellet. J Phys Chem Ref Data 9, 59(1980).

\section{Williams, M. L}

Soft X-Ray Emission Spectra of Metallic Solids: Critical Review of Selected Systems - Archie J. McAlister, Ronald C. Dobbyn, John R. Cuthill, and M. L. Williams. J Phys Chem Ref Data 2, 411(1973).

Soft X-Ray Emission Spectra of Metallic Solids: Critical Review of Selected Systems and Annotated Spectral Index - Archie J. McAlister, Ronald C. Dobbyn, John R. Cuthill, and M. L. Williams. NBS Spec. Publ. 369, 180p. (1974).

Wilson, William E., Jr.

A Critical Review of the Gas-Phase Reaction Kinetics of the Hydroxyl Radical - William E. Wilson, Jr. J Phys Chem Ref Data 1, 535(1972).

\section{Winkelmann, Frederick C.}

$\pi+\mathrm{p}, \pi+\mathrm{n}$, and $\pi+\mathrm{d}$ Interactions - A Compilation: Parts I and II Denyse M. Chew, Victor P. Henri, Thomas A. Lasinski, Thomas G. Trippe, Fumiyo Uchiyama, Frederick C. Winkelmann and Particle Data Group. UCRL 53, Springfield, VA: NTIS, 213p. (1973). LBL 53; Part II is on microfiche located in the back cover pocket, Al0.

\section{Winnewisser, G.}

Microwave Spectra of Molecules of Astrophysical Interest, X. Isocyanic Acid -- G. Winnewisser, W. H. Hocking, and M. C. L. Gerry. J Phys Chem Ref Data 5, 79(1976).
Microwave Spectra of Molecules of Astrophysical Interest, XIV. Vinyl Cyanide (Acrylonitrile) - M. C. L. Gerry, K. Yamada, and G. Winnewisser. J Phys Chem Ref Data 8, 107(1979).

\section{Wobbeking, Theresa F.}

A Compilation of Thermodynamic and Transport Properties of Aqueous Sulfuric Acid - Bert R. Staples and Theresa F. Wobbeking. NBSIR 81-2276, 26p. (1981).

\section{Wolcott, Norman $M$.}

A Contribution to Computer Typesetting Techniques: Tables of Coordinates for Hershey's Repertory of Occidental Type Fonts and Graphic Symbols - Norman M. Wolcott and Joseph Hilsenrath. NBS Spec. Publ. 424, 177p. (1976).

Computer Science \& Technology: FORTRAN IV Enhanced Character Graphics - Norman M. Wolcott. OSRD Mag. Tape, Washington, DC: NBS Office of Standard Reference Data,(1978). For specific instructions, call (301) 921-2468.

Tables of Coordinates for Hershey's Repertory of Type Fonts and Graphic Symbols - Norman M. Wolcott and Joseph Hilsenrath. OSRD Mag. Tape A12, Washington, DC: Office of Standard Reference Data,(1977). Hershey tape.

\section{Wolfsberg, Max}

Heavy-Atom Kinetic Isotope Effects, An Indexed Bibliography Marvin J. Stern and Max Wolfsberg. NBS Spec. Publ. 349, 43p. (1972).

\section{Wong, J.}

Molten Salts: Volume 2. Section 1. Electrochemistry of Molten Salts. Gibbs Free Energies and Excess Free Energies from EquilibriumType Cells, Section 2. Surface Tension Data - George J. Janz, Chr. G. M. Dijkhuis, G. R. Lakshminarayanan, Reginald P. T. Tomkins, and J. Wong. NSRDS-NBS 28, 116p. (1968).

\section{Wu, K. Y.}

Electrical Resistivity of Ten Selected Binary Alloy Systems - Cho Y. Ho, M. W. Ackerman, K. Y. Wu, T. N. Havill, R. H. Bogaard, R. A. Matula, S. G. Oh, and H. M. James. J Phys Chem Ref Data 12, 183(1983).

Thermal Conductivity of Ten Selected Binary Alloy Systems - Cho Y. Ho, M. W. Ackerman, K. Y. Wu, S. G. Oh, and T. N. Havill. J Phys Chem Ref Data 7, 959(1978).

\section{Wu, Yung-Chi}

Osmotic Coefficients and Mean Activity Coefficients of UniUnivalent Electrolytes in Water at $25{ }^{\circ} \mathrm{C}-$ Walter J. Hamer and Yung-Chi Wu. J Phys Chem Ref Data 1, 1047(1972).

Revised Values of the Osmotic Coefficients and Mean Activity Coefficients of Sodium Nitrate in Water at $25^{\circ} \mathrm{C}$ (Comments) - Yung-Chi Wu and Walter J. Hamer. J Phys Chem Ref Data 9, 513(1980).

\section{Wunderlich, Bernhard}

Heat Capacity and Other Thermodynamic Properties of Linear Macromolecules. I. Selenium - Umesh Gaur, Hua-Cheng Shu, Aspy Metha, and Bernhard Wunderlich. J Phys Chem Ref Data 10, 89(1981).

Heat Capacity and Other Thermodynamic Properties of Linear Macromolecules. II. Polyethylene - Umesh Gaur and Bernhard Wunderlich. J Phys Chem Ref Data 10, 119(1981).

Heat Capacity and Other Thermodynamic Properties of Linear Macromolecules. III. Polyoxides - Umesh Gaur and Bernhard Wunderlich. J Phys Chem Ref Data 10, 1001(1981).

Heat Capacity and Other Thermodynamic Properties of Linear Macromolecules. IV. Polypropylene - Umesh Gaur and Bernhard Wunderlich. J Phys Chem Ref Data 10, 1051(1981). 
Heat Capacity and Other Thermodynamic Properties of Linear Macromolecules. V. Folystyrene - Umesh Gaur and Bernhard Wunderlich. J Phys Chem Ref Data 11, 313(1982).

Heat Capacity and Other Thermodynamic Properties of Linear Macromolecules. VI. Acrylic Polymers - Umesh Gaur, Suk-fai Lau, Brent B. Wunderlich, and Bernhard Wunderlich. J Phys Chem Ref Data 11, 1065(1982).

Heat Capacity and Other Thermodynamic Properties of Linear Macromolecules. VII. Other Carbon Backbone Polymers - Umesh Gaur, Brent B. Wunderlich, and Bernhard Wunderlich. J Phys Chem Ref Data 12, 29(1983).

Heat Capacity and Other Thermodynamic Properties of Linear Macromolecules. VIII. Polyesters and Polyamides - Umesh Gaur, Suk-fai Lau, Brent B. Wunderlich, and Bernhard Wunderlich. J Phys Chem Ref Data 12, 65(1983).

Heat Capacity and Other Thermodynamic Properties of Linear Macromolecules. IX. Final Group of Aromatic and Inorganic Polymers Umesh Gaur, Suk-fai Lau, and Bernhard Wunderlich. J Phys Chem Ref Data 12, 91(1983).

\section{Wunderlich, Brent B.}

Heat Capacity and Other Thermodynamic Properties of Linear Macromolecules. VI. Acrylic Polymers - Umesh Gaur, Suk-fai Lau, Brent B. Wunderlich, and Bernhard Wunderlich. J Phys Chem Ref Data 11, 1065(1982).

Heat Capacity and Other Thermodynamic Properties of Linear Macromolecules. VII. Other Carbon Backbone Polyniers - Umesh Gaur, Brent B. Wunderlich, and Bernhard Wunderlich. J Phys Chem Ref Data 12, 29(1983).

Heat Capacity and Other Thermodynamic Properties of Linear Macromolecules. VIII. Polyesters and Polyamides - Umesh Gaur, Suk-fai Lau, Brent B. Wunderlich, and Bernhard Wunderlich. J Phys Chem Ref Data 12, 65(1983).

\section{Yalkowsky, Samuel H.}

Water Solubilities of Polynuclear Aromatic and Heteroaromatic Compounds - Robert S. Pearlman, Samuel H. Yalkowsky, and Sujit Banerjee. J Phys Chem Ref Data 13, 555(1984).

\section{Yamada, K.}

Microwave Spectra of Molecules of Astrophysical Interest, XIV. Vinyl Cyanide (Acrylonitrile) - M. C. L. Gerry, K. Yamada, and G. Winnewisser. J Phys Chem Ref Data 8, 107(1979).

\section{Yoshida, Toshihiro}

NN and ND Interactions - A Compilation - James E. Enstrom, Thomas Ferbel, Paul F. Slattery, Barry L. Werner, Zaven G. T. Guiragossian, Yoshio Sumi, Toshihiro Yoshida and Particle Data Group. UCRL-LBL 58, Berkeley, CA: Lawrence Berkeley Laboratory, U. of California, 281p. (1972). LBL 58.

\section{Yoshlno, $\mathrm{K}$.}

Atlas of the Schumann-Runge Absorption Bands of $\mathrm{O}_{2}$ in the Wavelength Region 175-205 nm - K. Yoshino, D. E. Freeman, and W. H. Parkinson. J Phys Chem Ref Data 13, 207(1984).

\section{Young, K. F.}

Compilation of the Static Dielectric Constant of Inorganic Solids K. F. Young and Hans P. R. Frederikse. J Phys Chem Ref Data 2, 313(1973).

\section{Younger, S. M.}

Atomic Transition Probabilities for Vanadium, Chromium, and Manganese (A Critical Data Compilation of Allowed Lines) - S. M. Younger, Jeffrey R. Fuhr, Georgia A. Martin, and Wolfgang L. Wiese. J Phys Chem Ref Data 7, 495(1978).

Atomic Transition Probabilities for Iron, Cobalt, Nickel: A Critical Data Compilation of Allowed Lines - Jeffrey R. Fuhr, Georgia A. Martin, Wolfgang L. Wiese, and S. M. Younger. J Phys Chem Ref Data 10, 305(1981).

\section{Younglove, Ben A.}

Interactive FORTRAN Program to Calculate Thermophysical Properties of Seven Fluids - Ben A. Younglove. NBS Tech. Note 1048, 56p. (1982).

Thermophysical Properties of Fluids. I. Argon, Ethylene, Parahydrogen, Nitrogen, Nitrogen Trifluoride, and Oxygen - Ben A. Younglove. J Phys Chem Ref Data 11, Suppl. 1(1982).

\section{Zagoruchenko, V. A.}

Thermophysical Properties of Gaseous and Liquid Methane - V.A. Zagoruchenko and A. M. Zhuravlev. Russian Transl. Springfield, VA: NTIS, 251p. (1970). TT 70-50097, A12.

\section{Zalubas, Romuald}

Atomic Energy Levels - The Rare-Earth Elements, the Spectra of La, Ce, Pr, Nd, Pm, Sm, Eu, Gd, Tb, Dy, Ho, Er, Tm, Yb, Lu William C. Martin, Romuald Zalubas, and Lucy Hagan. NSRDS-NBS 60, 422p. (1978).

Bibliography on Atomic Energy Levels and Spectra, July 1975 through June 1979 - Romuald Zalubas and Arlene Albright. NBS Spec. Publ. 363, Suppl. 2(1980).

Energy Levels of Magnesium, Mg I through Mg XII - William C. Martin and Romuald Zalubas. J Phys Chum Ref Data 9, 1(1980).

Energy Levels of Silicon, Si I through Si XIV - William C. Martin and Romuald Zalubas. I Phys Chem Ref Data 12, 323(1983).

Energy Levels of Sodium, Na I through Na XI - William C. Martin and Romuald Zalubas. J Phys Chem Ref Data 10, 153(1981).

Energy levels of Aluminum, Al I through Al XIII - William C. Martin and Romuald Zalubas. J Phys Chem Ref Data 8, 817(1979). 


\section{Actinide elements}

Ground Levels and Ionization Potentials for Lanthanide and Actinide Atoms and Ions - William C. Martin, Lucy Hagan, Joseph Reader, and Jack Sugar. J Phys Chem Ref Data 3, 771(1974)

Recommended Atomic Electron Binding Energies, 1 s to $6 \mathrm{p}_{3 / 2}$, for the Heavy Elements, $Z=84$ to $103-F$. T. Porter and M. S. Freedman. J Phys Chem Ref Data 7, 1267(1978).

Selected Values of Chemical Thermodynamic Properties: Compounds of Uranium, Protactinium, Thorium, Actinium, and the Alkali Metals Donald D. Wagman, William H. Evans, Vivian B. Parker, Richard H. Schumm, and Ralph L. Nuttall. NBS Tech. Note 270, 149p. (1981).

The Thermochemical Properties of Uranium-Halogen Containing Compounds - Vivian B. Parker. NBSIR 80-2029, 173p. (1980).

\section{Alcohols}

Physical and Thermodynamic Properties of Aliphatic Alcohols Randolph C. Wilhoit and Bruno J. Zwolinski. J Phys Chem Ref Data 2, Suppl. 1(1973).

Radiation Chemistry of Ethanol: A Review of Data on Yields, Reaction Rate Parameters, and Spectral Properties of Transients - Gordon R. Freeman. NSRDS-NBS 48, 44p. (1974).

Selected Specific Rates of Reactions of the Solvated Electron in Alcohols - Edgar Watson, Jr. and Sathyabhama Roy. NSRDS-NBS 42, 27p. (1972).

The Radiolysis of Methanol: Product Yields, Rate Constants, and Spectroscopic Parameters of Intermediates - J. H. Baxendale and Peter Wardman. NSRDS-NBS 54, 33p. (1975).

Thermodynamic Properties of Normal and Deuterated Methanols - S. S. Chen, Randolph C. Wilhoit, and Bruno J. Zwolinski. J Phys Chem Ref Data 6, 105(1977).

\section{Alkali halides}

Bibliography on Properties of Defect Centers in Alkali Halides Suresh C. Jain, S. A. Khan, H. K. Sehgal, V. K. Garg, and R. K. Jain. OSRD Bibl. 71-1, 293p. (1971).

Electronic Absorption and Internal and External Vibrational Data of Atomic and Molecular Ions Doped in Alkali Halide Crystals - Suresh C. Jain, A. V. R. Warrier, and Suresh K. Agarwal. NSRDS-NBS 52, 55p. (1974).

Physical Properties Data for Rock Salt - Lewis H. Gevantman. NBS Monograph 167, 288p. (1981).

Refractive Index of Alkali Halides and Its Wavelength and Temperature Derivatives - H. H. Li. J Phys Chem Ref Data 5, 329(1976).

Tables of the Dynamic and Kinematic Viscosity of Aqueous $\mathrm{KCl}$ Solutions in the Temperature Range $25-150^{\circ} \mathrm{C}$ and the Pressure Range 0.1-35 $\mathrm{MPa}$ - Joseph Kestin, H. Ezzat Khalifa, and Robert J. Correia. J Phys Chem Ref Data 10, 57(1981).

Tables of the Dynamic and Kinematic Viscosity of Aqueous $\mathrm{NaCl}$ Solutions in the Temperature Range $20-150^{\circ} \mathrm{C}$ and the Pressure Range 0.1-35 MPa - Joseph Kestin, H. Ezzat Khalifa, and Robert J. Correia. J Phys Chem Ref Data 10, 71(1981).

Thermodynamic Properties of Aqueous Sodium Chloride Solutions Kenneth S. Pitzer, J. Christopher Peiper, and R. H. Busey. J Phys Chem Ref Data 13, 1(1984).

Volumetric Properties of Aqueous Sodium Chloride Solutions - P. S. Z. Rogers and Kenneth S. Pitzer. J Phys Chem Ref Data 11, 15(1982).

\section{Alkali metals}

Activity and Osmotic Coefficients of Aqueous Alkali Metal Nitrites Bert R. Staples. J Phys Chem Ref Data 10, 765(1981).

Chemical Thermodynamic Properties of Compounds of Sodium, Potassium, and Rubidium: An Interim Tabulation of Selected Material Donald D. Wagman, William H. Evans, Vivian B. Parker, and Richard H. Schumm. NBSIR 76-1034, 76p. (1976).

Electrical Resistivity of Alkali Elements - T. C. Chi. J Phys Chem Ref Data 8, 339(1979).

Electron Impact Excitation of Atoms - Benjamin L. Moiseiwitsch and Steven J. Smith. NSRDS-NBS 25, 120p. (1968).

Energy Levels of Sodium, Na I through Na XI - William C. Martin and Romuald Zalubas. J Phys Chem Ref Data 10, 153(1981).

Selected Values of Chemical Thermodynamic Properties: Compounds of Uranium, Protactinium, Thorium, Actinium, and the Alkali Metals Donald D. Wagman, William H. Evans, Vivian B. Parker, Richard H. Schumm, and Ralph L. Nuttall. NBS Tech. Note 270, 149p. (1981).

\section{Alkaline earth halides}

Evaluated Activity and Osmotic Coefficients for Aqueous Solutions: The Alkaline Earth Metal Halides - Robert N. Goldberg and Ralph L. Nuttall. J Phys Chem Ref Data 7, 263(1978).

Refractive Index of Alkaline Earth Halides and Its Wavelength and Temperature Derivatives - H. H. Li. J Phys Chem Ref Data 9, 161(1980).

\section{Alkaline earth metals}

Electrical Resistivity of Alkaline Earth Elements - T. C. Chi. J Phys Chem Ref Data 8, 439(1979).

Selected Values of Chemical Thermodynamic Properties. Tables for the Alkaline Earth Elements (Elements 92 through 97 in the Standard Order of Arrangement) - Vivian B. Parker, Donald D. Wagman, and William H. Evans. NBS Tech. Note 270, 124p. (1971).

\section{Aqueous solutions}

A Bibliography of Sources of Experimental Data Leading to Activity or Osmotic Coefficients for Polyvalent Electrolytes in Aqueous Solution - Robert N. Goldberg, Bert R. Staples, Ralph L. Nuttall, and R. Arbuckle. NBS Spec. Publ. 485, 57p. (1977).

A Bibliography of Sources of Experimental Data Leading to Thermal Properties of Binary Aqueous Electrolyte Solutions - David SmithMagowan and Robert N. Goldberg. NBS Spec. Publ. 537, 94p. (1979).

A Report on Thermodynamic Data for Desulfurization Processes Vivian B. Parker, Bert R. Staples, Thomas L. Jobe, Jr., and David B. Neumann. NBSIR 81-2345, 89p. (1981).

Activity and Osmotic Coefficients of Aqueous Alkali Metal Nitrites Bert R. Staples. J Phys Chem Ref Data 10, 765(1981).

Activity and Osmotic Coefficients of Aqueous Sulfuric Acid at 298.15 K - Bert R. Staples. J Phys Chem Ref Data 10, 779(1981).

An Annotated Bibliography of Compiled Thermodynamic Data Sources for Biochemical and Aqueous Systems (1930 to 1975), Equilibrium, Enthalpy, Heat Capacity, and Entropy Data - George T. Armstrong and Robert N. Goldberg. NBS Spec. Publ. 454, 71p. (1976). 
Compilation of Rate Constants for the Reactions of Metal Ions in Inusual Valency States - George V. Buxton and Robin M. Sellers. ISRDS-NBS 62, 68p. (1978).

Computer Programs for the Evaluation of Activity and Osmotic Joefficients - Bert R. Staples and Ralph L. Nuttall. NBS Tech. Note 28, 60p. (1976).

Electrolytic Conductance and the Conductances of the Halogen scids in Water - Walter J. Hamer and H. J. DeWane. NSRDS-NBS 3, 37p. (1970).

Evaluated Activity and Osmotic Coefficients for Aqueous Solutions: The Alkaline Earth Metal Halides - Robert N. Goldberg and Ralph L. Juttall. J Phys Chem Ref Data 7, 263(1978).

Evaluated Activity and Osmotic Coefficients for Aqueous Solutions: ron Chloride and the Bi-Univalent Compounds of Nickel and Cobalt - Robert N. Goldberg, Ralph L. Nuttall, and Bert R. Staples. J Phys Them Ref Data 8, 923(1979).

Evaluated Activity and Osmotic Coefficients fo: Aqueous Solutions: 3i-Univalent Compounds of Lead, Copper, Manganese, and Uranium - Robert N. Goldberg. J Phys Chem Ref Data 8, 1005(1979).

Evaluated Activity and Osmotic Coefficients for Aqueous Solutions: 3i-Univalent Compounds of Zinc, Cadmium, and Ethylene Bis(Trimethylammonium) Chloride and Iodide - Robert N. Goldberg. J ?hys Chem Ref Data 10, 1(1981).

Evaluated Activity and Osmotic Coefficients for Aqueous Solutions: Thirty-Six Uni-Bivalent Electrolytes - Robert N. Goldberg. J Phys Chem Ref Data 10, 671(1981).

High Temperature Properties and Decomposition of Inorganic Salts,

Part 3. Nitrates and Nitrites - Kurt H. Stern. J Phys Chem Ref Data 1, 747(1972).

Optical Spectra of Nonmetallic Inorganic Transient Species in Aqueous Solution - Gordon L. Hug. NSRDS-NBS 69, 167p. (1981).

Rate Constants for Reactions of Aliphatic Carbon-Centered Radicals in Aqueous Solution - Alberta B. Ross and Pedatsur Neta. NSRDSNBS 70, 96p. (1982).

Rate Constants for Reactions of Inorganic Radicals in Aqueous Solution - Alberta B. Ross and Pedatsur Neta. NSRDS-NBS 65, 62p. (1979).

Tables of the Dynamic and Kinematic Viscosity of Aqueous $\mathrm{KCl}$ Solutions in the Temperature Range $25-150^{\circ} \mathrm{C}$ and the Pressure Range 0.1-35 MPa - Joseph Kestin, H. Ezzat Khalifa, and Robert J. Correia.

J Phys Chem Ref Data 10, 57(1981).

Tables of the Dynamic and Kinematic Viscosity of Aqueous $\mathrm{NaCl}$ Solutions in the Temperature Range $20-150^{\circ} \mathrm{C}$ and the Pressure Range 0.1-35 MPa - Joseph Kestin, H. Ezzat Khalifa, and Robert J. Correia. J Phys Chem Ref Data 10, 71(1981).

The Activity and Osmotic Coefficients of Aqueous Calcium Chloride at 298.15 K - Bert R. Staples and Ralph L. Nuttall. J Phys Chem Ref Data 6, 385(1977).

The Thermodynamic Properties of Aqueous Inorganic Copper Systems - Paul Duby. INCRA Monograph IV, New York: International Copper Research Association, Inc., 132p. (1977).

Theoretical Mean Activity Coefficients of Strong Electrolytes in Aqueous Solutions from 0 to $100^{\circ} \mathrm{C}-$ Walter J. Hamer. NSRDS-NBS 24, 271p. (1968).

Thermal Properties of Aqueous Uni-Univalent Electrolytes -

Vivian B. Parker. NSRDS-NBS 2, 68p. (1965).

Thermodynamic Properties of Aqueous Sodium Chloride Solutions - Kenneth S. Pitzer, J. Christopher Peiper, and R. H. Busey. J Phys Chem Ref Data 13, 1(1984).

Volumetric Properties of Aqueous Sodium Chloride Solutions - P.

S. Z. Rogers and Kenneth S. Pitzer. J Phys Chem Ref Data 11, 15(1982)

\section{Atmospheric gases}

A Bibliography of Kinetic Data on Gas Phase Reactions of Nitrogen, Oxygen, and Nitrous Oxides - Francis Westley. OSRD Bibl. 71-2, 140p. (1971).
A Review of Rate Constants of Selected Reactions of Interest in Re-Entry Flow Fields in the Atmosphere - M. H. Bortner. NBS Tech. Note 484, 62p. (1969).

A Supplementary Bibliography of Kinetic Data on Gas Phase Reactions of Nitrogen, Oxygen, and Nitrogen Oxides - Francis Westley. NBS Spec. Publ. 371, 93p. (1973).

A Survey of Electron Swarm Data - J. Dutton. J Phys Chem Ref Data 4, 577(1975).

An Annotated Compilation and Appraisal of Electron Swarm Data in Electronegative Gases - Jean W. Gallagher, Earl C. Beaty, J. Dutton, and L. C. Pitchford. J Phys Chem Ref Data 12, 109(1983).

Atlas of the Observed Absorption Spectrum of Carbon Monoxide between 1060 and $1900 \AA$ - S. G. Tilford and J. D. Simmons. J Phys Chem Ref Data 1, 147(1972).

Atlas of the Schumann-Runge Absorption Bands of $\mathrm{O}_{2}$ in the Wavelength Region 175-205 nm - K. Yoshino, D. E. Freeman, and W. H. Parkinson. J Phys Chem Ref Data 13, 207(1984).

Chemical Kinetic and Photochemical Data Sheets for Atmospheric Reactions - Robert F. Hampson, Jr. Fed Aviation Admin EE 80-17, Springfield, VA: NTIS, 490p. (1980). FAA-EE-80-17, A21.

Critical Review of Ultraviolet Photoabsorption Cross Sections for Molecules of Astrophysical and Aeronomic Interest - Robert D. Hudson. NSRDS-NBS 38, 114p. (1971).

Equilibrium Properties of Fluid Mixtures, A Bibliography on Fluids of Cryogenic Interest - M. J. Hiza, A.rthur J. Kidnay, and R. C. Miller. New York: IFI/Plenum, 166p. (1975), ISBN: 0-306-6601-6.

Equilibrium Properties of Fluid Mixtures, 2. A Bibliography of Experimental Data on Selected Fluids - M. J. Hiza, Arthur J. Kidnay, and R. C. Miller. New York: IFI/Plenum, 258p. (1982), ISBN: 0-306-6602-4

Evaluated Kinetic and Photochemical Data for Atmospheric Chemistry - D. L. Baulch, R. A. Cox, Robert F. Hampson, Jr., J. A. Kerr, J. Troe, and R. T. Watson. J Phys Chem Ref Data 9, 295(1980).

Evaluated Kinetic and Photochemical Data for Atmospheric Chemistry: Supplement I. CODATA Task Group on Chemical Kinetics D. L. Baulch, R. A. Cox, P. J. Crutzen, Robert F. Hampson, Jr., J. A. Kerr, J. Troe, and R. T. Watson. J Phys Chem Ref Data 11, 327(1982).

Evaluated Kinetic and Photochemical Data for Atmospheric Chemistry: Supplement II. CODATA Task Group on Gas Phase Chemical Kinetics - D. L. Baulch, R. A. Cox, Robert F. Hampson, Jr., J. A. Kerr, J. Troe, and R. T. Watson. J Phys Chem Ref Data 13, 1259(1984).

Evaluation of Kinetic and Mechanistic Data for Modeling of Photochemical Smog - Roger Atkinson and Alan C. Lloyd. J Phys Chem Ref Data 13, 315(1984).

Gaseous Diffusion Coefficients - T. R. Marrero and E. A. Mason. J Phys Chem Ref Data 1, 1(1972).

Interactive FORTRAN Program to Calculate Thermophysical Properties of Seven Fluids - Ben A. Younglove. NBS Tech. Note 1048, 56p. (1982).

Interactive Fortran Program to Calculate Thermophysical Properties of 6 Fluids NBS Standard Reference Database 6, Washington, D.C.; NBS, Office of Standard Reference Data,(updated periodically). Call (301)921-2228 for specific instructions.

Kinetic and Photochemical Data for Atmospheric Chernistry, Reactions of the Nitrogen Oxides - Robert F. Hampson, Jr. NBSIR 80-2032, 89p. (1980).

Liquid Densities of Oxygen, Nitrogen, Argon, and Parahydrogen Hans M. Roder, Robert D. McCarty, and V. J. Johnson. NBS Tech. Note 361, 1972(1973)

Rate Constants for Reactions of $\mathrm{ClO}_{\mathrm{x}}$ of Atmospheric Interest - R. T. Watson. J Phys Chem Ref Data 6, 871(1977).

Reaction Rate and Photochemical Data for Atmospheric Chemistry - 1977 - Robert F. Hampson, Jr. and David Garvin. NBS Spec. Publ. 513, 111p. (1978).

Scaled Equation of State Parameters for Gases in the Criuical Region - J. M. H. Levelt Sengers, W. L. Greer, and Jan V. Sengers. J Phys Chem Ref Data 5, 1(1976).

Supplementary Bibliography of Kinetic Data on Gas Phase Reactions of Nitrogen, Oxygen, and Nitrogen Oxides (1972 - 1973) - 
Supplementary Bibliography of Kinetic Data on Gas Phase Reactions of Nitrogen, Oxygen, and Nitrogen Oxides (1972 - 1973) - Francis Westley. NBS Spec. Publ. 371, Suppl. 1(1975)

Survey of Photochemical and Rate Data for Twenty-eight Reactions of Interest in Atmospheric Chemistry - Robert F. Hampson, Jr., W. Braun, R. L. Brown, David Garvin, John T. Herron, Robert E. Huie, M. J. Kurylo, A. H. Laufer, J. D. McKinley, H. Okabe, M. D. Scheer, W. Tsang, D. H. Stedman, editor(s). J Phys Chem Ref Data 2, 267(1973).

The Molar Volume (Density) of Solid Oxygen in Equilibrium with Vapor - Hans M. Roder. J Phys Chem Ref Data 7, 949(1978).

The Solubility of Nitrogen and Air in Liquids - Rubin Battino, Timothy R. Rettich, and Toshihiro Tominaga. J Phys Chem Ref Data 13, 563(1984).

The Solubility of Oxygen and Ozone in Liquids - Rubin Battino, Timothy R. Rettich, and Toshihiro Tominaga. J Phys Chem Ref Data 12 163(1983).

The Spectrum of Molecular Nitrogen - Alf Lofthus and Paul $\mathbf{H}$ Krupenie. J Phys Chem Ref Data 6, 113(1977).

The Spectrum of Molecular Oxygen - Paul H. Krupenie. J Phys Chem Ref Data 1, 423(1972).

The Viscosity and Thermal Conductivity Coefficients of Dilute Nitrogen and Oxygen - Howard J. M. Hanley and James F. Ely. J Phys Chem Ref Data 2, 735(1973).

The Viscosity and Thermal Conductivity Coefficients for Dense Gaseous and Liquid Argon, Krypton, Xenon, Nitrogen, and Oxygen - Howard J. M. Hanley, Robert D. McCarty, and W. M. Haynes. J Phys Chem Ref Data 3, 979(1974).

Thermodynamic Properties of Argon from the Triple Point to $300 \mathrm{~K}$ at Pressures to 1000 Atmospheres - A. L. Gosman, Robert D. McCarty, and Jerome G. Hust. NSRDS-NBS 27, 153p. (1969).

Thermodynamic Properties of Nitrogen Including Liquid and Vapor Phases from $63 \mathrm{~K}$ to $2000 \mathrm{~K}$ with Pressures to $10,000 \mathrm{Bar}$ - Richard T. Jacobsen and Richard B. Stewart. J Phys Chem Ref Data 2, 757(1973). Thermodynamic and Related Properties of Oxygen from the Triple Point to $300 \mathrm{~K}$ at Pressures to 1000 Bar - Lloyd A. Weber. NBSIR 77-865, 162p. (1977).

Thermodynamic and Thermophysical Properties of Combustion Products, Volume III. Oxygen- and Air-Based Propellant - V. P. Glushko, V. E. Alemasov, A. F. Dregalin, A. P. Tishin, V. A. Khudyakov, and V. N. Kostin. Russian Transl. Springfield, VA: NTIS, 648p. (1975). TT 75-50007, A26.

Thermophysical Properties of Air and Air Components - A. A. Vasserman, Ya. Z. Kazavchinskii, V. A. Rabinovich, and A. M. Zhuravlev. Russian Transl. Springfield, VA: NTIS, 402p. (1971). TT 70-50095, A18.

Thermophysical Properties of Fluids. I. Argon, Ethylene, Parahydrogen, Nitrogen, Nitrogen Trifluoride, and Oxygen - Ben A. Younglove. J Phys Chem Ref Data 11, Suppl. 1(1982).

Thermophysical Properties of Liquid Air and Its Components - A. A. Vasserman and V. A. Rabinovich. Russian Transl. Springfield, VA: NTIS, 255p. (1970). TT 69-55092, A12.

\section{Ceramics}

Applications of Phase Diagrams, Proceedings of a Workshop Held at the National Bureau of Standards, Gaithersburg, Maryland, January 10-12, 1977, Volumes 1 and 2 - Gesina Cynthia Carter, editor(s). NBS Spec. Publ. 496, 1622p. (1978).

Critical Surveys of Data Sources: Ceramics - Dorothea M. Johnson and James F. Lynch. NBS Spec. Publ. 396, 56p. (1975).

Electric Conductivity of Ferroelectrics - V. M. Gurevich. Russian Transl. Springfield, VA: NTIS, 366p. (1971). TT 70-50180, A 16.

Phase Diagrams for Ceramists - Ernest M. Levin, Carl R. Robbins, Howard F. McMurdie, editor(s). American Ceramic Society; Columbus, Ohio, 60lp. (1964), ISBN: 0-916094-04-9.

Phase Diagrams for Ceramists 1969 Supplement - Ernest M. Levin, Carl R. Robbins, Howard F. McMurdie, editor(s). American Ceramic Society; Columbus, Ohio, 625p. (1969), ISBN: 0-916094-05-7.

Phase Diagrams for Ceramists 1975 Supplement - Ernest M. Levin, Howard F. McMurdie, editor(s). American Ceramic Society; Columbus, Ohio, 513p. (1975).
Physical Properties Data Compilations Relevant to Energy Storage. III. Engineering Properties of Single and Polycrystalline Sodium Beta and Beta" Alumina - G. R. Miller and D. G. Paquette. NSRDS-NBS 61, 19p. (1979).

\section{Colloids}

Critical Micelle Concentrations of Aqueous Surfactant Systems Pasupati Mukerjee and Karol J. Mysels. NSRDS-NBS 36, 222p. (1971).

\section{Crystals}

Bibliography on Properties of Defect Centers in Alkali Halides Suresh C. Jain, S. A. Khan, H. K. Sehgal, V. K. Garg, and R. K. Jain. OSRD Bibl. 71-1, 293p. (1971).

Crystal Data Determinative Tables, Third Edition, Volume 5. Organic Compounds - Olga Kennard, David G. Watson, John E. Davies, John R. Rodgers, editor(s). 5, Swarthmore, PA, JCPDS-International Center for Diffraction Data,(1983).

Crystal Data Determinative Tables, Third Edition, Volume 6. Organic Compounds - Olga Kennard, David G. Watson, John E. Davies, editor(s). 6, Swarthmore, PA, JCPDS-International Center for Diffraction Data,(1983)

Crystal Data Space-Group Tables - Alan D. Mighell, Helen M. Ondik, and Bettijoyce Breen Molino. J Phys Chem Ref Data 6, 675(1977).

Crystal Data Determinative Tables, Third Edition Volume 1: Organic Compounds - Joseph D. H. Donnay and Helen M. Ondik. Swarthmore, PA: JCPDS-International Center for Diffraction Data, 855p. (1972).

Crystal Data Determinative Tables, Third Edition Volume 2: Inorganic Compounds - Joseph D. H. Donnay and Helen M. Ondik. Swarthmore, PA: JCPDS-International Center for Diffraction Data, 1748p. (1973).

Crystal Data Determinative Tables, Third Edition Volume 3. Organic Compounds - Joseph D. H. Donnay, Olga Kennard, David G. Watson, and John R. Rodgers. Swarthmore, PA: JCPDS-International Center for Diffraction Data, 748p. (1978).

Crystal Data Determinative Tables, Third Edition Volume 4. Inorganic Compounds - Joseph D. H. Donnay, Helen M. Ondik, and Alan D. Mighell. Swarthmore, PA: JCPDS-International Center for Diffraction Data, 1308p. (1978).

Crystal Structure Transformations in Binary Halides - C. N. R. Rao and M. Natarajan. NSRDS-NBS 41, 57p. (1972).

Crystal Structure Transformations in Inorganic Nitrites, Nitrates, and Carbonates - C. N. R. Rao, Brahm Prakash, and M. Natarajan. NSRDSNBS 53, 55p. (1975).

Crystal Structure Transformations in Inorganic Sulfates, Phosphates, Perchlorates, and Chromates - C. N. R. Rao and Brahm Prakash. NSRDS-NBS 56, 37p. (1975).

Electronic Absorption and Internal and External Vibrational Data of Atomic and Molecular Ions Doped in Alkali Halide Crystals - Suresh C. Jain, A. V. R. Warrier, and Suresh K. Agarwal. NSRDS-NBS 52, 55p. (1974).

NBS* AIDS80: A FORTRAN Program for Crystallographic Data Evaluation - Alan D. Mighell, C. R. Hubbard, and Judy K. Stalick. NBS Tech. Note 1141, 54p. (1981).

Space Groups and Lattice Complexes - W. Fisher, Hans Burzlaff, Erwin Hellner, and Joseph D. H. Donnay. NBS Monograph 134, 177p. (1973)

Transition Metal Oxides, Crystal Chemistry, Phase Transition, and Related Aspects - C. N. R. Rao and G. V. Subba Rao. NSRDS-NBS 49, 140p. (197.

\section{Diatomic molecules}

Atlas of the Absorption Spectrum of Nitric Oxide (NO) between 1420 and $1250 \AA-$ E. Miescher and F. Alberti. J Phys Chem Ref Data 5, 309(1976). 
Atlas of the Observed Absorption Spectrum of Carbon Monoxide between 1060 and $1900 \AA-$ S. G. Tilford and J. D. Simmons. J Phys Chem Ref Data 1, 147(1972).

Electron Impact Ionization Cross-Section Data for Atoms, Atomic Ions, and Diatomic Molecules: I. Experimental Data - Lee J. Kieffer and Gordon H. Dunn. Rev Mod Phys. 38, New York: American Institute of Physics, 35p. (1966).

Microwave Spectral Tables, I. Diatomic Molecules - Frank J. Lovas and Eberhard Tiemann. J Phys Chem Ref Data 3, 609(1974).

Microwave Spectral Tables, Volume I. Diatomic Molecules - Paul F. Wacker, M. Mizushima, J. D. Petersen, and J. R. Ballard. NBS Monograph 70, 171p. (1964).

Resonances in Electron Impact on Atoms and Diatomic Molecules - George J. Schulz. NSRDS-NBS 50, 120p. (1973).

The Band Spectrum of Carbon Monoxide - Paul H. Krupenie. NSRDS-NBS 5, 87p. (1966).

The Calculation of Rotational Energy Levels and Rotational Line Intensities in Diatomic Molecules - Jon T. Hougen. NBS Monograph 115, 54p. (1970).

The Spectrum of Molecular Nitrogen - Alf Lofthus and Paul H. Krupenie. J Phys Chem Ref Data 6, 113(1977).

The Spectrum of Molecular Oxygen - Paul H. Krupenie. J Phys Chem Ref Data 1, 423(1972).

\section{Elements}

A Multiplet Table of Astrophysical Interest, Revised Edition, Part I. Table of Multiplets, Part II. Finding List of All Lines in the Table of Multiplets - Charlotte E. Moore. NSRDS-NBS 40, 261p. (1972).

An Ultraviolet Multiplet Table, Section 1. The Spectra of Hydrogen through Vanadium - Charlotte E. Moore. NBS Circular 488, 78p. (1950).

An Ultraviolet Multiplet Table, Section 2. The Spectra of Chromium through Niobium - Charlotte E. Moore. NBS Circular 488, 115p. (1952).

An Ultraviolet Multiplet Table, Section 3. The Spectra of Molybdenum to Lanthanum and Hafnium to Radium - Charlotte E. Moore. NBS Circular 488, 94p. (1962).

An Ultraviolet Multiplet Table, Section 4. Finding List for Spectra of the Elements Hydrogen to Niobium ( $Z=1$ to 41$)$ - Charlotte E. Moore. NBS Circular 488, 65p. (1962).

An Ultraviolet Multiplet Table, Section 5. Finding List for Spectra of the Elements Molybdenum to Lanthanum ( $Z=42$ to 57 ), Hafnium to Radium ( $Z=72$ to 88$)$ - Charlotte E. Moore. NBS Circular 488, 30p. (1962).

Atomic Energy Levels - The Rare-Earth Elements, the Spectra of $\mathrm{La}, \mathrm{Ce}, \mathrm{Pr}, \mathrm{Nd}, \mathrm{Pm}, \mathrm{Sm}, \mathrm{Eu}, \mathrm{Gd}, \mathrm{Tb}, \mathrm{Dy}, \mathrm{Ho}, \mathrm{Er}, \mathrm{Tm}, \mathrm{Yb}, \mathrm{Lu}-$ William C. Martin, Romuald Zalubas, and Lucy Hagan. NSRDS-NBS 60, 422p. (1978).

Atomic Energy Levels as Derived from the Anasyses of Optical Spectra, Volume I. ' $\mathrm{H}$ to ${ }^{23} \mathrm{~V}$ - Charlotte E. Moore. NSRDS-NBS 35, 358p. (1971).

Atomic Energy Levels as Derived from the Analyses of Optical Spectra, Volume II. ${ }^{24} \mathrm{Cr}$ to ${ }^{41} \mathrm{Nb}-$ Charlotte E. Moore. NSRDS-NBS 35, 263p. (1971).

Atomic Energy Levels as Derived from the Analysis of Optical Spectra, Volume III. ${ }^{42} \mathrm{Mo}$ to ${ }^{57} \mathrm{La},{ }^{72} \mathrm{Hf}$ to ${ }^{89} \mathrm{Ac}-$ Charlotte E. Moore. NSRDS-NBS 35, 289p. (1971).

Atomic Form Factors, Incoherent Scattering Functions, and Photon Scattering Cross Sections - John H. Hubbell, W. J. Veigele, E. A Briggs, R. T. Brown, D. T. Cromer, and R. J. Howerton. J Phys Chem Ref Data 4, 471(1975).

Atomic Gas Laser Transition Data, A Critical Evaluation - William Ralph Bennett, Jr., New York: IFI/Plenum, 293p. (1979), ISBN: 0-306-65187-4.

Atomic Radiative and Radiationless Yields for $\mathrm{K}$ and L Shells Morris O. Krause. J Phys Chem Ref Data 8, 307(1979).

Atomic Transition Probabilities, Volume II. Sodium through Calcium - Wolfgang L. Wiese, Melvin W. Smith, and Barbara M. Miles. NSRDS-NBS 22, 268p. (1969).
Atomic Transition Probabilities. Elements Hydrogen through Neon - Wolfgang L. Wiese, Melvin W. Smith, and Barbara M. Glennon. NSRDS-NBS 4, 153p. (1966).

Behavior of the Elements at High Pressures - John Francis Cannon. J Phys Chem Ref Data 3, 781(1974).

Bibliography on Atomic Energy Levels and Spectra, July 1968 through June 1971 - Lucy Hagan and William C. Martin. NBS Spec. Publ. 363, 109p. (1972).

Bibliography on Atomic Energy Levels and Spectra, July 1971 through June 1975 - Lucy Hagan. NBS Spec. Publ. 363, Suppl. 1(1977).

Bibliography on Atomic Energy Levels and Spectra, July 1975 through June 1979 - Romuald Zalubas and Arlene Albright. NBS Spec. Publ. 363, Suppl. 2(1980).

Bibliography on Atomic Line Shapes and Shifts (1899 through March 1972) - Jeffrey R. Fuhr, Wolfgang L. Wiese, and Larry J. Roszman. NBS Spec. Publication 366, 165p. (1972).

Bibliography on Atomic Line Shapes and Shifts (April 1972 through June 1973) - Jeffrey R. Fuhr, Larry J. Roszman, and Wolfgang L. Wiese. NBS Spec. Publ. 366, Suppl. 1(1974).

Bibliography on Atomic Line Shapes and Shifts (July 1973 through May 1975) - Jeffrey R. Fuhr, Georgia A. Martin, and Beverly J. Specht. NBS Spec. Publ. 366, Suppl. 2(1975).

Bibliography on Atomic Line Shapes and Shifts (June 1975 through June 1978) - Jeffrey R. Fuhr, Beverly J. Miller, and Georgia A. Martin. NBS Spec. Publ. 366, Suppl. 3(1978).

Bibliography on Flame Spectroscopy. Analytical Applications, 1800-1966 - Radu Mavrodineanu. NBS Spec. Publ. 281, 155p. (1967).

Bibliography on the Analyses of Optical Atomic Spectra. Section 1. ${ }^{1} \mathrm{H}^{-23} \mathrm{~V}$ - Charlotte E. Moore. NBS Spec. Publ. 306, 80p. (1968).

Bibliography on the Analyses of Optical Atomic Spectra. Section 2. ${ }^{24} \mathrm{Cr}^{-41} \mathrm{Nb}$ - Charlotte E. Moore. NBS Spec. Publ. 306, 57p. (1969).

Bibliography on the Analyses of Optical Atomic Spectra. Section 3. ${ }^{42} \mathrm{Mo}-{ }^{57} \mathrm{La}$ and ${ }^{72} \mathrm{Hf}-{ }^{89} \mathrm{Ac}-$ Charlotte E. Moore. NBS Spec. Publ. 306, 37p. (1969).

Bibliography on the Analyses of Optical Atomic Spectra. Section 4. ${ }^{57} \mathrm{La}-{ }^{71} \mathrm{Lu}$ and ${ }^{89} \mathrm{Ac}-{ }^{99}$ Es - Charlotte E. Moore. NBS Spec. Publ. 306, 48p. (1969).

Binding Energies in Atomic Negative Ions - H. Hotop and W. C. Lineberger. J Phys Chem Ref Data 4, 539(1975).

Comparison of Theoretical and Experimental Photoeffect Data, 0.1 $\mathrm{keV}$ to $1.5 \mathrm{MeV}-$ John H. Hubbell and W. J. Veigele. NBS Tech. Note 901, 47p. (1976).

Energy Levels of One-Electron Atoms - Glen W. Erickson. J Phys Chem Ref Data 6, 831(1977).

Experimental Stark Widths and Shifts for Spectral Lines of Neutral Atoms (A Critical Review of Selected Data for the Period 1976 to 1982) - N. Konjević, M. S. Dimitrijević, and Wolfgang L. Wiese. J Phys Chem Ref Data 13, 619(1984).

Ionization Potentials and Ionization Limits Derived from the Analyses of Optical Spectra - Charlotte E. Moore. NSRDS-NBS 34, 22p. (1970).

Isotopic Abundances and Atomic Weights of the Elements - Paul De Bièvre, Marc Gallet, Norman E. Holden, and I. Lynus Barnes. J Phys Chem Ref Data 13, 809(1984).

Natural Widths of Atomic $\mathrm{K}$ and L Levels, Ka X-Ray Lines and Several KLL Auger Lines - Morris O. Krause and J. H. Oliver. J Phys Chem Ref Data 8, 329(1979).

Nuclear Moments and Moment Ratios as Determined by Mössbauer Spectroscopy - John G. Stevens and B. D. Dunlap. J Phys Chem Ref Data 5, 1093(1976).

Nuclear Spins and Moments - Gladys H. Fuller. J Phys Chem Ref Data 5, 835(1976).

Pair, Triplet, and Total Atomic Cross Sections (and Mass Attenuation Coefficients) for $1 \mathrm{MeV}-100 \mathrm{GeV}$ Photons in Elements $Z=1$ to 100 - John H. Hubbell, Heinz A. Gimm, and I. $\emptyset$ verb $\varnothing$. J Phys Chem Ref Data 9, 1023(1980). 
Partial Grotrian Diagrams of Astrophysical Interest - Charlotte E. Moore and Paul W. Merrill. NSRDS-NBS 23, 65p. (1968).

Photon Cross Sections, Attenuation Coefficients, and Energy Absorption Coefficients from $10 \mathrm{keV}$ to $100 \mathrm{GeV}$ - John H. Hubbell. NSRDS-NBS 29, 85p. (1969).

Photonuclear Data Index, 1973-1977 - Everett G. Fuller and Henry M. Gerstenberg. NBS Spec. Publ. 380, Suppl. 1(1978).

Photonuclear Reaction Data, 1973 - Everett G. Fuller, Henry M. Gerstenberg, H. J. Vander Molen, and T. C. Dunn. NBS Spec. Publ. 380, 134p. (1973).

Recommended Atomic Electron Binding Energies, 1 s to $6 p_{3 / 2}$, for the Heavy Elements, $Z=84$ to $103-F$. T. Porter and M. S. Freedman. J Phys Chem Ref Data 7, 1267(1978).

Reference Wavelengths from Atomic Spectra in the Range $5 \AA$ to $25000 \AA$ - Victor Kaufman and Bengt Edlén. J Phys Chem Ref Data 3, 825(1974).

Relativistic Atomic Form Factors and Photon Coherent Scattering Cross Sections - John H. Hubbell and I. Øverbø. J Phys Chem Ref Data 8, 69(1979).

Selected Values of the Thermodynamic Properties of the Elements - Ralph Hultgren, Pramond D. Desai, Donald T. Hawkins, M. Gleiser, Kenneth K. Kelley, and Donald D. Wagman. Metals Park, OH: American Society for Metals, 636p. (1973).

Small-Angle Rayleigh Scattering of Photons at High Energies: Tabulations of Relativisitic HFS Modified Atonic Form Factors - D. Schaupp, M. Schumacher, F. Smend, P. Rullhusen, and John H. Hubbell. J Phys Chem Ref Data 12, 467(1983).

Table of Isotopes, Seventh Edition - C. Michael Lederer, Virginia S. Shirley, Edgardo Browne, Janis M. Dairiki, and Raymond E. Doebler. New York: Wiley-Interscience, 1628p. (1978), ISBN: 0-471-0417-3.

Tables of Atomic Spectral Lines for the $10000 \AA$ to $40000 \AA$ Region - Michael Outred. J Phys Chem Ref Data 7, 1(1978).

Tables of Line Spectra of the Elements, Part 1. Wavelengths and Intensities, Part 2. Transition Probabilities - Joseph Reader, Charles H. Corliss, Wolfgang L. Wiese, and Georgia A. Martin. NSRDS-NBS 68, 415p. (1980).

Thermal Conductivity of the Elements - Cho Y. Ho, Robert W. Powell, and Peter E. Liley. J Phys Chem Ref Data 1, 279(1972).

Thermal Conductivity of the Elements: A Comprehensive Review Cho Y. Ho, Robert W. Powell, and Peter E. Liley. J Phys Chem Ref Data 3, Suppl. 1(1974).

Total Photon Absorption Cross Section Measurements, Theoretical Analysis and Evaluations for Energies above $10 \mathrm{MeV}-$ Heinz A. Gimm and John H. Hubbell. NBS Tech. Note 968, 81 p. (1978).

X-Ray Wavelengths and X-Ray Atomic Energy Levels - Joyce A. Bearden and A. F. Burr. NSRDS-NBS 14, 66p. (1967).

\section{Ferroelectrics}

Electric Conductivity of Ferroelectrics - V. M. Gurevich. Russian Transl. Springfield, VA: NTIS, 366p. (1971). TT 70-50180, A.16.

\section{Free radicals}

A Critical Review of H-Atom Transfer in the Liquid Phase: Chlorine Atom, Alkyl, Trichloromethyl, Alkoxy, and Alkylperoxy Radicals D. G. Hendry, T. Mill, L. Piszkiewicz, J. A. Howard, and H. K. Eigenmann. J Phys Chem Ref Data 3, 937(1974).

A Critical Review of the Gas-Phase Reaction Kinetics of the Hydroxyl Radical - William E. Wilson, Jr. J Phys Chem Ref Data 1, 535(1972).

Atlas of the Absorption Spectrum of Nitric Oxide (NO) between 1420 and $1250 \AA$ - E. Miescher and F. Alberti. J Phys Chem Ref Data 5, 309(1976)

Chemical Kinetic Data Sheets for High-Temperature Chemical Reactions - N. Cohen and K. R. Westberg. J Phys Chem Ref Data 12, 531(1983).

Chemical Kinetics of the Gas Phase Combustion of Fuels (A Bibliography on the Rates and Mechanisms of Oxidation of Aliphatic $\mathrm{C}_{1}$ to
$\mathrm{C}_{10}$ Hydrocarbons and of Their Oxygenated Derivatives) - Francis Westley. NBS Spec. Publ. 449, 142p. (1976).

Critically Evaluated Rate Constants for Gaseous Reactions of Several Electronically Excited Species - Keith Schofield. J Phys Chem Ref Data 8, 723(1979).

Drift Mobilities and Conduction Band Energies of Excess Electrons in Dielectric Liquids - Augustine O. Allen. NSRDS-NBS 58, 23p. (1976).

Evaluated Chemical Kinetic Rate Constants for Various Gas Phase Reactions - Keith Schofield. I Phys Chem Ref Data 2, 25(1973).

Evaluated Kinetic Data for High Temperature Reactions, Volume 4. Homogeneous Gas Phase Reactions of Halogen- and CyanideContaining Species - D. L. Baulch, J. Duxbury, S. J. Grant, and D. C. Montague. J Phys Chem Ref Data 10, Suppl. 1(1981).

Evaluated Kinetic and Photochemical Data for Atmospheric Chemistry - D. L. Baulch, R. A. Cox, Robert F. Hampson, Jr., J. A. Kerr, J. Troe, and R. T. Watson. J Phys Chem Ref Data 9, 295(1980).

Evaluated Kinetic and Photochemical Data for Atmospheric Chemistry: Supplement I. CODATA Task Group on Chemical Kinetics D. L. Baulch, R. A. Cox, P. J. Crutzen, Robert F. Hampson, Jr., J. A. Kerr, J. Troe, and R. T. Watson. J Phys Chem Ref Data 11, 327(1982).

Evaluated Kinetic and Photochemical Data for Atmospheric Chemistry: Supplement II. CODATA Task Group on Gas Phase Chemical Kinetics - D. L. Baulch, R. A. Cox, Robert F. Hampson, Jr., J. A. Kerr, J. Troe, and R. T. Watson. J Phys Chem Ref Data 13, 1259(1984).

Gas Phase Reaction Kinetics of Neutral Oxygen Species - Harold S. Johnston. NSRDS-NBS 20, 49p. (1968).

Ground-State Vibrational Energy Levels of Polyatomic Transient Molecules - Marilyn E. Jacox. J Phys Chem Ref Data 13, 945(1984).

Kinetic Data on Gas Phase Unimolecular Reactions - Sidney W. Benson and Harry E. O'Neal. NSRDS-NBS 21, 645p. (1970).

Microwave Spectra of Molecules of Astrophysical Interest, XII. Hydroxyl Radical - Robert A. Beaudet and Robert L. Poynter. J Phys Chem Ref Data 7, 311(1978).

Optical Spectra of Nonmetallic Inorganic Transient Species in Aqueous Solution - Gordon L. Hug. NSRDS-NBS 69, 167p. (1981).

Radiation Chemistry of Nitrous Oxide Gas, Primary Processes, Elementary Reactions and Yields - George R. A. Johnson. NSRDS-NBS 45, 29p. (1973).

Radiation Chemistry of Ethanol: A Review of Data on Yields, Reaction Rate Parameters, and Spectral Properties of Transients - Gordon R. Freeman. NSRDS-NBS 48, 44p. (1974).

Rate Constants for Reactions of Aliphatic Carbon-Centered Radicals in Aqueous Solution - Alberta B. Ross and Pedatsur Neta. NSRDSNBS 70, 96p. (1982).

Rate Constants for Reactions of $\mathrm{ClO}_{\mathrm{x}}$ of Atmospheric Interest $-\mathrm{R}$. T. Watson. J Phys Chem Ref Data 6, 871(1977).

Rate Constants for Reactions of Inorganic Radicals in Aqueous Solution - Alberta B. Ross and Pedatsur Neta. NSRDS-NBS 65, 62p. (1979).

Rate Constants for the Decay and Reactions of the Lowest Electronically Excited Singlet State of Molecular Oxygen in Solution - Francis Wilkinson and James G. Brummer. J Phys Chem Ref Data 10, 809(1981).

Rate Constants for the Reactions of Atomic Oxygen $\left(\mathrm{O}{ }^{3} \mathrm{P}\right)$ with Organic Compounds in the Gas Phase - John T. Herron and Robert E. Huie. J Phys Chem Ref Data 2, 467(1973).

Reactivity of the Hydroxyl Radical in Aqueous Solutions - Leon M. Dorfman and Gerald E. Adams. NSRDS-NBS 46, 72p. (1973).

Selected Specific Rates of Reactions of the Solvated Electron in Alcohols - Edgar Watson, Jr. and Sathyabhama Roy. NSRDS-NBS 42, 27p. (1972).

Selected Specific Rates of Reactions of Transients from Water in Aqueous Solution, 1. Hydrated Electron - Michael Anbar, Mark Bambenek, and Alberta B. Ross. NSRDS-NBS 43, 69p. (1973).

Selected Specific Rates of Reactions of Transients from Water in Aqueous Solution, 1. Hydrated Electron, Supplemental Data Alberta B. Ross. NSRDS-NBS 43, Suppl.(1975). 
Selected Specific Rates of Reactions of Transients from Water in Aqueous Solution, II. Hydrogen Atom - Michael Anbar, Farhataziz, and Alberta B. Ross. NSRDS-NBS 51, 66p. (1975).

Selected Specific Rates of Reactions of Transients from Water in Aqueous Solution, III. Hydroxyl Radical and Perhydroxyl Radical and Their Radical Ions - Farhataziz and Alberta B. Ross. NSRDS-NBS 59, 126p. (1977).

Semi-Empirical Extrapolation and Estimation of Rate Constants for Abstraction of $\mathrm{H}$ from Methane by $\mathrm{H}, \mathrm{O}, \mathrm{HO}$, and $\mathrm{O}_{2}-$ Robert Shaw. J Phys Chem Ref Data 7, 1179(1978).

Survey of Photochemical and Rate Data for Twenty-eight Reactions of Interest in Atmospheric Chemistry - Robert F. Hampson, Jr., W. Braun, R. L. Brown, David Garvin, John T. Herron, Robert E. Huie, M. J. Kurylo, A. H. Laufer, J. D. McKinley, H. Okabe, M. D. Scheer, W. Tsang, D. H. Stedman, editor(s). J Phys Chem Ref Data 2, 267(1973).

Table of Recommended Rate Constants for Chemical Reactions Occurring in Combustion - Francis Westley. NSRDS-NBS 67, 110p. (1980).

Tables of Bimolecular Gas Reactions - Aubrey F. TrotmanDickenson and G. S. Milne. NSRDS-NBS 9, 129p. (1967).

Tables of Experimental Rate Constants for Chemical Reactions Occurring in Combustion (1971-1977) - Francis Westley. NBSIR 81-2254, 302p. (1981).

Tables of Rate Constants for Gas Phase Chemical Reactions of Sulfur Compounds (1971-1980) - Francis Westley. NSRDS-NBS 72, 42p. (1982).

The Radiation Chemistry of Gaseous Ammonia - Donald B. Peterson. NSRDS-NBS 44, 41 p. (1974).

The Radiolysis of Methanol: Product Yields, Rate Constants, and Spectroscopic Parameters of Intermediates - J. H. Baxendale and Peter Wardman. NSRDS-NBS 54, 33p. (1975).

Yields of Free Ions Formed in Liquids by Radiation - Augustine O. Allen. NSRDS-NBS 57, 38p. (1976).

\section{Geologlc substances}

Handbook of Thermodynamic Data on Geological Substances - G. B. Naumov, B. N. Ryzhenko, and I. L. Khodakovsky. Russian Transl. Springfield, VA: NTIS, 340p. (1974). TT 73-53051 or PB226 722, A15.

\section{Glasses}

Critical Surveys of Data Sources: Ceramics - Dorothea M. Johnson and James F. Lynch. NBS Spec. Publ. 396, 56p. (1975).

\section{Halogenated hydrocarbons}

A Critical Review of Henry's Law Constants for Chemicals of Environmental Interest - Donald Mackay and Wan Ying Shiu. J Phys Chem Ref Data 10, 1175(1981).

An Annotated Compilation and Appraisal of Electron Swarm Data in Electronegative Gases - Jean W. Gallagher, Earl C. Beaty, J. Dutton, and L. C. Pitchford. J Phys Chem Ref Data 12, 109(1983).

Densities of Liquid $\mathrm{CH}_{4-\mathrm{a}} \mathrm{X}_{\mathrm{a}}(\mathrm{X}=\mathrm{Br}, \mathrm{I})$ and $\mathrm{CH}_{4(\mathrm{a}+b+c+d)} \mathrm{F}_{\mathrm{a}} \mathrm{Cl}_{b} \mathrm{Br}_{\mathrm{c}} \mathrm{I}_{d}$ Halomethanes - Arvind P. Kudchadker, Shanti A. Kudchadker, P. R. Patnaik, and P. P. Mishra. J Phys Chem Ref Data 7, 425(1978).

Ideal Gas Thermodynamic Properties of Eight Chloro- and Fluoromethanes - A. S. Rodgers, Jing Chao, Randolph C. Wilhoit, and Bruno J. Zwolinski. J Phys Chem Ref Data 3, 117(1974).

Ideal Gas Thermodynamic Properties of Six Chloroethanes - Jing Chao, A. S. Rodgers, Randolph C. Wilhoit, and Bruno J. Zwolinski. J Phys Chem Ref Data 3, 141(1974).

Ideal Gas Thermodynamic Properties of Six Fluoroethanes - S. S. Chen, A. S. Rodgers, Jing Chao, Randolph C. Wilhoit, and Bruno J. Zwolinski. J Phys Chem Ref Data 4, 441(1975).

Ideal Gas Thermodynamic Properties of the Eight Bromo- and Iodomethanes - Shanti A. Kudchadker and Arvind P. Kudchadker. J Phys Chem Ref Data 4, 457(1975).
Ideal Gas Thermodynamic Properties of Six Chlorofluoromethanes - S. S. Chen, Randolph C. Wilhoit, and Bruno J. Zwolinski. J Phys Chem Ref Data 5, 571(1976).

Ideal Gas Thermodynamic Properties of $\mathrm{CH}_{4(\mathrm{a}+b+c+d)} \mathrm{F}_{\mathrm{a}} \mathrm{Cl}_{b} \mathrm{Br}_{\mathrm{c}} \mathrm{I}_{d}$ Halomethanes - Shanti A. Kudchadker and Arvind P. Kudchadker. J Phys Chem Ref Data 7, 1285(1978).

Ideal Gas Thermodynamic Properties of Selected Bromoethanes and Iodoethane - Shanti A. Kudchadker and Arvind P. Kudchadker. J Phys Chem Ref Data 8, 519(1979).

Infrared Spectra of Halogenated Hydrocarbons - Clara D. Craver and Coblentz Society; Joint Committee on Atomic and Molecular Physical Data. Kirkwood, MO: The Coblentz Society, 125p. (1977).

Tables of Molecular Vibrational Frequencies, Part 1 - Takehiko Shimanouchi. NSRDS-NBS 6, 56p. (1967).

Tables of Molecular Vibrational Frequencies, Part 6 - Takehiko Shimanouchi. J Phys Chem Ref Data 2, 121(1973).

Tables of Molecular Vibrational Frequencies, Part 7 - Takehiko Shimanouchi. J Phys Chem Ref Data 2, 225(1973).

Tables of Molecular Vibrational Frequencies, Part 8 - Takehiko Shimanouchi. J Phys Chem Ref Data 3, 269(1974).

Tables of Molecular Vibrational Frequencies. Consolidated Volume II - Takehiko Shimanouchi. J Phys Chem Ref Data 6, 993(1977).

Thermophysical Properties of Freon-22 - A. V. Kletskii. Russian Transl. Springfield, VA: NTIS, 72p. (1971). TT 70-50178, A04.

Vapor Pressures and Boiling Points of Selected Halomethanes Arvind P. Kudchadker, Shanti A. Kudchadker, R. P. Shukla, and P. R. Patnaik. J Phys Chem Ref Data 8, 499(1979).

\section{Helium}

Thermophysical Properties of Helium NBS Standard Reference Database 5, Washington, D.C.; NBS, Office of Standard Reference Data,(updated periodically). Call (301)921-2228 for specific in structions.

\section{Hydrocarbons}

A Compilation of Kinetic Parameters for the Thermal Degradation of n-Alkane Molecules - D. L. Allara and Robert Shaw. J Phys Chem Ref Data 9, 523(1980).

A Computer Program for the Prediction of Viscosity and Thermal Conductivity in Hydrocarbon Mixtures - James F. Ely and Howard J. M. Hanley. NBS Tech. Note 1039, 83p. (1981).

A Correlation of the Existing Viscosity and Thermal Conductivity Data of Gaseous and Liquid Ethane - Howard J. M. Hanley, K. E. Gubbins, and S. Murad. J Phys Chem Ref Data 6, 1167(1977).

A Correlation of the Viscosity and Thermal Conductivity Data of Gaseous and Liquid Propane - Paul M. Holland, Howard J. M. Hanley, K. E. Gubbins, and J. M. Haile. J Phys Chem Ref Data 8, 559(1979).

A Correlation of the Viscosity and Thermal Conductivity Data of Gaseous and Liquid Ethylene - Paul M. Holland, B. E. Eaton, and Howard J. M. Hanley. J Phys Chem Ref Data 12, 917(1983).

A Critical Review of Henry's Law Constants for Chemicals of Environmental Interest - Donald Mackay and Wan Ying Shiu. J Phys Chem Ref Data 10, 1175(1981).

A Review, Evaluation, and Correlation of the Phase Equilibria, Heat of Mixing, and Change in Volume on Mixing for Liquid Mixtures of Methane + Ethane - M. J. Hiza, R. C. Miller, and Arthur J. Kidnay. J Phys Chem Ref Data 8, 799(1979).

A Review, Evaluation, and Correlation of the Phase Equilibria, Heat of Mixing, and Change in Volume on Mixing for Liquid Mixtures of Methane + Propane - R. C. Miller, Arthur J. Kidnay, and M. J. Hiza. J Phys Chem Ref Data 9, 721(1980).

An Equation of State for Fluid Ethylene - Robert D. McCarty and Richard T. Jacobsen. NBS Tech. Note 1045, 164p. (1981).

Chemical Kinetics of the Gas Phase Combustion of Fuels (A Bibliography on the Rates and Mechanisms of Oxidation of Aliphatic $C_{1}$ to $\mathrm{C}_{10}$ Hydrocarbons and of Their Oxygenated Derivatives) $\rightarrow$ Francis Westley. NBS Spec. Publ. 449, 142p. (1976). 
Critical Evaluation of Vapor-Liquid Equilibrium, Heat of Mixing, and Volume Change of Mixing Data. General Procedures - Buford D. Smith, O1 Muthu, Ashok Dewan, and Matthew Gierlach. J Phys Chem Ref Data 11, 941(1982).

Critical Review of Vibrational Data and Force Field Constants for Polyethylene - John Barnes and Bruno Fanconi. J Phys Chem Ref Data 7, 1309(1978).

Derived Thermodynamic Properties of Ethylene - Roland $\mathrm{H}$. Harrison and Donald R. Douslin. J Chem Eng Data. 22, Washington, DC: American Chemical Society, 24p. (1977).

Drift Mobilities and Conduction Band Energies of Excess Electrons in Dielectric Liquids - Augustine O. Allen. NSRDS-NBS 58, 23p. (1976).

Equilibrium Properties of Fluid Mixtures, A Bibliography on Fluids of Cryogenic Interest - M. J. Hiza, Arthur J. Kidnay, and R. C. Miller. New York: IFI/Plenum, 166p. (1975), ISBN: 0-306-6601-6.

Equilibrium Properties of Fluid Mixtures, 2. A Bibliography of Experimental Data on Selected Fluids - M. J. Hiza, Arthur J. Kidnay, and R. C. Miller. New York: IFI/Plenum, 258p. (1982), ISBN: 0-306-6602-4.

Erratum: A Correlation of the Existing Viscosity and Thermal Conductivity Data of Gaseous and Liquid Ethane - Howard J. M. Hanley, K. E. Gubbins, and S. Murad. J Phys Chem Ref Data 10, 799(1981).

Evaluation of Binary Excess Enthalpy Data for $\mathrm{C}_{6}$ Hydrocarbons. Benzene + Cyclohexane - Buford D. Smith, Ol Muthu, Ashok Dewan, and Matthew Gierlach. J Phys Chem Ref Data 11, 1127(1982).

Evaluation of Binary Excess Enthalpy Data for $\mathrm{C}_{6}$ Hydrocarbons. Benzene + Hexane - Buford D. Smith, Ol Muthu, and Ashok Dewan. J Phys Chem Ref Data 12, 389(1983).

Evaluation of Binary Excess Volume Data for $\mathrm{C}_{6}$ Hydrocarbons. Benzene + Cyclohexane - Buford D. Smith, O1 Muthu, Ashok Dewan, and Matthew Gierlach. J Phys Chem Ref Data 11, 1151(1982).

Evaluation of Binary Excess Volume Data for $\mathrm{C}_{6}$ Hydrocarbons. Benzene + Hexane - Buford D. Smith, Ol Muthu, and Ashok Dewan. J Phys Chem Ref Data 12, 395(1983).

Evaluation of Binary PTxy Vapor-Liquid Equilibrium Data for $\mathrm{C}_{6}$ Hydrocarbons. Benzene + Cyclohexane - Buford D. Smith, Ol Muthu, Ashok Dewan, and Matthew Gierlach. J Phys Chem Ref Data 11, 1099(1982).

Evaluation of Binary $P T$ xy Vapor-Liquid Equilibrium Data for $\mathrm{C}_{6}$ Hydrocarbons. Benzene + Hexane - Buford D. Smith, O1 Muthu, and Ashok Dewan. J Phys Chem Ref Data 12, 381(1983).

Heat Capacity and Other Thermodynamic Properties of Linear Macromolecules. II. Polyethylene - Umesh Gaur and Bernhard Wunderlich. J Phys Chem Ref Data 10, 119(1981).

Heat Capacity and Other Thermodynamic Properties of Linear Macromolecules. IV. Polypropylene - Umesh Gaur and Bernhard Wunderlich. J Phys Chem Ref Data 10, 1051(1981).

Hydrogenation of Ethylene on Metallic Catalysts - Juro Horiuti and Koshiro Miyahara. NSRDS-NBS 13, 62p. (1968).

Ideal Gas Thermodynamic Properties of Ethane and Propane - Jing Chao, Randolph C. Wilhoit, and Bruno J. Zwolinski. J Phys Chem Ref Data 2, 427(1973).

Ideal Gas Thermodynamic Properties of Ethylene and Propylene Jing Chao and Bruno J. Zwolinski. J Phys Chem Ref Data 4, 251(1975).

Ideal Gas Thermodynamic Properties and Isomerization of n-Butane and Isobutane - S. S. Chen, Randolph C. Wilhoit, and Bruno J. Zwolinski. J Phys Chem Ref Data 4, 859(1975).

Ideal Gas Thermodynamic Properties of $\mathrm{CH}_{3}, \mathrm{CD}_{3}, \mathrm{CD}_{4}, \mathrm{C}_{2} \mathrm{D}_{2}$, $\mathrm{C}_{2} \mathrm{D}_{4}, \mathrm{C}_{2} \mathrm{D}_{6}, \mathrm{C}_{2} \mathrm{H}_{6}, \mathrm{CH}_{3} \mathrm{~N}_{2} \mathrm{CH}_{3}$, and $\mathrm{CD}_{3} \mathrm{~N}_{2} \mathrm{CD}_{3}-$ Krishna $\mathrm{M}$. Pamidimukkala, David Rogers, and Gordon B. Skinner. J Phys Chem Ref Data 11, 83(1982).

LNG Materials \& Fluids, A User's Manual of Property Data in Graphic Format - Douglas Mann and U.S. National Bureau of Standards. Boulder, CO: U.S. National Bureau of Standards, Cryogenic Division, 11p. (1977).

LNG Materials \& Fluids, A User's Manual of Property Data in Graphic Format, First Supplement - Douglas Mann and U.S. National
Bureau of Standards. Suppl. 1, Boulder, CO: U.S. National Bureau of Standards, 11p. (1978).

LNG Materials \& Fluids, A User's Manual of Property Data in Graphic Format, Second Supplement - Douglas Mann and U.S. National Bureau of Standards. Suppl. 2, Boulder, CO: U.S. National Bureau of Standards, 11p. (1980).

Microwave Spectra of Molecules of Astrophyical Interest. XX. Methane - I. Ozier, M. C. L. Gerry, and A. G. Robiette. J Phys Chem Ref Data 10, 1085(1981).

Phase Behavior in Binary and Multicomponent Systems at Elevated Pressures: n-Pentane and Methane-n-Pentane - Virginia M. Berry and Bruce H. Sage. NSRDS-NBS 32, 79p. (1970).

Pressure, Volume, Temperature Relations of Ethylene - Donald R. Douslin and Roland H. Harrison. J Chem Thermody 76, New York, London:, 301p. (1976).

Provisional Thermodynamic Functions of Propane from 85 to $700 \mathrm{~K}$ at Pressures to $700 \mathrm{Bar}-$ Robert D. Goodwin. NBSIR 77-860, 240p. (1977).

Rate Coefficients for Ion-Molecule Reactions, I. Ions Containing C and $\mathrm{H}-\mathrm{L}$. Wayne Sieck and Sharon G. Lias. J Phys Chem Ref Data 5, 1123(1976).

Semi-Empirical Extrapolation and Estimation of Rate Constants for Abstraction of $\mathrm{H}$ from Methane by $\mathrm{H}, \mathrm{O}, \mathrm{HO}$, and $\mathrm{O}_{2}-$ Robert Shaw. J Phys Chem Ref Data 7, 1179(1978).

Standard Chemical Thermodynamic Properties of Alkane Isomer Groups - Robert A. Alberty and Catherine A. Gehrig. J Phys Chem Ref Data 13, 1173(1984).

Table of Recommended Rate Constants for Chemical Reactions Occurring in Combustion - Francis Westley. NBSIR 79-1941, 169p. (1979).

Table of Recommended Rate Constants for Chemical Reactions Occurring in Combustion - Francis Westley. NSRDS-NBS 67, 110p. (1980).

Tables of Experimental Rate Constants for Chemical Reactions Occurring in Combustion (1971-1977) - Francis Westley. NBSIR 81-2254, 302p. (1981).

The Critical-Region Equation of State of Ethene and the Effect of Small Impurities - J. R. Hastings, J. M. H. Levelt Sengers, and F. W. Balfour. J Chem Thermody 12, London: Academic Press Inc., 1009p. (1980).

The Viscosity and Thermal Conductivity Coefficients for Dense Gaseous and Liquid Methane - Howard J. M. Hanley, W. M. Haynes, and Robert D. McCarty. J Phys Chem Ref Data 6, 597(1977).

Thermodynamic Properties of Normal and Deuterated Naphthalenes - S. S. Chen, Shanti A. Kudchadker, and Randolph C. Wilhoit. J Phys Chem Ref Data 8, 527(1979).

Thermodynamic and Transport Properties of Ethylene and Propylene - I. A. Neduzhii. Russian Transl. Springfield, VA: NTIS, 206p. (1972). COM 75-11276, A 10.

Thermophysical Properties of Gaseous and Liquid Methane - V. A. Zagoruchenko and A. M. Zhuravlev. Russian Transl. Springfield, VA: NTIS, 251p. (1970). TT 70-50097, A12.

Thermophysical Properties of Hydrocarbon Mixtures (TRAPP) NBS Standard Reference Database 4, Washington, D.C.; NBS, Office of Standard Reference Data,(updated periodically). Call (301)921-2228 for specific instructions.

Thermophysical Properties of Isobutane from 114 to $700 \mathrm{~K}$ at Pres4sures to $70 \mathrm{MPa}$ - Robert D. Goodwin and W. M. Haynes. NBS Tech Note 1051, 199p. (1982).

Thermophysical Properties of Normal Butane from 135 to $700 \mathrm{~K}$ at Pressures to $70 \mathrm{MPa}-\mathrm{W}$. M. Haynes and Robert D. Goodwin. NBS Monograph 169, 197p. (1982).

Thermophysical Properties of Propane from 85 to $700 \mathrm{~K}$ at Pressures to $70 \mathrm{MPa}$ - Robert D. Goodwin and W. M. Haynes. NBS Monograph 170, 249p. (1982).

Water Solubilities of Polynuclear Aromatic and Heteroaromatic Compounds - Robert S. Pearlman, Samuel H. Yalkowsky, and Sujit Banerjee. J Phys Chem Ref Data 13, 555(1984). 


\section{Hydrogen}

Equilibrium Properties of Fluid Mixtures, A Bibliography on Fluids of Cryogenic Interest - M. J. Hiza, Arthur J. Kidnay, and R. C. Miller. New York: IFI/Plenum, 166p. (1975), ISBN: 0-306-6601-6.

Equilibrium Properties of Fluid Mixtures, 2. A Bibliography of Experimental Data on Selected Fluids - M. J. Hiza, Arthur J. Kidnay, and R. C. Miller. New York: IFI/Plenum, 258p. (1982), ISBN: 0-306-6602-4.

Properties of Liquid and Solid Hydrogen - B. N. Esel'son, Y. P. Blagoi, V.N. Grigor'ev, V. G. Manzhelii, S. A. Mikhailenko, and N. P. Neklyudov. Russian Transl. Springfield, VA: NTIS, 126p. (1971). TT 70-50179, A07.

Selected Specific Rates of Reactions of Transients from Water in Aqueous Solution, II. Hydrogen Atom - Michael Anbar, Farhataziz, and Alberta B. Ross. NSRDS-NBS 51, 66p. (1975).

Table of Recommended Rate Constants for Chemical Reactions Occurring in Combustion - Francis Westley. NSRDS-NBS 67, 110p. (1980).

Thermodynamic and Related Properties of Parahydrogen from the Triple Point to $100 \mathrm{~K}$ at Pressures to 340 Atmospheres - Hans M. Roder, Lloyd A. Weber, and Robert D. Goodwin. NBS Monograph 94,, 116p. (1965).

\section{Inorganic materials}

Analysis of Specific Heat Data in the Critical Region of Magnetic Solids - F. J. Cook. J Phys Chem Ref Data 2, 11(1973).

Behavior of the AB-Type Compounds at High Pressures and High Temperatures - Leo Merrill. J Phys Chem Ref Data 6, 1205(1977).

Behavior of the $\mathrm{AB}_{2}$-Type Compounds at High Pressures and High Temperatures - Leo Merrill. J Phys Chem Ref Data 11, 1005(1982).

Biweekly List of Papers on Radiation Chemistry, Annual Cumulation with Keyword and Author Indexes, Vol. 7. 1974 - Radiation Chemistry Data Center. Rad Chem 7, Springfield, VA: NTIS, 553p. (1975). COM 75-11475, A24.

Biweekly List of Papers on Radiation Chemistry, Annual Cumulation with Keyword and Author Indexes, Vol. 8. 1975 - Radiation Chemistry Data Center. Rad Chem 8, Springfield, VA: NTIS, 670p. (1976). PB 275 025, A26.

Biweekly List of Papers on Radiation Chemistry, Annual Cumulation with Keyword and Author Indexes, Vol. 9. 1976 - Radiation Chemistry Data Center. Rad Chem 9, Springfield, VA: NTIS, 707p. (1977). PB 268 699, A26.

Biweekly List of Papers on Radiation Chemistry, Annual Cumulation with Keyword and Author Indexes, Vol. 10. 1977 - Radiation Chemistry Data Center. Rad Chem 10, Springfield, VA: NTIS, 695p. (1978). PB 291 876, A26.

Biweekly List of Papers on Radiation Chemistry and Photochemistry Annual Cumulation with Keyword and Author indexes, Vol. 11. 1978 - Radiation Chemistry Data Center. Rad Chem 11, Springfield, VA: NTIS, 768p. (1979). PB 226 368, A99.

Biweekly List of Papers on Radiation Chemistry and Photochemistry Annual Cumulation with Keyword and Author Indexes, Vol. 12. 1979 - Radiation Chemistry Data Center. Rad Chem 12, Springfield, VA: NTIS, 748p. (1980). PB 81-113 680, A26.

Biweekly List of Papers on Radiation Chemistry and Photochemistry Annual Cumulation with Keyword and Author Indexes, Vol. 13. 1980 - Radiation Chemistry Data Center. Rad Chem 13, Springfield, VA: NTIS, 704p. (1981). PB 82-122 995, A26.

Biweekly List of Papers on Radiation Chemistry and Photochemistry Annual Cumulation with Keyword and Author Indexes, Vol. 14. 1981 - Radiation Chemistry Data Center. Rad Chem 14, Springfield, VA: NTIS, 534p. (1982). PB 82-214 487, A22.

Biweekly List of Papers on Radiation Chemistry and Photochemistry Annual Cumuluation with Keyword and Author Indexes, Vol. 15. 1982 - Radiation Chemistry Data Center. Rad Chem 15, Springfield, VA: NTIS, 448p. (1983). PB 83-20363, A19.
Biweekly List of Papers on Radiation Chemistry and Photochemistry Vol. 17. 1984 - Radiation Chemistry Data Center. Rad Chem, Notre Dame, IN: Radiation Chem. Data Center, U. of Notre Dame, 449 p. (1984). \$25.00; the Biweekly List, Vol. 17 (1984) plus the Annual Cumulation, Vol. 16 (1983), $\$ 35.00$; foreign and airmail postage rates available upon request.

Biweekly List of Papers on Radiation Chemistry and Photochemistry Annual Cumuluation with Keyword and Author Indexes, Vol. 16. 1983 - Radiation Chemistry Data Center. Rad Chem 16, Springfield, VA: NTIS, 444p. (1984).

Bond Dissociation Energies in Simple Molecules - B. DeB. Darwent. NSRDS-NBS 31, 48p. (1970).

Bulletin of Chemical Thermodynamics, Volume 24/1981 - Robert D. Freeman, editor(s) and International Union of Pure and Applied Chemistry, Commission 1.2 on Thermodynamics. Bull Chem Thermody 24, Stillwater, OK: Thermochemistry, Department of Chemistry, Oklahoma State University, 504p. (1982). 0149-2268, bona fide personal subscriptions are less; prices of previous Bulletins available upon request.

Bulletin of Chemical Thermodynamics, Volume 25/1982 - Robert D. Freeman and International Union of Pure and Applied Chemistry. Bull Chem Thermody 25, Stillwater, OK: Thermochemistry, Department of Chemistry, Oklahoma State University, 544p. (1982). 0149-2268, bona fide personal subscriptions are less; prices of previous Bulletins are available upon request.

Compilation and Evaluation of Solubility Data in the Mercury (I) Chloride-Water System - Y. Marcus. J Phys Chem Ref Data 9, 1307(1980).

Compilation of Volumes V-IX of the Bibliography on High Pressure Research with Author and Subject Indexes - Leo Merrill. Provo, UT: High Pressure Data Center, Brigham Young University, (1979).

Compilation of the Static Dielectric Constant of Inorganic Solids K. F. Young and Hans P. R. Frederikse. J Phys Chem Ref Data 2, 313(1973).

Crystal Data Space-Group Tables - Alan D. Mighell, Helen M. Ondik, and Bettijoyce Breen Molino. J Phys Chem Ref Data 6, 675(1977).

Crystal Data Determinative Tables, Third Edition Volume 2: Inorganic Compounds - Joseph D. H. Donnay and Helen M. Ondik. Swarthmore, PA: JCPDS-International Center for Diffraction Data, 1748p. (1973).

Crystal Data Determinative Tables, Third Edition Volume 4. Inorganic Compounds - Joseph D. H. Donnay, Helen M. Ondik, and Alan D. Mighell. Swarthmore, PA: JCPDS-International Center for Diffraction Data, 1308p. (1978).

Crystal Structure Transformations in Binary Halides - C. N. R. Rao and M. Natarajan. NSRDS-NBS 41, 57p. (1972).

EPA/NIH Mass Spectral Data Base, Supplenient 1 - Stephen R. Heller and G. W. A. Milne. NSRDS-NBS 63, Suppl. 1(1980).

EPA/NIH Mass Spectral Data Base, Supplement 2 - Stephen R. Heller, G. W. A. Milne, and Lewis H. Gevantman. NSRDS-NBS 63, Suppl. 2(1983).

EPA/NIH Mass Spectral Data Base, Volume 1. Molecular Weights 30-186; Volume 2. Molecular Weights 16-273; Volume 3. Molecular Weights 273-381; Volume 4. Molecular Weights 381-1674 - Stephen R. Heller and G. W. A. Milne. NSRDS-NBS 63, 1,2,3,4(1978).

Energetics of Gaseous Ions - Henry M. Rosenstock, Keith Draxl, B. W. Steiner, and John T. Herron. J Phys Chem Ref Data 6, Suppl. 1(1977).

Evaluated Activity and Osmotic Coefficients for Aqueous Solutions: The Alkaline Earth Metal Halides - Robert N. Goldberg and Ralph L. Nuttall. J Phys Chem Ref Data 7, 263(1978).

Evaluated Activity and Osmotic Coefficients for Aqueous Solutions: Iron Chloride and the Bi-Univalent Compounds of Nickel and Cobalt - Robert N. Goldberg, Ralph L. Nuttall, and Bert R. Staples. J Phys Chem Ref Data 8, 923(1979).

Evaluated Activity and Osmotic Coefficients for Aqueous Solutions: Bi-Univalent Compounds of Lead, Copper, Manganese, and Uranium - Robert N. Goldberg. J Phys Chem Ref Data 8, 1005(1979). 
JANAF Thermochemical Tables, 1974 Supplement - Malcolm W. Chase, Jr., J. L. Curnutt, A. T. Hu, H. Prophet, A. N. Syverud, and L. C. Walker. J Phys Chem Ref Data 3, 311(1974).

JANAF Thermochemical Tables, 1975 Supplement - Malcolm W. Chase, Jr., J. L. Curnutt, H. Prophet, R. A. McDonald, and A. N. Syverud. J Phys Chem Ref Data 4, 1(1975).

JANAF Thermochemical Tables, 1978 Supplement - Malcolm W. Chase, Jr., J. L. Curnutt, R. A. McDonald, and A. N. Syverud. J Phys Chem Ref Data 7, 793(1978).

JANAF Thermochemical Tables, 1982 Supplement - Malcolm W. Chase, Jr., J. L. Curnutt, J. R. Downey, Jr., R. A. McDonald, A. N. Syverud, and E. A. Valenzuela. J Phys Chem Ref Data 11, 695(1982).

JANAF Thermochemical Tables, Second Edition - Daniel R. Stull and $H$. Prophet. NSRDS-NBS 37, 1141 p. (1971).

Kinetic Data on Gas Phase Unimolecular Reactions - Sidney W. Benson and Harry E. O'Neal. NSRDS-NBS 21, 645p. (1970).

Molten Salts: Volume 2. Section 1. Electrochemistry of Molten Salts. Gibbs Free Energies and Excess Free Energies from Equilibrium-Type Cells, Section 2. Surface Tension Data - George J. Janz, Chr. G. M. Dijkhuis, G. R. Lakshminarayanan, Reginald P. T. Tomkins, and J. Wong. NSRDS-NBS 28, 116p. (1968).

NBS Crystal Data Identification File NBS Standard Reference Database 3, Washington, D.C.; NBS, Office of Standard Reference Data,(updated periodically). Lease agreements obtained from JCPDS 1601 Park Ln Swarthmore PA (215)328-9400.

Phase Diagrams and Thermodynamic Properties of Ternary CopperSulfur-Metal Systems - Y. Austin Chang, Joachim P. Neumann, and U. V. Choudary. INCRA Monograph VII, New York: International Copper Research Association, Inc., 191p. (1979).

Phase Diagrams for Ceramists - Ernest M. Levin, Carl R. Robbins, Howard F. McMurdie, editor(s). American Ceramic Society; Columbus, Ohio, 601p. (1964), ISBN: 0-916094-04-9.

Phase Diagrams for Ceramists 1969 Supplement - Ernest M. Levin, Carl R. Robbins, Howard F. McMurdie, editor(s). American Ceramic Society; Columbus, Ohio, 625p. (1969), ISBN: 0-916094-05-7.

Phase Diagrams for Ceramists 1975 Supplement - Ernest M. Levin, Howard F. McMurdie, editor(s). American Ceramic Society; Columbus, Ohio, 513p. (1975).

Physical Properties Data Compilations Relevant to Energy Storage. I. Molten Salts: Eutectic Data - George J. Janz, Carolyn B. Allen, J. R. Downey, Jr., and Reginald P. T. Tomkins. NSRDS-NBS 61, 244p. (1978).

Physical Properties Data Compilations Relevant to Energy Storage. II. Molten Salts: Data on Single and Multi-Component Systems George J. Janz, Carolyn B. Allen, Narottam P. Bansal, R. M. Murphy, and Reginald P. T. Tomkins. NSRDS-NBS 61, 420p. (1979).

Physical Properties Data Compilations Relevant to Energy Storage. III. Engineering Properties of Single and Polycrystalline Sodium Beta and Beta" Alumina - G. R. Miller and D. G. Paquette. NSRDS-NBS 61, 19p. (1979).

Rate Coefficients for Vibrational Energy Transfer Involving the $\mathbf{H y}$. drogen Halides - Stephen R. Leone. J Phys Chem Ref Data 11, 953(1982).

Rate Constants for Reactions of Inorganic Radicals in Aqueous Solution - Alberta B. Ross and Pedatsur Neta. NSRDS-NBS 65, 62p. (1979).

Refractive Index of Alkali Halides and Its Wavelength and Temperature Derivatives - H. H. Li. J Phys Chem Ref Data 5, 329(1976).

Selected Values of Chemical Thermodynamic Properties. Tables for the First Thirty-Four Elements in the Standard Order of Arrangement - Donald D. Wagman, William H. Evans, Vivian B. Parker, Iva Halow, Sylvia M. Bailey, and Richard H. Schumm. NBS Tech. Note 270, 264p. (1968).

Selected Values of Chemical Thermodynamic Properties. Tables for Elements 35 through 53 in the Standard Order of Arrangement Donald D. Wagman, William H. Evans, Vivian B. Parker, Iva Halow, Sylvia M. Bailey, and Richard H. Schumm. NBS Tech. Note 270, 152p. (1969).
Selected Values of Chemical Thermodynamic Properties. Tables for Elements 54 through 61 in the Standard Order of Arrangement Donald D. Wagman, William H. Evans, Vivian B. Parker, Iva Halow, Sylvia M. Bailey, Richard H. Schumm, and Kenneth L. Churney. NBS Tech. Note 270, 49p. (1971).

Selected Values of Chemical Thermodynamic Properties. Tables for the Alkaline Earth Elements (Elements 92 through 97 in the Standard Order of Arrangement) - Vivian B. Parker, Donald D. Wagman, and William H. Evans. NBS Tech. Note 270, 124p. (1971).

Selected Values of Electric Dipole Moments for Molecules in the Gas Phase - Ralph D. Nelson, Jr., David R. Lide, Jr., and Arthur A. Maryott. NSRDS-NBS 10, 49p. (1967).

Tables of Bimolecular Gas Reactions - Aubrey F. TrotmanDickenson and G. S. Milne. NSRDS-NBS 9, 129p. (1967).

Tables of Molecular Vibrational Frequencies, Part 2 - Takehiko Shimanouchi. NSRDS-NBS 11, 38p. (1967).

Tables of Molecular Vibrational Frequencies, Part 3 - Takehiko Shimanouchi. NSRDS-NBS 17, 39p. (1968).

Tables of Molecular Vibrational Frequencies, Consolidated Volume I - Takehiko Shimanouchi. NSRDS-NBS 39, 167p. (1972).

Tables of Molecular Vibrational Frequencies, Part $5-$ Takehiko Shimanouchi. J Phys Chem Ref Data 1, 189(1972).

Tables of Molecular Vibrational Frequencies, Part 6 - Takehiko Shimanouchi. J Phys Chem Ref Data 2, 121(1973).

Tables of Molecular Vibrational Frequencies, Part 7 - Takehiko Shimanouchi. J Phys Chem Ref Data 2, 225(1973).

Tables of Molecular Vibrational Frequencies, Part 8 - Takehiko Shimanouchi. J Phys Chem Ref Data 3, 269(1974).

Tables of Molecular Vibrational Frequencies. Consolidated Volume II - Takehiko Shimanouchi. J Phys Chem Ref Data 6, 993(1977).

The NBS Tables of Chemical Thermodynamic Properties. Selected Values for Inorganic and $C_{1}$ and $C_{2}$ Organic Substances in SI Units Donald D. Wagman, William H. Evans, Vivian B. Parker, Richard H. Schumm, Iva Halow, Sylvia M. Bailey, Kenneth L. Churney, and Ralph L. Nuttall. J Phys Chem Ref Data 11, Suppl. 2(1982).

The Surface Tension of Pure Liquid Compounds - Joseph J. Jasper. J Phys Chem Ref Data 1, 841(1972).

The Viscosity and Thermal Conductivity Coefficients of Gaseous and Liquid Fluorine - Howard J. M. Hanley and R. Prydz. J Phys Chem Ref Data 1, 1101(1972).

Thermal Conductivity of Selected Materials, Part 2 - Cho Y. Ho, Robert W. Powell, and Peter E. Liley. NSRDS-NBS 16, 146p. (1968).

Thermodynamic Properties of Ammonia - Lester Haar and John S. Gallagher. J Phys Chem Ref Data 7, 635(1978).

Thermodynamic Properties of Copper and Its Inorganic Compounds - Edward G. King, Alla D. Mah, and Louis B. Pankratz. INCRA Monograph II, New York: International Copper Research Association, Inc., 257p. (1973).

Thermodynamic Properties of Copper-Slag Systems - Carlos Diaz. INCRA Monograph III, New York: International Copper Research Association, Inc., 178p. (1976).

Thermodynamic Tabulations for Selected Phases in the System CaO$\mathrm{Al}_{2} \mathrm{O}_{3}-\mathrm{SiO}_{2}-\mathrm{H}_{2} \mathrm{O}$ at $101.325 \mathrm{kPa}$ (1 atm.) between 273.15 and $1800 \mathrm{~K}-$ John L. Haas, Jr., Gilpin R. Robinson, Jr., and Bruce S. Hemingway. J Phys Chem Ref Data 10, 575(1981).

\section{Interstellar molecules}

Microwave Spectra of Molecules of Astrophysical Interest, I. Formaldehyde, Formamide, and Thioformaldehyde - Donald R. Johnson, Frank J. Lovas, and William H. Kirchhoff. J Phys Chem Ref Data 1, 1011(1972).

Microwave Spectra of Molecules of Astrophysical Interest, II. Methylenimine - William H. Kirchhoff, Donald R. Johnson, and Frank J. Lovas. J Phys Chem Ref Data 2, 1(1973).

Microwave Spectra of Molecules of Astrophysical Interest, III. Methanol - R. M. Lees, Frank J. Lovas, William H. Kirchhoff, and Donald R. Johnson. J Phys Chem Ref Data 2, 205(1973). 
Microwave Spectra of Molecules of Astrophysical Interest, IV. HyIrogen Sulfide - Paul Helminger, Frank C. De Lucia, and William H. Kirchhoff. J Phys Chem Ref Data 2, 215(1973).

Microwave Spectra of Molecules of Astrophysical Interest, V. Water Vapor - Frank C. De Lucia, Paul Helminger, and William H. Kirchhoff. J Phys Chem Ref Data 3, 211(1974).

Microwave Spectra of Molecules of Astrophysical Interest, VI. Carbonyl Sulfide and Hydrogen Cyanide - Arthur G. Maki. J Phys Chem Ref Data 3, 221(1974).

Microwave Spectra of Molecules of Astrophysical Interest, VII. Carbon Monoxide, Carbon Monosulfide, and Silicon Monoxide - Frank J. Lovas and Paul H. Krupenie. J Phys Chem Ref Data 3, 245(1974).

Microwave Spectra of Molecules of Astrophysical Interest, VIII. Sulfur Monoxide - Eberhard Tiemann. J Phys Chem Ref Data 3, 259(1974).

Microwave Spectra of Molecules of Astrophysical Interest, IX. Acetaldehyde - A. Bauder, Frank J. Lovas, and Donald R. Johnson. J Phys Chem Ref Data 5, 53(1976).

Microwave Spectra of Molecules of Astrophysical Interest, X. Isozyanic Acid - G. Winnewisser, W. H. Hocking, and M. C. L. Gerry. I Phys Chem Ref Data 5, 79(1976).

Microwave Spectra of Molecules of Astrophysical Interest, XI. Silicon Sulfide - Eberhard Tiemann. J Phys Chem Ref Data 5, 1147(1976).

Microwave Spectra of Molecules of Astrophysical Interest, XII. Hydroxyl Radical - Robert A. Beaudet and Robert L. Poynter. J Phys Chem Ref Data 7, 311(1978).

Microwave Spectra of Molecules of Astrophysical Interest, XIII. Cyanoacetylene - Walter J. Lafferty and Frank J. Lovas. J Phys Chem Ref Data 7, 441(1978).

Microwave Spectra of Molecules of Astrophysical Interest, XIV. Vinyl Cyanide (Acrylonitrile) - M. C. L. Gerry, K. Yamada, and G. Winnewisser. J Phys Chem Ref Data 8, 107(1979).

Microwave Spectra of Molecules of Astrophysical Interest, XV. Propyne - A. Bauer, D. Boucher, J. Burie, J. Demaison, and A. Dubrulle. I Phys Chem Ref Data 8, 537(1979).

Microwave Spectra of Molecules of Astrophysical Interest, XVI. Methyl Formate - A. Bauder. J Phys Chem Ref Data 8, 583(1979).

Microwave Spectra of Molecules of Astrophysical Interest, XVII.

Dimethyl Ether - Frank J. Lovas, H. Lutz, and H. Dreizler. J Phys Chem Ref Data 8, 1051(1979).

Microwave Spectra of Molecules of Astrophysical Interest. XVIII. Formic Acid - Edmond Willemot, Didier Dangoisse, Nicole Monnanteuil, and Jean Bellet. J Phys Chem Ref Data 9, 59(1980).

Microwave Spectra of Molecules of Astrophysical Interest. XIX. Methyl Cyanide - D. Boucher, J. Burie, A. Bauer, A. Dubrulle, and J. Demaison. J Phys Chem Ref Data 9, 659(1980).

Microwave Spectra of Molecules of Astrophyical Interest. XX. Methane - I. Ozier, M. C. L. Gerry, and A. G. Robiette. J Phys Chem Ref Data 10, 1085(1981).

Microwave Spectra of Molecules of Astrophysical Interest. XXI. Ethanol $\left(\mathrm{C}_{2} \mathrm{H}_{3} \mathrm{OH}\right)$ and Propionitrile $\left(\mathrm{C}_{2} \mathrm{H}_{3} \mathrm{CN}\right)$ - Frank J. Lovas. J Phys Chem Ref Data 11, 251(1982).

lons

A Bibliography on Ion-Molecule Reactions. January 1900 to March 1966 - F. N. Harllee, Henry M. Rosenstock, and John T. Herron. NBS Tech. Note 291, 40p. (1966).

A Compendium of Gas Phase Basicity and Proton Affinity Measurements - K. N. Hartman, Sharon G. Lias, P. J. Ausloos, Henry M. Rosenstock, S. S. Schroyer, C. Schmidt, D. Martinsen, and G. W. A. Milne. NBSIR 79-1777, 563p. (1979).

A Report on Thermodynamic Data for Desulfurization Processes Vivian B. Parker, Bert R. Staples, Thomas L. Jobe, Jr., and David B. Neumann. NBSIR 81-2345, 89p. (1981).

A Survey of Electron Swarm Data - J. Dutton. J Phys Chem Ref Data 4, 577(1975).

Annotated Bibliography on Proton Affinities - K. N. Hartman, Sharon G. Lias, P. J. Ausloos, and Henry M. Rosenstock. NBSIR 76-1061, 52p. (1976).
Bibliography of Ion-Molecule Reaction Rate Data (January 1950 October 1971) - George A. Sinnott. NBS Spec. Publ. 381, 75p. (1973). Binding Energies in Atomic Negative Ions - H. Hotop and W. C. Lineberger. J Phys Chem Ref Data 4, 539(1975).

Biweekly List of Papers on Radiation Chemistry, Annual Cumulation with Keyword and Author Indexes, Vol. 7. 1974 - Radiation Chemistry Data Center. Rad Chem 7, Springfield, VA: NTIS, 553p. (1975). COM 75-11475, A24.

Biweekly List of Papers on Radiation Chemistry, Annual Cumulation with Keyword and Author Indexes, Vol. 8. 1975 - Radiation Chemistry Data Center. Rad Chem 8, Springfield, VA: NTIS, 670p. (1976). PB 275 025, A26.

Biweekly List of Papers on Radiation Chemistry, Annual Cumulation with Keyword and Author Indexes, Vol. 9. 1976 - Radiation Chemistry Data Center. Rad Chem 9, Springfield, VA: NTIS, 707p. (1977). PB 268 699, A26.

Biweekly List of Papers on Radiation Chemistry, Annual Cumulation with Keyword and Author Indexes, Vol. 10. 1977 - Radiation Chemistry Data Center. Rad Chem 10, Springfield, VA: NTIS, 695p. (1978). PB 291 876, A26.

Biweekly List of Papers on Radiation Chemistry and Photochemistry Annual Cumulation with Keyword and Author indexes, Vol. 11. 1978 - Radiation Chemistry Data Center. Rad Chem 11, Springfield, VA: NTIS, 768p. (1979). PB 226 368, A99.

Biweekly List of Papers on Radiation Chemistry and Photochemistry Annual Cumulation with Keyword and Author Indexes, Vol. 12. 1979 - Radiation Chemistry Data Center. Rad Chem 12, Springfield, VA: NTIS, 748p. (1980). PB 81-113 680, A26.

Biweekly List of Papers on Radiation Chemistry and Photochemistry Annual Cumulation with Keyword and Author Indexes, Vol. 13. 1980 - Radiation Chemistry Data Center. Rad Chem 13, Springfield, VA: NTIS, 704p. (1981). PB 82-122 995, A26.

Biweekly List of Papers on Radiation Chemistry and Photochemistry Annual Cumulation with Keyword and Author Indexes, Vol. 14. 1981 - Radiation Chemistry Data Center. Rad Chem 14, Springfield, VA: NTIS, 534p. (1982). PB 82-214 487, A22.

Biweekly List of Papers on Radiation Chemistry and Photochemistry Annual Cumuluation with Keyword and Author Indexes, Vol. 15. 1982 - Radiation Chemistry Data Center. Rad Chem 15, Springfield, VA: NTIS, 448p. (1983). PB 83-203638, A 19.

Biweekly List of Papers on Radiation Chemistry and Photochemistry Vol. 17. 1984 - Radiation Chemistry Data Center. Rad Chem, Notre Dame, IN: Radiation Chem. Data Center, U. of Notre Dame, 449p. (1984). \$25.00; the Biweekly List, Vol. 17 (1984) plus the Annual Cumulation, Vol. 16 (1983), $\$ 35.00$; foreign and airmail postage rates available upon request.

Biweekly List of Papers on Radiation Chemistry and Photochemistry Annual Cumuluation with Keyword and Author Indexes, Vol. 16. 1983 - Radiation Chemistry Data Center. Rad Chem 16, Springfield, VA: NTIS, 444p. (1984).

Compilation of Rate Constants for the Reactions of Metal Ions in Unusual Valency States - George V. Buxton and Robin M. Sellers. NSRDS-NBS 62, 68p. (1978).

Drift Mobilities and Conduction Band Energies of Excess Electrons in Dielectric Liquids - Augustine O. Allen. NSRDS-NBS 58, 23p. (1976).

Electron Impact Ionization Cross-Section Data for Atoms, Atomic Ions, and Diatomic Molecules: I. Experimental Data - Lee J. Kieffer and Gordon H. Dunn. Rev Mod Phys. 38. New York: American Institute of Physics, 35p. (1966).

Energetics of Gaseous Ions - Henry M. Rosenstock, Keith Draxl, B. W. Steiner, and John T. Merron. J Phys Chem Ref Data 6, Suppl. 1(1977).

Evaluated Gas Phase Basicities and Proton Affinities of Molecules: Heats of Formation of Protonated Molecules - Sharon G. Lias, Joel F. Liebman, and Rhoda D. Levin. J Phys Chem Ref Data 13, 695(1984). 
Evaluated Theoretical Cross Section Data for Charge Exchange of Multiply Charged Ions with Atoms. I. Hydrogen Atom-Fully Stripped Ion Systems - R. K. Janev, B. H. Bransden, and Jean W. Gallagher. J Phys Chem Ref Data 12, 829(1983).

Evaluated Theoretical Cross Section Data for Charge Exchange of Multiply Cliarged Ions with Atoms. II. Hydrogen Atom-Partially Stripped Ions Systems - Jean W. Gallagher, B. H. Bransden, and R. K. Janev. J Phys Chem Ref Data 12, 873(1983).

Evaluated Theoretical Cross Section Data for Charge Exchange of Multiply Charged Ion with Atoms. III. Non-Hydrogenic Target Atoms - R. K. Janev and Jean W. Gallagher. J Phys Chem Ref Data 13, 1199(1984)

Experimental Stark Widths and Shifts for Non-Hydrogenic Spectral Lines of Ionized Atoms (A Critical Review and Tabulation of Selected Data) - N. Konjević and Wolfgang L. Wiese. J Phys Chem Ref Data 5, 259(1976).

Experimental Stark Widths and Shifts for Spectral Lines of Positive Ions (A Critical Review and Tabulation of Selected Data for the Period 1976 to 1982) - N. Konjević, M. S. Dimitrijević, and Wolfgang L. Wiese. J Phys Chem Ref Data 13, 649(1984).

Ground Levels and Ionization Potentials for Lanthanide and Actinide Atoms and Ions - William C. Martin, Lucy Hagan, Joseph Reader, and Jack Sugar. $J$ Phys Chem Ref Data 3, 771(1974).

Ion Energetics Measurements, Supplement I. 1971-1973 - Henry M. Rosenstock, D. Sims, S. S. Schroyer, and W. J. Webb. NSRDS-NBS 66, 380p. (1980).

Ion-Molecule Reactions - Earl W. McDaniel, V. Cermak, A. Dalgarno, E. E. Ferguson, and L. Friedman. At Mol Collis Proc Ser, New York: Wiley-Interscience, 374p. (1970), ISBN: 0-471-5838-3.

Ionization Potential and Appearance Potential Measurements, 1971-1981 - Rhoda D. Levin and Sharon G. Lias. NSRDS-NBS 71, 634p. (1982).

Ionization Potentials, Appearance Potentials, and Heats of Formation of Gaseous Positive Ions - Joseph L. Franklin, J. G. Dillard, Henry M. Rosenstock, John T. Herron, Keith Draxl, and Frank H. Field. NSRDS-NBS 26, 289p. (1969).

Rate Coefficients for Ion-Molecule Reactions, I. Ions Containing C and $\mathrm{H}-\mathrm{L}$. Wayne Sieck and Sharon G. Lias. J Phys Chem Ref Data 5, 1123(1976).

Rate Coefficients for Ion-Molecule Reactions, Organic Ions Other Than Those Containing Only $\mathrm{C}$ and $\mathrm{H}-\mathrm{L}$. Wayne Sieck. NSRDSNBS 64, 27p. (1980).

Recommended Data on the Electron Impact Ionization of Light Atoms and Ions - K. L. Bell, H. B. Gilbody, J. G. Hughes, A. E. Kingston, and Francis J. Smith. J Phys Chem Ref Data 12, 891(1983).

Selected Specific Rates of Reactions of Transients from Water in Aqueous Solution, III. Hydroxyl Radical and Perhydroxyl Radical and Their Radical Ions - Farhataziz and Alberta B. Ross. NSRDS-NBS 59, 126p. (1977).

Surface Ionization - E. Ya. Zandberg and N. L. Ionov. Russian Transl. Springfield, VA: NTIS, 364p. (1971). TT 70-50148, A16.

Theory of Charge Exchange - R. A. Mapleton. New York: WileyInterscience, 284p. (1971), ISBN: 0-471-5678-7.

Theory of the Ionization of Atoms by Electron Impact - M. R. H. Rudge. Rev Mod Phys 40, .., 564p. (1968).

Yields of Free Ions Formed in Liquids by Radiation - Augustine O. Allen. NSRDS-NBS 57, 38p. (1976).

\section{Lanthanide elements}

Atomic Energy Levels - The Rare-Earth Elements, the Spectra of La, Ce, Pr, Nd, Pm, Sm, Eu, Gd, Tb, Dy, Ho, Er, Tm, Yb, Lu William C. Martin, Romuald Zalubas, and Lucy Hagan. NSRDS-NBS 60, 422p. (1978).

Ground Levels and Ionization Potentials for Lanthanide and Actinide Atoms and Ions - William C. Martin, Lucy Hagan, Joseph Reader, and Jack Sugar. J Phys Chem Ref Data 3, 771(1974).

Selected Values of Chemical Thermodynamic Properties. Tables for the Lanthanide (Rare Earth) Elements (Elements 62 through 76 in the
Standard Order of Arrangement) - Richard H. Schumm, Donald D. Wagman, Sylvia M. Bailey, William H. Evans, and Vivian B. Parker. NBS Tech. Note 270, 84p. (1973).

\section{Magnetic solids}

Analysis of Specific Heat Data in the Critical Region of Magnetic Solids - F. J. Cook. J Phys Chem Ref Data 2, 11(1973).

\section{Metal oxides}

Handbook of Phase Diagrams of Silicate Systems, Vol. II. MetalOxygen Compounds in Silicate Systems, Second Revised Edition - N. A. Toropov, V. P. Barzakovskii, I. A. Bondar', and Yu. P. Udalov. Russian Transl. Springfield, VA: NTIS, 329p. (1972). TT 71-50041, A15.

High Temperature Vaporization Behavior of Oxides. I. Alkali Metal Binary Oxides - R. H. Lamoreaux and D. L. Hildenbrand. J Phys Chem Ref Data 13, 151(1984).

Thermochemical Data for Gaseous Monoxides - J. B. Pedley and E. M. Marshall. J Phys Chem Ref Data 12, 967(1983).

Transition Metal Oxides, Crystal Chemistry, Phase Transition, and Related Aspects - C. N. R. Rao and G. V. Subba Rao. NSRDS-NBS 49, 140p. (1974).

\section{Metals}

Computerizing Materials Data-A Workshop for the Nuclear Power Industry - John Jr. Rumble and Jack H. Westbrook. NBS Spec. Publ. 689, 37p. (1985).

\section{Metals and alloys}

Applications of Phase Diagrams, Proceedings of a Workshop Held at the National Bureau of Standards, Gaithersburg, Maryland, January 10-12, 1977, Volumes 1 and 2 - Gesina Cynthia Carter, editor(s). NBS Spec. Publ. 496, 1622p. (1978).

Bulletin of Alloy Phase Diagrams - Joanne Murray, editor(s) and American Society for Metals. Bull Alloy Phase Diag 3, Metals Park, OH: American Society for Metals, 130p. (1982), ISBN: 01970216.

Contributions to the Data on Theoretical Metallurgy, XVI. Thermodynamic Properties of Nickel and Its Inorganic Compounds - Alla D. Mah and Louis B. Pankratz. U.S. Bur Mines Bull 668, Springfield, VA: NTIS, 125p. (1976). U.S. Bureau of Mines Bulletin 668, A06.

Critical Analysis of Heat-Capacity Data and Evaluation of Thermodynamic Properties of $\mathrm{Ru}, \mathrm{Ph}, \mathrm{Pd}$, Ir, and $\mathrm{Pt}$ from 0 to $300 \mathrm{~K}$. A Survey of the Literature Data on Osmium - George T. Furukawa, Martin L. Reilly, and John S. Gallagher. J Phys Chem Ref Data 3, 163(1974).

Critical Analysis of the Heat-Capacity Data of the Literature and Evaluation of Thermodynamic Properties of Copper, Silver, and Gold from 0 to $300 \mathrm{~K}-$ George T. Furukawa, W. G. Saba, and Martin L. Reilly. NSRDS-NBS 18, 49p. (1968).

Critical Surveys of Data Sources: Mechanical Properties of Metals R. B. Gavert, Robert L. Moore, and John H. Westbrook. NBS Spec. Publ. 396, 90p. (1974).

Critical Surveys of Data Sources: Corrosion of Metals - Ronald Diegle and Walter K. Boyd. NBS Spec. Publ. 396, 42p. (1976).

Critical Surveys of Data Sources: Electrical and Magnetic Properties of Metals - M. J. Carr, R. B. Gavert, Robert L. Moore, H. W. Wawrousek, and John H. Westbrook. NBS Spec. Publ. 396, 96p. (1976).

Diffusion Rate Data and Mass Transport Phenomena in Copper Systems - Daniel B. Butrymowicz, John R. Manning, and Michael E. Read. INCRA Monograph V, New York: International Copper Research Association, Inc., 322p. (1977).

Diffusion Rate Data and Mass Transport Phenomena for Copper Systems, Part II - Daniel B. Butrymowicz, John R. Manning, and Michael E. Read. INCRA Monograph VIII, New York: International Copper Research Association, Inc., 701p. (1982).

Diffusion in Copper and Copper Alloys, Part I. Volume and Surface Self-Diffusion in Copper - Daniel B. Butrymowicz, John R. Manning, and Michael E. Read. J Phys Chem Ref Data 2, 643(1973). 
Diffusion in Copper and Copper Alloys, Part II. Copper-Silver and Copper-Gold Systems - Daniel B. Butrymowicz, John R. Manning, and Michael E. Read. J Phys Chem Ref Data 3, 527(1974).

Diffusion in Copper and Copper Alloys, Part III. Diffusion in Systems Involving Elements of the Groups IA, IIA, IIIB, IVB, VB, and VIIB - Daniel B. Butrymowicz, John R. Manning, and Michael E. Read. J Phys Chem Ref Data 4, 177(1975).

Diffusion in Copper and Copper Alloys, Part IV. Diffusion in Systems Involving Elements of Group VIII - Daniel B. Butrymowicz, John R. Manning, and Michael E. Read. J Phys Chem Ref Data 5, 103(1976).

Diffusion in Copper and Copper Alloys, Part V. Diffusion in Systems Involving Elements of Group VA - Daniel B. Butrymowicz, John R. Manning, and Michael E. Read. J Phys Chem Ref Data 6, 1(1977).

Elastic Properties of Metals and Alloys, I. Iron, Nickel, and IronNickel Alloys - Hassell M. Ledbetter and R. P. Reed. J Phys Chem Ref Data 2, 531(1973).

Elastic Properties of Metals and Alloys, II. Copper - Hassell M. Ledbetter and E. R. Naimon. J Phys Chem Ref Data 3, 897(1974).

Elastic Properties of Zinc: A Compilation and a Review - Hassell M. Ledbetter. J Phys Chem Ref Data 6, 1181(1977).

Electrical Resistivity of Aluminum and Manganese - P. D. Desai, H. M. James, and Cho Y. Ho. J Phys Chem Ref Data 13, 1131(1984).

Electrical Resistivity of Selected Elements - P. D. Desai, T. K. Chu, H. M. James, and Cho Y. Ho. J Phys Chem Ref Data 13, 1069(1984).

Electrical Resistivity of Ten Selected Binary Alloy Systems - Cho Y. Ho, M. W. Ackerman, K. Y. Wu, T. N. Havill, R. H. Bogaard, R. A. Matula, S. G. Oh, and H. M. James. J Phys Chem Ref Data 12, 183(1983).

Electrical Resistivity of Vanadium and Zirconium - P. D. Desai, H. M. James, and Cho Y. Ho. J Phys Chem Ref Data 13, 1097(1984).

Handbook of Hardness Data - G. V. Samsonov and A. A. Ivan'ko. Russian Transl. Springfield, VA: NTIS, 69p. (1970). TT 70-50177, A04.

Heat Capacity of Reference Materials: $\mathrm{Cu}$ and W - G. K. White and S. J. Collocott. J Phys Chem Ref Data 13, 1251(1984).

LNG Materials \& Fluids, A User's Manual of Property Data in Graphic Format - Douglas Mann and U.S. National Bureau of Standards. Boulder, CO: U.S. National Bureau of Standards, Cryogenic Division, 11p. (1977).

LNG Materials \& Fluids, A User's Manual of Property Data in Graphic Format, First Supplement — Douglas Mann and U.S. National Bureau of Standards. Suppl. 1, Boulder, CO: U.S. National Bureau of Standards, $11 \mathrm{p}$. (1978).

LNG Materials \& Fluids, A User's Manual of Property Data in Graphic Format, Second Supplement - Douglas Mann and U.S. National Bureau of Standards. Suppl, 2, Boulder, CO: U.S. National Bureau of Standards, 11p. (1980).

Metallic Shifts in NMR: A Review of the Theory and Comprehensive Critical Data Compilation of Metallic Materials - Gesina Cynthia Carter, Lawrence H. Bennett, and Daniel J. Kahan. Prog Mater Sci, Oxford, New York: Pergamon Press, 2350p. (1977), ISBN: 0-08-02114-7.

Phase Diagrams and Thermodynamic Properties of Ternary CopperSilver Systems - Y. Austin Chang, Daniel Goldberg, and Joachim P. Neumann. J Phys Chem Ref Data 6, 621(1977).

Phase Diagrams and Thermodynamic Properties of Ternary CopperMetal Systems - Y. Austin Chang, Joachim P. Neumann, A. Mikula, and Daniel Goldberg. INCRA Monograph VI, New York: International Copper Research Association, Inc., 702p. (1979).

Phase Diagrams and Thermodynamic Properties of Ternary CopperSulfur-Metal Systems - Y. Austin Chang, Joachim P. Neumann, and U. V. Choudary. INCRA Monograph VII, New York: International Copper Research Association, Inc., 191p. (1979).

Physical Properties Data Compilations Relevant to Energy Storage. V. Mechanical Properties Data on Alloys for Use in Flywheels Hassell M. Ledbetter. NSRDS-NBS 61, 42p. (1982).
Selected Thermodynamic Values and Phase Diagrams for Copper and Some of Its Binary Alloys - Ralph Hultgren and Pramond D. Desai. INCRA Monograph I, New York: International Copper Research Association, Inc., 204p. (1973).

Selected Values of the Thermodynamic Properties of Binary Alloys - Ralph Hultgren, Pramond D. Desai, Donald T. Hawkins, M. Gleiser, and Kenneth K. Kelley. Metals Park, OH: American Society for Metals, 1435p. (1973).

Soft X-Ray Emission Spectra of Metallic Solids: Critical Review of Selected Systems - Archie J. McAlister, Ronald C. Dobbyn, John R. Cuthill, and M. L. Williams. J Phys Chem Ref Data 2, 411(1973).

Soft X-Ray Emission Spectra of Metallic Solids: Critical Review of Selected Systems and Annotated Spectral Index - Archie J. McAlister, Ronald C. Dobbyn, John R. Cuthill, and M. L. Williams. NBS Spec. Publ. 369, 180p. (1974).

Surface Ionization - E. Ya. Zandberg and N. L. Ionov. Russian Transl. Springfield, VA: NTIS, 364p. (1971). TT 70-50148, A16.

The NBS Alloy Data Center: Author Index - Gesina Cynthia Carter, Daniel J. Kahan, Lawrence H. Bennett, John R. Cuthill, and Ronald C. Dobbyn. OSRD Bibl. 70-2, 413p. (1970).

The NBS Alloy Data Center: Function, Bibliographic System, Related Data Centers, and Reference Books - Gesina Cynthia Carter, Lawrence H. Bennett, John R. Cuthill, and Daniel J. Kahan. NBS Tech. Note 464, 163p. (1968).

The NBS Alloy Data Center: Permuted Materials Index - Gesina Cynthia Carter, Daniel J. Kahan, Lawrence H. Bennett, John R. Cuthill, and Ronald C. Dobbyn. NBS Spec. Publ. 324, 683p. (1971).

Thermal Conductivity of Selected Materials - Robert W. Powell, Cho Y. Ho, and Peter E. Liley. NSRDS-NBS 8, 68p. (1966).

Thermal Conductivity of Selected Materials, Part $2-$ Cho Y. Ho, Robert W. Powell, and Peter E. Liley. NSRDS-NBS 16, 146p. (1968).

Thermal Conductivity of Ten Selected Binary Alloy Systems - Cho Y. Ho, M. W. Ackerman, K. Y. Wu, S. G. Oh, and T. N. Havill. J Phys Chem Ref Data 7, 959(1978).

Thermal Conductivity of the Elements - Cho Y. Ho, Robert W. Powell, and Peter E. Liley. J Phys Chem Ref Data 1, 279(1972).

Thermal Conductivity of the Elements: A Comprehensive Review Cho Y. Ho, Robert W. Powell, and Peter E. Liley. J Phys Chem Ref Data 3, Suppl. 1(1974)

Thermodynamic Properties of Copper-Slag Systems - Carlos Diaz. INCRA Monograph III, New York: International Copper Research Association, Inc., 178p. (1976).

\section{Minerals}

Crystal Data Determinative Tables, Third Edition Volume 2: Inorganic Compounds - Joseph D. H. Donnay and Helen M. Ondik. Swarthmore, PA: JCPDS-International Center for Diffraction Data, 1748p. (1973).

Crystal Data Determinative Tables, Third Edition Volume 4. Inoganic Compounds - Joseph D. H. Donnay, Helen M. Ondik, and Alan D. Mighell. Swarthmore, PA: JCPDS-International Center for Diffraction Data, 1308p. (1978).

Feasiblility Study: Compilation and Evaluation of Properties Data for Basalt, Granite, Tuff, and Shale - Lewis H. Gevantman. NBSIR 81-2217, 259p. (1981).

Handbook of Thermodynamic Data on Geological Substances - G. B. Naumov, B. N. Ryzhenko, and I. L. Khodakovsky. Russian Transl. Springfield, VA: NTIS, 340p. (1974). TT 73-53051 or PB226 722, A15.

Physical Properties Data for Basalt - Lewis H. Gevantman. NBSIR 82-2587, 751p. (1982).

\section{Noble gases}

A Survey of Electron Swarm Data - J. Dutton. J Phys Chem Ref Data 4, 577(1975).

Energy Levels of Neutral Helium $\left({ }^{4} \mathrm{He}\right.$ I) - William C. Martin. J Phys Chem Ref Data 2, 257(1973). 
Equilibrium and Transport Properties of the Noble Gases and Their Mixtures at Low Density - Joseph Kestin, K. Knierim, E. A. Mason, B. Najafi, S. T. Ro, and M. Waldman. J Phys Chem Ref Data 13, 229(1984).

First Spectra of Neon, Argon, and Xenon 136 in the 1.2-4.0 $\mu \mathrm{m}$ Region - Curtis J. Humphreys. J Phys Chem Ref Data 2, 519(1973).

Gaseous Diffusion Coefficients - T. R. Marrero and E. A. Mason. J Phys Chem Ref Data 1, 1(1972).

Interactive Fortran Program to Calculate Thermophysical Properties of 6 Fluids NBS Standard Reference Database 6, Washington, D.C.; NBS, Office of Standard Reference Data,(updated periodically). Call (301)921-2228 for specific instructions.

NBS Chemical Thermodynamics Database NBS Standard Reference Database 2, Washington, D.C.; NBS, Office of Standard Reference Data,(updated periodically). Call (301)921-2228 for specific instructions.

Scaled Equation of State Parameters for Gases in the Critical Region - J. M. H. Levelt Sengers, W. L. Greer, and Jan V. Sengers. J Phys Chem Ref Data 5, 1(1976).

The Calculated Thermodynamic Properties of Superfluid Helium-4 - James S. Brooks and Russell J. Donnelly. J Phys Chem Ref Data 6, 51(1977).

The Viscosity and Thermal Conductivity Coefficients of Dilute Argon, Krypton, and Xenon - Howard J. M. Hanley. J Phys Chem Ref Data 2, 619(1973).

The Viscosity and Thermal Conductivity Coefficients for Dense Gaseous and Liquid Argon, Krypton, Xenon, Nitrogen, and Oxygen Howard J. M. Hanley, Robert D. McCarty, and W. M. Haynes. J Phys Chem Ref Data 3, 979(1974).

Thermodynamic Properties of Argon from the Triple Point to $300 \mathrm{~K}$ at Pressures to 1000 Atmospheres - A. L. Gosman, Robert D. McCarty, and Jerome G. Hust. NSRDS-NBS 27, 153p. (1969).

Thermodynamic Properties of Helium-4 from 2 to $1500 \mathrm{~K}$ at Pressures to $10^{8} \mathrm{~Pa}-$ Robert D. McCarty. J Phys Chem Ref Data 2, 923(1973).

Thermodynamic and Thermophysical Properties of Helium - A. F. Alyab'ev, N. V. Tsederberg, V. N. Popov, and N. A. Morozova. Russian Transl. Springfield, VA: NTIS, 260p. (1971). TT 70-50096, A12.

Thermophysical Properties of Fluids. I. Argon, Ethylene, Parahydrogen, Nitrogen, Nitrogen Trifluoride, and Oxygen - Ben A. Younglove. J Phys Chem Ref Data 11, Suppl. 1(1982).

\section{Organic compounds}

A Correlation of the Existing Viscosity and Thermal Conductivity Data of Gaseous and Liquid Ethane - Howard J. M. Hanley, K. E. Gubbins, and S. Murad. J Phys Chem Ref Data 6, 1167(1977).

A Correlation of the Viscosity and Thermal Conductivity Data of Gaseous and Liquid Propane - Paul M. Holland, Howard J. M. Hanley, K. E. Gubbins, and J. M. Haile. J Phys Chem Ref Data 8, 559(1979).

A Review, Evaluation, and Correlation of the Phase Equilibria, Heat of Mixing, and Change in Volume on Mixing for Liquid Mixtures of Methane + Ethane - M. J. Hiza, R. C. Miller, and Arthur J. Kidnay. J Phys Chem Ref Data 8, 799(1979).

An Analysis of Coexistence Curve Data for Several Binary Liquid Mixtures Near Their Critical Points - A. Stein and G. F. Allen. J Phys Chem Ref Data 2, 439(1973).

Critical Review of Hydrolysis of Organic Compounds in Water Under Environmental Conditions - W. Mabey and T. Mill. J Phys Chem Ref Data 7, 383(1978).

Crystal Data Determinative Tables, Third Edition, Volume 6. Organic Compounds - Olga Kennard, David G. Watson, John E. Davies, editor(s). 6, Swarthmore, PA, JCPDS-International Center for Diffraction Data,(1983).

Crystal Data Space-Group Tables - Alan D. Mighell, Helen M. Ondik, and Bettijoyce Breen Molino. J Phys Chem Ref Data 6, 675(1977).

Crystal Data Determinative Tables, Third Edition Volume 1: Organic Compounds - Joseph D. H. Donnay and Helen M. Ondik.
Swarthmore, PA: JCPDS-International Center for Diffraction Data, 855p. (1972).

Crystal Data Determinative Tables, Third Edition Volume 3. Organic Compounds - Joseph D. H. Donnay, Olga Kennard, David G. Watson, and John R. Rodgers. Swarthmore, PA: JCPDS-International Center for Diffraction Data, 748p. (1978).

Definition of Recommended Values of Certain Thermodynamic Properties for the Ketones - Buford D. Smith and Ol Muthu. NBSIR 84-2811, 162p. (1983).

Densities of Liquid $\mathrm{CH}_{4 \mathrm{a}} \mathrm{X}_{\mathrm{u}}(\mathrm{X}=\mathrm{Br}, \mathrm{I})$ and $\mathrm{CH}_{4(a+b+c+d)} \mathrm{F}_{\mathrm{a}} \mathrm{Cl}_{b} \mathrm{Br}_{\mathrm{c}} \mathrm{I}_{\mathrm{d}}$ Halomethanes - Arvind P. Kudchadker, Shanti A. Kudchadker, P. R. Patnaik, and P. P. Mishra. J Phys Chem Ref Data 7, 425(1978).

EPA/NIH Mass Spectral Data Base, Supplement 1 - Stephen R. Heller and G. W. A. Milne. NSRDS-NBS 63, Suppl. 1(1980).

EPA/NIH Mass Spectral Data Base, Supplement 2 - Stephen R. Heller, G. W. A. Milne, and Lewis H. Gevantman. NSRDS-NBS 63, Suppl. 2(1983).

EPA/NIH Mass Spectral Data Base, Volume 1. Molecular Weights 30-186; Volume 2. Molecular Weights 16-273; Volume 3. Molecular Weights 273-381; Volume 4. Molecular Weights 381-1674 - Stephen R. Heller and G. W. A. Milne. NSRDS-NBS 63, 1,2,3,4(1978).

Energetics of Gaseous Ions - Henry M. Rosenstock, Keith Draxl, B. W. Steiner, and John T. Herron. J Phys Chem Ref Data 6, Suppl. 1(1977).

Erratum: A Correlation of the Existing Viscosity and Thermal Conductivity Data of Gaseous and Liquid Ethane - Howard J. M. Hanley, K. E. Gubbins, and S. Murad. J Phys Chem Ref Data 10, 799(1981).

Heat Capacities and Entropies of Organic Compounds in the Condensed Phase - Eugene S. Domalski, William H. Evans, and Elizabeth D. Hearing. J Phys Chem Ref Data 13, Suppl. 1(1984).

Ideal Gas Thermodynamic Properties of Ethane and Propane - Jing Chao, Randolph C. Wilhoit, and Bruno J. Zwolinski. J Phys Chem Ref Data 2, 427(1973).

Ideal Gas Thermodynamic Properties of Eight Chloro- and Fluoromethanes - A. S. Rodgers, Jing Chao, Randolph C. Wilhoit, and Bruno J. Zwolinski. J Phys Chem Ref Data 3, 117(1974).

Ideal Gas Thermodynamic Properties of Six Chloroethanes - Jing Chao, A. S. Rodgers, Randolph C. Wilhoit, and Bruno J. Zwolinski. J Phys Chem Ref Data 3, 141(1974).

Ideal Gas Thermodynamic Properties of Ethylene and Propylene Jing Chao and Bruno J. Zwolinski. J Phys Chem Ref Data 4, 251(1975). Ideal Gas Thermodynamic Properties of Six Fluoroethanes - S. S. Chen, A. S. Rodgers, Jing Chao, Randolph C. Wilhoit, and Bruno J. Zwolinski. J Phys Chem Ref Data 4, 441(1975).

Ideal Gas Thermodynamic Properties of the Eight Bromo- an Iodomethanes - Shanti A. Kudchadker and Arvind P. Kudchadker. J Phys Chem Ref Data 4, 457(1975).

Ideal Gas Thermodynamic Properties and Isomerization of n-Butane and Isobutane - S. S. Chen, Randolph C. Wilhoit, and Bruno J. Zwolinski. J Phys Chem Ref Data 4, 859(1975).

Ideal Gas Thermodynamic Properties of Propanone and 2-Butanone - Jing Chao and Bruno J. Zwolinski. J Phys Chem Ref Data 5, 319(1976).

Ideal Gas Thermodynamic Properties of Six Chlorofluoromethanes - S. S. Chen, Randolph C. Wilhoit, and Bruno J. Zwolinski. J Phys Chem Ref Data 5, 571(1976).

Ideal Gas Thermodynamic Properties of Methanoic and Ethanoic Acids - Jing Chao and Bruno J. Zwolinski. J Phys Chem Ref Data 7, 363(1978).

Ideal Gas Thermodynamic Properties of Phenol and Cresols Shanti A. Kudchadker, Arvind P. Kudchadker, Randolph C. Wilhoit, and Bruno J. Zwolinski. J Phys Chem Ref Data 7, 417(1978).

Ideal Gas Thermodynamic Properties of $\mathrm{CH}_{4(a+b+c+d)} \mathrm{F}_{a} \mathrm{Cl}_{b} \mathrm{Br}_{c} \mathrm{I}_{d}$ Halomethanes - Shanti A. Kudchadker and Arvind P. Kudchadker. J Phys Chem Ref Data 7, 1285(1978).

Ideal Gas Thermodynamic Properties of Selected Bromoethanes and Iodoethane - Shanti A. Kudchadker and Arvind P. Kudchadker. J Phys Chem Ref Data 8, 519(1979). 
Ideal Gas Thermodynamic Properties of $\mathrm{CH}_{3}, \mathrm{CD}_{3}, \mathrm{CD}_{4}, \mathrm{C}_{2} \mathrm{D}_{2}$, $\mathrm{C}_{2} \mathrm{D}_{4}, \mathrm{C}_{2} \mathrm{D}_{6}, \mathrm{C}_{2} \mathrm{H}_{6}, \mathrm{CH}_{3} \mathrm{~N}_{2} \mathrm{CH}_{3}$, and $\mathrm{CD}_{3} \mathrm{~N}_{2} \mathrm{CD}_{3}-$ Krishna $\mathrm{M}$. Pamidimukkala, David Rogers, and Gordon B. Skinner. J Phys Chem Ref Data 11, 83(1982).

Kinetic Data on Gas Phase Unimolecular Reactions - Sidney W. Benson and Harry E. O'Neal. NSRDS-NBS 21, 645p. (1970).

NBS Crystal Data Identification File NBS Standard Reference Database 3, Washington, D.C.; NBS, Office of Standard Reference Data,(updated periodically). Lease agreements obtained from JCPDS 1601 Park Ln Swarthmore PA (215)328-9400.

NMR Spectral Data: A Compilation of Aromatic Proton Chemical Shifts in Mono- and Di-Substituted Benzene - B. L. Shapiro and L. E. Mohrmann. J Phys Chem Ref Data 6, 919(1977).

Physical and Thermodynamic Properties of Aliphatic Alcohols Randolph C. Wilhoit and Bruno J. Zwolinski. J Phys Chem Ref Data 2, Suppl. 1(1973).

Provisional Thermodynamic Functions of Propane from 85 to $700 \mathrm{~K}$ at Pressures to 700 Bar - Robert D. Goodwin. NBSIR 77-860, 240p. (1977).

Rate Constants for the Reactions of Atomic Oxygen ( $\left({ }^{3} \mathrm{P}\right)$ with Organic Compounds in the Gas Phase - John T. Herron and Robert E. Huie. J Phys Chem Ref Data 2, 467(1973).

Selected Values of Electric Dipole Moments for Molecules in the Gas Phase - Ralph D. Nelson, Jr., David R. Lide, Jr., and Arthur A. Maryott. NSRDS-NBS 10, 49p. (1967).

Selected Values of Heats of Combustion and Heats of Formation of Organic Compounds Containing the Elements $\mathrm{C}, \mathrm{H}, \mathrm{N}, \mathrm{O}, \mathrm{P}$, and $\mathrm{S}-$ Eugene S. Domalski. J Phys Chem Ref Data 1, 221(1972).

Table of Recommended Rate Constants for Chemical Reactions Occurring in Combustion - Francis Westley. NBSIR 79-1941, 169p. (1979).

Tables of Bimolecular Gas Reactions - Aubrey F. Trotman-

Dickenson and G. S. Milne. NSRDS-NBS 9, 129p. (1967).

Tables of Molecular Vibrational Frequencies, Part 1 - Takehiko Shimanouchi. NSRDS-NBS 6, 56p. (1967).

Tables of Molecular Vibrational Frequencies, Part 2 - Takehiko Shimanouchi. NSRDS-NBS 11, 38p. (1967)

Tables of Molecular Vibrational Frequencies, Part 3 - Takehiko

Shimanouchi. NSRDS-NBS 17, 39p. (1968).

Tables of Molecular Vibrational Frequencies, Consolidated Volume

I - Takehiko Shimanouchi. NSRDS-NBS 39, 167p. (1972).

Tables of Molecular Vibrational Frequencies, Part 9 - Takehiko Shimanouchi, Hiroatsu Matsuura, Yoshiki Ogawa, and Issei Harada. J Phys Chem Ref Data 7, 1323(1978).

Tables of Molecular Vibrational Frequencies, Part 10 - Takehiko Shimanouchi, Hiroatsu Matsuura, Yoshiki Ogawa, and Issei Harada. J Phys Chem Ref Data 9, 1149(1980).

The Surface Tension of Pure Liquid Compounds - Joseph J. Jasper. J Phys Chem Ref Data 1, 841(1972).

The Viscosity and Thermal Conductivity Coefficients for Dense Gaseous and Liquid Methane - Howard J. M. Hanley, W. M. Haynes, and Robert D. McCarty. J Phys Chem Ref Data 6, 597(1977).

Thermal Conductivity of Selected Materials - Robert W. Powell,

Cho Y. Ho, and Peter E. Liley. NSRDS-NBS 8, 68p. (1966).

Thermal Conductivity of Selected Materials, Part 2 - Cho Y. Ho,

Robert W. Powell, and Peter E. Liley. NSRDS-NBS 16, 146p. (1968).

Thermodynamic Properties of Normal and Deuterated Methanols -

S. S. Chen, Randolph C. Wilhoit, and Bruno J. Zwolinski. J Phys Chem Ref Data 6, 105(1977).

Thermodynamic Properties of Normal and Deuterated Naphthalenes - S. S. Chen, Shanti A. Kudchadker, and Randolph C. Wilhoit. J Phys Chem Ref Data 8, 527(1979).

Thermodynamic and Thermophysical Properties of Combustion Products, Volume II. Oxygen-Based Propellants - V. P. Glushko, V. E. Alemasov, A. F. Dregalin, A. P. Tishin, V. A. Khudyakov, and V. N. Kostin. Russian Transl. Springfield, VA: NTIS, 505p. (1975). TT 74-50032, A22.

Vapor Pressure of Coal Chemicals - Jing Chao, C. T. Lin, and T. H. Chung. J Phys Chem Ref Data 12, 1033(1983).
Vapor Pressures and Boiling Points of Selected Halomethanes Arvind P. Kudchadker, Shanti A: Kudchadker, R. P. Shukla, and P. R. Patnaik. J Phys Chem Ref Data 8, 499(1979).

\section{Polymers}

Computerizing Materials Data-A Workshop for the Nuclear Power Industry - John Jr. Rumble and Jack H. Westbrook. NBS Spec. Publ. 689, 37p. (1985).

Critical Review of Vibrational Data and Force Field Constants for Polyethylene - John Barnes and Bruno Fanconi. J Phys Chem Ref Data 7, 1309(1978).

Heat Capacity and Other Thermodynamic Properties of Linear Macromolecules. I. Selenium - Umesh Gaur, Hua-Cheng Shu, Aspy Metha, and Bernhard Wunderlich. J Phys Chem Ref Data 10, 89(1981).

Heat Capacity and Other Thermodynamic Properties of Linear Macromolecules. II. Polyethylene - Umesh Gaur and Bernhard Wunderlich. J Phys Chem Ref Data 10, 119(1981).

Heat Capacity and Other Thermodynamic Properties of Linear Macromolecules. III. Polyoxides - Umesh Gaur and Bernhard Wunderlich. J Phys Chem Ref Data 10, 1001(1981).

Heat Capacity and Other Thermodynamic Properties of Linear Macromolecules. IV. Polypropylene - Umesh Gaur and Bernhard Wunderlich. J Phys Chem Ref Data 10, 1051(1981).

Heat Capacity and Other Thermod ynamic Properties of Linear Macromolecules. V. Polystyrene - Umesh Gaur and Bernhard Wunderlich. J Phys Chem Ref Data 11, 313(1982).

Heat Capacity and Other Thermodynamic Properties of Linear Macromolecules. VI. Acrylic Polymers - Umesh Gaur, Suk-fai Lau, Brent B. Wunderlich, and Bernhard Wunderlich. J Phys Chem Ref Data 11, 1065(1982).

Heat Capacity and Other Thermodynamic Properties of Linear Macromolecules. VII. Other Carbon Backbone Polymers - Umesh Gaur, Brent B. Wunderlich, and Bernhard Wunderlich. J Phys Chem Ref Data 12, 29(1983).

Heat Capacity and Other Thermodynamic Properties of Linear Macromolecules. VIII. Polyesters and Polyamides - Umesh Gaur, Suk-fai Lau, Brent B. Wunderlich, and Bernhard Wunderlich. J Phys Chem Ref Data 12, 65(1983).

Heat Capacity and Other Thermodynamic Properties of Linear Macromolecules. IX. Final Group of A romatic and Inorganic Polymers Umesh Gaur, Suk-fai Lau, and Bernhard Wunderlich. J Phys Chem Ref Data 12, 91(1983).

Infrared Spectra of Plasticizers and Other Additives - Clara D. Craver and Coblentz Society; Joint Committee on Atomic and Molecular Physical Data., Kirkwood, MO: The Coblentz Society, 152p. (1977).

\section{Salts}

Activity and Osmotic Coefficients of Aqueous Alkali Metal Nitrites - Bert R. Staples. J Phys Chem Ref Data 10, 765(1981).

Erratum: Molten Salts Data: Diffusion Coefficients in Single and Multi-Component Salt Systems - George J. Janz and Narottam P. Bansal. J Phys Chem Ref Data 13, 305(1984).

Evaluated Activity and Osmotic Coefficients for Aqueous Solutions: The Alkaline Earth Metal Halides - Robert N. Goldberg and Ralph L. Nuttall. J Phys Chem Ref Data 7, 263(1978).

Evaluated Activity and Osmotic Coefficients for Aqueous Solutions: Iron Chloride and the Bi-Univalent Compounds of Nickel and Cobalt - Robert N. Goldberg, Ralph L. Nuttall, and Bert R. Staples. J Phys Chem Ref Data 8, 923(1979).

Evaluated Activity and Osmotic Coefficients for Aqueous Solutions: Bi-Univalent Compounds of Lead, Copper, Manganese, and Uranium - Robert N. Goldberg. J Phys Chem Ref Data 8, 1005(1979). 
Evaluated Activity and Osmotic Coefficients for Aqueous Solutions: Thirty-Six Uni-Bivalent Electrolytes - Robert N. Goldberg. J Phys Chem Ref Data 10, 671(1981).

High Temperature Properties and Decomposition of Inorganic Salts, Part 1. Sulfates - Kurt H. Stern and E. L. Weise. NSRDS-NBS 7, 38p. (1966).

High Temperature Properties and Decomposition of Inorganic Saits, Part 2. Carbonates - Kurt H. Stern and E. L. Weise. NSRDS-NBS 30, 27p. (1969).

High Temperature Properties and Decomposition of Inorganic Salts, Part 3. Nitrates and Nitrites - Kurt H. Stern. J Phys Chem Ref Data 1, 747(1972).

High Temperature Properties and Decomposition of Inorganic Salts, Part 4. Oxy-Salts of the Halogens - Kurt H. Stern. J Phys Chem Ref Data 3, 481(1974).

Molten Salts Data As Reference Standards for Density, Surface Tension, Viscosity and Electrical Conductance: $\mathrm{KNO}_{3}$ and $\mathrm{NaCl}-$ George J. Janz. J Phys Chem Ref Data 9, 791(1980).

Molten Salts Data: Diffusion Coefficients in Single and MultiComponent Salt Systems - George J. Janz and Narottam P. Bansal. J Phys Chem Ref Data 11, 505(1982).

Molten Salts: Volume 1. Electrical Conductance, Density, and Viscosity Data - George J. Janz, F. W. Dampier, G. R. Lakshminarayanan, P. K. Lorenz, and Reginald P. T. Tomkins. NSRDS-NBS 15, 140p. (1968).

Molten Salts: Volume 2. Section 1. Electrochemistry of Molten Salts. Gibbs Free Energies and Excess Free Energies from Equilibrium-Type Cells, Section 2. Surface Tension Data - George J. Janz, Chr. G. M. Dijkhuis, G. R. Lakshminarayanan, Reginald P. T. Tomkins, and J. Wong. NSRDS-NBS 28, 116p. (1968).

Molten Salts: Volume 5, Part 1. Additional Single and MultiComponent Salt Systems. Electrical Conductance, Density, Viscosity, and Surface Tension Data - George J. Janz and Reginald P. T. Tomkins. J Phys Chem Ref Data 9, 831(1980).

Molten Salts: Volume 5, Part 2. Additional Single and MultiComponent Salt Systems. Electrical Conductance, Density, Vicosity and Surface Tension Data - George J. Janz and Reginald P. T. Tomkins. J Phys Chem Ref Data 12, 591(1983).

Molten Salts: Volume 3, Nitrates, Nitrites, and Mixtures. Electrical Conductance, Density, Viscosity, and Surface Tension Data - George J. Janz, Ursula Krebs, H. F. Siegenthaler, and Reginald P. T. Tomkins. J Phys Chem Ref Data 1, 581(1972).

Molten Salts: Volume 4, Part 1, Fluorides and Mixtures. Electrical Conductance, Density, Viscosity, and Surface Tension Data - George J. Janz, G. L. Gardner, Ursula Krebs, and Reginald P. T. Tomkins. J Phys Chem Ref Data 3, 1(1974).

Molten Salts: Volume 4, Part 2, Chlorides and Mixtures. Electrical Conductance, Density, Viscosity, and Surface Tension Data - George J. Janz, Reginald P. T. Tomkins, Carolyn B. Allen, J. R. Downey, Jr., G. L. Gardner, Ursula Krebs, and S. K. Singer. J Phys Chem Ref Data 4, 871(1975).

Molten Salts: Volume 4, Part 3, Bromides and Mixtures, Iodides and Mixtures. Electrical Conductance, Density, Viscosity, and Surface Tension Data - George J. Janz, Reginald P. T. Tomkins, Carolyn B. Allen, J. R. Downey, Jr., and S. K. Singer. J Phys Chem Ref Data 6, 409(1977).

Molten Salts: Volume 4, Part 4, Mixed Halide Melts. Electrical Conductance, Density, Viscosity, and Surface Tension Data - George J. Janz, Reginald P. T. Tomkins, and Carolyn B. Allen. J Phys Chem Ref Data 8, 125(1979).

Osmotic Coefficients and Mean Activity Coefficients of UniUnivalent Electrolytes in Water at $25^{\circ} \mathrm{C}-$ Walter J. Hamer and Yung-Chi Wu. J Phys Chem Ref Data 1, 1047(1972).

Physical Properties Data Compilations Relevant to Energy Storage. I. Molten Salts: Eutectic Data - George J. Janz, Carolyn B. Allen, J. R. Downey, Jr., and Reginald P. T. Tomkins. NSRDS-NBS 61, 244p. (1978).
Physical Properties Data Compilations Relevant to Energy Storage. II. Molten Salts: Data on Single and Multi-Component Systems George J. Janz, Carolyn B. Allen, Narottam P. Bansal, R. M. Murphy, and Reginald P. T. Tomkins. NSRDS-NBS 61, 420p. (1979).

Physical Properties Data Compilations Relevant to Energy Storage. IV. Molten Salts: Data on Additional Single and Multi-Component Salt Systems - George J. Janz and Reginald P. T. Tomkins. NSRDS-NBS 61, 870p. (1981).

Refractive Index of Alkali Halides and Its Wavelength and Temperature Derivatives - H. H. Li. J Phys Chem Ref Data 5, 329(1976).

Revised Values of the Osmotic Coefficients and Mean Activity Coefficients of Sodium Nitrate in Water at $25^{\circ} \mathrm{C}$ (Comments) - Yung-Chi Wu and Walter J. Hamer. J Phys Chem Ref Data 9, 513(1980).

Tables of the Dynamic and Kinematic Viscosity of Aqueous $\mathrm{KCl}$ Solutions in the Temperature Range $25-150^{\circ} \mathrm{C}$ and the Pressure Range 0.1-35 MPa - Joseph Kestin, H. Ezzat Khalifa, and Robert J. Correia. J Phys Chem Ref Data 10, 57(1981).

Tables of the Dynamic and Kinematic Viscosity of Aqueous $\mathrm{NaCl}$ Solutions in the Temperature Range $20-150^{\circ} \mathrm{C}$ and the Pressure Range 0.1-35 MPa - Joseph Kestin, H. Ezzat Khalifa, and Robert J. Correia. J Phys Chem Ref Data 10, 71(1981).

The Activity and Osmotic Coefficients of Aqueous Calcium Chloride at 298.15 K - Bert R. Staples and Ralph L. Nuttall. J Phys Chem Ref Data 6, 385(1977).

The Solubility of Some Sparingly Soluble Lead Salts: An Evaluation of the Solubility in Water and Aqueous Electrolyte Solution - $\mathrm{H}$. Lawrence Clever and Francis J. Johnston. J Phys Chem Ref Data 9, $751(1980)$.

Volumetric Properties of Aqueous Sodium Chloride Solutions - P. S. Z. Rogers and Kenneth S. Pitzer. J Phys Chem Ref Data 11, 15(1982).

\section{Semiconductors}

Compilation of Energy Band Gaps in Elemental and Binary Compound Semiconductors and Insulators - W. H. Strehlow and E. L. Cook. J Phys Chem Ref Data 2, 163(1973).

Handbook of Hardness Data - G. V. Samsonov and A. A. Ivan'ko. Russian Transl. Springfield, VA: NTIS, 69p. (1970). TT 70-50177, A04.

Recommemded Values for the Thermal Expansivity of Silicon from 0 to $1000 \mathrm{~K}-$ C. A. Swenson. J Phys Chem Ref Data 12, 179(1983).

Survey of Superconductive Materials and Critical Evaluation of Selected Properties - Benjamin W. Roberts. J Phys Chem Ref Data 5, 581(1976).

\section{Superconductors}

Properties of Selected Superconductive Materials, 1978 Supplement - Benjamin W. Roberts. NBS Tech. Note 983, 103p. (1978).

Survey of Superconductive Materials and Critical Evaluation of Selected Properties - Benjamin W. Roberts. J Phys Chem Ref Data 5, $581(1976)$.

\section{Surfactants}

Critical Micelle Concentrations of Aqueous Surfactant Systems Pasupati Mukerjee and Karol J. Mysels. NSRDS-NBS 36, 222p. (1971).

\section{Transition eiements}

Atomic Transition Probabilities for Forbidden Lines of the Iron Group Elements (A Critical Data Compilation for Selected Lines) Melvin W. Smith and Wolfgang L. Wiese. J Phys Chem Ref Data 2, 85(1973).

Atomic Transition Probabilities for Scandium and Titanium (A Critical Data Compilation of Allowed Lines) - Wolfgang L. Wiese and Jeffrey R. Fuhr. J Phys Chem Ref Data 4, 263(1975).

Atomic Transition Probabilities for Vanadium, Chromium, and Manganese (A Critical Data Compilation of Allowed Lines) - S. M. Younger, Jeffrey R. Fuhr, Georgia A. Martin, and Wolfgang L. Wiese. J Phys Chem Ref Data 7, 495(1978). 
Atomic Transition Probabilities for Iron, Cobalt, Nickel: A Critical Data Compilation of Allowed Lines - Jeffrey R. Fuhr, Georgia A. Martin, Wolfgang L. Wiese, and S. M. Younger. J Phys Chem Ref Data 10, 305(1981).

Electrical Resistivity of Copper, Gold, Palladium, and Silver - R. A. Matula. J Phys Chem Ref Data 8, 1147(1979).

Energy Levels of Chromium, Cr I through Cr XXIV - Jack Sugar and Charles H. Corliss. J Phys Chem Ref Data 6, 317(1977).

Energy Levels of Cobalt, Co I through Co XXVII - Jack Sugar and Charles H. Corliss. J Phys Chem Ref Data 10, 1097(1981).

Energy Levels of Iron, Fe I through Fe XXVI - Joseph Reader and Jack Sugar. J Phys Chem Ref Data 4, 353(1975).

Energy Levels of Iron, Fe I through Fe XXVI - Charles H. Corliss and Jack Sugar. J Phys Chem Ref Data 11, 135(1982).

Energy Levels of Manganese, Mn I through Mn XXV - Charles H. Corliss and Jack Sugar. J Phys Chem Ref Data 6, 1253(1977).

Energy Levels of Nickel, Ni I through Ni XXVIII - Charles H. Corliss and Jack Sugar. J Phys Chem Ref Data 10, 197(1981).

Energy Levels of Titanium, Ti I through Ti XXII - Charles H. Corliss and Jack Sugar. J Phys Chem Ref Data 8, 1(1979).

Energy Levels of Vanadium, V I through V XXIII - Jack Sugar and Charles H. Corliss. J Phys Chem Ref Data 7, 1191(1978).

Refractive Index of $\mathrm{ZnS}, \mathrm{ZnSe}$, and $\mathrm{ZnTe}$ and Its Wavelength and Temperature Derivatives - H. H. Li. J Phys Chem Ref Data 13, 103(1984).

Transition Metal Oxides, Crystal Chemistry, Phase Transition, and Related Aspects - C. N. R. Rao and G. V. Subba Rao. NSRDS-NBS 49, 140p. (1974).

\section{Water}

A Fundamental Equation of State for Heavy Water - P. G. Hill, R. D. Chris MacMillan, and V. Lee. J Phys Chem Ref Data 11, 1(1982).

A Thermodynamic Surface for Water: The Formulation and Computer Program - Lester Haar, John S. Gallagher, and George S. Kell. NBSIR 81-2253, 38p. (1981).

An Annotated Compilation and Appraisal of Electron Swarm Data in Electronegative Gases - Jean W. Gallagher, Earl C. Beaty, J. Dutton, and L. C. Pitchford. J Phys Chem Ref Data 12, 109(1983).

An Improved Representative Equation for the Dynamic Viscosity of Water Substance - J. T. R. Watson, R. S. Basu, and Jan V. Sengers. J Phys Chem Ref Data 9, 1255(1980).

Atlas of the High Temperature Water Vapor Spectrum in the 3000 to $4000 \mathrm{~cm}^{-1}$ Region - A. S. Pine, M. J. Coulombe, C. Camy-Peyret, and J-M. Flaud. J Phys Chem Ref Data 12, 413(1983).

Effects of Isotopic Composition, Temperature, Pressure, and Dissolved Gases on the Density of Liquid Water - George S. Kell. J Phys Chem Ref Data 6, 1109(1977).

Equilibrium Properties of Fluid Mixtures, 2. A Bibliography of Experimental Data on Selected Fluids - M. J. Hiza, Arthur J. Kidnay, and R. C. Miller. New York: IFI/Plenum, 258p. (1982), ISBN: 0-306-6602-4.

Erratum: A Fundamental Equation of State for Heavy Water - P. G. Hill, R. D. Chris MacMillan, and V. Lee. J Phys Chem Ref Data 12, 1065(1983).

Erratum: Viscosity of Water Substance - New International Formulation and Its Background - A. Nagashima. J Phys Chem Ref Data 12, 403p. (1983).
Heavy Water, Thermophysical Properties - V. A. Kirillin, Ya. Z. Kazavchinskii, P. M. Kessel'man, S. L. Rivkin, A. E. Sheindlin, E. E. Shpil'rain, V. V. Sychev, and D. L. Timrot. Russian Transl. Springfield, VA: NTIS, 273p. (1971). TT 70-50094, A12.

International Tables of the Surface Tension of Water - N. B. Vargaftik, B. N. Volkov, and L. D. Voljak. J Phys Chem Ref Data 12, 817(1983).

Ion Product of Water Substance, $0-1000^{\circ} \mathrm{C}, 1-10,000$ Bars. New International Formulation and Its Background - William L. Marshall and E. U. Franck. J Phys Chem Ref Data 10, 295(1981).

Isochoric Heat Capacity of Water and Steam - M. P. Vukalovich, Kh. I. Amirkhanov, G. V. Stepanov, and B. G. Alibekov. Russian Transl. Springfield, VA: NTIS, 215p. (1974). TT 72-52002, A 10.

Microwave Spectra of Molecules of Astrophysical Interest, V. Water Vapor - Frank C. De Lucia, Paul Helminger, and William $\mathrm{H}$. Kirchhoff. J Phys Chem Ref Data 3, 211(1974).

Molecular Form Factors and Photon Coherent Scattering Cross Sections of Water - L. R. M. Morin. J Phys Chem Ref Data 11, 1091(1982).

NBS/NRC Steam Tables, Thermodynamic and Transport Properties and Computer Programs for Vapor and Liquid States of Water Lester Haar, John S. Gallagher, and George S. Kell. New York: Hemisphere Press, 320p. (1984).

Problems with the Prandtl Number of Steam - Jan V. Sengers, R. S. Basu, B. Kamgar-Parsi, and Joseph Kestin. Mech Eng 104, New York, NY, 60p. (1982).

Representative Equations for the Thermal Conductivity of Water Substance - Jan V. Sengers, J. T. R. Watson, R. S. Basu, B. KamgarParsi, and R. C. Hendricks. J Phys Chem Ref Data 13, 893(1984).

Representative Equations for the Viscosity of Water Substance Jan V. Sengers and B. Kamgar-Parsi. J Phys Chem Ref Data 13, 185(1984).

Saturation States of Heavy Water - P. G. Hill and R. D. Chris MacMillan. J Phys Chem Ref Data 9, 735(1980).

Static Dielectric Constant of Water and Steam - M. Uematsu and E. U. Franck. J Phys Chem Ref Data 9, 1291(1980).

Thermodynamic Properties of $\mathrm{D}_{2} \mathrm{O}$ in the Critical Region - B. Kamgar-Parsi, J. M. H. Levelt Sengers, and Jan V. Sengers. J Phys Chem Ref Data 12, 513(1983).

Thermodynamic Properties of Steam in the Critical Region - J. M. H. Levelt Sengers, B. Kamgar-Parsi, F. W. Balfour, and Jan V. Sengers. J Phys Chem Ref Data 12, 1(1983).

Thermophysical Properties of Fluid $\mathrm{H}_{2} \mathrm{O}$ - Joseph Kestin, Jan V. Sengers, B. Kamgar-Parsi, and J. M. H. Levelt Sengers. J Phys Chem Ref Data 13, 175(1984).

Thermophysical Properties of Fluid $\mathrm{D}_{2} \mathrm{O}$ - Joseph Kestin, Jan V. Sengers, B. Kamgar-Parsi, and J. M. H. Levelt Sengers. J Phys Chem Ref Data 13, 602(1984).

Transport Properties of Liquid and Gaseous $\mathrm{D}_{2} \mathrm{O}$ over a Wide Range of Temperature and Pressure - N. Matsunaga and A. Nagashima. J Phys Chem Ref Data 12, 933(1983).

Viscosity of Liquid Water in the Range $-8^{\circ} \mathrm{C}$ to $150^{\circ} \mathrm{C}$ - Joseph Kestin, Mordechai Sokolov, and William A. Wakeham. J Phys Chem Ref Data 7, 941(1978).

Viscosity of Water Substance - New International Formulation and Its Background - A. Nagashima. J Phys Chem Ref Data 6, 1133(1977). 


\section{Properties index}

\section{Absorption coefficient, spectral}

See: Transition probabilities for atoms and molecules Photon cross section

\section{Activation energies of chemical reactions}

See: Rate constants of chemical reactions

\section{Activity coefficients}

A Bibliography of Sources of Experimental Data Leading to Activity or Osmotic Coefficients for Polyvalent Electrolytes in Aqueous Solution - Robert N. Goldberg, Bert R. Staples, Ralph L. Nuttall, and R. Arbuckle. NBS Spec. Publ. 485, 57p. (1977).

A Report on Thermodynamic Data for Desulfurization Processes Vivian B. Parker, Bert R. Staples, Thomas L. Jobe, Jr., and David B. Neumann. NBSIR 81-2345, 89p. (1981).

Activity and Osmotic Coefficients of Aqueous Alkali Metal Nitrites - Bert R. Staples. J Phys Chem Ref Data 10, 765(1981).

Activity and Osmotic Coefficielsts of Aqueous Sulfuric Acid at 298.15 K - Bert R. Staples. J Phys Chem Ref Data 10, 779(1981).

Computer Programs for the Evaluation of Activity and Osmotic Coefficients - Bert R. Staples and Ralph L. Nuttall. NBS Tech. Note 928, 60p. (1976).

Evaluated Activity and Osmotic Coefficients for Aqueous Solutions: The Alkaline Earth Metal Halides - Robert N. Goldberg and Ralph L. Nuttall. J Phys Chem Ref Data 7, 263(1978).

Evaluated Activity and Osmotic Coefficients for Aqueous Solutions: Iron Chloride and the Bi-Univalent Compounds of Nickel and Cobalt - Robert N. Goldberg, Ralph L. Nuttall, and Bert R. Staples. J Phys Chem Ref Data 8, 923(1979).

Evaluated Activity and Osmotic Coefficients for Aqueous Solutions: Bi-Univalent Compounds of Lead, Copper, Manganese, and Uranium - Robert N. Goldberg. J Phys Chem Ref Data 8, 1005(1979).

Evaluated Activity and Osmotic Coefficients for Aqueous Solutions: Bi-Univalent Compounds of Zinc, Cadmium, and Ethylene Bis(Trimethylammonium) Chloride and Iodide - Robert N. Goldberg. J Phys Chem Ref Data 10, 1(1981).

Evaluated Activity and Osmotic Coefficients for Aqueous Solutions: Thirty-Six Uni-Bivalent Electrolytes - Robert N. Goldberg. J Phys Chem Ref Data 10, 671(1981).

Osmotic Coefficients and Mean Activity Coefficients of UniUnivalent Electrolytes in Water at $25^{\circ} \mathrm{C}-$ Walter J. Hamer and Yung-Chi Wu. J Phys Chem Ref Data 1, 1047(1972).

Revised Values of the Osmotic Coefficients and Mean Activity Coefficients of Sodium Nitrate in Water at $25^{\circ} \mathrm{C}$ (Comments) - Yung-Chi Wu and Walter J. Hamer. J Phys Chem Ref Data 9, 513(1980).

The Activity and Osmotic Coefficients of Aqueous Calcium Chloride at 298.15 K - Bert R. Staples and Ralph L. Nuttall. J Phys Chem Ref Data 6, 385(1977).

Theoretical Mean Activity Coefficients of Strong Electrolytes in Aqueous Solutions from 0 to $100^{\circ} \mathrm{C}$ - Walter J. Hamer. NSRDS-NBS 24, 271p. (1968).

Thermodynamic Properties of Aqueous Sodium Chloride Solutions - Kenneth S. Pitzer, J. Christopher Peiper, and R. H. Busey. J Phys Chem Ref Data 13, 1(1984).

\section{Appearance potentiais}

A Bibliography on Ion-Molecule Reactions. January 1900 to March 1966 - F. N. Harllee, Henry M. Rosenstock, and John T. Herron. NBS Tech. Note 291, 40p. (1966).

Energetics of Gaseous Ions - Henry M. Rosenstock, Keith Draxl, B. W. Steiner, and John T. Herron. J Phys Chem Ref Data 6, Suppl. 1(1977).

Ion Energetics Measurements, Supplement I. 1971-1973 - Henry M. Rosenstock, D. Sims, S. S. Schroyer, and W. J. Webb. NSRDS-NBS 66, 380p. (1980).
Ionization Potentials, Appearance Potentials, and Heats of Formation of Gaseous Positive Ions - Joseph L. Franklin, J. G. Dillard, Henry M. Rosenstock, John T. Herron, Keith Draxl, and Frank H. Field. NSRDS-NBS 26, 289p. (1969).

Ionization Potential and Appearance Potential Measurements, 1971-1981 - Rhoda D. Levin and Sharon G. Lias. NSRDS-NBS 71, 634p. (1982).

\section{Atomic energy leveis and spectra}

A Critical Review of the Stark Widths and Shifts of Spectral Lines from Non-Hydrogenic Atoms - N. Konjević and J. R. Roberts. J Phys Chem Ref Data 5, 209(1976).

A Multiplet Table of Astrophysical Interest, Revised Edition, Part I. Table of Multiplets, Part II. Finding List of All Lines in the Table of Multiplets - Charlotte E. Moore. NSRDS-NBS 40, 261p. (1972).

An Ultraviolet Multiplet Table, Section 1. The Spectra of Hydrogen through Vanadium - Charlotte E. Moore. NBS Circular 488, 78p. (1950).

An Ultraviolet Multiplet Table, Section 2. The Spectra of Chromium through Niobium - Charlotte E. Moore. NBS Circular 488, 115p. (1952).

An Ultraviolet Multiplet Table, Section 3. The Spectra of Molybdenum to Lanthanum and Hafnium to Radium - Charlotte E. Moore. NBS Circular 488, 94p. (1962).

An Ultraviolet Multiplet Table, Section 4. Finding List for Spectra of the Elements Hydrogen to Niobium ( $\mathrm{Z}=1$ to 41$)$ - Charlotte E. Moore. NBS Circular 488, 65p. (1962).

An Ultraviolet Multiplet Table, Section 5. Finding List for Spectra of the Elements Molybdenum to Lanthanum ( $Z=42$ to 57 ), Hafnium to Radium ( $Z=72$ to 88$)$ - Charlotte E. Moore. NBS Circular 488, 30p. (1962).

Atomic Energy Levels as Derived from the Analyses of Optical Spectra, Volume I. ' $\mathrm{H}$ to ${ }^{23} \mathrm{~V}$ - Charlotte E. Moore. NSRDS-NBS 35, 358p. (1971).

Atomic Energy Levels as Derived from the Analyses of Optical Spectra, Volume II. ${ }^{24} \mathrm{Cr}$ to ${ }^{41} \mathrm{Nb}$ - Charlotte E. Moore. NSRDS-NBS 35, 263p. (1971).

Atomic Energy Levels as Derived from the Analysis of Optical Spectra, Volume III. ${ }^{42} \mathrm{Mo}$ to ${ }^{57} \mathrm{La},{ }^{12} \mathrm{Hf}$ to ${ }^{89} \mathrm{Ac}$ - Charlotte E. Moore. NSRDS-NBS 35, 289p. (1971).

Atomic Energy Levels - The Rare-Earth Elements, the Spectra of La, Ce, Pr, Nd, Pm, Sm, Eu, Gd, Tb, Dy, Ho, Er, Tm, Yb, Lu William C. Martin, Romuald Zalubas, and Lucy Hagan. NSRDS-NBS 60, 422p. (1978).

Bibliography on the Analyses of Optical Atomic Spectra. Section 1. ${ }^{1} \mathrm{H}^{23} \mathrm{~V}$ - Charlotte E. Moore. NBS Spec. Publ. 306, 80p. (1968).

Bibliography on the Analyses of Optical Atomic Spectra. Section 2. ${ }^{24} \mathrm{Cr}^{-41} \mathrm{Nb}$ - Charlotte E. Moore. NBS Spec, Publ. 306, 57p. (1969).

Bibliography on the Analyses of Optical Atomic Spectra. Section 3. ${ }^{42} \mathrm{Mo}-{ }^{57} \mathrm{La}$ and ${ }^{72} \mathrm{Hf}-{ }^{89} \mathrm{Ac}$ - Charlotte E. Moore. NBS Spec. Publ. 306, 37p. (1969)

Bibliography on the Analyses of Optical Atomic Spectra. Section 4. ${ }^{57} \mathrm{La}-{ }^{71} \mathrm{Lu}$ and ${ }^{89} \mathrm{Ac}-{ }^{99} \mathrm{Es}$ - Charlotte E. Moore. NBS Spec. Publ. 306, 48p. (1969).

Bibliography on Atomic Energy Levels and Spectra, July 1968 through June 1971 - Lucy Hagan and William C. Martin. NBS Spec. Publ. 363, 109p. (1972).

Bibliography on Atomic Energy Levels and Spectra, July 1971 through June 1975 - Lucy Hagan. NBS Spec. Publ. 363, Suppl. 1(1977).

Bibliography on Atomic Energy Levels and Spectra, July 1975 through June 1979 - Romuald Zalubas and Arlene Albright. NBS Spec. Publ. 363, Suppl. 2(1980).

Bibliography on Atomic Line Shapes and Shifts (1899 through March 1972) - Jeffrey R. Fuhr, Wolfgang L. Wiese, and Larry J. Roszman. NBS Spec. Publ. 366, 165 p. (1974). 
Bibliography on Atomic Line Shapes and Shifts (April 1972 through June 1973) - Jeffrey R. Fuhr, Larry J. Roszman, and Wolfgang L. Wiese. NBS Spec. Publ. 366, Supp1. 1(1974).

Bibliography on Atomic Line Shapes and Shifts (July 1973 through May 1975) - Jeffrey R. Fuhr, Georgia A. Martin, and Beverly J. Specht. NBS Spec. Publ. 366, Suppl. 2(1975).

Bibliography on Atomic Line Shapes and Shifts (June 1975 through June 1978) - Jeffrey R. Fuhr, Beverly J. Miller, and Georgia A. Martin. NBS Spec. Publ. 366, Suppl. 3(1978).

Binding Energies in Atomic Negative Ions - H. Hotop and W. C. Lineberger. J Phys Chem Ref Data 4, 539(1975).

Energy Levels of Neutral Helium $\left({ }^{4} \mathrm{He}\right.$ I) - William C. Martin. J Phys Chem Ref Data 2, 257(1973).

Energy Levels of Iron, Fe I through Fe XXVI - Joseph Reader and Jack Sugar. J Phys Chem Ref Data 4, 353(1975).

Energy Levels of Chromium, Cr I through Cr XXIV - Jack Sugar and Charles H. Corliss. J Phys Chem Ref Data ú, 317(1977).

Energy Levels of One-Electron Atoms - Glen W. Erickson. J Phys Chem Ref Data 6, 831(1977).

Energy Levels of Manganese, Mn I through Mn XXV - Charles $\mathrm{H}$. Corliss and Jack Sugar. J Phys Chem Ref Data 6, 1253(1977).

Energy Levels of Vanadium, V I through V XXIII - Jack Sugar and Charles H. Corliss. J Phys Chem Ref Data 7, 1191(1978).

Energy Levels of Titanium, Ti I through Ti XXII - Charles $\mathrm{H}$. Corliss and Jack Sugar. J Phys Chem Ref Data 8, 1(1979).

Energy levels of Aluminum, Al I through Al XIII - William C.

Martin and Romuald Zalubas. J Phys Chem Reî Data 8, 817(1979).

Energy Levels of Calcium, Ca I through Ca XX - Jack Sugar and

Charles H. Corliss. J Phys Chem Ref Data 8, 865(1979).

Energy Levels of Potassium, K I through K XIX -- Charles H.

Corliss and Jack Sugar. J Phys Chem Ref Data 8, 1109(1979).

Energy Levels of Magnesium, Mg I through Mg XII - William C.

Martin and Romuald Zalubas. J Phys Chem Ref Data 9, 1(1980).

Energy Levels of Scandium, Sc I through Sc XXI — Jack Sugar and

Charles H. Corliss. J Phys Chem Ref Data 9, 473(1980).

Energy Levels of Sodium, Na I through Na XI - William C. Martin and Romuald Zalubas. J Phys Chem Ref Data 10, 153(1981).

Energy Levels of Nickel, Ni I through Ni XXVIII - Charles H.

Corliss and Jack Sugar. J Phys Chem Ref Data 10, 197(1981).

Energy Levels of Cobalt, Co I through Co XXVII - Jack Sugar and Charles H. Corliss. J Phys Chem Ref Data 10, 1097(1981).

Energy Levels of Iron, Fe I through Fe XXVI - Charles H. Corliss and Jack Sugar. J Phys Chem Ref Data 11, 135(1982).

Energy Levels of Silicon, Si I through Si XIV - William C. Martin and Romuald Zalubas. J Phys Chem Ref Data 12, 323(1983).

Experimental Stark Widths and Shifts for Non-Hydrogenic Spectral Lines of Ionized Atoms (A Critical Review and Tabulation of Selected Data) - N. Konjević and Wolfgang L. Wiese. J Phys Chem Ref Data 5, 259(1976).

Experimental Stark Widths and Shifts for Spectral Lines of Neutral Atoms (A Critical Review of Selected Data for the Period 1976 to 1982)

- N. Konjević, M. S. Dimitrijević, and Wolfgang L. Wiese. J Phys Chem Ref Data 13, 619(1984).

Experimental Stark Widths and Shifts for Spectral Lines of Positive Ions (A Critical Review and Tabulation of Selected Data for the Period 1976 to 1982) - N. Konjević, M. S. Dimitrijević, and Wolfgang L. Wiese. J Phys Chem Ref Data 13, 649(1984).

First Spectra of Neon, Argon, and Xenon 136 in the 1.2-4.0 $\mu \mathrm{m}$

Region - Curtis J. Humphreys. J Phys Chem Ref Data 2, 519(1973).

Ground Levels and Ionization Potentials for Lanthanide and Actinide Atoms and Ions - William C. Martin, Lucy Hagan, Joseph Reader, and Jack Sugar. J Phys Chem Ref Data 3, 771(1974).

Ionization Potentials and Ionization Limits Derived from the Analyses of Optical Spectra - Charlotte E. Moore. NSRDS-NBS 34, 22p. (1970).

Partial Grotrian Diagrams of Astrophysical Interest - Charlotte E. Moore and Paul W. Merrill. NSRDS-NBS 23, 65p. (1968).
Recommended Atomic Electron Binding Energies, 1s to $6 \mathrm{p}_{3 / 2}$, for the Heavy Elements, $Z=84$ to $103-F$. T. Porter and M. S. Freedman. J Phys Chem Ref Data 7, 1267(1978).

Reference Wavelengths from Atomic Spectra in the Range $5 \AA$ to $25000 \AA$ - Victor Kaufman and Bengt Edlén. J Phys Chem Ref Data 3, 825(1974).

Resonances in Electron Impact on Atoms and Diatomic Molecules - George J. Schulz. NSRDS-NBS 50, 120p. (1973).

Selected Tables of Atomic Spectra: A. Atomic Energy Levels - Second Edition; B. Multiplet Tables; Si II, Si III, Si IV - Charlotte E. Moore. NSRDS-NBS 3, 35p. (1965).

Selected Tables of Atomic Spectra: A. Atomic Energy Levels - Second Edition: B. Multiplet Tables; Si I - Charlotte E. Moore. NSRDSNBS 3, 22p. (1967).

Selected Tables of Atomic Spectra: A. Atomic Energy Levels - Second Edition; B. Multiplet Tables; C I, C II, C III - Charlotte E. Moore. NSRDS-NBS 3, 73p. (1970).

Selected Tables of Atomic Spectra: A. Atomic Energy Levels - Second Edition; B. Multiplet Tables; N IV, N V, N VI, N VII — Charlotte E. Moore. NSRDS-NBS 3, 46p. (1971).

Selected Tables of Atomic Spectra: A. Atomic Energy Levels - Second Edition; B. Multiplet Tables; N I, N II, N III - Charlotte E. Moore. NSRDS-NBS 3, 80p. (1975).

Selected Tables oî Atomic Spectra: A. Atomic Energy Levels - Second Edition; B. Multiplet Tables; H I, D, T - Charlotte E. Moore. NSRDS-NBS 3, 32p. (1972).

Selected Tables of Atomic Spectra: A. Atomic Energy Levels - Second Edition; B. Multiplet Tables; O I - Charlotte E. Moore. NSRDSNBS 3, 33p. (1976).

Selected Tables of Atomic Spectra: A. Atomic Energy Levels - Second Edition; B. Multiplet Tables; O VI, O VII , O VIII - Charlotte E. Moore. NSRDS-NBS 3, 31p. (1979).

Selected Tables of Atomic Spectra: A. Atomic Energy Levels - Second Edition; B. Multiplet Tables; O V - Charlotte E. Moore. NSRDSNBS 3, 21p. (1980).

Selected Tables of Atomic Spectra: A. Atomic Energy levels - Second Edition; B. Multiplet Tables; O IV - Charlotte E. Moore. NSRDS-NBS 3, 21p. (1983).

Selected Tables of Atomic Spectra: A. Atomic Energy Levels -f Second Edition; B. Multiplet Tables; O III - Charlotte E. Moore. NSRDS-NBS 3, ...p. (1985).

Soft X-Ray Emission Spectra of Metallic Solids: Critical Review of Selected Systems and Annotated Spectral Index - Archie J. McAlister, Ronald C. Dobbyn, John R. Cuthill, and M. L. Williams. NBS Spec. Publ. 369, 180p. (1974).

Tables of Line Spectra of the Elements, Part 1. Wavelengths and Intensities, Part 2. Transition Probabilities - Joseph Reader, Charles H. Corliss, Wolfgang L. Wiese, and Georgia A. Martin. NSRDS-NBS 68, 415p. (1980).

Tables of Atomic Spectral Lines for the $10000 \AA$ to $40000 \AA$ Region - Michael Outred. J Phys Chem Ref Data 7, 1(1978).

The First Spectrum of Hafnium (Hf I) - William F. Meggers and Charlotte E. Moore. NBS Monograph 153, 123p. (1976).

The Spectrum and Energy Levels of the Neutral Atom of Boron (B I) - G. A. Odintzova and A. R. Striganov. J Phys Chem Ref Data 8, 63(1979).

X-Ray Wavelengths and X-Ray Atomic Energy Levels - Joyce A.. Bearden and A. F. Burr. NSRDS-NBS 14, 66p. (1967).

\section{Atomic form factor}

Atomic Form Factors, Incoherent Scattering Functions, and Photon Scattering Cross Sections - John H. Hubbell, W. J. Veigele, E. A. Briggs, R. T. Brown, D. T. Cromer, and R. J. Howerton. J Phys Chem Ref Data 4, 471(1975).

Molecular Form Factors and Photon Coherent Scattering Cross Sections of Water - L. R. M. Morin. J Phys Chem Ref Data 11, 1091(1982).

Small-Angle Rayleigh Scattering of Photons at High Energies: Tabulations of Relativisitic HFS Modified Atomic Form Factors - D 
S̀chaupp, M. Schumacher, F. Smend, P. Rullhusen, and John H. Hubbell. J Phys Chem Ref Data 12, 467(1983).

\section{Atomic weight}

Isotopic Abundances and Atomic Weights of the Elements - Paul De Bièvre, Marc Gallet, Norman E. Holden, and I. Lynus Barnes. J Phys Chem Ref Data 13, 809(1984).

\section{Attenuation coefficients for $\mathrm{x}$-rays and gamma rays}

Comparison of Theoretical and Experimental Photoeffect Data, 0.1 $\mathrm{keV}$ to $1.5 \mathrm{MeV}$ - John H. Hubbell and W. J. Veigele. NBS Tech. Note 901, 47p. (1976).

Molecular Form Factors and Photon Coherent Scattering Cross Sections of Water - L. R. M. Morin. J Phys Chem Ref Data 11, 1091(1982).

Photon Cross Sections, Attenuation Coefficients, and Energy Absorption Coefficients from $10 \mathrm{keV}$ to $100 \mathrm{GeV}$ - John H. Hubbell. NSRDS-NBS 29, 85p. (1969).

\section{Band gap}

See: Energy bands of solids

\section{Band spectra}

See: Electronic molecular spectra

\section{Binding energy}

See: Atomic energy levels and spectra Bond dissociation energy

\section{Boiling point}

A Critical Review of Henry's Law Constants for Chemicals of Environmental Interest - Donald Mackay and Wan Ying Shiu. J Phys Chem Ref Data 10, 1175(1981).

Definition of Recommended Values of Certain Thermodynamic Properties for the Ketones - Buford D. Smith and Ol Muthu. NBSIR 84-2811, 162p. (1983).

High Temperature Properties and Decomposition of Inorganic Salts, Part 1. Sulfates - Kurt H. Stern and E. L. Weise. NSRDS-NBS 7, 38p. (1966).

JANAF Thermochemical Tables, Second Edition - Daniel R. Stull and H. Prophet. NSRDS-NBS 37, 1141 p. (1971).

JANAF Thermochemical Tables, 1974 Supplement - Malcolm W. Chase, Jr., J. L. Curnutt, A. T. Hu, H. Prophet, A. N. Syverud, and L. C. Walker. J Phys Chem Ref Data 3, 311(1974).

JANAF Thermochemical Tables, 1975 Supplement - Malcolm W. Chase, Jr., J. L. Curnutt, H. Prophet, R. A. McDonald, and A. N. Syverud. J Phys Chem Ref Data 4, 1(1975).

JANAF Thermochemical Tables, 1978 Supplement - Malcolm W. Chase, Jr., J. L. Curnutt, R. A. McDonald, and A. N. Syverud. J Phys Chem Ref Data 7, 793(1978).

JANAF Thermochemical Tables, 1982 Supplement - Malcolm W. Chase, Jr., J. L. Curnutt, J. R. Downey, Jr., R. A. McDonald, A. N. Syverud, and E. A. Valenzuela. J Phys Chem Ref Data 11, 695(1982).

Physical and Thermodynamic Properties of Aliphatic Alcohols Randolph C. Wilhoit and Bruno J. Zwolinski. J Phys Chem Ref Data 2, Suppl. 1(1973).

Thermodynamic and Thermophysical Properties of Combustion Products, Volume III. Oxygen- and Air-Based Propellant - V. P. Glushko, V. E. Alemasov, A. F. Dregalin, A. P. Tishin, V. A. Khudyakov, and V. N. Kostin. Russian Transl., Springfield, VA: NTIS, 648p. (1975). TT 75-50007, A26.

Vapor Pressures and Boiling Points of Selected Halomethanes Arvind P. Kudchadker, Shanti A. Kudchadker, R. P. Shukla, and P. R. Patnaik. J Phys Chem Ref Data 8, 499(1979).
Bond dissociation energy (see also Thermodynamic properties)

Bond Dissociation Energies in Simple Molecules - B. DeB. Darwent. NSRDS-NBS 31, 48p. (1970).

Compendium of $a b$ initio Calculations of Molecular Energies and Properties - Morris Krauss. NBS Tech. Note 438, 139p. (1967).

The Band Spectrum of Carbon Monoxide - Paul H. Krupenie. NSRDS-NBS 5, 87p. (1966).

The Spectrum of Molecular Oxygen - Paul H. Krupenie. J Phys Chem Ref Data 1, 423(1972).

The Spectrum of Molecular Nitrogen - Alf Lofthus and Paul H. Krupenie. J Phys Chem Ref Data 6, $113(1977)$.

Thermochemical Data for Gaseous Monoxides - J. B. Pedley and E. M. Marshall. J Phys Chem Ref Data 12, 967(1983).

\section{Bulk modulus}

See: Elastic constants

\section{Cell constants}

See: Lattice constants

\section{Charge exchange cross section}

Evaluated Theoretical Cross Section Data for Charge Exchange of Multiply Charged Ions with Atoms. I. Hydrogen Atom-Fully Stripped Ion Systems - R. K. Janev, B. H. Bransden, and Jean W. Gallagher. J Phys Chem Ref Data 12, 829(1983).

Evaluated Theoretical Cross Section Data for Charge Exchange of Multiply Charged Ions with Atoms. II. Hydrogen Atom-Partially Stripped Ions Systems - Jean W. Gallagher, B. H. Bransden, and R. K. Janev. J Phys Chem Ref Data 12, 873(1983).

Evaluated Theoretical Cross Section Data for Charge Exchange of Multiply Charged Ion with Atoms. III. Non-Hydrogenic Target Atoms - R. K. Janev and Jean W. Gallagher. J Phys Chem Ref Data 13, 1199(1984)

\section{Combustion, heat of}

See: Thermodynamic properties Heat of combustion

\section{Compressibility factor}

See: Equation of state

\section{Compton scattering cross section}

Atomic Form Factors, Incoherent Scattering Functions, and Photon Scattering Cross Sections - John H. Hubbell, W. J. Veigele, E. A Briggs, R. T. Brown, D. T. Cromer, and R. J. Howerton. J Phys Chem Ref Data 4, 471(1975).

Comparison of Theoretical and Experimental Photoeffect Data, 0.1 $\mathrm{keV}$ to $1.5 \mathrm{MeV}$ - John H. Hubbell and W. J. Veigele. NBS Tech. Note 901, 47p. (1976).

Photon Cross Sections, Attenuation Coefficients, and Energy Absorption Coefficients from $10 \mathrm{keV}$ to $100 \mathrm{GeV}$ - John H. Hubbell. NSRDS-NBS 29, 85p. (1969).

\section{Conductance}

See: Electrical conductance

Conductivity, electrical

See: Electrical resistivity

Conductivity, thermal

See: Thermal conductivity 


\section{Consolute point}

An Analysis of Coexistence Curve Data for Several Binary Liquid Mixtures Near Their Critical Points - A. Stein and G. F. Allen. J Phys Chem Ref Data 2, 439(1973).

\section{Corrosion rate}

Critical Surveys of Data Sources: Corrosion of Metals - Ronald Diegle and Walter K. Boyd. NBS Spec. Publ. 396, 42p. (1976).

\section{Critical micelle concentration}

Critical Micelle Concentrations of Aqueous Surfactant Systems Pasupati Mukerjee and Karol J. Mysels. NSRDS-NBS 36, 222p. (1971).

\section{Critical supersaturation ratio}

Selected Values of Critical Supersaturation for Nucleation of Liquids from the Vapor - G. M. Pound. J Phys Chem Ref Data 1, 119(1972).

\section{Critical temperature, pressure (see also Equation of state)}

An Analysis of Coexistence Curve Data for Several Binary Liquid Mixtures Near Their Critical Points - A. Stein and G. F. Allen. J Phys Chem Ref Data 2, 439(1973).

Analysis of Specific Heat Data in the Critical Region of Magnetic Solids - F. J. Cook. J Phys Chem Ref Data 2, i1(1973).

Definition of Recommended Values of Certain Thermodynamic Properties for the Ketones - Buford D. Smith and O1 Muthu. NBSIR 84-2811, 162p. (1983).

Heavy Water, Thermophysical Properties - V. A. Kirillin, Ya. Z. Kazavchinskii, P. M. Kessel'man, S. L. Rivkin, A. E. Sheindlin, E. E. Shpil'rain, V. V. Sychev, and D. L. Timrot. Russian Transl., Springfield, VA: NTIS, 273p. (1971). TT 70-50094, A12.

Properties of Selected Superconductive Materials, 1978 Supplement - Benjamin W. Roberts. NBS Tech. Note 983, 103p. (1978).

Scaled Equation of State Parameters for Gases in the Critical Region - J. M. H. Levelt Sengers, W. L. Greer, and Jan V. Sengers. J Phys Chem Ref Data 5, 1(1976).

Thermophysical Properties of Gaseous and Liquid Methane - V. A. Zagoruchenko and A. M. Zhuravlev. Russian Transl. Springfield, VA: NTIS, 251p. (1970). TT 70-50097, A12.

Thermodynamic Properties of Steam in the Critical Region - J. M. H. Levelt Sengers, B. Kamgar-Parsi, F. W. Balfour, and Jan V. Sengers. J Phys Chem Ref Data 12, 1(1983).

Thermodynamic Properties of $\mathrm{D}_{2} \mathrm{O}$ in the Critical Region - B. Kamgar-Parsi, J. M. H. Levelt Sengers, and Jan V. Sengers. J Phys Chem Ref Data 12, 513(1983).

\section{Cross section}

See: Charge exchange cross section

Electron collision cross section

Photon cross section

Rayleigh scattering cross section

\section{Crystal structure}

Behavior of the Elements at High Pressures - John Francis Cannon. J Phys Chem Ref Data 3, 781(1974).

Behavior of the AB-Type Compounds at High Pressures and High Temperatures - Leo Merrill. J Phys Chem Ref Data 6, 1205(1977).

Behavior of the $\mathrm{AB}_{2}$-Type Compounds at High Pressures and High Temperatures - Leo Merrill. J Phys Chem Ref Data 11, 1005(1982).

Crystal Structure Transformations in Binary Halides - C. N. R. Rao and M. Natarajan. NSRDS-NBS 41, 57p. (1972).

Crystal Structure Transformations in Inorganic Nitrites, Nitrates, and Carbonates - C. N. R. Rao, Brahm Prakash, and M. Natarajan. NSRDS-NBS 53, 55p. (1975).
Crystal Structure Transformations in Inorganic Sulfates, Phosphates, Perchlorates, and Chromates - C. N. R. Rao and Brahm Prakash. NSRDS-NBS 56, 37p. (1975).

Crystal Data Determinative Tables, Third Edition Volume 1: Organic Compounds - Joseph D. H. Donnay and Helen M. Ondik., Swarthmore, PA: JCPDS-International Center for Diffraction Data, 855p. (1972).

Crystal Data Determinative Tables, Third Edition Volume 2: Inorganic Compounds - Joseph D. H. Donnay and Helen M. Ondik., Swarthmore, PA: JCPDS-International Center for Diffraction Data, 1748p. (1973).

Crystal Data Determinative Tables, Third Edition Volume 3. Organic Compounds - Joseph D. H. Donnay, Olga Kennard, David G. Watson, and John R. Rodgers., Swarthmore, PA: JCPDS-International Center for Diffraction Data, 748p. (1978).

Crystal Data Determinative Tables, Third Edition Volume 4. Inorganic Compounds - Joseph D. H. Donnay, Helen M. Ondik, and Alan D. Mighell., Swarthmore, PA: JCPDS-International Center for Diffraction Data, 1308p. (1978).

Crystal Data Determinative Tables, Third Edition, Volume 5. Organic Compounds - Olga Kennard, David G. Watson, John E. Davies, John R. Rodgers, editor(s). 5, Swarthmore, PA, JCPDS-International Center for Diffraction Data,(1983).

Crystal Data Determinative Tables, Third Edition, Volume 6. Organic Compounds - Olga Kennard, David G. Watson, John E. Davies, editor(s). 6, Swarthmore, PA, JCPDS-International Center for Diffraction Data,(1983).

Crystal Data Space-Group Tables - Alan D. Mighell, Helen M. Ondik, and Bettijoyce Breen Molino. J Phys Chem Ref Data 6, 675(1977).

Electronic Absorption and Internal and External Vibrational Data of Atomic and Molecular Ions Doped in Alkali Halide Crystals - Suresh C. Jain, A. V. R. Warrier, and Suresh K. Agarwal. NSRDS-NBS 52, 55p. (1974).

Handbook of Phase Diagrams of Silicate Systems, Vol. I. Binary Systems, Second Revised Edition - N. A. Toropov, V. P. Barzakovskii, V. V. Lapin, N. N. Kurtseva, J. Schmorak, editor(s). Russian Transl., Springfield, VA: NTIS, 730p. (1970). TT 71-50040, A26.

Handbook of Phase Diagrams of Silicate Systems, Vol. II. MetalOxygen Compounds in Silicate Systems, Second Revised Edition - N. A. Toropov, V. P. Barzakovskii, I. A. Bondar', and Yu. P. Udalov. Russian Transl., Springfield, VA: NTIS, 329p. (1972). TT 71-50041, A.15.

NBS Crystal Data Identification File NBS Standard Reference Database 3, Washington, D.C.; NBS, Office of Standard Reference Data,(updated periodically). Lease agreements obtained from JCPDS 1601 Park Ln Swarthmore PA (215)328-9400.

NBS* AIDS80: A FORTRAN Program for Crystallographic Data Evaluation - Alan D. Mighell, C. R. Hubbard, and Judy K. Stalick. NBS Tech. Note 1141, 54p. (1981).

Properties of Selected Superconductive Materials, 1978 Supplement - Benjamin W. Roberts. NBS Tech. Note 983, 103p. (1978).

Space Groups and Lattice Complexes - W. Fisher, Hans Burzlaff, Erwin Hellner, and Joseph D. H. Donnay. NBS Monograph 134, 177p. (1973).

Transition Metal Oxides, Crystal Chemistry, Phase Transition, and Related Aspects - C. N. R. Rao and G. V. Subba Rao. NSRDS-NBS 49, 140p. (1974).

\section{Debye characteristic temperature}

Critical Analysis of the Heat-Capacity Data of the Literature and Evaluation of Thermodynamic Properties of Copper, Silver, and Gold from 0 to $300 \mathrm{~K}-$ George T. Furukawa, W. G. Saba, and Martin L. Reilly. NSRDS-NBS 18, 49p. (1968).

Critical Analysis of Heat-Capacity Data and Evaluation of Thermodynamic Properties of $\mathrm{Ru}, \mathrm{Ph}, \mathrm{Pd}$, Ir, and $\mathrm{Pt}$ from 0 to $300 \mathrm{~K}$. A Survey of the Literature Data on Osmium - George T. Furukawa, Martin L. Reilly, and John S. Gallagher. J Phys Chem Ref Data 3, 163(1974). 
Elastic Properties of Metals and Alloys, I. Iron, Nickel, and IronNickel Alloys - Hassell M. Ledbetter and R. P. Reed. J Phys Chem Ref Data 2, 531(1973).

Survey of Superconductive Materials and Critical Evaluation of Selected Properties - Benjamin W. Roberts. J Phys Chem Ref Data 5, 581(1976).

\section{Density}

A Computer Program for the Prediction of Viscosity and Thermal Conductivity in Hydrocarbon Mixtures - James F. Ely and Howard J. M. Hanley. NBS Tech. Note 1039, 83p. (1981).

A Review, Evaluation, and Correlation of the Phase Equilibria, Heat of Mixing, and Change in Volume on Mixing for Liquid Mixtures of Methane + Ethane - M. J. Hiza, R. C. Miller, and Arthur J. Kidnay. J Phys Chem Ref Data 8, 799(1979).

A Review, Evaluation, and Correlation of the Phase Equilibria, Heat of Mixing, and Change in Volume on Mixing for Liquid Mixtures of Methane + Propane - R. C. Miller, Arthur J. Kidnay, and M. J. Hiza. J Phys Chem Ref Data 9, 721(1980).

Critical Evaluation of Vapor-Liquid Equilibrium, Heat of Mixing, and Volume Change of Mixing Data. General Procedures - Buford D. Smith, Ol Muthu, Ashok Dewan, and Matthew Gierlach. J Phys Chem Ref Data 11, 941(1982).

Crystal Data Determinative Tables, Third Edition Volume 1: Organic Compounds - Joseph D. H. Donnay and Helen M. Ondik., Swarthmore, PA: JCPDS-International Center for Diffraction Data, 855p. (1972).

Crystal Data Determinative Tables, Third Edition Volume 2: Inorganic Compounds - Joseph D. H. Donnay and Helen M. Ondik., Swarthmore, PA: JCPDS-International Center for Diffraction Data, 1748p. (1973).

Crystal Data Determinative Tables, Third Edition Volume 3. Organic Compounds - Joseph D. H. Donnay, Olga Kennard, David G. Watson, and John R. Rodgers., Swarthmore, PA: JCPDS-International Center for Diffraction Data, 748p. (1978).

Crystal Data Determinative Tables, Third Edition Volume 4. Inorganic Compounds - Joseph D. H. Donnay, Helen M. Ondik, and Alan D. Mighell., Swarthmore, PA: JCPDS-International Center for Diffraction Data, 1308p. (1978).

Crystal Data Determinative Tables, Third Edition, Volume 5. Organic Compounds - Olga Kennard, David G. Watson, John E. Davies, John R. Rodgers, editor(s). 5, Swarthmore, PA, JCPDS-International Center for Diffraction Data,(1983).

Crystal Data Determinative Tables, Third Edition, Volume 6. Organic Compounds - Olga Kennard, David G. Watson, John E. Davies, editor(s). 6, Swarthmore, PA, JCPDS-International Center for Diffraction Data,(1983).

Definition of Recommended Values of Certain Thermodynamic Properties for the Ketones - Buford D. Smith and Ol Muthu. NBSIR 84-2811, 162p. (1983).

Densities of Liquid $\mathrm{CH}_{4-\mathrm{a}} \mathrm{X}_{\mathrm{a}}(\mathrm{X}=\mathrm{Br}, \mathrm{I})$ and $\mathrm{CH}_{4-(\mathrm{a}+\mathrm{b}+\mathrm{c}+\mathrm{d})} \mathrm{F}_{\mathrm{a}} \mathrm{Cl}_{\mathrm{b}} \mathrm{Br}_{\mathrm{c}} \mathrm{I}_{\mathrm{d}}$ Halomethanes - Arvind P. Kudchadker, Shanti A. Kudchadker, P. R. Patnaik, and P. P. Mishra. J Phys Chem Ref Data 7, 425(1978).

Effects of Isotopic Composition, Temperature, Pressure, and Dissolved Gases on the Density of Liquid Water - George S. Kell. J Phys Chem Ref Data 6, 1109(1977).

Electrolytic Conductance and the Conductances of the Halogen Acids in Water - Walter J. Hamer and H. J. DeWane. NSRDS-NBS 33, 37p. (1970).

Equilibrium Properties of Fluid Mixtures, A Bibliography on Fluids of Cryogenic Interest - M. J. Hiza, Arthur J. Kidnay, and R. C. Miller., New York: IFI/Plenum, 166p. (1975), ISBN: 0-306-6601-6.

Equilibrium Properties of Fluid Mixtures, 2. A Bibliography of Experimental Data on Selected Fluids - M. J. Hiza, Arthur J. Kidnay, and R. C. Miller., New York: IFI/Plenum, 258p. (1982), ISBN: 0-306-6602-4.

Erratum: Viscosity of Water Substance - New International Formulation and Its Background - A. Nagashima. J Phys Chem Ref Data 12, 403p. (1983).
Evaluation of Binary Excess Volume Data for $\mathrm{C}_{6}$ Hydrocarbons. Benzene + Cyclohexane - Buford D. Smith, Ol Muthu, Ashok Dewan, and Matthew Gierlach. J Phys Chem Ref Data 11, 1151(1982).

Evaluation of Binary Excess Volume Data for $\mathrm{C}_{6}$ Hydrocarbons. Benzene + Hexane - Buford D. Smith, Ol Muthu, and Ashok Dewan. J Phys Chem Ref Data 12, 395(1983).

Heat Capacity and Other Thermodynamic Properties of Linear Macromolecules. III. Polyoxides - Umesh Gaur and Bernhard Wunderlich. J Phys Chem Ref Data 10, 1001(1981).

Heat Capacity and Other Thermodynamic Properties of Linear Macromolecules. IV. Polypropylene - Umesh Gaur and Bernhard Wunderlich. J Phys Chem Ref Data 10, 1051(1981).

Heavy Water, Thermophysical Properties - V. A. Kirillin, Ya. Z Kazavchinskii, P. M. Kessel'man, S. L. Rivkin, A. E. Sheindlin, E. E. Shpil'rain, V. V. Sychev, and D. L. Timrot. Russian Transl., Springfield, VA: NTIS, 273p. (1971). TT 70-50094, A12.

High Temperature Properties and Decomposition of Inorganic Salts, Part 1. Sulfates - Kurt H. Stern and E. L. Weise. NSRDS-NBS 7, 38p. (1966).

High Temperature Properties and Decomposition of Inorganic Salts, Part 2. Carbonates - Kurt H. Stern and E. L. Weise. NSRDS-NBS 30, 27p. (1969).

High Temperature Properties and Decomposition of Inorganic Salts, Part 3. Nitrates and Nitrites - Kurt H. Stern. J Phys Chem Ref Data 1, 747(1972).

High Temperature Properties and Decomposition of Inorganic Salts, Part 4. Oxy-Salts of the Halogens - Kurt H. Stern. J Phys Chem Ref Data 3, 481(1974).

Interactive FORTRAN Program to Calculate Thermophysical Properties of Seven Fluids - Ben A. Younglove. NBS Tech. Note 1048, 56p. (1982).

Interactive Fortran Program to Calculate Thermophysical Properties of 6 Fluids NBS Standard Reference Database 6, Washington, D.C.; NBS, Office of Standard Reference Data,(updated periodically). Call (301)921-2228 for specific instructions.

LNG Materials \& Fluids, A User's Manual of Property Data in Graphic Format - Douglas Mann and U.S. National Bureau of Standards., Boulder, CO: U.S. National Bureau of Standards, Cryogenic Division, 11p. (1977).

LNG Materials \& Fluids, A User's Manual of Property Data in Graphic Format, First Supplement — Douglas Mann and U.S. National Bureau of Standards. Suppl. 1, Boulder, CO: U.S. National Bureau of Standards, 11p. (1978).

LNG Materials \& Fluids, A User's Manual of Property Data in Graphic Format, Second Supplement - Douglas Mann and U.S. National Bureau of Standards. Suppl. 2, Boulder, CO: U.S. National Bureau of Standards, 11 p. (1980).

Liquid Densities of Oxygen, Nitrogen, Argon, and Parahydrogen Hans M. Roder, Robert D. McCarty, and V. J. Johnson. NBS Tech. Note 361, 1972(1973).

Molten Salts: Volume 1. Electrical Conductance, Density, and Viscosity Data - George J. Janz, F. W. Dampier, G. R. Lakshminarayanan, P. K. Lorenz, and Reginald P. T. Tomkins. NSRDS-NBS 15, 140p. (1968).

Molten Salts: Volume 2. Section 1. Electrochemistry of Molten Salts. Gibbs Free Energies and Excess Free Energies from Equilibrium-Type Cells, Section 2. Surface Tension Data - George J. Janz, Chr. G. M. Dijkhuis, G. R. Lakshminarayanan, Reginald P. T. Tomkins, and J. Wong. NSRDS-NBS 28, 116p. (1968).

Molten Salts: Volume 3, Nitrates, Nitrites, and Mixtures. Electrical Conductance, Density, Viscosity, and Surface Tension Data - George J. Janz, Ursula Krebs, H. F. Siegenthaler, and Reginald P. T. Tomkins. J Phys Chem Ref Data 1, 581(1972).

Molten Salts: Volume 4, Part 1, Fluorides and Mixtures. Electrical Conductance, Density, Viscosity, and Surface Tension Data - George J. Janz, G. L. Gardner, Ursula Krebs, and Reginald P. T. Tomkins. J Phys Chem Ref Data 3, 1(1974). 
Molten Salts: Volume 4, Part 2, Chlorides and Mixtures. Electrical Conductance, Density, Viscosity, and Surface Tension Data - George J. Janz, Reginald P. T. Tomkins, Carolyn B. Allen, J. R. Downey, Jr., G. L. Gardner, Ursula Krebs, and S. K. Singer. J Phys Chem Ref Data 4, 871(1975).

Molten Salts: Volume 4, Part 3, Bromides and Mixtures, Iodides and Mixtures. Electrical Conductance, Density, Viscosity, and Surface Tension Data - George J. Janz, Reginald P. T. Tomkins, Carolyn B. Allen, J. R. Downey, Jr., and S. K. Singer. J Phys Chem Ref Data 6, 409(1977).

Molten Salts: Volume 4, Part 4, Mixed Halide Melts. Electrical Conductance, Density, Viscosity, and Surface Tension Data - George J. Janz, Reginald P. T. Tomkins, and Carolyn B. Allen. J Phys Chem Ref Data 8, 125(1979).

Molten Salts Data As Reference Standards for Density, Surface Tension, Viscosity and Electrical Conductance: $\mathrm{KNO}_{3}$ and $\mathrm{NaCl}-\mathrm{George}$ J. Janz. J Phys Chem Ref Data 9, 791(1980).

Molten Salts: Volume 5, Part 1. Additional Single and MultiComponent Salt Systems. Electrical Conductance, Density, Viscosity, and Surface Tension Data - George J. Janz and Reginald P. T. Tomkins. J Phys Chem Ref Data 9, 831(1980).

Molten Salts: Volume 5, Part 2. Additional Single and MultiComponent Salt Systems. Electrical Conductance, Density, Vicosity and Surface Tension Data - George J. Janz and Reginald P. T. Tomkins. J Phys Chem Ref Data 12, 591(1983).

NBS Chemical Thermodynamics Database NBS Standard Reference Database 2, Washington, D.C.; NBS, Office of Standard Reference Data,(updated periodically). Call (301)921-2228 for specific instructions.

NBS Crystal Data Identification File NBS Standard Reference Database 3, Washington, D.C.; NBS, Office of Standard Reference Data,(updated periodically). Lease agreements obtained from JCPDS 1601 Park Ln Swarthmore PA (215)328-9400.

Phase Behavior in Binary and Multicomponent Systems at Elevated Pressures: n-Pentane and Methane-n-Pentane - Virginia M. Berry and Bruce H. Sage. NSRDS-NBS 32, 79p. (1970).

Physical Properties Data Compilations Relevant to Energy Storage. V. Mechanical Properties Data on Alloys for Use in Flywheels Hassell M. Ledbetter. NSRDS-NBS 61, 42p. (1982).

Physical and Thermodynamic Properties of Aliphatic Alcohols Randolph C. Wilhoit and Bruno J. Zwolinski. J Phys Chem Ref Data 2 , Suppl. 1(1973).

Pressure, Volume, Temperature Relations of Ethylene - Donald R. Douslin and Roland H. Harrison. J Chem Thermody 76, New York, London:, 301p. (1976).

Properties of Liquid and Solid Hydrogen - B. N. Esel'son, Y. P. Blagoi, V.N. Grigor'ev, V. G. Manzhelii, S. A. Mikhailenko, and N. P. Neklyudov. Russian Transl., Springfield, VA: NTIS, 126p. (1971). TT 70-50179, A07.

The Critical-Region Equation of State of Ethene and the Effect of Small Impurities - J. R. Hastings, J. M. H. Levelt Sengers, and F. W. Balfour. J Chem Thermody 12, London: Academic Press Inc., 1009p. (1980).

The Calculated Thermodynamic Properties of Superfluid Helium-4 - James S. Brooks and Russell J. Donnelly. J Phys Chem Ref Data 6, 51(1977).

The Molar Volume (Density) of Solid Oxygen in Equilibrium with Vapor - Hans M. Roder. J Phys Chem Ref Data 7, 949(1978).

Theoretical Mean Activity Coefficients of Strong Electrolytes in Aqueous Solutions from 0 to $100^{\circ} \mathrm{C}-$ Walter J. Hamer. NSRDS-NBS 24, 271p. (1968).

Thermodynamic Properties of Argon from the Triple Point to $300 \mathrm{~K}$ at Pressures to 1000 Atmospheres - A. L. Gosman, Robert D. McCarty, and Jerome G. Hust. NSRDS-NBS 27, 153p. (1969).

Thermophysical Properties of Isobutane from 114 to $700 \mathrm{~K}$ at Pressures to $70 \mathrm{MPa}$ - Robert D. Goodwin and W. M. Haynes. NBS Tech. Note 1051, 199p. (1982).

Thermodynamic and Related Properties of Parahydrogen from the Triple Point to $100 \mathrm{~K}$ at Pressures to 340 Atmospheres - Hans M.
Roder, Lloyd A. Weber, and Robert D. Goodwin. NBS Monograph 94, 116p. (1965).

Thermophysical Properties of Normal Butane from 135 to $700 \mathrm{~K}$ at Pressures to $70 \mathrm{MPa}-$ W. M. Haynes and Robert D. Goodwin. NBS Monograph 169, 197p. (1982).

Thermodynamic and Thermophysical Properties of Combustion Products, Volume II. Oxygen-Based Propellants - V. P. Glushko, V. E. Alemasov, A. F. Dregalin, A. P. Tishin, V. A. Khudyakov, and V. N. Kostin. Russian Transl., Springfield, VA: NTIS, 505p. (1975). TT 74-50032, A22.

Thermodynamic and Thermophysical Properties of Combustion Products, Volume III. Oxygen- and Air-Based Propellant - V. P. Glushko, V. E. Alemasov, A. F. Dregalin, A. P. Tishin, V. A. Khudyakov, and V. N. Kostin. Russian Transl., Springfield, VA: NTIS, 648p. (1975). TT 75-50007, A26.

Thermodynamic and Thermophysical Properties of Combustion Products, Volume IV. Nitrogen Tetroxide-Based Propellants - V. P. Glushko, V. E. Alemasov, A. F. Dregalin, A. P. Tishin, V. A. Khudyakov, and V. N. Kostin. Russian Transl., Springfield, VA: NTIS, 540p. (1976). TT 76-50007, A23.

Thermodynamic and Transport Properties of Ethylene and Propylene - I. A. Neduzhii. Russian Transl. Springfield, VA: NTIS, 206p. (1972). COM 75-11276, A 10.

Thermophysical Properties of Gases and Liquids, No. $1-$ V. A. Rabinovich. Russian Transl. Springfield, VA: NTIS, 214p. (1970). TT 69-55091, A 10, the translation of volumes 2, 3, and 4 have the title: Thermophysical Properties of Matter and Substances.

Thermophysical Properties of Gaseous and Liquid Methane - V. A. Zagoruchenko and A. M. Zhuravlev. Russian Transl. Springfield, VA: NTIS, 251p. (1970). TT 70-50097, A12.

Thermophysical Properties of Matter and Substances, Volume 2 V. A. Rabinovich. Russian Transl., Springfield, VA: NTIS, 395p. (1974). TT 72-52001, A17, the translation of volume 1 has the title: Thermophysical Properties of Gases and Liquids.

Thermophysical Properties of Matter and Substances, Volume 3 V. A. Rabinovich. Russian Transl. Springfield, VA: NTIS, 212p. (1975). TT 73-52009, A10, the translation of volume 1 has the title: Thermophysical Properties of Gases and Liquids.

Thermophysical Properties of Matter and Substances, Volume 4 V. A. Rabinovich. Russian Transl., Springfield, VA: NTIS, 179p. (1975). TT 73-52029, A09, the translation of volume 1 has the title: Thermophysical Properties of Gases and Liquids.

Thermodynamic Properties of Nitrogen Including Liquid and Vapor Phases from $63 \mathrm{~K}$ to $2000 \mathrm{~K}$ with Pressures to $10,000 \mathrm{Bar}$ - Richard T. Jacobsen and Richard B. Stewart. J Phys Chem Ref Data 2, 757(1973).

Thermodynamic Properties of Helium-4 from 2 to $1500 \mathrm{~K}$ at Pressures to $10^{8} \mathrm{~Pa}-$ Robert $\mathbb{D}$. McCarty. J Phys Chem Ref Data 2, 923(1973).

Thermodynamic Properties of Ammonia - Lester Haar and John S. Gallagher. J Phys Chem Ref Data 7, 635(1978).

Thermophysical Properties of Fluids. I. Argon, Ethylene, Parahydrogen, Nitrogen, Nitrogen Trifluoride, and Oxygen - Ben A. Younglove. J Phys Chem Ref Data 11, Suppl. 1(1982).

Viscosity of Water Substance - New International Formulation and Its Background - A. Nagashima. J Phys Chem Ref Data 6, 1133(1977).

Volumetric Properties of Aqueous Sodium Chloride Solutions - P. S. Z. Rogers and Kenneth S. Pitzer. J Phys Chem Ref Data 11, 15(1982).

Dielectric constant (see also Electric dipole moment of molecules)

Compendium of ab initio Calculations of Molecular Energies and Properties - Morris Krauss. NBS Tech. Note 438, 139p. (1967).

Compilation of the Static Dielectric Constant of Inorganic Solids K. F. Young and Hans P. R. Frederikse. J Phys Chem Ref Data 2, 313(1973). 
Crystal Structure Transformations in Inorganic Sulfates, Phosphates, Perchlorates, and Chromates - C. N. R. Rao and Brahm Prakash. NSRDS-NBS 56, 37p. (1975).

Electrolytic Conductance and the Conductances of the Halogen Acids in Water - Walter J. Hamer and H. J. DeWane. NSRDS-NBS 33, 37p. (1970).

Electric Conductivity of Ferroelectrics - V. M. Gurevich. Russian Transl., Springfield, VA: NTIS, 366p. (1971). TT 70-50180, A16.

Interactive Fortran Program to Calculate Thermophysical Properties of 6 Fluids NBS Standard Reference Database 6, Washington, D.C.; NBS, Office of Standard Reference Data,(updated periodically). Call (301)921-2228 for specific instructions.

NBS/NRC Steam Tables, Thermodynamic and Transport Properties and Computer Programs for Vapor and Liquid States of Water Lester Haar, John S. Gallagher, and George S. Kell., New York: Hemisphere Press, 320p. (1984).

Static Dielectric Constant of Water and Steam - M. Uematsu and E. U. Franck. J Phys Chem Ref Data 9, 1291(1980).

Theoretical Mean Activity Coefficients of Strong Electrolytes in Aqueous Solutions from 0 to $100^{\circ} \mathrm{C}-$ Walter J. Hamer. NSRDS-NBS 24, 271p. (1968).

Thermophysical Properties of Isobutane from 114 to $700 \mathrm{~K}$ at Pressures to $70 \mathrm{MPa}$ - Robert D. Goodwin and W. M. Haynes. NBS Tech. Note 1051, 199p. (1982).

Thermophysical Properties of Normal Butane from 135 to $700 \mathrm{~K}$ at Pressures to $70 \mathrm{MPa}-$ W. M. Haynes and Robert D. Goodwin. NBS Monograph 169, 197p. (1982).

Thermophysical Properties of Fluids. I. Argon, Ethylene, Para hydrogen, Nitrogen, Nitrogen Trifluoride, and Oxygen - Ben A. Younglove. J Phys Chem Ref Data 11, Suppl. 1(1982).

\section{Diffusion coefficient}

A Survey of Electron Swarm Data - J. Dutton. J Phys Chem Ref Data 4, 577(1975).

An Annotated Compilation and Appraisal of Electron Swarm Data in Electronegative Gases - Jean W. Gallagher, Earl C. Beaty, J. Dutton, and L. C. Pitchford. J Phys Chem Ref Data 12, 109(1983).

Bibliography on Properties of Defect Centers in Alkali Halides Suresh C. Jain, S. A. Khan, H. K. Sehgal, V. K. Garg, and R. K. Jain. OSRD Bibl. 71-1, 293p. (1971).

Diffusion Rate Data and Mass Transport Phenomena in Copper Systems - Daniel B. Butrymowicz, John R. Manning, and Michael E. Read. INCRA Monograph V, New York: International Copper Research Association, Inc., 322p. (1977).

Diffusion Rate Data and Mass Transport Phenomena for Copper Systems, Part II - Daniel B. Butrymowicz, John R. Manning, and Michael E. Read. INCRA Monograph VIII, New York: International Copper Research Association, Inc., 701p. (1982).

Diffusion in Copper and Copper Alloys, Part I. Volume and Surface Self-Diffusion in Copper - Daniel B. Butrymowicz, John R. Manning, and Michael E. Read. J Phys Chem Ref Data 2, 643(1973).

Diffusion in Copper and Copper Alloys, Part II. Copper-Silver and Copper-Gold Systems - Daniel B. Butrymowicz, John R. Manning, and Michael E. Read. J Phys Chem Ref Data 3, 527(1974).

Diffusion in Copper and Copper Alloys, Part III. Diffusion in Systems Involving Elements of the Groups IA, IIA, IIIB, IVB, VB, and VIIB - Daniel B. Butrymowicz, John R. Manning, and Michael E. Read. J Phys Chem Ref Data 4, 177(1975).

Diffusion in Copper and Copper Alloys, Part IV. Diffusion in Systems Involving Elements of Group VIII - Daniel B. Butrymowicz, John R. Manning, and Michael E. Read. J Phys Chem Ref Data 5, 103(1976).

Diffusion in Copper and Copper Alloys, Part V. Diffusion in Systems Involving Elements of Group VA - Daniel B. Butrymowicz, John R. Manning, and Michael E. Read. J Phys Chem Ref Data 6, 1(1977).

Equilibrium and Transport Properties of the Noble Gases and Their Mixtures at Low Density - Joseph Kestin, K. Knierim, E. A. Mason, B. Najafi, S. T. Ro, and M. Waldman. J Phys Chem Ref Data 13, 229(1984).
Erratum: Molten Salts Data: Diffusion Coefficients in Single and Multi-Component Salt Systems - George J. Janz and Narottam P. Bansal. J Phys Chem Ref Data 13, 305(1984).

Gaseous Diffusion Coefficients - T. R. Marrero and E. A. Mason. J Phys Chem Ref Data 1, 1(1972).

Molten Salts Data: Diffusion Coefficients in Single and MultiComponent Salt Systems - George J. Janz and Narottam P. Bansal. J Phys Chem Ref Data 11, 505(1982).

Tables of Collision Integrals and Second Virial Coefficients for the $(m, 6,8)$ Intermolecular Potential Function - Max Klein, Howard J. M. Hanley, Francis J. Smith, and Paul M. Holland. NSRDS-NBS 47, 161p. (1974).

Transport Properties of Liquid and Gaseous $\mathrm{D}_{2} \mathrm{O}$ over a Wide Range of Temperature and Pressure - N. Matsunaga and A. Nagashima. J Phys Chem Ref Data 12, 933(1983).

\section{Diffusivity}

See: Thermal conductivity

\section{Dipole moment}

See: Electric dipole moment of molecules

\section{Dissociation energy}

See: Bond dissociation energy

\section{Effective mass}

See: Semiconductor properties

\section{Elastic constants}

Elastic Properties of Metals and Alloys, I. Iron, Nickel, and IronNickel Alloys - Hassell M. Ledbetter and R. P. Reed. J Phys Chem Ref Data 2, 531(1973).

Elastic Properties of Metals and Alloys, II. Copper - Hassell M. Ledbetter and E. R. Naimon. J Phys Chem Ref Data 3, 897(1974).

Elastic Properties of Zinc: A Compilation and a Review - Hassell M. Ledbetter. J Phys Chem Ref Data 6, 1181(1977).

LNG Materials \& Fluids, A User's Manual of Property Data in Graphic Format - Douglas Mann and U.S. National Bureau of Standards., Boulder, CO: U.S. National Bureau of Standards, Cryogenic Division, 11 p. (1977).

LNG Materials \& Fluids, A User's Manual of Property Data in Graphic Format, First Supplement - Douglas Mann and U.S. National Bureau of Standards. Suppl. 1, Boulder, CO: U.S. National Bureau of Standards, 11p. (1978).

LNG Materials \& Fluids, A User's Manual of Property Data in Graphic Format, Second Supplement - Douglas Mann and U.S. National Bureau of Standards. Suppl. 2, Boulder, CO: U.S. National Bureau of Standards, 11p. (1980).

Physical Properties Data Compilations Relevant to Energy Storage. V. Mechanical Properties Data on Alloys for Use in Flywheels Hassell M. Ledbetter. NSRDS-NBS 61, 42p. (1982).

\section{Electric dipole moment of molecules}

Compendium of ab initio Calculations of Molecular Energies and Properties - Morris Krauss. NBS Tech. Note 438, 139p. (1967).

Microwave Spectral Tables, Volume I. Diatomic Molecules - Paul F. Wacker, M. Mizushima, J. D. Petersen, and J. R. Ballard. NBS Monograph 70, 171p. (1964).

Microwave Spectral Tables, Volume III. Polyatomic Molecules with Internal Rotation - Paul F. Wacker, M. S. Cord, D. G. Burkhard, J. D. Petersen, and R. F. Kukol. NBS Monograph 70, 275p. (1969).

Microwave Spectral Tables, Volume IV. Polyatomic Molecules without Internal Rotation - M. S. Cord, J. D. Petersen, M. S. Lojko, and R. H. Haas. NBS Monograph 70, 419p. (1968). 
Microwave Spectra of Molecules of Astrophysical Interest, I. Formaldehyde, Formamide, and Thioformaldehyde - Donald R. Johnson, Frank J. Lovas, and William H. Kirchhoff. J Phys Chem Ref Data 1, 1011(1972).

Microwave Spectra of Molecules of Astrophysical Interest, II. Methylenimine - William H. Kirchhoff, Donald R. Johnson, and Frank J. Lovas. J Phys Chem Ref Data 2, 1(1973).

Microwave Spectra of Molecules of Astrophysical Interest, III. Methanol - R. M. Lees, Frank J. Lovas, William H. Kirchhoff, and Donald R. Johnson. J Phys Chem Ref Data 2, 205(1973).

Microwave Spectra of Molecules of Astrophysical Interest, IV. Hydrogen Sulfide - Paul Helminger, Frank C. De Lucia, and William H. Kirchhoff. J Phys Chem Ref Data 2, 215(1973).

Microwave Spectra of Molecules of Astrophysical Interest, V. Water Vapor - Frank C. De Lucia, Paul Helminger, and William H. Kirchhoff. J Phys Chem Ref Data 3, 211(1974).

Microwave Spectra of Molecules of Astrophysical Interest, VI. Carbonyl Sulfide and Hydrogen Cyanide - Arthur G. Maki. J Phys Chem Ref Data 3, 221(1974).

Microwave Spectra of Molecules of Astrophysical Interest, VII. Carbon Monoxide, Carbon Monosulfide, and Silicon Monoxide - Frank J. Lovas and Paul H. Krupenie. J Phys Chem Ref Data 3, 245(1974).

Microwave Spectra of Molecules of Astrophysical Interest, VIII. Sulfur Monoxide - Eberhard Tiemann. J Phys Chem Ref Data 3, 259(1974).

Microwave Spectral Tables, I. Diatomic Molecules - Frank J. Lovas and Eberhard Tiemann. J Phys Chem Ref Data 3, 609(1974).

Microwave Spectra of Molecules of Astrophysical Interest, IX. Acetaldehyde - A. Bauder, Frank J. Lovas, and Donald R. Johnson. J Phys Chem Ref Data 5, 53(1976).

Microwave Spectra of Molecules of Astrophysical Interest, X. Isocyanic Acid - G. Winnewisser, W. H. Hocking, and M. C. L. Gerry. J Phys Chem Ref Data 5, 79(1976).

Microwave Spectra of Molecules of Astrophysical Interest, XI. Silicon Sulfide - Eberhard Tiemann. J Phys Chem Ref Data 5, 1147(1976).

Microwave Spectra of Molecules of Astrophysical Interest, XII. Hydroxyl Radical - Robert A. Beaudet and Robert L. Poynter. J Phys Chem Ref Data 7, 311(1978).

Microwave Spectra of Molecules of Astrophysical Interest, XIII. Cyanoacetylene - Walter J. Lafferty and Frank J. Lovas. J Phys Chem Ref Data 7, 441(1978).

Microwave Spectral Tables II. Triatomic Molecules - Frank J. Lovas. J Phys Chem Ref Data 7, 1445(1978).

Microwave Spectra of Molecules of Astrophysical Interest, XIV. Vinyl Cyanide (Acrylonitrile) - M. C. L. Gerry, K. Yamada, and G. Winnewisser. J Phys Chem Ref Data 8, 107(1979).

Microwave Spectra of Molecules of Astrophysical Interest, XV. Propyne - A. Bauer, D. Boucher, J. Burie, J. Demaison, and A. Dubrulle. J Phys Chem Ref Data 8, 537(1979).

Microwave Spectra of Molecules of Astrophysical Interest, XVI. Methyl Formate - A. Bauder. J Phys Chem Ref Data 8, 583(1979).

Microwave Spectra of Molecules of Astrophysical Interest, XVII. Dimethyl Ether - Frank J. Lovas, H. Lutz, and H. Dreizler. J Phys Chem Ref Data 8, 1051(1979).

Microwave Spectra of Molecules of Astrophysical Interest. XVIII. Formic Acid - Edmond Willemot, Didier Dangoisse, Nicole Monnanteuil, and Jean Bellet. J Phys Chem Ref Data 9, 59(1980).

Microwave Spectra of Molecules of Astrophysical Interest. XIX. Methyl Cyanide - D. Boucher, J. Burie, A. Bauer, A. Dubrulle, and J. Demaison. J Phys Chem Ref Data 9, 659(1980).

Microwave Spectra of Molecules of Astrophysical Interest. XXI. Ethanol $\left(\mathrm{C}_{2} \mathrm{H}_{5} \mathrm{OH}\right)$ and Propionitrile $\left(\mathrm{C}_{2} \mathrm{H}_{5} \mathrm{CN}\right)$ - Frank J. Lovas. J Phys Chem Ref Data 11, 251(1982).

Selected Values of Electric Dipole Moments for Molecules in the Gas Phase - Ralph D. Nelson, Jr., David R. Lide, Jr., and Arthur A. Maryott. NSRDS-NBS 10, 49p. (1967).

The Band Spectrum of Carbon Monoxide - Paul H. Krupenie. -.annC.NBS 5, 87p. (1966).

\section{Electrical conductance}

A Bibliography of Sources of Experimental Data Leading to Thermal Properties of Binary Aqueous Electrolyte Solutions - David Smith-Magowan and Robert N. Goldberg. NBS Spec. Publ. 537, 94p. (1979).

Drift Mobilities and Conduction Band Energies of Excess Electrons in Dielectric Liquids - Augustine O. Allen. NSRDS-NBS 58, 23p. (1976).

Electrolytic Conductance and the Conductances of the Halogen Acids in Water - Walter J. Hamer and H. J. DeWane. NSRDS-NBS 33, 37p. (1970).

Electric Conductivity of Ferroelectrics - V. M. Gurevich. Russian Transl., Springfield, VA: NTIS, 366p. (1971). TT 70-50180, Al6.

Molten Salts: Volume 1. Electrical Conductance, Density, and Viscosity Data - George J. Janz, F. W. Dampier, G. R. Lakshminarayanan, P. K. Lorenz, and Reginald P. T. Tomkins. NSRDS-NBS 15, 140p. (1968).

Molten Salts: Volume 3, Nitrates, Nitrites, and Mixtures. Electrical Conductance, Density, Viscosity, and Surface Tension Data - George J. Janz, Ursula Krebs, H. F. Siegenthaler, and Reginald P. T. Tomkins. J Phys Chem Ref Data 1, 581(1972).

Molten Salts: Volume 4, Part 1, Fluorides and Mixtures. Electrical Conductance, Density, Viscosity, and Surface Tension Data - George J. Janz, G. L. Gardner, Ursula Krebs, and Reginald P. T. Tomkins. J Phys Chem Ref Data 3, 1(1974).

Molten Salts: Volume 4, Part 2, Chlorides and Mixtures. Electrical Conductance, Density, Viscosity, and Surface Tension Data - George J. Janz, Reginald P. T. Tomkins, Carolyn B. Allen, J. R. Downey, Jr., G. L. Gardner, Ursula Krebs, and S. K. Singer. J Phys Chem Ref Data 4, 871(1975).

Molten Salts: Volume 4, Part 3, Bromides and Mixtures, Iodides and Mixtures. Electrical Conductance, Density, Viscosity, and Surface Tension Data - George J. Janz, Reginald P. T. Tomkins, Carolyn B. Allen, J. R. Downey, Jr., and S. K. Singer. J Phys Chem Ref Data 6, 409(1977).

Molten Salts: Volume 4, Part 4, Mixed Halide Melts. Electrical Conductance, Density, Viscosity, and Surface Tension Data - George J. Janz, Reginald P. T. Tomkins, and Carolyn B. Allen. J Phys Chem Ref Data 8, 125(1979).

Molten Salts Data As Reference Standards for Density, Surface Tension, Viscosity and Electrical Conductance: $\mathrm{KNO}_{3}$ and $\mathrm{NaCl}-$ George J. Janz. J Phys Chem Ref Data 9, 791(1980).

Molten Salts: Volume 5, Part 1. Additional Single and MultiComponent Salt Systems. Electrical Conductance, Density, Viscosity, and Surface Tension Data - George J. Janz and Reginald P. T. Tomkins. J Phys Chem Ref Data 9, 831(1980).

Molten Salts: Volume 5, Part 2. Additional Single and MultiComponent Salt Systems. Electrical Conductance, Density, Vicosity and Surface Tension Data - George J. Janz and Reginald P. T. Tomkins. J Phys Chem Ref Data 12, 591(1983).

Physical Properties Data Compilations Relevant to Energy Storage. III. Engineering Properties of Single and Polycrystalline Sodium Beta and Beta" Alumina - G. R. Miller and D. G. Paquette. NSRDS-NBS 61, 19p. (1979).

\section{Electrical resistivity}

Critical Surveys of Data Sources: Electrical and Magnetic Proper ties of Metals - M. J. Carr, R. B. Gavert, Robert L. Moore, H. W. Wawrousek, and John H. Westbrook. NBS Spec. Publ. 396, 96p. (1976).

Electrical Resistivity of Alkali Elements - T. C. Chi. J Phys Chem Ref Data 8, 339(1979).

Electrical Resistivity of Alkaline Earth Elements - T. C. Chi. J Phys Chem Ref Data 8, 439(1979).

Electrical Resistivity of Copper, Gold, Palladium, and Silver - R. A. Matula. J Phys Chem Ref Data 8, 1147(1979). 
Electrical Resistivity of Ten Selected Binary Alloy Systems - Cho Y. Ho, M. W. Ackerman, K. Y. Wu, T. N. Havill, R. H. Bogaard, R. A. Matula, S. G. Oh, and H. M. James. J Phys Chem Ref Data 12, 183(1983).

Electrical Resistivity of Selected Elements - P. D. Desai, T. K. Chu, H. M. James, and Cho Y. Ho. J Phys Chem Ref Data 13, 1069(1984).

Electrical Resistivity of Vanadium and Zirconium - P. D. Desai, H. M. James, and Cho Y. Ho. J Phys Chem Ref Data 13, 1097(1984).

Electrical Resistivity of Aluminum and Manganese - P. D. Desai, H M. James, and Cho Y. Ho. J Phys Chem Ref Data 13, 1131(1984).

Feasiblility Study: Compilation and Evaluation of Properties Data for Basalt, Granite, Tuff, and Shale - Lewis H. Gevantman. NBSIR 81-2217, 259p. (1981).

Physical Properties Data Compilations Relevant to Energy Storage. III. Engineering Properties of Single and Polycrystalline Sodium Beta and Beta" Alumina - G. R. Miller and D. G. Paquette. NSRDS-NBS 61, 19p. (1979).

Physical Properties Data Compilations Relevant to Energy Storage. IV. Molten Salts: Data on Additional Single and Multi-Component Salt Systems - George J. Janz and Reginald P. T. Tomkins. NSRDS-NBS 61, 870p. (1981).

Physical Properties Data for Rock Salt - Lewis H. Gevantman NBS Monograph 167, 288p. (1981).

Physical Properties Data for Basalt - Lewis H. Gevantman. NBSIR 82-2587, 751p. (1982).

\section{Electron affinity}

Binding Energies in Atomic Negative Ions - H. Hotop and W. C. Lineberger. J Phys Chem Ref Data 4, 539(1975).

Energetics of Gaseous Ions - Henry M. Rosenstock, Keith Draxl, B. W. Steiner, and John T. Herron. J Phys Chem Ref Data 6, Suppl. 1(1977).

Ion Energetics Measurements, Supplement I. 1971-1973 - Henry M. ¿.osenstock, D. Sims, S. S. Schroyer, and W. J. Webb. NSRDS-NBS 66, 380p. (1980).

\section{Electron collision cross section}

Bibliography of Low Energy Electron and Photon Cross Section Data (1978) - Jean W. Gallagher and Earl C. Beaty. JILA Report 18, 148p. (1980).

Bibliography of Low Energy Electron and Photon Cross Section Data (1979) - Jean W. Gallagher and Earl C. Beaty. JILA Report 21, 127p. (1981).

Compilation of Low Energy Electron Collision Cross Section Data Part I. Ionization, Dissociative Processes, Vibrational and Rotational Excitation - Lee J. Kieffer. JILA Report 6, 95p. (1969).

Compilation of Low Energy Electron Collsion Cross Section Data. Part II. Line and Level Excitation - Lee J. Kieffer. JILA Report 7, 167p. (1969).

Compilation of Electron Collision Cross Section Data for Modelling Gas Discharge Lasers - Lee J. Kieffer. JILA Report 13, 139p. (1973).

Electron Impact Excitation of Atoms - Benjamin L. Moiseiwitsch and Steven J. Smith. NSRDS-NBS 25, 120p. (1968).

Electron Impact Ionization Cross-Section Data for Atoms, Atomic Ions, and Diatomic Molecules: I. Experimental Data - Lee J. Kieffer and Gordon H. Dunn. Rev Mod Phys. 38, New York: American Institute of Physics, 35p. (1966).

Low Energy Electron-Collision Cross Section Data. Part III. Total Scattering; Differential Elastic Scattering - Lee J. Kieffer. At Data. 2, New York: Academic Press, 293p. (1971).

Recommended Data on the Electron Impact Ionization of Light Atoms and Ions - K. L. Bell, H. B. Gilbody, J. G. Hughes, A. E. Kingston, and Francis J. Smith. J Phys Chem Ref Data 12, 891(1983).

Theory of the Ionization of Atoms by Electron Impact - M. R. H. Rudge. Rev Mod Phys 40, .., 564p. (1968).

Total Electron-Atom Collision Cross Sections at Low Energies - A Critical Review - Benjamin Bederson. Rev Mod Phys 43, 999, 601p. (1971).

\section{Electron swarm parameters}

A Bibliography of Electron Swarm Data - Earl C. Beaty, J. Dutton, and L. C. Pitchford. JILA Report 20, 252p. (1979).

A Survey of Electron Swarm Data - J. Dutton. J Phys Chem Ref Data 4, 577(1975).

An Annotated Compilation and Appraisal of Electron Swarm Data in Electronegative Gases - Jean W. Gallagher, Earl C. Beaty, J. Dutton, and L. C. Pitchford. J Phys Chem Ref Data 12, 109(1983).

\section{Electronic molecular spectra}

Atlas of the Observed Absorption Spectrum of Carbon Monoxide between 1060 and $1900 \AA$ - S. G. Tilford and J. D. Simmons. J Phys Chem Ref Data 1, 147(1972)

Atlas of the Absorption Spectrum of Nitric Oxide (NO) between 1420 and $1250 \AA-$ E. Miescher and F. Alberti. J Phys Chem Ref Data 5, 309(1976).

Atlas of the Schumann-Runge Absorption Bands of $\mathrm{O}_{2}$ in the Wavelength Region 175-205 nm - K. Yoshino, D. E. Freeman, and W. H. Parkinson. J Phys Chem Ref Data 13, 207(1984).

Bibliography on Flame Spectroscopy. Analytical Applications, 1800-1966 - Radu Mavrodineanu. NBS Spec. Publ. 281, 155p. (1967).

Biweekly List of Papers on Radiation Chemistry and Photochemistry Vol. 17. 1984 - Radiation Chemistry Data Center. Rad Chem, Notre Dame, IN: Radiation Chem. Data Center, U. of Notre Dame,... p. (1984). \$25.00; the Biweekly List, Vol. 17 (1984) plus the Annual Cumulation, Vol. 16 (1983), \$35.00; foreign and airmail postage rates available upon request.

Biweekly List of Papers on Radiation Chemistry and Photochemistry Annual Cumuluation with Keyword and Author Indexes, Vol. 16. 1983 - Radiation Chemistry Data Center. Rad Chem 16, Springfield, VA: NTIS, 444p. (1984).

Biweekly List of Papers on Radiation Chemistry and Photochemistry Annual Cumuluation with Keyword and Author Indexes, Vol. 15. 1982 - Radiation Chemistry Data Center. Rad Chem 15, Springfield, VA: NTIS, 448p. (1983). PB 83-203638, A19.

Biweekly List of Papers on Radiation Chemistry and Photochemistry Annual Cumulation with Keyword and Author Indexes, Vol. 14. 1981- Radiation Chemistry Data Center. Rad Chem 14, Springfield, VA: NTIS, 534p. (1982). PB 82-214 487, A22.

Biweekly List of Papers on Radiation Chemistry and Photochemistry Annual Cumulation with Keyword and Author Indexes, Vol. 13. 1980 - Radiation Chemistry Data Center. Rad Chem 13, Springfield, VA: NTIS, 704p. (1981). PB 82-122 995, A26.

Biweekly List of Papers on Radiation Chemistry and Photochemistry Annual Cumulation with Keyword and Author Indexes, Vol. 12. 1979 - Radiation Chemistry Data Center. Rad Chem 12, Springfield, VA: NTIS, 748p. (1980). PB 81-113 680, A26.

Biweekly List of Papers on Radiation Chemistry and Photochemistry Annual Cumulation with Keyword and Author indexes, Vol. 11. 1978 - Radiation Chemistry Data Center. Rad Chem 11, Springfield, VA: NTIS, 768p. (1979). PB 226 368, A99.

Biweekly List of Papers on Radiation Chemistry, Annual Cumulation with Keyword and Author Indexes, Vol. 10. 1977 - Radiation Chemistry Data Center, Rad Chem 10, Springfield, VA: NTIS, 695p. (1978). PB 291 876, A26.

Biweekly List of Papers on Radiation Chemistry, Annual Cumulation with Keyword and Author Indexes, Vol. 9. 1976 - Radiation Chemistry Data Center. Rad Chem 9, Springfield, VA: NTIS, 707p. (1977). PB 268 699, A26.

Biweekly List of Papers on Radiation Chemistry, Annual Cumulation with Keyword and Author Indexes, Vol. 8. 1975 - Radiation Chemistry Data Center. Rad Chem 8, Springfield, VA: NTIS, 670p. (1976). PB 275 025, A26.

Biweekly List of Papers on Radiation Chemistry, Annual Cumulation with Keyword and Author Indexes, Vol. 7. 1974 - Radiation Chemistry Data Center. Rad Chem 7, Springfield, VA: NTIS, 553p. (1975). COM 75-11475, A24., 
Electronic Absorption and Internal and External Vibrational Data of Atomic and Molecular Ions Doped in Alkali Halide Crystals - Suresh C. Jain, A. V. R. Warrier, and Suresh K. Agarwal. NSRDS-NBS 52, 55p. (1974).

Optical Spectra of Nonmetallic Inorganic Transient Species in Aqueous Solution - Gordon L. Hug. NSRDS-NBS 69, 167p. (1981).

Radiation Chemistry of Ethanol: A Review of Data on Yields, Reaction Rate Parameters, and Spectral Properties of Transients - Gordon R. Freeman. NSRDS-NBS 48, 44p. (1974).

The Band Spectrum of Carbon Monoxide - Paul H. Krupenie. NSRDS-NBS 5, 87p. (1966).

The Radiolysis of Methanol: Product Yields, Rate Constants, and Spectroscopic Parameters of Intermediates - J. H. Baxendale and Peter Wardman. NSRDS-NBS 54, 33p. (1975).

The Spectrum of Molecular Nitrogen - Alf Lofthus and Paul H. Krupenie. J Phys Chem Ref Data 6, 113(1977).

\section{Energy bands of solids}

Compilation of Energy Band Gaps in Elemental and Binary Compound Semiconductors and Insulators - W. H. Strehlow and E. L. Cook. J Phys Chem Ref Data 2, 163(1973).

Soft X-Ray Emission Spectra of Metallic Solids: Critical Review of Selected Systems - Archie J. McAlister, Ronald C. Dobbyn, John R. Cuthill, and M. L. Williams. J Phys Chem Ref Data 2, 411(1973).

\section{Energy gap}

See: Energy bands of solids Semiconductor properties

\section{Energy levels}

See: Atomic energy levels and spectra Molecular energy levels and constants

\section{Energy transfer coefficients}

Data Index for Energy Transfer Collisions of Atoms and Molecules - 1970-1979 - Jean W. Gallagher, Janet Van Blerkom, Earl C. Beaty, and John R. Rumble, Jr. NBS Spec. Publ. 593, 349p. (1981).

Rate Coefficients for Vibrational Energy Transfer Involving the $\mathrm{Hy}-$ drogen Halides - Stephen R. Leone. J Phys Chem Ref Data 11, 953(1982).

Rate Data for Inelastic Collision Processes in the Diatomic Halogen Molecules - J. I. Steinfeld. J Phys Chem Ref Data 13, 445(1984).

\section{Energy, binding}

See: Bond Dissociation energy Bond dissociation energy Electron affinity

\section{Energy, dissociation}

See: Bond dissociation energy Thermodynamic properties

\section{Enthalpy}

See: Thermodynamic properties

\section{Enthalpy of formation}

See: Heat of formation

Thermodynamic properties

\section{Entropy}

See: Thermodynamic properties

\section{Equation of state}

A Fundamental Equation of State for Heavy Water - P. G. Hill, R. D. Chris MacMillan, and V. Lee. J Phys Chem Ref Data 11, 1(1982).

A Review, Evaluation, and Correlation of the Phase Equilibria, Heat of Mixing, and Change in Volume on Mixing for Liquid Mixtures of Methane + Ethane - M. J. Hiza, R. C. Miller, and Arthur J. Kianay. J Phys Chem Ref Data 8, 799(1979).

A Review, Evaluation, and Correlation of the Phase Equilibria, Heat of Mixing, and Change in Volume on Mixing for Liquid Mixtures of Methane + Propane - R. C. Miller, Arthur J. Kidnay, and M. J. Hiza. J Phys Chem Ref Data 9, 721(1980).

A Review of Deuterium Triple-Point Temperatures - L. A. Schwalbe and E. R. Grilly. J Phys Chem Ref Data 13, 687(1984).

A Thermodynamic Surface for Water: The Formulation and Computer Program - Lester Haar, John S. Gallagher, and George S. Kell. NBSIR 81-2253, 38p. (1981).

An Analysis of Coexistence Curve Data for Several Binary Liquid Mixtures Near Their Critical Points - A. Stein and G. F. Allen. J Phys Chem Ref Data 2, 439(1973).

An Equation of State for Fluid Ethylene - Robert D. McCarty and Richard T. Jacobsen. NBS Tech. Note 1045, 164p. (1981).

Critical Evaluation of Vapor-Liquid Equilibrium, Heat of Mixing, and Volume Change of Mixing Data. General Procedures - Buford D. Smith, O1 Muthu, Ashok Dewan, and Matthew Gierlach. J Phys Chem Ref Data 11, 941(1982).

Definition of Recommended Values of Certain Thermodynamic Properties for the Ketones - Buford D. Smith and Ol Muthu. NBSIR 84-2811, 162p. (1983).

Effects of Isotopic Composition, Temperature, Pressure, and Dissolved Gases on the Density of Liquid Water - George S. Kell. J Phys Chem Ref Data 6, 1109(1977).

Equation of State for Ammonia - Lester Haar and John S. Gallagher. NBSIR 75-770, 27p. (1975).

Equilibrium and Transport Properties of the Noble Gases and Their Mixtures at Low Density - Joseph Kestin, K. Knierim, E. A. Mason, B. Najafi, S. T. Ro, and M. Waldman. J Phys Chem Ref Data 13, 229(1984).

Erratum: A Fundamental Equation of State for Heavy Water - P. G. Hill, R. D. Chris MacMillan, and V. Lee. J Phys Chem Ref Data 12, 1065(1983).

Evaluation of Binary PTxy Vapor-Liquid Equilibrium Data for $\mathrm{C}_{6}$ Hydrocarbons. Benzene + Cyclohexane - Buford D. Smith, Ol Muthu, Ashok Dewan, and Matthew Gierlach. J Phys Chem Ref Data 11, 1099(1982).

Evaluation of Binary Excess Volume Data for $\mathrm{C}_{6}$ Hydrocarbons. Benzene + Cyclohexane - Buford D. Smith, Ol Muthu, Ashok Dewan, and Matthew Gierlach. J Phys Chem Ref Data 11, 1151(1982).

Evaluation of Binary PTxy Vapor-Liquid Equilibrium Data for $\mathrm{C}_{6}$ Hydrocarbons. Benzene + Hexane - Buford D. Smith, Ol Muthu, and Ashok Dewan. J Phys Chem Ref Data 12, 381(1983).

Evaluation of Binary Excess Volume Data for $\mathrm{C}_{6}$ Hydrocarbons. Benzene + Hexane - Buford D. Smith, O1 Muthu, and Ashok Dewan. J Phys Chem Ref Data 12, 395(1983).

Heavy Water, Thermophysical Properties - V. A. Kirillin, Ya. Z. Kazavchinskii, P. M. Kessel'man, S. L. Rivkin, A. E. Sheindlin, E. E. Shpil'rain, V. V. Sychev, and D. L. Timrot. Russian Transl., Springfield, VA: NTIS, 273p. (1971). TT 70-50094, A 12.

High Pressure Bibliography 1900-1968, Volume I. Section I. Bibliography, Section II. Author Index - Leo Merrill. OSRD Bibl. 70-1, Vol. 1(1970).

High Pressure Bibliography 1900-1968, Volume II. Subject Index Leo Merrill. OSRD Bibl. 70-1, Vol. 2(1970).

High-Pressure Calibration: A Critical Review - D. L. Decker, W. A. Bassett, Leo Merrill, H. T. Hall, and J. D. Barnett. J Phys Chem Ref Data 1, 773(1972).

Interactive FORTRAN Program to Calculate Thermophysical Properties of Seven Fluids - Ben A. Younglove. NBS Tech. Note 1048, 56p. (1982) 
Phase Behavior in Binary and Multicomponent Systems at Elevated Pressures: n-Pentane and Methane-n-Pentane - Virginia M. Berry and Bruce H. Sage. NSRDS-NBS 32, 79p. (1970).

Physical and Thermodynamic Properties of Aliphatic Alcohols Randolph C. Wilhoit and Bruno J. Zwolinski. J Phys Chem Ref Data 2, Suppl. 1(1973).

Saturation States of Heavy Water - P. G. Hill and R. D. Chris MacMillan. J Phys Chem Ref Data 9, 735(1980).

Scaled Equation of State Parameters for Gases in the Critical Region - J. M. H. Levelt Sengers, W. L. Greer, and Jan V. Sengers. J Phys Chem Ref Data 5, 1(1976).

The Critical-Region Equation of State of Ethene and the Effect of Small Impurities - J. R. Hastings, J. M. H. Levelt Sengers, and F. W. Balfour. J Chem Thermody 12, London: Academic Press Inc., 1009p. (1980).

The Calculated Thermodynamic Properties of Superfluid Helium-4 - James S. Brooks and Russell J. Donnelly. J Phys Chem Ref Data 6, 51(1977).

The Molar Volume (Density) of Solid Oxygen in Equilibrium with Vapor - Hans M. Roder. J Phys Chem Ref Data 7, 949(1978).

Thermodynamic Properties of Argon from the Triple Point to $300 \mathrm{~K}$ at Pressures to 1000 Atmospheres - A. L. Gosman, Robert D. McCarty, and Jerome G. Hust. NSRDS-NBS 27, 153p. (1969).

Thermophysical Properties of Isobutane from 114 to $700 \mathrm{~K}$ at Pressures to $70 \mathrm{MPa}$ - Robert D. Goodwin and W. M. Haynes. NBS Tech. Note 1051, 199p. (1982).

Thermodynamic and Related Properties of Parahydrogen from the Triple Point to $100 \mathrm{~K}$ at Pressures to 340 Atmospheres - Hans M. Roder, Lloyd A. Weber, and Robert D. Goodwin. NBS Monograph 94, 116p. (1965).

Thermophysical Properties of Normal Butane from 135 to $700 \mathrm{~K}$ at Pressures to $70 \mathrm{MPa}-$ W. M. Haynes and Robert D. Goodwin. NBS Monograph 169, 197p. (1982).

Thermodynamic and Thermophysical Properties of Helium - A. F. Alyab'ev, N. V. Tsederberg, V. N. Popov, and N. A. Morozova. Russian Transl., Springfield, VA: NTIS, 260p. (1971). TT 70-50096, A 12.

Thermodynamic and Transport Properties of Ethylene and Propylene - I. A. Neduzhii. Russian Transl. Springfield, VA: NTIS, 206p. (1972). COM 75-11276, A 10.

Thermophysical Properties of Air and Air Components - A. A. Vasserman, Ya. Z. Kazavchinskii, V. A. Rabinovich, and A. M. Zhuravlev. Russian Transl. Springfield, VA: NTIS, 402p. (1971). TT 70-50095, A 18.

Thermophysical Properties of Gases and Liquids, No. 1 - V. A. Rabinovich. Russian Transl. Springfield, VA: NTIS, 214p. (1970). TT 69-55091, A 10, the translation of volumes 2, 3, and 4 have the title: Thermophysical Properties of Matter and Substances.

Thermophysical Properties of Gaseous and Liquid Methane - V. A. Zagoruchenko and A. M. Zhuravlev. Russian Transl. Springfield, VA: NTIS, 251p. (1970). TT 70-50097, A 12.

Thermophysical Properties of Liquid Air and Its Components - A. A. Vasserman and V. A. Rabinovich. Russian Transl. Springfield, VA: NTIS, 255p. (1970). TT 69-55092, A 12.

Thermophysical Properties of Matter and Substances, Volume 2 V. A. Rabinovich. Russian Transl., Springfield, VA: NTIS, 395p. (1974). TT 72-52001, A17, the translation of volume 1 has the title: Thermophysical Properties of Gases and Liquids.

Thermophysical Properties of Matter and Substances, Volume 3 V. A. Rabinovich. Russian Transl. Springfield, VA: NTIS, 212p. (1975). TT 73-52009, A 10, the translation of volume 1 has the title: Thermophysical Properties of Gases and Liquids.

Thermophysical Properties of Hydrocarbon Mixtures (TRAPP) NBS Standard Reference Database 4, Washington, D.C.; NBS, Office of Standard Reference Data,(updated periodically). Call (301)921-2228 for specific instructions.

Thermophysical Properties of Helium NBS Standard Reference Database 5, Washington, D.C.; NBS, Office of Standard Reference Data,(updated periodically). Call (301)921-2228 for specific instructions.
Thermodynamic Properties of Nitrogen Including Liquid and Vapor Phases from $63 \mathrm{~K}$ to $2000 \mathrm{~K}$ with Pressures to $10,000 \mathrm{Bar}$ - Richard T. Jacobsen and Richard B. Stewart. J Phys Chem Ref Data 2, 757(1973).

Thermodynamic Properties of Helium-4 from 2 to $1500 \mathrm{~K}$ at Pressures to $10^{8} \mathrm{~Pa}$ - Robert D. McCarty. J Phys Chem Ref Data 2, 923(1973).

Thermodynamic Properties of Ammonia - Lester Haar and John S. Gallagher. J Phys Chem Ref Data 7, 635(1978).

Thermodynamic Properties of Steam in the Critical Region - J. M. H. Levelt Sengers, B. Kamgar-Parsi, F. W. Balfour, and Jan V. Sengers. J Phys Chem Ref Data 12, 1(1983).

Thermodynamic Properties of $\mathrm{D}_{2} \mathrm{O}$ in the Critical Region - B. Kamgar-Parsi, J. M. H. Levelt Sengers, and Jan V. Sengers. J Phys Chem Ref Data 12, 513(1983).

Thermodynamic Properties of Aqueous Sodium Chloride Solutions - Kenneth S. Pitzer, J. Christopher Peiper, and R. H. Busey. J Phys Chem Ref Data 13, 1(1984).

Thermophysical Properties of Fluid $\mathrm{H}_{2} \mathrm{O}$ - Joseph Kestin, Jan V. Sengers, B. Kamgar-Parsi, and J. M. H. Levelt Sengers. J Phys Chem Ref Data 13, 175(1984).

Thermophysical Properties of Fluid $\mathrm{D}_{2} \mathrm{O}$ - Joseph Kestin, Jan V. Sengers, B. Kamgar-Parsi, and J. M. H. Levelt Sengers. J Phys Chem Ref Data 13, 602(1984).

Volumetric Properties of Aqueous Sodium Chloride Solutions - P. S. Z. Rogers and Kenneth S. Pitzer. J Phys Chem Ref Data 11, 15(1982).

\section{Equilibrium constant}

A Critical Review of the Gas-Phase Reaction Kinetics of the Hydroxyl Radical - William E. Wilson, Jr. J Phys Chem Ref Data 1, 535(1972).

An Annotated Bibliography of Compiled Thermodynamic Data Sources for Biochemical and Aqueous Systems (1930 to 1975), Equilibrium, Enthalpy, Heat Capacity, and Entropy Data - George T. Armstrong and Robert N. Goldberg. NBS Spec. Publ. 454, 71p. (1976).

Bulletin of Chemical Thermodynamics, Volume 24/1981 - Robert D. Freeman, editor(s) and International Union of Pure and Applied Chemistry, Commission 1.2 on Thermodynamics. Bull Chem Thermody 24, Stillwater, OK: Thermochemistry, Department of Chemistry, Oklahoma State University, 504p. (1982). 0149-2268, bona fide personal subscriptions are less; prices of previous Bulletins available upon request.

Bulletin of Chemical Thermodynamics, Volume 25/1982 - Robert D. Freeman and International Union of Pure and Applied Chemistry. Bull Chem Thermody 25, Stillwater, OK: Thermochemistry, Department of Chemistry, Oklahoma State University, 544p. (1982). 0149-2268, bona fide personal subscriptions are less; prices of previous Bulletins are available upon request.

Compilation and Evaluation of Solubility Data in the Mercury (I) Chloride-Water System - Y. Marcus. J Phys Chem Ref Data 9, 1307(1980).

Evaluated Chemical Kinetic Rate Constants for Various Gas Phase Reactions - Keith Schofield. J Phys Chem Ref Data 2, 25(1973).

Gas Phase Reaction Kinetics of Neutral Oxygen Species - Harold S. Johnston. NSRDS-NBS 20, 49p. (1968).

High Temperature Properties and Decomposition of Inorganic Salts, Part 1. Sulfates - Kurt H. Stern and E. L. Weise. NSRDS-NBS 7, 38p. (1966).

High Temperature Properties and Decomposition of Inorganic Salts, Part 2. Carbonates - Kurt H. Stern and E. L. Weise. NSRDS-NBS 30, 27p. (1969).

High Temperature Properties and Decomposition of Inorganic Salts, Part 3. Nitrates and Nitrites - Kurt H. Stern. J Phys Chem Ref Data 1, 747(1972).

Ion Product of Water Substance, $0-1000^{\circ} \mathrm{C}, 1-10,000$ Bars. New International Formulation and Its Background - William L. Marshall and E. U. Franck. J Phys Chem Ref Data 10, 295(1981) 
Rate Constants of Gas Phase Reactions, Reference Book - V. N. Kondratiev, L. J. Holtschlag, R. M. Fristrom, editor(s). Russian Transl., Springfield, VA: NTIS, 434p. (1972). COM 72-10014, A19.

The Solubility of Some Sparingly Soluble Lead Salts: An Evaluation of the Solubility in Water and Aqueous Electrolyte Solution - $\mathrm{H}$. Lawrence Clever and Francis J. Johnston. J Phys Chem Ref Data 9, 751(1980)

\section{'Equivalent conductance}

See: Electrical conductance

\section{Eutectic data}

Physical Properties Data Compilations Relevant to Energy Storage. I. Molten Salts: Eutectic Data - George J. Janz, Carolyn B. Allen, J. R. Downey, Jr., and Reginald P. T. Tomkins. NSRDS-NBS 61, 244p. (1978).

\section{Evaporation and condensation coefficients}

Selected Values of Evaporation and Condensation Coefficients for Simple Substances - G. M. Pound. J Phys Chem Ref Data 1, 135(1972).

\section{Excitation potential}

See: Atomic energy levels and spectra

\section{F-values}

See: Transition probabilities for atoms and molecules

\section{Force constants}

Binary Fluorides, Free Molecular Structures and Force Fields, A Bibliography (1957-1975) - Donald T. Hawkins, Lawrence S. Bernstein, Warren E. Falconer, and William Klemperer., New York: IFI/Plenum, 253p. (1976), ISBN: 0-306-6601-3.

Critical Review of Vibrational Data and Force Field Constants for Polyethylene - John Barnes and Bruno Fanconi. J Phys Chem Ref Data 7, 1309(1978).

Tables of Molecular Vibrational Frequencies, Part 9 - Takehiko Shimanouchi, Hiroatsu Matsuura, Yoshiki Ogawa, and Issei Harada. J Phys Chem Ref Data 7, 1323(1978).

Tables of Molecular Vibrational Frequencies, Part 10 - Takehiko Shimanouchi, Hiroatsu Matsuura, Yoshiki Ogawa, and Issei Harada. J Phys Chem Ref Data 9, 1149(1980).

\section{Formation, heat of}

See: Heat of formation Thermodynamic properties

\section{Franck-Condon factor}

See: Transition probabilities for atoms and molecules

\section{Free energy}

See: Thermodynamic properties

\section{Frequencies, vibrational}

See: Vibrational frequencies of molecules

\section{Fundamental physical constants}

Energy Levels of One-Electron Atoms - Glen W. Erickson. J Phys Chem Ref Data 6, 831(1977).

Numerical Comparisons of Several Algorithms for Treating Inconsistent Data in a Least-Squares Adjustment of the Fundamental Constants - Barry N. Taylor. NBSIR 81-2426, 87p. (1982).
The 1973 Least-Squares Adjustment of the Fundamental Constants - E. Richard Cohen and Barry N. Taylor. J Phys Chem Ref Data 2, 663(1973).

\section{G-Factor}

See: Magnetic moments of molecules

\section{Gaseous diffusion coefficient}

See: Diffusion coefficient

\section{Gibbs energy}

See: Thermodynamic properties

\section{Hardness data}

Handbook of Hardness Data - G. V. Samsonov and A. A. Ivan'ko. Russian Transl., Springfield, VA: NTIS, 69p. (1970). TT 70-50177, A04.

\section{Heat capacity (see also Thermodynamic properties)}

A Bibliography of Sources of Experimental Data Leading to Thermal Properties of Binary Aqueous Electrolyte Solutions - David Smith-Magowan and Robert N. Goldberg. NBS Spec. Publ. 537, 94p. (1979).

A Thermodynamic Surface for Water: The Formulation and Computer Program - Lester Haar, John S. Gallagher, and George S. Kell. NBSIR 81-2253, 38p. (1981).

An Annotated Bibliography of Compiled Thermodynamic Data Sources for Biochemical and Aqueous Systems (1930 to 1975), Equilibrium, Enthalpy, Heat Capacity, and Entropy Data - George T. Armstrong and Robert N. Goldberg. NBS Spec. Publ. 454, 71p. (1976).

Analysis of Specific Heat Data in the Critical Region of Magnetic Solids - F. J. Cook. J Phys Chem Ref Data 2, 11(1973).

Bulletin of Chemical Thermodynamics, Volume 24/1981 - Robert D. Freeman, editor(s) and International Union of Pure and Applied Chemistry, Commission 1.2 on Thermodynamics. Bull Chem Thermody 24, Stillwater, OK: Thermochemistry, Department of Chemistry, Oklahoma State University, 504p. (1982). 0149-2268, bona fide personal subscriptions are less; prices of previous Bulletins available upon request.

Bulletin of Chemical Thermodynamics, Volume 25/1982 - Robert D. Freeman and International Union of Pure and Applied Chemistry. Bull Chem Thermody 25, Stillwater, OK: Thermochemistry, Department of Chemistry, Oklahoma State University, 544p. (1982). 0149-2268, bona fide personal subscriptions are less; prices of previous Bulletins are available upon request.

Chemical Thermodynamic Properties of Compounds of Sodium, Potassium, and Rubidium: An Interim Tabulation of Selected Material Donald D. Wagman, William H. Evans, Vivian B. Parker, and Richard H. Schumm. NBSIR 76-1034, 76p. (1976).

Combustion Fundamen als for Waste Incineration - American Society of Mechanical Engineers, Research Committee on Industrial and Municipal Wastes., New York: American Society of Mechanical Engineers, 212p. (1974).

Critical Analysis of the Heat-Capacity Data of the Literature and Evaluation of Thermodynamic Properties of Copper, Silver, and Gold from 0 to $300 \mathrm{~K}-$ George T. Furukawa, W. G. Saba, and Martin L. Reilly. NSRDS-NBS 18, 49p. (1968).

Critical Analysis of Heat-Capacity Data and Evaluation of Thermodynamic Properties of $\mathrm{Ru}, \mathrm{Ph}, \mathrm{Pd}, \mathrm{Ir}$, and $\mathrm{Pt}$ from 0 to $300 \mathrm{~K}$. A Survey of the Literature Data on Osmium - George T. Furukawa, Martin L. Reilly, and John S. Gallagher. J Phys Chem Ref Data 3, 163(1974).

Heat Capacity and Other Thermodynamic Properties of Linear Macromolecules. I. Selenium - Umesh Gaur, Hua-Cheng Shu, Aspy Metha, and Bernhard Wunderlich. J Phys Chem Ref Data 10, 89(1981) 
Heat Capacity and Other Thermodynamic Properties of Linear Macromolecules. II. Polyethylene - Umesh Gaur and Bernhard Wunderlich. J Phys Chem Ref Data 10, 119(1981).

Heat Capacity and Other Thermodynamic Properties of Linear Macromolecules. III. Polyoxides - Umesh Gaur and Bernhard Wunderlich. J Phys Chem Ref Data 10, 1001(1981).

Heat Capacity and Other Thermodynamic Properties of Linear Macromolecules. IV. Polypropylene - Umesh Gaur and Bernhard Wunderlich. J Phys Chem Ref Data 10, 1051(1981).

Heat Capacity and Other Thermodynamic Properties of Linear Macromolecules. V. Polystyrene - Umesh Gaur and Bernhard Wunderlich. J Phys Chem Ref Data 11, 313(1982).

Heat Capacity and Other Thermodynamic Properties of Linear Macromolecules. VI. Acrylic Polymers - Umesh Gaur, Suk-fai Lau, Brent B. Wunderlich, and Bernhard Wunderlich. J Phys Chem Ref Data 11, 1065(1982).

Heat Capacity and Other Thermodynamic Properties of Linear Macromolecules. VII. Other Carbon Backbone Polymers - Umesh Gaur, Brent B. Wunderlich, and Bernhard Wunderlich. J Phys Chem Ref $\mathrm{Da}^{ \pm}$2 12, 29(1983).

Heat Capacity and Other Thermodynamic Properties of Linear Macromoiecules. VIII. Polyesters and Polyamides - Umesh Gaur, Suk-fai Lau, Brent B. Wunderlich, and Bernhard Wunderlich. J Phys Chem Ref Data 12, 65(1983).

Heat Capacity and Other Thermodynamic Properties of Linear Macromolecules. IX. Final Group of Aromatic and Inorganic Polymers Umesh Gaur, Suk-fai Lau, and Bernhard Wunderlich. J Phys Chem Ref Data 12, 91(1983).

Heat Capacity of Reference Materials: $\mathrm{Cu}$ and W - G. K. White and S. J. Collocott. J Phys Chem Ref Data 13, 1251(1984).

Heat Capacities and Entropies of Organic Compounds in the Condensed Phase - Eugene S. Domalski, William H. Evans, and Elizabeth D. Hearing. J Phys Chem Ref Data 13, Suppl. 1(1984).

Heavy Water, Thermophysical Properties - V. A. Kirillin, Ya. Z. Kazavchinskii, P. M. Kessel'man, S. L. Rivkin, A. E. Sheindlin, E. E. Shpil'rain, V. V. Sychev, and D. L. Timrot. Russian Transl., Springfield, VA: NTIS, 273p. (1971). TT 70-50094, A 12.

Interactive Fortran Program to Calculate Thermophysical Properties of 6 Fluids NBS Standard Reference Database 6, Washington, DC; NBS, Office of Standard Reference Data,(updated periodically). Call (301) $921-2228$ for specific instructions.

Isochoric Heat Capacity of Water and Steam - M. P. Vukalovich, Kh. I. Amirkhanov, G. V. Stepanov, and B. G. Alibekov. Russian Transl., Springfield, VA: NTIS, 215p. (1974). TT 72-52002, A 10.

NBS Chemical Thermodynamics Database NBS Standard Reference Database 2, Washington, DC; NBS, Office of Standard Reference Data,(updated periodically). Call (301)921-2228 for specific instructions.

Properties of Liquid and Solid Hydrogen - B. N. Esel'son, Y. P. Blagoi, V.N. Grigor'ev, V. G. Manzhelii, S. A. Mikhailenko, and N. P. Neklyudov. Russian Transl., Springfield, VA: NTIS, 126p. (1971). TT 70-50179, A07.

Selected Values of Chemical Thermodynamic Properties. Tables for the First Thirty-Four Elements in the Standard Order of Arrangement - Donald D. Wagman, William H. Evans, Vivian B. Parker, Iva Halow, Sylvia M. Bailey, and Richard H. Schumm. NBS Tech. Note 270, 264p. (1968).

Selected Values of Chemical Thermodynamic Properties. Tables for Elements 35 through 53 in the Standard Order of Arrangement Donald D. Wagman, William H. Evans, Vivian B. Parker, Iva Halow, Sylvia M. Bailey, and Richard H. Schumm. NBS Tech. Note 270, 152p. (1969).

Selected Values of Chemical Thermodynamic Properties. Tables for Elements 54 through 61 in the Standard Order of Arrangement Donald D. Wagman, William H. Evans, Vivian B. Parker, Iva Halow, Sylvia M. Bailey, Richard H. Schumm, and Kenneth L. Churney. NBS Tech. Note 270, 49p. (1971).

Selected Values of Chemical Thermodynamic Properties. Tables for the Alkaline Earth Elements (Elements 92 through 97 in the Standard
Order of Arrangement) - Vivian B. Parker, Donald D. Wagman, and William H. Evans. NBS Tech. Note 270, 124p. (1971).

Selected Values of Chemical Thermodynamic Properties. Tables for the Lanthanide (Rare Earth) Elements (Elements 62 through 76 in the Standard Order of Arrangement) - Richard H. Schumm, Donald D. Wagman, Sylvia M. Bailey, William H. Evans, and Vivian B. Parker. NBS Tech. Note 270, 84p. (1973).

Selected Values of Chemical Thermodynamic Properties: Compounds of Uranium, Protactinium, Thorium, Actinium, and the Alkali Metals - Donald D. Wagman, William H. Evans, Vivian B. Parker, Richard H. Schumm, and Ralph L. Nuttall. NBS Tech. Note 270, 149p. (1981).

Selected Thermochemical Data Compatible with CODATA Recommendations - Vivian B. Parker, Donald D. Wagman, and David Garvin. NBSIR 75-968, 35p. (1976).

The Thermochemical Properties of Uranium-Halogen Containing Compounds - Vivian B. Parker. NBSIR 80-2029, 173p. (1980).

The NBS Tables of Chemical Thermodynamic Properties. Selected Values for Inorganic and $C_{1}$ and $C_{2}$ Organic Substances in SI Units Donald D. Wagman, William H. Evans, Vivian B. Parker, Richard H. Schumm, Iva Halow, Sylvia M. Bailey, Kenneth L. Churney, and Ralph L. Nuttall. J Phys Chem Ref Data 11, Suppl. 2(1982).

Thermal Properties of Aqueous Uni-Univalent Electrolytes Vivian B. Parker. NSRDS-NBS 2, 68p. (1965).

Thermophysical Properties of Isobutane from 114 to $700 \mathrm{~K}$ at Pressures to $70 \mathrm{MPa}$ - Robert D. Goodwin and W. M. Haynes. NBS Tech. Note 1051, 199p. (1982).

Thermodynamic and Related Properties of Parahydrogen from the Triple Point to $100 \mathrm{~K}$ at Pressures to 340 Atmospheres - Hans M. Roder, Lloyd A. Weber, and Robert D. Goodwin. NBS Monograph 94, $116 \mathrm{p}$. (1965).

Thermophysical Properties of Normal Butane from 135 to $700 \mathrm{~K}$ at Pressures to $70 \mathrm{MPa}-$ W. M. Haynes and Robert D. Goodwin. NBS Monograph 169, 197p. (1982).

Thermodynamic Properties of Solid Aluminosilicates at Elevated Temperatures - Richard H. Schumm. NBSIR 81-2343, 57p. (1981).

Thermodynamic and Thermophysical Properties of Combustion Products, Volume II. Oxygen-Based Propellants - V. P. Glushko, V. E. Alemasov, A. F. Dregalin, A. P. Tishin, V. A. Khudyakov, and V. N. Kostin. Russian Transl,, Springfield, VA: NTIS, 505p. (1975). TT 74-50032, A22.

Thermodynamic and Thermophysical Properties of Combustion Products, Volume IIl. Oxygen- and Air-Based Propellant - V. P. Glushko, V. E. Alemasov, A. F. Dregalin, A. P. Tishin, V. A. Khudyakov, and V. N. Kostin. Russian Transl., Springfield, VA: NTIS, 648p. (1975). TT 75-50007, A26.

Thermodynamic and Thermophysical Properties of Combustion Products, Volume IV. Nitrogen Tetroxide-Based Propellants - V. P. Glushko, V. E. Alemasov, A. F. Dregalin, A. P. Tishin, V. A. Khudyakov, and V. N. Kostin. Russian Transl., Springfield, VA: NTIS, 540p. (1976). TT 76-50007, A23.

Thermodynamic and Thermophysical Properties of Helium - A. F. Alyab'ev, N. V. Tsederberg, V. N. Popov, and N. A. Morozova. Russian Transl., Springfield, VA: NTIS, 260p. (1971). TT 70-50096, A12.

Thermodynamic and Transport Properties of Ethylene and Propylene - I. A. Neduzhii. Russian Transl. Springfield, VA: NTIS, 206p. (1972). COM 75-11276, A 10.

Thermophysical Properties of Freon-22 - A. V. Kletskii. Russian Transl. Springfield, VA: NTIS, 72p. (1971). TT 70-50178, A04.

Thermophysical Properties of Gaseous and Liquid Methane - V. A. Zagoruchenko and A. M. Zhuravlev. Russian Transl. Springfield, VA: NTIS, 251p. (1970). TT 70-50097, A12.

Thermophysical Properties of Matter and Substances, Volume $2-$ V. A. Rabinovich. Russian Transl., Springfield, VA: NTIS, 395p. (1974). TT 72-52001, A17, the translation of volume 1 has the title: Thermophysical Properties of Gases and Liquids.

Thermophysical Properties of Matter and Substances, Volume $4-$ V. A. Rabinovich. Russian Transl., Springfield, VA: NTIS, 179p. 
(1975). TT 73-52029, A09, the translation of volume 1 has the title: Thermophysical Properties of Gases and Liquids.

Thermodynamic Tabulations for Selected Phases in the System $\mathrm{CaO}$ $\mathrm{Al}_{2} \mathrm{O}_{3}-\mathrm{SiO}_{2}-\mathrm{H}_{2} \mathrm{O}$ at $101.325 \mathrm{kPa}$ ( $1 \mathrm{~atm}$.) between 273.15 and $1800 \mathrm{~K}-$ John L. Haas, Jr., Gilpin R. Robinson, Jr., and Bruce S. Hemingway. J Phys Chem Ref Data 10, 575(1981).

Thermophysical Properties of Fluids. I. Argon, Ethylene, Parahydrogen, Nitrogen, Nitrogen Trifluoride, and Oxygen - Ben A. Younglove. J Phys Chem Ref Data 11, Suppl. 1(1982).

Thermodynamic Properties of Aqueous Sodium Chloride Solutions - Kenneth S. Pitzer, J. Christopher Peiper, and R. H. Busey. J Phys Chem Ref Data 13, 1(1984).

\section{Heat of combustion}

Chemical Kinetics of the Gas Phase Combustion of Fuels (A Bibliography on the Rates and Mechanisms of Oxidation of Aliphatic $C_{1}$ to $\mathrm{C}_{10}$ Hydrocarbons and of Their Oxygenated Lerivatives) - Francis Westley. NBS Spec. Publ. 449, 142p. (1976).

Combustion Fundamentals for Waste Incineration - American Society of Mechanical Engineers, Research Committee on Industrial and Municipal Wastes., New York: American Society of Mechanical Engineers, 212p. (1974).

Selected Values of Heats of Combustion and Heats of Formation of Organic Compounds Containing the Elements C, H, N, O, P, and S Eugene S. Domalski. J Phys Chem Ref Data 1, 221(1972).

Table of Recommended Rate Constants for Chemical Reactions Occurring in Combustion - Francis Westley. NBSIR 79-1941, 169p. (1979).

Tables of Experimental Rate Constants for Chemical Reactions Occurring in Combustion (1971-1977) - Francis Westley. NBSIR 81-2254, 302p. (1981).

Thermodynamic and Thermophysical Properties of Combustion Products, Volume I. Computation Methods - V. P. Glushko, V. E. Alemasov, A. F. Dregalin, A. P. Tishin, and V. A. Khudyakov. Russian Transl., Springfield, VA: NTIS, 453p. (1974). TT 74-50019, A20.

Thermodynamic and Thermophysical Properties of Combustion Products, Volume III. Oxygen- and Air-Based Propellant - V. P. Glushko, V. E. Alemasov, A. F. Dregalin, A. P. Tishin, V. A. Khudyakov, and V. N. Kostin. Russian Transl., Springfield, VA: NTIS, 648p. (1975). TT 75-50007, A26.

Thermodynamic and Thermophysical Properties of Combustion Products, Volume IV. Nitrogen Tetroxide-Based Propellants - V. P. Glushko, V. E. Alemasov, A. F. Dregalin, A. P. Tishin, V. A. Khudyakov, and V. N. Kostin. Russian Transl., Springfield, VA: NTIS,

\section{Heat of formation (see also Thermodynamic properties)}

Annotated Bibliography on Proton Affinities - K. N. Hartman, Sharon G. Lias, P. J. Ausloos, and Henry M. Rosenstock. NBSIR 76-1061, 52p. (1976).

Energetics of Gaseous Ions - Henry M. Rosenstock, Keith Draxl, B. W. Steiner, and John T. Herron. J Phys Chem Ref Data 6, Suppl. 1(1977).

Evaluated Gas Phase Basicities and Proton Affinities of Molecules: Heats of Formation of Protonated Molecules - Sharon G. Lias, Joel F. Liebman, and Rhoda D. Levin. J Phys Chem Ref Data 13, 695(1984).

High Temperature Properties and Decomposition of Inorganic Salts,

Part 1. Sulfates - Kurt H. Stern and E. L. Weise. NSRDS-NBS 7, 38p. (1966).

High Temperature Properties and Decomposition of Inorganic Salts, Part 2. Carbonates - Kurt H. Stern and E. L. Weise. NSRDS-NBS 30, 27p. (1969).

High Temperature Properties and Decomposition of Inorganic Salts, Part 3. Nitrates and Nitrites - Kurt H. Stern. J Phys Chem Ref Data 1, 747(1972).

High Temperature Properties and Decomposition of Inorganic Salts, Part 4. Oxy-Salts of the Halogens - Kurt H. Stern. J Phys Chem Ref Data 3, 481(1974).
High Temperature Vaporization Behavior of Oxides. I. Alkali Metal Binary Oxides - R. H. Lamoreaux and D. L. Hildenbrand. J Phys Chem Ref Data 13, 151(1984).

Ionization Potentials, Appearance Potentials, and Heats of Formation of Gaseous Positive Ions - Joseph L. Franklin, J. G. Dillard, Henry M. Rosenstock, John T. Herron, Keith Draxl, and Frank H. Field. NSRDS-NBS 26, 289p. (1969).

Kinetic Data on Gas Phase Unimolecular Reactions - Sidney W. Benson and Harry E. O'Neal. NSRDS-NBS 21, 645p. (1970).

Selected Values of Chemical Thermodynamic Properties. Tables for the First Thirty-Four Elements in the Standard Order of Arrangement - Donald D. Wagman, William H. Evans, Vivian B. Parker, Iva Halow, Sylvia M. Bailey, and Richard H. Schumm. NBS Tech. Note 270, 264p. (1968).

Selected Values of Chemical Thermodynamic Properties. Tables for Elements 35 through 53 in the Standard Order of Arrangement Donald D. Wagman, William H. Evans, Vivian B. Parker, Iva Halow, Sylvia M. Bailey, and Richard H. Schumm. NBS Tech. Note 270, 152p. (1969).

Selected Values of Chemical Thermodynamic Properties. Tables for Elements 54 through 61 in the Standard Order of Arrangement Donald D. Wagman, William H. Evans, Vivian B. Parker, Iva Halow, Sylvia M. Bailey, Richard H. Schumm, and Kenneth L. Churney. NBS Tech. Note 270, 49p. (1971).

Selected Values of Chemical Thermodynamic Properties. Tables for the Alkaline Earth Elements (Elements 92 through 97 in the Standard Order of Arrangement) - Vivian B. Parker, Donald D. Wagman, and William H. Evans. NBS Tech. Note 270, 124p. (1971).

Selected Values of Chemical Thermodynamic Properties. Tables for the Lanthanide (Rare Earth) Elements (Elements 62 through 76 in the Standard Order of Arrangement) - Richard H. Schumm, Donald D. Wagman, Sylvia M. Bailey, William H. Evans, and Vivian B. Parker. NBS Tech. Note 270, 84p. (1973).

Selected Values of Chemical Thermodynamic Properties: Compounds of Uranium, Protactinium, Thorium, Actinium, and the Alkali Metals - Donald D. Wagman, William H. Evans, Vivian B. Parker, Richard H. Schumm, and Ralph L. Nuttall. NBS Tech. Note 270, 149p. (1981).

Selected Thermochemical Data Compatible with CODATA Recommendations - Vivian B. Parker, Donald D. Wagman, and David Garvin. NBSIR 75-968, 35p. (1976).

Selected Values of Heats of Combustion and Heats of Formation of Organic Compounds Containing the Elements $\mathrm{C}, \mathrm{H}, \mathrm{N}, \mathrm{O}, \mathrm{P}$, and S Eugene S. Domalski. J Phys Chem Ref Data 1, 221(1972).

The NBS Tables of Chemical Thermodynamic Properties. Selected Values for Inorganic and $C_{1}$ and $C_{2}$ Organic Substances in SI Units Donald D. Wagman, William H. Evans, Vivian B. Parker, Richard H. Schumm, Iva Halow, Sylvia M. Bailey, Kenneth L. Churney, and Ralph L. Nuttall. J Phys Chem Ref Data 11, Suppl. 2(1982).

Thermodynamic and Thermophysical Properties of Combustion Products, Volume III. Oxygen- and Air-Based Propellant - V. P. Glushko, V. E. Alemasov, A. F. Dregalin, A. P. Tishin, V. A. Khudyakov, and V. N. Kostin. Russian Transl., Springfield, VA: NTIS, 648p. (1975). TT 75-50007, A26.

Thermochemical Data for Gaseous Monoxides - J. B. Pedley and E. M. Marshall. J Phys Chem Ref Data 12, 967(1983).

\section{Heat of mixing}

A Review, Evaluation, and Correlation of the Phase Equilibria, Heat of Mixing, and Change in Volume on Mixing for Liquid Mixtures of Methane + Ethane - M. J. Hiza, R. C. Miller, and Arthur J. Kidnay. J Phys Chem Ref Data 8, 799(1979).

A Review, Evaluation, and Correlation of the Phase Equilibria, Heat of Mixing, and Change in Volume on Mixing for Liquid Mixtures of Methane + Propane - R. C. Miller, Arthur J. Kidnay, and M. J. Hiza. J Phys Chem Ref Data 9, 721(1980). 
Critical Evaluation of Vapor-Liquid Equilibrium, Heat of Mixing, and Volume Change of Mixing Data. General Procedures - Buford D. Smith, Ol Muthu, Ashok Dewan, and Matthew Gierlach. J Phys Chem Ref Data 11, 941(1982).

Evaluation of Binary Excess Enthalpy Data for $\mathrm{C}_{6}$ Hydrocarbons. Benzene + Cyclohexane - Buford D. Smith, Ol Muthu, Ashok Dewan, and Matthew Gierlach. J Phys Chem Ref Data 11, 1127(1982).

Evaluation of Binary Excess Enthalpy Data for $\mathrm{C}_{6}$ Hydrocarbons.

Benzene + Hexane - Buford D. Smith, Ol Muthu, and Ashok Dewan.

J Phys Chem Ref Data 12, 389(1983).

Thermal Properties of Aqueous Uni-Univalent Electrolytes Vivian B. Parke1. NSRDS-NBS 2, 68p. (1965).

Thermodynamic and Thermophysical Properties of Combustion Products, Volume III. Oxygen- and Air-Based Propellant - V. P. Glushko, V. E. Alemasov, A. F. Dregalin, A. P. Tishin, V. A. Khudyakov, and V. N. Kostin. Russian Transl., Springfield, VA: NTIS, 648p. (1975). TT 75-50007, A26.

\section{Heat of vaporization}

Properties of Liquid and Solid Hydrogen - B. N. Esel'son, Y. P. Blagoi, V.N. Grigor'ev, V. G. Manzhelii, S. A. Mikhailenko, and N. P. Neklyudov, Russian Transl,, Springfield, VA: NTIS, 126p. (1971). TT 70-50179, A07.

Thermodynamic and Transport Properties of Ethylene and Propylene - I. A. Neduzhii. Russian Transl. Springfield, VA: NTIS, 206p. (1972). COM 75-11276, A10.

Thermophysical Properties of Air and Air Components - A. A. Vasserman, Ya. Z. Kazavchinskii, V. A. Rabinovich, and A. M. Zhuravlev. Russian Transl. Springfield, VA: NTIS, 402p. (1971). TT 70-50095, A18.

\section{Henry's law constant}

See: Solubility

\section{High pressure properties}

A Compilation of Volumes I-IV of Bibliography on High Pressure Research with Author and Subject Indexes - John Francis Cannon and Leo Merrill., Springfield, VA: NTIS, 385p. (1972). in two volumes, Vol. 1. PB 191 174, A17; Vol. 2. PB 191174.

Behavior of the Elements at High Pressures - John Francis Cannon. J Phys Chem Ref Data 3, 781(1974).

Behavior of the AB-Type Compounds at High Pressures and High Temperatures - Leo Merrill. J Phys Chem Ref Data 6, 1205(1977).

Behavior of the $\mathrm{AB}_{2}$-Type Compounds at High Pressures and High

Temperatures - Leo Merrill. J Phys Chem Ref Data 11, 1005(1982).

Bibliography of High Pressure Research, Volume XII (1979) - Leo Merrill., Provo, UT: High Pressure Data Center, Brigham Young University,(1979). Bimonthly, order from Data Center.

Compilation of Volumes V-IX of the Bibliography on High Pressure Research with Author and Subject Indexes - Leo Merrill., Provo, UT: High Pressure Data Center, Brigham Young University, (1979). in microfiche only.

High Pressure Bibliography 1900-1968, Volume I. Section I. Bibliography, Section II. Author Index - Leo Merrill. OSRD Eibl. 70-1, Vol. 1(1970).

High Pressure Bibliography 1900-1968, Volume II. Subject Index Leo Merrill. OSRD Bibl. 70-1, Vol. 2(1970).

High Pressure Bibliography, 1968-1971, with Author and Subject Indexes -- John Francis Cannon and Leo Merrill., Provo, UT: High Pressure Data Center, Brigham Young University, 189p. (1972). in microfiche only.

High-Pressure Calibration: A Critical Review - D. L. Decker, W. A. Bassett, Leo Merrill, H. T. Hall, and J. D. Barnett. J Phys Chem Ref Data 1, 773(1972).

\section{Index of refractlon}

See: Refractive index

\section{Infrared spectra}

See: Vibrational spectra (infrared, Raman)

\section{Intensities, spectral}

See: Transition probabilities for atoms and molecules

\section{Interatomic distances}

See: Molecular structure

Ionization potentials (see also Atomic energy levels and spectra)

A Bibliography on Ion-Molecule Reactions. January 1900 to March 1966 - F. N. Harllee, Henry M. Rosenstock, and John T. Herron. NBS Tech. Note 291, 40p. (1966).

Electron Impact Excitation of Atoms - Benjamin L. Moiseiwitsch and Steven J. Smith. NSRDS-NBS 25, 120p. (1968).

Electron Impact Ionization Cross-Section Data for Atoms, Atomic Ions, and Diatomic Molecules: I. Experimental Data - Lee J. Kieffer and Gordon H. Dunn. Rev Mod Phys. 38, New York: American Institute of Physics, 35p. (1966).

Energy Levels of Iron, Fe I through Fe XXVI — Joseph Reader and Jack Sugar. J Phys Chem Ref Data 4, 353(1975).

Energy Levels of Chromium, Cr I through Cr XXIV - Jack Sugar and Charles H. Corliss. J Phys Chem Ref Data 6, 317(1977).

Energy Levels of Manganese, Mn I through Mn XXV - Charles H. Corliss and Jack Sugar. J Phys Chem Ref Data 6, 1253(1977).

Energetics of Gaseous Ions - Henry M. Rosenstock, Keith Draxl, B. W. Steiner, and John T. Herron. J Phys Chem Ref Data 6, Suppl. 1(1977).

Energy Levels of Vanadium, V I through V XXIII - Jack Sugar and Charles H. Corliss. J Phys Chem Ref Data 7, 1191(1978).

Energy Levels of Titanium, Ti I through Ti XXII - Charles H. Corliss and Jack Sugar. J Phys Chem Ref Data 8, I(1979).

Energy levels of Aluminum, Al I through Al XIII - William C. Martin and Romuald Zalubas. J Phys Chem Ref Data 8, 817(1979).

Energy Levels of Calcium, Ca I through Ca XX - Jack Sugar and Charles H. Corliss. J Phys Chem Ref Data 8, 865(1979).

Energy Levels of Potassium, K I through K XIX - Charles H. Corliss and Jack Sugar. J Phys Chem Ref Data 8, 1109(1979).

Energy Levels of Magnesium, Mg I through Mg XII - William C. Martin and Romuald Zalubas. J Phys Chem Ref Data 9, 1(1980).

Energy Levels of Scandium, Sc I through Sc XXI - Jack Sugar and Charles H. Corliss. J Phys Chem Ref Data 9, 473(1980).

Energy Levels of Sodium, Na I through Na XI - William C. Martin and Romuald Zalubas. J Phys Chem Ref Data 10, 153(1981).

Energy Levels of Nickel, Ni I through Ni XXVIII - Charles H. Corliss and Jack Sugar. J Phys Chem Ref Data 10, 197(1981).

Energy Levels of Cobalt, Co I through Co XXVII — Jack Sugar and Charles H. Corliss. J Phys Chem Ref Data 10. 1097(1981).

Energy Levels of Iron, Fe I through Fe XxvI - Charles H. Corliss and Jack Sugar. J Phys Chem Ref Data 11, 135(1982).

Energy Levels of Silicon, Si I through Si XIV - William C. Martin and Romuald Zalubas. J Phys Chem Ref Data 12, 323(1983).

Ground Levels and Ionization Potentials for Lanthanide and Actinide Atoms and Ions - William C. Martin, Lucy Hagan, Joseph Reader, and Jack Sugar. J Phys Chem Ref Data 3, 771(1974).

Ion Energetics Measurements, Supplement I. 1971-1973 - Henry M. Rosenstock, D. Sims, S. S. Schroyer, and W. J. Webb. NSRDS-NBS 66, 380p. (1980).

Ionization Potentials, Appearance Potentials, and Heats of Formation of Gaseous Positive Ions - Joseph L. Franklin, J. G. Dillard, Henry M. Rosenstock, John T. Herron, Keith Draxl, and Frank H. Field. NSRDS-NBS 26, 289p. (1969). 
Ionization Potentials and Ionization Limits Derived from the Analyses of Optical Spectra - Charlotte E. Moore. NSRDS-NBS 34, 22p. (1970).

Ionization Potential and Appearance Potential Measurements, 1971-1981 - Rhoda D. Levin and Sharon G. Lias. NSRDS-NBS 71, 634p. (1982).

Surface Ionization - E. Ya. Zandberg and N. L. Ionov. Russian Transl., Springfield, VA: NTIS, 364p. (1971). TT 70-50148, A16.

Tables of Atomic Spectral Lines for the $10000 \AA$ to $40000 \AA$ Region - Michael Outred. J Phys Chem Ref Data 7, 1(1978).

The Band Spectrum of Carbon Monoxide - Paul H. Krupenie. NSRDS-NBS 5, 87p. (1966).

The Spectrum of Molecular Nitrogen - Alf Lofthus and Paul H. Krupenie. J Phys Chem Ref Data 6, $113(1977)$.

The Spectrum and Energy Levels of the Neutral Atom of Boron (B I) - G. A. Odintzova and A. R. Striganov. J Phys Chem Ref Data 8, 63(1979).

Theory of the Ionization of Atoms by Electron Impact - M. R. H. Rudge. Rev Mod Phys 40, .., 564p. (1968).

\section{Isotopic abundance}

Isotopic Abundances and Atomic Weights of the Elements - Paul De Bièvre, Marc Gallet, Norman E. Holden, and I. Lynus Barnes. J Phys Chem Ref Data 13, 809(1984).

\section{Kinetic rate constants}

See: Rate constants of chemical reactions

\section{Lattice constants}

Behavior of the Elements at High Pressures - John Francis Cannon. J Phys Chem Ref Data 3, 781(1974).

Behavior of the AB-Type Compounds at High Pressures and High Temperatures - Leo Merrill. J Phys Chem Ref Data 6, 1205(1977).

Behavior of the $\mathrm{AB}_{2}$-Type Compounds at High Pressures and High Temperatures - Leo Merrill. J Phys Chem Ref Data 11, 1005(1982).

Crystal Structure Transformations in Binary Halides - C. N. R. Rao and M. Natarajan. NSRDS-NBS 41, 57p. (1972).

Crystal Structure Transformations in Inorganic Nitrites, Nitrates, and Carbonates - C. N. R. Rao, Brahm Prakash, and M. Natarajan. NSRDS-NBS 53, 55p. (1975).

Crystal Structure Transformations in Inorganic Sulfates, Phosphates, Perchlorates, and Chromates - C. N. R. Rao and Brahm Prakash. NSRDS-NBS 56, 37p. (1975).

Crystal Data Determinative Tables, Third Edition Volume 1: Organic Compounds - Joseph D. H. Donnay and Helen M. Ondik., Swarthmore, PA: JCPDS-International Center for Diffraction Data, 855p. (1972).

Crystal Data Determinative Tables, Third Edition Volume 2: Inorganic Compounds - Joseph D. H. Donnay and Helen M. Ondik., Swarthmore, PA: JCPDS-International Center for Diffraction Data, 1748p. (1973).

Crystal Data Determinative Tables, Third Edition Volume 3. Organic Compounds - Joseph D. H. Donnay, Olga Kennard, David G. Watson, and John R. Rodgers., Swarthmore, PA: JCPDS-International Center for Diffraction Data, 748p. (1978).

Crystal Data Determinative Tables, Third Edition Volume 4. Inorganic Compounds - Joseph D. H. Donnay, Helen M. Ondik, and Alan D. Mighell., Swarthmore, PA: JCPDS-International Center for Diffraction Data, 1308p. (1978).

Crystal Data Determinative Tables, Third Edition, Volume 5. Organic Compounds - Olga Kennard, David G. Watson, John E. Davies, John R. Rodgers, editor(s). 5, Swarthmore, PA, JCPDS-International Center for Diffraction Data,(1983).

Crystal Data Determinative Tables, Third Edition, Volume 6. Organic Compounds - Olga Kennard, David G. Watson, John E. Davies, editor(s). 6, Swarthmore, PA, JCPDS-International Center for Diffraction Data,(1983).
Crystal Data Space-Group Tables - Alan D. Mighell, Helen M. Ondik, and Bettijoyce Breen Molino. J Phys Chem Ref Data 6, 675(1977).

Electronic Absorption and Internal and External Vibrational Data of Atomic and Molecular Ions Doped in Alkali Halide Crystals - Suresh C. Jain, A. V. R. Warrier, and Suresh K. Agarwal. NSRDS-NBS 52, 55p. (1974).

NBS Crystal Data Identification File NBS Standard Reference Database 3, Washington, D.C.; NBS, Office of Standard Reference Data,(updated periodically). Lease agreements obtained from JCPDS 1601 Park Ln Swarthmore PA (215)328-9400.

Space Groups and Lattice Complexes - W. Fisher, Hans Burzlaff, Erwin Hellner, and Joseph D. H. Donnay. NBS Monograph 134, 177p. (1973).

Transition Metal Oxides, Crystal Chemistry, Phase Transition, and Related Aspects - C. N. R. Rao and G. V. Subba Rao. NSRDS-NBS 49, 140p. (1974).

\section{Lifetimes}

See: Transition probablities for atoms and molecules

\section{Line strengths}

See: Transition probabilities for atoms and molecules

\section{Line widths}

See: Spectral line widths

\section{Loss tangent}

See: Dielectric constant

\section{Magnetic moments of molecules}

Bibliography on Properties of Defect Centers in Alkali Halides Suresh C. Jain, S. A. Khan, H. K. Sehgal, V. K. Garg, and R. K. Jain. OSRD Bibl. 71-1, 293p. (1971).

Compendium of ab initio Calculations of Molecular Energies and Properties - Morris Krauss. NBS Tech. Note 438, 139p. (1967).

The Band Spectrum of Carbon Monoxide - Paul H. Krupenie. NSRDS-NBS 5, 87p. (1966).

\section{Magnetic properties}

Critical Surveys of Data Sources: Electrical and Magnetic Properties of Metals - M. J. Carr, R. B. Gavert, Robert L. Moore, H. W. Wawrousek, and John H. Westbrook. NBS Spec. Publ. 396, 96p. (1976).

Physical Properties Data for Rock Salt - Lewis H. Gevantman. NBS Monograph 167, 288p. (1981).

Physical Properties Data for Basalt - Lewis H. Gevantman. NBSIR 82-2587, 75lp. (1982).

\section{Mass spectra}

EPA/NIH Mass Spectral Data Base, Volume 1. Molecular Weights 30-186; Volume 2. Molecular Weights 16-273; Volume 3. Molecular Weights 273-381; Volume 4. Molecular Weights 381-1674 - Stephen R. Heller and G. W. A. Milne. NSRDS-NBS 63, 1,2,3,4(1978).

EPA/NIH Mass Spectral Data Base, Supplement 1 - Stephen R. Heller and G. W. A. Milne. NSRDS-NBS 63, Suppl. 1(1980).

EPA/NIH Mass Spectral Data Base, Supplement 2 - Stephen R. Heller, G. W. A. Milne, and Lewis H. Gevantman. NSRDS-NBS 63, Suppl. 2(1983).

EPA/NIH Mass Spectral Data Base Magnetic Tape - Stephen R. Heller and G. W. A. Milne. NBS Standard Reference Database 1 A1, Washington, DC: NBS Office of Standard Reference Data,(updated periodically). Call (301) $921-2228$ for specific instructions. 


\section{Mechanical propertles}

Computerizing Materials Data-A Workshop for the Nuclear Power Ind ustry - John Jr. Rumble and Jack H. Westbrook. NBS Spec. Publ. 689, 37p. (1985).

Critical Surveys of Data Sources: Mechanical Properties of Metals R. B. Gavert, Robert L. Moore, and John H. Westbrook. NBS Spec. Publ. 396, 90p. (1974).

Feasiblility Study: Compilation and Evaluation of Properties Data for Basalt, Granite, Tuff, and Shale - Lewis H. Gevantman. NBSIR 81-2217, 259p. (1981).

Handbook of Hardness Data - G. V. Samsonov and A. A. Ivan'ko. Russian Transl., Springfield, VA: NTIS, 69p. (1970). TT 70-50177, A04. LNG Materials \& Fluids, A User's Manual of Property Data in Graphic Format - Douglas Mann and U.S. National Bureau of Standards., Boulder, CO: U.S. National Bureau of Standards, Cryogenic Division, 11p. (1977).

LNG Materials \& Fluids, A User's Manual of Property Data in Graphic Format, First Supplement - Douglas Mann and U.S. National Bureau of Standards. Suppl, 1, Boulder, CO: U.S. National Bureau of Standards, 11p. (1978).

LNG Materials \& Fluids, A User's Manual of Property Data in Graphic Format, Second Supplement - Douglas Mann and U.S. National Bureau of Standards. Suppl. 2, Boulder, CO: U.S. National Bureau of Standards, 11p. (1980).

Physical Properties Data Compilations Relevant to Energy Storage. III. Engineering Properties of Single and Polycrystalline Sodium Beta and Beta" Alumina - G. R. Miller and D. G. Paquette. NSRDS-NBS 61, 19p. (1979).

Physical Properties Data Compilations Relevant to Energy Storage. V. Mechanical Properties Data on Alloys for Use in Flywheels Hassell M. Ledbetter. NSRDS-NBS 61, 42p. (1982).

Physical Properties Data for Rock Salt - Lewis H. Gevantman. NBS Monograph 167, 288p. (1981).

Physical Properties Data for Basalt - Lewis H. Gevantman. NBSIR 82-2587, 751p. (1982).

\section{Melting point}

A Critical Review of Henry's Law Constants for Chemicals of Environmental Interest - Donald Mackay and Wan Ying Shiu. J Phys Chem Ref Data 10, 1175(1981).

A Review of Deuterium Triple-Point Temperatures - L. A. Schwalbe and E. R. Grilly. J Phys Chem Ref Data 13, 687(1984).

Behavior of the AB-Type Compounds at High Pressures and High

Temperatures - Leo Merrill. J Phys Chem Ref Data 6, 1205(1977).

Behavior of the $\mathrm{AB}_{2}$-Type Compounds at High Pressures and High Temperatures - Leo Merrill. J Phys Chem Ref Data 11, 1005(1982).

Definition of Recommended Values of Certain Thermodynamic Properties for the Ketones - Buford D. Smith and Ol Muthu. NBSIR 84-2811, 162p. (1983).

Heat Capacities and Entropies of Organic Compounds in the Condensed Phase - Eugene S. Domalski, William H. Evans, and Elizabeth D. Hearing. J Phys Chem Ref Data 13, Suppl. 1(1984).

High Temperature Properties and Decomposition of Inorganic Salts, Part 1. Sulfates - Kurt H. Stern and E. L. Weise. NSRDS-NBS 7, 38p. (1966).

High Temperature Properties and Decomposition of Inorganic Salts, Part 2. Carbonates - Kurt H. Stern and E. L. Weise. NSRDS-NBS 30, 27p. (1969).

High Temperature Properties and Decomposition of Inorganic Salts, Part 3. Nitrates and Nitrites - Kurt H. Stern. J Phys Chem Ref Data 1, 747(1972).

High Temperature Properties and Decomposition of Inorganic Salts, Part 4. Oxy-Salts of the Halogens - Kurt H. Stern. J Phys Chem Ref Data 3, 481(1974).

JANAF Thermochemical Tables, Second Edition - Daniel R. Stull and H. Prophet. NSRDS-NBS 37, 1141p. (1971).

JANAF Thermochemical Tables, 1974 Supplement - Malcolm W. Chase, Jr., J. L. Curnutt, A. T. Hu, H. Prophet, A. N. Syverud, and L. C. Walker. J Phys Chem Ref Data 3, 311(1974).
JANAF Thermochemical Tables, 1975 Supplement - Malcolm W. Chase, Jr., J. L. Curnutt, H. Prophet, R. A. McDonald, and A. N. Syverud. J Phys Chem Ref Data 4, 1(1975).

JANAF Thermochemical Tables, 1978 Supplement - Malcolm W. Chase, Jr., J. L. Curnutt, R. A. McDonald, and A. N. Syverud. J Phys Chem Ref Data 7, 793(1978).

JANAF Thermochemical Tables, 1982 Supplement - Malcolm W. Chase, Jr., J. L. Curnutt, J. R. Downey, Jr., R. A. McDonald, A. N. Syverud, and E. A. Valenzuela. J Phys Chem Ref Data 11, 695(1982),

Molten Salts: Volume 1. Electrical Conductance, Density, and Viscosity Data - George J. Janz, F. W. Dampier, G. R. Lakshminarayanan, P. K. Lorenz, and Reginald P. T. Tomkins. NSRDS-NBS 15, 140p. (1968).

Molten Salts: Volume 2. Section 1. Electrochemistry of Molten Salts. Gibbs Free Energies and Excess Free Energies from Equilibrium-Type Cells, Section 2. Surface Tension Data - George J. Janz, Chr. G. M. Dijkhuis, G. R. Lakshminarayanan, Reginald P. T. Tomkins, and J. Wong. NSRDS-NBS 28, 116p. (1968).

Phase Diagrams for Ceramists - Ernest M. Levin, Carl R. Robbins, Howard F. McMurdie, editor(s)., American Ceramic Society; Columbus, Ohio, 60lp. (1964), ISBN: 0-916094-04-9.

Phase Diagrams for Ceramists 1969 Supplement - Ernest M. Levin, Carl R. Robbins, Howard F. McMurdie, editor(s)., American Ceramic Society; Columbus, Ohio, 625p. (1969), ISBN: 0-916094-05-7.

Phase Diagrams for Ceramists 1975 Supplement - Ernest M. Levin, Howard F. McMurdie, editor(s),, American Ceramic Society; Columbus, Ohio, 513p. (1975).

Physical Properties Data Compilations Relevant to Energy Storage. I. Molten Salts: Eutectic Data - George J. Janz, Carolyn B. Allen, J. R. Downey, Jr., and Reginald P. T. Tomkins. NSRDS-NBS 61, 244p. (1978).

Physical and Thermodynamic Properties of Aliphatic Alcohols Randolph C. Wilhoit and Bruno J. Zwolinski. J Phys Chem Ref Data 2, Suppl. 1(1973).

Thermophysical Properties of Isobutane from 114 to $700 \mathrm{~K}$ at Pressures to $70 \mathrm{MPa}$ - Robert D. Goodwin and W. M. Haynes. NBS Tech. Note 1051, 199p. (1982).

Thermophysical Properties of Normal Butane from 135 to $700 \mathrm{~K}$ at Pressures to $70 \mathrm{MPa}-$ W. M. Haynes and Robert D. Goodwin. NBS Monograph 169, 197p. (1982).

\section{Microwave spectra}

See: Rotational spectra

\section{Mobility of electrons and holes}

See: Electron swarm parameters

\section{Molecular energy leveis and constants}

Atlas of the Observed Absorption Spectrum of Carbon Monoxide between 1060 and $1900 \AA-$ S. G. Tilford and J. D. Simmons. J Phys Chem Ref Data 1, 147(1972).

Atlas of the High Temperature Water Vapor Spectrum in the 3000 to $4000 \mathrm{~cm}^{-1}$ Region - A. S. Pine, M. J. Coulombe, C. Camy-Peyret, and J-M. Flaud. J Phys Chem Ref Data 12, 413(1983).

Atlas of the Schumann-Runge Absorption Bands of $\mathrm{O}_{2}$ in the Wavelength Region 175-205 nm - K. Yoshino, D. E. Freeman, and W. H. Parkinson. J Phys Chem Ref Data 13, 207(1984).

Compendium of ab initio Calculations of Molecular Energies and Properties - Morris Krauss. NBS Tech. Note 438, 139p. (1967).

Critical Review of Vibrational Data and Force Field Constants for Polyethylene - John Barnes and Bruno Fanconi. J Phys Chem Ref Data 7, 1309(1978).

Drift Mobilities and Conduction Band Energies of Excess Electrons in Dielectric Liquids - Augustine O. Allen. NSRDS-NBS 58, 23p. (1976).

Ground-State Vibrational Energy Levels of Polyatomic Transient Molecules - Marilyn E. Jacox. J Phys Chem Ref Data 13, 945(1984). 
JANAF Thermochemical Tables, Second Edition - Daniel R. Stull and H. Prophet. NSRDS-NBS 37, 1141p. (1971).

JANAF Thermochemical Tables, 1974 Supplement - Malcolm W. Chase, Jr., J. L. Curnutt, A. T. Hu, H. Prophet, A. N. Syverud, and L. C. Walker. J Phys Chem Ref Data 3, 311(1974).

JANAF Thermochemical Tables, 1975 Supplement - Malcolm W. Chase, Jr., J. L. Curnutt, H. Prophet, R. A. McDonald, and A. N. Syverud. J Phys Chem Ref Data 4, 1(1975).

JANAF Thermochemical Tables, 1978 Supplement - Malcolm W. Chase, Jr., J. L. Curnutt, R. A. McDonald, and A. N. Syverud. J Phys Chem Ref Data 7, 793(1978).

JANAF Thermochemical Tables, 1982 Supplement - Malcolm W. Chase, Jr., J. L. Curnutt, J. R. Downey, Jr., R. A. McDonald, A. N. Syverud, and E. A. Valenzuela. J Phys Chem Ref Data 11, 695(1982).

Microwave Spectral Tables, Volume I. Diatomic Molecules - Paul F. Wacker, M. Mizushima, J. D. Petersen, and J. R. Ballard. NBS Monograph 70, 171p. (1964).

Microwave Spectral Tables, Volume II. Line Strengths of Asymmetric Rotors - Paul F. Wacker and M. R. Pratto. NBS Monograph 70, 349p. (1964).

Microwave Spectral Tables, Volume III. Polyatomic Molecules with Internal Rotation - Paul F. Wacker, M. S. Cord, D. G. Burkhard, J. D. Petersen, and R. F. Kukol. NBS Monograph 70, 275p. (1969).

Microwave Spectral Tables, Volume IV. Polyatomic Molecules without Internal Rotation - M. S. Cord, J. D. Petersen, M. S. Lojko, and R. H. Haas. NBS Monograph 70, 419p. (1968).

Microwave Spectral Tables, Volume V. Spectral Line Listing - M. S. Cord, M. S. Lojko, and J. D. Petersen. NBS Monograph 70, 533p. (1968).

Microwave Spectra of Molecules of Astrophysical Interest, I. Formaldehyde, Formamide, and Thioformaldehyde - Donald R. Johnson, Frank J. Lovas, and William H. Kirchhoff. J Phys Chem Ref Data 1, 1011(1972).

Microwave Spectra of Molecules of Astrophysical Interest, II. Methylenimine - William H. Kirchhoff, Donald R. Johnson, and Frank J. Lovas. J Phys Chem Ref Data 2, 1(1973).

Microwave Spectra of Molecules of Astrophysical Interest, III. Methanol - R. M. Lees, Frank J. Lovas, William H. Kirchhoff, and Donald R. Johnson. J Phys Chem Ref Data 2, 205(1973).

Microwave Spectra of Molecules of Astrophysical Interest, IV. Hydrogen Sulfide - Paul Helminger, Frank C. De Lucia, and William

H. Kirchhoff. J Phys Chem Ref Data 2, 215(1973).

Microwave Spectra of Molecules of Astrophysical Interest, V. Water Vapor - Frank C. De Lucia, Paul Helmirger, and William H. Kirchhoff. J Phys Chem Ref Data 3, 211(1974).

Microwave Spectra of Molecules of Astrophysical Interest, VI. Carbonyl Sulfide and Hydrogen Cyanide - Arthur G. Maki. J Phys Chem Ref Data 3, 221(1974).

Microwave Spectra of Molecules of Astrophysical Interest, VII. Carbon Monoxide, Carbon Monosulfide, and Silicon Monoxide Frank J. Lovas and Paul H. Krupenie. J Phys Chem Ref Data 3, 245(1974).

Microwave Spectra of Molecules of Astrophysical Interest, VIII. Sulfur Monoxide - Eberhard Tiemann. J Phys Chem Ref Data 3, 259(1974).

Microwave Spectral Tables, I. Diatomic Molecules - Frank J.

Lovas and Eberhard Tiemann. J Phys Chem Ref Data 3, 609(1974).

Microwave Spectra of Molecules of Astrophysical Interest, IX. Acetaldehyde - A. Bauder, Frank J. Lovas, and Donald R. Johnson. J Phys Chem Ref Data 5, 53(1976).

Microwave Spectra of Molecules of Astrophysical Interest, X. Isocyanic Acid - G. Winnewisser, W. H. Hocking, and M. C. L. Gerry. J Phys Chem Ref Data 5, 79(1976).

Microwave Spectra of Molecules of Astrophysical Interest, XI. Silicon Sulfide - Eberhard Tiemann. J Phys Chem Ref Data 5, 1147(1976).

Microwave Spectra of Molecules of Astrophysical Interest, XII. Hydroxyl Radical - Robert A. Beaudet and Robert L. Poynter. J Phys Chem Ref Data 7, 311(1978).
Microwave Spectra of Molecules of Astrophysical Interest, XIII. Cyanoacetylene - Walter J. Lafferty and Frank J. Lovas. J Phys Chem Ref Data 7, 441(1978).

Microwave Spectral Tables II. Triatomic Molecules - Frank J. Lovas. J Phys Chem Ref Data 7, 1445(1978).

Microwave Spectra of Molecules of Astrophysical Interest, XIV. Vinyl Cyanide (Acrylonitrile) - M. C. L. Gerry, K. Yamada, and G. Winnewisser. J Phys Chem Ref Data 8, 107(1979).

Microwave Spectra of Molecules of Astrophysical Interest, XV. Propyne - A. Bauer, D. Boucher, J. Burie, J. Demaison, and A. Dubrulle. J Phys Chem Ref Data 8, 537(1979).

Microwave Spectra of Molecules of Astrophysical Interest, XVI. Methyl Formate - A. Bauder. J Phys Chem Ref Data 8, 583(1979).

Microwave Spectra of Molecules of Astrophysical Interest, XVII. Dimethyl Ether - Frank J. Lovas, H. Lutz, and H. Dreizler. J Phys Chem Ref Data 8, 1051(1979).

Microwave Spectra of Molecules of Astrophysical Interest. XVIII. Formic Acid - Edmond Willemot, Didier Dangoisse, Nicole Monnanteuil, and Jean Bellet. J Phys Chem Ref Data 9, 59(1980).

Microwave Spectra of Molecules of Astrophysical Interest. XIX. Methyl Cyanide - D. Boucher, J. Burie, A. Bauer, A. Dubrulle, and J. Demaison. J Phys Chem Ref Data 9, 659(1980).

Microwave Spectra of Molecules of Astrophyical Interest. XX. Methane - I. Ozier, M. C. L. Gerry, and A. G. Robiette. J Phys Chem Ref Data 10, 1085(1981).

Microwave Spectra of Molecules of Astrophysical Interest. XXI. Ethanol $\left(\mathrm{C}_{2} \mathrm{H}_{5} \mathrm{OH}\right)$ and Propionitrile $\left(\mathrm{C}_{2} \mathrm{H}_{5} \mathrm{CN}\right)$ - Frank J. Lovas. J Phys Chem Ref Data 11, 251(1982).

Resonances in Electron Impact on Atoms and Diatomic Molecules — George J. Schulz. NSRDS.NBS 50, 120p. (1973).

Tables of Molecular Vibrational Frequencies, Part 1 - Takehiko Shimanouchi. NSRDS-NBS 6, 56p. (1967).

Tables of Molecular Vibrational Frequencies, Part 2 - Takehiko Shimanouchi. NSRDS-NBS 11, 38p. (1967).

Tables of Molecular Vibrational Frequencies, Part 3 - Takehiko Shimanouchi. NSRDS-NBS 17, 39p. (1968).

Tables of Molecular Vibrational Frequencies, Consolidated Volume I - Takehiko Shimanouchi. NSRDS-NBS 39, 167p. (1972).

Tables of Molecular Vibrational Frequencies, Part 5 - Takehiko Shimanouchi. J Phys Chem Ref Data 1, 189(1972).

Tables of Molecular Vibrational Frequencies, Part 6 - Takehiko Shimanouchi. J Phys Chem Ref Data 2, 121(1973).

Tables of Molecular Vibrational Frequencies, Part 7 - Takehiko

Shimanouchi. J Phys Chem Ref Data 2, 225(1973).

Tables of Molecular Vibrational Frequencies, Part 8 - Takehiko Shimanouchi. J Phys Chem Ref Data 3, 269(1974).

Tables of Molecular Vibrational Frequencies. Consolidated Volume II - Takehiko Shimanouchi. J Phys Chem Ref Data 6, 993(1977).

Tables of Molecular Vibrational Frequencies, Part 9 - Takehiko Shimanouchi, Hiroatsu Matsuura, Yoshiki Ogawa, and Issei Harada. J Phys Chem Ref Data 7, 1323(1978).

Tables of Molecular Vibrational Frequencies, Part 10 - Takehiko Shimanouchi, Hiroatsu Matsuura, Yoshiki Ogawa, and Issei Harada. J Phys Chem Ref Data 9, 1149(1980).

Tables of $\mathrm{N}_{2} \mathrm{O}$ Absorption Lines for the Calibration of Tunable Infrared Lasers from $522 \mathrm{~cm}^{-1}$ to $657 \mathrm{~cm}^{-1}$ and from $1115 \mathrm{~cm}^{-1}$ to 1340 $\mathrm{cm}^{-1}$ - W. B. Olson, Arthur G. Maki, and Walter J. Lafferty. J Phys Chem Ref Data 10, 1065(1981).

The Band Spectrum of Carbon Monoxide - Paul H. Krupenie. NSRDS-NBS 5, 87p. (1966).

The Calculation of Rotational Energy Levels and Rotational Line Intensities in Diatomic Molecules - Jon T. Hougen. NBS Monograph 115, 54p. (1970).

The Spectrum of Molecular Nitrogen - Alf Lofthus and Paul H. Krupenie. J Phys Chem Ref Data 6, 113(1977).

Thermodynamic Properties of Ammonia as an Ideal Gas - Lester Haar. NSRDS-NBS 19, 10p. (1968). 


\section{Molecular spectra}

See: Rotational spectra

Vibrational spectra (infrared, Raman)

\section{Molecular structure}

Binary Fluorides, Free Molecular Structures and Force Fields, A Bibliography (1957-1975) - Donald T. Hawkins, Lawrence S. Bernstein, Warren E. Falconer, and Willian Klemperer., New York: IFI/Plenum, 253p. (1976), ISBN: 0-306-6601-3.

JANAF Thermochemical Tables, 1974 Supplement - Malcolm W. Chase, Jr., J. L. Curnutt, A. T. Hu, H. Prophet, A. N. Syverud, and L. C. Walker. J Phys Chem Ref Data 3, 311(1974).

JANAF Thermochemical Tables, 1975 Supplement - Malcolm W. Chase, Jr., J. L. Curnutt, H. Prophet, R. A. McDonald, and A. N. Syverud. J Phys Chem Ref Data 4, 1(1975).

JANAF Thermochemical Tables, 1978 Supplement - Malcolm W. Chase, Jr., J. L. Curnutt, R. A. McDonald, and A. N. Syverud. J Phys Chem Ref Data 7, 793(1978).

Microwave Spectra of Molecules of Astrophysical Interest, I. Formaldehyde, Formamide, and Thioformaldehyde - Donald R. Johnson, Frank J. Lovas, and William H. Kirchhoff. J Phys Chem Ref Data 1, 1011(1972).

Microwave Spectra of Molecules of Astrophysical Interest, II. Methylenimine - William H. Kirchhoff, Donald R. Johnson, and Frank J. Lovas. J Phys Chem Ref Data 2, 1(1973).

Microwave Spectra of Molecules of Astrophysical Interest, III. Methanol - R. M. Lees, Frank J. Lovas, William H. Kirchhoff, and Donald R. Johnson. J Phys Chem Ref Data 2, 205(1973).

Microwave Spectra of Molecules of Astrophysical Interest, IV. Hydrogen Sulfide - Paul Helminger, Frank C. De Lucia, and William H. Kirchhoff. J Phys Chem Ref Data 2, 215(1973).

Microwave Spectra of Molecules of Astrophysical Interest, VI. Carbonyl Sulfide and Hydrogen Cyanide - Arthur G. Maki. J Phys Chem Ref Data 3, 221(1974).

Microwave Spectra of Molecules of Astrophysical Interest, VII. Carbon Monoxide, Carbon Monosulfide, and Silicon Monoxide - Frank J. Lovas and Paul H. Krupenie. J Phys Chem Ref Data 3, 245(1974).

Microwave Spectral Tables, I. Diatomic Molecules - Frank J. Lovas and Eberhard Tiemann. J Phys Chem Ref Data 3, 609(1974).

Microwave Spectra of Molecules of Astrophysical Interest, IX. Acetaldehyde - A. Bauder, Frank J. Lovas, and Donald R. Johnson. J Phys Chem Ref Data 5, 5.3(1976).

Microwave Spectra of Molecules of Astrophysical Interest, X. Isocyanic Acid - G. Winnewisser, W. H. Hocking, and M. C. L. Gerry. J Phys Chem Ref Data 5, 79(1976).

Microwave Spectra of Molecules of Astrophysical Interest, XII. Hydroxyl Radical - Robert A. Beaudet and Robert L. Poynter. J Phys Chem Ref Data 7, 311(1978).

Microwave Spectra of Molecules of Astrophysical Interest, XIII. Cyanoacetylene - Walter J. Lafferty and Frank J. Lovas. J Phys Chem Ref Data 7, 441(1978).

Microwave Spectral Tables II. Triatomic Molecules - Frank J. Lovas. J Phys Chem Ref Data 7, 1445(1978).

Microwave Spectra of Molecules of Astrophysical Interest, XIV. Vinyl Cyanide (Acrylonitrile) - M. C. L. Gerry, K. Yamada, and G. Winnewisser. J Phys Chem Ref Data 8, 107(1979).

Microwave Spectra of Molecules of Astrophysical Interest, XV. Propyne - A. Bauer, D. Boucher, J. Burie, J. Demaison, and A. Dubrulle. J Phys Chem Ref Data 8, 537(1979).

Microwave Spectra of Molecules of Astrophysical Interest, XVI. Methyl Formate - A. Bauder. J Phys Chem Ref Data 8, 583(1979).

Microwave Spectra of Molecules of Astrophysical Interest, XVII. Dimethyl Ether - Frank J. Lovas, H. Lutz, and H. Dreizler. J Phys
Chem Ref Data 8, 1051(1979).

Microwave Spectra of Molecules of Astrophysical Interest. XVIII. Formic Acid - Edmond Willemot, Didier Dangoisse, Nicole Monnanteuil, and Jean Bellet. J Phys Chem Ref Data 9, 59(1980).

Microwave Spectra of Molecules of Astrophysical Interest. XIX. Methyl Cyanide - D. Boucher, J. Burie, A. Bauer, A. Dubrulle, and J. Demaison. J Phys Chem Ref Data 9, 659(1980).

Molecular Structures of Gas-Phase Polyatomic Molecules Determined by Spectroscopic Methods - Mariin D. Harmony, Victor W. Laurie, Robert L. Kuczkowski, Richard H. Schwendeman, D. A. Ramsay, Frank J. Lovas, Walter J. Lafferty, and Arthur G. Maki. J Phys Chem Ref Data 8, 619(1979).

\section{Mossbauer effect}

Mossbauer Effect Data Index, 1958-1965 - A. H. Muir, K. J. Ando, and Helen M. Coogan., New York: Interscience Publishers, 351p. (1966).

Mossbauer Effect Data Index Covering the 1966-1968 Literature John G. Stevens and Virginia E. Stevens., New York: IFI/Plenum, 522p. (1975), ISBN: 0-306-6516-9.

Mossbauer Effect Data Index Covering the 1969 Literature - John G. Stevens and Virginia E. Stevens., New York: IFI/Plenum, 281p. (1970), ISBN: 0-306-6514-8.

Mossbauer Effect Data Index Covering the 1970 Literature - John G. Stevens and Virginia E. Stevens., New York: IFI/Plenum, 369p. (1972), ISBN: 0-306-6514-6.

Mossbauer Effect Data Index Covering the 1971 Literature - John G. Stevens and Virginia E. Stevens., New York: IFI/Plenum, 430p. (1972), ISBN: 0-306-6514-4.

Mossbauer Effect Data Index Covering the 1972 Literature - John G. Stevens and Virginia E. Stevens., New York: IFI/Plenum, 488p. (1973), ISBN: 0-306-6514-2.

Mossbauer Effect Data Index Covering the 1973 Literature - John G. Stevens and Virginia E. Stevens., New York: IFI/Plenum, 495p. (1975), ISBN: 0-306-6514-0.

Mossbauer Effect Data Index Covering the 1974 Literature - John G. Stevens and Virginia E. Stevens., New York: IFI/Plenum, 397p. (1975), ISBN: 0-306-6514-9.

Mossbauer Effect Data Index Covering the 1975 Literature - John G. Stevens and Virginia E. Stevens., New York: IFI/Plenum, 445p. (1977), ISBN: 0-306-6514-7.

Mossbauer Effect Data Index Covering the 1976 Literature - John G. Stevens and Virginia E. Stevens., New York: IFI/Plenum, 355p. (1978), ISBN: 0-306-6514-1.

Mossbauer Effect Reference and Data Journal - John G. Stevens, Virginia E. Stevens, Richard M. White, Janet L. Gibson, editor(s). Moss Eff Ref Data J 6, Ashville, NC: Mossbauer Effect Data Center, U. of N. C., ...p. (1983).

\section{Nuclear and particle properties}

$\pi+\mathrm{p}, \pi+\mathrm{n}$, and $\pi+\mathrm{d}$ Interactions - A Compilation: Parts I and II - Denyse M. Chew, Victor P. Henri, Thomas A. Lasinski, Thomas G. Trippe, Fumiyo Uchiyama, Frederick C. Winkelmann and Particle Data Group. UCRL 53, Springfield, VA: NTIS, 213p. (1973). LBL 53; Part II is on microfiche located in the back cover pocket, Al0.

$\pi \mathrm{N}$ Particle-Wave Amplitudes - David J. Herndon, Angela Barbaro-Galtieri, Arthur H. Rosenfeld and Particle Data Group. UCRL 20030 $\pi$ N, Springfield, VA: NTIS, 85p. (1970). UCRL 20030 $\pi \mathrm{N}, \mathrm{A} 05$.

$\pi \mathrm{N}$ Two-Body Scattering Data, I. A User's Guide to the LovelaceAlmehed Data Tape - Claude Lovelace, Sverkei Almehed, Fumiyo Uchiyama, Robert Kelly, Victor P. Henri and Particle Data Group. UCRL 63, Springfield, VA: NTIS, 146p. (1973). LBL 63, A07. 
A Compilation of YN Reactions - Odette Benary, Naomi BarashSchmidt, LeRoy R. Price, Arthur H. Rosenfeld, Gideon Alexander and Particle Data Group. UCRL 20000YN, Springfield, VA: NTIS, 70p. (1970). UCRL.20 000 YN, A04.

An Indexed Compilation of Experimental High Energy Physics Literature - Particle Data Group. UCRL-LBL 90, Springfield, VA: NTIS, 430p. (1978). LBL 90, A 19.

Dissociation in Heavy Particle Collisions - G. W. McClure and James M. Peek. At Mol Collis Proc Ser, New York: Wiley-Interscience, 198p. (1972), ISBN: 0-471-5816-8.

Excitation in Heavy Particle Collisions - Edward W. Thomas. At Mol Collis Proc Ser, New York: Wiley-Interscience, 436p. (1972), ISBN: 0-471-8589-0.

$\mathrm{K}^{0}<-1 \mathrm{~N}$ Interactions - A Compilation - Particle Data Group. UCRL-LBL 55, Springfield, VA: NTIS, 56p. (1972). LBL 55, A04.

Microwave Spectral Tables, Volume III. Polyatomic Molecules with Internal Rotation - Paul F. Wacker, M. S. Cord, D. G. Burkhard, J. D. Petersen, and R. F. Kukol. NBS Monograph 70, 275p. (1969).

Microwave Spectral Tables, Volume V. Spectral Line Listing - M. S. Cord, M. S. Lojko, and J. D. Petersen. NBS Monograph 70, 533p. (1968).

NN and ND Interactions - A Compilation - James E. Enstrom, Thomas Ferbel, Paul F. Slattery, Barry L. Werner, Zaven G. T. Guiragossian, Yoshio Sumi, Toshihiro Yoshida and Particle Data Group. UCRL-LBL 58, Berkeley, CA: Lawrence Berkeley Laboratory, U. of California, 281p. (1972). LBL 58.

Nuclear Wallet Cards - Virginia S. Shirley, C. Michael Lederer and National Nuclear Data Center. 1979, Upton, NY: National Nuclear Data Center, Brookhaven National Laboratory, 40p. (1979). Title, no charge.

Nuclear Spins and Moments - Gladys H. Fuller. J Phys Chem Ref Data 5, 835(1976).

Nuclear Moments and Moment Ratios as Determined by Mössbauer Spectroscopy - John G. Stevens and B. D. Dunlap. J Phys Chem Ref Data 5, 1093(1976).

Photonuclear Reaction Data, 1973 - Everett G. Fuller, Henry M. Gerstenberg, H. J. Vander Molen, and T. C. Dunn. NBS Spec. Publ. 380, 134p. (1973).

Photonuclear Data Index, 1973-1977 — Everett G. Fuller and Henry M. Gerstenberg. NBS Spec. Publ. 380, Suppl. 1(1978).

Review of Particle Properties, 25th Anniversary Edition - Particle Data Group. Phys Lett B 111B, Springfield, VA: NTIS, 316p. (1982).

Table of Isotopes, Seventh Edition - C. Michael Lederer, Virginia S. Shirley, Edgardo Browne, Janis M. Dairiki, and Raymond E. Doebler., New York: Wiley-Interscience, 1628p. (1978), ISBN: 0-471-0417-3.

\section{Nuclear magnetic resonance}

Metallic Shifts in NMR: A Review of the Theory and Comprehensive Critical Data Compilation of Metallic Materials - Gesina Cynthia Carter, Lawrence H. Bennett, and Daniel J. Kahan. Prog Mater Sci, Oxford, New York: Pergamon Press, 2350p. (1977), ISBN: 0-08-02114-7.

NMR Spectral Data: A Compilation of Aromatic Proton Chemical Shifts in Mono- and Di-Substituted Benzene - B. L. Shapiro and L. E. Mohrmann. J Phys Chem Ref Data 6, 919(1977).

The NBS Alloy Data Center: Function, Bibliographic System, Related Data Centers, and Reference Books - Gesina Cynthia Carter, Lawrence H. Bennett, John R. Cuthill, and Daniel J. Kahan. NBS Tech. Note 464, 163p. (1968).

The NBS Alloy Data Center: Author Index - Gesina Cynthia Carter, Daniel J. Kahan, Lawrence H. Bennett, John R. Cuthill, and Ronald C. Dobbyn. OSRD Bibl. 70-2, 413p. (1970).

\section{Nuclear moments}

Microwave Spectral Tables, Volume III. Polyatomic Molecules with Internal Rotation - Paul F. Wacker, M. S. Cord, D. G. Burkhard, J. D. Petersen, and R. F. Kukol. NBS Monograph 70, 275p. (1969).
Microwave Spectral Tables, Volume V. Spectral Line Listing - M. S. Cord, M. S. Lojko, and J. D. Petersen. NBS Monograph 70, 533p. (1968).

Nuclear Spins and Moments - Gladys H. Fuller. J Phys Chem Ref Data 5, 835(1976).

Nuclear Moments and Moment Ratios as Determined by Mössbauer Spectroscopy - John G. Stevens and B. D. Dunlap. J Phys Chem Ref Data 5, 1093(1976)

\section{Optical spectra}

See: Electronic molecular spectra

\section{Oscillator strengths}

See: Transition probabilities for atoms and molecules

\section{Osmotic coefficients}

A Bibliography of Sources of Experimental Data Leading to Activity or Osmotic Coefficients for Polyvalent Electrolytes in Aqueous Solution - Robert N. Goldberg, Bert R. Staples, Ralph L. Nuttall, and R. Arbuckle. NBS Spec. Publ. 485, 57p. (1977).

A Report on Thermodynamic Data for Desulfurization Processes Vivian B. Parker, Bert R. Staples, Thomas L. Jobe, Jr., and David B. Neumann. NBSIR 81-2345, 89p. (1981).

Activity and Osmotic Coefficients of Aqueous Alkali Metal Nitrites

- Bert R. Staples. J Phys Chem Ref Data 10, 765(1981).

Activity and Osmotic Coefficients of Aqueous Sulfuric Acid at 298.15 K - Bert R. Staples. J Phys Chem Ref Data 10, 779(1981).

Computer Programs for the Evaluation of Activity and Osmotic Coefficients - Bert R. Staples and Ralph L. Nuttall. NBS Tech. Note 928, 60p. (1976).

Evaluated Activity and Osmotic Coefficients for Aqueous Solutions: The Alkaline Earth Metal Halides - Robert N. Goldberg and Ralph L. Nuttall. J Phys Chem Ref Data 7, 263(1978).

Evaluated Activity and Osmotic Coefficients for Aqueous Solutions: Iron Chloride and the Bi-Univalent Compounds of Nickel and Cobalt

- Robert N. Goldberg, Ralph L. Nuttall, and Bert R. Staples. J Phys Chem Ref Data 8, 923(1979).

Evaluated Activity and Osmotic Coefficients for Aqueous Solutions: Bi-Univalent Compounds of Lead, Copper, Manganese, and Uranium — Robert N. Goldberg. J Phys Chem Ref Data 8, 1005(1979).

Evaluated Activity and Osmotic Coefficients for Aqueous Solutions: Bi-Univalent Compounds of Zinc, Cadmium, and Ethylene Bis(Trimethylammonium) Chloride and Iodide - Robert N. Goldberg. J Phys Chem Ref Data 10, 1(1981).

Evaluated Activity and Osmotic Coefficients for Aqueous Solutions: Thirty-Six Uni-Bivalent Electrolytes - Robert N. Goldberg. J Phys Chem Ref Data 10, 671(1981).

Osmotic Coefficients and Mean Activity Coefficients of UniUnivalent Electrolytes in Water at $25{ }^{\circ} \mathrm{C}-$ Walter J. Hamer and Yung-Chi Wu. J Phys Chem Ref Data 1, 1047(1972).

Revised Values of the Osmotic Coefficients and Mean Activity Coefficients of Sodium Nitrate in Water at $25^{\circ} \mathrm{C}$ (Comments) - Yung-Chi Wu and Walter J. Hamer. J Phys Chem Ref Data 9, 513(1980).

The Activity and Osmotic Coefficients of Aqueous Calcium Chloride ride at 298.15 K - Bert R. Staples and Ralph L. Nuttall. J Phys Chem Ref Data 6, 385(1977).

Thermodynamic Properties of Aqueous Sodium Chloride Solutions - Kenneth S. Pitzer, J. Christopher Peiper, and R. H. Busey. J Phys Chem Ref Data 13, 1(1984).

\section{PVT surface}

See: Equation of state

\section{Pair production cross section}

Comparison of Theoretical and Experimental Photoeffect Data, 0.1 $\mathrm{keV}$ to $1.5 \mathrm{MeV}-$ John H. Hubbell and W. J. Veigele. NBS Tech. Note 901, 47p. (1976). 
Pair, Triplet, and Total Atomic Cross Sections (and Mass Attenuation Coefficients) for $1 \mathrm{MeV}-100 \mathrm{GeV}$ Photons in Elements $\mathrm{Z}=1$ to $100-$ John H. Hubbell, Heinz A. Gimm, and I. $\emptyset$ verbø. J Phys Chem Ref Data 9, 1023(1980).

Photon Cross Sections, Attenuation Coefficients, and Energy Absorption Coefficients from $10 \mathrm{keV}$ to $100 \mathrm{GeV}$ - John H. Hubbell. NSRDS-NBS 29, 85p. (1969).

\section{Phase diagrams}

Applications of Phase Diagrams, Proceedings of a Workshop Held at the National Bureau of Standards, Gaithersburg, Maryland, January 10-12, 1977, Volumes 1 and $2-$ Gesina Cynthia Carter, editor(s). NBS Spec. Publ. 496, 1622p. (1978).

Behavior of the Elements at High Pressures - John Francis Cannon.

J Phys Chem Ref Data 3, 781(1974).

Behavior of the AB-Type Compounds at High Pressures and High Temperatures - Leo Merrill. J Phys Chem Ref Data 6, 1205(1977).

Behavior of the $\mathrm{AB}_{2}$-Type Compounds at High Pressures and High Temperatures - Leo Merrill. J Phys Chem Ref Data 11, 1005(1982).

Bulletin of Alloy Phase Diagrams - Joanne Murray, editor(s) and American Society for Metals. Bull Alloy Phase Diag 3, Metals Park, OH: American Society for Metals, 130p. (1982), ISBN: 01970216.

Handbook of Phase Diagrams of Silicate Systems, Vol. I. Binary Systems, Second Revised Edition - N. A. Toropov, V. P. Barzakovskii, V. V. Lapin, N. N. Kurtseva, J. Schmorak, editor(s). Russian Transl., Springfield, VA: NTIS, 730p. (1970). TT 71-50040, A26.

Handbook of Phase Diagrams of Silicate Systems, Vol. II. MetalOxygen Compounds in Silicate Systems, Second Revised Edition - N. A. Toropov, V. P. Barzakovskii, I. A. Bondar', and Yu. P. Udalov. Russian Transl., Springfield, VA: NTIS, 329p. (1972). TT 71-50041, A 15.

Phase Diagrams and Thermodynamic Properties of Ternary CopperMetal Systems - Y. Austin Chang, Joachim P. Neumann, A. Mikula, and Daniel Goldberg. INCRA Monograph VI, New York: International Copper Research Association, Inc., 702p. (1979).

Phase Diagrams and Thermodynamic Properties of Ternary CopperSulfur-Metal Systems - Y. Austin Chang, Joachim P. Neumann, and U. V. Choudary. INCRA Monograph VII, New York: International Copper Research Association, Inc., 191p. (1979).

Phase Diagrams for Ceramists - Ernest M. Levin, Carl R. Robbins, Howard F. McMurdie, editor(s)., American Ceramic Society; Columbus, Ohio, 601p. (1964), ISBN: 0-916094-04-9.

Phase Diagrams for Ceramists 1969 Supplement - Ernest M. Levin, Carl R. Robbins, Howard F. McMurdie, editor(s)., American Ceramic Society; Columbus, Ohio, 625p. (1969), ISBN: 0-916094-05-7.

Phase Diagrams for Ceramists 1975 Supplement - Ernest M. Levin, Howard F. McMurdie, editor(s)., American Ceramic Society; Columbus, Ohio, 513p. (1975).

Phase Diagrams and Thermodynamic Properties of Ternary CopperSilver Systems - Y. Austin Chang, Daniel Goldberg, and Joachim P. Neumann. J Phys Chem Ref Data 6, 621(1977).

Physical Properties Data Compilations Relevant to Energy Storage. I. Molten Salts: Eutectic Data - George J. Janz, Carolyn B. Allen, J. R. Downey, Jr., and Reginald P. T. Tomkins. NSRDS-NBS 61, 244p. (1978).

Selected Thermodynamic Values and Phase Diagrams for Copper and Some of Its Binary Alloys - Ralph Hultgren and Pramond D. Desai. INCRA Monograph I, New York: International Copper Research Association, Inc., 204p. (1973).

Selected Values of the Thermodynamic Properties of Binary Alloys - Ralph Hultgren, Pramond D. Desai, Donald T. Hawkins, M. Gleiser, and Kenneth K. Kelley., Metals Park, OH: American Society for Met als, 1435p. (1973).

\section{Phase transition data}

Behavior of the AB-Type Compounds at High Pressures and High Temperatures - Leo Merrill. J Phys Chem Ref Data 6, 1205(1977).
Behavior of the $\mathrm{AB}_{2}$-Type Compounds at High Pressures and High Temperatures - Leo Merrill. J Phys Chem Ref Data 11, 1005(1982).

Crystal Structure Transformations in Binary Halides - C. N. R. Rao and M. Natarajan. NSRDS-NBS 41, 57p. (1972).

Crystal Structure Transformations in Inorganic Nitrites, Nitrates, and Carbonates - C. N. R. Rao, Brahm Prakash, and M. Natarajan. NSRDS-NBS 53, 55p. (1975).

Crystal Structure Transformations in Inorganic Sulfates, Phosphates, Perchlorates, and Chromates - C. N. R. Rao and Brahm Prakash. NSRDS-NBS 56, 37p. (1975).

Equilibrium Properties of Fluid Mixtures, A Bibliography on Fluids of Cryogenic Interest - M. J. Hiza, Arthur J. Kidnay, and R. C. Miller., New York: IFI/Plenum, 166p. (1975), ISBN: 0-306-6601-6.

Equilibrium Properties of Fluid Mixtures, 2. A Bibliography of Experimental Data on Selected Fluids - M. J. Hiza, Arthur J. Kidnay, and R. C. Miller., New York: IFI/Plenum, 258p. (1982), ISBN: 0-306-6602-4.

Heat Capacity and Other Thermodynamic Properties of Linear Macromolecules. VI. Acrylic Polymers - Umesh Gaur, Suk-fai Lau, Brent B. Wunderlich, and Bernhard Wunderlich. J Phys Chem Ref Data 11, 1065(1982).

Heat Capacities and Entropies of Organic Compounds in the Condensed Phase - Eugene S. Domalski, William H. Evans, and Elizabeth D. Hearing. J Phys Chem Ref Data 13, Suppl. 1(1984).

High Temperature Properties and Decomposition of Inorganic Salts, Part 1. Sulfates - Kurt H. Stern and E. L. Weise. NSRDS-NBS 7, 38p. (1966).

High Temperature Properties and Decomposition of Inorganic Salts, Part 2. Carbonates - Kurt H. Stern and E. L. Weise. NSRDS-NBS 30, 27p. (1969).

High Pressure Bibliography 1900-1968, Volume I. Section I. Bibliography, Section II. Author Index - Leo Merrill. OSRD Bibl. 70-1, Vol. 1(1970).

High Pressure Bibliography 1900-1968, Volume II. Subject Index Leo Merrill. OSRD Bibl. 70-1, Vol. 2(1970).

High Temperature Properties and Decomposition of Inorganic Salts, Part 3. Nitrates and Nitrites - Kurt H. Stern. J Phys Chem Ref Data 1, 747(1972).

High-Pressure Calibration: A Critical Review - D. L. Decker, W. A. Bassett, Leo Merrill, H. T. Hall, and J. D. Barnett. J Phys Chem Ref Data 1, 773(1972).

High Temperature Properties and Decomposition of Inorganic Salts, Part 4. Oxy-Salts of the Halogens - Kurt H. Stern. J Phys Chem Ref Data 3, 481(1974).

JANAF Thermochemical Tables, Second Edition - Daniel R. Stull and H. Prophet. NSRDS-NBS 37, 1141p. (1971).

JANAF Thermochemical Tables, 1974 Supplement - Malcolm W. Chase, Jr., J. L. Curnutt, A. T. Hu, H. Prophet, A. N. Syverud, and L. C. Walker. J Phys Chem Ref Data 3, 311(1974).

JANAF Thermochemical Tables, 1975 Supplement - Malcolm W. Chase, Jr., J. L. Curnutt, H. Prophet, R. A. McDonald, and A. N. Syverud. J Phys Chem Ref Data 4, 1(1975).

JANAF Thermochemical Tables, 1978 Supplement - Malcolm W. Chase, Jr., J. L. Curnutt, R. A. McDonald, and A. N. Syverud. J Phys Chem Ref Data 7, 793(1978).

JANAF Thermochemical Tables, 1982 Supplement - Malcolm W. Chase, Jr., J. L. Curnutt, J. R. Downey, Jr., R. A. McDonald, A. N. Syverud, and E. A. Valenzuela. J Phys Chem Ref Data 11, 695(1982).

Liquid Vapor Equilibria on Systems of Interest in Cryogenics, A Survey - Arthur J. Kidnay, M. J. Hiza, and R. C. Miller. Cryogenics 13, London: Academic Press, 575p. (1973).

Physical and Thermodynamic Properties of Aliphatic Alcohols Randolph C. Wilhoit and Bruno J. Zwolinski. J Phys Chem Ref Data 2, Suppl. 1(1973).

Properties of Liquid and Solid Hydrogen - B. N. Esel'son, Y. P. Blagoi, V.N. Grigor'ev, V. G. Manzhelii, S. A. Mikhailenko, and N. P. Neklyudov. Russian Transl., Springfield, VA: NTIS, 126p. (1971). TT 70-50179, A07. 
The Molar Volume (Density) of Solid Oxygen in Equilibrium with Vapor - Hans M. Roder. J Phys Chem Ref Data 7, 949(1978).

Thermophysical Properties of Isobutane from 114 to $700 \mathrm{~K}$ at Pressures to $70 \mathrm{MPa}$ - Robert D. Goodwin and W. M. Haynes. NBS Tech. Note 1051, 199p. (1982).

Thermophysical Properties of Normal Butane from 135 to $700 \mathrm{~K}$ at Pressures to $70 \mathrm{MPa}-\mathrm{W}$. M. Haynes and Robert D. Goodwin. NBS Monograph 169, 197p. (1982).

Thermophysical Properties of Propane from 85 to $700 \mathrm{~K}$ at Pressures to $70 \mathrm{MPa}$ - Robert D. Goodwin and W. M. Haynes. NBS Monograph 170, 249p. (1982).

Transition Metal Oxides, Crystal Chemistry, Phase Transition, and Related Aspects - C. N. R. Rao and G. V. Subba Rao. NSRDS-NBS 49, 140p. (1974).

\section{Photon cross sectlon}

A Catalog of Data Compilations on Photcchemical and Photophysical Processes in Solution - James G. Brummer, W. Phillip Helman, and Alberta B. Ross. NBS Spec. Publ. 578, 27p. (1980).

Atomic Form Factors, Incoherent Scattering Functions, and Photon Scattering Cross Sections - John H. Hubbell, W. J. Veigele, E. A Briggs, R. T. Brown, D. T. Cromer, and R. J. Howerton. J Phys Chem Ref Data 4, 471(1975).

Bibliography of Low Energy Electron and Photon Cross Section Data (through December 1974) - Lee J. Kieffer. NBS Spec. Publ. 426, 222p. (1976).

Bibliography of Low Energy Electron and Photon Cross Section Data (January 1975 to December 1977) - Jean W. Gallagher, John R. Rumble, Jr., and Earl C. Beaty. NBS Spec. Publ. 426, Suppl. 1(1979).

Bibliography of Photoabsorption Cross Section Data - Robert D.Hudson and Lee J. Kieffer. OSRD Bibl. 70-4, 47p. (1970).

Bibliography of Low Energy Electron and Photon Cross Section Data (1978) - Jean W. Gallagher and Earl C. Beaty. JILA Report 18, 148p. (1980).

Bibliography of Low Energy Electron and Photon Cross Section Data (1979) - Jean W. Gallagher and Earl C. Beaty. JILA Report 21, 127p. (1981).

Comparison of Theoretical and Experimental Photoeffect Data, 0.1 $\mathrm{keV}$ to $1.5 \mathrm{MeV}$ - John H. Hubbell and W. J. Veigele. NBS Tech. Note 901, 47p. (1976).

Critical Review of Ultraviolet Photoabsorption Cross Sections for Molecules of Astrophysical and Aeronomic Interest - Robert D. Hudson. NSRDS-NBS 38, 114p. (1971).

Evaluated Kinetic and Photochemical Data for Atmospheric Chemistry - D. L. Baulch, R. A. Cox, Robert F. Hampson, Jr., J. A. Kerr, J. Troe, and R. T. Watson. J Phys Chem Ref Data 9, 295(1980).

Evaluated Kinetic and Photochemical Data for Atmospheric Chemistry: Supplement I. CODATA Task Group on Chemical Kinetics D. L. Baulch, R. A. Cox, P. J. Crutzen, Robert F. Hampson, Jr., J. A. Kerr, J. Troe, and R. T. Watson. J Phys Chem Ref Data 11, 327(1982).

Evaluated Kinetic and Photochemical Data for Atmospheric Chemistry: Supplement II. CODATA Task Group on Gas Phase Chemical Kinetics - D. L. Baulch, R. A. Cox, Robert F. Hampson, Jr, J. A. Kerr, J. Troe, and R. T. Watson. J Phys Chem Ref Data 13, 1259(1984).

Molecular Form Factors and Photon Coherent Scattering Cross Sections of Water - L. R. M. Morin. J Phys Chem Ref Data 11, 1091(1982).

Pair, Triplet, and Total Atomic Cross Sections (and Mass Attenuation Coefficients) for $1 \mathrm{MeV} \cdot 100 \mathrm{GeV}$ Photons in Elements $\mathrm{Z}=1$ to 100 - John H. Hubbell, Heinz A. Gimm, and I. Øverbø. J Phys Chem Ref Data 9, 1023(1980).

Photon Cross Sections, Attenuation Coefficients, and Energy Absorption Coefficients from $10 \mathrm{keV}$ to $100 \mathrm{GeV}$ - John H. Hubbell. NSRDS-NBS 29, 85p. (1969).

Rate Constants for Reactions of $\mathrm{ClO}_{x}$ of Atmospheric Interest - $\mathbf{R}$. T. Watson. J Phys Chem Ref Data 6, 871(1977).

Relativistic Atomic Form Factors and Photon Coherent Scattering Cross Sections - John H. Hubbell and I. $\emptyset$ verbø. J Phys Chem Ref Data 8, 69(1979).
Small-Angle Rayleigh Scattering of Photons at High Energies: Tabulations of Relativisitic HFS Modified Atomic Form Factors - D. Schaupp, M. Schumacher, F. Smend, P. Rullhusen, and John H. Hubbell. J Phys Chem Ref Data 12, 467(1983).

Survey of Photochemical and Rate Data for Twenty-eight Reactions of Interest in Atmospheric Chemistry - Robert F. Hampson, Jr., W. Braun, R. L. Brown, David Garvin, John T. Herron, Robert E. Huie, M. J. Kurylo, A. H. Laufer, J. D. McKinley, H. Okabe, M. D. Scheer, W. Tsang, D. H. Stedman, editor(s). J Phys Chem Ref Data 2, 267(1973).

Total Photon Absorption Cross Section Measurements, Theoretical Analysis and Evaluations for Energies above $10 \mathrm{MeV}-$ Heinz A. Gimm and John H. Hubbell. NBS Tech. Note 968, 81p. (1978).

\section{Polarizablilty}

Vibrational Contributions to Molecular Dipole Polarizabilities David M. Bishop and Lap M. Cheung. J Phys Chem Ref Data 11, 119(1982).

\section{Potential energy curves for atoms and molecules}

Atlas of the Observed Absorption Spectrum of Carbon Monoxide between 1060 and $1900 \AA-$ S. G. Tilford and J. D. Simmons. J Phys Chem Ref Data 1, 147(1972).

Gaseous Diffusion Coefficients - T. R. Marrero and E. A. Mason. J Phys Chem Ref Data 1, 1(1972).

The Spectrum of Molecular Oxygen - Paul H. Krupenie. J Phys Chem Ref Data 1, 423(1972).

The Spectrum of Molecular Nitrogen - Alf Lofthus and Paul H. Krupenie. J Phys Chem Ref Data 6, 113(1977).

\section{Proton affinity}

A Compendium of Gas Phase Basicity and Proton Affinity Measurements - K. N. Hartman, Sharon G. Lias, P. J. Ausloos, Henry M. Rosenstock, S. S. Schroyer, C. Schmidt, D. Martinsen, and G. W. A. Milne. NBSIR 79.1777, 563p. (1979).

Annotated Bibliography on Proton Affinities - K. N. Hartman, Sharon G. Lias, P. J. Ausloos, and Henry M. Rosenstock. NBSIR 76-1061, 52p. (1976).

Evaluated Gas Phase Basicities and Proton Affinities of Molecules: Heats of Formation of Protonated Molecules - Sharon G. Lias, Joel F. Liebman, and Rhoda D. Levin. J Phys Chem Ref Data 13, 695(1984).

\section{Quadrupole moments}

See: Nuclear moments

\section{Quantum yield}

Survey of Photochemical and Rate Data for Twenty-eight Reactions of Interest in Atmospheric Chemistry - Robert F. Hampson, Jr., W. Braun, R. L. Brown, David Garvin, John T. Herron, Robert E. Huie, M. J. Kurylo, A. H. Laufer, J. D. McKinley, H. Okabe, M. D. Scheer, W. Tsang, D. H. Stedman, editor(s). J Phys Chem Ref Data 2, 267(1973).

\section{Raman spectra}

See: Vibrational spectra (infrared, Raman)

\section{Rate constants of chemical reactions}

A Bibliography on Ion-Molecule Reactions. January 1900 to March 1966 - F. N. Harllee, Henry M. Rosenstock, and John T. Herron. NBS Tech. Note 291, 40p. (1966).

A Bibliography of Kinetic Data on Gas Phase Reactions of Nitrogen, Oxygen, and Nitrous Oxides - Francis Westley. OSRD Bibl. 71-2, 140p. (1971) 
A Compilation of Kinetic Parameters for the Thermal Degradation of n-Alkane Molecules - D. L. Allara and Robert Shaw. J Phys Chem Ref Data 9, 523(1980).

A Critical Review of the Gas-Phase Reaction Kinetics of the Hydroxyl Radical - William E. Wilson, Jr. J Phys Chem Ref Data 1, 535(1972).

A Critical Review of H-Atom Transfer in the Liquid Phase: Chlorine Atom, Alkyl, Trichloromethyl, Alkoxy, and Alkylperoxy Radicals D. G. Hendry, T. Mill, L. Piszkiewicz, J. A. Howard, and H. K. Eigenmann. J Phys Chem Ref Data 3, 937(1974).

A Review of Rate Constants of Selected Reactions of Interest in Re-Entry Flow Fields in the Atmosphere - M. H. Bortner. NBS Tech. Note 484, 62p. (1969).

A Supplementary Bibliography of Kinetic Data on Gas Phase Reactions of Nitrogen, Oxygen, and Nitrogen Oxides - Francis Westley. NBS Spec. Publ. 371, 93p. (1973).

Bibliography of Ion-Molecule Reaction Rate Data (January 1950 October 1971) - George A. Sinnott. NBS Spec. Publ. 381, 75p. (1973).

Biweekly List of Papers on Radiation Chemistry and Photochemistry Vol. 17. 1984 - Radiation Chemistry Data Center. Rad Chem, Notre Dame, IN: Radiation Chem. Data Center, U. of Notre Dame, ..p. (1984). \$25.00; the Bir,veekly List, Vol. 17 (1984) plus the Annual Cumulation, Vol. 16 (1983), $\$ 35.00$; foreign and airmail postage rates available upon request.

Biweekly List of Papers on Radiation Chemistry and Photochemistry Annual Cumuluation with Keyword and Author Indexes, Vol. 16. 1983 - Radiation Chemistry Data Center. Rad Chem 16, Springfield, VA: NTIS, 444p. (1984).

Biweekly List of Papers on Radiation Chemistry and Photochemistry Annual Cumuluation with Keyword and Author Indexes, Vol. 15. 1982 - Radiation Chemistry Data Center. Rad Chem 15, Springfield, VA: NTIS, 448p. (1983). PB 83-203638, A19.

Biweekly List of Papers on Radiation Chemistry and Photochemistry Annual Cumulation with Keyword and Author Indexes, Vol 14. 1981 - Radiation Chemistry Data Center. Rad Chem 14, Springfield, VA: NTIS, 534p. (1982). PB 82-214 487, A22.

Biweekly List of Papers on Radiation Chemistry and Photochemistry Annual Cumulation with Keyword and Author Indexes, Vol. 13. 1980 - Radiation Chemistry Data Center. Rad Chem 13, Springfield, VA: NTIS, 704p. (1981). PB 82-122 995, A26.

Biweekly List of Papers on Radiation Chemistry and Photochemistry Annual Cumulation with Keyword and Author Indexes, Vol 12. 1979 - Radiation Chemistry Data Center. Rad Chem 12, Springfield, VA: NTIS, 748p. (1980). PB 81-113 680, A26.

Biweekly List of Papers on Radiation Chemistry and Photochemistry Annual Cumulation with Keyword and Author indexes, Vol. 11. 1978 - Radiation Chemistry Data Center. Rad Chem 11, Springfield, VA: NTIS, 768p. (1979). PB 226 368, A99.

Biweekly List of Papers on Radiation Chemistry, Annual Cumulation with Keyword and Author Indexes, Vol. 10. 1977 - Radiation Chemistry Data Center. Rad Chem 10, Springfield, VA: NTIS, 695p. (1978). PB 291 876, A26.

Biweekly List of Papers on Radiation Chemistry, Annual Cumulation with Keyword and Author Indexes, Vol. 9. 1976 - Radiation Chemistry Data Center. Rad Chem 9, Springfield, VA: NTIS, 707p. (1977). PB 268 699, A26.

Biweekly List of Papers on Radiation Chemistry, Annual Cumulation with Keyword and Author Indexes, Vol. 8. 1975 - Radiation Chemistry Data Center. Rad Chem 8, Springfield, VA: NTIS, 670p. (1976). PB 275 025, A26.

Biweekly List of Papers on Radiation Chemistry, Annual Cumulation with Keyword and Author Indexes, Vol. 7. 1974 - Radiation Chemistry Data Center. Rad Chem 7, Springfield, VA: NTIS, 553p. (1975). COM 75-11475, A24.

Chemical Kinetics in the C-O-S and H-N-O-S Systems: A Bibliography - 1899 through June 1971 - Francis Westley. NBS Spec. Publ. 362, 75p. (1972).

Chemical Kinetics of the Gas Phase Combustion of Fuels (A Bibliography on the Rates and Mechanisms of Oxidation of Aliphatic $C_{1}$ to
$\mathrm{C}_{10}$ Hydrocarbons and of Their Oxygenated Derivatives) - Francis Westley. NBS Spec. Publ. 449, 142p. (1976).

Chemical Kinetic and Photochemical Data Sheets for Atmospheric Reactions - Robert F. Hampson, Jr. Fed Aviation Admin EE 80-17, Springfield, VA: NTIS, 490p. (1980). FAA-EE-80-17, A211.

Chemical Kinetic Data Sheets for High-Temperature Chemical Reactions - N. Cohen and K. R. Westberg. J Phys Chem Ref Data 12, 531(1983).

Compilation of Rate Constants for the Reactions of Metal Ions in Unusual Valency States - George V. Buxton and Robin M. Sellers. NSRDS-NBS 62, 68p. (1978).

Compendium of ab initio Calculations of Molecular Energies and Properties - Morris Krauss. NBS Tech. Note 438, 139p. (1967).

Critical Review of Hydrolysis of Organic Compounds in Water Under Environmental Conditions - W. Mabey and T. Mill. J Phys Chem Ref Data 7, 383(1978).

Critically Evaluated Rate Constants for Gaseous Reactions of Several Electronically Excited Species - Keith Schofield. J Phys Chem Ref Data 8, 723(1979).

Data Index for Energy Transfer Collisions of Atoms and Molecules - 1970-1979 - Jean W. Gallagher, Janet Van Blerkom, Earl C. Beaty, and John R. Rumble, Jr. NBS Spec. Publ. 593, 349p. (1981).

Evaluated Chemical Kinetic Rate Constants for Various Gas Phase Reactions - Keith Schofield. J Phys Chem Ref Data 2, 25(1973).

Evaluated Kinetic and Photochemical Data for Atmospheric Chemistry - D. L. Baulch, R. A. Cox, Robert F. Hampson, Jr., J. A. Kerr, J. Troe, and R. T. Watson. J Phys Chem Ref Data 9, 295(1980).

Evaluated Kinetic Data for High Temperature Reactions, Volume 4. Homogeneous Gas Phase Reactions of Halogen- and CyanideContaining Species - D. L. Baulch, J. Duxbury, S. J. Grant, and D. C. Montague. J Phys Chem Ref Data 10, Suppl. 1(1981).

Evaluated Kinetic and Photochemical Data for Atmospheric Chemistry: Supplement I. CODATA Task Group on Chemical Kinetics D. L. Baulch, R. A. Cox, P. J. Crutzen, Robert F. Hampson, Jr., J. A. Kerr, J. Troe, and R. T. Watson. J Phys Chem Ref Data 11, 327(1982).

Evaluation of Kinetic and Mechanistic Data for Modeling of Photochemical Smog - Roger Atkinson and Alan C. Lloyd. J Phys Chem Ref Data 13, 315(1984).

Evaluated Kinetic and Photochemical Data for Atmospheric Chemistry: Supplement II. CODATA Task Group on Gas Phase Chemical Kinetics - D. L. Baulch, R. A. Cox, Robert F. Hampson, Jr., J. A. Kerr, J. Troe, and R. T. Watson. J Phys Chem Ref Data 13, 1259(1984).

Gas Phase Reaction Kinetics of Neutral Oxygen Species - Harold S. Johnston. NSRDS-NBS 20, 49p. (1968).

Heavy-Atom Kinetic Isotope Effects, An Indexed Bibliography Marvin J. Stern and Max Wolfsberg. NBS Spec. Publ. 349, 43p. (1972).

High Temperature Properties and Decomposition of Inorganic Salts, Part 1. Sulfates - Kurt H. Stern and E. L. Weise. NSRDS-NBS 7, 38p. (1966).

High Temperature Properties and Decomposition of Inorganic Salts, Part 2. Carbonates - Kurt H. Stern and E. L. Weise. NSRDS-NBS 30, 27p. (1969).

High Temperature Properties and Decomposition of Inorganic Salts, Part 4. Oxy-Salts of the Halogens - Kurt H. Stern. J Phys Chem Ref Data 3, 481(1974).

Hydrogenation of Ethylene on Metallic Catalysts - Juro Horiuti and Koshiro Miyahara. NSRDS-NBS 13, 62p. (1968).

Ion-Molecule Reactions - Earl W. McDaniel, V. Cermak, A. Dalgarno, E. E. Ferguson, and L. Friedman. At Mol Collis Proc Ser, New York: Wiley-Interscience, 374p. (1970), ISBN: 0-471-5838-3.

Kinetic Data on Gas Phase Unimolecular Reactions - Sidney W. Benson and Harry E. O'Neal. NSRDS-NBS 21, 645p. (1970).

Kinetic and Photochemical Data for Atmospheric Chemistry, Reactions of the Nitrogen Oxides - Robert F. Hampson, Jr. NBSIR 80-2032, 89p. (1980). 
Nitrogen Oxychlorides: A Bibliography on Data for Physical and Chemical Properties of $\mathrm{ClNO}, \mathrm{ClNO}_{2}$, and $\mathrm{ClNO}_{3}-$ Francis Westley. NBS Spec. Publ. 478, 54p. (1977).

Radiation Chemistry of Nitrous Oxide Gas, Primary Processes, Elementary Reactions and Yields - George R. A. Johnson. NSRDS-NBS 45, 29p. (1973).

Radiation Chemistry of Ethanol: A Review of Data on Yields, Reaction Rate Parameters, and Spectral Properties of Transients - Gordon R. Freeman. NSRDS-NBS 48, 44p. (1974).

Rate Coefficients for Ion-Molecule Reactions, Organic Ions Other Than Those Containing Only $\mathrm{C}$ and $\mathrm{H}-\mathrm{L}$. Wayne Sieck. NSRDSNBS 64, 27p. (1980).

Rate Constants for Reactions of Inorganic Radicals in Aqueous Solution - Alberta B. Ross and Pedatsur Neta. NSRDS-NBS 65, 62p. (1979).

Rate Constants for Reactions of Aliphatic Carbon-Centered Radicals in Aqueous Solution - Alberta B. Ross and Pedatsur Neta. NSRDSNBS 70, 96p. (1982).

Rate Constants of Gas Phase Reactions, Reference Book - V. N. Kondratiev, L. J. Holtschlag, R. M. Fristrom, editor(s). Russian Transl., Springfield, VA: NTIS, 434p. (1972). COM 72-10014, A19.

Rate Constants for the Reactions of Atomic Oxygen ( $\left.O{ }^{3} \mathrm{P}\right)$ with Organic Compounds in the Gas Phase - John T. Herron and Robert E. Huie. J Phys Chem Ref Data 2, 467(1973).

Rate Coefficients for Ion-Molecule Reactions, I. Ions Containing C and $\mathrm{H}-\mathrm{L}$. Wayne Sieck and Sharon G. Lias. J Phys Chem Ref Data 5, 1123(1976).

Rate Constants for Reactions of $\mathrm{ClO}_{\mathrm{x}}$ of Atmospheric Interest - R. T. Watson. J Phys Chem Ref Data 6, 871(1977).

Rate Constants for the Decay and Reactions of the Lowest Electronically Excited Singlet State of Molecular Oxygen in Solution - Francis Wilkinson and James G. Brummer. J Phys Chem Ref Data 10, 809(1981).

Rate Coefficients for Vibrational Energy Transfer Involving the Hydrogen Halides - Stephen R. Leone. J Phys Chem Ref Data 11, 953(1982).

Reactivity of the Hydroxyl Radical in Aqueous Solutions - Leon M.

Dorfman and Gerald E. Adams. NSRDS-NBS 46, 72p. (1973).

Reaction Rate and Photochemical Data for Atmospheric Chemistry - 1977 - Robert F. Hampson, Jr. and David Garvin. NBS Spec. Publ. 513, 111p. (1978).

Selected Specific Rates of Reactions of the Solvated Electron in Alcohols - Edgar Watson, Jr. and Sathyabhama Roy. NSRDS-NBS 42, 27p. (1972).

Selected Specific Rates of Reactions of Transients from Water in Aqueous Solution, 1. Hydrated Electron - Michael Anbar, Mark Bambenek, and Alberta B. Ross. NSRDS-NBS 43, 69p. (1973).

Selected Specific Rates of Reactions of Transients from Water in Aqueous Solution, 1. Hydrated Electron, Supplemental Data Alberta B. Ross. NSRDS-NBS 43, Suppl.(1975).

Selected Specific Rates of Reactions of Transients from Water in Aqueous Solution, II. Hydrogen Atom - Michael Anbar, Farhataziz, and Alberta B. Ross. NSRDS-NBS 51, 66p. (1975).

Selected Specific Rates of Reactions of Transients from Water in Aqueous Solution, III. Hydroxyl Radical and Perhydroxyl Radical and Their Radical Ions - Farhataziz and Alberta B. Ross. NSRDS-NBS 59, 126p. (1977).

Semi-Empirical Extrapolation and Estimation of Rate Constants for Abstraction of $\mathrm{H}$ from Methane by $\mathrm{H}, \mathrm{O}, \mathrm{HO}$, and $\mathrm{O}_{2}-$ Robert Shaw. J Phys Chem Ref Data 7, 1179(1978).

Summary Report on the Workshop on High Temperature Chemical Kinetics: Applications to Combustion Research - David Garvin, R: L. Brown, Robert F. Hampson, Jr., M. J. Kurylo, and W. Tsang. NBS Spec. Publ. 531, 94p. (1978).

Supplementary Bibliography of Kinetic Data on Gas Phase Reactions of Nitrogen, Oxygen, and Nitrogen Oxides (1972 - 1973) Francis Westley. NBS Spec. Pub1. 371, Suppl. 1(1975).

Survey of Photochemical and Rate Data for Twenty-eight Reactions of Interest in Atmospheric Chemistry - Robert F. Hampson, Jr., W.
Braun, R. L. Brown, David Garvin, John T. Herron, Robert E. Huie, M. J. Kurylo, A. H. Laufer, J. D. McKinley, H. Okabe, M. D. Scheer, W. Tsang, D. H. Stedman, editor(s). J Phys Chem Ref Data 2, 267(1973).

Tables of Bimolecular Gas Reactions - Aubrey F. TrotmanDickenson and G. S. Milne. NSRDS-NBS 9, 129p. (1967).

Table of Recommended Rate Constants for Chemical Reactions Occurring in Combustion - Francis Westley. NSRDS-NBS 67, 110p. (1980).

Table of Recommended Rate Constants for Chemical Reactions Occurring in Combustion - Francis Westley. NBSIR 79-1941, 169p. (1979).

Tables of Experimental Rate Constants for Chemical Reactions Occurring in Combustion (1971-1977) - Francis Westley. NBSIR 81-2254, 302p. (1981).

The Radiation Chemistry of Gaseous Ammonia - Donald B. Peterson. NSRDS-NBS 44, 41p. (1974).

The Radiolysis of Methanol: Product Yields, Rate Constants, and Spectroscopic Parameters of Intermediates - J. H. Baxendale and Peter Wardman. NSRDS-NBS 54, 33p. (1975).

Theory of Charge Exchange - R. A. Mapleton., New York: WileyInterscience, 284p. (1971), ISBN: 0-471-5678-7.

Thermodynamic and Thermophysical Properties of Combustion Products, Volume II. Oxygen-Based Propellants - V. P. Glushko, V. E. Alemasov, A. F. Dregalin, A. P. Tishin, V. A. Khudyakov, and V. N. Kostin. Russian Transl., Springfield, VA: NTIS, 505p. (1975). TT 74-50032, A22.

Thermodynamic and Thermophysical Properties of Combustion Products, Volume IV. Nitrogen Tetroxide-Based Propellants - V. P. Glushko, V. E. Alemasov, A. F. Dregalin, A. P. Tishin, V. A. Khudyakov, and V. N. Kostin. Russian Transl., Springfield, VA: NTIS, 540p. (1976). TT 76-50007, A23.

Vibrationally Excited Hydrogen Halides: A Bibliography on Chemical Kinetics of Chemiexcitation and Energy Transfer Processes (1958 through 1973) - Francis Westley. NBS Spec. Publ. 392, 84p. (1974).

Yields of Free Ions Formed in Liquids by Radiation - Augustine O. Allen. NSRDS-NBS 57, 38p. (1976).

\section{Rayleigh scattering cross section}

Atomic Form Factors, Incoherent Scattering Functions, and Photon Scattering Cross Sections - John H. Hubbell, W. J. Veigele, E. A Briggs, R. T. Brown, D. T. Cromer, and R. J. Howerton. J Phys Chem Ref Data 4, 471(1975).

Molecular Form Factors and Photon Coherent Scattering Cross Sections of Water - L. R. M. Morin. J Phys Chem Ref Data 11, 1091(1982).

Relativistic Atomic Form Factors and Photon Coherent Scattering Cross Sections - John H. Hubbell and I. $\emptyset$ verb $\varnothing$. J Phys Chem Ref Data 8, 69(1979).

Small-Angle Rayleigh Scattering of Photons at High Energies: Tabulations of Relativisitic HFS Modified Atomic Form Factors - D. Schaupp, M. Schumacher, F. Smend, P. Rullhusen, and John H. Hubbell. J Phys Chem Ref Data 12, 467(1983).

\section{Refractive index}

Physical and Thermodynamic Properties of Aliphatic Alcohols Randolph C. Wilhoit and Bruno J. Zwolinski. J Phys Chem Ref Data 2, Suppl. 1(1973).

Refractive Index of Alkali Halides and Its Wavelength and Temperature Derivatives - H. H. Li. J Phys Chem Ref Data 5, 329(1976).

Refractive Index of Alkaline Earth Halides and Its Wavelength and Temperature Derivatives - H. H. Li. J Phys Chem Ref Data 9, 161(1980).

Refractive Index of Silicon and Germanium and Its Wavelength and Temperature Derivatives - H. H. Li. J Phys Chem Ref Data 9, 561(1980).

Refractive Index of $\mathrm{ZnS}, \mathrm{ZnSe}$, and $\mathrm{ZnTe}$ and Its Wavelength and Temperature Derivatives - H. H. Li. J Phys Chem Ref Data 13, 103(1984). 
Refractive Index of $\mathrm{ZnS}, \mathrm{ZnSe}$, and $\mathrm{ZnTe}$ and Its Wavelength and Temperature Derivatives - H. H. Li. J Phys Chem Ref Data 13, 103(1984).

Thermophysical Properties of Gases and Liquids, No. $1-$ V. A. Rabinovich. Russian Transl. Springfield, VA: NTIS, 214p. (1970). TT 69.55091, A 10, the translation of volumes 2, 3, and 4 have the title: Thermophysical Properties of Matter and Substances.

\section{Resistlvity}

See: Electrical resistivity

\section{Rotational constants}

See: Molecular energy levels and constants

\section{Rotatlonal spectra}

The Band Spectrum of Carbon Monoxide - Paul H. Krupenie. NSRDS-NBS 5, 87p. (1966).

Microwave Spectral Tables, Volume I. Diatomic Molecules - Paul F. Wacker, M. Mizushima, J. D. Petersen, and J. R. Ballard. NBS Monograph 70, 17lp. (1964).

Microwave Spectral Tables, Volume II. Line Strengths of Asymmetric Rotors - Paul F. Wacker and M. R. Pratto. NBS Monograph 70, 349p. (1964).

Microwave Spectral Tables, Volume III. Polyatomic Molecules with Internal Rotation - Paul F. Wacker, M. S. Cord, D. G. Burkhard, J. D. Petersen, and R. F. Kukol. NBS Monograph 70, 275p. (1969).

Microwave Spectral Tables, Volume IV. Polyatomic Molecules without Internal Rotation - M. S. Cord, J. D. Petersen, M. S. Lojko, and R. H. Haas. NBS Monograph 70, 419p. (1968).

Microwave Spectral Tables, Volume V. Spectral Line Listing - M. S. Cord, M. S. Lojko, and J. D. Petersen. NBS Monograph 70, 533p. (1968).

Microwave Spectra of Molecules of Astrophysical Interest, I. Formaldehyde, Formamide, and Thioformaldehyde - Donald R. Johnson, Frank J. Lovas, and William H. Kirchhoff. J Phys Chem Ref Data 1, 1011(1972).

Microwave Spectra of Molecules of Astrophysical Interest, II. Methylenimine - William H. Kirchhoff, Donald R. Johnson, and Frank J. Lovas. J Phys Chem Ref Data 2, 1(1973).

Microwave Spectra of Molecules of Astrophysical Interest, III. Methanol - R. M. Lees, Frank J. Lovas, William H. Kirchhoff, and Donald R. Johnson. J Phys Chem Ref Data 2, 205(1973).

Microwave Spectra of Molecules of Astrophysical Interest, IV. Hy. drogen Sulfide - Paul Helminger, Frank C. De Lucia, and William H. Kirchhoff. J Phys Chem Ref Data 2, 215(1973).

Microwave Spectra of Molecules of Astrophysical Interest, V. Water Vapor - Frank C. De Lucia, Paul Helminger, and William H. Kirch. hoff. J Phys Chem Ref Data 3, 211(1974).

Microwave Spectra of Molecules of Astrophysical Interest, VI. Carbonyl Sulfide and Hydrogen Cyanide - Arthur G. Maki. J Phys Chem Ref Data 3, 221(1974).

Microwave Spectra of Molecules of Astrophysical Interest, VII. Carbon Monoxide, Carbon Monosulfide, and Silicon Monoxide - Frank J. Lovas and Paul H. Krupenie. J Phys Chem Ref Data 3, 245(1974).

Microwave Spectra of Molecules of Astrophysical Interest, VIII. Sulfur Monoxide - Eberhard Tiemann. J Phys Chem Ref Data 3, 259(1974).

Microwave Spectral Tables, I. Diatomic Molecules - Frank J. Lovas and Eberhard Tiemann. J Phys Chem Ref Data 3, 609(1974).

Microwave Spectra of Molecules of Astrophysical Interest, IX. Acetaldehyde - A. Bauder, Frank J. Lovas, and Donald R. Johnson. J Phys Chem Ref Data 5, 53(1976).

Microwave Spectra of Molecules of Astrophysical Interest, X. Isocyanic Acid - G. Winnewisser, W. H. Hocking, and M. C. L. Gerry. J Phys Chem Ref Data 5, 79(1976).

Microwave Spectra of Molecules of Astrophysical Interest, XI. Silicon Sulfide - Eberhard Tiemann. J Phys Chem Ref Data 5, 1147(1976).
Microwave Spectra of Molecules of Astrophysical Interest, XII. Hydroxyl Radical - Robert A. Beaudet and Robert L. Poynter. J Phys Chem Ref Data 7, 311(1978).

Microwave Spectra of Molecules of Astrophysical Interest, XIII. Cyanoacetylene - Walter J. Lafferty and Frank J. Lovas. J Phys Chem Ref Data 7, 441(1978).

Microwave Spectral Tables II. Triatomic Molecules - Frank J. Lovas. J Phys Chem Ref Data 7, 1445(1978).

Microwave Spectra of Molecules of Astrophysical Interest, XIV. Vinyl Cyanide (Acrylonitrile) - M. C. L. Gerry, K. Yamada, and G. Winnewisser. J Phys Chem Ref Data 8, 107(1979).

Microwave Spectra of Molecules of Astrophysical Interest, XV. Propyne - A. Bauer, D. Boucher, J. Burie, J. Demaison, and A. Dubrulle. J Phys Chem Ref Data 8, 537(1979).

Microwave Spectra of Molecules of Astrophysical Interest, XVI. Methyl Formate - A. Bauder. J Phys Chem Ref Data 8, 583(1979).

Microwave Spectra of Molecules of Astrophysical Interest, XVII. Dimethyl Ether - Frank J. Lovas, H. Lutz, and H. Dreizler. J Phys Chem Ref Data 8, 1051(1979).

Microwave Spectra of Molecules of Astrophysical Interest. XVIII. Formic Acid - Edmond Willemot, Didier Dangoisse, Nicole Monnanteuil, and Jean Bellet. J Phys Chem Ref Data 9, 59(1980).

Microwave Spectra of Molecules of Astrophysical Interest. XIX. Methyl Cyanide - D. Boucher, J. Burie, A. Bauer, A. Dubrulle, and J. Demaison. J Phys Chem Ref Data 9, 659(1980).

Microwave Spectra of Molecules of Astrophyical Interest. XX. Methane - I. Ozier, M. C. L. Gerry, and A. G. Robiette. J Phys Chem Ref Data 10, 1085(1981).

Microwave Spectra of Molecules of Astrophysical Interest. XXI. Ethanol $\left(\mathrm{C}_{2} \mathrm{H}_{3} \mathrm{OH}\right)$ and Propionitrile $\left(\mathrm{C}_{2} \mathrm{H}_{5} \mathrm{CN}\right)$ - Frank J. Lovas. J Phys Chem Ref Data 11, 251(1982).

Peak Absorption Coefficients of Microwave Absorption Lines of Carbonyl Sulphide - Z. Kisiel and D. J. Millen. J Phys Chem Ref Data 11, 101(1982).

Resonances in Electron Impact on Atoms and Diatomic Molecules - George J. Schulz. NSRDS-NBS 50, 120p. (1973).

Tables for the Rigid Asymmetric Rotor: Transformation Coefficients from Symmetric to Asymmetric Bases and Expectation Values of $\mathrm{P}^{2<-}$, $\mathrm{P}^{4<{ }_{2}}$, and $\mathrm{P}^{6<-}{ }_{2}-$ Richard H. Schwendeman. NSRDS-NBS 12, 102p. (1968).

The Calculation of Rotational Energy Levels and Rotational Line Intensities in Diatomic Molecules - Jon T. Hougen. NBS Monograph 115, 54p. (1970).

The Spectrum of Molecular Oxygen - Paul H. Krupenie. J Phys Chem Ref Data 1, 423(1972).

\section{Semiconductor properties: mobility, effective mass, energy gap}

Compilation of Energy Band Gaps in Elemental and Binary Com. pound Semiconductors and Insulators - W. H. Strehlow and E. L. Cook. J Phys Chem Ref Data 2, 163(1973).

\section{Solubility}

A Critical Review of Henry's Law Constants for Chemicals of Environmental Interest - Donald Mackay and Wan Ying Shiu. J Phys Chem Ref Data 10, 1175(1981).

Compilation and Evaluation of Solubility Data in the Mercury (I) Chloride-Water System - Y. Marcus. J Phys Chem Ref Data 9, 1307(1980).

The Solubility of Some Sparingly Soluble Lead Salts: An Evaluation Lawrence Clever and Francis J. Johnston. J Phys Chem Ref Data 9, 751(1980).

The Solubility of Oxygen and Ozone in Liquids - Rubin Battino, Timothy R. Rettich, and Toshihiro Tominaga. J Phys Chem Ref Data 12, 163(1983) 
The Solubility of Nitrogen and Air in Liquids - Rubin Battino, [imothy R. Rettich, and Toshihiro Tominaga. J Phys Chem Ref Data 3, 563(1984).

Water Solubilities of Polynuclear Aromatic and Heteroaromatic zompounds - Robert S. Pearlman, Samuel H. Yalkowsky, and Sujit 3anerjee. J Phys Chem Ref Data 13, 555(1984).

\section{Specific conductance}

See: Electrical conductance

\section{Specific gravity}

See: Density

\section{Specific heat}

See: Heat capacity

Thermodynamic properties

\section{Spectra}

See: Atomic energy levels and spectra Rotational spectra Vibrational spectra (infrared, Raman)

\section{Spectral line widths}

A Critical Review of the Stark Widths and Shifts of Spectral Lines from Non-Hydrogenic Atoms - N. Konjević and J. R. Roberts. J Phys Chem Ref Data 5, 209(1976).

Atomic Radiative and Radiationless Yields for $\mathrm{K}$ and $\mathrm{L}$ Shells -

Morris O. Krause. J Phys Chem Ref Data 8, 307(1979).

Bibliography on Atomic Line Shapes and Shifts (1899 through March 1972) - Jeffrey R. Fuhr, Wolfgang L. Wiese, and Larry J. Roszman. NBS Spec. Publication 366, 165p. (1972).

Bibliography on Atomic Line Shapes and Shifts (April 1972 through June 1973) - Jeffrey R. Fuhr, Larry J. Roszman, and Wolfgang L. Wiese. NBS Spec. Publ. 366, Suppl. 1(1974).

Bibliography on Atomic Line Shapes and Shifts (July 1973 through May 1975) - Jeffrey R. Fuhr, Georgia A. Martin, and Beverly J. Specht. NBS Spec. Publ. 366, Suppl. 2(1975).

Bibliography on Atomic Line Shapes and Shifts (June 1975 through June 1978) - Jeffrey R. Fuhr, Beverly J. Miller, and Georgia A. Martin. NBS Spec. Publ. 366, Suppl. 3(1978).

Experimental Stark Widths and Shifts for Non-Hydrogenic Spectral Lines of Ionized Atoms (A Critical Review and Tabulation of Selected Data) - N. Konjević and Wolfgang L. Wiese. J Phys Chem Ref Data 5, 259(1976).

Experimental Stark Widths and Shifts for Spectral Lines of Neutral Atoms (A Critical Review of Selected Data for the Period 1976 to 1982)

- N. Konjević, M. S. Dimitrijević, and Wolfgang L. Wiese. J Phys Chem Ref Data 13, 619(1984).

Experimental Stark Widths and Shifts for Spectral Lines of Positive Ions (A Critical Review and Tabulation of Selected Data for the Period 1976 to 1982) - N. Konjević, M. S. Dimitrijević, and Wolfgang L. Wiese. J Phys Chem Ref Data 13, 649(1984).

Natural Widths of Atomic $\mathrm{K}$ and L Levels, $\mathrm{K} \alpha \mathrm{X}$-Ray Lines and Several KLL Auger Lines - Morris O. Krause and J. H. Oliver. J Phys Chem Ref Data 8, 329(1979).

Peak Absorption Coefficients of Microwave Absorption Lines of Carbonyl Sulphide - Z. Kisiel and D. J. Millen. J Phys Chem Ref Data 11, 101(1982).

The Spectrum of Molecular Oxygen - Paul H. Krupenie. J Phys Chem Ref Data 1, 423(1972).

\section{Structure, crystal}

See: Crystal structure

\section{Structure, molecular}

See: Molecular structure

\section{Superconductivity}

Properties of Selected Superconductive Materials, 1978 Supplement - Benjamin W. Roberts. NBS Tech. Note 983, 103p. (1978).

Survey of Superconductive Materials and Critical Evaluation of Se lected Properties - Benjamin W. Roberts. J Phys Chem Ref Data 5, 581(1976).

\section{Surface tension}

Critical Micelle Concentrations of Aquenus Surfactant Systems Pasupati Mukerjee and Karol J. Mysels. NSRDS-NBS 36, 222p. (1971). International Tables of the Surface Tension of Water - N. B. -Vargaftik, B. N. Volkov, and L. D. Voljak. J Phys Chem Ref Data 12, 817(1983),

Molten Salts: Volume 2. Section 1. Electrochemistry of Molten Salts. Gibbs Free Energies and Excess Free Energies from Equilibrium-Type Cells, Section 2. Surface Tension Data - George J. Janz, Chr. G. M. Dijkhuis, G. R. Lakshminarayanan, Reginald P. T. Tomkins, and J. Wong. NSRDS-NBS 28, 116p. (1968).

Molten Salts: Volume 3, Nitrates, Nitrites, and Mixtures. Electrical Conductance, Density, Viscosity, and Surface Tension Data - George J. Janz, Ursula Krebs, H. F. Siegenthaler, and Reginald P. T. Tomkins. J Phys Chem Ref Data 1, 581(1972).

Molten Salts: Volume 4, Part 1, Fluorides and Mixtures. Electrical Conductance, Density, Viscosity, and Surface Tension Data - George J. Janz, G. L. Gardner, Ursula Krebs, and Reginald P. T. Tomkins. J Phys Chem Ref Data 3, 1(1974).

Molten Salts: Volume 4, Part 2, Chlorides and Mixtures. Electrical Conductance, Density, Viscosity, and Surface Tension Data - George J. Janz, Reginald P. T. Tomkins, Carolyn B. Allen, J. R. Downey, Jr., G. L. Gardner, Ursula Krebs, and S. K. Singer. J Phys Chem Ref Data 4, 871(1975).

Molten Salts: Volume 4, Part 3, Bromides and Mixtures, lodides and Mixtures. Electrical Conductance, Density, Viscosity, and Surface Tension Data - George J. Janz, Reginald P. T. Tomkins, Carolyn B. Allen, J. R. Downey, Jr., and S. K. Singer. J Phys Chem Ref Data 6, 409(1977).

Molten Salts: Volume 4, Part 4, Mixed Halide Melts. Electrical Conductance, Density, Viscosity, and Surface Tension Data - George J. Janz, Reginald P. T. Tomkins, and Carolyn B. Allen. J Phys Chem Ref Data 8, 125(1979).

Molten Salts Data As Reference Standards for Density, Surface Tension, Viscosity and Electrical Conductance: $\mathrm{KNO}_{3}$ and $\mathrm{NaCl}-$ George J. Janz. J Phys Chem Ref Data 9, 791(1980).

Molten Salts: Volume 5, Part 1. Additional Single and MultiComponent Salt Systems. Electrical Conductance, Density, Viscosity, and Surface Tension Data - George J. Janz and Reginald P. T. Tomkins. J Phys Chem Ref Data 9, 831(1980).

Molten Salts: Volume 5, Part 2. Additional Single and MultiComponent Salt Systems. Electrical Conductance, Density, Vicosity and Surface Tension Data - George J. Janz and Reginald P. T. Tomkins. J Phys Chem Ref Data 12, 591(1983).

NBS/NRC Steam Tables, Thermodynamic and Transport Properties and Computer Programs for Vapor and Liquid States of Water Lester Haar, John S. Gallagher, and George S. Kell., New York: Hemisphere Press, 320p. (1984).

Properties of Liquid and Solid Hydrogen - B. N. Esel'son, Y. P. Blagoi, V.N. Grigor'ev, V. G. Manzhelii, S. A. Mikhailenko, and N. P. Neklyudov. Russian Transl., Springfield, VA: NTIS, 126p. (1971). TT 70-50179, A07.

The Surface Tension of Pure Liquid Compounds - Joseph J. Jasper. J Phys Chem Ref Data 1, 841(1972).

Thermophysical Properties of Fluid $\mathrm{H}_{2} \mathrm{O}$ - Joseph Kestin, Jan V. Sengers, B. Kamgar-Parsi, and J. M. H. Levelt Sengers. J Phys Chem Ref Data 13, 175(1984). 


\section{Thermal conductivlty}

A Computer Program for the Prediction of Viscosity and Thermal Conductivity in Hydrocarbon Mixtures - James F. Ely and Howard J. M. Hanley. NBS Tech. Note 1039, 83p. (1981).

A Correlation of the Existing Viscosity and Thermal Conductivity Data of Gaseous and Liquid Ethane - Howard J. M. Hanley, K. E. Gubbins, and S. Murad. J Phys Chem Ref Data 6, 1167(1977).

A Correlation of the Viscosity and Thermal Conductivity Data of Gaseous and Liquid Propane - Paul M. Holland, Howard J. M. Hanley, K. E. Gubbins, and J. M. Haile. J Phys Chem Ref Data 8, 559(1979).

A Correlation of the Viscosity and Thermal Conductivity Data of Gaseous and Liquid Ethylene - Paul M. Holland, B. E. Eaton, and Howard J. M. Hanley. J Phys Chem Ref Data 12, 917(1983).

Diffusion Rate Data and Mass Transport Phenomena in Copper Systems - Daniel B. Butrymowicz, John R. Manning, and Michael E. Read. INCRA Monograph V, New York: International Copper Research Association, Inc., 322p. (1977).

Diffusion Rate Data and Mass Transport Phenomena for Copper Systems, Part II - Daniel B. Butrymowicz, John R. Manning, and Michael E. Read. INCRA Monograph VIII, New York: International Copper Research Association, Inc., 701p. (1982).

Equilibrium and Transport Properties of the Noble Gases and Their Mixtures at Low Density - Joseph Kestin, K. Knierim, E. A. Mason, B. Najafi, S. T. Ro, and M. Waldman. J Phys Chem Ref Data 13, 229(1984).

Erratum: A Correlation of the Existing Viscosity and Thermal Conductivity Data of Gaseous and Liquid Ethane - Howard J. M. Hanley, K. E. Gubbins, and S. Murad. J Phys Chem Ref Data 10, 799(1981).

Heavy Water, Thermophysical Properties - V. A. Kirillin, Ya. Z. Kazavchinskii, P. M. Kessel'man, S. L. Rivkin, A. E. Sheindlin, E. E. Shpil'rain, V. V. Sychev, and D. L. Timrot. Russian Transl., Springfield, VA: NTIS, 273p. (1971). TT 70-50094, A12.

Interactive Fortran Program to Calculate Thermophysical Properties of 6 Fluids NBS Standard Reference Database 6, Washington, D.C.; NBS, Office of Standard Reference Data,(updated periodically). Call (301)921-2228 for specific instructions.

LNG Materials \& Fluids, A User's Manual of Property Data in Graphic Format - Douglas Mann and U.S. National Bureau of Standards., Boulder, CO: U.S. National Bureau of Standards, Cryogenic Division, 11p. (1977).

LNG Materials \& Fluids, A User's Manual of Property Data in Graphic Format, First Supplement - Douglas Mann and U.S. National Bureau of Standards. Suppl. 1, Boulder, CO: U.S. National Bureau of Standards, 11p. (1978).

LNG Materials \& Fluids, A User's Manual of Property Data in Graphic Format, Second Supplement - Douglas Mann and U.S. National Bureau of Standards. Suppl. 2, Boulder, CO: U.S. National Bureau of Standards, 11p. (1980).

NBS Chemical Thermodynamics Database NBS Standard Reference Database 2, Washington, D.C.; NBS, Office of Standard Reference Data,(updated periodically). Call (301)921-2228 for specific instructions.

Physical Properties Data for Rock Salt - Lewis H. Gevantman. NBS Monograph 167, 288p. (1981).

Physical Properties Data for Basalt - Lewis H. Gevantman. NBSIR 82-2587, 751p. (1982).

Properties of Liquid and Solid Hydrogen - B. N. Esel'son, Y. P. Blagoi, V.N. Grigor'ev, V. G. Manzhelii, S. A. Mikhailenko, and N. P. Neklyudov. Russian Transl., Springfield, VA: NTIS, 126p. (1971). TT 70-50179, A07.

Representative Equations for the Thermal Conductivity of Water Substance - Jan V. Sengers, J. T. R. Watson, R. S. Basu, B. KamgarParsi, and R. C. Hendricks. J Phys Chem Ref Data 13, 893(1984).

Tables of Collision Integrals and Second Virial Coefficients for the $(m, 6,8)$ Intermolecular Potential Function - Max Klein, Howard J. M. Hanley, Francis J. Smith, and Paul M. Holland. NSRDS-NBS 47, 161 p. (1974).

The Viscosity and Thermal Conductivity Coefficients of Gaseous and Liquid Fluorine - Howard J. M. Hanley and R. Prydz. J Phys Chem Ref Data 1, 1101(1972).

The Viscosity and Thermal Conductivity Coefficients of Dilute Argon, Krypton, and Xenon - Howard J. M. Hanley. J Phys Chem Ref Data 2, 619(1973).

The Viscosity and Thermal Conductivity Coefficients of Dilute Nitrogen and Oxygen - Howard J. M. Hanley and James F. Ely. J Phys Chem Ref Data 2, 735(1973).

The Viscosity and Thermal Conductivity Coefficients for Dense Gaseous and Liquid Argon, Krypton, Xenon, Nitrogen, and Oxygen Howard J. M. Hanley, Robert D. McCarty, and W. M. Haynes. J Phys Chem Ref Data 3, 979(1974).

The Viscosity and Thermal Conductivity Coefficients for Dense Gaseous and Liquid Methane - Howard J. M. Hanley, W. M. Haynes, and Robert D. McCarty. J Phys Chem Ref Data 6, 597(1977).

Thermal Conductivity of Selected Materials - Robert W. Powell, Cho Y. Ho, and Peter E. Liley. NSRDS-NBS 8, 68p. (1966).

Thermal Conductivity of Selected Materials, Part $2-$ Cho X. Ho, Robert W. Powell, and Peter E. Liley. NSRDS-NBS 16, 146p. (1968)

Thermodynamic and Thermophysical Properties of Combustion Products, Volume II. Oxygen-Based Propellants - V. P. Glushko, V. E. Alemasov, A. F. Dregalin, A. P. Tishin, V. A. Khudyakov, and V. N. Kostin. Russian Transl., Springfield, VA: NTIS, 505p. (1975). TT 74-50032, A22.

Thermodynamic and Thermophysical Properties of Combustion Products, Volume III. Oxygen- and Air-Based Propellant - V. P. Glushko, V. E. Alemasov, A. F. Dregalin, A. P. Tishin, V. A. Khudyakov, and V. N. Kostin. Russian Transl., Springfield, VA: NTIS, 648p. (1975). TT 75-50007, A26.

Thermodynamic and Thermophysical Properties of Counbustion Products, Volume IV. Nitrogen Tetroxide-Based Propellants - V. P. Glushko, V. E. Alemasov, A. F. Dregalin, A. P. Tishin, V. A. Khudyakov, and V. N. Kostin. Russian Transl., Springfield, VA: NTIS, 540p. (1976). TT 76-50007, A23.

Thermophysical Properties of Air and Air Components - A. A. Vasserman, Ya. Z. Kazavchinskii, V. A. Rabinovich, and A. M. Zhuravlev. Russian Transl. Springfield, VA: NTIS, 402p. (1971). TT 70-50095, Al 18.

Thermophysical Properties of Gases and Liquids, No. 1 - V. A. Rabinovich. Russian Transl. Springfield, VA: NTIS, 214p. (1970). TT 69-55091, A 10, the translation of volumes 2, 3, and 4 have the title: Thermophysical Properties of Matter and Substances.

Thermophysical Properties of Gaseous and Liquid Methane - V. A. Zagoruchenko and A. M. Zhuravlev. Russian Transl. Springfield, VA: NTIS, 25lp. (1970). TT 70-50097, A12.

Thermophysical Properties of Liquid Air and Its Components - A. A. Vasserman and V. A. Rabinovich. Russian Transl. Springfield, VA: NTIS, 255p. (1970). TT 69-55092, A 12.

Thermophysical Properties of Matter and Substances, Volume 2 V. A. Rabinovich. Russian Transl., Springfield, VA: NTIS, 395p. (1974). TT 72-52001, A17, the translation of volume 1 has the title: Thermophysical Properties of Gases and Liquids.

Thermophysical Properties of Matter and Substances, Volume 3 V. A. Rabinovich. Russian Transl. Springfield, VA: NTIS, 212p. (1975). TT 73-52009, A10, the translation of volume 1 has the title: Thermophysical Properties of Gases and Liquids.

Thermal Conductivity of the Elements - Cho Y. Ho, Robert W. Powell, and Peter E. Liley. J Phys Chem Ref Data 1, 279(1972).

Thermal Conductivity of the Elements: A Comprehensive Review - Cho Y. Ho, Robert W. Powell, and Peter E. Liley. J Phys Chem Ref Data 3, Suppl. 1(1974).

Thermal Conductivity of Ten Selected Binary Alloy Systems - Cho Y. Ho, M. W. Ackerman, K. Y. Wu, S. G. Oh, and T. N. Havill. J Phys Chem Ref Data 7, 959(1978).

Thermophysical Properties of Fluids. I. Argon, Ethylene, Parahydrogen, Nitrogen, Nitrogen Trifluoride, and Oxygen - Ben A. Younglove. J Phys Chem Ref Data 11, Suppl. 1(1982).

Thermophysical Properties of Fluid $\mathrm{H}_{2} \mathrm{O}$ - Joseph Kestin, Jan V. Sengers, B. Kamgar-Parsi, and J. M. H. Levelt Sengers. J Phys ChemRef Data 13, 175(1984). 
Thermophysical Properties of Fluid $\mathrm{D}_{2} \mathrm{O}$ - Joseph Kestin, Jan V. Sengers, B. Kamgar-Parsi, and J. M. H. Levelt Sengers. J Phys Chem Ref Data 13, 602(1984).

Transport Properties of Liquid and Gaseous $\mathrm{D}_{2} \mathrm{O}$ over a Wide Range of Temperature and Pressure - N. Matsunaga and A. Nagashima. J Phys Chem Ref Data 12, 933(1983).

\section{Thermal diffusivity}

See: Thermal conductivity

\section{Thermal expanslon coefficient}

High Temperature Properties and Decomposition of Inorganic Salts, Part 2. Carbonates - Kurt H. Stern and E. L. Weise. NSRDS-NBS 30, 27p. (1969).

LNG Materials \& Fluids, A User's Manual of Property Data in Graphic Format - Douglas Mann and U.S. National Bureau of Standards., Boulder, CO: U.S. National Bureau of Standards, Cryogenic Division, 11p. (1977).

LNG Materials \& Fluids, A User's Manual of Property Data in Graphic Format, First Supplement - Douglas Mann and U.S. National Bureau of Standards. Suppl. 1, Boulder, CO: U.S. National Bureau of Standards, 11p. (1978).

LNG Materials \& Fluids, A User's Manual of Property Data in Graphic Format, Second Supplement - Douglas Mann and U.S. National Bureau of Standards. Suppl. 2, Boulder, CO: U.S. National Bureau of Standards, 11p. (1980).

Physical Properties Data Compilations Relevant to Energy Storage. III. Engineering Properties of Single and Polycrystalline Sodium Beta and Beta" Alumina - G. R. Miller and D. G. Paquette. NSRDS-NBS 61, 19p. (1979).

Recommemded Values for the Thermal Expansivity of Silicon from 0 to $1000 \mathrm{~K}-\mathrm{C}$. A. Swenson. J Phys Chem Ref Data 12, 179(1983).

The Calculated Thermodynamic Properties of Superfluid Helium-4 - James S. Brooks and Russell J. Donnelly. J Phys Chem Ref Data 6, 51(1977).

Thermophysical Properties of Matter and Substances, Volume 2 V. A. Rabinovich. Russian Transl., Springfield, VA: NTIS, 395p. (1974). TT 72-52001, A17, the transiation of volume 1 has the title: Thermophysical Properties of Gases and Liquids.

Volumetric Properties of Aqueous Sodium Chloride Solutions - P. S. Z. Rogers and Kenneth S. Pitzer. J Phys Chem Ref Data 11, 15(1982).

\section{Thermodynamic propertles}

See: enthalpy, entropy, Gibbs energy, heat capacity (see also Heat of formation, Heat capacity, and other individual properties)

A Bibliography of Sources of Experimental Data Leading to Thermal Properties of Binary Aqueous Electrolyte Solutions - David Smith-Magowan and Robert N. Goldberg. NBS Spec. Publ. 537, 94p. (1979).

A Combined Least Sums and Least Squares Approach to the Evaluation of Thermodynamic Data Networks - David Garvin, Vivian B. Parker, Donald D. Wagman, and William H. Evans. NBSIR 76-1147, 41p. (1976).

A Computer Assisted Evaluation of the Thermochemical Data of the Compounds of Thorium - Donald D. Wagman, Richard H. Schumm, and Vivian B. Parker. NBSIR 77-1300, 94p. (1977).

A Compilation of Kinetic Parameters for the Thermal Degradation of n-Alkane Molecules - D. L. Allara and Robert Shaw. J Phys Chem Ref Data 9, 523(1980).

A Fundamental Equation of State for Heavy Water - P. G. Hill, R. D. Chris MacMillan, and V. Lee. J Phys Chem Ref Data 11, I(1982).

A Report on Thermodynamic Data for Desulfurization Processes Vivian B. Parker, Bert R. Staples, Thomas L. Jobe, Jr., and David B. Neumann. NBSIR 81-2345, 89p. (1981).

A Review, Evaluation, and Correlation of the Phase Equilibria, Heat of Mixing, and Change in Volume on Mixing for Liquid Mixtures of
Methane + Ethane - M. J. Hiza, R. C. Miller, and Arthur J. Kidnay. J Phys Chem Ref Data 8, 799(1979).

A Review, Evaluation, and Correlation of the Phase Equilibria, Heat of Mixing, and Change in Volume on Mixing for Liquid Mixtures of Methane + Propane - R. C. Miller, Arthur J. Kidnay, and M. J. Hiza. J Phys Chem Ref Data 9, 721(1980).

A Thermodynamic Surface for Water: The Formulation and Computer Program - Lester Haar, John S. Gallagher, and George S. Kell. NBSIR 81-2253, 38p. (1981).

An Annotated Bibliography of Compiled Thermodynamic Data Sources for Biochemical and Aqueous Systems (1930 to 1975), Equilibrium, Enthalpy, Heat Capacity, and Entropy Data - George T. Armstrong and Robert N. Goldberg. NBS Spec. Publ. 454, 71p. (1976).

An Equation of State for Fluid Ethylene - Robert D. McCarty and Richard T. Jacobsen. NBS Tech. Note 1045, 164p. (1981).

Applications of Phase Diagrams, Proceedings of a Workshop Held at the National Bureau of Standards, Gaithersburg, Maryland, January 10-12, 1977, Volumes 1 and 2 - Gesina Cynthia Carter, editor(s). NBS Spec. Publ. 496, 1622p. (1978).

Bulletin of Chemical Thermodynamics, Volume 24/1981 - Robert D. Freeman, editor(s) and International Union of Pure and Applied Chemistry, Commission 1.2 on Thermodynamics. Bull Chem Thermody 24, Stillwater, OK: Thermochemistry, Department of Chemistry, Oklahoma State University, 504p. (1982). 0149-2268, bona fide personal subscriptions are less; prices of previous Bulletins available upon request.

Bulletin of Chemical Thermodynamics, Volume 25/1982 - Robert D. Freeman and International Union of Pure and Applied Chemistry. Buli Chem Thermody 25, Stillwater, OK: Thermochemistry, Department of Chemistry, Oklahoma State University, 544p. (1982). 0149-2268, bona fide personal subscriptions are less; prices of previous Bulletins are available upon request.

Chemical Thermodynamic Properties of Compounds of Sodium, Potassium, and Rubidium: An Interim Tabulation of Selected Material Donald D. Wagman, William H. Evans, Vivian B. Parker, and Richard H. Schumm. NBSIR 76-1034, 76p. (1976).

Combustion Fundamentals for Waste Incineration - American Society of Mechanical Engineers, Research Committee on Industrial and Municipal Wastes., New York: American Society of Mechanical Engineers, 212p. (1974).

Computer Programs for the Evaluation of Activity and Osmotic Coefficients - Bert R. Staples and Ralph L. Nuttall. NBS Tech. Note 928, 60p. (1976).

Contributions to the Data on Theoretical Metallurgy, XVI. Thermodynamic Properties of Nickel and Its Inorganic Compounds - Alla D. Mah and Louis B. Pankratz. U.S. Bur Mines Bull 668, Springfield, VA: NTIS, 125p. (1976). U.S. Bureau of Mines Bulletin 668, A06.

Critical Analysis of the Heat-Capacity Data of the Literature and Evaluation of Thermodynamic Properties of Copper, Silver, and Gold from 0 to $300 \mathrm{~K}-$ George T. Furukawa, W. G. Saba, and Martin L. Reilly. NSRDS-NBS 18, 49p. (1968).

Critical Analysis of Heat-Capacity Data and Evaluation of Thermodynamic Properties of Ru, $\mathrm{Ph}, \mathrm{Pd}, \mathrm{Ir}$, and $\mathrm{Pt}$ from 0 to $300 \mathrm{~K}$. A Survey of the Literature Data on Osmium - George T. Furukawa, Martin L. Reilly, and John S. Gallagher. J Phys Chem Ref Data 3, 163(1974).

Critical Evaluation of Vapor-Liquid Equilibrium, Heat of Mixing, and Volume Change of Mixing Data. General Procedures - Buford D. Smith, Ol Muthu, Ashok Dewan, and Matthew Gierlach. J Phys Chem Ref Data 11, 941(1982).

Crystal Structure Transformations in Inorganic Sulfates, Phosphates, Perchlorates, and Chromates - C. N. R. Rao and Brahm Prakash. NSRDS-NBS 56, 37p. (1975).

Derived Thermodynamic Properties of Ethylene - Roland H. Harrison and Donald R. Douslin. J Chem Eng Data. 22, Washington, DC: American Chemical Society, 24p. (1977).

Energetics of Gaseous Ions - Henry M. Rosenstock, Keith Draxl, B. W. Steiner, and John T. Herron. J Phys Chem Ref Data 6, Suppl. 1(1977). 
Equation of State for Ammonia - Lester Haar and John S. Gallagher. NBSIR 75-770, 27p. (1975).

Equilibrium Properties of Fluid Mixtures, A Bibliography on Fluids of Cryogenic Interest - M. J. Hiza, Arthur J. Kidnay, and R. C. Miller., New York: IFI/Plenum, 166p. (1975), ISBN: 0-306-6601-6.

Equilibrium Properties of Fluid Mixtures, 2. A Bibliography of Experimental Data on Selected Fluids - M. J. Hiza, Arthur J. Kidnay, and R. C. Miller., New York: IFI/Plenum, 258p. (1982), ISBN: 0-306-6602-4.

Equilibrium and Transport Properties of the Noble Gases and Their Mixtures at Low Density - Joseph Kestin, K. Knierim, E. A. Mason, B. Najafi, S. T. Ro, and M. Waldman. J Phys Chem Ref Data 13, 229(1984).

Erratum: A Fundamental Equation of State for Heavy Water - P. G. Hill, R. D. Chris MacMillan, and V. Lee. J Phys Chem Ref Data 12, 1065(1983).

Evaluated Chemical Kinetic Rate Constants for Various Gas Phase Reactions - Keith Schofield. J Phys Chem Ref Data 2, 25(1973).

Evaluated Kinetic Data for High Temperature Reactions, Volume 4. Homogeneous Gas Phase Reactions of Halogen- and CyanideContaining Species - D. L. Baulch, J. Duxbury, S. J. Grant, and D. C. Montague. J Phys Chem Ref Data 10, Suppl. 1(1981).

Evaluation of Binary PT xy Vapor-Liquid Equilibrium Data for $\mathrm{C}_{6}$ Hydrocarbons. Benzene + Cyclohexane - Buford D. Smith, Ol Muthu, Ashok Dewan, and Matthew Gierlach. J Phys Chem Ref Data 11, 1099(1982).

Evaluation of Binary Excess Enthalpy Data for $\mathrm{C}_{6}$ Hydrocarbons. Benzene + Cyclohexane - Buford D. Smith, Ol Muthu, Ashok Dewan, and Matthew Gierlach. J Phys Chem Ref Data 11, 1127(1982).

Evaluation of Binary Excess Volume Data for $C_{6}$ Hydrocarbons. Benzene + Cyclohexane - Buford D. Smith, Ol Muthu, Ashok Dewan, and Matthew Gierlach. J Phys Chem Ref Data 11, 1151(1982).

Evaluation of Binary $P T$ xy Vapor-Liquid Equilibrium Data for $\mathrm{C}_{6}$ Hydrocarbons. Benzene + Hexane - Buford D. Smith, Ol Muthu, and Ashok Dewan. J Phys Chem Ref Data 12, 381(1983).

Evaluation of Binary Excess Enthalpy Data for $\mathrm{C}_{6}$ Hydrocarbons.

Benzene + Hexane - Buford D. Smith, Ol Muthu, and Ashok Dewan.

J Phys Chem Ref Data 12, 389(1983).

Evaluation of Binary Excess Volume Data for $\mathrm{C}_{6}$ Hydrocarbons. Benzene + Hexane - Buford D. Smith, Ol Muthu, and Ashok Dewan. J Phys Chem Ref Data 12, 395(1983).

Feasiblility Study: Compilation and Evaluation of Properties Data for Basalt, Granite, Tuff, and Shale - Lewis H. Gevantman. NBSIR 81-2217, 259p. (1981).

Handbook of Phase Diagrams of Silicate Systems, Vol. I. Binary Systems, Second Revised Edition - N. A. Toropov, V. P. Barzakovskii, V. V. Lapin, N. N. Kurtseva, J. Schmorak, editor(s). Russian Transl., Springfield, VA: NTIS, 730p. (1970). TT 71-50040, A26.

Handbook of Phase Diagrams of Silicate Systems, Vol. II. MetalOxygen Compounds in Silicate Systems, Second Revised Edition - N. A. Toropov, V. P. Barzakovskii, I. A. Bondar', and Yu. P. Udalov. Russian Transl., Springfield, VA: NTIS, 329p. (1972). TT 71-50041, A15.

Handbook of Thermodynamic Data on Geological Substances - G. B. Naumov, B. N. Ryzhenko, and I. L. Khodakovsky. Russian Transl., Springfield, VA: NTIS, 340p. (1974). TT 73-53051 or PB226 722, A15.

Heat Capacity and Other Thermodynamic Properties of Linear Macromolecules. I. Selenium - Umesh Gaur, Hua-Cheng Shu, Aspy Metha, and Bernhard Wunderlich. J Phys Chem Ref Data 10, 89(1981).

Heat Capacity and Other Thermodynamic Properties of Linear Macromolecules. II. Polyethylene - Umesh Gaur and Bernhard Wunderlich. J Phys Chem Ref Data 10, 119(1981).

Heat Capacity and Other Thermodynamic Properties of Linear Macromolecules. III. Polyoxides - Umesh Gaur and Bernhard Wunderlich. I Phys Chem Ref Data 10, 1001(1981).

Heat Capacity and Other Thermodynamic Properties of Linear Macromolecules. IV. Polypropylene - Umesh Gaur and Bernhard Wunderlich. J Phys Chem Ref Data 10, 1051(1981).
Heat Capacity and Other Thermodynamic Properties of Linear Macromolecules. V. Polystyrene - Umesh Gaur and Bernhard Wunderlich. J Phys Chem Ref Data 11, 313(1982).

Heat Capacity and Other Thermodynamic Properties of Linear Macromolecules. VI. Acrylic Polymers - Umesh Gaur, Suk-fai Lau, Brent B. Wunderlich, and Bernhard Wunderlich. J Phys Chem Ref Data 11, 1065(1982).

Heat Capacity and Other Thermodynamic Properties of Linear Macromolecules. VII. Other Carbon Backbone Polymers - Umesh Gaur, Brent B. Wunderlich, and Bernhard Wunderlich. J Phys Chem Ref Data 12, 29(1983).

Heat Capacity and Other Thermodynamic Properties of Linear Macromolecules. VIII. Polyesters and Polyamides - Umesh Gaur, Suk-fai Lau, Brent B. Wunderlich, and Bernhard Wunderlich. J Phys Chem Ref Data 12, 65(1983).

Heat Capacity and Other Thermodynamic Properties of Linear Macromolecules. IX. Final Group of Aromatic and Inorganic Polymers Umesh Gaur, Suk-fai Lau, and Bernhard Wunderlich. J Phys Chem Ref Data 12, 91(1983).

Heat Capacities and Entropies of Organic Compounds in the Condensed Phase - Eugene S. Domalski, William H. Evans, and Elizabeth D. Hearing. J Phys Chem Ref Data 13, Suppl. 1(1984).

Heavy Water, Thermophysical Properties - V. A. Kirillin, Ya. Z. Kazavchinskii, P. M. Kessel'man, S. L. Rivkin, A. E. Sheindlin, E. E. Shpil'rain, V. V. Sychev, and D. L. Timrot. Russian Transl., Springfield, VA: NTIS, 273p. (1971). TT 70-50094, A 12.

High Temperature Properties and Decomposition of Inorganic Salts, Part 1. Sulfates - Kurt H. Stern and E. L. Weise. NSRDS-NBS 7, 38p. (1966).

High Temperature Properties and Decomposition of Inorganic Salts, Part 2. Carbonates - Kurt H. Stern and E. L. Weise. NSRDS-NBS 30, 27p. (1969).

High Temperature Properties and Decomposition of Inorganic Salts, Part 3. Nitrates and Nitrites - Kurt H. Stern. J Phys Chem Ref Data 1, 747(1972).

High Temperature Properties and Decomposition of Inorganic Salts, Part 4. Oxy-Salts of the Halogens - Kurt H. Stern. J Phys Chem Ref Data 3, 481(1974).

High Temperature Vaporization Behavior of Oxides. I. Alkali Metal Binary Oxides - R. H. Lamoreaux and D. L. Hildenbrand. J Phys Chem Ref Data 13, 151(1984).

Ideal Gas Thermodynamic Properties of Ethane and Propane - Jing Chao, Randolph C. Wilhoit, and Bruno J. Zwolinski. J Phys Chem Ref Data 2, 427(1973).

Ideal Gas Thermodynamic Properties of Eight Chloro- and Fluoromethanes - A. S. Rodgers, Jing Chao, Randolph C. Wilhoit, and Bruno J. Zwolinski. J Phys Chem Ref Data 3, 117(1974).

Ideal Gas Thermodynamic Properties of Six Chloroethanes - Jing Chao, A. S. Rodgers, Randolph C. Wilhoit, and Bruno J. Zwolinski. J Phys Chem Ref Data 3, 141(1974).

Ideal Gas Thermodynamic Properties of Ethylene and Propylene Jing Chao and Bruno J. Zwolinski. J Phys Chem Ref Data 4, 251(1975).

Ideal Gas Thermodynamic Properties of Six Fluoroethanes - S. S. Chen, A. S. Rodgers, Jing Chao, Randolph C. Wilhoit, and Bruno J. Zwolinski. J Phys Chem Ref Data 4, 441(1975).

Ideal Gas Thermodynamic Properties of the Eight Bromo- an Iodomethanes - Shanti A. Kudchadker and Arvind P. Kudchadker. J Phys Chem Ref Data 4, 457(1975).

Ideal Gas Thermodynamic Properties and Isomerization of n-Butane and Isobutane - S. S. Chen, Randolph C. Wilhoit, and Bruno J. Zwolinski. J Phys Chem Ref Data 4, 859(1975).

Ideal Gas Thermodynamic Properties of Propanone and 2-Butanone - Jing Chao and Bruno J. Zwolinski. J Phys Chem Ref Data 5, 319(1976)

Ideal Gas Thermodynamic Properties of Six Chlorofluoromethanes - S. S. Chen, Randolph C. Wilhoit, and Bruno J. Zwolinski. J Phys Chem Ref Data 5, 571(1976). 
Ideal Gas Thermodynamic Properties of Methanoic and Ethanoic Acids - Jing Chao and Bruno J. Zwolinski. J Phys Chem Ref Data 7, 363(1978).

Ideal Gas Thermodynamic Properties of Phenol and Cresols Shanti A. Kudchadker, Arvind P. Kudchadker, Randolph C. Wilhoit, and Bruno J. Zwolinski. J Phys Chem Ref Data 7, 417(1978).

Ideal Gas Thermodynamic Properties of $\mathrm{CH}_{4(a+b+c+d)} \mathrm{F}_{\mathrm{a}} \mathrm{Cl}_{\mathrm{b}} \mathrm{Br}_{\mathrm{c}} \mathrm{I}_{d}$ Halomethanes - Shanti A. Kudchadker and Arvind P. Kudchadker. J Phys Chem Ref Data 7, 1285(1978).

Ideal Gas Thermodynamic Properties of Selected Bromoethanes and Io. doethane - Shanti A. Kudchadker and Arvind P. Kudchadker. J Phys Chem Ref Data 8, 519(1979).

Ideal Gas Thermodynamic Properties of $\mathrm{CH}_{3}, \mathrm{CD}_{3}, \mathrm{CD}_{4}, \mathrm{C}_{2} \mathrm{D}_{2}, \mathrm{C}_{2} \mathrm{D}_{4}, \mathrm{C}_{2} \mathrm{D}_{6}$, $\mathrm{C}_{2} \mathrm{H}_{6}, \mathrm{CH}_{3} \mathrm{~N}_{2} \mathrm{CH}_{3}$, and $\mathrm{CD}_{3} \mathrm{~N}_{2} \mathrm{CD}_{3}-$ Krishna M. Pamidimukkala, David Rogers, and Gordon B. Skinner. J Phys Chem Ref Data 11, 83(1982).

Interactive Fortran Program to Calculate Thermophysical Properties of 6 Fluids NBS Standard Reference Database 6, Washington, D.C.; NBS, Office of Standard Reference Data,(updated periodically). Call (301)921.2228 for specific instructions.

Isochoric Heat Capacity of Water and Steam - M. P. Vukalovich, Kh. I. Amirkhanov, G. V. Stepanov, and B. G. Alibekov. Russian Transl., Springfield, VA: NTIS, 215p. (1974). TT 72-52002, Al0.

JANAF Thermochemical Tables, Second Edition - Daniel R. Stull and H. Prophet. NSRDS-NBS 37, 1141p. (1971).

JANAF Thermochemical Tables, 1974 Supplement - Malcolm W. Chase, Jr., J. L. Curnutt, A. T. Hu, H. Prophet, A. N. Syverud, and L. C. Walker. J Phys Chem Ref Data 3, 311(1974).

JANAF Thermochemical Tables, 1975 Supplement - Malcolm W. Chase, Jr., J. L. Curnutt, H. Prophet, R. A. McDonald, and A. N. Syverud. J Phys Chem Ref Data 4, 1(1975).

JANAF Thermochemical Tables, 1978 Supplement - Malcolm W. Chase, Jr., J. L. Curnutt, R. A. McDonald, and A. N. Syverud. J Phys Chem Ref Data 7, 793(1978).

JANAF Thermochemical Tables, 1982 Supplement - Malcolm W. Chase, Jr., J. L. Curnutt, J. R. Downey, Jr., R. A. McDonald, A. N. Syverud, and E. A. Valenzuela. J Phys Chem Ref Data 11, 695(1982).

Kinetic Data on Gas Phase Unimolecular Reactions - Sidney W. Benson and Harry E. O'Neal. NSRDS-NBS 21, 645p. (1970).

Molten Salts: Volume 2. Section 1. Electrochemistry of Molten Salts. Gibbs Free Energies and Excess Free Energies from Equilibrium-Type Cells, Section 2. Surface Tension Data - George J. Janz, Chr. G. M. Dijkhuis, G. R. Lakshminarayanan, Reginald P. T. Tomkins, and J. Wong. NSRDS-NBS 28, 116p. (1968).

NBS Chemical Thermodynamics Database NBS Siandard Reference Database 2, Washington, D.C.; NBS, Office of Standard Reference Data,(updated periodically). Call (301)921-2228 for specific instructions.

NBS/NRC Steam Tables, Thermodynamic and Transport Properties and Computer Programs for Vapor and Liquid States of Water - Lester Haar, John S. Gallagher, and George S. Kell., New York: Hemisphere Press, 320p. (1984).

Nitrogen Oxychlorides: A Bibliography on Data for Physical and Chemical Properties of $\mathrm{ClNO}, \mathrm{ClNO}_{2}$, and $\mathrm{ClNO}_{3}$ - Francis Westley. NBS Spec. Publ. 478, 54p. (1977).

Phase Diagrams and Thermodynamic Properties of Ternary Copper-Metal Systems - Y. Austin Chang, Joachim P. Neumann, A. Mikula, and Daniel Goldberg. INCRA Monograph VI, New York: International Copper Research Association, Inc., 702p. (1979).

Phase Diagrams and Thermodynamic Properties of Ternary Copper-SulfurMetal Systems - Y. Austin Chang, Joachim P. Neumann, and U. V. Choudary. INCRA Monograph VII, New York: International Copper Research Association, Inc., 191p. (1979).

Physical Properties Data Compilations Relevant to Energy Storage. II. Molten Salts: Data on Single and Multi-Component Systems - George J. Janz, Carolyn B. Allen, Narottam P. Bansal, R. M. Murphy, and Reginald P. T. Tomkins. NSRDS-NBS 61, 420p. (1979).

Physical Properties Data Compilations Relevant to Energy Storage. IV. Molten Salts: Data on Additional Single and Multi-Component Salt Systems George J. Janz and Reginald P. T. Tomkins. NSRDS-NBS 61, 870p. (1981).
Physical Properties Data for Rock Salt - Lewis H. Gevantman. NBS Monograph 167, 288p. (1981).

Physical Properties Data for Basalt - Lewis H. Gevantman. NBSIR 82-2587, 751p. (1982).

Physical and Thermodynamic Properties of Aliphatic Alcohols - Randolph C. Wilhoit and Bruno J. Zwolinski. J Phys Chem Ref Data 2, Suppl. 1(1973).

Pressure, Volume, Temperature Relations of Ethylene - Donald R. Douslin and Roland H. Harrison. J Chem Thermody 76, New York, London:, 301p. (1976).

Problems with the Prandtl Number of Steam - Jan V. Sengers, R. S. Basu, B. Kamgar-Parsi, and Joseph Kestin. Mech Eng 104, New York, NY, 60p. (1982).

Provisional Thermodynamic Functions of Propane from 85 to $700 \mathrm{~K}$ at Pressures to 700 Bar - Robert D. Goodwin. NBSIR 77-860, 240p. (1977).

Saturation States of Heavy Water - P. G. Hill and R. D. Chris MacMillan. J Phys Chem Ref Data 9, 735(1980).

Selected Values of Chemical Thermodynamic Properties. Tables for the First Thirty-Four Elements in the Standard Order of Arrangement - Donald D. Wagman, William H. Evans, Vivian B. Parker, Iva Halow, Sylvia M. Bailey, and Richard H. Schumm. NBS Tech. Note 270, 264p. (1968).

Selected Values of Chemical Thermodynamic Properties. Tables for Elements 35 through 53 in the Standard Order of Arrangement - Donald D. Wagman, William H. Evans, Vivian B. Parker, Iva Halow, Sylvia M. Bailey, and Richard H. Schumm. NBS Tech. Note 270, 152p. (1969).

Selected Values of Chemical Thermodynamic Properties. Tables for Elements 54 through 61 in the Standard Order of Arrangement - Donald D. Wagman, William H. Evans, Vivian B. Parker, Iva Halow, Sylvia M. Bailey, Richard H. Schumm, and Kenneth L. Churney. NBS Tech. Note 270, 49p. (1971).

Selected Values of Chemical Thermodynamic Properties. Tables for the Alkaline Earth Elements (Elements 92 through 97 in the Standard Order of Arrangement) - Vivian B. Parker, Donald D. Wagman, and William H. Evans. NBS Tech. Note 270, 124p. (1971).

Selected Values of Chemical Thermodynamic Properties. Tables for the Lanthanide (Rare Earth) Elements (Elements 62 through 76 in the Standard Order of Arrangement) - Richard H. Schumm, Donald D. Wagman, Sylvia M. Bailey, William H. Evans, and Vivian B. Parker. NBS Tech. Note 270, 84p. (1973).

Selected Values of Chemical Thermodynamic Properties: Compounds of Uranium, Protactinium, Thorium, Actinium, and the Alkali Metals - Donald D. Wagınan, William H. Evans, Vivian B. Parker, Richard H. Schumm, and Ralph L. Nuttall. NBS Tech. Note 270, 149p. (1981).

Selected Thermochemical Data Compatible with CODATA Recommendations - Vivian B. Parker, Donald D. Wagman, and David Garvin. NBSIR 75.968, 35p. (1976).

Selected Thermodynamic Values and Phase Diagrams for Copper and Some of Its Binary Alloys - Ralph Hultgren and Pramond D. Desai. INCRA Monograph I, New York: International Copper Research Association, Inc., 204p. (1973).

Selected Values of the Thermodynamic Properties of Binary Alloys Ralph Hultgren, Pramond D. Desai, Donald T. Hawkins, M. Gleiser, and Kenneth K. Kelley., Metals Park, OH: American Society for Metals, 1435p. (1973).

Selected Values of the Thermodynamic Properties of the Elements - Ralph Hultgren, Pramond D. Desai, Donald T. Hawkins, M. Gleiser, Kenneth K. Kelley, and Donald D. Wagman., Metals Park, OH: American Society for Metals, 636p. (1973).

Simplification of Thermodynamic Calculations Through Dimensionless Entropies (Comments) - Kenneth S. Pitzer and Leo Brewer. J Phys Chem Ref Data 8, 917(1979).

Standard Chemical Thermodynamic Properties of Alkane Isomer Groups Robert A. Alberty and Catherine A. Gehrig. J Phys Chem Ref Data 13, 1173(1984).

Surface Ionization - E. Ya. Zandberg and N. L. Ionov. Russian Transl., Springfield, VA: NTIS, 364p. (1971). TT 70-50148, A16.

The Thermochemical Properties of Uranium-Halogen Containing Compounds - Vivian B. Parker. NBSIR 80.2029, 173p. (1980). 
The Thermodynamic Properties of Aqueous Inorganic Copper Systems Paul Duby. INCRA Monograph IV, New York: International Copper Research Association, Inc., 132p. (1977).

The Calculated Thermodynamic Properties of Superfluid Helium-4 James S. Brooks and Russell J. Donnelly. J Phys Chem Ref Data 6, 51(1977).

The NBS Tables of Chemical Thermodynamic Properties. Selected Values for Inorganic and $C_{1}$ and $C_{2}$ Organic Substances in SI Units - Donald D. Wagman, William H. Evans, Vivian B. Parker, Richard H. Schumm, Iva Halow, Sylvia M. Bailey, Kenneth L. Churney, and Ralph L. Nuttall. J Phys Chem Ref Data 11. Suppl. 2(1982).

Thermodynamic Properties of Ammonia as an Ideal Gas - Lester Haar. NSRDS-NBS 19, 10p. (1968).

Thermodynamic Properties of Argon from the Triple Point to $300 \mathrm{~K}$ at Pressures to 1000 Atmospheres - A. L. Gosman, Robert D. McCarty, and Jerome G. Hust. NSRDS-NBS 27, 153p. (1969).

Thermophysical Properties of Isobutane from 114 to $700 \mathrm{~K}$ at Pressures to $70 \mathrm{MPa}-$ Robert D. Goodwin and W. M. Haynes. NBS Tech. Note 1051, 199p. (1982).

Thermodynamic and Related Properties of Parahydrogen from the Triple Point to $100 \mathrm{~K}$ at Pressures to 340 Atmospheres - Hans M. Roder, Lloyd A. Weber, and Robert D. Goodwin. NBS Monograph 94, 116p. (1965).

Thermophysical Properties of Normal Butane from 135 to $700 \mathrm{~K}$ at Pres. sures to $70 \mathrm{MPa}-$ W. M. Haynes and Robert D. Goodwin. NBS Monograph 169. 197p. (1982).

Thermophysical Properties of Propane from 85 to $700 \mathrm{~K}$ at Pressures to 70 $\mathrm{MPa}$ - Robert D. Goodwin and W. M. Haynes. NBS Monograph 170, 249p. (1982).

Thermodynamic and Related Properties of Oxygen from the Triple Point to $300 \mathrm{~K}$ at Pressures to 1000 Bar - Lloyd A. Weber. NBSIR 77-865, 162p. (1977).

Thermodynamic Properties of Miscellaneous Materials - Eugene S. Domalski, William H. Evans, and Thomas L. Jobe, Jr. NBSIR 78-1479, 69p. (1981).

Thermodynamic Properties of Solid Aluminosilicates at Elevated Temperatures - Richard H. Schumm. NBSIR 81-2343, 57p. (1981).

Thermodynamic and Thermophysical Properties of Combustion Products, Volume 1. Computation Methods - V. P. Glushko, V. E. Alemasov, A. F. Dregalin, A. P. Tishin, and V. A. Khudyakov. Russian Transl., Springfield, VA: NTIS, 453p. (1974). TT 74-50019, A20.

Thermodynamic and Thermophysical Properties of Combustion Products, Volume II. Oxygen-Based Propellants - V. P. Glushko, V. E. Alemasov, A. F. Dregalin, A. P. Tishin, V. A. Khudyakov, and V. N. Kostin. Russian Transl., Springfield, VA: NTIS, 505p. (1975). TT 74-50032, A22.

Thermodynamic and Thermophysical Properties of Combustion Products, Volume III. Oxygen- and Air-Based Propellant - V. P. Glushko, V. E. Alemasov, A. F. Dregalin, A. P. Tishin, V. A. Khudyakov, and V. N. Kostin. Russian Transl., Springfield, VA: NTIS, 648p. (1975). TT 75-50007, A26.

Thermodynamic and Thermophysical Properties of Combustion Products, Volume IV. Nitrogen Tetroxide-Based Propellants - V. P. Glushko, V. E. Alemasov, A. F. Dregalin, A. P. Tishin, V. A. Khudyakov, and V. N. Kostin. Russian Transl., Springfield, VA: NTIS, 540p. (1976). TT 76-50007, A23.

Thermodynamic and Thermophysical Properties of Helium - A. F. Alyab'ev, N. V. Tsederberg, V. N. Popov, and N. A. Morozova. Russian [ransl., Springfield, VA: NTIS, 260p. (1971). TT 70-50096, A12.

Thermophysical Properties of Air and Air Components - A. A. Vasserman, Ya. Z. Kazavchinskii, V. A. Rabinovich, and A. M. Zhuravlev. Russian Transl. jpringfield, VA: NTIS, 402p. (1971). TT 70-50095, A18.

Thermophysical Properties of Freon-22 - A. V. Kletskii. Russian Transl. springfield, VA: NTIS, 72p. (1971). TT 70-50178, A04.

Thermophysical Properties of Gases and Liquids, No. $1-$ V. A. Zabinovich. Russian Transl. Springfield, VA: NTIS, 214p. (1970). TT $59-55091$, A10, the translation of volumes 2,3 , and 4 have the title: Thermoshysical Properties of Matter and Substances.

Thermophysical Properties of Gaseous and Liquid Methane - V. A. Zagruchenko and A. M. Zhuravlev. Russian Transl. Springfield, VA: NTIS, 251p. (1970). TT 70-50097, A12.

Thermophysical Properties of Liquid Air and Its Components - A. A. Vasserman and V. A. Rabinovich. Russian Transl. Springfield, VA: NTIS, 255p. (1970). TT 69-55092, A12.
Thermophysical Properties of Matter and Substances, Volume $2-$ V. A. Rabinovich. Russian Transl., Springfield, VA: NTIS, 395p. (1974). TT 72-52001, A17, the translation of volume 1 has the title: Thermophysical Properties of Gases and Liquids.

Thermophysical Properties of Matter and Substances, Volume $3-$ V. A. Rabinovich. Russian Transl. Springfield, VA: NTIS, 212p. (1975). TT 73-52009, A10, the translation of volume 1 has the title: Thermophysical Properties of Gases and Liquids.

Thermophysical Properties of Matter and Substances, Volume 4-V. A. Rabinovich. Russian Transl., Springfield, VA: NTIS, 179p. (1975). TT 73-52029, A09, the translation of volume 1 has the title: Thermophysical Properties of Gases and Liquids.

Thermodynamic Data for Waste Incineration - American Society of Mechanical Engineers, Research Committee on Industrial and Municipal Wastes., New York: American Society of Mechanical Engineers, 160p. (1979).

Thermodynamic Properties of Copper and Its Inorganic Compounds Edward G. King, Alla D. Mah, and Louis B. Pankratz. INCRA Monograph II, New York: International Copper Research Association, Inc., 257p. (1973).

Thermodynamic Properties of Copper-Slag Systems - Carlos Diaz. INCRA Monograph III, New York: International Copper Research Association, Inc., 178p. (1976).

Thermodynamic Properties of Nitrogen Including Liquid and Vapor Phases from $63 \mathrm{~K}$ to $2000 \mathrm{~K}$ with Pressures to $10,000 \mathrm{Bar}$ - Richard T. Jacobsen and Richard B. Stewart. J Phys Chem Ref Data 2, 757(1973).

Thermodynamic Properties of Helium-4 from 2 to $1500 \mathrm{~K}$ at Pressures to $10^{8} \mathrm{~Pa}$ - Robert D. McCarty. J Phys Chem Ref Data 2, 923(1973).

Thermodynamic Properties of Normal and Deuterated Methanols - S. S. Chen, Randolph C. Wilhoit, and Bruno J. Zwolinski. J Phys Chem Ref Data 6, 105(1977).

Thermodynamic Properties of Ammonia - Lester Haar and John S. Gallagher. J Phys Chem Ref Data 7, 635(1978).

Thermodynamic Properties of Normal and Deuterated Naphthalenes - S. S. Chen, Shanti A. Kudchadker, and Randolph C. Wilhoit. J Phys Chem Ref Data 8, 527(1979).

Thermodynamic Tabulations for Selected Phases in the System CaO$\mathrm{Al}_{2} \mathrm{O}_{3} \cdot \mathrm{SiO}_{2} \cdot \mathrm{H}_{2} \mathrm{O}$ at $101.325 \mathrm{kPa}$ (1 atm.) between 273.15 and $1800 \mathrm{~K}-\mathrm{John}$ L. Haas, Jr, Gilpin R. Robinson, Jr., and Bruce S. Hemingway. J Phys Chem Ref Data 10, 575(1981).

Thermophysical Properties of Fluids. I. Argon, Ethylene, Parahydrogen, Nitrogen, Nitrogen Trifluoride, and Oxygen - Ben A. Younglove. J Phys Chem Ref Data 11, Suppl. 1(1982).

Thermodynamic Properties of Steam in the Critical Region - J. M. H. Levelt Sengers, B. Kamgar-Parsi, F. W. Balfour, and Jan V. Sengers. J Phys Chem Ref Data 12, 1(1983).

Thermodynamic Properties of $\mathrm{D}_{2} \mathrm{O}$ in the Critical Region - B. KamgarParsi, J. M. H. Levelt Sengers, and Jan V. Sengers. J Phys Chem Ref Data 12, $513(1983)$.

Thermochemical Data for Gaseous Monoxides - J. B. Pedley and E. M. Marshall. J Phys Chem Ref Data 12, 967(1983).

Thermodynamic Properties of Aqueous Sodium Chloride Solutions - Kenneth S. Pitzer, J. Christopher Peiper, and R. H. Busey. J Phys Chem Ref Data $13,1(1984)$.

Thermophysical Properties of Fluid $\mathrm{H}_{2} \mathrm{O}$ - Joseph Kestin, Jan V. Sengers, B. Kamgar-Parsi, and J. M. H. Levelt Sengers. J Phys Chem Ref Data 13, 175(1984).

Thermophysical Properties of Fluid $\mathrm{D}_{2} \mathrm{O}$ - Joseph Kestin, Jan V. Sengers, B. Kamgar-Parsi, and J. M. H. Levelt Sengers. J Phys Chem Ref Data 13, 602(1984).

Volumetric Properties of Aqueous Sodium Chloride Solutions - P. S. Z. Rogers and Kenneth S. Pitzer. J Phys Chem Ref Data 11, 15(1982).

\section{Transition probabilities for atoms and molecules}

Atomic Transition Probabilities. Elements Hydrogen through Neon - Wolfgang L. Wiese, Melvin W. Smith, and Barbara M. Glennon. NSRDS-NBS 4, I53p. (I966).

Atomic Transition Probabilities, Volume II. Sodium through Calcium - Wolfgang L. Wiese, MeIvin W. Smith, and Barbara M. Miles. NSRDS-NBS 22, 268p. (I969). 
Atomic Gas Laser Transition Data, A Critical Evaluation - William Ralph Bennett, Jr., New York: IFI/Plenum, 293p. (1979), ISBN: 0-306-65187-4.

Atomic Transition Probabilities for Forbidden Lines of the Iron Group Elements (A Critical Data Compilation for Selected Lines) Melvin W. Smith and Wolfgang L. Wiese. J Phys Chem Ref Data 2, 85(1973).

Atomic Transition Probabilities for Scandium and Titanium (A Critical Data Compilation of Allowed Lines) - Wolfgang L. Wiese and Jeffrey R. Fuhr. J Phys Chem Ref Data 4, 263(1975).

Atomic Transition Probabilities for Vanadium, Chromium, and Manganese (A Critical Data Compilation of Allowed Lines) - S. M. Younger, Jeffrey R. Fuhr, Georgia A. Martin, and Wolfgang L. Wiese. J Phys Chem Ref Data 7, 495(1978).

Atomic Radiative and Radiationless Yields for K and L Shells Morris O. Krause. J Phys Chem Ref Data 8, 307(1979).

Atomic Transition Probabilities for Iron, Cobalt, Nickel: A Critical Data Compilation of Allowed Lines - Jeffrey R. Fuhr, Georgia A. Martin, Wolfgang L. Wiese, and S. M. Younger. J Phys Chem Ref Data 10, 305(1981).

Bibliography on Flame Spectroscopy. Analytical Applications, 1800-1966 - Radu Mavrodineanu. NBS Spec. Publ. 281, 155p. (1967).

Bibliography on Atomic Transition Probabilities (1914 through October 1977) - Beverly J. Miller, Jeffrey R. Fuhr, and Georgia A. Martin. NBS Spec. Publ. 505, 283p. (1978).

Bibliography on Atomic Transition Probabilities (November 1977 through March 1980) - Beverly J. Miller, Jeffrey R. Fuhr, and Georgia A. Martin. NBS Spec. Publ. 505, Suppl.(1980).

Critical Review of Ultraviolet Photoabsorption Cross Sections for Molecules of Astrophysical and Aeronomic Interest - Robert D. Hudson. NSRDS-NBS 38, 114p. (1971).

Critically Evaluated Transition Probabilities for Ba I and II Barbara M. Miles and Wolfgang L. Wiese. NBS Tech. Note 474, 22p. (1969).

Critically Evaluated Rate Constants for Gaseous Reactions of Several Electronically Excited Species - Keith Schofield. J Phys Chem Ref Data 8, 723(1979).

Natural Widths of Atomic $\mathrm{K}$ and L Levels, $\mathrm{K} \alpha \mathrm{X}$-Ray Lines and Several KLL Auger Lines - Morris O. Krause and J. H. Oliver. J Phys Chem Ref Data 8, 329(1979).

Peak Absorption Coefficients of Microwave Absorption Lines of Carbonyl Sulphide - Z. Kisiel and D. J. Millen. J Phys Chem Ref Data 11, 101(1982).

Resonances in Electron Impact on Atoms and Diatomic Molecules - George J. Schulz. NSRDS-NBS 50, 120p. (1973).

Semiempirical and Approximate Methods for Molecular Calculations - Bibliography and KWIC Index - George A. Henderson and Sandra Frattali. OSRD Bibl. 70-3, 293p. (1970).

Survey of Photochemical and Rate Data for Twenty-eight Reactions of Interest in Atmospheric Chemistry - Robert F. Hampson, Jr., W. Braun, R. L. Brown, David Garvin, John T. Herron, Robert E. Huie, M. J. Kurylo, A. H. Laufer, J. D. McKinley, H. Okabe, M. D. Scheer, W. Tsang, D. H. Stedman, editor(s). J Phys Chem Ref Data 2, 267(1973).

Tables of Line Spectra of the Elements, Part 1. Wavelengths and Intensities, Part 2. Transition Probabilities - Joseph Reader, Charles H. Corliss, Wolfgang L. Wiese, and Georgia A. Martin. NSRDS-NBS 68, 415p. (1980).

Tables of Critically Evaluated Oscillator Strengths for the Lithium Isoelectronic Sequence - Georgia A. Martin and Wolfgang L. Wiese. J Phys Chem Ref Data 5, 537(1976).

The Band Spectrum of Carbon Monoxide - Paul H. Krupenie. NSRDS-NBS 5, 87p. (1966).

The Spectrum of Molecular Nitrogen - Alf Lofthus and Paul H. Krupenie. J Phys Chem Ref Data 6, 113(1977).

Vibrational Contributions to Molecular Dipole Polarizabilities David M. Bishop and Lap M. Cheung. J Phys Chem Ref Data 11, 119(1982).

\section{Transport properties}

See: Diffusion coefficient Thermal conductivity Viscosity

\section{Vapor pressure (see also Equation of state)}

A Bibliography of Sources of Experimental Data Leading to Thermal Properties of Binary Aqueous Electrolyte Solutions - David Smith-Magowan and Robert N. Goldberg. NBS Spec. Publ. 537, 94p. (1979)

A Critical Review of Henry's Law Constants for Chemicals of Environmental Interest - Donald Mackay and Wan Ying Shiu. J Phys Chem Ref Data 10, 1175(1981).

A Fundamental Equation of State for Heavy Water - P. G. Hill, R. D. Chris MacMillan, and V. Lee. J Phys Chem Ref Data 11, 1(1982).

Computer Programs for the Evaluation of Activity and Osmotic Coefficients - Bert R. Staples and Ralph L. Nuttall. NBS Tech. Note 928, 60p. (1976).

Critical Evaluation of Vapor-Liquid Equilibrium, Heat of Mixing, and Volume Change of Mixing Data. General Procedures - Buford D. Smith, Ol Muthu, Ashok Dewan, and Matthew Gierlach. J Phys Chem Ref Data 11, 941(1982).

Definition of Recommended Values of Certain Thermodynamic Properties for the Ketones - Buford D. Smith and Ol Muthu. NBSIR 84-2811, 162p. (1983).

Erratum: A Fundamental Equation of State for Heavy Water - P. G. Hill, R. D. Chris MacMillan, and V. Lee. J Phys Chem Ref Data 12, 1065(1983).

Evaluation of Binary $P T$ xy Vapor-Liquid Equilibrium Data for $\mathrm{C}_{6}$ Hydrocarbons. Benzene + Cyclohexane - Buford D. Smith, Ol Muthu, Ashok Dewan, and Matthew Gierlach. J Phys Chem Ref Data 11, 1099(1982).

Evaluation of Binary PTxy Vapor-Liquid Equilibrium Data for $\mathrm{C}_{6}$ Hydrocarbons. Benzene + Hexane - Buford D. Smith, Ol Muthu, and Ashok Dewan. J Phys Chem Ref Data 12, 381(1983).

High Temperature Vaporization Behavior of Oxides. I. Alkali Metal Binary Oxides - R. H. Lamoreaux and D. L. Hildenbrand. J Phys Chem Ref Data 13, 151(1984).

Interactive Fortran Program to Calculate Thermophysical Properties of 6 Fluids NBS Standard Reference Database 6, Washington, D.C.; NBS, Office of Standard Reference Data,(updated periodically). Call (301)921-2228 for specific instructions.

Phase Behavior in Binary and Multicomponent Systems at Elevated Pressures: n-Pentane and Methane-n-Pentane - Virginia M. Berry and Bruce H. Sage. NSRDS-NBS 32, 79p. (1970).

Physical and Thermodynamic Properties of Aliphatic Alcohols Randolph C. Wilhoit and Bruno J. Zwolinski. J Phys Chem Ref Data 2, Suppl. 1(1973).

Saturation States of Heavy Water - P. G. Hill and R. D. Chris MacMillan. J Phys Chem Ref Data 9, 735(1980).

Thermodynamic Properties of Argon from the Triple Point to $300 \mathrm{~K}$ at Pressures to 1000 Atmospheres - A. L. Gosman, Robert D. McCarty, and Jerome G. Hust. NSRDS-NBS 27, 153p. (1969).

Thermophysical Properties of Isobutane from 114 to $700 \mathrm{~K}$ at Pressures to $70 \mathrm{MPa}$ - Robert D. Goodwin and W. M. Haynes. NBS Tech. Note 1051, 199p. (1982).

Thermodynamic and Related Properties of Parahydrogen from the Triple Point to $100 \mathrm{~K}$ at Pressures to 340 Atmospheres - Hans M. Roder, Lloyd A. Weber, and Robert D. Goodwin. NBS Monograph 94, 116p. (1965).

Thermophysical Properties of Normal Butane from 135 to $700 \mathrm{~K}$ at Pressures to $70 \mathrm{MPa}-$ W. M. Haynes and Robert D. Goodwin. NBS Monograph 169, 197p. (1982).

Thermophysical Properties of Propane from 85 to $700 \mathrm{~K}$ at Pressures to $70 \mathrm{MPa}-$ Robert D. Goodwin and W. M. Haynes. NBS Monograph 170, 249p. (1982) 
Thermophysical Properties of Gaseous and Liquid Methane - V. A. Zagoruchenko and A. M. Zhuravlev. Russian Transl. Springfield, VA: NTIS, 25lp. (1970). TT 70-50097, Al2.

Thermophysical Properties of Matter and Substances, Volume 3 V. A. Rabinovich. Russian Transl. Springfield, VA: NTIS, 212p. (1975). TT 73-52009, A10, the translation of volume 1 has the title: Thermophysical Properties of Gases and Liquids.

Thermophysical Properties of Fluids. I. Argon, Ethylene, Parahydrogen, Nitrogen, Nitrogen Trifluoride, and Oxygen - Ben A. Younglove. J Phys Chem Ref Data 11, Suppl. 1(1982).

Vapor Pressures and Boiling Points of Selected Halomethanes Arvind P. Kudchadker, Shanti A. Kudchadker, R. P. Shukla, and P. R. Patnaik. J Phys Chem Ref Data 8, 499(1979).

Vapor Pressure of Coal Chemicals - Jing Chao, C. T. Lin, and T. H. Chung. J Phys Chem Ref Data 12, 1033(1983).

\section{VIbrational frequencles of molecules}

(see also Molecular energy levels and constants)

Critical Review of Vibrational Data and Force Field Constants for Polyethylene - John Barnes and Bruno Fanconi. J Phys Chem Ref Data 7, 1309(1978).

Grourd-State Vibrational Energy Levels of Polyatomic Transient Molecules - Marilyn E. Jacox. J Phys Chem Ref Data 13, 945(1984).

JANAF Thermochemical Tables, Second Edition - Daniel R. Stull and H. Prophet. NSRDS-NBS 37, 1141p. (1971).

JANAF Thermochemical Tables, 1974 Supplement - Malcolm W. Chase, Jr., J. L. Curnutt, A. T. Hu, H. Prophet, A. N. Syverud, and L. C. Walker. J Phys Chem Ref Data 3, 311(1974).

JANAF Thermochemical Tables, 1975 Supplement - Malcolm W. Chase, Jr., J. L. Curnutt, H. Prophet, R. A. McDonald, and A. N. Syverud. J Phys Chem Ref Data 4, 1(1975).

JANAF Thermochemical Tables, 1978 Supplement - Malcolm W. Chase, Jr., J. L. Curnutt, R. A. McDonald, and A. N. Syverud. J Phys Chem Ref Data 7, 793(1978).

JANAF Thermochemical Tables, 1982 Supplement - Malcolm W. Chase, Jr., J. L. Curnutt, J. R. Downey, Jr., R. A. McDonald, A. N. Syverud, and E. A. Valenzuela. J Phys Chem Ref Data 11, 695(1982).

Tables of Molecular Vibrational Frequencies, Part 1 - Takehiko Shimanouchi. NSRDS-NBS 6, 56p. (1967).

Tables of Molecular Vibrational Frequencies, Part 2 - Takehiko

Shimanouchi. NSRDS-NBS 11, 38p. (1967).

Tables of Molecular Vibrational Frequencies, Part 3 - Takehiko Shimanouchi. NSRDS-NBS 17, 39p. (1968).

Tables of Molecular Vibrational Frequencies, Consolidated Volume I - Takehiko Shimanouchi. NSRDS-NBS 39, 167p. (1972).

Tables of Molecular Vibrational Frequencies, Part 5 - Takehiko Shimanouchi. J Phys Chem Ref Data 1, 189(1972).

Tables of Molecular Vibrational Frequencies, Part 6 - Takehiko

Shimanouchi. J Phys Chem Ref Data 2, 121(1973).

Tables of Molecular Vibrational Frequencies, Part 7 - Takehiko Shimanouchi. J Phys Chem Ref Data 2, 225(1973).

Tables of Molecular Vibrational Frequencies, Part 8 - Takehiko Shimanouchi. J Phys Chem Ref Data 3, 269(1974).

Tables of Molecular Vibrational Frequencies. Consolidated Volume II - Takehiko Shimanouchi. J Phys Chem Ref Data 6, 993(1977).

Tables of Molecular Vibrational Frequencies, Part 9 - Takehiko Shimanouchi, Hiroatsu Matsuura, Yoshiki Ogawa, and Issei Harada. J Phys Chem Ref Data 7, 1323(1978).

Tables of Molecular Vibrational Frequencies, Part 10 - Takehiko Shimanouchi, Hiroatsu Matsuura, Yoshiki Ogawa, and Issei Harada. J Phys Chem Ref Data 9, 1149(1980).

\section{Vlbratlonal spectra}

(Infrared, Raman)

Atlas of the High Temperature Water Vapor Spectrum in the 3000 to $4000 \mathrm{~cm}^{-1}$ Region - A. S. Pine, M. J. Coulombe, C. Camy-Peyret, and J-M. Flaud. J Phys Chem Ref Data 12, 413(1983).

Bibliography of Infrared Spectroscopy through 1960 - C. N. R.
Rao, S. K. Dikshit, Shanti A. Kudchadker, D. S. Gupta, V. A. Narayan, and John J. Comeford. NBS Spec. Publ. 428, 1,2,3(1976).

Coblentz Society Evaluated Infrared Reference Spectra, Volumes 6 to 10 and Cumulative Coblentz Indexes - American Society for Testing and Materials; Coblentz Society; Joint Committee on Atomic and Molecular Physical Data. Coblentz Soc Infr Spect 6-10, Philadelphia, PA: Sadtler Research Laboratories, 5001p. (1975).

Critical Review of Vibrational Data and Force Field Constants for Polyethylene - John Barnes and Bruno Fanconi. J Phys Chem Ref Data 7, 1309(1978).

Desk Book of Infrared Spectra - Clara D. Craver and Coblentz Society; Joint Committee on Atomic and Molecular Physical Data., Kirkwood, MO: The Coblentz Society, 498p. (1977).

Electronic Absorption and Internal and External Vibrational Data of Atomic and Molecular Ions Doped in Alkali Halide Crystals - Suresh C. Jain, A. V. R. Warrier, and Suresh K. Agarwal. NSRDS-NBS 52, 55p. (1974).

Ground-State Vibrational Energy Levels of Polyatomic Transient Molecules - Marilyn E. Jacox. J Phys Chem Ref Data 13, 945(1984).

Infrared Spectra of Halogenated Hydrocarbons - Clara D. Craver and Coblentz Society; Joint Committee on Atomic and Molecular Physical Data., Kirkwood, MO: The Coblentz Society, 125p. (1977).

Infrared Spectra of Plasticizers and Other Additives - Clara D. Craver and Coblentz Society; Joint Committee on Atomic and Molecular Physical Data. , Kirkwood, MO: The Coblentz Society, 152p. (1977).

Resonances in Electron Impact on Atoms and Diatomic Molecules - George J. Schulz. NSRDS-NBS 50, 120p. (1973).

Semiempirical and Approximate Methods for Molecular Calculations - Bibliography and KWIC Index - George A. Henderson and Sandra Frattali. OSRD Bibl. 70-3, 293p. (1970).

Tables of Molecular Vibrational Frequencies, Part 1 - Takehiko Shimanouchi. NSRDS-NBS 6, 56p. (1967).

Tables of Molecular Vibrational Frequencies, Part 2 - Takehiko Shimanouchi. NSRDS-NBS 11, 38p. (1967).

Tables of Molecular Vibrational Frequencies, Part 3 - Takehiko Shimanouchi. NSRDS-NBS 17, 39p. (1968).

Tables of Molecular Vibrational Frequencies, Consolidated Volume I - Takehiko Shimanouchi. NSRDS-NBS 39, 167p. (1972).

Tables of Molecular Vibrational Frequencies, Part 5 - Takehiko Shimanouchi. J Phys Chem Ref Data 1, 189(1972).

Tables of Molecular Vibrational Frequencies, Part 6 - Takehiko Shimanouchi. J Phys Chem Ref Data 2, 121(1973).

Tables of Molecular Vibrational Frequencies, Part 7 - Takehiko Shimanouchi. J Phys Chem Ref Data 2, 225(1973).

Tables of Molecular Vibrational Frequencies, Part 8 - Takehiko Shimanouchi. J Phys Chem Ref Data 3, 269(1974).

Tables of Molecular Vibrational Frequencies. Consolidated Volume II - Takehiko Shimanouchi. J Phys Chem Ref Data 6, 993(1977).

Tables of Molecular Vibrational Frequencies, Part 9 - Takehiko Shimanouchi, Hiroatsu Matsuura, Yoshiki Ogawa, and Issei Harada. J Phys Chem Ref Data 7, 1323(1978).

Tables of Molecular Vibrational Frequencies, Part 10 - Takehiko Shimanouchi, Hiroatsu Matsuura, Yoshiki Ogawa, and Issei Harada. J Phys Chem Ref Data 9, 1149(1980).

Tables of $\mathrm{N}_{2} \mathrm{O}$ Absorption Lines for the Calibration of Tunable Infrared Lasers from $522 \mathrm{~cm}^{-1}$ to $657 \mathrm{~cm}^{-1}$ and from $1115 \mathrm{~cm}^{-1}$ to $1340 \mathrm{~cm}^{-1}$ - W. B. Olson, Arthur G. Maki, and Walter J. Lafferty. J Phys Chem Ref Data 10, 1065(1981).

Vibrational Contributions to Molecular Dipole Polarizabilities David M. Bishop and Lap M. Cheung. J Phys Chem Ref Data 11, 119(1982).

\section{Vlbratlonal spectra potentlal energy curves for at- oms and molecules}

The Band Spectrum of Carbon Monoxide - Paul H. Krupenie. NSRDS-NBS 5, 87p. (1966). 


\section{Viscosity}

A Computer Program for the Prediction of Viscosity and Thermal Conductivity in Hydrocarbon Mixtures - James F. Ely and Howard J. M. Hanley. NBS Tech. Note 1039, 83p. (1981).

A Correlation of the Existing Viscosity and Thermal Conductivity Data of Gaseous and Liquid Ethane - Howard J. M. Hanley, K. E. Gubbins, and S. Murad. J Phys Chem Ref Data 6, 1167(1977).

A Correlation of the Viscosity and Thermal Conductivity Data of Gaseous and Liquid Propane - Paul M. Holland, Howard J. M. Hanley, K. E. Gubbins, and J. M. Haile. J Phys Chem Ref Data 8, 559(1979).

A Correlation of the Viscosity and Thermal Conductivity Data of Gaseous and Liquid Ethylene - Paul M. Holland, B. E. Eaton, and Howard J. M. Hanley. J Phys Chem Ref Data 12, 917(1983).

An Improved Representative Equation for the Dynamic Viscosity of Water Substance - J. T. R. Watson, R. S. Basu, and Jan V. Sengers. J Phys Chem Ref Data 9, 1255(1980).

Electrolytic Conductance and the Conductances of the Halogen Acids in Water - Walter J. Hamer and H. J. DeWane. NSRDS-NBS 33, 37p. (1970).

Equilibrium and Transport Properties of the Noble Gases and Their Mixtures at Low Density - Joseph Kestin, K. Knierim, E. A. Mason, B. Najafi, S. T. Ro, and M. Waldman. J Phys Chem Ref Data 13, 229(1984).

Erratum: A Correlation of the Existing Viscosity and Thermal Conductivity Data of Gaseous and Liquid Ethane - Howard J. M. Hanley, K. E. Gubbins, and S. Murad. J Phys Chem Ref Data 10, 799(1981).

Erratum: Viscosity of Water Substance - New International Formulation and Its Background - A. Nagashima. J Phys Chem Ref Data 12, 403p. (1983).

Interactive Fortran Program to Calculate Thermophysical Properties of 6 Fluids NBS Standard Reference Database 6, Washington, D.C.; NBS, Office of Standard Reference Data,(updated periodically). Call (301)921-2228 for specific instructions.

Molten Salts: Volume 1. Electrical Conductance, Density, and Viscosity Data - George J. Janz, F. W. Dampier, G. R. Lakshminarayanan, P. K. Lorenz, and Reginald P. T. Tomkins. NSRDS-NBS 15, 140p. (1968).

Molten Salts: Volume 3, Nitrates, Nitrites, and Mixtures. Electrical Conductance, Density, Viscosity, and Surface Tension Data - George J. Janz, Ursula Krebs, H. F. Siegenthaler, and Reginald P. T. Tomkins. J Phys Chem Ref Data 1, 581(1972).

Molten Salts: Volume 4, Part 1, Fluorides and Mixtures. Electrical Conductance, Density, Viscosity, and Surface Tension Data - George J. Janz, G. L. Gardner, Ursula Krebs, and Reginald P. T. Tomkins. J Phys Chem Ref Data 3, 1(1974).

Molten Salts: Volume 4, Part 2, Chlorides and Mixtures. Electrical Conductance, Density, Viscosity, and Surface Tension Data - George J. Janz, Reginald P. T. Tomkins, Carolyn B. Allen, J. R. Downey, Jr., G. L. Gardner, Ursula Krebs, and S. K. Singer. J Phys Chem Ref Data 4, 871(1975).

Molten Salts: Volume 4, Part 3, Bromides and Mixtures, Iodides and Mixtures. Electrical Conductance, Density, Viscosity, and Surface Tension Data - George J. Janz, Reginald P. T. Tomkins, Carolyn B. Allen, J. R. Downey, Jr., and S. K. Singer. J Phys Chem Ref Data 6, 409(1977).

Molten Salts: Volume 4, Part 4, Mixed Halide Melts. Electrical Conductance, Density, Viscosity, and Surface Tension Data - George J. Janz, Reginald P. T. Tomkins, and Carolyn B. Allen. J Phys Chem Ref Data 8, 125(1979).

Molten Salts Data As Reference Standards for Density, Surface Tension, Viscosity and Electrical Conductance: $\mathrm{KNO}_{3}$ and $\mathrm{NaCl}-$ George J. Janz. J Phys Chem Ref Data 9, 791(1980).

Molten Salts: Volume 5, Part 1. Additional Single and MultiComponent Salt Systems. Electrical Conductance, Density, Viscosity, and Surface Tension Data - George J. Janz and Reginald P. T. Tomkins. J Phys Chem Ref Data 9, 831(1980).

Molten Salts: Volume 5, Part 2. Additional Single and MultiComponent Salt Systems. Electrical Conductance, Density, Vicosity and Surface Tension Data - George J. Janz and Reginald P. T. Tomkins. J Phys Chem Ref Data 12, 591(1983).

NBS Chemical Thermodynamics Database NBS Standard Reference Database 2, Washington, D.C.; NBS, Office of Standard Reference Data,(updated periodically). Call (301)921-2228 for specific instructions.

Problems with the Prandtl Number of Steam - Jan V. Sengers, R. S. Basu, B. Kamgar-Parsi, and Joseph Kestin. Mech Eng 104, New York, NY, 60p. (1982).

Properties of Liquid and Solid Hydrogen - B. N. Esel'son, Y. P. Blagoi, V.N. Grigor'ev, V. G. Manzhelii, S. A. Mikhailenko, and N. P. Neklyudov. Russian Transl., Springfield, VA: NTIS, 126p. (1971). TT 70-50179, A07.

Representative Equations for the Viscosity of Water Substance Jan V. Sengers and B. Kamgar-Parsi. J Phys Chem Ref Data 13, 185(1984).

Tables of Collision Integrals and Second Virial Coefficients for the $(\mathrm{m}, 6,8)$ Intermolecular Potential Function - Max Klein, Howard J. M. Hanley, Francis J. Smith, and Paul M. Holland. NSRDS-NBS 47, 161 p. (1974).

Tables of the Dynamic and Kinematic Viscosity of Aqueous $\mathrm{KCl}$ Solutions in the Temperature Range $25-150^{\circ} \mathrm{C}$ and the Pressure Range 0.1-35 MPa - Joseph Kestin, H. Ezzat Khalifa, and Robert J. Correia. J Phys Chem Ref Data 10, 57(1981).

Tables of the Dynamic and Kinematic Viscosity of Aqueous $\mathrm{NaCl}$ Solutions in the Temperature Range $20-150^{\circ} \mathrm{C}$ and the Pressure Range 0.1-35 MPa - Joseph Kestin, H. Ezzat Khalifa, and Robert J. Correia. J Phys Chem Ref Data 10, 71(1981).

The Viscosity and Thermal Conductivity Coefficients of Gaseous and Liquid Fluorine - Howard J. M. Hanley and R. Prydz. J Phys Chem Ref Data 1, 1101(1972).

The Viscosity and Thermal Conductivity Coefficients of Dilute Argon, Krypton, and Xenon - Howard J. M. Hanley. J Phys Chem Ref Data 2, 619(1973).

The Viscosity and Thermal Conductivity Coefficients of Dilute Nitrogen and Oxygen - Howard J. M. Hanley and James F. Ely. J Phys Chem Ref Data 2, 735(1973).

The Viscosity and Thermal Conductivity Coefficients for Dense Gaseous and Liquid Argon, Krypton, Xenon, Nitrogen, and Oxygen Howard J. M. Hanley, Robert D. McCarty, and W. M. Haynes. J Phys Chem Ref Data 3, 979(1974).

The Viscosity and Thermal Conductivity Coefficients for Dense Gaseous and Liquid Methane - Howard J. M. Hanley, W. M. Haynes, and Robert D. McCarty. J Phys Chem Ref Data 6, 597(1977).

Thermodynamic and Thermophysical Properties of Combustion Products, Volume II. Oxygen-Based Propellants - V. P. Glushko, V. E. Alemasov, A. F. Dregalin, A. P. Tishin, V A. Khudyakov, and V. N. Kostin. Russian Transl., Springfield, VA: NTIS, 505p. (1975). TT 74-50032, A22.

Thermodynamic and Thermophysical Properties of Combustion Products, Volume III. Oxygen- and Air-Based Propellant - V. P. Glushko, V. E. Alemasov, A. F. Dregalin, A. P. Tishin, V. A. Khudyakov, and V. N. Kostin. Russian Transl., Springfield, VA: NTIS, 648p. (1975). TT 75-50007, A26.

Thermodynamic and Thermophysical Properties of Combustion Products, Volume IV. Nitrogen Tetroxide-Based Propellants - V. P. Glushko, V. E. Alemasov, A. F. Dregalin, A. P. Tishin, V. A. Khudyakov, and V. N. Kostin. Russian Transl., Springfield, VA: NTIS, 540p. (1976). TT 76-50007, A23.

Thermodynamic and Thermophysical Properties of Helium - A. F. Alyab'ev, N. V. Tsederberg, V. N. Popov, and N. A. Morozova. Russian Transl., Springfield, VA: NTIS, 260p. (1971). TT 70-50096, A12.

Thermophysical Properties of Air and Air Components - A. A. Vasserman, Ya. Z. Kazavchinskii, V. A. Rabinovich, and A. M. Zhuravlev. Russian Transl. Springfield, VA: NTIS, 402p. (1971). TT 70-50095, A18.

Thermophysical Properties of Freon-22 - A. V. Kletskii. Russian Transl. Springfield, VA: NTIS, 72p. (1971). TT 70-50178, A04. 
Thermophysical Properties of Gases and Liquids, No. 1 - V. A. Rabinovich. Russian Transl. Springfield, VA: NTIS, 214p. (1970). TT 69-55091, A 10, the translation of volumes 2, 3, and 4 have the title: Thermophysical Properties of Matter and Substances.

Thermophysical Properties of Gaseous and Liquid Methane - V. A. Zagoruchenko and A. M. Zhuravlev. Russian Transl. Springfield, VA: NTIS, 251p. (1970). TT 70-50097, A 12.

Thermophysical Properties of Liquid Air and Its Components - A. A. Vasserman and V. A. Rabinovich. Russian Transl. Springfield, VA: NTIS, 255p. (1970). TT 69-55092, A12.

Thermophysical Properties of Matter and Substances, Volume 2 V. A. Rabinovich. Russian Transl., Springfield, VA: NTIS, 395p. (1974). TT 72-52001, A17, the translation of volume 1 has the title: Thermophysical Properties of Gases and Liquids.

Thermophysical Properties of Matter and Substances, Volume 3 V. A. Rabinovich. Russian Transl. Springfield, VA: NTIS, 212p. (1975). TT 73-52009, A 10, the translation of volume 1 has the title: Thermophysical Properties of Gases and Liquids.

Thermophysical Properties of Matter and Substances, Volume 4 V. A. Rabinovich. Russian Transl., Springfield, VA: NTIS, 179p. (1975). TT 73-52029, A09, the translation of volume 1 has the title: Thermophysical Properties of Gases and Liquids.

Thermophysical Properties of Hydrocarbon Mixtures (TRAPP) NBS Standard Reference Database 4, Washington, D.C.; NBS, Office of Standard Reference Data,(updated periodically). Call (301)921-2228 for specific instructions.

Thermophysical Properties of Helium NBS Standard Reference Database 5, Washington, D.C.; NBS, Office of Standard Reference Data,(updated periodically). Call (301)921-2228 for specific instructions.
Thermophysical Properties of Fluids. I. Argon, Ethylene, Parahydrogen, Nitrogen, Nitrogen Trifluoride, and Oxygen - Ben A. Younglove. J Phys Chem Ref Data 11, Suppl. 1(1982).

Thermophysical Properties of Fluid $\mathrm{H}_{2} \mathrm{O}$ - Joseph Kestin, Jan V. Sengers, B. Kamgar-Parsi, and J. M. H. Levelt Sengers. J Phys Chem Ref Data 13, 175(1984).

Thermophysical Properties of Fluid $\mathrm{D}_{2} \mathrm{O}$ - Joseph Kestin, Jan V. Sengers, B. Kamgar-Parsi, and J. M. H. Levelt Sengers. J Phys Chem Ref Data 13, 602(1984).

Transport Properties of Liquid and Gaseous $\mathrm{D}_{2} \mathrm{O}$ over a Wide Range of Temperature and Pressure - N. Matsunaga and A. Nagashima. J Phys Chem Ref Data 12, 933(1983).

Viscosity of Water Substance - New International Formulation and Its Background - A. Nagashima. J Phys Chem Ref Data 6, 1133(1977).

Viscosity of Liquid Water in the Range $-8^{\circ} \mathrm{C}$ to $150^{\circ} \mathrm{C}$ - Joseph Kestin, Mordechai Sokolov, and William A. Wakeham. J Phys Chem Ref Data 7, 941(1978).

\section{Wavelengths of spectral lines}

See: Atomic energy levels and spectra Rotational spectra Vibrational spectra (infrared, Raman)

Electronic molecular spectra

\section{Young's modulus}

See: Elastic constants 


\section{Ordering Information}

The National Standard Reference Data System publications are available from a variety of sources, including the American Chemical Society (ACS); the American Institute of Physics (AIP); the Superintendent of Documents, U.S. Government Printing Office (GPO); the National Technical Information Service (NTIS); and the Office of Standard Reference Data (OSRD), as well as private publishers and other societies. Ordering information for all publications is included in the Price List chapter. It provides the following information for each publication: the publication number; number of pages; date of publication; hard copy price and order number; and microfiche copy order number as appropriate. Microfiche copies of many U.S. Government documents are available from NTIS for $\$ 4.50$. The source codes used in the price list are explained below.

\section{SOURCE ORDERING INSTRUCTIONS CODE}

\section{ACS}

American Chemical Society

Distribution Office

Room 210

1155 Sixteenth Street, N.W.

Washington, D.C 20036

Telephone: (202)872-4539 Mr. Leon Viloria

Payment must accompany the order. Charge accounts acceptable include MasterCard, VISA, BarclayCard, and Access. Include the full account number, the Interbank number (MasterCard and Access only), card expiration date, and signature. Checks must be made payable to the American Chemical Society. Bulk rates: subtract 20 percent from the listed price for orders of 50 or more copies of any one item of the same title. No book dealer discount other than the bulk rate.

AIP

American Institute of Physics

Department S/F

500 Sunnyside Blvd.

Woodbury, N. Y. 11797

Telephone: (212)661-9409

Write for price quotes and further information on the availability of the journal in microfilm.

GPO Superintendent of Documents

U.S. Government Printing Office

Washington, D.C. 20402

Telephone: (202)783-3238
Payment must accompany the order. Make money order or check payable to the Superintendent of Documents. Foreign remittances should be made either by international money order, draft on an American bank, or UNESCO coupons. Postage stamps will not be accepted. No charge is made for postage on documents sent to points in the United States and its possessions. In computing foreign postage, the charge for surface mail is approximately one-fourth of the current selling price of the publication.

JILA Joint Institute for Laboratory Astrophysics

Information Center

University of Colorado

Box 440

Boulder, CO 80309

Most items are free from the Information Center.

NTIS National Technical Information Service

U.S. Department of Commerce

5285 Port Royal Road

Springfield, VA 22161

Telex: 89-9405

Telephone:

Order Desk: (703)487-4650

Rush Handling: (703)487-4700

Customer Service:(703)487-4660

Orders may be placed with NTIS by one of the following methods:

1. Rush handling - guarantees the order is filled within 24 hours

- must be placed by telephore or telex

- adds $\$ 10.00$ for each mailed document

- adds $\$ 6.00$ for each document picked up locally

- must be charged to an NTIS deposit account or your American Express, Visa, or MasterCard account

2. Regular service - orders completed in 9 to 30 working days

- optional priority mail service available, $\$ 3.00$ extra in North America, $\$ 4.00$ extra elsewhere

- ship and bill service available - $\$ 7.50$ used only by businesses (an individual cannot order this way). A purchase order, accounting office telephone number, and 9 digit federal tax ID number is necessary.

3. Online Ordering - under development by commercial vendors of the NTIS Bibliographic Data Base. Contact individual vendors. 


\section{Telex 89-9405}

5. Orders for foreign destinations - NTIS has arranged that dealers be the exclusive agents in many countries. Only those orders originating in countries not served by an agent should be placed directly with NTIS. Please write to NTIS for further details.

NTIS price codes are used for items in this list. As an aid to users of the publications list, the price code schedule is given below.
OSRD Office of Standard Reference Data

National Bureau of Standards

Gaithersburg, MD 20899

Payment must accompany order. Checks should be drawn on an American bank and made payable to the National Bureau of Standards.

RCDC Radiation Chemistry Data Center

Radiation Laboratory

University of Notre Dame

Notre Dame, IN 46556

Write to the Center for price quotes and availability.

Standard Price Schedule

NTIS Code Schedule A

Price List

\begin{tabular}{lccc}
\hline $\begin{array}{l}\text { Price } \\
\text { Code }\end{array}$ & $\begin{array}{c}\text { Page } \\
\text { Range }\end{array}$ & $\begin{array}{c}\text { U.S. } \\
\text { Domestic }\end{array}$ & $\begin{array}{c}\text { Foreign } \\
\text { Price }\end{array}$ \\
\hline A01 & Microfiche & $\$ 4.50$ & $\$ 9.00$ \\
A02 & $001-025$ & 7.00 & 14.00 \\
A03 & $026-050$ & 8.50 & 17.00 \\
A04 & $051-075$ & 10.00 & 20.00 \\
A05 & $076-100$ & 11.50 & 23.00 \\
A06 & $101-125$ & 13.00 & 26.00 \\
A07 & $126-150$ & 14.50 & 29.00 \\
A08 & $151-175$ & 16.00 & 32.00 \\
A09 & $176-200$ & 17.50 & 35.00 \\
A10 & $201-225$ & 19.00 & 38.00 \\
A11 & $226-250$ & 20.50 & 41.00 \\
A12 & $251-275$ & 22.00 & 44.00 \\
A13 & $276-300$ & 23.50 & 47.00 \\
A14 & $301-325$ & 25.00 & 50.00 \\
A15 & $326-350$ & 26.50 & 53.00 \\
A16 & $351-375$ & 28.00 & 56.00 \\
A17 & $376-400$ & 29.50 & 59.00 \\
A18 & $401-425$ & 31.00 & 62.00 \\
A19 & $426-450$ & 32.50 & 65.00 \\
A20 & $451-475$ & 34.00 & 68.00 \\
A21 & $476-500$ & 35.50 & 71.00 \\
A22 & $501-525$ & 37.00 & 74.00 \\
A23 & $526-550$ & 38.50 & 77.00 \\
A24 & $551-575$ & 40.00 & 80.00 \\
A25 & $576-600$ & 41.50 & 83.00 \\
A26 & $601-u p$ & $*$ & \\
A99 & Please write for a price quote & \\
\hline
\end{tabular}

"For documents over 600 pages, add $\$ 1.50$ for each additional 25 page increment or portion thereof.

* For documents over 600 pages, add $\$ 3.00$ for each additional 25 page increment or portion thereof. 


\section{Reprints}

Vol(No)

$\begin{array}{ccc}\text { Page (year) } & \begin{array}{c}\text { Reprint } \\ \text { No. }\end{array} & \text { Price }\end{array}$

$\begin{array}{llll}1.118 & 1972 & 1 & \$ 7.00\end{array}$

$\begin{array}{llll}119.134 & 1972 & 2 & 3.00\end{array}$

$\begin{array}{llll}135.146 & 1972 & 3 & 3.00\end{array}$

$\begin{array}{llll}147.188 & 1972 & 4 & 4.50\end{array}$

$\begin{array}{llll}189.216 & 1972 & 5 & 4.00\end{array}$

$\begin{array}{llll}221.278 & 1972 & 6 & 5.00\end{array}$

$\begin{array}{llll}279.422 & 1972 & 7 & 7.50\end{array}$

$\begin{array}{llll}423.534 & 1972 & 8 & 6.50\end{array}$

$\begin{array}{llll}535.574 & 1972 & 9 & 4.50\end{array}$

$\begin{array}{llll}581.746 & 1972 & 10 & 8.50\end{array}$

$\begin{array}{llll}747.772 & 1972 & 11 & 4.00\end{array}$

$\begin{array}{llll}773.836 & 1972 & 12 & 5.00\end{array}$

$841.1009 \quad 1972$

$1011.1045 \quad 1972$

1047.1099 1972

$1101-1113 \quad 1972$

$1.10 \quad 1973$

$11.24 \quad 1973$

25-84 1973

85.120 1973

$121.162 \quad 1973$

$163.200 \quad 1973$

205-214 1973

215-224 $\quad 1973$

225.256 1973

$257.266 \quad 1973$

$267.312 \quad 1973$

$313-410 \quad 1973$

$411-426 \quad 1973$

$427.438 \quad 1973$

$439.466 \quad 1973$

$467.518 \quad 1973$

$519.530 \quad 1973$

$531.618 \quad 1973$

$619.642 \quad 1973$

$643.656 \quad 1973$

$663.734 \quad 1973$

$735.756 \quad 1973$

$757.922 \quad 1973$

923-1042 1973

$1.115 \quad 1974$

$117.140 \quad 1974$

$141.162 \quad 1974$

$163.209 \quad 1974$

$211.219 \quad 1974$

$221.244 \quad 1974$

24.5.257 1974

$259.268 \quad 1974$

269.308 1974

$311.480 \quad 1974$

$481.526 \quad 1974$

$527.602 \quad 1974$

$609.770 \quad 1974$

$771-780 \quad 1974$

$781.824 \quad 1974$

$825.895 \quad 1974$

$897.935 \quad 1974$

$937.978 \quad 1974$

$979.1017 \quad 1974$

$1.175 \quad 1975$

177.249

1975
Vol(No)

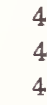

138.50

$14 \quad 4.50$

$15 \quad 5.00$

$16 \quad 3.00$

$17 \quad 3.00$

$18 \quad 3.00$

$19 \quad 5.00$

$20 \quad 4.50$

$21 \quad 4.50$

$22 \quad 4.50$

$23 \quad 3.00$

$24 \quad 3.00$

$25 \quad 4.00$

$26 \quad 3.00$

$27 \quad 4.50$

$28 \quad 6.50$

$29 \quad 3.00$

$30 \quad 3.00$

$31 \quad 4.00$

$32 \quad 5.00$

$33 \quad 3.00$

$34 \quad 6.00$

$35 \quad 4.00$

$36 \quad 3.00$

$37 \quad 5.50$

$38 \quad 4.00$

$40 \quad 7.00$

$41 \quad 7.00$

$42 \quad 4.00$

$43 \quad 4.00$

$44 \quad 4.50$

$45 \quad 3.00$

$46 \quad 4.00$

$47 \quad 3.00$

$48 \quad 3.00$

$49 \quad 4.50$

$50 \quad 8.50$

$51 \quad 4.50$

$52 \quad 5.50$

$53 \quad 8.50$

$54 \quad 3.00$

$55 \quad 4.50$

$56 \quad 5.50$

$57 \quad 4.50$

$58 \quad 4.50$

$59 \quad 4.50$

60

8.50

61
$39 \quad 8.50$

\section{Page (Year) Reprint Price No.}

$62 \quad 3.00$

$\begin{array}{rrrr}251.261 & 1975 & 62 & 3.00 \\ 263.352 & 1975 & 63 & 6.00 \\ 353.440 & 1975 & 64 & 6.00 \\ 441.456 & 1975 & 65 & 3.00 \\ 457.470 & 1975 & 66 & 3.00 \\ 471.538 & 1975 & 67 & 5.50 \\ 539.576 & 1975 & 68 & 4.50 \\ 577.856 & 1975 & 69 & 12.00 \\ 859.870 & 1975 & 70 & 3.00\end{array}$

$\begin{array}{llll}871.11 .78 & 1975 & 71 & 13.00\end{array}$

$\begin{array}{llll}1.51 & 1976 & 73 & 5.00\end{array}$

$\begin{array}{llll}53.77 & 1976 & 74 & 4.00\end{array}$

$\begin{array}{llll}79.101 & 1976 & 75 & 4.00\end{array}$

$\begin{array}{llll}103-200 & 1976 & 76 & 6.50\end{array}$

$\begin{array}{llll}209.257 & 1976 & 77 & 5.00\end{array}$

$\begin{array}{llll}259.308 & 1976 & 78 & 5.00\end{array}$

$\begin{array}{llll}309.317 & 1976 & 79 & 3.00\end{array}$

$\begin{array}{llll}319.328 & 1976 & 80 & 3.00\end{array}$

$\begin{array}{llll}329.528 & 1976 & 81 & 9.50\end{array}$

$\begin{array}{llll}537.570 & 1976 & 82 & 4.50\end{array}$

$\begin{array}{llll}571.580 & 1976 & 83 & 3.00\end{array}$

$\begin{array}{llll}581-821 & 1976 & 84 & 12.50\end{array}$

$\begin{array}{llll}835.1092 & 1976 & 85 & 11.50\end{array}$

$\begin{array}{llll}1093.1121 & 1976 & 86 & 4.00\end{array}$

$\begin{array}{llll}1123.1146 & 1976 & 87 & 4.00\end{array}$

$\begin{array}{llll}1147.1156 & 1976 & 88 & 3.00\end{array}$

$\begin{array}{llll}1.50 & 1977 & 90 & 5.00\end{array}$

$\begin{array}{llll}51.104 & 1977 & 91 & 5.00\end{array}$

$\begin{array}{llll}105.112 & 1977 & 92 & 3.00\end{array}$

$\begin{array}{llll}113.307 & 1977 & 93 & 9.50\end{array}$

$\begin{array}{llll}317.383 & 1977 & 94 & 5.50\end{array}$

$\begin{array}{llll}385.407 & 1977 & 95 & 4.00\end{array}$

$\begin{array}{llll}409.596 & 1977 & 96 & 9.00\end{array}$

$\begin{array}{llll}597.609 & 1977 & 97 & 3.00\end{array}$

$\begin{array}{llll}621.673 & 1977 & 98 & 5.00\end{array}$

$\begin{array}{llll}675.829 & 1977 & 99 & 8.00\end{array}$

$\begin{array}{llll}831.869 & 1977 & 100 & 4.50\end{array}$

$\begin{array}{llll}871.917 & 1977 & 101 & 4.50\end{array}$

$\begin{array}{llll}919.991 & 1977 & 102 & 5.50\end{array}$

$\begin{array}{llll}993.1102 & 1977 & 103 & 6.50\end{array}$

$\begin{array}{llll}1109.1132 & 1977 & 104 & 4.00\end{array}$

$\begin{array}{llll}1133.1166 & 1977 & 105 & 4.50\end{array}$

$\begin{array}{llll}1167.1180 & 1977 & 106 & 3.00\end{array}$

$\begin{array}{llll}1181-1204 & 1977 & 107 & 4.00\end{array}$

$\begin{array}{llll}1205.1252 & 1977 & 108 & 4.50\end{array}$

$\begin{array}{llll}1253-1330 & 1977 & 109 & 5.50\end{array}$

$\begin{array}{llll}1.262 & 1978 & 110 & 11.50\end{array}$

$\begin{array}{llll}263.310 & 1978 & 111 & 4.50\end{array}$

$\begin{array}{llll}311.362 & 1978 & 112 & 5.00\end{array}$

$\begin{array}{llll}363.377 & 1978 & 113 & 3.00\end{array}$

$\begin{array}{llll}383-415 & 1978 & 114 & 4.50\end{array}$

$\begin{array}{llll}417-423 & 1978 & 115 & 3.00\end{array}$

$\begin{array}{llll}425.439 & 1978 & 116 & 3.00\end{array}$

$\begin{array}{llll}441.493 & 1978 & 117 & 5.00\end{array}$

$\begin{array}{llll}495.629 & 1978 & 118 & 7.50\end{array}$

$\begin{array}{llll}635.792 & 1978 & 119 & 8.00\end{array}$

$\begin{array}{llll}793.940 & 1978 & 120 & 8.00\end{array}$

$\begin{array}{llll}941.948 & 1978 & 121 & 3.00\end{array}$

$\begin{array}{llll}949.957 & 1978 & 122 & 3.00\end{array}$

$\begin{array}{llll}959.1177 & 1978 & 123 & 10.00\end{array}$

$\begin{array}{llll}1179.1190 & 1978 & 124 & 3.00\end{array}$ 
Reprints

\begin{tabular}{|c|c|c|c|c|}
\hline Vol(No) & Page & (year) & $\begin{array}{c}\text { Reprint } \\
\text { No. }\end{array}$ & Price \\
\hline 7 & $1191-1262$ & 1978 & 125 & 5.50 \\
\hline 7 & $1267-1284$ & 1978 & 126 & 4.00 \\
\hline 7 & $1285 \cdot 1307$ & 1978 & 127 & 4.00 \\
\hline 7 & 1309-1321 & 1978 & 128 & 3.00 \\
\hline 7 & $1323-1443$ & 1978 & 129 & 7.00 \\
\hline 7 & $1445-1750$ & 1978 & 130 & 13.00 \\
\hline 8 & $1-62$ & 1979 & 131 & 5.00 \\
\hline 8 & $63-68$ & 1979 & 132 & 3.00 \\
\hline 8 & $69-105$ & 1979 & 133 & 4.50 \\
\hline 8 & $107-123$ & 1979 & 134 & 4.00 \\
\hline 8 & $125-302$ & 1979 & 135 & 9.00 \\
\hline 8 & $307-327$ & 1979 & 136 & 4.00 \\
\hline 8 & 329.338 & 1979 & 137 & 3.00 \\
\hline 8 & $339-438$ & 1979 & 138 & 6.50 \\
\hline 8 & $439-497$ & 1979 & 139 & 5.00 \\
\hline 8 & 499.517 & $19 \% / 9$ & 140 & 4.00 \\
\hline 8 & $519-526$ & 1979 & 141 & 3.00 \\
\hline 8 & 527.535 & 1979 & 142 & 3.00 \\
\hline 8 & 537.558 & 1979 & 143 & 4.00 \\
\hline 8 & $559-575$ & 1979 & 144 & 4.00 \\
\hline 8 & $583-618$ & 1979 & 145 & 4.50 \\
\hline 8 & 619.722 & 1979 & 146 & 6.50 \\
\hline 8 & $723-798$ & 1979 & 147 & 5.50 \\
\hline 8 & 799.816 & 1979 & 148 & 4.00 \\
\hline 8 & $817-864$ & 1979 & 149 & 4.50 \\
\hline 8 & 865.916 & 1979 & 150 & 5.00 \\
\hline 8 & $923-1004$ & 1979 & 151 & 6.00 \\
\hline 8 & $1005-1050$ & 1979 & 152 & 4.50 \\
\hline 8 & $1051-1108$ & 1979 & 153 & 5.00 \\
\hline 8 & $1109-1146$ & 1979 & 154 & 4.50 \\
\hline 8 & $1147-1298$ & 1979 & 155 & 8.00 \\
\hline 9 & $1-58$ & 1980 & 156 & 6.00 \\
\hline 9 & $59-160$ & 1980 & 157 & 7.50 \\
\hline 9 & $161 \cdot 289$ & 1980 & 158 & 8.50 \\
\hline 9 & 295-471 & 1980 & 159 & 10.00 \\
\hline 9 & $473-511$ & 1980 & 160 & 5.50 \\
\hline 9 & 523.560 & 1980 & 161 & 5.50 \\
\hline 9 & 561.658 & 1980 & 162 & 7.50 \\
\hline 9 & 659.720 & 1980 & 163 & 6.00 \\
\hline 9 & $721-734$ & 1980 & 164 & 4.00 \\
\hline 9 & 735.750 & 1980 & 165 & 4.00 \\
\hline 9 & 751.790 & 1980 & 166 & 5.50 \\
\hline 9 & $791-830$ & 1980 & 167 & 5.50 \\
\hline 9 & $831 \cdot 1022$ & 1980 & 168 & 10.50 \\
\hline 9 & $1023-1148$ & 1980 & 169 & 8.00 \\
\hline 9 & $1149-1254$ & 1980 & 170 & 7.50 \\
\hline 9 & $1255-1290$ & 1980 & 171 & 5.50 \\
\hline 9 & 1291.1306 & 1980 & 172 & 4.00 \\
\hline 9 & $1307 \cdot 1328$ & 1980 & 173 & 5.00 \\
\hline 10 & $1-55$ & 1981 & 174 & 6.00 \\
\hline 10 & 57.70 & 1981 & 175 & 4.00 \\
\hline 10 & 71.87 & 1981 & 176 & 5.00 \\
\hline 10 & 89.117 & 1981 & 177 & 5.00 \\
\hline 10 & $119-152$ & 1981 & 178 & 5.50 \\
\hline 10 & $153-196$ & 1981 & 179 & 5.50 \\
\hline 10 & $197-289$ & 1981 & 180 & 7.00 \\
\hline 10 & 295-304 & 1981 & 181 & 4.00 \\
\hline 10 & $305-565$ & 1981 & 182 & 12.50 \\
\hline 10 & $575-669$ & 1981 & 183 & 7.00 \\
\hline 10 & $671 \cdot 764$ & 1981 & 184 & 7.00 \\
\hline 10 & $765-778$ & 1981 & 185 & 4.00 \\
\hline 10 & 779.798 & 1981 & 186 & 5.00 \\
\hline
\end{tabular}

\section{Reprints}

\begin{tabular}{|c|c|c|c|c|}
\hline Vol(No) & Page & (year) & $\begin{array}{c}\text { Reprint } \\
\text { No. }\end{array}$ & Price \\
\hline 10 & 809-999 & 1981 & 187 & 10.00 \\
\hline 10 & $1001 \cdot 1049$ & 1981 & 188 & 5.50 \\
\hline 10 & $1051 \cdot 1064$ & 1981 & 189 & 4.00 \\
\hline 10 & $1065-1084$ & 1981 & 190 & 5.00 \\
\hline 10 & $1085 \cdot 1095$ & 1981 & 191 & 4.00 \\
\hline 10 & 1097.1174 & 1981 & 192 & 6.50 \\
\hline 10 & $1175-1199$ & 1981 & 193 & 5.00 \\
\hline 10 & $1205 \cdot 1240$ & 1981 & 194 & 5.00 \\
\hline 11 & $1-14$ & 1982 & 195 & 5.00 \\
\hline 11 & $15-81$ & 1982 & 196 & 9.00 \\
\hline 11 & 83-99 & 1982 & 197 & 6.00 \\
\hline 11 & $101 \cdot 117$ & 1982 & 198 & 6.00 \\
\hline 11 & 119.133 & 1982 & 199 & 5.00 \\
\hline 11 & $135-241$ & 1982 & 200 & 11.00 \\
\hline 11 & $251-312$ & 1982 & 201 & 8.00 \\
\hline 11 & $313-325$ & 1982 & 202 & 5.00 \\
\hline 11 & 327.496 & 1982 & 203 & 15.00 \\
\hline 11 & $505-693$ & 1982 & 204 & 16.00 \\
\hline 11 & 695.940 & 1982 & 205 & 20.00 \\
\hline 11 & 941.951 & 1982 & 206 & 5.00 \\
\hline 11 & $953-996$ & 1982 & 207 & 7.00 \\
\hline 11 & $1005-1064$ & 1982 & 208 & 8.00 \\
\hline 11 & $1065 \cdot 1089$ & 1982 & 209 & 6.00 \\
\hline 11 & $1091 \cdot 1098$ & 1982 & 210 & 5.00 \\
\hline 11 & $1099-1127$ & 1982 & 211 & 6.00 \\
\hline 11 & $1127 \cdot 1151$ & 1982 & 212 & 6.00 \\
\hline 11 & $1151-1171$ & 1982 & 213 & 6.00 \\
\hline 12 & $1-28$ & 1983 & 214 & 6.00 \\
\hline 12 & 29.63 & 1983 & 215 & 7.00 \\
\hline 12 & $65-89$ & 1983 & 216 & 6.00 \\
\hline 12 & $91-108$ & 1983 & 217 & 6.00 \\
\hline 12 & 109-152 & 1983 & 218 & 7.00 \\
\hline 12 & $163-178$ & 1983 & 219 & 5.00 \\
\hline 12 & 179.182 & 1983 & 220 & 5.00 \\
\hline 12 & $183-322$ & 1983 & 221 & 13.00 \\
\hline 12 & $323-380$ & 1983 & 222 & 8.00 \\
\hline 12 & $381 \cdot 387$ & 1983 & 223 & 5.00 \\
\hline 12 & 389.393 & 1983 & 224 & 5.00 \\
\hline 12 & $395-401$ & 1983 & 225 & 5.00 \\
\hline 12 & $413-465$ & 1983 & 226 & 8.00 \\
\hline 12 & $467-512$ & 1983 & 227 & 7.00 \\
\hline 12 & $513-529$ & 1983 & 228 & 6.00 \\
\hline 12 & $531-590$ & 1983 & 229 & 8.00 \\
\hline 12 & 591.815 & 1983 & 230 & 19.00 \\
\hline 12 & $817 \cdot 820$ & 1983 & 231 & 5.00 \\
\hline 12 & 829.872 & 1983 & 232 & 7.00 \\
\hline 12 & $873 \cdot 890$ & 1983 & 233 & 6.00 \\
\hline 12 & 891.916 & 1983 & 234 & 6.00 \\
\hline 12 & 917.932 & 1983 & 235 & 5.00 \\
\hline 12 & 933.966 & 1983 & 236 & 7.00 \\
\hline 12 & $967-1031$ & 1983 & 237 & 9.00 \\
\hline 12 & $1033-1063$ & 1983 & 238 & 6.00 \\
\hline 13 & 1.102 & 1984 & 239 & 11.00 \\
\hline 13 & $103-150$ & 1984 & 240 & 7.00 \\
\hline 13 & $151-173$ & 1984 & 241 & 6.00 \\
\hline 13 & $175 \cdot 183$ & 1984 & 242 & 5.00 \\
\hline 13 & 185.205 & 1984 & 243 & 6.00 \\
\hline 13 & $207-227$ & 1984 & 244 & 6.00 \\
\hline 13 & 229.303 & 1984 & 245 & 9.00 \\
\hline 13 & $315-444$ & 1984 & 246 & 13.00 \\
\hline 13 & $445-553$ & 1984 & 247 & 11.00 \\
\hline 13 & $555-562$ & 1984 & 248 & 5.00 \\
\hline
\end{tabular}


Reprints

$\begin{array}{rlrrr}13 & 563-600 & 1984 & 249 & 7.00 \\ 13 & 602-609 & 1984 & 250 & 5.00 \\ 13 & 619-648 & 1984 & 251 & 6.00 \\ 13 & 649-686 & 1984 & 252 & 7.00 \\ 13 & 687-694 & 1984 & 253 & 5.00 \\ 13 & 695 \cdot 808 & 1984 & 254 & 12.00 \\ 13 & 809-892 & 1984 & 255 & 10.00 \\ 13 & 893-934 & 1984 & 256 & 7.00 \\ 13 & 945-1068 & 1984 & 257 & 12.00 \\ 13 & 1069-1096 & 1984 & 258 & 6.00 \\ 13 & 1097-1130 & 1984 & 259 & 7.00 \\ 13 & 1131-1172 & 1984 & 260 & 7.00 \\ 13 & 1173-1197 & 1984 & 261 & 6.00 \\ 13 & 1199-1250 & 1984 & 262 & 8.00 \\ 13 & 1251-1257 & 1984 & 263 & 5.00 \\ 13 & 1259-1380 & 1984 & 264 & 12.00\end{array}$

\section{Special Reprint Packages}

Package No. Title Price
$\$ 22.00$

due 85

JANAF Thermochemical

Tables

A3 19 Atomic Energy Levels

66.00

27.00

28.00

58.00

40.00

41.00

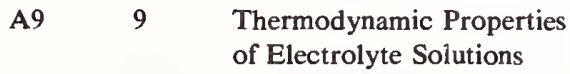

B1 12 Ideal Gas Thermodynamic

Properties

B2 3 Elastic Properties of

Metals and Alloys

B3 3 Resistivity

B4 7 Molten Salts

B5 3 Refractive Index

B6 11

Viscosity and Thermal

Conductivity of Fluids

B7 $10 \quad$ Properties of Water

B8 4 Properties of Heavy Water

B9 9 Linear Micromolecules

Supplements to the Journal

Vol. 2, Supplement 1, 420 p. (1973)

hard cover $\$ 33.00$

soft cover $\$ 30.00$

Vol. 3 Supplement 1, 796 p. (1974)

hard cover $\$ 60.00$

soft cover $\$ 55.00$

Vol. 6, Supplement 1, 783 p. (1977)

hard cover $\$ 70.00$

soft cover $\$ 65.00$

Vol. 10. Supplement 1, 720 p. (1981) hard cover $\$ 80.00$

Vol. 11, Supplement 1, 354 p. (1982) hard cover $\$ 40.00$

Volume 11, Supplement 2, 394 p. (1982) hard cover $\$ 40.00$

Volume 12, Supplement 1 (1983) hard cover $\$ 40.00$
37.00

31.00

12.00

16.00

44.00

21.00

35.00

37.00

16.00

38.00 
National Standard Reference Data System-National Bureau of Standards (NSRDS-NBS)

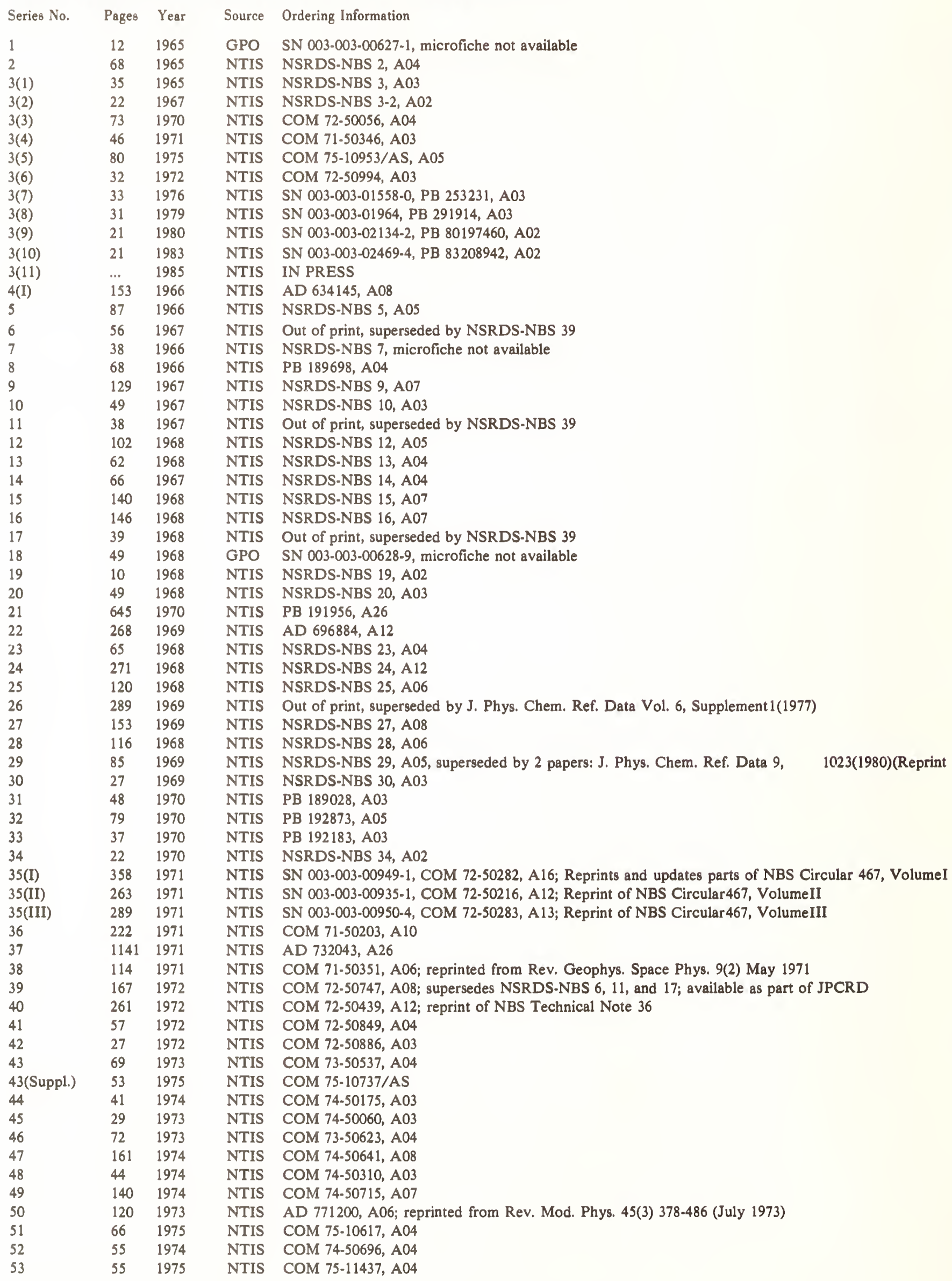


National Standard Reference Data Systems-National Bureau of Standards (NSRDS-NBS)—Continued

\begin{tabular}{lllll} 
Series No. & Pages & Year & \multicolumn{2}{c}{ Ordering Information } \\
54 & 33 & 1975 & NTIS & COM 75-10625, A03 \\
55 & 21 & 1975 & NTIS & COM 75-10917/AS, A02 \\
56 & 37 & 1975 & NTIS & PB 248991, A03 \\
57 & 38 & 1976 & NTIS & PB 255 004, A03 \\
58 & 23 & 1976 & NTIS & PB 254 470, A02 \\
59 & 126 & 1976 & NTIS & PB 263 198, A07 \\
60 & 422 & 1978 & NTIS & PB 282 067, A 18 \\
$61($ I) & 244 & 1978 & NTIS & PB 281 463, A11 \\
$61($ II) & 420 & 1979 & NTIS & PB 295 406, A18 \\
$61($ III) & 19 & 1979 & NTIS & PB 297847, A02 \\
$61($ IV) & 870 & 1981 & NTIS & PB 81-244 121, A26 \\
$61($ V) & 42 & 1982 & NTIS & PB 82-232 919, A03 \\
62 & 68 & 1978 & NTIS & PB 283487, A04 \\
$63(1,2,3,4)$ & 3975 & 1978 & NTIS & PB 290 661 A26 \\
$63($ Suppl. 1) & 2040 & 1980 & NTIS & PB 81-189 367, A26 \\
$63($ Suppl. 2$)$ & 1110 & 1983 & NTIS & PB 84-156 496, A26 \\
64 & 27 & 1980 & NTIS & PB 294304, A03 \\
65 & 62 & 1979 & NTIS & PB 296 734, A04 \\
66 & 380 & 1980 & NTIS & out of print, superseded by NSRDS-NBS 71 \\
67 & 110 & 1980 & NTIS & PB 208 887, A06 \\
68 & 415 & 1980 & NTIS & PB 81-206 120, A18 \\
69 & 167 & 1981 & NTIS & SN003-003-02322-1, PB 82-10941, A08 \\
70 & 96 & 1982 & NTIS & SN003-003-02431-7, microfiche from NTIS as PB 82-109 141, A05 \\
71 & 634 & 1982 & NTIS & SN003-003-02424-4, supersedes NSRDS-NBS 66 \\
72 & 42 & 1982 & NTIS & PB 82-215 401, A03 \\
& & & &
\end{tabular}

\section{NBS Circulars}

$\begin{array}{lll}488(1) & 78 & 1950 \\ 488(2) & 115 & 1952 \\ 488(3) & 94 & 1962 \\ 488(4) & 65 & 1962 \\ 488(5) & 30 & 1962\end{array}$

NTIS PB 252 093, A09, bound together with section 2 NTIS PB 252 093, A09, bound together with section 1 NTIS PB 252 094, A09, bound together with sections 4 and 5 NTIS PB 252 094, A09, bound together with sections 3 and 5 NTIS PB 252 094, A09, bound together with sections 3 and 4

NBS Handbooks

$\begin{array}{lll}101 & 256 & 1968 \\ 125 & 294 & 1978 \\ 138 & 127 & 198\end{array}$

NTIS NBS-H101, A12, reprinting with corrections of the 1966 edition

$138-127-1982$

NTIS SN003-003-01972-1, microfiche from NTIS as NBS-H-125

NTIS SN003-003-02391-4, PB 82-217175

\section{NBS Monographs}

$\begin{array}{lll}70(\mathrm{I}) & 171 & 1964 \\ 70 \text { (II) } & 349 & 1964 \\ 70(\mathrm{III}) & 275 & 1969 \\ 70(\mathrm{IV}) & 419 & 1968 \\ 70(\mathrm{~V}) & 533 & 1968 \\ 94 & 116 & 1965 \\ 115 & 54 & 1970 \\ 134 & 177 & 1973 \\ 153 & 123 & 1976 \\ 167 & 288 & 1981 \\ 169 & 197 & 1982 \\ 170 & 249 & 1982\end{array}$

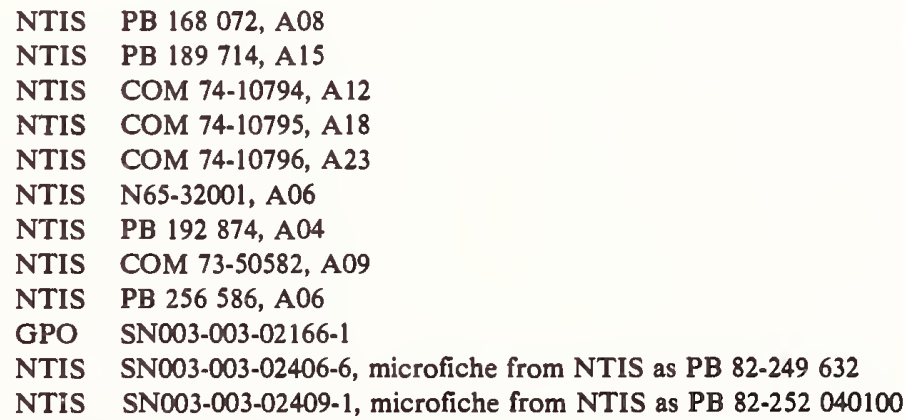

NBS Office of Standard Reference Data Bibliographies (OSRDB)

$\begin{array}{lllll}70-1(\text { Vol. 1) } & 692 & 1970 & \text { NTIS } & \text { PB 191 174, A26 } \\ 70-1(\text { Vol. 2) } & 748 & 1970 & \text { NTIS } & \text { PB 191 175, A26 } \\ 70-2 & 413 & 1970 & \text { NTIS } & \text { COM 71-00722, A18 } \\ 70-3 & 293 & 1970 & \text { NTIS } & \text { AD 705 110, A13 } \\ 70-4 & 47 & 1970 & \text { NTIS } & \text { COM 71-00025, A03 } \\ 71-1 & 293 & 1971 & \text { NTIS } & \text { COM 71-00248, A13 } \\ 71-2 & 140 & 1971 & \text { NTIS } & \text { COM 71-00841, A07; supplemented by NBS Spec. Publ. } 371 \text { and } 371 \text { Suppl. }\end{array}$


National Standard Reference Data System-National Bureau of Standards (NSRDS-NBS)

Joint Institute for Laboratory Astrophysics (JILA Reports)

$\begin{array}{lll}6 & 95 & 1969 \\ 7 & 167 & 1969 \\ 13 & 139 & 1973 \\ 18 & 148 & 1980 \\ 20 & 252 & 1979 \\ 21 & 127 & 1981\end{array}$

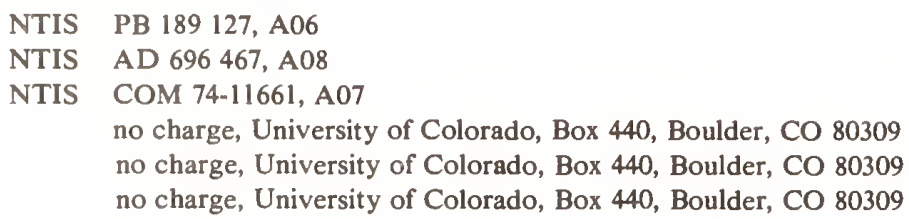

NBS Special Publications

\begin{tabular}{|c|c|c|}
\hline Series No. & Pages & Year \\
\hline 281 & 155 & 1967 \\
\hline $306(I)$ & 80 & 1968 \\
\hline 306(II) & 57 & 1969 \\
\hline 306(III) & 37 & 1969 \\
\hline 306(IV) & 48 & 1969 \\
\hline 324 & 683 & 1971 \\
\hline 349 & 43 & 1972 \\
\hline 362 & 75 & 1972 \\
\hline 363 & 109 & 1972 \\
\hline 363(Suppl. 1) & 190 & 1977 \\
\hline 363(Suppl. 2) & 119 & 1980 \\
\hline 366 & 165 & 1972 \\
\hline 366(Suppl. 1) & 76 & 1974 \\
\hline 366(Suppl. 2) & 75 & 1975 \\
\hline 366(Suppl. 3) & 87 & 1978 \\
\hline 369 & 180 & 1974 \\
\hline 371 & 93 & 1973 \\
\hline 371(Suppl. 1) & 91 & 1975 \\
\hline 380 & 134 & 1973 \\
\hline 380(Suppl. 1) & 106 & 1978 \\
\hline 381 & 75 & 1973 \\
\hline 392 & 84 & 1974 \\
\hline $396(1)$ & 90 & 1974 \\
\hline $396(2)$ & 56 & 1975 \\
\hline $396(3)$ & 42 & 1976 \\
\hline $396(4)$ & 96 & 1976 \\
\hline 424 & 177 & 1976 \\
\hline 426 & 222 & 1976 \\
\hline 426(Suppl. 1) & 115 & 1979 \\
\hline $428(1,2,3)$ & 2414 & 1976 \\
\hline 449 & 142 & 1976 \\
\hline 454 & 71 & 1976 \\
\hline 478 & 54 & 1977 \\
\hline 485 & 57 & 1977 \\
\hline $496(1,2)$ & 1622 & 1978 \\
\hline 505 & 283 & 1978 \\
\hline 505(Suppl.) & 126 & 1980 \\
\hline 513 & 111 & 1978 \\
\hline 531 & 94 & 1978 \\
\hline 537 & 94 & 1979 \\
\hline 578 & 27 & 1980 \\
\hline 593 & 349 & 1981 \\
\hline 612 & 125 & 1981 \\
\hline 689 & 37 & 1985 \\
\hline
\end{tabular}

\section{Ordering Information}

NTIS NBS SP-281, A08

NTIS NBS SP 306, A05

NTIS NBS SP-306-2, A04

NTIS PB 264245, A03

NTIS COM 73-10870, A02

NTIS COM 71-50070, A26

NTIS COM 72-50807, A03

NTIS COM 72-50466, A04

NTIS COM 72-50676, A06

NTIS PB 263 199, A05

NTIS SN003-003-02267-5, PB 81 125833, A06

NTIS COM 72-50943, A08

NTIS COM 74-50063, A05

NTIS PB 245714 , A04

NTIS PB 289815 , A05

NTIS COM 74-50302, A09

NTIS COM 73-50245, A05; supplements NBS-OSRDB 71-2 (1971)

NTIS COM 75-10687, A05; supplements NBS-OSRDB 71-2 (1972) and NBS Special Publication 371

NTIS COM 73-50244, A07

NTIS PB 284 499, A06

NTIS COM 73-50932, A04

NTIS COM 74-50348, A05

NTIS COM 74-51060, A05

NTIS PB 248989, A04

NTIS PB 250844, A03

NTIS SN003-003-01572-5, PB 258 557, A05

NTIS PB 251845 , A09

NTIS SN003-003-01465-6, PB 252 687, A 10

NTIS PB 296736, A06

NTIS SN003-003-01541-5, sold as a three volume set PB 249160, 161, 162

NTIS PB 263 122, A07

NTIS PB 257 765, A04

NTIS SN003-003-01824-4, PB 270 972, A04

NTIS PB 270367, A04

NTIS Vol. 1: PB 280 244,

Vol. 2: PB 280245

NTIS PB 280736, A 13

NTIS PB 80-213 739, A07

NTIS PB 280549, A06

NTIS PB 289 918, A05

NTIS PB 292 163, A05

NTIS PB 81167025, A03

NTIS PB 81-204 760, A 15

NTIS NBS Special Publication 612, no charge; microfiche from NTIS as PB 82-134 362

GPO SP 689
NBS Technical Notes

$\begin{array}{lll}270(3) & 264 & 1968 \\ 270(4) & 152 & 1969 \\ 270(5) & 49 & 1971 \\ 270(6) & 124 & 1971 \\ 270(7) & 84 & 1973 \\ 270(8) & 149 & 1981\end{array}$

NTIS NBS TN 270(3), A 12. Superseded by J. Phys. Chem. Ref. Data 11, Supplement 2 (1982) GPO SN003-003-00407-3, microfiche not available. Superseded by J. Phys. Chem. Ref. Data 11, Suppl NTIS COM 71-50171 A03. Superseded by J. Phys. Chem. Ref. Data 11, Supplement 2 (1982) NTIS COM 71-50608, A06. Superseded by J. Phys. Chem. Ref. Data, 11, Supplement 2 (1982) NTIS COM 73-50435, A05. Superseded by J. Phys. Chem. Ref. Data 11, Supplement 2 (1982) GPO SN003-003-02318-3, superseded by J. Phys. Chem. Ref. Data 11, Supplement 2 (1982) 
NBS Technical Notes-Continued

\begin{tabular}{|c|c|c|c|c|}
\hline Series No. & Pages & Year & \multicolumn{2}{|c|}{ Ordering Information } \\
\hline 291 & 40 & 1966 & NTIS & NBS-TN-291, A03 \\
\hline 361 & 118 & 1973 & NTIS & COM 74-50760, A06 \\
\hline 438 & 139 & 1967 & NTIS & AD $665245, A 07$ \\
\hline 444 & 25 & 1968 & NTIS & NBS-TN-444, A02 \\
\hline 446 & 84 & 1968 & NTIS & NBS-TN-446, A04 \\
\hline 464 & 163 & 1968 & NTIS & NBS-TN-464, A08 \\
\hline 470 & 76 & 1969 & NTIS & NBS-TN-470, A05 \\
\hline 474 & 22 & 1969 & NTIS & AD $681351, A 02$ \\
\hline 484 & 62 & 1969 & NTIS & AD 692 231, A04 \\
\hline 500 & 47 & 1970 & NTIS & PB 191352, A03 \\
\hline 554 & 196 & 1970 & NTIS & PB 194750, A09 \\
\hline 700 & 72 & 1972 & NTIS & COM 73-50015, A04 \\
\hline 738 & 16 & 1972 & NTIS & COM 72-50810, A02 \\
\hline 740 & 32 & 1973 & NTIS & COM 73-50986, A03 \\
\hline 760 & 32 & 1973 & NTIS & SN003-003-0112-6, COM 73-50242, A03 \\
\hline 820 & 58 & 1974 & NTIS & COM 74-50140, A04 \\
\hline 848 & 23 & 1974 & NTIS & COM $74-50943$, A02 \\
\hline 901 & 47 & 1976 & NTIS & PB 251269, A03 \\
\hline 903 & 34 & 1976 & NTIS & PB 249541, A04 \\
\hline 928 & 60 & 1976 & NTIS & PB 262600, A04 \\
\hline 947 & 88 & 1977 & NTIS & PB 268513, A05 \\
\hline 968 & 81 & 1978 & NTIS & PB $84-148717$, A05 \\
\hline 983 & 103 & 1978 & NTIS & PB 287 013, A06; supplements J. Phys. Chem. Reference Data 5(3)581-821(1976), Reprint No. 84 \\
\hline 1039 & 83 & 1981 & NTIS & PB $81-214165$, A05 \\
\hline 1045 & 164 & 1981 & NTIS & SN003-003-02351-5, PB 82-107673, A08 \\
\hline 1048 & 56 & 1982 & NTIS & PB 83117523, A04 \\
\hline 1051 & 199 & 1982 & NTIS & PB $82-225988$, A09 \\
\hline 1122 & 29 & 1980 & NTIS & PB $81-11511$, A03 \\
\hline 1141 & 54 & 1981 & NTIS & SN003-003-02309-4, PB 81 205437, A04 \\
\hline 1147 & 316 & 1981 & NTIS & SN003-003-02379-5; supersedes NBS Technical Note 551; PB 82 136474, A14 \\
\hline 1176 & 49 & 1983 & NTIS & SN003-003-02490-2, PB 83220467, A03 \\
\hline
\end{tabular}

Translations from the Russian

Russian Tran. $366 \quad 1971$

Russian Tran. 691970

Russian Tran. $730 \quad 1970$

Russian Tran. $329 \quad 1972$

Russian Tran. 3401974

Russian Tran. $273 \quad 1971$

Russian Tran. $215 \quad 1974$

Russian Tran. $126 \quad 1971$

Russian Tran. $434 \quad 1972$

Russian Tran. $364 \quad 1971$

Russian Tran. 4531974

Russian Tran. 5051975

Russian Tran. $648 \quad 1975$

Russian Tran. $540 \quad 1976$

Russian Tran. $260 \quad 1971$

Russian Tran. $206 \quad 1972$

Russian Tran. $402 \quad 1971$

Russian Tran. $72 \quad 1971$

Russian Tran. $214 \quad 1970$

Russian Tran. $251 \quad 1970$

Russian Tran. 2551970

Russian Tran. $395 \quad 1974$

Russian Tran. $212 \quad 1975$

Russian Tran. $179 \quad 1975$
NTIS TT 70-50180, A16

NTIS TT 70-50177, A04

NTIS TT 71-50040, A26

NTIS TT 71-50041, A 15

NTIS TT 73-53051 or PB226 722, A 15

NTIS TT 70-50094, A12

NTIS TT 72.52002, A 10

NTIS TT 70-50179, A07

NTIS COM 72-10014, A19

NTIS TT $70-50148$, A 16

NTIS TT 74-50019, A20

NTIS TT 74-50032, A22

NTIS TT 75-50007, A26

NTIS TT 76-50007, A23

NTIS TT 70-50096, A 12

NTIS COM 75-11276, A 10

NTIS TT 70-50095, A 18

NTIS TT 70-50178, A04

NTIS TT 69-55091, A10

NTIS TT 70-50097, A 12

NTIS TT 69-55092, A12

NTIS TT 72.52001, A 17

NTIS TT 73-52009, A 10

NTIS TT 73-52029, A09,

NBS Interim Reports (NBSIR)

$\begin{array}{lllll}75-770 & 27 & 1975 & \text { NTIS } & \text { COM 75-11370, A03 } \\ 75-968 & 35 & 1976 & \text { NTIS } & \text { PB 250 845, A03 } \\ 76-1002 & 54 & 1976 & \text { NTIS } & \text { PB 257 469, A04 } \\ 76-1034 & 76 & 1976 & \text { NTIS } & \text { PB 254 460, A05 }\end{array}$


SBS Interim Reports (NBSIR)—Continued

$\begin{array}{lllll}76-1061 & 52 & 1976 & \text { NTIS } & \text { PB 256 328, A04 } \\ 76-1147 & 41 & 1976 & \text { NTIS } & \text { PB 259 637, A03 } \\ 77-860 & 240 & 1977 & \text { NTIS } & \text { PB 272 355, A11 } \\ 77-865 & 162 & 1977 & \text { NTIS } & \text { N-78-16119, A08 } \\ 77-1300 & 94 & 1977 & \text { NTIS } & \text { PB 273 171, A05 } \\ 78-1432 & 84 & 1978 & \text { NTIS } & \text { PB 293 918, A05 } \\ 78-1479 & 69 & 1981 & \text { NTIS } & \text { PB } 80-284659, \text { A08 } \\ 79-1777 & 563 & 1979 & \text { NTIS } & \text { PB 299 289, A24 } \\ 79-1941 & 169 & 1979 & \text { NTIS } & \text { PB 80-128 531, A08 } \\ 80-2029 & 173 & 1980 & \text { NTIS } & \text { PB 80-204 605, A08 } \\ 80-2032 & 89 & 1980 & \text { NTIS } & \text { PB 80-198 799, A05 } \\ 81-2217 & 259 & 1981 & \text { NTIS } & \text { For Official distribution only } \\ 81-2253 & 38 & 1981 & \text { NTIS } & \text { PB 83-249 789, A03 } \\ 81-2254 & 302 & 1981 & \text { NTIS } & \text { PB 81-205 429, A15 } \\ 81-2276 & 26 & 1981 & \text { NTIS } & \text { PB 81-229 171, A03 } \\ 81-2343 & 57 & 1981 & \text { NTIS } & \text { PB 82-131 525, A04 } \\ 81-2345 & 89 & 1981 & \text { NTIS } & \text { PB 82-184 904, A05 } \\ 81-2356 & 17 & 1982 & \text { NTIS } & \text { PB 82-171 091, A02 } \\ 82-2401 & 164 & 1982 & \text { NTIS } & \text { PB 82-259373, A08 } \\ 81-2426 & 87 & 1982 & \text { NTIS } & \text { PB 83-216358, A05 } \\ 82-2543 & 139 & 1982 & \text { NTIS } & \text { PB 83-25 363, A07; supplements NBS Spec. Publ. 380 and 380-1 } \\ 82-2550 & 164 & 1982 & \text { NTIS } & \text { PB 82-2550, A08 } \\ 82-2587 & 751 & 1982 & \text { NTIS } & \text { PB 83-115 311, A26 } \\ 75-763 & 206 & 1972 & \text { NTIS } & \text { COM 75-11276, A10 } \\ 84-2811 & 162 & 1983 & \text { NTIS } & \text { Order from NTIS NBSIR 84-2811 } \\ 84-2907 & 55 & 1984 & \text { NTIS } & \text { Order from NTIS NBSIR 84-2907 }\end{array}$


NBS.114A IREV. 2.80)

U.S. DEPT. OF COMM.

BIBLIOGRAPHIC DATA

SHEET (See Instructions)
1. PUBLICATION OR REPORT NO. NBS/SPR708

2. Performlng Organ. Report Nod 3. Publicatlon Date

December 1985

4. TITLE AND SUBTITLE

Standard Reference Data Publications 1964-1984

5. AUTHOR(S)

Joan C. Sauerwein and Geraldine R. Dalton

6. PERFORMING ORGANIZATION (If jolnt or other than NBS, see Instructions)

National Bureau of Standards

Department of Commerce

Gaithersburg, MD 20899

7. Contract Grant No.

3. Type of Report \& Perlod Covered $1964-1984$

9. SPONSORING ORGANIZATION NAME AND COMPLETE ADDRESS (Street, CIty, Stote, ZIP)

Same as item 6.

10. SUPPLEMENTARY NOTES

Supersedes NBS SP 612

Library of Congress Catalog Card Number: 85-600607

Document describes a computer program; SF-185, FIPS Software Summary, is attached.

11. ABSTRACT (A 200-word or less factual summary of most significant Informatlon. If document includes a significant b/bliogrophy or literoture survey, mention it here)

The National Bureau of Standards' Office of Standard Reference Data manages a network of data centers that prepare evaluated data bases of physical and chemical properties of substances. Data bases are available in printed form, on magnetic tapes and through on-line computer networks. This document provides a comprehensive list of the products available from the National standard Reference Data system (NSRDS) for the years 1964-1984, including indexes qualified by author, material, and property terms. Ordering information and current prices can be found at the end of this document.

12. KEY WORDS (Six to twelve entrles; alphabetical order; capitalize only proper names; and separate key words by semicolons) bibliographies; chemical properties; evaluated data; indexes; materials properties; physical properties; publication list

13. AVAILABILITY

X] Unilimited

$\square$ For Official Distribution. Do Not Reiease to NTiS

Order From Superintendent of Documents, U.S. Government Printing Office, Washington, D.C. 20402.

Order From National Technicai Information Service (NTIS), Springfieid, VA. 22161
14. NO. OF

PRINTED PAGES

143

15. Price 


\section{Technical Publications}

\section{Periodical}

Journal of Research-The Journal of Research of the National Bureau of Standards reports NBS research and development in those disciplines of the physical and engineering sciences in which the Bureau is active. These include physics, chemistry, engineering, mathematics, and computer sciences. Papers cover a broad range of subjects, with major emphasis on measurement methodology and the basic technology underlying standardization. Also included from time to time are survey articles on topics closely related to the Bureau's technical and scientific programs. Issued six times a year.

\section{Nonperiodicals}

Monographs-Major contributions to the technical literature on various subjects related to the Bureau's scientific and technical activities.

Handbooks-Recommended codes of engineering and industrial practice (including safety codes) developed in cooperation with interested industries, professional organizations, and regulatory bodies.

Special Publications-Include proceedings of conferences sponsored by NBS, NBS annual reports, and other special publications appropriate to this grouping such as wall charts, pocket cards, and bibliographies.

Applied Mathematies Series-Mathematical tables, manuals, and studies of special interest to physicists, engineers, chemists, biologists, mathematicians, computer programmers, and others engaged in scientific and technical work.

National Standard Reference Data Series-Provides quantitative data on the physical and chemical properties of materials, compiled from the world's literature and critically evaluated. Developed under a worldwide program coordinated by NBS under the authority of the National Standard Data Act (Public Law 90-396).

NOTE: The Journal of Physical and Chemical Reference Data (JPCRD) is published quarterly for NBS by the American Chemical Society (ACS) and the American Institute of Physics (AIP). Subscriptions, reprints, and supplements are available from ACS, 1155 Sixteenth St., NW, Washington, DC 20056.

Building Science Series-Disseminates technical information developed at the Bureau on building materials, components, systems, and whole structures. The series presents research results, test methods, and performance criteria related to the structural and environmental functions and the durability and safety characteristics of building elements and systems.

Technical Notes-Studies or reports which are complete in themselves but restrictive in their treatment of a subject. Analogous to monographs but not so comprehensive in scope or definitive in treatment of the subject area. Often serve as a vehicle for final reports of work performed at NBS under the sponsorship of other government agencies.

Voluntary Product Standards-Developed under procedures published by the Department of Commerce in Part 10, Title 15, of the Code of Federal Regulations. The standards establish nationally recognized requirements for products, and provide all concerned interests with a basis for common understanding of the characteristics of the products. NBS administers this program as a supplement to the activities of the private sector standardizing organizations.

Consumer Information Series-Practical information, based on NBS research and experience, covering areas of interest to the consumer. Easily understandable language and illustrations provide useful background knowledge for shopping in today's technological marketplace.

Order the above NBS publications from: Superintendent of Documents, Government Printing Office, Washington, DC 20402.

Order the following NBS publications-FIPS and NBSIR's-from the National Technical Information Service, Springfield, VA 22161.

Federal Information Processing Standards Publications (FIPS PUB)-Publications in this series collectively constitute the Federal Information Processing Standards Register. The Register serves as the official source of information in the Federal Government regarding standards issued by NBS pursuant to the Federal Property and Administrative Services Act of 1949 as amended, Public Law 89-306 (79 Stat. 1127), and as implemented by Executive Order 11717 (38 FR 12315, dated May 11, 1973) and Part 6 of Title 15 CFR (Code of Federal Regulations).

NBS Interagency Reports (NBSIR)-A special series of interim or final reports on work performed by NBS for outside sponsors (both government and non-government). In general, initial distribution is handled by the sponsor; public distribution is by the National Technical Information Service, Springfield, VA 22161, in paper copy or microfiche form. 
U.S. Department of Commerce

National Bureau of Standards

Gaithersburg. MD 20899

\section{Official Business}

Penalty for Private Use $\$ 300$ 